\title{
Isolation and Structure Elucidation of New Secondary Metabolites from New Zealand Marine Red Algae
}

by

Wendy Lynne Popplewell

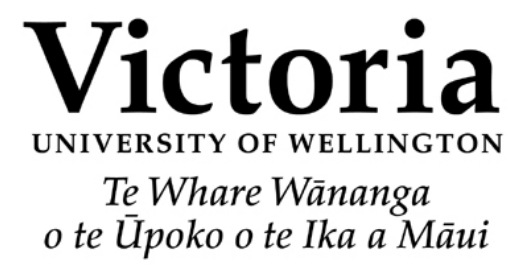

iq

\author{
A thesis \\ submitted to Victoria University of Wellington \\ in fulfilment of the \\ requirements for the degree of \\ Doctor of Philosophy \\ in Chemistry.
}

Victoria University of Wellington 2008 


\begin{abstract}
The natural product analysis of New Zealand red algae has been neglected in recent years, and there is obvious scope for the chemical re-evaluation of New Zealand marine red algae. This study describes the isolation and structure elucidation of 12 new and eight known compounds from four different genera of red algae. To aid in this process, 34 red algae were screened in order to generate a digital HSQC spectra mask, a screening tool developed by the VUW Marine Natural Products group to identify extracts of interest for further analysis. All 34 algal extracts were screened using the HSQC mask and four extracts were identified as interesting and analysed in detail. Examination of extracts of the red algae Plocamium costatum and Ballia callitricha lead to the isolation of three known metabolites.
\end{abstract}

Eleven new oxylipins, labillarides A-K (60-70), are reported from the alga Phacelocarpus labillardieri. Labillarides $\mathrm{A}-\mathrm{H}(\mathbf{6 0}-\mathbf{6 7})$ are polyunsaturated $\alpha$-pyrone macrocycles, all of which show similarities to the previously reported compounds isolated from southern Australian collections of the algae. Labillarides E-H (64-67) are of particular interest as they represent the two diastereomeric pairs associated with variation at the C-3 and C-8 chiral centres. Labillarides I (68) and J (69) are related enol macrocycles while labillaride K (70) is a furan-3-one oxylipin, all of which have biogenic significance to the macrocyclic $\alpha$-pyrones. Labillarides A (60), B (61) and I (68) exhibit moderate cytotoxicity while labillaride C (62) shows moderate antibacterial activity.

A new nitrogenous bromophenol, colensolide A (124), was isolated from the alga Osmundaria colensoi along with five known bromophenols. The presence of nitrogencontaining sidechains in bromophenols is unusual but not unprecedented. The bicyclic nitrogenous moiety observed in colensolide A (124) is proposed to be of histidine origin. Several of the known bromophenols exhibit antibacterial activity and one shows moderate cytotoxicity. 
<smiles></smiles>

60<smiles></smiles>

61<smiles>CC/C=C\C/C=C\C1/C=C\CCCCCCc2cc(O)c1c(=O)o2</smiles>

62<smiles></smiles>

63

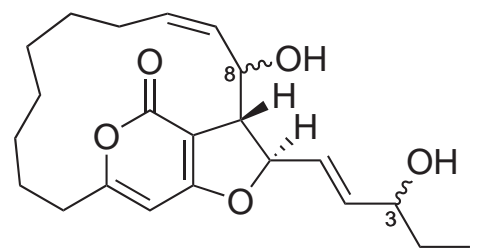

64-67

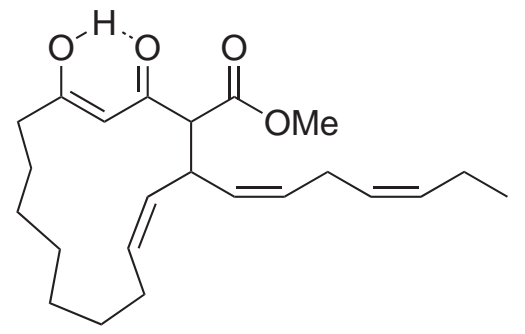

68

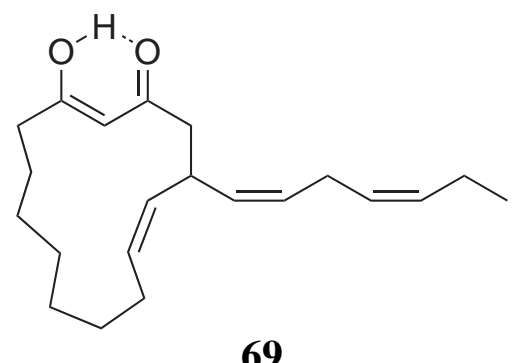

69

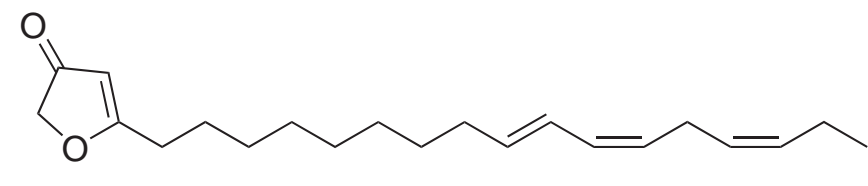

70

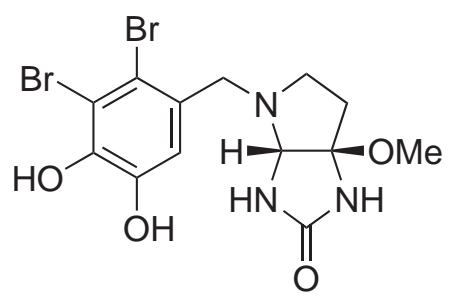

124 


\section{Dedicated to my grandfathers.}

\section{To Kenneth Popplewell,}

Who I truly hope would have been proud enough to say:

"Well of course you got a PhD... I never expected any less!".

\section{And to Huia Knowles,}

Who I am lucky enough to know is proud. 


\section{Acknowledgements}

Completing my $\mathrm{PhD}$ was never going to be easy, but the support that I have received from the people around me has made it an incredible experience that I will cherish for the rest of my life.

Firstly, I would like to thank my supervisor, Peter Northcote. Your infectious enthusiasm for natural product chemistry had me hooked from my honours year, and I truly could not imagine having done my PhD under anyone else. Thank you for your advice, guidance, and uncanny ability to predict structures from a quick glance at the proton! Thank you for introducing me to diving, a part of my research that never felt like hard work - especially when we were $30 \mathrm{~m}$ down, checking out nudis off the Northern Arch. It has been a pleasure working for you.

Secondly I would like to thank my "partner in crime", Joanna Wojnar, who has travelled through this journey with me. Thank you for helping me re-word my sentences and always have a suggestion when I felt like I had hit a wall. From organising the NZIC quizzes to traveling to conferences and dive-trips, I have utterly enjoyed all that we have done together and am privileged to call you a dear friend.

I would have struggled to get to this point in my $\mathrm{PhD}$ without the support of another great friend, Rob Keyzers. Thank you for always being there for me when I needed to vent, no matter what corner of the world you were on. And most importantly, thank you for your tireless and meticulous editing of my thesis.

One of the most influential parts of my time in post-grad has been the fantastic group of people that I have had the pleasure of working with. Thank you to the members of the lab, for generating such a great atmosphere in which to work. Thank you to John Ryan, for your invaluable NMR knowledge, for introducing me to $\mathrm{LT}_{\mathrm{E}} \mathrm{X}$ (as Microsoft would have driven me mad during the writing process), for editing parts of my thesis and for being my all round go-to-guy. Thank you to Mina Razzak, Katie Dowle and Jono Singh for being great friends as well as fantastic colleagues. Also, thank you to Izabela Pomer, Mike Page, Steve Mackey and Greta Moraes for making the lab what it was. And thank you to the synthetic chemists next door, especially Shivali Gulab, Lynton Baird, and Emma Dangerfield, for letting me "borrow" reagents and answer my questions when I attempted to do synthetic chemistry.

Thank you to all the technical and admin staff in SCPS - the often unsung heroes of a research institution. Thank you to Alan, Manu, Rhys, Jackie, Teresa, Sally, Gordon, Grant, Scott, Dave, Kathy, Jenny and Darren. Also, thank you to the academic staff, particularly Joanne Harvey and Brendan Burkett for your help with synthetic chemistry, Brian Halton for his editing help and Pablo Etchegoin for assistance with the ellipsometer.

I have made some true friends in my time at VUW. I would like to thank all the SPCS postgrad students, especially (in no particular order) Aaron Small, Kathryn Allan, Chris Munro, Almas Zayya and James Grindrod. Thank you in particular to Melissa Marshall for all the lunch dates at $\mathrm{KK}$ and movie nights that kept me in the real world, and to Emma Turner for getting me outside and running up and down hills, and being a great friend. Also, thank you to my "outside world" friends, especially Cheryl Smith, Jo Sims, Ly Tan, Mel Russell and Alex Barr. 
One of the best parts of studying marine natural product chemistry is the dive trips. Thank you to all the members of the various dive crews - particularly Noel Erickson, Rhys, Moera and Gareth Jones, Des McAllister, Mary Carney, Kel Nairn (you are a true diving gentleman!) and Toby Pugno (our comic relief!).

Thank you to James Matthews, Anja Wilmes, Ariane Chan and Chris Miller from the School of Biological Sciences (SBS) for running various bioassays on my compounds.

Also, thank you to Wendy Nelson of NIWA and Malcolm Francis for several of the underwater photos used in my thesis, and to Joe Zuccarello of SBS for identifying the algae that I worked on.

I would like to gratefully acknowledge my sources of funding that I have received during my PhD - the Cancer Society Training Scholarship, the Marine Natural Products Scholarship, the Curtis-Gordon Scholarship and the NZIC Student Travel Grant.

Finally, I must thank my family, without whom I would never have got this far. Thank you Mum, Dad and Hayley for always believing in me, encouraging me to follow my passion for science, standing by me in the good times and the bad, sending me home with food, and "walking" me home when I have worked late. I am so lucky to have such an amazing family. And most importantly of all, thank you to my partner Duncan. Thank you for loving and supporting me unconditionally. Thank you for sharing the good times with me, and helping me through all the bad ones. Thank you for making me laugh and letting me cry. Thank you for keeping me sane by being just a little bit crazy. You are my rock.

Thank you, one and all. 


\section{Table of Contents}

$\begin{array}{lll}\text { Abstract } & \text { ii }\end{array}$

Dedication iv

$\begin{array}{ll}\text { Acknowledgements } & \text { v }\end{array}$

Table of Contents vii

List of Figures $\quad$ xi

$\begin{array}{ll}\text { List of Schemes } & \text { Xv }\end{array}$

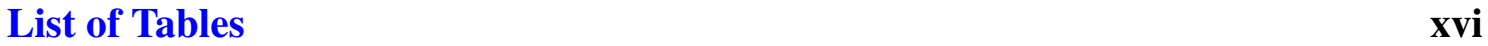

Glossary $\quad$ xix

1 Introduction 1

1.1 Natural Products . . . . . . . . . . . . . . . . . . . 1

1.2 The Golden Age of Natural Products . . . . . . . . . . . . . . . . . . 2

1.3 Modern Drug Discovery . . . . . . . . . . . . . . . . 2

1.4 Marine Natural Products . . . . . . . . . . . . . . . . . . . . 4

1.5 Marine Red Algae . . . . . . . . . . . . . . . . . . . 6

2 Red Algae Screening 12

2.1 Methods of Natural Product Screening and Isolation . . . . . . . . . . . . 12

2.2 VUW Screening . . . . . . . . . . . . . . . . . . . . . 14

2.3 Algal Screening . . . . . . . . . . . . . . . . . . 18

2.4 Summary . . . . . . . . . . . . . . . . . . . . 24 
3.1 Phacelocarpus labillardieri . . . . . . . . . . . . . . 25

3.2 Isolation . . . . . . . . . . . . . . . . . . . . . . 29

3.3 Labillaride A . . . . . . . . . . . . . . . 32

3.4 Labillaride B . . . . . . . . . . . . . . . . . . . . 38

3.5 Labillaride $\mathrm{C} \ldots \ldots \ldots \ldots \ldots$. . . . . . . . . . . . . . . 44

3.6 Labillaride D . . . . . . . . . . . . . . . . . 47

3.7 Labillaride $\mathrm{E} \ldots \ldots \ldots \ldots \ldots \ldots$

3.8 Isolation of Labillaride E Isomers _ . . . . . . . . . . . . . . . 57

3.9 Labillaride $\mathrm{F} \ldots \ldots \ldots \ldots$. . . . . . . . . . . . . . . 60

3.10 Labillaride $\mathrm{G} \ldots \ldots \ldots \ldots$

3.11 Labillaride $\mathrm{H} \ldots \ldots \ldots \ldots \ldots \ldots$

3.12 Discussion of Isomers Labillarides E to H . . . . . . . . . . . 69

3.13 Labillaride I . . . . . . . . . . . . . . . . . 72

3.14 Labillaride $\mathrm{J} \ldots \ldots \ldots$. . . . . . . . . . . . . . . . . 76

3.15 Labillaride $\mathrm{K} \ldots \ldots \ldots \ldots$. . . . . . . . . . . . 80

3.16 Degradation of Labillarides A to D . . . . . . . . . . . . . . 83

3.17 Biological Activity of Labillarides A to K . . . . . . . . . . . . 91

3.18 Oxylipins from Marine Macro-algae . . . . . . . . . . . . . . 91

3.19 Labillaride Biogenesis . . . . . . . . . . . . . . . . . 94

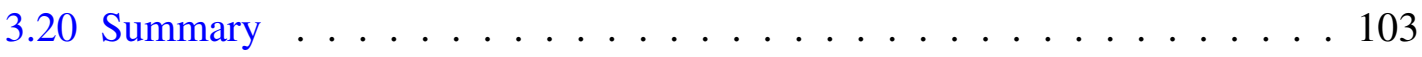

4 Colensolide A: A New Nitrogenous Bromophenol from Osmundaria colensoi 105

4.1 Osmundaria colensoi . . . . . . . . . . . . . . 105

4.2 Isolation . . . . . . . . . . . . . . . . . . 109

4.3 Colensolide A . . . . . . . . . . . . . . . . . 114

4.4 Synthetic Derivatives of Colensolide A . . . . . . . . . . . . . . . 119 
4.5 Biological Activity . . . . . . . . . . . . . . 126

4.6 Bromophenols . . . . . . . . . . . . . . . . . . . . 127

4.7 Biogenesis of Colensolide A . . . . . . . . . . . . . 133

4.8 Summary . . . . . . . . . . . . . . . . . . 135

5 Conclusion 136

$\begin{array}{lll}6 & \text { Experimental } & 138\end{array}$

6.1 General Experimental . . . . . . . . . . . . . . . . . 138

6.2 Isolation of Costatone from Plocamium costatum . . . . . . . . . . . 139

6.3 Isolation of Indoles from Ballia callitricha . . . . . . . . . . . . . . . 140

6.4 Isolation of Labillarides A to K from Phacelocarpus labillardieri . . . . . 141

6.5 Isolation of Bromophenols from Osmundaria colensoi . . . . . . . . . 152

$\begin{array}{lr}\text { A Existing Sponge Screening Protocol } & 158\end{array}$

B NMR Data for the Known Compounds 165

$\begin{array}{lll}\text { C } & { }^{1} \mathrm{H} \text { NMR Spectra of the Known Compounds } & 169\end{array}$

D NMR Spectra of Labillaride A 177

$\begin{array}{llr}\text { E } & \text { NMR Spectra of Labillaride B } & 183\end{array}$

$\begin{array}{lrr}\text { F NMR Spectra of Labillaride C } & 189\end{array}$

G NMR Spectra of Labillaride D $\quad 195$

H NMR Spectra of Labillaride E $\quad 201$

$\begin{array}{lr}\text { I NMR Spectra of Labillaride F } & 208\end{array}$

$\begin{array}{llr}\text { J NMR Spectra of Labillaride G } & 214\end{array}$ 
K NMR Spectra of Labillaride $H$

L ${ }^{1} \mathrm{H}$ NMR Spectrum of 3,8-Diacetyl-labillaride $\mathrm{H}$

M NMR Spectra of Labillaride I

N NMR Spectra of Labillaride J

233

O NMR Spectra of Labillaride K

239

P NMR Spectra of the Degradation Product

244

Q NMR Spectra of Colensolide A

R ${ }^{1}$ H NMR Spectrum of Acidified Colensolide A

S ${ }^{1} \mathrm{H}$ NMR Spectrum of 5-O-Methylcolensolide A

T ${ }^{1} \mathrm{H}$ NMR Spectrum of 4,5-Di- $O$-methylcolensolide A

References

259 


\section{List of Figures}

1.1 New Zealand Exclusive Economic Zone. . . . . . . . . . . . . . . . . . 6

1.2 A variety of red, green and brown marine algae at low tide. . . . . . . 7

2.1 Cyclic loading. . . . . . . . . . . . . . . . . 15

2.2 Algal HSQC mask showing the common correlations in white and the uncommon correlations in blue. . . . . . . . . . . . . . . . 19

2.3 HSQC mask of $C$. coriacea showing the common correlations in green and the unusual correlations in red. . . . . . . . . . . . . . 20

2.4 Plocamium costatum. . . . . . . . . . . . . . . . . . . 21

2.5 HSQC mask of $P$. costatum showing the common correlations in green and the unusual correlations in red. . . . . . . . . . . . . . 21

2.6 NMR spectra of the $75 \% \mathrm{Me}_{2} \mathrm{CO}$ in $\mathrm{H}_{2} \mathrm{O}$ screening fraction of P. costatum. 22

2.7 Ballia callitricha. . . . . . . . . . . . . . . 23

2.8 HSQC mask of B. callitricha showing the common correlations in green and the unusual correlations in red. . . . . . . . . . . . . . 23

3.1 Phacelocarpus labillardieri. . . . . . . . . . . . . . 25

3.2 HSQC mask showing the common correlations in green and the unusual correlations in red. . . . . . . . . . . . . . . . . 27

3.3 NMR spectra of a semi-purified fraction of P. labillardieri. . . . . . . . . 29

3.4 Selected COSY correlations and NOE enhancements establishing the 1,5,7-triene substructure of labillaride A. . . . . . . . . . . . . . 33

3.5 Selected COSY and HMBC correlations establishing part of the $\alpha$-pyrone containing substructure of labillaride A. . . . . . . . . . . . 33

3.6 Selected COSY and HMBC correlations establishing the $\alpha$-pyrone containing substructure of labillaride A. . . . . . . . . . . . . . 34

3.7 Methylene region of the ${ }^{13} \mathrm{C}$ NMR spectrum of labillaride A. . . . . . . . 35

3.8 Selected TOCSY and HMBC correlations connecting the substructures of labillaride A, completing the alkyl chain. . . . . . . . . . . . . . 36

3.9 Selected COSY and HMBC correlations and NOE enhancements establishing two substructures of labillaride B. 
3.10 Selected TOCSY and HMBC correlations connecting the substructures of labillaride B.

3.11 Steric hindrance discounting an eclipsed relationship between H-8 and $\mathrm{H}-9$ in both possible relative configurations of labillaride $\mathrm{B} . . . .$.

3.12 The selected NOE enhancement establishing a gauche relationship between $\mathrm{H}-9$ and $\mathrm{H}-10 \mathrm{a}$, and $\mathrm{H}-10 \mathrm{~b}$ in both possible relative configurations of labillaride B. . . . . . . . . . . . . . . . . . . . . .

3.13 Selected NOE enhancements suggesting the $R^{*}, S^{*}$ relative configuration of labillaride B

3.14 Selected COSY correlations and NOE enhancements establishing the 1,4,7-triene substructure of labillaride C . . . . . . . . . . . . . . . . .

3.15 Selected HMBC correlations establishing the $\alpha$-pyrone substructure of labillaride $\mathrm{C}$.

3.16 Selected COSY and HMBC correlations and NOE enhancements establishing the structure of labillaride D . . . . . . . . . . . . . . . .

3.17 Selected COSY correlations establishing the 1,6-diene substructure of labillaride E. . . . . . . . . . . . . . . . . . . . .

3.18 Selected HMBC correlations establishing the $\alpha$-pyrone substructure of labillaride E. . . . . . . . . . . . . . . . . . . . . . . .

3.19 Selected COSY and HMBC correlations connecting the substructures of labillaride E. . . . . . . . . . . . . . . . . . . . . . .

$3.20{ }^{1} \mathrm{H}$ NMR spectrum of $\mathrm{H}-7$ of labillaride $\mathrm{E}$ (red) and homonuclear decoupled ${ }^{1} \mathrm{H}$ NMR spectra of H-7 selectively decoupled at H-6 (blue) and $\mathrm{H}-8$ (green) . . . . . . . . . . . . . . . . . . . .

3.21 The selected NOE enhancement supporting the trans assignment of H-6 and H-7 in labillaride E. . . . . . . . . . . . . . . . . . . 54

3.22 ${ }^{1} \mathrm{H}$ NMR spectra of labillaride $\mathrm{E}$ and the mixture of labillarides $\mathrm{F}$ and G. . $\quad 57$

$3.23{ }^{1} \mathrm{H}$ NMR spectra of labillarides $\mathrm{E}, \mathrm{F}, \mathrm{G}$ and $\mathrm{H}\left(\mathrm{CDCl}_{3}, 1.3 \mathrm{mg} \mathrm{mL}^{-1}\right) \ldots \ldots 58$

$3.24{ }^{1} \mathrm{H}$ NMR spectra of labillarides E, F, G and $\mathrm{H}\left(\mathrm{C}_{6} \mathrm{D}_{6}, 1.6 \mathrm{mg} \mathrm{mL}^{-1}\right) . \quad \ldots \quad 58$

3.25 Single wavelength $(300 \mathrm{~nm})$ traces of HPLC injections of labillarides E, $\mathrm{F}, \mathrm{G}$ and $\mathrm{H} . \ldots \ldots \ldots \ldots$

$3.26 \mathrm{UV}$ traces of labillarides E, F, G and H. . . . . . . . . . . . . . 59

3.27 Selected COSY and HMBC correlations and NOE enhancements establishing the structure of labillaride F. 
3.28 Selected COSY and HMBC correlations and NOE enhancements establishing the structure of labillaride $\mathrm{G} . \ldots \ldots \ldots$

3.29 Selected COSY and HMBC correlations and NOE enhancements establishing the structure of labillaride $\mathrm{H} . \ldots \ldots \ldots$. . . . . . . . . . 65

3.30 ${ }^{1} \mathrm{H}$ NMR spectra of labillaride $\mathrm{H}$ in $\mathrm{C}_{6} \mathrm{D}_{6}$ at $4.8 \mathrm{mg} \mathrm{mL}^{-1}$ (bottom) and $1.6 \mathrm{mg} \mathrm{mL}^{-1}$ (top). . . . . . . . . . . . . . . . . . 70

3.31 Selected COSY correlations establishing the 1,4,7-triene substructure of labillaride I. . . . . . . . . . . . . . . . . . . . . . 73

3.32 Selected COSY and HMBC correlations establishing the second substructure of labillaride I in its resonance forms. . . . . . . . . . . . . . . . . 74

3.33 Selected TOCSY and HMBC correlations connecting the substructures of labillaride I.

3.34 Selected COSY and HMBC correlations and NOE enhancements establishing the 1,4,7-triene substructure of labillaride $\mathrm{J}$.

3.35 Selected COSY and HMBC correlations establishing the second substructure of labillaride $\mathrm{J}$, in its resonance forms. . . . . . . . . . . . . . 78

3.36 Selected TOCSY and HMBC correlations connecting the substructures of labillaride J. . . . . . . . . . . . . . . . . . . . . . . . . 78

3.37 Selected COSY and HMBC correlations and NOE enhancements establishing the two substructures of labillaride $\mathrm{K}$.

3.38 Selected COSY and HMBC correlations connecting the two substructures of labillaride K. . . . . . . . . . . . . . . . . . . . . 82

$3.39{ }^{1}$ H NMR spectra of labillaride D pure (black) and degraded (red). . . . . 83

$3.40{ }^{1} \mathrm{H}$ NMR spectra of labillaride B pure (black) and degraded (red). . . . . . 84

$3.41{ }^{1} \mathrm{H}$ NMR spectra of the isolated degradation product from labillarides $\mathrm{C}$ (black) and D (blue). . . . . . . . . . . . . . . . . . . . . .

3.42 Selected COSY and HMBC correlations establishing part of the 1,4-diene substructure of the degradation product.

3.43 Selected COSY and HMBC correlations completing the 1,4-diene substructure of the degradation product. . . . . . . . . . . . . . . 86

3.44 Selected COSY and HMBC correlations establishing the second substructure of the degradation product. . . . . . . . . . . . . . . . . 87

3.45 Selected TOCSY and HMBC correlations connecting the substructures of the degradation product. 
3.46 The selected NOE enhancement and antiperiplanar relationships used to determine the relative configuration of the degradation product. . . . . . . 88

4.1 Osmundaria colensoi. . . . . . . . . . . . . . . . . . . 105

4.2 HSQC mask showing the common correlations in green and the unusual correlations in red.

4.3 NMR spectra of a semi-purified fraction of $O$. colensoi showing correlations of interest. . . . . . . . . . . . . . . . . . . 112

4.4 Selected COSY and HMBC correlations establishing the bromophenol substructure of colensolide A. . . . . . . . . . . . . . . . 115

4.5 Selected COSY and HMBC correlations and NOE enhancements establishing part of the bicyclic substructure of colensolide A . . . . . . . . 116

4.6 Selected COSY and HMBC correlations establishing more of the bicyclic substructure of colensolide A. . . . . . . . . . . . . . . . . 117

4.7 Selected HMBC correlations establishing the bicyclic substructure of colensolide A. . . . . . . . . . . . . . . . . . . . . . 118

4.8 Selected NOE enhancements used to determine the relative configuration of colensolide A. . . . . . . . . . . . . . . . . . . . . . . 119 


\section{List of Schemes}

3.1 Schematic of the overall isolation strategy for labillarides A-K. . . . . . . 30

3.2 Full isolation procedure for the labillarides A-K . . . . . . . . . . 31

3.3 A proposed degradation pathway of labillarides $\mathrm{C}$ and $\mathrm{D}$ to the degradation product. . . . . . . . . . . . . . . . 90

3.4 The 5-LPO-catalysed oxidation of arachidonic acid to 5-HPETE and two proposed transformations from the hydroperoxide. . . . . . . . . . . . 94

3.5 A proposed biogenesis of the $\alpha$-pyrone precursor. . . . . . . . . . . . 95

3.6 A simplified polyketide synthase producing polyketone products. . . . . . 96

3.7 An alternative proposed biogenesis of the $\alpha$-pyrone precursor. . . . . . . 96

3.8 A proposed biogenesis of labillaride A. . . . . . . . . . . . . . 97

3.9 Overall reaction scheme of vanadium bromoperoxidases. . . . . . . . . . 97

3.10 A proposed biogenesis of labillaride B . . . . . . . . . . . . . 98

3.11 A proposed biogenesis of labillarides $\mathrm{C}$ and $\mathrm{D} \ldots \ldots \ldots$

3.12 A proposed biogenesis of labillarides E-H. . . . . . . . . . . . . . 99

3.13 A proposed biogenesis of labillarides I and J. . . . . . . . . . . 100

3.14 A possible mechanism for the formation of a furan-3-one from a $\alpha$ pyrone, as proposed by Kong et al. . . . . . . . . . . . . . . . . 101

3.15 A proposed biogenesis of labillaride K. . . . . . . . . . . . . . 101

3.16 An overview of the proposed biogenic pathways of labillarides A-K. . . . 102

4.1 The isolation procedure for the $O$. colensoi metabolites. . . . . . . . . . 113

4.2 Simplified reaction scheme for formation of histidine photo-product as proposed by Agon et al. . . . . . . . . . . . . . . . . . . . . 134 


\section{List of Tables}

1.1 Taxonomic classification of phylum Rhodophyta to the order level as presented in AlgaeBase. . . . . . . . . . . . . . . . 8

$2.1{ }^{13} \mathrm{C}(150 \mathrm{MHz})$ and ${ }^{1} \mathrm{H}(600 \mathrm{MHz}) \mathrm{NMR}$ data $\left(\mathrm{CD}_{3} \mathrm{OD}\right)$ for $(E)-N$-formyl3-(1H-indol-3-yl)prop-2-enamide. . . . . . . . . . . . . 24

3.1 Taxonomic classification of genus Phacelocarpus from order Gigartinales as presented by AlgaeBase. . . . . . . . . . . . . . . . 26

3.2 Chemical shift differences of the $\alpha$-pyrone moiety of the known compound and labillaride A. . . . . . . . . . . . . . . 34

3.3 ${ }^{13} \mathrm{C}(150 \mathrm{MHz})$ and ${ }^{1} \mathrm{H}(600 \mathrm{MHz}) \mathrm{NMR}$ data $\left(\mathrm{CDCl}_{3}\right)$ for labillaride A. . 37

3.4 Chemical shift differences of the $\alpha$-pyrone moiety for labillarides A and B. 39

3.5 ${ }^{13} \mathrm{C}(150 \mathrm{MHz})$ and ${ }^{1} \mathrm{H}(600 \mathrm{MHz}) \mathrm{NMR}$ data $\left(\mathrm{CDCl}_{3}\right)$ for labillaride B. . 43

3.6 ${ }^{13} \mathrm{C}(150 \mathrm{MHz})$ and ${ }^{1} \mathrm{H}(600 \mathrm{MHz}) \mathrm{NMR}$ data $\left(\mathrm{CDCl}_{3}\right)$ for labillaride C. . 46

3.7 ${ }^{13} \mathrm{C}(150 \mathrm{MHz})$ and ${ }^{1} \mathrm{H}(600 \mathrm{MHz}) \mathrm{NMR}$ data $\left(\mathrm{CDCl}_{3}\right)$ for labillaride D. . 49

3.8 ${ }^{13} \mathrm{C}$ chemical shift differences of the dihydrofuro[3,2-c]pyran-4-one moiety for labillaride $\mathrm{E}$ and phelligridimer $\mathrm{A} \ldots \ldots . . . . . . . .53$

3.9 ${ }^{13} \mathrm{C}(150 \mathrm{MHz})$ and ${ }^{1} \mathrm{H}(600 \mathrm{MHz}) \mathrm{NMR}$ data $\left(\mathrm{CDCl}_{3}\right)$ for labillaride E. . $\quad 55$

$3.10{ }^{13} \mathrm{C}(150 \mathrm{MHz})$ and ${ }^{1} \mathrm{H}(600 \mathrm{MHz}) \mathrm{NMR}$ data $\left(\mathrm{C}_{6} \mathrm{D}_{6}\right)$ for labillaride $\mathrm{E}$ $\left(5.6 \mathrm{mg} \mathrm{mL}^{-1}\right) \ldots \ldots \ldots \ldots \ldots \ldots$

$3.11{ }^{13} \mathrm{C}(150 \mathrm{MHz})$ and ${ }^{1} \mathrm{H}(600 \mathrm{MHz}) \mathrm{NMR}$ data $\left(\mathrm{C}_{6} \mathrm{D}_{6}\right)$ for labillaride $\mathrm{F}$ $\left(2.0 \mathrm{mg} \mathrm{mL}^{-1}\right) \ldots \ldots \ldots \ldots \ldots$. . . . . . . . . . . . . . 62

$3.12{ }^{13} \mathrm{C}(150 \mathrm{MHz})$ and ${ }^{1} \mathrm{H}(600 \mathrm{MHz}) \mathrm{NMR}$ data $\left(\mathrm{C}_{6} \mathrm{D}_{6}\right)$ for labillaride $\mathrm{G}$ $\left(1.5 \mathrm{mg} \mathrm{mL}^{-1}\right) \ldots \ldots \ldots \ldots \ldots$. . . . . . . . . . . . . . 64

$3.13{ }^{13} \mathrm{C}(150 \mathrm{MHz})$ and ${ }^{1} \mathrm{H}(600 \mathrm{MHz}) \mathrm{NMR}$ data $\left(\mathrm{C}_{6} \mathrm{D}_{6}\right)$ for labillaride $\mathrm{H}$ $\left(4.8 \mathrm{mg} \mathrm{mL}^{-1}\right) \ldots \ldots \ldots \ldots 6$

$3.14{ }^{13} \mathrm{C}(150 \mathrm{MHz})$ and ${ }^{1} \mathrm{H}(600 \mathrm{MHz}) \mathrm{NMR}$ data $\left(\mathrm{C}_{6} \mathrm{D}_{6}\right)$ for 3,8-diacetyllabillaride $\mathrm{H}\left(0.5 \mathrm{mg} \mathrm{mL}^{-1}\right) . \ldots \ldots$. . . . . . . . . . 68

3.15 ${ }^{1} \mathrm{H}$ chemical shift differences of labillarides $\mathrm{F}-\mathrm{H}$ as compared to labillaride E. . . . . . . . . . . . . . . . . . 70

$3.16{ }^{13} \mathrm{C}(150 \mathrm{MHz})$ and ${ }^{1} \mathrm{H}(600 \mathrm{MHz}) \mathrm{NMR}$ data $\left(\mathrm{CDCl}_{3}\right)$ for labillaride I. . $\quad 75$ 
$3.17{ }^{13} \mathrm{C}(150 \mathrm{MHz})$ and ${ }^{1} \mathrm{H}(600 \mathrm{MHz}) \mathrm{NMR}$ data $\left(\mathrm{CDCl}_{3}\right)$ for labillaride $\mathrm{J}$.

3.18 Chemical shift differences of the furan-3-one moiety for labillaride $\mathrm{K}$ and 5-hexyl-furan-3-one.

$3.19{ }^{13} \mathrm{C}(150 \mathrm{MHz})$ and ${ }^{1} \mathrm{H}(600 \mathrm{MHz}) \mathrm{NMR}$ data $\left(\mathrm{CDCl}_{3}\right)$ for labillaride K. . 82

$3.20{ }^{13} \mathrm{C}(150 \mathrm{MHz})$ and ${ }^{1} \mathrm{H}(600 \mathrm{MHz}) \mathrm{NMR}$ data $\left(\mathrm{CDCl}_{3}\right)$ for the degradation product. . . . . . . . . . . . . . . . 89

3.21 Biological activity of labillarides A-K. . . . . . . . . . . . . 91

4.1 Taxonomic classification of genus Osmundaria from order Ceramiales as presented by AlgaeBase. . . . . . . . . . . . . . . 106

4.2 ${ }^{13} \mathrm{C}(150 \mathrm{MHz})$ and ${ }^{1} \mathrm{H}(600 \mathrm{MHz}) \mathrm{NMR}$ data $\left(\mathrm{CD}_{3} \mathrm{OD}\right)$ for $(3 E)-4-(2,3-$ dibromo-4,5-dihydroxyphenyl)-3-butene-2-one. . . . . . . . . . . 110

$4.3{ }^{13} \mathrm{C}(150 \mathrm{MHz})$ and ${ }^{1} \mathrm{H}(600 \mathrm{MHz}) \mathrm{NMR}$ data $\left(\left(\mathrm{CD}_{3}\right)_{2} \mathrm{CO}\right)$ for $(3 E)-4-$ (2,3-dibromo-4,5-dihydroxyphenyl)-3-butene-2-one. . . . . . . . . 110

4.4 ${ }^{13} \mathrm{C}(150 \mathrm{MHz})$ and ${ }^{1} \mathrm{H}(600 \mathrm{MHz}) \mathrm{NMR}$ data $\left(\mathrm{CD}_{3} \mathrm{OD}\right)$ for rhodomelol. . 111

4.5 ${ }^{13} \mathrm{C}(150 \mathrm{MHz})$ and ${ }^{1} \mathrm{H}(600 \mathrm{MHz}) \mathrm{NMR}$ data $\left(\left(\mathrm{CD}_{3}\right)_{2} \mathrm{CO}\right)$ for rhodomelol. 111

4.6 A comparison of ${ }^{13} \mathrm{C}$ chemical shifts of positions 1-6 in colensolide $\mathrm{A}$, lanosol, lanosol methyl ether and rhodomelol. . . . . . . . . . . . 116

4.7 Chemical shift differences of colensolide A and acidified colensolide A. . 117

$4.8{ }^{15} \mathrm{~N}(60 \mathrm{MHz}),{ }^{13} \mathrm{C}(150 \mathrm{MHz})$ and ${ }^{1} \mathrm{H}(600 \mathrm{MHz}) \mathrm{NMR}$ data $\left(\mathrm{CD}_{3} \mathrm{OD}\right)$ for colensolide A. . . . . . . . . . . . . . . 120

$4.9{ }^{15} \mathrm{~N}(60 \mathrm{MHz}),{ }^{13} \mathrm{C}(150 \mathrm{MHz})$ and ${ }^{1} \mathrm{H}(600 \mathrm{MHz}) \mathrm{NMR}$ data $\left(d_{6}-\mathrm{DMSO}\right)$ for colensolide A. . . . . . . . . . . . . . . . 121

$4.10{ }^{13} \mathrm{C}(150 \mathrm{MHz})$ and ${ }^{1} \mathrm{H}(600 \mathrm{MHz}) \mathrm{NMR}$ data $\left(\mathrm{CD}_{3} \mathrm{OD}\right)$ for acidified colensolide A. . . . . . . . . . . . . . . . . . 122

$4.11{ }^{13} \mathrm{C}(150 \mathrm{MHz})$ and ${ }^{1} \mathrm{H}(600 \mathrm{MHz}) \mathrm{NMR}$ data $\left(\mathrm{CD}_{3} \mathrm{OD}\right)$ for 5-O-methylcolensolide A. . . . . . . . . . . . . . . . . . . . 124

$4.12{ }^{13} \mathrm{C}(150 \mathrm{MHz})$ and ${ }^{1} \mathrm{H}(600 \mathrm{MHz}) \mathrm{NMR}$ data $\left(\mathrm{CD}_{3} \mathrm{OD}\right)$ for 4,5-di- $O$ methylcolensolide A. . . . . . . . . . . . . 125

4.13 Biological activity of colensolide A, 4,5-di- $O$-methylcolensolide A, lanosol, lanosol methyl ether, lanosol aldehyde, lanosol butenone and rhodomelol. 126

B.1 ${ }^{13} \mathrm{C}(150 \mathrm{MHz})$ and ${ }^{1} \mathrm{H}(600 \mathrm{MHz}) \mathrm{NMR}$ data $\left(\mathrm{CDCl}_{3}\right)$ for costatone. . . . 165 
B.2 ${ }^{13} \mathrm{C}(150 \mathrm{MHz})$ and ${ }^{1} \mathrm{H}(600 \mathrm{MHz}) \mathrm{NMR}$ data $\left(\mathrm{CDCl}_{3}\right)$ for $1 H$-indole-3carboxaldehyde. . . . . . . . . . . . . . . 165

B.3 ${ }^{13} \mathrm{C}(150 \mathrm{MHz})$ and ${ }^{1} \mathrm{H}(600 \mathrm{MHz}) \mathrm{NMR}$ data $\left(\mathrm{CD}_{3} \mathrm{OD}\right)$ for lanosol. . . . 166

B.4 ${ }^{13} \mathrm{C}(150 \mathrm{MHz})$ and ${ }^{1} \mathrm{H}(600 \mathrm{MHz}) \mathrm{NMR}$ data $\left(\left(\mathrm{CD}_{3}\right)_{2} \mathrm{CO}\right)$ for lanosol. . . 166

B.5 ${ }^{13} \mathrm{C}(150 \mathrm{MHz})$ and ${ }^{1} \mathrm{H}(600 \mathrm{MHz}) \mathrm{NMR}$ data $\left(\mathrm{CD}_{3} \mathrm{OD}\right)$ for 2,3-dibromo4,5-dihydroxybenzyl methyl ether. . . . . . . . . . . . . . . 167

B.6 ${ }^{13} \mathrm{C}(150 \mathrm{MHz})$ and ${ }^{1} \mathrm{H}(600 \mathrm{MHz}) \mathrm{NMR}$ data $\left(\left(\mathrm{CD}_{3}\right)_{2} \mathrm{CO}\right)$ for $2,3-$ dibromo-4,5-dihydroxybenzyl methyl ether. . . . . . . . . . . . 167

B.7 ${ }^{13} \mathrm{C}(150 \mathrm{MHz})$ and ${ }^{1} \mathrm{H}(600 \mathrm{MHz}) \mathrm{NMR}$ data $\left(\mathrm{CD}_{3} \mathrm{OD}\right)$ for 2,3-dibromo4,5-dihydroxybenzaldehyde. . . . . . . . . . . . . . . 168

B.8 ${ }^{13} \mathrm{C}(150 \mathrm{MHz})$ and ${ }^{1} \mathrm{H}(600 \mathrm{MHz}) \mathrm{NMR}$ data $\left(\left(\mathrm{CD}_{3}\right)_{2} \mathrm{CO}\right)$ for 2,3dibromo-4,5-dihydroxybenzaldehyde. . . . . . . . . . . . . 168 


\section{Glossary}

\begin{tabular}{|c|c|}
\hline Amberchrom & PSDVB stationary support (Tosohaas) \\
\hline br. & Broad \\
\hline${ }^{13} \mathrm{C}$ & Carbon-13 NMR \\
\hline $\mathbf{C}_{18}$ & Octadecyl derivatised silica gel \\
\hline $\mathrm{CDCl}_{3}$ & Deuterated chloroform \\
\hline$\left(\mathrm{CD}_{3}\right)_{2} \mathrm{CO}$ & Deuterated acetone \\
\hline $\mathrm{CD}_{3} \mathrm{OD}$ & Deuterated methanol \\
\hline $\mathrm{CH}_{2} \mathrm{Cl}_{2}$ & Dichloromethane \\
\hline COSY & $\begin{array}{l}\text { Correlation spectroscopy (correlations depicted from }{ }^{1} \mathrm{H} \text { to }{ }^{1} \mathrm{H} \\
\text { by }- \text { ) }\end{array}$ \\
\hline d & Doublet \\
\hline$\delta$ & Chemical shift (ppm) \\
\hline$d_{6}$-DMSO & Deuterated dimethyl sulfoxide \\
\hline DIOL & 2,3-Dihydroxy-1-propoxypropyl-derivatise silica gel \\
\hline DMSO & Dimethyl sulfoxide \\
\hline DOSY & Diffusion ordered spectroscopy \\
\hline DQF-COSY & Double quantum filtered correlation spectroscopy \\
\hline $\mathbf{E D}_{\mathbf{5 0}}$ & Concentration that is an effective dose in $50 \%$ of test subjects \\
\hline EEZ & Exclusive Economic Zone \\
\hline EtOAc & Ethyl acetate \\
\hline FDA & The United States of America Food and Drug Administration \\
\hline${ }^{1} \mathbf{H}$ & Proton NMR \\
\hline $\mathbf{H}_{2} \mathbf{O}$ & Water \\
\hline HMBC & $\begin{array}{l}\text { Heteronuclear multiply-bond correlation (correlations depicted } \\
\text { from }{ }^{1} \mathrm{H} \text { to }{ }^{13} \mathrm{C} \text { by }\end{array}$ \\
\hline HP20 & PSDVB stationary support (Mitsubishi) \\
\hline HP20S & PSDVB stationary support (Supelco) \\
\hline HP20SS & PSDVB stationary support (Supelco) \\
\hline HPLC & High pressure liquid chromatography \\
\hline
\end{tabular}


HRESIMS

HSQC

HTS

$\mathrm{IC}_{50}$

ICL

IPA

J

LC-MS

m

$m / z$

$\mathrm{Me}_{2} \mathrm{CO}$

MPLC

mult

MTT

MS

NOE

pet. ether

NOESY

PLA $_{2}$

Pos

ppm

PSDVB

q

quin

S

SCUBA

t

TLC

TMS
High-resolution electrospray ionisation mass spectrometry

Gradient hetronuclear single-quantum correlation

High throughput screening

Concentration that is inhibitory in $50 \%$ of test subjects

Isocitrate lyase

2-Propanol (isopropyl alcohol)

Scalar coupling constant

Coupled liquid chromatography mass spectrometry

Multiplet

Mass to charge ratio

Acetone

Medium pressure liquid chromatography

Multiplicity

3-(4,5-Dimethylthiazol-2-yl)-2,5-diphenyltetrazolium bromide used as an indicator of metabolic viability in cytotoxicity assays Mass spectrometry

Nuclear Overhauser effect (enhancements depicted from ${ }^{1} \mathrm{H}$ to ${ }^{1} \mathrm{H}$ by $\sim$ )

Petroleum ether

Nuclear Overhauser enhancement spectroscopy

Phospholipase $\mathrm{A}_{2}$

Position

Parts per million

Poly(styrene-divinylbenzene)

Quartet

Quintet

Singlet

Self-contained underwater breathing apparatus

Triplet

Thin layer chromatography

Tetramethylsilane 
TOCSY

VUW
Total correlation spectroscopy (correlations depicted from ${ }^{1} \mathrm{H}$ to ${ }^{1} \mathrm{H}$ by $\longrightarrow$ or

Victoria University of Wellington 


\section{Chapter 1}

\section{Introduction}

\subsection{Natural Products}

Throughout the millennia, humans have relied on nature for their basic needs; from food, shelter and clothing, to flavours, fragrances and medicines. ${ }^{1}$ In particular, the use of natural products as medicinal agents presumably predates recorded history. The earliest known records date back to around $2600 \mathrm{BC}$ and were written on clay tablets in cuneiform, the earliest known form of written expression. ${ }^{1}$ Some of the most famous written records include the Ebers papyrus dating from about $1500 \mathrm{BC}$, which detailed plants and some animal organs and minerals used in Egyptian medicine, the Chinese Materia Medica, with the first recording dating from about $1100 \mathrm{BC}$, and various documents detailing the Indian Ayurvedic system, dating from about 1000 BC. ${ }^{1,2}$ These early texts describe numerous plants and other natural remedies that have been sources of extremely important modern medicines. The Ebers papyrus, for example, indicates the use of willow leaves as an antipyretic, and early English herbalists also recommended the use of teas made from willow bark for treatment of fever. The active compound, salicin (1), was identified in the mid 1800s, however it was its derivatives, salicylic acid (2) and acetylsalicylic acid (aspirin, 3), that were commercialised in the late 1800s. ${ }^{3}$ Over 100 years later, aspirin is considered the most successful drug worldwide. ${ }^{4}$

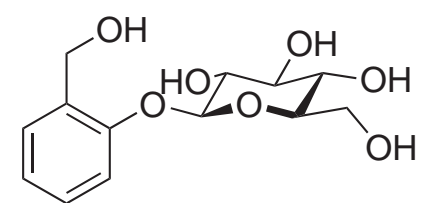

1<smiles>O=C(O)c1ccccc1O</smiles>

$2 \mathrm{R}=\mathrm{H}$

$3 \mathrm{R}=\mathrm{Ac}$ 


\subsection{The Golden Age of Natural Products}

Following the fortuitous discovery of penicillin G (4) from the fungus Penicillium notatum by Fleming in 1929, and the recognition of its many uses in the 1940s, a new age of medicine and what has been referred to as the "Golden Age" of antibiotics intensified the investigation of natural products. ${ }^{1}$ From the 1940s to the 1970s, micro-organisms were examined in detail, and were found to be prolific sources of structurally diverse bioactive metabolites, many of which form important parts of the pharmaceutical industry today. ${ }^{1,2}$ From antibacterial compounds such as the penicillins, aminoglycosides and tetracyclines, and antiparasitic drugs such as the ivermectins, to immunosuppressive agents such as rapamycin (5), micro-organisms became, and continue to be, excellent sources of antibiotics. ${ }^{1}$

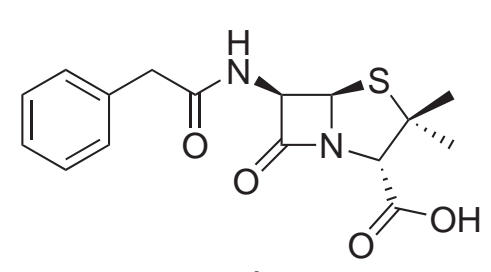

4

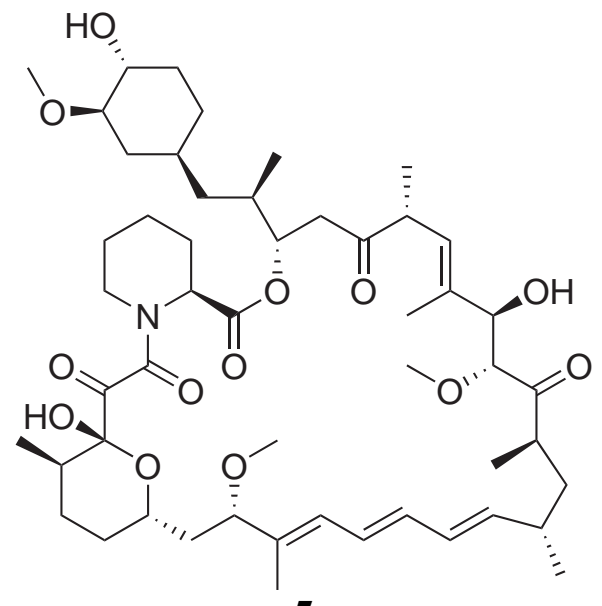

5

\subsection{Modern Drug Discovery}

Following the early successes in drug discovery and development programs based on natural products, many pharmaceutical companies moved away from natural product discovery in the 1990s and early 2000s. ${ }^{5}$ The development of high throughput screening (HTS) put a strain on natural product programs as they struggled to provide the sheer numbers of compounds desired for HTS. Similarly, the introduction of combinatorial chemistry and its promotion as a better approach to creating large sets of "drug-like" compounds led to diminishing numbers of natural product discovery programs in the 
pharmaceutical industry. ${ }^{5}$

The "chemical space" occupied by natural products is now considered both more varied and more drug-like than that of combinatorial chemical collections. ${ }^{6}$ Despite being the most productive source of leads for new drugs, natural products are still currently out of fashion with the pharmaceutical industry, who continue to favour combinatorial techniques. ${ }^{6}$ Interestingly, combinatorial chemistry has not proved very fruitful so far, with only one de novo new compound approved for drug use. Sorafenib (Nexavar, 6) is an anti-tumor compound produced by Bayer and was approved by the United States of America Food and Drug Administration Agency (FDA) in 2005. ${ }^{7}$

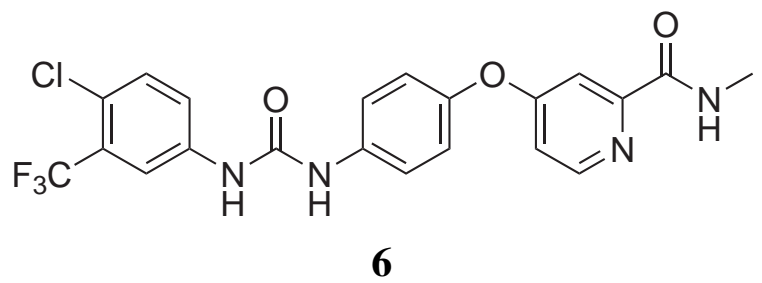

The authors of a recently published statistical comparison between three classes of compounds, marketed drugs, combinatorial compounds, and natural products, suggested that "by mimicking certain distribution properties of natural compounds, combinatorial products might be made that are substantially more diverse and have greater biological relevance." 8 This statement was based on the assumption that most natural products have a function, and the biosynthetic routes which generate these metabolites have coevolved with the specific receptor systems which they target. It is therefore thought that combinatorial chemistry must also evolve beyond "synthetic feasibility" to focus on the creation of compounds with desired biological function. ${ }^{8}$

Despite the trends in the pharmaceutical industry away from natural product discovery, the field has continued to deliver new drugs and drug leads. In the 25 years from January 1981 to June 2006, nearly two thirds of the small molecule new drugs approved world-wide were natural products, natural product derivatives, synthetic mimics of natural product action, or derivatives from natural product pharmacophores. ${ }^{7}$ Newman and Cragg et al. have published several reviews on natural products as sources of new drugs. ${ }^{2,7,9}$ In their most recent review, they summarise their findings by stating "we strongly advocate expanding, not decreasing, the exploration of Nature as a source of novel active agents that 
may serve as the leads and scaffolds for elaboration into desperately needed efficacious drugs for a multitude of disease indications." 7

\subsection{Marine Natural Products}

Marine natural products chemistry has been described as "a child of the 1970s". ${ }^{10}$ Following the development of the first inexpensive and reliable SCUBA apparatus by Jacques Cousteau in the 1940s, natural products chemists and biologists began to consider the marine environment as an untapped resource. ${ }^{11}$ More than $70 \%$ of Earth's surface is covered by oceans and experts estimate that marine biological diversity is higher than that of the tropical rain forests. ${ }^{12}$ Furthermore, plants and many marine invertebrates that lack physical forms of protection are sessile and therefore require chemical defenses that enable an individual organism to establish a particular niche and thrive there. ${ }^{11}$ These natural products released into the water are rapidly diluted and therefore need to be highly potent to have any effect. ${ }^{12}$ It is this defense strategy, necessary to survive in the highly competitive marine environment, that results in a tremendous diversity of highly toxic compounds affecting numerous biological targets and therefore making these organisms of great interest to natural products chemists. ${ }^{13}$

Since the 1970 s, more than 15,000 structurally diverse natural products with varying bioactivites have been reported from marine microbes, algae and invertebrates. ${ }^{5} \mathrm{~A}$ clear indication of the potential for drug development from marine natural products, or compounds derived from them, is the number of compounds currently in clinical or pre-clinical trials for treatments of a large variety of diseases. As of early 2004, 44 marine-derived natural products were in clinical and pre-clinical trials, including three in Phase III. Since then, the cone snail toxin known as Prialt (ziconotide, 7) has been approved by the FDA, making 7 the first "direct from the sea" compound to become a licensed pharmaceutical. ${ }^{7}$ Isolated from the venom of the marine snail Conus magus, $\mathbf{7}$ is a very potent and highly selective blocker of mammalian neuronal $\mathrm{N}$-type voltage-sensitive calcium channels, inhibiting the activity of a subset of neurons including pain-sensing primary nociceptors, making it an ideal treatment for severe chronic pain. ${ }^{14}$ 
The isolation of the C-nucleosides spongouridine (8) and spongothymidine (9) from the Caribbean sponge Cryptotheca crypta in the early 1950s is considered to be the first notable discovery of biologically-active compounds from marine sources. ${ }^{2}$ Found to exhibit antiviral activity, studies of $\mathbf{8}$ and $\mathbf{9}$ eventually led to the development of cytosine arabinoside (Ara-C, 10) as a commercialised antileukemic agent. ${ }^{11}$ The structurally related antiviral compound adenine arabinoside (Ara-A, 11) was synthesised and produced commercially and later found in the Mediterranean gorgonian Eunicella cavolini. ${ }^{11}$ Compounds $\mathbf{1 0}$ and $\mathbf{1 1}$ are argued by some to be the first drugs derived form the marine environment, ${ }^{12}$ though Prialt (7) provided the first direct transition from a marine organism to man. ${ }^{7}$<smiles>[R]c1cn(C2O[C@H](CO)[C@@H](O)[C@H]2O)c(=O)[nH]c1=O</smiles>

$8 \mathrm{R}=\mathrm{H}$

$9 \mathrm{R}=\mathrm{Me}$<smiles>Nc1ccn(C2OC(CO)[C@@H](O)C2O)c(=O)n1</smiles>

10<smiles>Nc1ncnc2c1ncn2C1O[C@H](CO)[C@@H](O)[C@H]1O</smiles>

11

\section{New Zealand Marine Biodiversity}

New Zealand has an extremely biologically diverse marine environment, influenced by its geographical location, range and complexity of habitats, and the number of major ocean currents that pass within its Exclusive Economic Zone (EEZ). Spanning over $30^{\circ}$ of latitude from subtropical to subantarctic waters, and extending from the shallows to the deep seas, New Zealand's EEZ encompasses more than 4.2 million $\mathrm{km}^{2}$, around 15 times its land area (see Figure 1.1). ${ }^{15}$

There are an estimated 22,000-23,000 species inhabiting New Zealand's marine environment, less than 12,000 of which have been identified. ${ }^{15}$ New Zealand has a particularly 


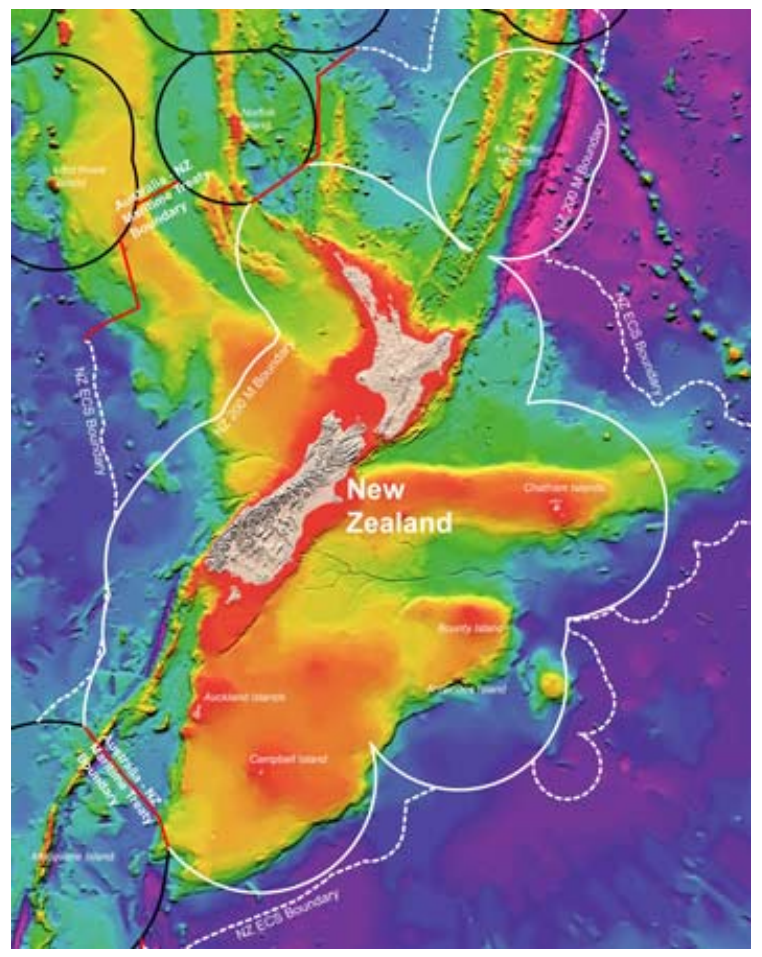

Figure 1.1. New Zealand Exclusive Economic Zone (outlined in solid white). Image courtesy of National Institute of Water and Atmospheric Research (NIWA).

rich diversity of marine macro-algae, supporting over 600 species from 80 families, ${ }^{16}$ making this a viable source for marine natural product evaluation.

\subsection{Marine Red Algae}

Algae are abundant and ancient organisms that can be found in virtually every ecosystem on Earth. ${ }^{17}$ From tiny single-celled species $1 \mu \mathrm{m}$ in diameter to giant kelp over $50 \mathrm{~m}$ long, the term algae encompasses a diverse range of organisms which fossil records show were living at least 500 million years ago. ${ }^{18}$ Algae are polyphyletic as they do not fall within a single group linked by a common ancestor and therefore cannot be given a formal unified placement within biological nomenclature. ${ }^{17}$ The taxonomic descriptions and the relationships of major evolutionary lineages remain controversial and are subject to ongoing research. ${ }^{18}$

The composition and amount of photosynthetic pigments give algae their wide variety of colours and, for several algal groups, their common names such as brown, red and green algae (Figure 1.2). ${ }^{17}$ Red algae (phylum Rhodophyta) are unicellular to multicellular 
organisms. Most red algae are pink to deep red in colour due the the presence of large quantities of the red accessory pigment phycoerythrin, which obscures the chlorophyll $a$ and any other pigments present (including chlorophyll $b$ and carotenoids). ${ }^{19,20}$ It is generally accepted that most marine algae need a minimum irradiance of $0.05-0.1 \%$ of the available surface light in order to survive. Red algae, however, have been found growing on a seamount in the Bahamas $268 \mathrm{~m}$ deep, where the light is estimated to be as low as $0.0005 \%$ of the surface light levels. ${ }^{20}$ It is thought to be the pigment composition of red seaweeds, in particular the phycoerythrin concentrations, that allows the absorption of the spectrum of light which pentrates deeper waters. ${ }^{20}$

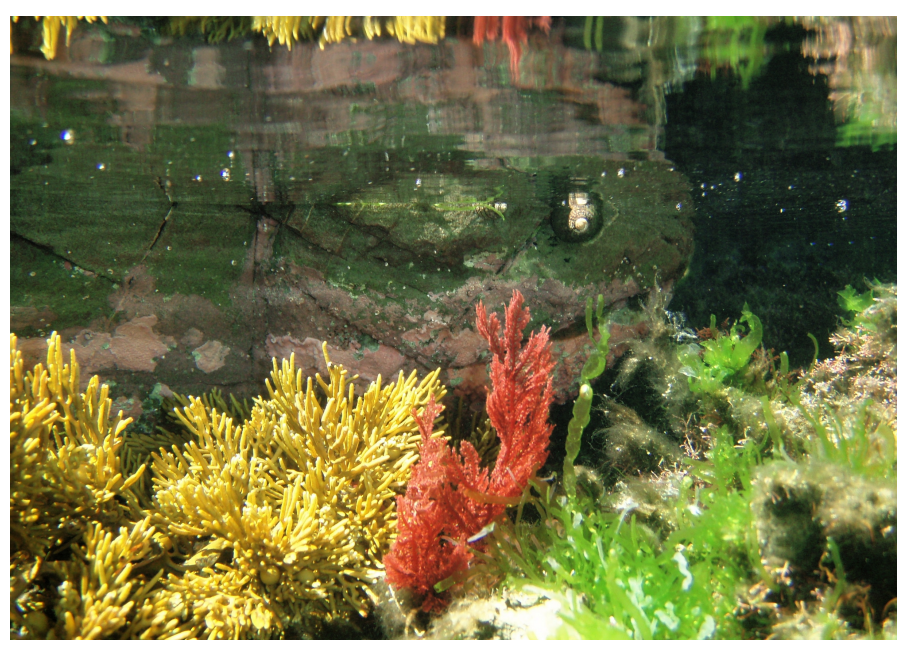

Figure 1.2. A variety of red, green and brown marine algae at low tide.

Currently, the phylum Rhodophyta is divided into two subphyla, six classes, five subclasses, 33 orders, 94 families and over 910 genera. ${ }^{21}$ There are over 6000 species of Rhodophyta classified, which are common inhabitants of tropical and temperate coastal marine waters. ${ }^{19}$ Red algae are the only algae to have a complete lack of flagellate stages, and are also distinctive in their use of floridean starch as their food reserve. ${ }^{22}$ The taxonomy of Rhodophyta to the order level is shown in Table 1.1 with blue entries representing the orders examined in detail in this study.

\section{Red Algal Natural Products}

Seaweeds, particularly red algae, were among the first group of marine organisms to be investigated around the middle of the $20^{\text {th }}$ century, largely due to their ease of accessibility 
Table 1.1. Taxonomic classification of phylum Rhodophyta to the order level as presented in AlgaeBase. ${ }^{21}$

\begin{tabular}{|c|c|c|c|c|}
\hline Phylum & Sub-phylum & Class & Sub-class & Order \\
\hline \multirow{33}{*}{ Rhodophyta } & Cyanidophytina & Cyanidiophyceae & & Cyanidiales \\
\hline & \multirow{32}{*}{ Rhodophytina } & \multirow{2}{*}{ Bangiophyceae } & \multirow{2}{*}{ Bangiophycidae } & Bangiales \\
\hline & & & & Goniotrichales \\
\hline & & \multirow{3}{*}{ Compsopogonophyceae } & & Compsopogonales \\
\hline & & & & Erythropeltidales \\
\hline & & & & Rhodochaetales \\
\hline & & \multirow{24}{*}{ Florideophyceae } & Ahnfeltiophycidae & Ahnfeltiales \\
\hline & & & Hildenbrandiophycidae & Hildenbrandiales \\
\hline & & & Nemaliophycidae & Nemaliales \\
\hline & & & \multirow{21}{*}{ Rhodymeniophycidae } & Acrochaetiales \\
\hline & & & & Acrosymphytales \\
\hline & & & & Balbianiales \\
\hline & & & & Balliales \\
\hline & & & & Batrachospermales \\
\hline & & & & Bonnemaisoniales \\
\hline & & & & Ceramiales \\
\hline & & & & Colaconematales \\
\hline & & & & Corallinales \\
\hline & & & & Gelidiales \\
\hline & & & & Gigartinales \\
\hline & & & & Gracilariales \\
\hline & & & & Halymeniales \\
\hline & & & & Nemastomatales \\
\hline & & & & Palmariales \\
\hline & & & & Pihiellales \\
\hline & & & & Plocamiales \\
\hline & & & & Rhodogorgonales \\
\hline & & & & Rhodymeniales \\
\hline & & & & Sebdeniales \\
\hline & & & & Thoreales \\
\hline & & \multirow{2}{*}{ Rhodellophyceae } & & Porphyridiales \\
\hline & & & & Rhodellales \\
\hline & & Stylonematophyceae & & Stylonematales \\
\hline
\end{tabular}


prior to the introduction of SCUBA. Recently, there has been a renewed interest in seaweeds, however there is a distinct lack of work on algae from the southern hemisphere, where there is a diverse range of algae quite different to those found in more tropical and northerly locations. ${ }^{23}$

Marine macro-algae are known to produce a plethora of secondary metabolites, many of which are halogenated. Common compounds include terpenoids such as the squalenederived polyether compounds thyrsiferol (12), thyrsiferol 23-acetate (13) and venustatriol (14), isolated from the genus Laurencia. ${ }^{24-26}$ These compounds have a range of potent biological activities, venustatriol (14) exhibits potent antiviral activity, ${ }^{26}$ while thyrsiferol 23 -acetate $(\mathbf{1 3})$ possesses in vitro cytotoxicity toward P388 murine leukaemia $\left(\mathrm{ED}_{50}=\right.$ $0.5 \mathrm{nM})^{25}$ and selective inhibition of the protein serine/threonine phosphatase PP2A $\left(\mathrm{IC}_{50}\right.$ $=4-16 \mu \mathrm{M}) .^{27}$

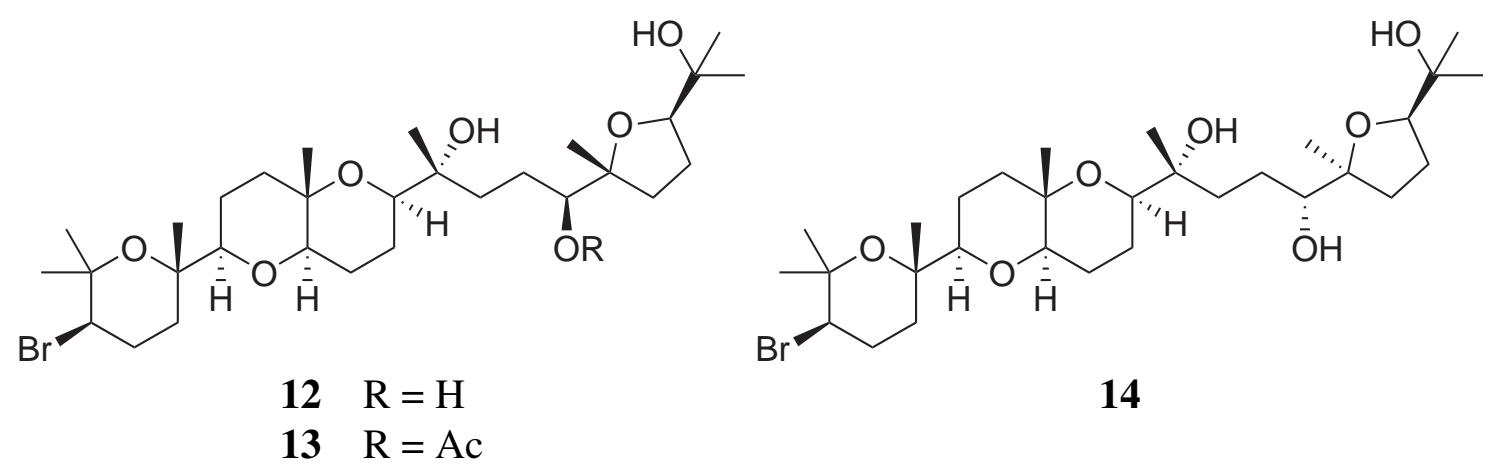

Halogenated sesquiterpenes are prevalent in red algae, such as the chamigrenes 1517. ${ }^{28,29}$ The tribrominated chamigrene $\mathbf{1 5}$ is cytotoxic in the NCI 60-cell line human tumour screen and has displayed potent activity against the NCI/ADR-RES breast cancer cell line. ${ }^{28}$

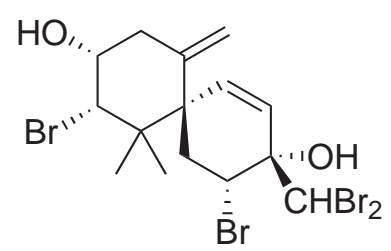

15

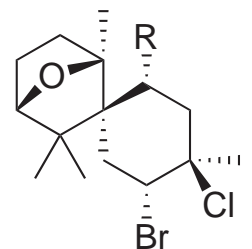

$16 \mathrm{R}=\mathrm{H}$

$17 \mathrm{R}=\mathrm{Ac}$

Nitrogen containing compounds such as indoles are also frequently reported. Recent examples of bioactive indoles include five sulfur-containing polybromoindoles from Laurencia brongniartii (18-22), of which 21 was active against P388 cells and HT-29 
cells, while 22 was active against P388 cells. ${ }^{30}$ A further five bisindoles (23-27) were reported from a Japanese collection of the same alga in the same year. ${ }^{31}$ Oxylipins, such as $\mathbf{2 8}$ and $\mathbf{2 9}$ from Rhodymenia pertusa, ${ }^{32}$ are highly prevalent and are discussed in detail in Chapter 3. Bromophenols also represent a significant group of red algal metabolites, such as the aldose reductase inhibitors $\mathbf{3 0 - 3 2},{ }^{33}$ and are discussed in detail in Chapter 4.<smiles>[R]c1[nH]c2cc(Br)c([R])c(Br)c2c1[R2]</smiles><smiles>[R7]c1[nH]c2cc(Br)cc(Br)c2c1-c1c(Br)[nH]c2cc(Br)cc(Br)c12</smiles>

$$
\begin{array}{llll}
\mathbf{1 8} & \mathrm{R}_{1}=\mathrm{Br} & \mathrm{R}_{2}=\mathrm{SMe} & \mathrm{R}_{3}=\mathrm{SOMe} \\
\mathbf{1 9} & \mathrm{R}_{1}=\mathrm{H} & \mathrm{R}_{2}=\mathrm{SOMe} & \mathrm{R}_{3}=\mathrm{Br} \\
\mathbf{2 0} & \mathrm{R}_{1}=\mathrm{H} & \mathrm{R}_{2}=\mathrm{SOMe} & \mathrm{R}_{3}=\mathrm{SOMe}
\end{array}
$$$$
21 \quad \mathrm{R}_{1}=\mathrm{SMe} \quad \mathrm{R}_{2}=\mathrm{SOMe}
$$$$
22 \mathrm{R}_{1}=\mathrm{SOMe} \quad \mathrm{R}_{2}=\mathrm{SOMe}
$$$$
27 \quad \mathrm{R}_{1}=\mathrm{SMe} \quad \mathrm{R}_{2}=\mathrm{Br}
$$<smiles>[R6]c1c(Br)cc2c(c1Br)c(S(C)(=O)=O)c(Br)n2-c1c(C)[nH]c2cc(Br)c(Br)c(Br)c12</smiles>

$$
\begin{array}{lll}
\text { 23 } & \mathrm{R}_{1}=H & \mathrm{R}_{2}=H \\
\text { 24 } & \mathrm{R}_{1}=H & \mathrm{R}_{2}=\mathrm{Br} \\
\text { 25 } & \mathrm{R}_{1}=\mathrm{Br} & \mathrm{R}_{2}=H \\
\text { 26 } & \mathrm{R}_{1}=\mathrm{Br} & \mathrm{R}_{2}=\mathrm{Br}
\end{array}
$$<smiles>CCC=CCC=CCCC(O)C(O)C=CC=CC=CCCC(=O)O</smiles><smiles>Oc1cc(Br)c(COCc2c(Br)c(O)c(O)c(Br)c2Br)c(Br)c1O</smiles>

30<smiles>[R]c1c(Br)c(O)c(O)c(Br)c1Cc1c(Br)c(O)c(O)c(Br)c1Br</smiles>

$31 \mathrm{R}=\mathrm{Br}$

$32 \mathrm{R}=\mathrm{H}$

\section{New Zealand Red Algal Natural Products}

A total of 24 new compounds have been reported from New Zealand red algae in eight papers mainly from the University of Canterbury Marine Chemistry group, dating from 1978 to $1994 .{ }^{24,34-40}$ The metabolites include a large number of halogenated monoterpenes (such as $\mathbf{3 3}$ and $\mathbf{3 4}$ ) and sesquiterpenes (35 and 36), ${ }^{37,40}$ halogenated furanones (such as $\mathbf{3 7}$ and $\mathbf{3 8}$ ), ${ }^{39}$ and $\mathrm{C}_{15}$ acetogenins (such as $\mathbf{3 9 - 4 3}$ ). ${ }^{36,40}$ 
<smiles>[R]C(Br)[C@H](Cl)/C(C)=C/C[C@H](Cl)[C@](C)(Br)CCl</smiles>

$33 \mathrm{R}=\mathrm{Br}$

$34 \mathrm{R}=\mathrm{H}$<smiles>CCCCC1=C(Br)/C(=C(Br)\C(Br)=C2/OC(=O)C(CCCC)=C2Br)OC1=O</smiles>

37

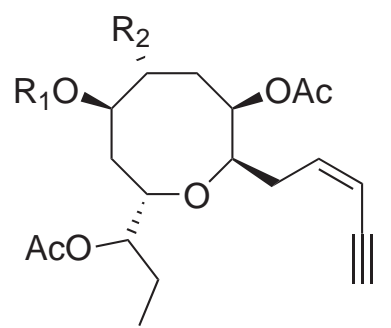

$39 \mathrm{R}_{1}=\mathrm{Ac} \quad \mathrm{R}_{2}=\mathrm{Cl}$

$40 \quad \mathrm{R}_{1}=\mathrm{H} \quad \mathrm{R}_{2}=\mathrm{Ac}$

$41 \mathrm{R}_{1}=\mathrm{Ac} \quad \mathrm{R}_{2}=\mathrm{H}$<smiles>Cc1ccc(C2(C)CC[C@@H](C)/C2=C\Br)c(O)c1</smiles>

35<smiles>Cc1ccc(C2(C)CCC(=CBr)[C@@H]2C)c(O)c1</smiles>

36<smiles>CCCCC1=C(Br)[C@]23C[C@]4(OC(=O)C(Br)=C4Br)C(Br)=C(Br)[C@@]2(C3)OC1=O</smiles>

38

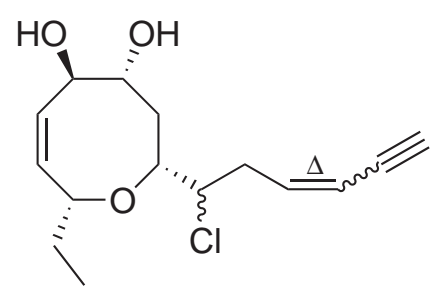

$42 \Delta=Z$

$43 \Delta=E$

The study of natural products from New Zealand marine macro-algae, and red algae in particular, has been neglected in recent years. When this study began, the most recent reported new compounds from a New Zealand macro-algae was a series of $\mathrm{C}_{15}$ acetogenins and sesquiterpenes from a species of the red alga Laurencia, reported in 1994. ${ }^{40}$ In 2007, Sansom et al. reported two new compounds from the New Zealand brown alga Pertihalia capillaris. ${ }^{41}$ With this information in hand, coupled with unusual activity-independent screening and isolation style employed by the Victoria University of Wellington Marine Natural Products group, there was obvious scope for the re-evaluation of New Zealand marine red algae. 


\section{Chapter 2}

\section{Red Algae Screening}

\subsection{Methods of Natural Product Screening and Isolation}

The general paradigm used for identifying novel compounds from crude natural product extracts has not significantly changed in the past few decades. ${ }^{5}$ The most common technique employed, bioassay guided isolation, involves testing extracts of biological material for a specific activity. Extracts with positive biological activity are iteratively fractionated and the fractions tested in the bioassay until a pure compound is isolated. The major advantage of this method is the isolation of a compound with guaranteed biological activity against the desired target.

This "tried and true" technique has served the field of natural products extremely well, however it has several disadvantages. The screening and isolation technique is, by definition, very narrowly focused on one activity. Bioassay processing time and cost can be significant, meaning the isolation process is often slow and expensive. The assay process is destructive, consuming valuable quantities of the active compound at each step of isolation and dereplication of known compounds is not possible in a purely bioassay guided isolation. Finally, an organism may produce multiple interesting bioactive secondary metabolites in differing quantities, and those found in higher concentrations can "mask" the activity of the minor metabolites present in the organism.

The efficient analysis of crude extracts requires sensitive techniques. For this reason, mass spectroscopy (MS) and LC-MS analysis are widely used. ${ }^{42}$ In contrast to MS, NMR is a non-destructive method for mixture analysis, however it has not, until recently, been considered a feasible technique due to its relative insensitivity. Advances in microcoil and cryogenic technology for NMR probes, however, has significantly reduced the sample mass requirements, making NMR screening much more viable. ${ }^{43}$ Compared to MS analysis, 2D NMR spectroscopic investigation offers more detailed structural 
information, a great advantage in the detection of novel chemotypes. New approaches to screening and isolating natural products entailing NMR spectroscopic analysis have been reported, including diffusion-ordered spectroscopy (DOSY) and characterisation of crude or semipurified extracts using routine NMR spectra. ${ }^{42}$

Taggi et al. reported the use of 1D and 2D NMR spectroscopic analysis of unpurified spider venom in the identification and isolation of a family of unusual sulfated nucleoside derivatives. ${ }^{44}$ It was found that sufficient data to identify some or all of the components of interest could be acquired from 1D and 2D NMR spectra of a mixture. When this was not the case, preliminary structural information was used to develop purification schemes specific to the functionality of the compounds of interest. Such individualised purification schemes increased the efficiency of fractionation and reduced the likelihood of changing the unknown structures in vitro resulting in artefacts of isolation.

The complexity of 2D spectra has been a limiting factor in the use of NMR spectroscopy in the characterisation of crude extracts. ${ }^{42}$ Schroeder et al. have recently developed a screening system involving the stacking of DQF-COSY spectra of fungal extracts in an effort to make use of this complexity. ${ }^{42}$ This technique distinguished signals present in only one spectrum from signals common to several spectra. The multiplicative stacking with spectra of extracts of one fungal strain derived from seven culturing protocols and four media controls lead to the isolation of two new natural products. The results were validated by comparison with LC-MS analysis of the the same extracts. Interestingly, it was found that the method of ionisation (positive ESI) strongly skewed the representation of the actual compositions, validating the NMR technique over the use of LC-MS for semi-quantitative analysis in this instance.

There are several examples of the use of diffusion-edited NMR experiments in the dereplication of known compounds. ${ }^{45,46}$ This technique "takes advantage of the variance in translational diffusion of organic compounds as a function of their molecular size." ${ }^{45}$ By measuring DOSY spectra of semi-purified fractions, known components were identified along with unknown components with a unique ${ }^{1} \mathrm{H}$ NMR profile. ${ }^{46}$ This work led to the isolation of two new bromopyrrole alkaloids from a marine sponge. ${ }^{46}$ 


\subsection{VUW Screening}

Over the last 12 years, the Victoria University of Wellington (VUW) Marine Natural Products group have developed an in-house NMR screening protocol born out of a novel isolation procedure developed for crude extracts - cyclic loading. This protocol has evolved from a 1D NMR-based screening system into one using a digitised 2D NMR mask, utilising the functional information that can be obtained from an HSQC spectrum to distinguish between correlations of interesting secondary metabolites and those of common components within semi-purified extracts.

\section{Cyclic Loading}

Crude extracts of marine organisms contain a wide array of compounds with varying polarity ranging from very polar salts, proteins and sugars, to non-polar fats and steroids. This characteristic, coupled with the fact that the extract is usually saturated, makes these mixtures problematic to work with due to their propensity to precipitate with any adjustment of polarity or concentration. The initial fractionation of an extract is therefore often considered the most challenging part of an isolation procedure. ${ }^{47}$

The compounds of interest to natural products chemists, biologically active secondary metabolites, often possess a mixture of both polar and non-polar properties in order to traverse both hydrophilic and hydrophobic environments, and are therefore generally amphiphilic. This allows the compounds to be both partially water soluble and easily transported across cell membranes and other biological barriers. The components of biological extracts can therefore be thought to belong in one of three groups; the polar salts, proteins and sugars at one extreme, the non-polar fats and steroids at the other extreme, and the compounds of mid-polarity in between. Few primary metabolites are found in the mid-polarity group, making this "mass window" an ideal target for the first stage of fractionation of a crude extract.

West and Northcote developed cyclic loading in 1996 to aid in the fractionation of an extract. ${ }^{48}$ In its initial form, this technique involves passing a crude extract 
through a column of poly(styrene-divinylbenzene) (PSDVB) resin, allowing the non-polar metabolites to be adsorbed to the stationary phase. The eluent is then sequentially diluted with $\mathrm{H}_{2} \mathrm{O}$ in order to increase its polarity, and is then passed through the same column, forcing more polar compounds to adsorb to the column. This technique is repeated until all compounds of interest have adsorbed to the stationary phase - typically achieved by a four-fold dilution of the original solvent concentration (see Figure 2.1). The principle behind this approach is that as the eluent is progressively made more polar by dilution with $\mathrm{H}_{2} \mathrm{O}$, mid-polarity compounds will have more of an affinity for the stationary phase and will therefore adsorb to the column. ${ }^{49}$

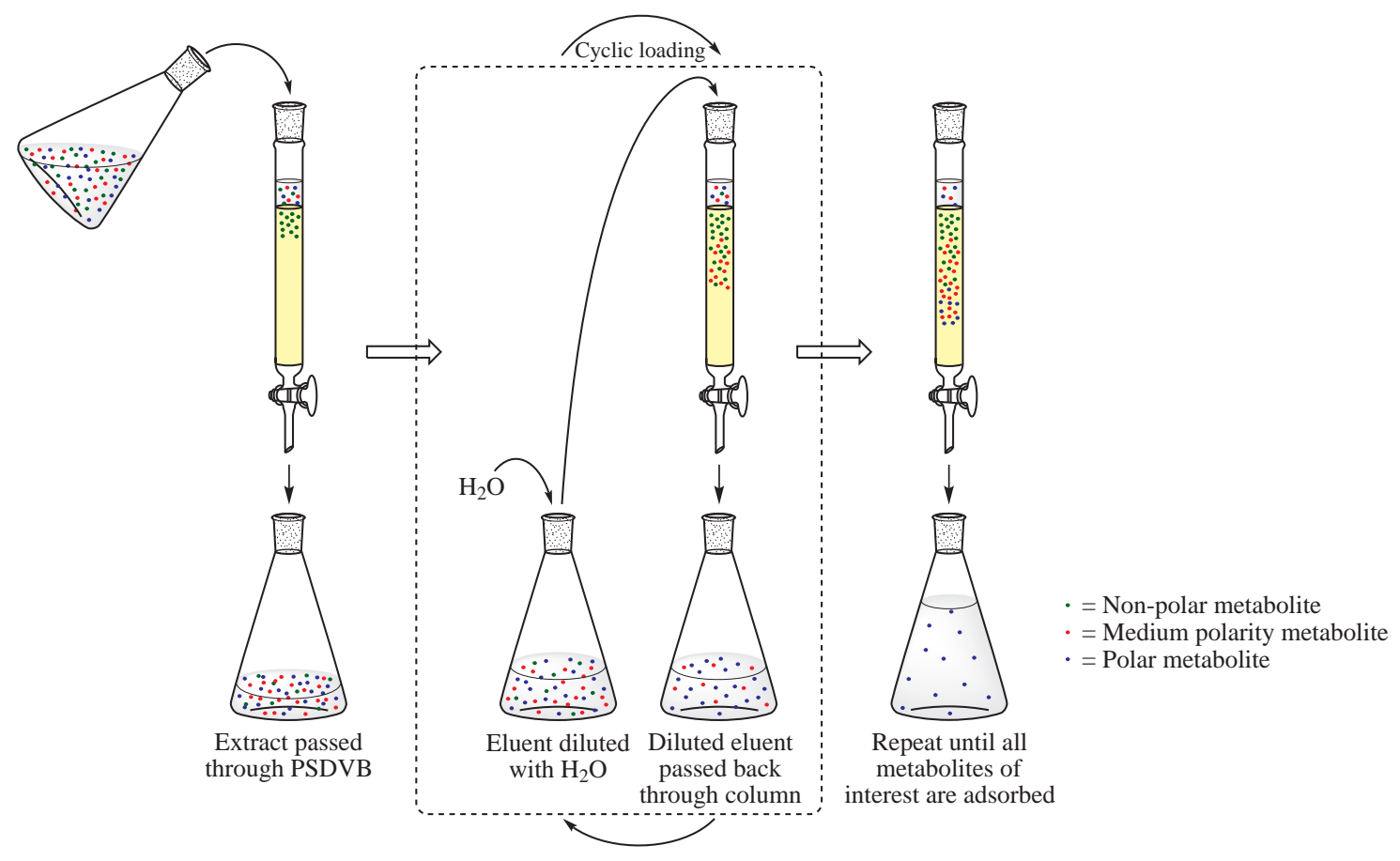

Figure 2.1. Cyclic loading.

Once loading has been completed, the column is eluted using a stepped or gradient system of increasing organic solvent $\left(\mathrm{MeOH}\right.$ or $\left.\mathrm{Me}_{2} \mathrm{CO}\right)$ in $\mathrm{H}_{2} \mathrm{O}$, such that the increasing organic modifier concentration partitions the variety of compounds from the initial crude extract according to polarity. ${ }^{48}$ The mid-polarity metabolites are targeted during the cyclic loading process by first desalting the column with $\mathrm{H}_{2} \mathrm{O}$, and then batch eluting with mixes of increasing organic solvent modifiers, typically $30 \%, 75 \%$ and $100 \% \mathrm{Me}_{2} \mathrm{CO}$ in $\mathrm{H}_{2} \mathrm{O}$. Biologically active amphiphilic metabolites tend to elute in the mid-polarity fraction $\left(75 \% \mathrm{Me}_{2} \mathrm{CO}\right)$. This process is not perfect and in practice the $75 \% \mathrm{Me}_{2} \mathrm{CO}$ fraction will often contain some primary metabolites of little interest, while potentially 
interesting compounds are sometimes found in the $30 \%$ and $100 \% \mathrm{Me}_{2} \mathrm{CO}$ fractions. It is, however, a useful first step in order to provide some insight into the secondary metabolite composition of the extract as a whole. ${ }^{49}$

A common problem encountered during reversed-phase chromatographic fractionation is that mixtures of organic solvents and $\mathrm{H}_{2} \mathrm{O}$ are notoriously problematic to concentrate under reduced pressure due to their propensity to froth or "bump". This problem is overcome by an extension of the cyclic loading method, backloading. Fractions are cyclic loaded onto a smaller column of PSDVB which can then be eluted with a pure organic solvent, eliminating the $\mathrm{H}_{2} \mathrm{O}$ content and therefore enabling easier concentration by evaporation under reduced pressure.

\section{Development of the NMR Screening Protocol}

The in-house NMR screening protocol instigated by the VUW Marine Natural Products Group has been used for the screening of sponge extracts, or more correctly semi-purified extracts, for several years. The screening protocol was based on the search for novel structures, and on the assumption that novel structures often have novel activities that can be determined after isolation, rather than using a bioassay guided isolation. Also, in-house methods are preferable to external assays with respect to speed, economy and accuracy of results. ${ }^{47}$ However, a major problem with NMR screening is the inability to dissolve crude marine extracts in any one solvent due to the large range of polarities observed in the mixture of primary and secondary metabolites. This issue was overcome by the use of cyclic loading as the first stage of fractionation.

The concept of the screening protocol was to distinguish between common and unusual correlations present in the NMR spectra of semi-purified sponge extracts by analysing the soluble $75 \% \mathrm{Me}_{2} \mathrm{CO}$ fraction. Initial work involved only the analysis of ${ }^{1} \mathrm{H} \mathrm{NMR}$ spectra, however this system was found to be rather limited as many of the semi-purified extracts screened still contained large amounts of primary metabolites, the signals of which obscured most of the other resonances below $5.5 \mathrm{ppm}$ in the $1 \mathrm{D}{ }^{1} \mathrm{H}$ NMR spectrum. ${ }^{47}$ At this point, the protocol was extended to using 2D NMR spectra, specifically COSY 
and HSQC, to introduce a second dimension in which to separate the resonances.

A paper mask was generated for both the COSY and HSQC spectra by correlating a number of screen spectra to produce a mask sheet showing positions of correlations of common metabolite resonances. New COSY or HSQC spectra generated from a sponge screen were overlaid on the relevant mask sheet and any unusual correlations were marked. The individual screen was then assessed, considering signal strength, number and uniqueness of interesting peaks, available mass and organism recollectability.

Although the principal of the paper mask was successful, ${ }^{47}$ it became evident that the manual interpretation of the complex spectra was difficult and prone to error, especially in crowded regions of the spectrum. Also, the effectiveness of the masks themselves were limited as only 10-20 spectra were used to generate the mask sheets. A more robust system was required in which the mask would continue to develop as more organisms were screened. Such detailed analysis is better performed by a computer, and therefore a digital mask was proposed.

\section{HSQC Mask}

A digital HSQC mask was developed by our laboratory for the screening of sponge extracts. COSY, HSQC and HMBC experiments were considered for the NMR screening method. The HSQC experiment was preferred to the quicker COSY experiment due to the increase in functional information obtained from the carbon data. The HMBC was discounted due to the complexity of the data and the time required to obtain a reasonable spectrum, however this experiment is now being re-evaluated as a screening tool.

To construct the mask, the HSQC data is exported and added together to generate a digital mask. Through adding the NMR data sets together, the generated mask displays common correlations as strong peaks while the less common correlations are weak. This is illustrated in Figure 2.2, where the common peaks are shown in white, and uncommon peaks appear as blue. It is important to note that the intensity of the peaks in the original HSQC spectra are not considered when the mask is generated. The mask simply adds 
" 1 " if a peak exists in a particular region, or adds " 0 " if it is absent. Once the mask is generated, HSQC spectra of newly screened extracts are added to the mask.

The initial HSQC data of red algal extracts were screened with the existing sponge HSQC mask. This proved unsatisfactory as all the HSQC spectra analysed appeared to be very interesting with respect to common sponge metabolites. It became evident that the resonances of common metabolites in red algal extracts were significantly different to those observed in sponge extracts; the mask is phylum specific. Thirty-four red algae were therefore screened in order to generate an algal HSQC mask. Figure 2.3 shows the sponge HSQC mask applied to a seemingly interesting algal extract (a), and the algal mask applied to the same data showing, in fact, very few unique correlations (b), illustrating this phylum specificity. When the mask has been applied to an HSQC, common correlations are displayed in green, while unusual correlations are red.

\subsection{Algal Screening}

A standard protocol for the screening of sponge extracts through 2D NMR experiments was developed by our laboratory (see Appendix A). ${ }^{47-49}$ This protocol involves the extraction of $\sim 100 \mathrm{~g}$ (wet weight) of sponge material and analysis of the 2D NMR data of the $75 \% \mathrm{Me}_{2} \mathrm{CO}$ fraction following cyclic loading. In this study, it was found that the procedure was easily adapted to macro-algae though, with the acquisition of a more powerful NMR instrument, less material was required in order to obtain reasonable NMR data. This increase in sensitivity coupled with the finding that the red algal $75 \%$ fractions were, on average, slightly richer than those of the sponge extracts meant that the screening protocol could be applied to as little as $2 \mathrm{~g}$ of macro-algae.

In this study, 34 algal extracts were screened using the HSQC mask and four extracts were analysed in detail. Two of these led to the isolation of novel compounds and are detailed in later chapters (Phacelocarpus labillardieri, see Chapter 3, Osmundaria colensoi, see Chapter 4). The remaining two extracts are discussed briefly here. 


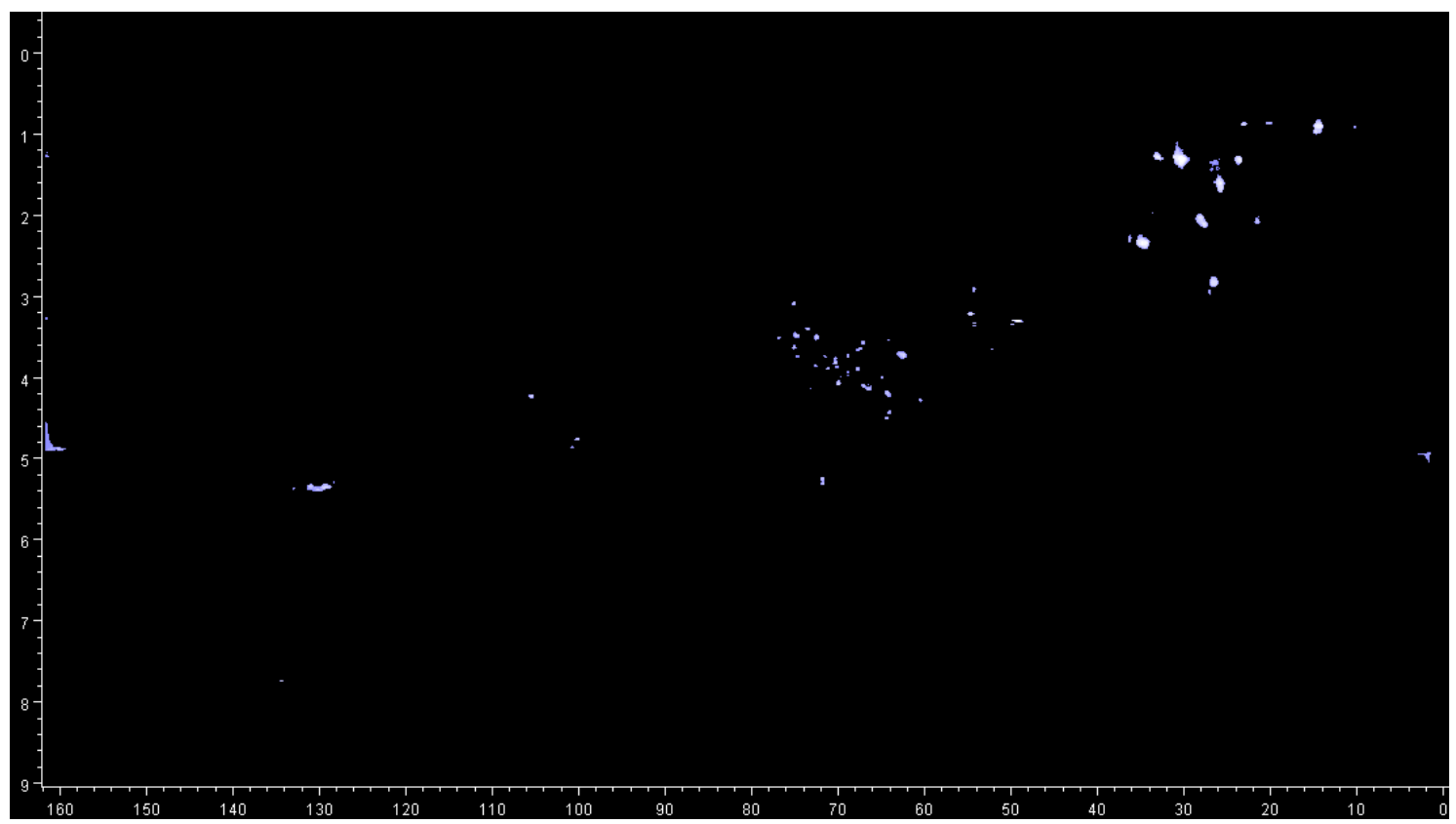

(a) Common correlations in the algal HSQC mask.

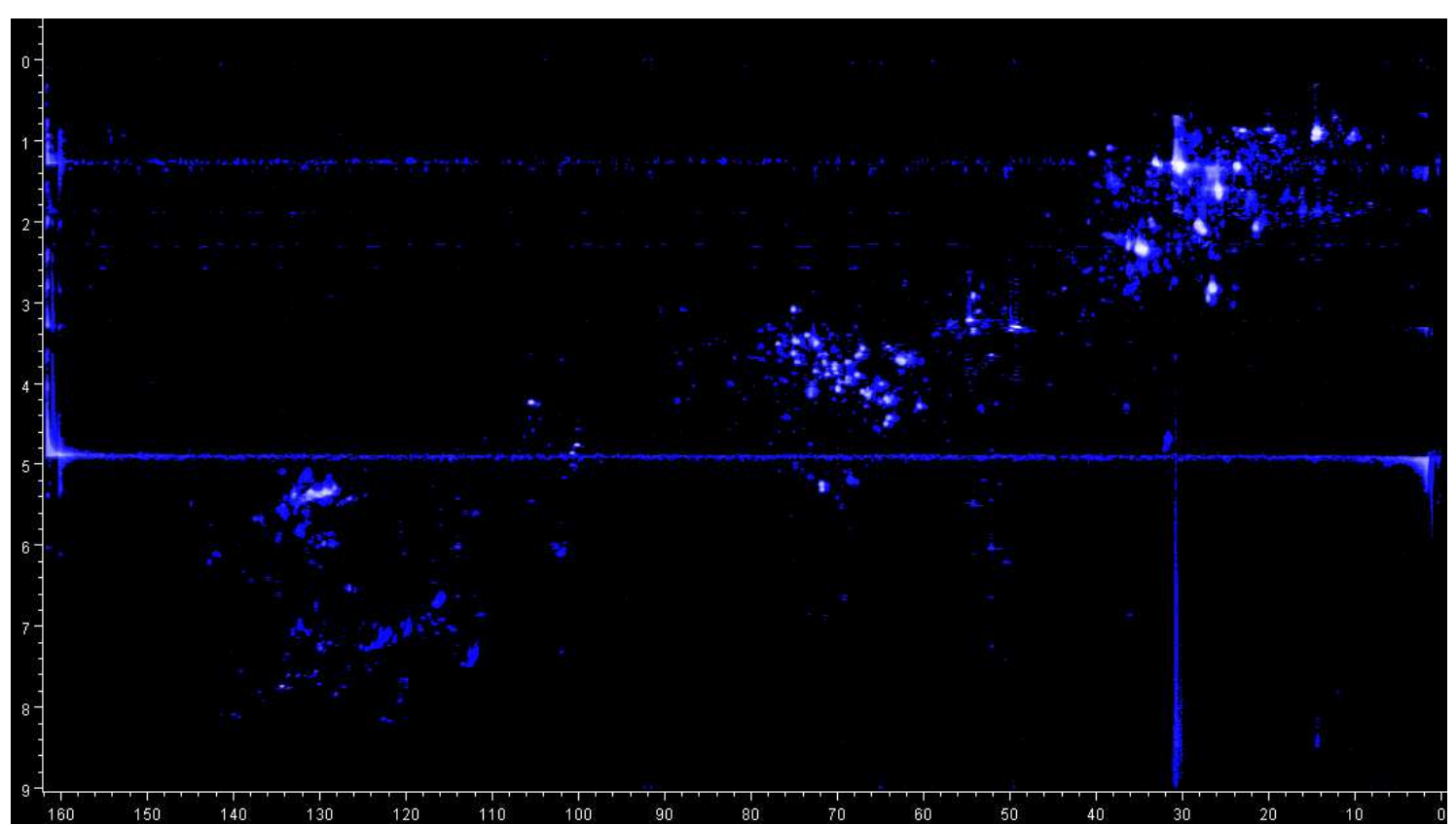

(b) The full algal HSQC mask.

Figure 2.2. Algal HSQC mask showing the common correlations in white and the uncommon correlations in blue. 


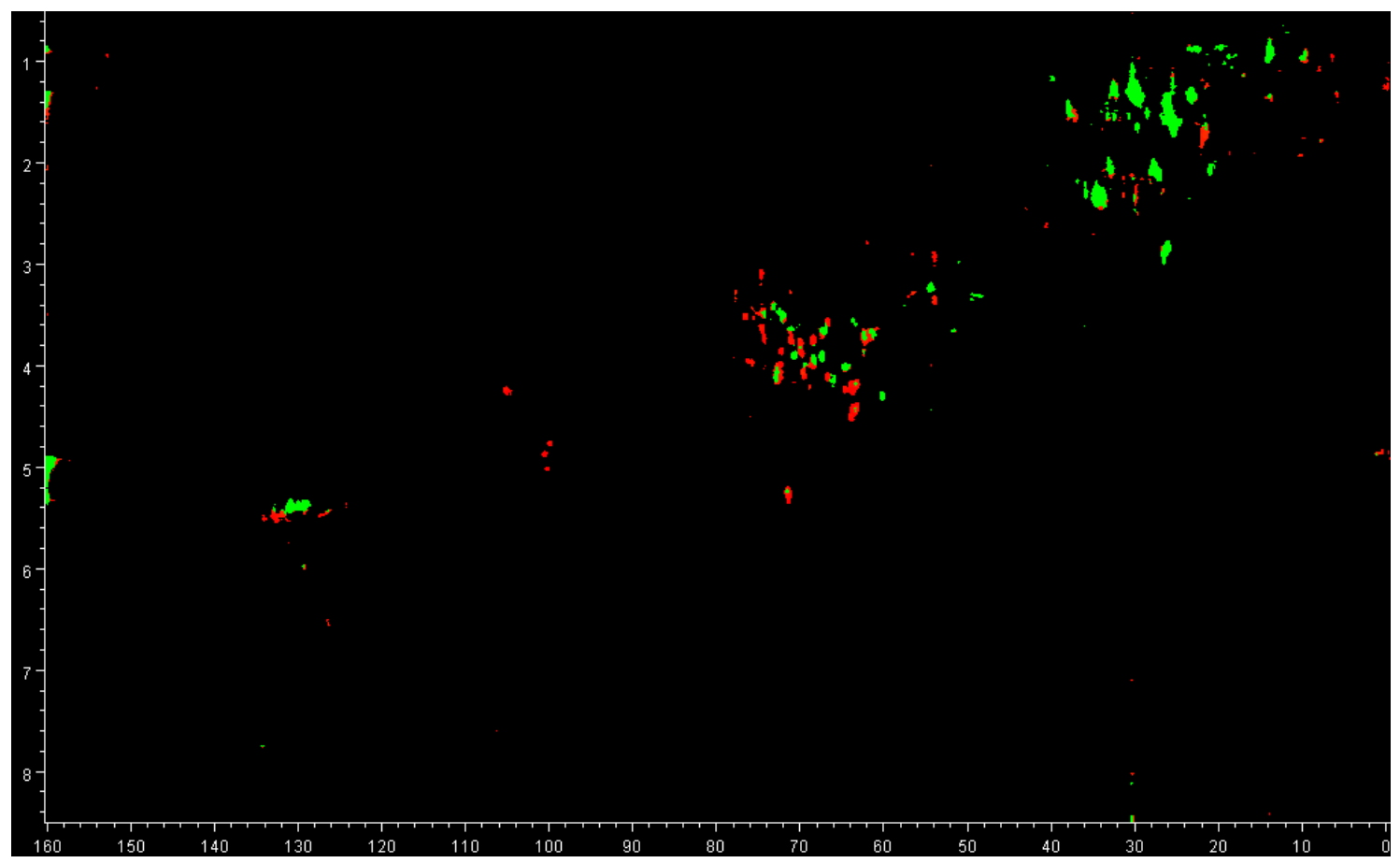

(a) Sponge HSQC mask applied to Curdiea coriacea.

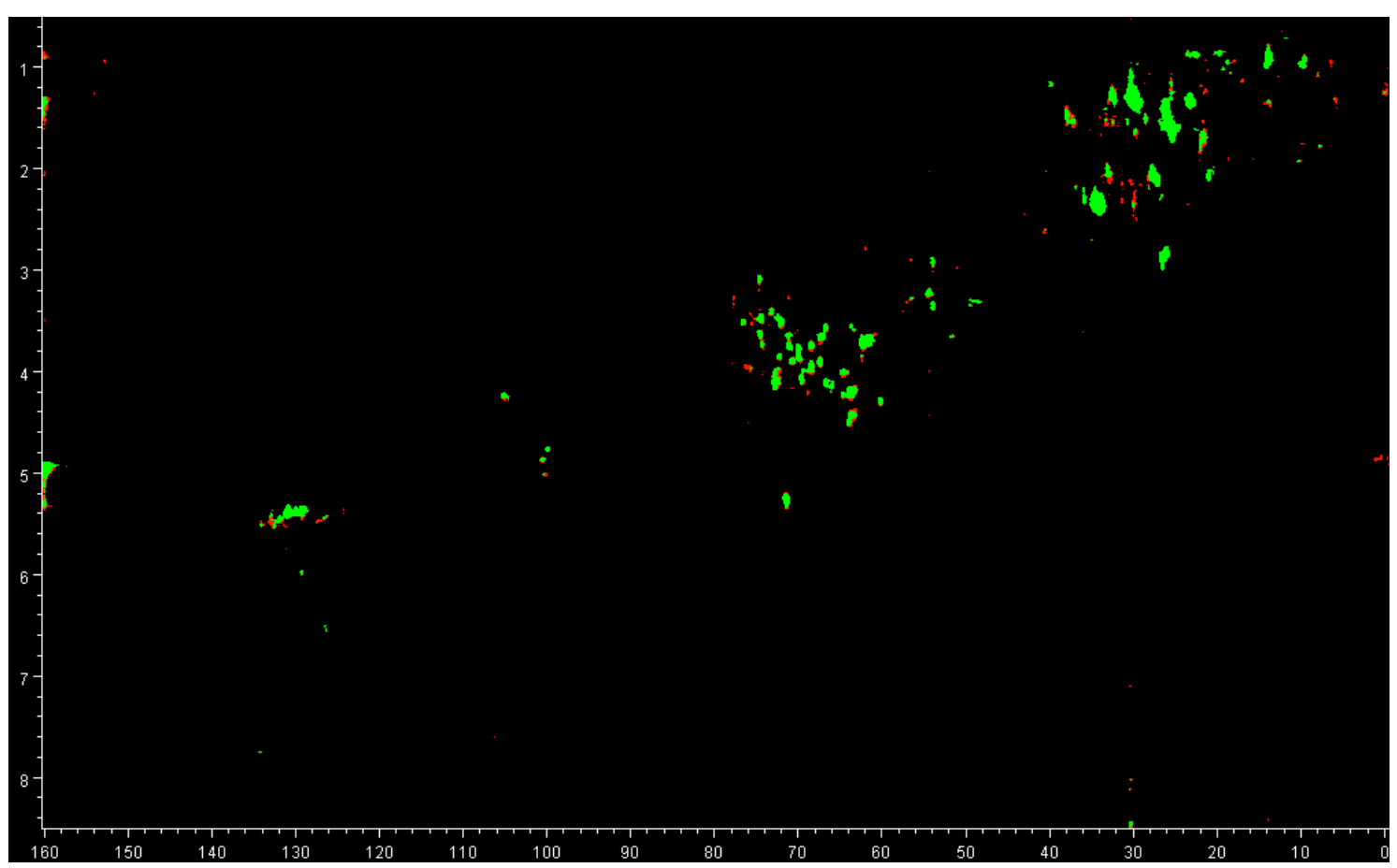

(b) Algal HSQC mask applied to Curdiea coriacea.

Figure 2.3. HSQC mask of $C$. coriacea showing the common correlations in green and the unusual correlations in red. 


\section{Plocamium costatum}

The spectra obtained from screening Plocamium costatum (126 g, collected from Doubtless Bay, Northland, Figure 2.4) was recognised as being interesting using the HSQC mask (Figure 2.5). Inspection of the screening NMR spectra revealed what appeared to be one major compound (Figure 2.6).

One further step of purification of the $75 \% \mathrm{Me}_{2} \mathrm{CO}$ fraction lead to the isolation of the known monoterpene costatone (44). Originally isolated in 1976 from two separate South Australian collections of $P$. costatum, 44 was first synthesised in $1984 .^{50-52}$ The NMR assignment of $\mathbf{4 4}$ is well documented in the literature, therefore it is unnecessary to give a

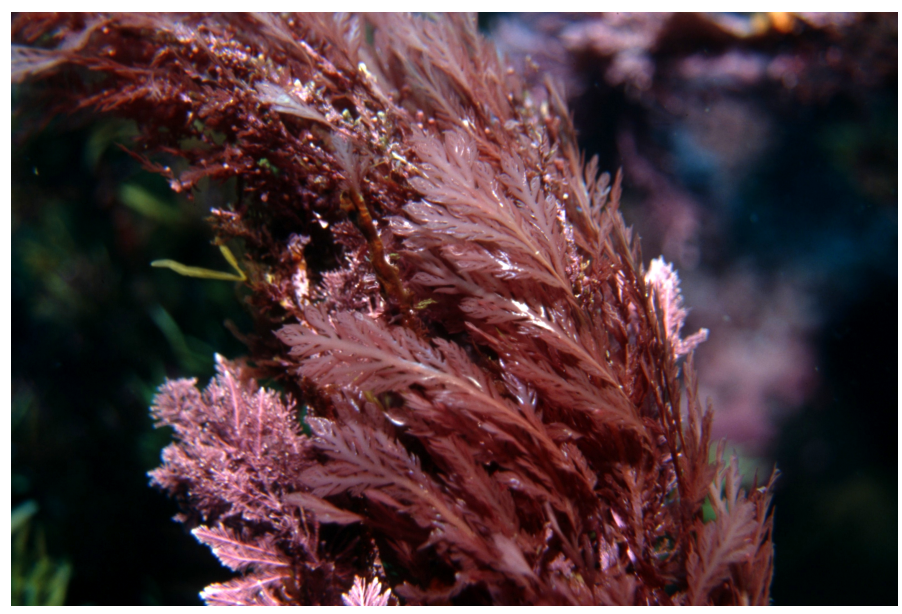

Figure 2.4. Plocamium costatum. Image courtesy of Malcolm Francis.

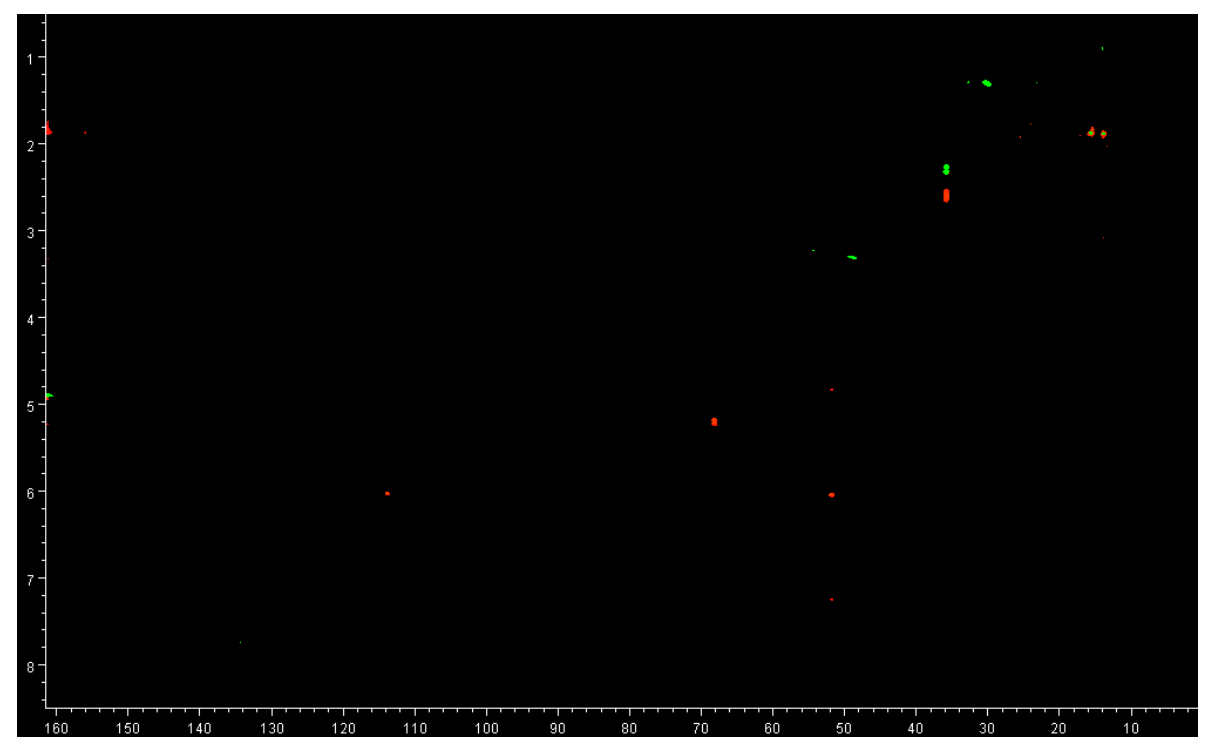

Figure 2.5. HSQC mask of $P$. costatum showing the common correlations in green and the unusual correlations in red. 


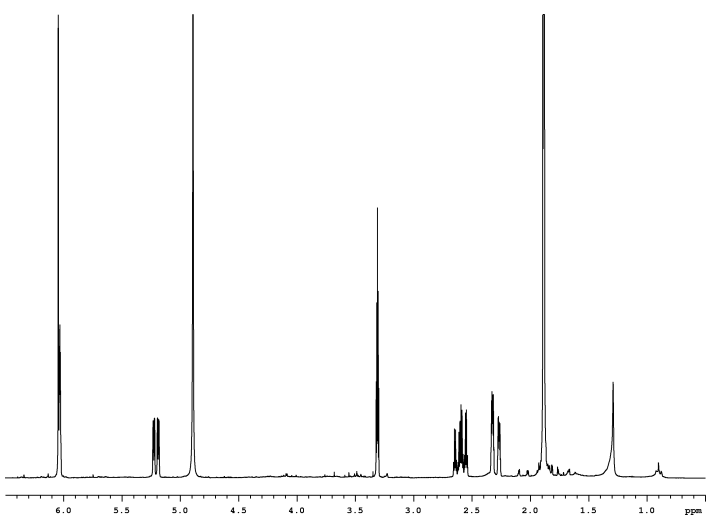

(a) ${ }^{1} \mathrm{H}$ spectrum

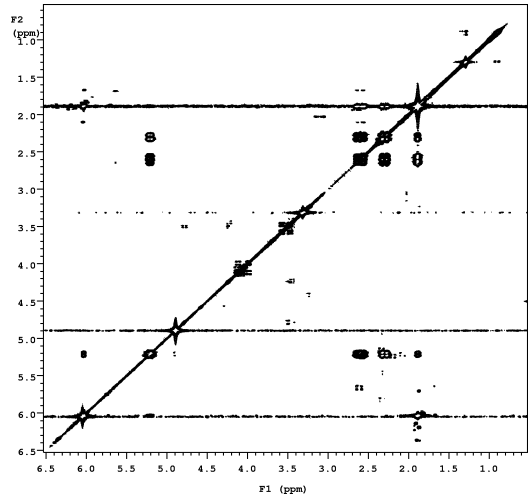

(b) COSY spectrum

Figure 2.6. NMR spectra of the $75 \% \mathrm{Me}_{2} \mathrm{CO}$ in $\mathrm{H}_{2} \mathrm{O}$ screening fraction of $P$. costatum.

detailed analysis of the sample isolated in this study. Full NMR data for $\mathbf{4 4}$ can be found in Appendix B. The optical rotation of the isolated sample of $44\left([\alpha]_{\mathrm{D}}^{25}-48.0(c\right.$ 1.12, $\left.\mathrm{CH}_{2} \mathrm{Cl}_{2}\right)$ ) was in excellent agreement with that reported in literature $\left([\alpha]_{\mathrm{D}}^{25}-54.0(c\right.$ 1.02, $\left.\left.\mathrm{CHCl}_{3}\right)\right),{ }^{51}$ suggesting the same absolute configuration. As costatone (44) accounted for all the correlations of interest present in the screen spectra, further analysis of the extract was discontinued.<smiles>CC1=C(Cl)C[C@@H](/C(C)=C/Cl)O[C@]1(O)C(Br)Br</smiles>

44

\section{Ballia callitricha}

The screen spectra of an Owhiro Bay, Wellington collection of Ballia callitricha (Figure 2.7) displayed interesting resonances attributed to aromatics and low strength resonances in the aliphatic region (Figure 2.8).

A largescale extraction of the red algae was performed (664 g), from which the known compounds, $1 H$-indole-3-carboxaldehyde (45) and $(E)$ - $N$-formyl-3-(1H-indol-3-yl)prop2-enamide (46), were isolated. Compound $\mathbf{4 5}$ has long been known as a synthetic compound, but has also been isolated from various cruciferous vegetables as well as from the marine environment. ${ }^{53-56}$ Compound 46 was first reported in 1992 from the red 


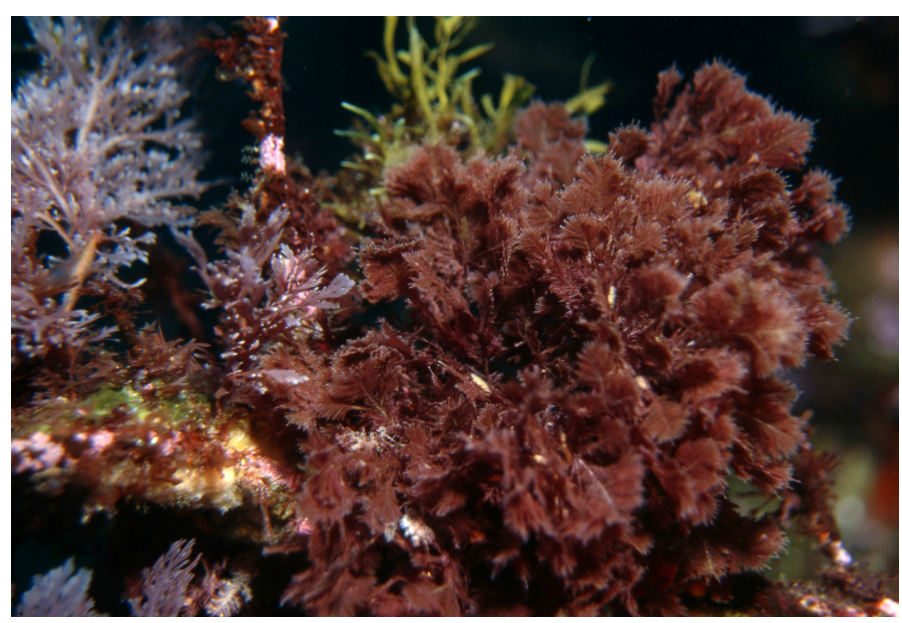

Figure 2.7. Ballia callitricha. Image courtesy of Malcolm Francis.

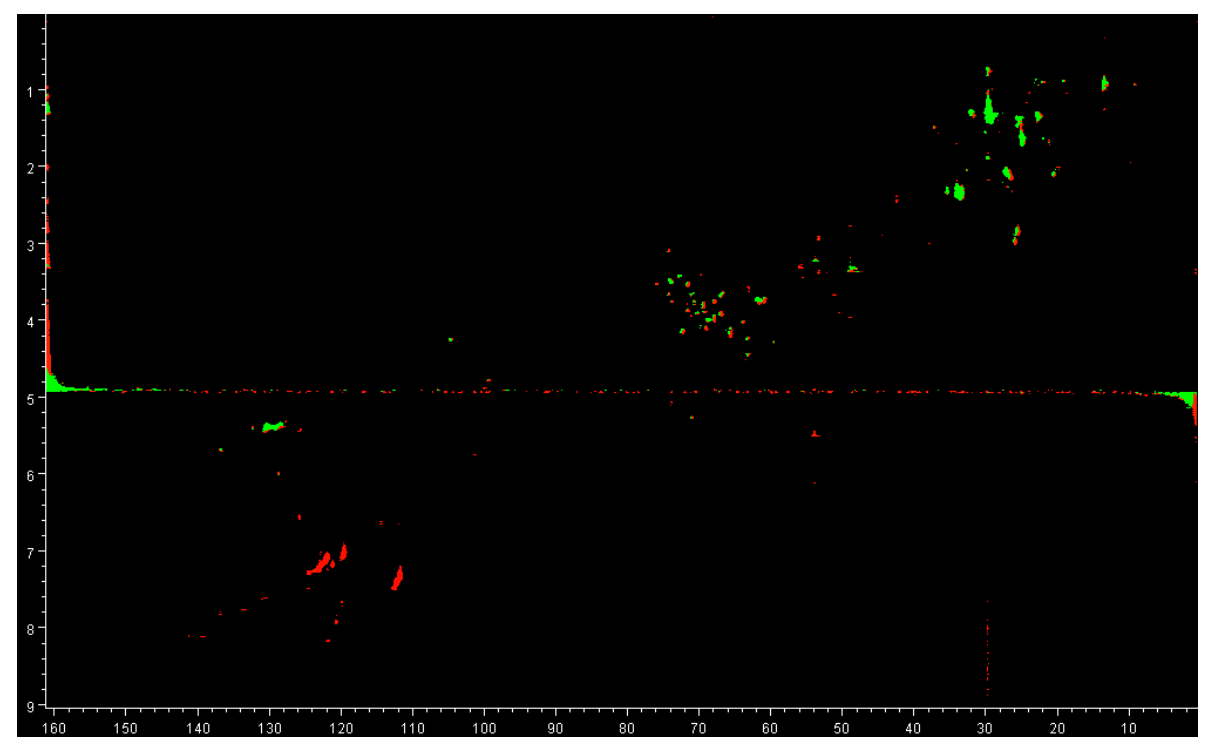

Figure 2.8. HSQC mask of $B$. callitricha showing the common correlations in green and the unusual correlations in red.

alga Chondria sp., along with chondriamides A (47) and B (48). ${ }^{56}$ Both 45 and 46 were considered possible oxidation products of chondriamide A (47), as the two were formed when a methanolic solution of $\mathbf{4 7}$ was left standing overnight. ${ }^{56}$<smiles>O=Cc1c[nH]c2ccccc12</smiles>

45<smiles>O=CNC(=O)/C=C/c1c[nH]c2ccccc12</smiles>

46<smiles>[R]c1cccc2c(/C=C/C(=O)N/C=C/c3c[nH]c4ccccc34)c[nH]c12</smiles>

$47 \quad \mathrm{R}=\mathrm{H}$

$48 \mathrm{R}=\mathrm{OH}$

A detailed analysis of the NMR data obtained in this study led to the reassignment of two olefinic methines in (E)- $N$-formyl-3-(1H-indol-3-yl)prop-2-enamide (46). Specifically, 
the assignment of the ${ }^{1} \mathrm{H}$ and ${ }^{13} \mathrm{C}$ resonances for $\mathrm{C}-10$ and $\mathrm{C}-11$ were interchanged. The revised NMR data is presented in Table 2.1.

Table 2.1. ${ }^{13} \mathrm{C}(150 \mathrm{MHz})$ and ${ }^{1} \mathrm{H}(600 \mathrm{MHz}) \mathrm{NMR}$ data $\left(\mathrm{CD}_{3} \mathrm{OD}\right)$ for (E)- $N$-formyl-3-(1H-indol-3-yl)prop-2-enamide (46).

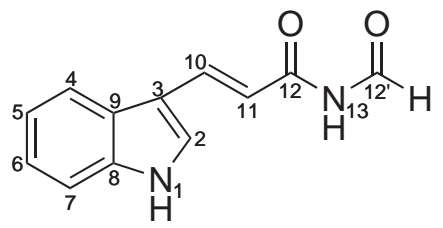

\begin{tabular}{|c|c|c|c|c|c|c|c|}
\hline \multirow[b]{2}{*}{ Pos } & \multicolumn{2}{|c|}{${ }^{13} \mathrm{C}$ or ${ }^{15} \mathrm{~N}$} & \multicolumn{3}{|c|}{${ }^{1} \mathrm{H}$} & \multirow[b]{2}{*}{ COSY } & \multirow{2}{*}{$\begin{array}{c}\text { HMBC } \\
\left({ }^{1} \mathrm{H} \text { to }{ }^{13} \mathrm{C} \text { or }{ }^{15} \mathrm{~N}\right)\end{array}$} \\
\hline & $\delta(\mathrm{ppm})$ & mult & $\delta(\mathrm{ppm})$ & mult & $J(\mathrm{~Hz})$ & & \\
\hline 1 & -240.5 & $\mathrm{NH}$ & & & & & \\
\hline 2 & 133.7 & $\mathrm{CH}$ & 7.75 & $\mathrm{~s}$ & & & $1,3,7,8,9,10$ \\
\hline 3 & 114.2 & $\mathrm{C}$ & & & & & \\
\hline 4 & 121.3 & $\mathrm{CH}$ & 7.92 & d & 7.4 & 5 & $3,6,8,9$ \\
\hline 5 & 122.5 & $\mathrm{CH}$ & 7.22 & $\operatorname{td}$ & $7.2,1.4$ & 4,6 & 7,9 \\
\hline 6 & 124.1 & $\mathrm{CH}$ & 7.25 & $\mathrm{td}$ & $7.2,1.4$ & 5,7 & 4,7 \\
\hline 7 & 113.3 & $\mathrm{CH}$ & 7.46 & d & 7.3 & 6 & 5,9 \\
\hline 8 & 139.4 & $\mathrm{C}$ & & & & & \\
\hline 9 & 126.5 & $\mathrm{C}$ & & & & & \\
\hline 10 & 141.7 & $\mathrm{CH}$ & 8.09 & d & 15.9 & 11 & $2,3,9,11,12$ \\
\hline 11 & 112.5 & $\mathrm{CH}$ & 6.62 & d & 15.1 & 10 & 3,12 \\
\hline 12 & 169.5 & $\mathrm{C}$ & & & & & \\
\hline 13 & $\dagger$ & $\mathrm{NH}$ & & & & & \\
\hline $12^{\prime}$ & 165.2 & $\mathrm{CH}$ & 9.21 & s & & & \\
\hline
\end{tabular}

Further examination of the fractions generated during this isolation indicated that all peaks of interest were clearly related indole-containing compounds. Indoles are well studied both as natural products and as synthetic compounds and therefore analysis of the extract was discontinued. Full NMR data for $1 H$-indole-3-carboxaldehyde (45) can be found in Appendix B.

\subsection{Summary}

Over the past 12 years, the VUW Marine Natural Products group have developed a unique in-house NMR screening protocol. In this study, 34 red algal extracts were screened in order to generate a digital algal HSQC mask which was used to analyse the extracts using the NMR based screening protocol. Four extracts were analysed in detail, two of which are discussed in subsequent chapters. The remaining two extracts produced three known compounds, costatone (44), $1 H$-indole-3-carboxaldehyde (45) and (E)- $N$-formyl-3-(1Hindol-3-yl)prop-2-enamide (46). 


\section{Chapter 3}

\section{Labillarides A to K: Eleven New Oxylipins from Phacelocarpus labillardieri}

\subsection{Phacelocarpus labillardieri}

In this study, extracts of a number of specimens of the New Zealand marine macro-algae Phacelocarpus labillardieri [(Mertens ex Turner) J. Agardh] (Figure 3.1) were examined. P. labillardieri, of the monotypic family Phacelocarpaceae, is found primarily in the southern hemisphere, with a northern distribution in New Zealand waters (taxonomy see Table 3.1). It is an erect plant and is characterised by narrow, parallel-sided fronds with "marginal teeth of even length giving a minute saw-edge." 57

The NMR spectra obtained from screening P. labillardieri with our standard protocol displayed a large number of clusters recognised as being of great interest using the HSQC mask (Figure 3.2). These included two clusters of olefinic methines centred around $\delta_{\mathrm{H}} 5.5$ and $\delta_{\mathrm{C}} 130$, and $\delta_{\mathrm{H}} 6.0$ and $\delta_{\mathrm{C}} 100$, respectively.

There have been a number of compounds reported from Australian specimens of Phacelocarpus labillardieri, most of which form a novel group of polyunsaturated macrocycles containing $\alpha$ - and $\gamma$-pyrones. In 1982, the first of the macrocyclic $\gamma$-pyrone

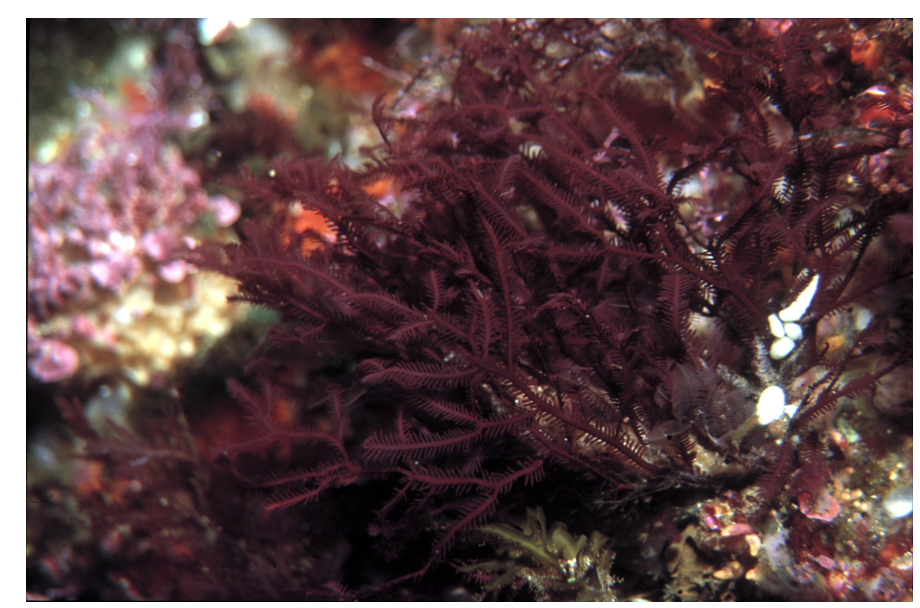

Figure 3.1. Phacelocarpus labillardieri. Image courtesy of Malcolm Francis. 
Table 3.1. Taxonomic classification of genus Phacelocarpus from order Gigartinales as presented by AlgaeBase. ${ }^{21}$

\begin{tabular}{|c|c|c|}
\hline Order & Family & Genus \\
\hline \multirow{38}{*}{ Gigartinales } & Acrotylaceae & $\ldots$ \\
\hline & Areschougiaceae & $\ldots$ \\
\hline & Blinksiaceae & $\ldots$ \\
\hline & Calosiphonaceae & $\ldots$ \\
\hline & Catenellopsidaceae & $\ldots$ \\
\hline & Caulacanthaceae & $\ldots$ \\
\hline & Chondriellaceae & $\ldots$ \\
\hline & Corynocystaceae & $\ldots$ \\
\hline & Corynomorphaceae & $\ldots$ \\
\hline & Crossocarpaceae & $\ldots$ \\
\hline & Cruoriaceae & $\ldots$ \\
\hline & Cubiculosporaceae & $\ldots$ \\
\hline & Cystocloniaceae & $\ldots$ \\
\hline & Dicranemataceae & $\ldots$ \\
\hline & Dumontiaceae & $\ldots$ \\
\hline & Endocladiaceae & $\ldots$ \\
\hline & Furcellariaceae & $\ldots$ \\
\hline & Gainiaceae & $\ldots$ \\
\hline & Gigartinaceae & $\ldots$ \\
\hline & Gloiosiphoniaceae & $\ldots$ \\
\hline & Haemeschariaceae & $\ldots$ \\
\hline & Hypneaceae & $\ldots$ \\
\hline & Kallymeniaceae & $\ldots$ \\
\hline & Mychodeaceae & $\ldots$ \\
\hline & Mychodeophyllaceae & $\ldots$ \\
\hline & Nizymeniaceae & $\ldots$ \\
\hline & Peyssonneliaceae & $\ldots$ \\
\hline & Phacelocarpaceae & Phacelocarpus \\
\hline & Phyllophoraceae & $\ldots$ \\
\hline & Polyidaceae & $\ldots$ \\
\hline & Pseudoanemoniaceae & $\ldots$ \\
\hline & Rhizophyllidaceae & $\ldots$ \\
\hline & Rissoellaceae & $\ldots$ \\
\hline & Sarcodiaceae & $\ldots$ \\
\hline & Solieriaceae & $\ldots$ \\
\hline & Sphaerococcaceae & $\ldots$ \\
\hline & Stictosporaceae & $\ldots$ \\
\hline & Tichocarpaceae & $\ldots$ \\
\hline
\end{tabular}




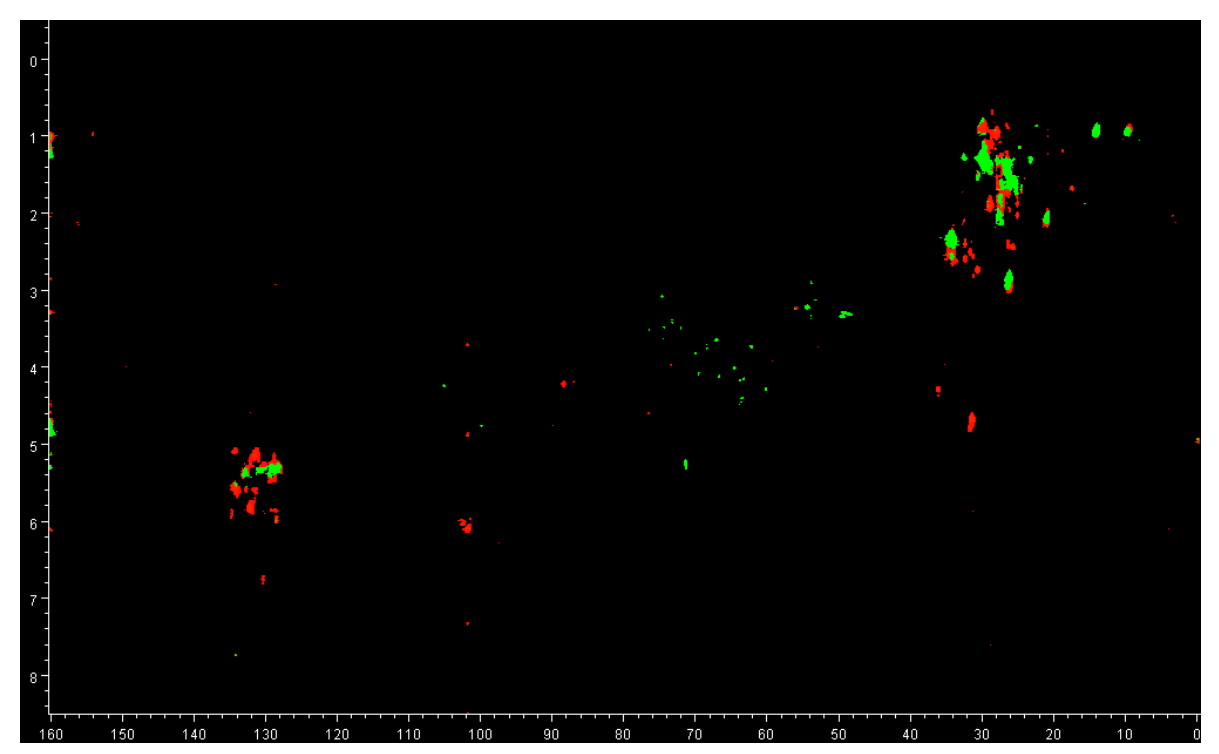

Figure 3.2. HSQC mask showing the common correlations in green and the unusual correlations in red.

group were reported from southern Australian collections of P. labillardieri (49-51), along with a straight-chain $\alpha$-pyrone (52). ${ }^{58}$ The geometry of the enol-ether double bond of 49 was not confirmed until 1986, when the NMR data reported for 49 was compared with those of four new related compounds reported by Shin et al. from another Australian collection of $P$. labillardieri. The four new compounds consisted of the $(E) \gamma$-pyrone $(\mathbf{5 3})$ and $\alpha$-pyrone (54) enol-ether isomers of 49, a dibrominated macrocyclic $\alpha$-pyrone (55) and a hydroxylated $\gamma$-pyrone (56) macrocycle. ${ }^{59}$ In 1990, 57, the dibrominated analogue of 50, was reported from a Tasmanian collection of P. labillardieri. ${ }^{60}$ Compound $\mathbf{5 7}$ was reported along with the isolation of $\beta$-farnesene (58), a common terrestrial sesquiterpene which is rarely reported from marine organisms. Finally, the tenth member of this class, a macrocyclic $\gamma$-pyrone (59), was reported in 1995 from a South Australian collection of $P$. peperocarpus (now considered a synonym of P. labillardieri). ${ }^{61}$ The $(Z)$ geometry of the enol-ether of $\mathbf{5 0}$ was also confirmed in this study. The geometry of the enol-ether of 56 remains undetermined. In 2003, the use of ring closing alkyne metathesis allowed the synthesis of a model of the core structure of the macrocyclic pyrone derivatives. ${ }^{62}$ To date, there has been no report of a total synthesis to confirm the proposed structure of any of these macrocyclic compounds. 
<smiles>CC/C1=C/C/C=C\C/C=C\CC#CCCCCc2cc(=O)cc(o2)O1</smiles>

49<smiles>CCCCC/C=C\C/C=C\C/C=C\CCCCC1CC=CC(=O)O1</smiles>

52<smiles></smiles>

55

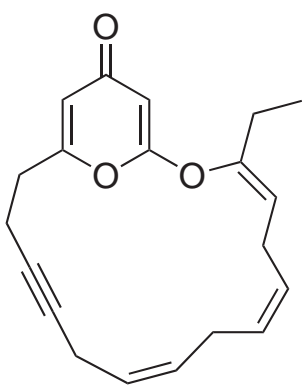

50<smiles>CC/C1=C\C/C=C\C/C=C\CC#CCCCCc2cc(=O)cc(o2)O1</smiles>

53<smiles>CCC(=CC=CC(O)CC#CCC=CCCCc1cc(=O)cc(OC(CC)CC)o1)CC</smiles>

56<smiles>CCC1Oc2oc(cc(=O)c2Br)CCCCC#CC/C=C\C/C=C\CC1Br</smiles>

51<smiles>CC/C1=C\C/C=C\C/C=C\CC#CCCCCc2cc(cc(=O)o2)O1</smiles>

54

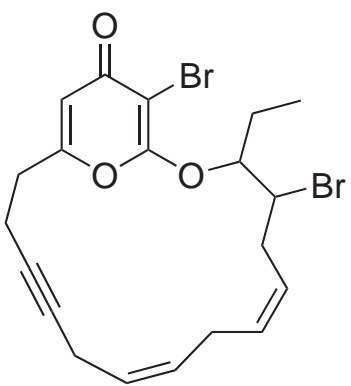

57<smiles>C=CC(=C)CCC=C(C)CCC=C(C)C</smiles>

58<smiles>CC/C1=C/C/C=C/C=C\CC(=O)/C=C\CCCCc2cc(=O)cc(o2)O1</smiles>

59

Very little biological activity has been reported for this class of compounds, though some crude extracts of $P$. labillardieri were shown to exhibit neuromuscular blocking activity, which may be due to pyrones of this type ${ }^{58}$ Compound 49 has been shown to act as a potent deterrent to marine herbivorous shellfish, snails and other gastropods, implying its likely involvement in the chemical defense of the algae against predators. ${ }^{63}$ Moreover, a study of phospholipase $A_{2}$ inhibitors from marine algae revealed that $\mathbf{5 1}$ exhibited potent activity (93\% inhibition of bee venom $\mathrm{PLA}_{2}$ at $\left.4.4 \mu \mathrm{M}\right) .{ }^{64}$ 


\subsection{Isolation}

Purification of the screen extract and two further bulk extracts of collections of $P$. labillardieri from Rimariki Island, Northland, by a series of reversed-phase (PSDVB) and normal-phase (DIOL) chromatographic steps ultimately led to the isolation of eight new $\alpha$-pyrone macrocycles, named labillarides A-H (60-67), two enol macrocycles, labillarides I and J (68 and 69) and a furan-3-one oxylipin, labillaride K (70).

The NMR spectra of an extract of $P$. labillardieri obtained from the single bench-top reversed-phase chromatographic separation (PSDVB) typical to our screening protocol (Section 2.2), indicated the presence of one major constituent with lower levels of structurally-related compounds (Figure 3.3).

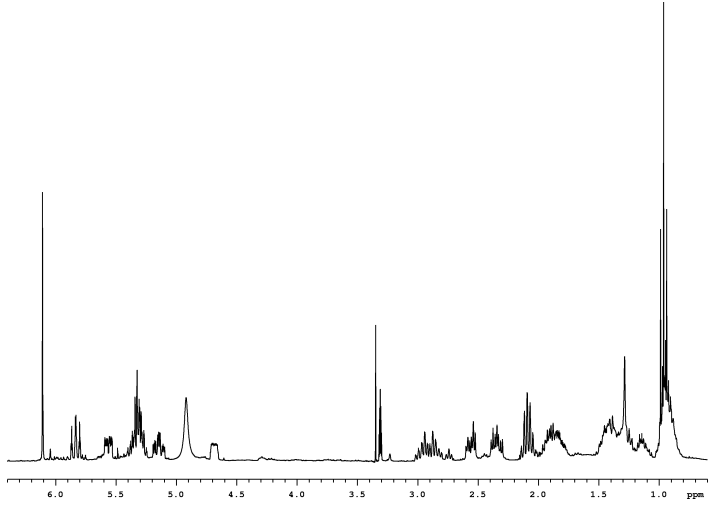

(a) ${ }^{1} \mathrm{H}$ spectrum

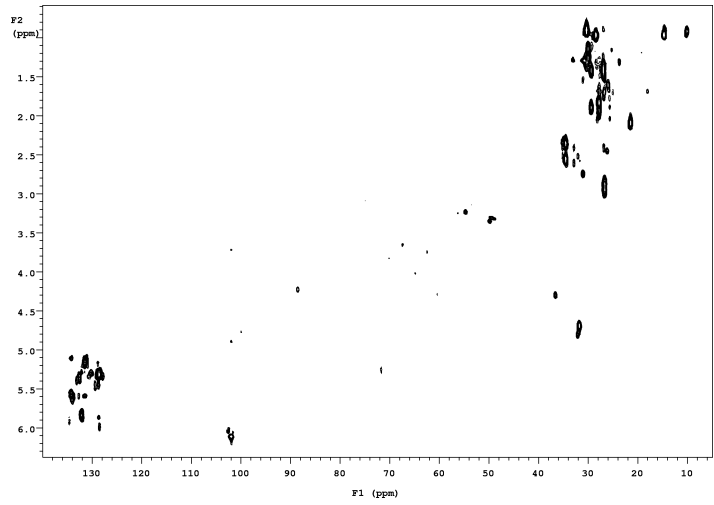

(b) HSQC spectrum

Figure 3.3. NMR spectra of a semi-purified fraction of P. labillardieri.

Several different bench-top chromatographic techniques were employed in the attempts to isolate the compounds of interest. Further reversed-phase (PSDVB) chromatography gave poor separation, suggesting reasonably non-polar compounds. In contrast, normalphase media appeared to give good separation on silica gel TLC plates. However, chromatography on silica gel led to degradation of material, suggesting acid-sensitivity. It was therefore found that the best results were achieved on DIOL in both the early stages of separation and in the final steps of isolation by HPLC.

The overall isolation strategy involved an initial reversed-phase (PSDVB) separation, followed by two open column DIOL steps to yield several non-polar fractions from the first stage $\left(\mathrm{CH}_{2} \mathrm{Cl}_{2}\right)$ and polar fractions from the $50 \% \mathrm{MeOH}$ in $\mathrm{CH}_{2} \mathrm{Cl}_{2}$ strip. Fractions 
were then either purified further by bench-top DIOL using mixtures of $\mathrm{CH}_{2} \mathrm{Cl}_{2}$ in pet. ether or EtOAc in $\mathrm{CH}_{2} \mathrm{Cl}_{2}$ as the mobile phase, or purified directly by DIOL HPLC using varying mixtures of IPA in hexane to yield labillarides A-K (60-70) (Scheme 3.1).

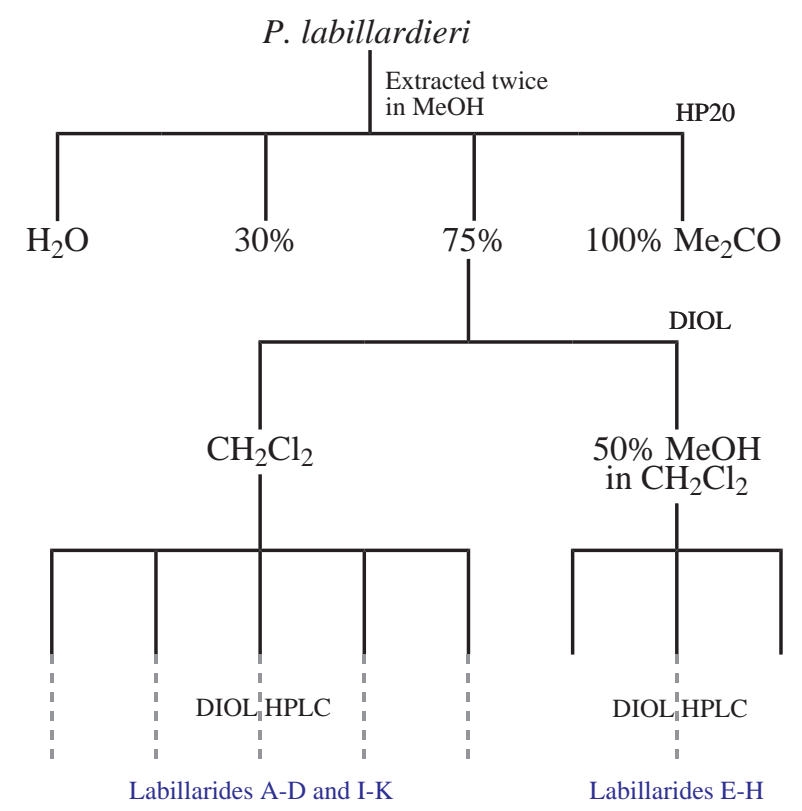

Scheme 3.1. Schematic of the overall isolation strategy for labillarides A-K (60-70).

After the initial purification of the screen extract and the first bulk extract, it was discovered that pure labillarides A-D quickly degraded when stored above $-20^{\circ} \mathrm{C}$. To counter this instability, samples obtained during the purification of the second bulk extract were stored in liquid nitrogen. An overview of the actual individual isolation procedures for these 11 metabolites is presented in Scheme 3.2. 


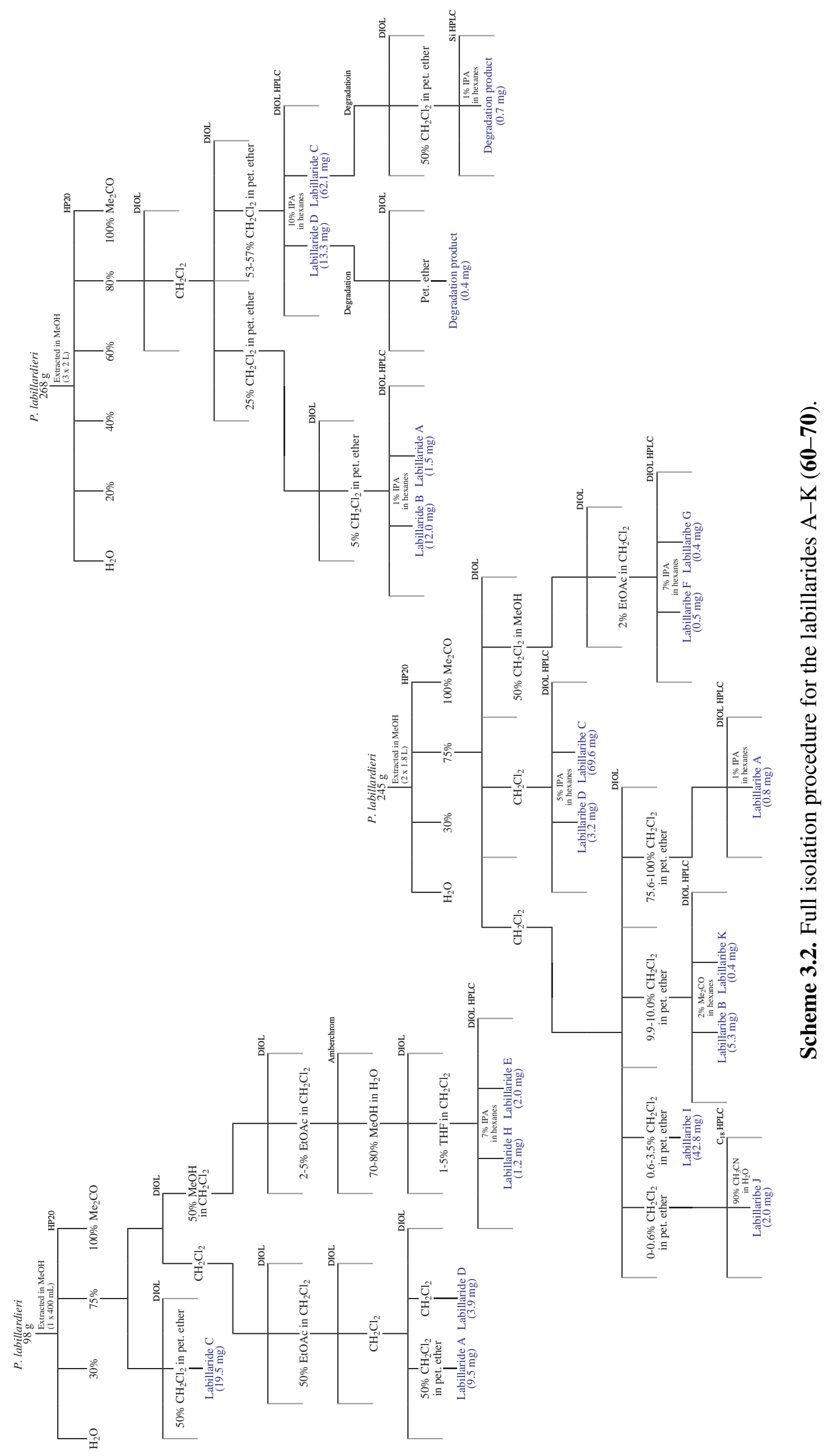




\subsection{Labillaride A}

Labillaride A (60) was isolated as a colourless oil (11.8 $\mathrm{mg}$ in total). Positive-ion mode HRESIMS analysis of $\mathbf{6 0}$ gave rise to a single pseudomolecular ion indicative of a molecular formula of $\mathrm{C}_{22} \mathrm{H}_{30} \mathrm{O}_{3}\left(343.2280[\mathrm{M}+\mathrm{H}]^{+}, \Delta 3.6 \mathrm{ppm}\right)$, requiring eight double-bond equivalents. The ${ }^{13} \mathrm{C}$ NMR spectrum contained only 21 distinct resonances while the ${ }^{1} \mathrm{H}$ NMR spectrum in $\mathrm{CDCl}_{3}$ accounted for all 30 protons. The absence of one resonance in the ${ }^{13} \mathrm{C}$ NMR spectrum suggested symmetry or overlap within the molecule. A multiplicity-edited HSQC experiment confirmed correlations between all the observed proton resonances and carbon resonances indicating that all protons were attached to carbon. Identifiable features of the NMR spectra included three strongly deshielded nonprotonated carbons $\left(\delta_{\mathrm{C}} 166.7,165.4\right.$ and 170.0$)$, two strongly shielded olefinic methines $\left[\left(\delta_{\mathrm{C}} 91.5, \delta_{\mathrm{H}} 5.41\right)\right.$ and $\left.\left(\delta_{\mathrm{C}} 99.5, \delta_{\mathrm{H}} 5.97\right)\right]$, six typical olefinic methines $\left[\left(\delta_{\mathrm{C}} 122.7\right.\right.$, $\left.\delta_{\mathrm{H}} 5.35\right),\left(\delta_{\mathrm{C}} 127.3, \delta_{\mathrm{H}} 6.39\right),\left(\delta_{\mathrm{C}} 127.3, \delta_{\mathrm{H}} 5.96\right),\left(\delta_{\mathrm{C}} 128.7, \delta_{\mathrm{H}} 5.54\right),\left(\delta_{\mathrm{C}} 134.4, \delta_{\mathrm{H}} 5.47\right)$ and $\left.\left(\delta_{\mathrm{C}} 135.4, \delta_{\mathrm{H}} 5.54\right)\right]$, a deshielded oxymethine $\left(\delta_{\mathrm{C}} 78.5, \delta_{\mathrm{H}} 4.78\right)$ and a methyl triplet $\left(\delta_{\mathrm{C}} 14.3, \delta_{\mathrm{H}} 0.98, \mathrm{t}, 7.5 \mathrm{~Hz}\right)$.

Beginning at the methyl terminus, analysis of ${ }^{1} \mathrm{H}-{ }^{1} \mathrm{H}$ coupling led to the construction of the 1,5,7-triene containing substructure (C-1 to C-13) (see Figure 3.4). A series of sequential COSY correlations starting from the methyl triplet $\left(\mathrm{C}-1: \delta_{\mathrm{C}} 14.3, \delta_{\mathrm{H}} 0.98\right)$ to a methylene $\left(\mathrm{C}-2: \delta_{\mathrm{C}} 20.9, \delta_{\mathrm{H}} 2.06\right)$ to an olefinic methine $\left(\mathrm{C}-3: \delta_{\mathrm{C}} 135.4, \delta_{\mathrm{H}} 5.54\right)$ to a second olefinic methine $\left(\mathrm{C}-4: \delta_{\mathrm{C}} 122.7, \delta_{\mathrm{H}} 5.35\right)$ established the first section of the substructure. The geometry of the double bond was determined to be $(Z)$ on the basis of the observed coupling constants $(10.3 \mathrm{~Hz}, \mathrm{H}-3$ and $10.7 \mathrm{~Hz}, \mathrm{H}-4)$ and an NOE enhancement between $\mathrm{H}_{2}-2$ and $\mathrm{H}-5$. Further COSY correlations from $\mathrm{H}-4$ to a methylene $\left(\mathrm{C}-5: \delta_{\mathrm{C}} 33.4, \delta_{\mathrm{H}} 2.46\right)$ to a deshielded oxymethine $\left(\mathrm{C}-6: \delta_{\mathrm{C}} 78.5, \delta_{\mathrm{H}} 4.78\right)$ to a olefinic methine $\left(\mathrm{C}-7: \delta_{\mathrm{C}} 128.7, \delta_{\mathrm{H}} 5.54\right)$ and to a further olefinic methine $\left(\mathrm{C}-8: \delta_{\mathrm{C}} 127.3, \delta_{\mathrm{H}} 6.39\right)$ extended this substructure to a second double bond. The coupling constants $(15.6 \mathrm{~Hz}, \mathrm{H}-7$ and $15.4 \mathrm{~Hz}, \mathrm{H}-8)$ defined $\Delta_{7-8}$ as $(E)$. Observed NOE enhancements between H-6 and H-8 confirmed this assignment. Finally, a series of sequential COSY correlations starting from $\mathrm{H}-8$ to a fifth olefinic methine $\left(\mathrm{C}-9: \delta_{\mathrm{C}} 127.3, \delta_{\mathrm{H}} 5.96\right)$ to the final typical olefinic 
methine $\left(\mathrm{C}-10: \delta_{\mathrm{C}} 134.4, \delta_{\mathrm{H}} 5.47\right)$ to three methylenes in turn $\left[\left(\mathrm{C}-11: \delta_{\mathrm{C}} 26.5, \delta_{\mathrm{H}} 2.16\right.\right.$ and 2.06), (C-12: $\delta_{\mathrm{C}} 27.7, \delta_{\mathrm{H}} 1.43$ and 1.24) and (C-13: $\delta_{\mathrm{C}} 27.5, \delta_{\mathrm{H}} 1.35$ and 1.18)] completed the substructure. The geometry of the third double bond was defined as $(Z)$ by the coupling constants of 10.7 and $10.9 \mathrm{~Hz}$ for $\mathrm{H}-9$ and $\mathrm{H}-10$ respectively, and through observed NOE enhancements between $\mathrm{H}-8$ and $\mathrm{H}_{2}-11$. Observed HMBC correlations confirmed this substructure (see Table 3.3).

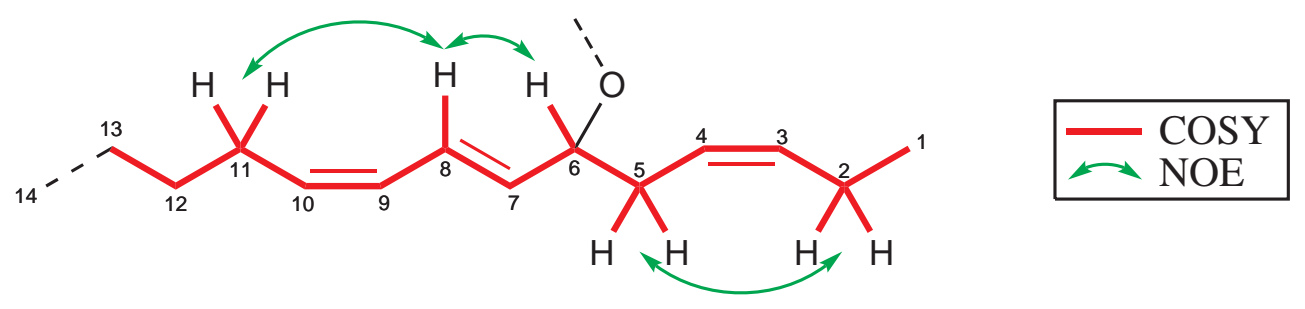

Figure 3.4. Selected COSY correlations and NOE enhancements establishing the 1,5,7-triene substructure of labillaride A (60).

An $\alpha$-pyrone containing substructure was established from a distinctive deshielded methylene $\left(\mathrm{C}-17: \delta_{\mathrm{C}} 33.0, \delta_{\mathrm{H}} 2.52\right)$ which exhibited a COSY correlation to a second methylene $\left(\mathrm{C}-16: \delta_{\mathrm{C}} 26.1, \delta_{\mathrm{H}}\right.$ 1.73). An HMBC correlation from $\mathrm{H}_{2}-16$ to a downfield non-protonated carbon $\left(\mathrm{C}-18: \delta_{\mathrm{C}} 166.7\right)$ along with $\mathrm{HMBC}$ correlations from $\mathrm{H}_{2}-17$ to C-18 and a strongly shielded olefinic methine $\left(\mathrm{C}-19: \delta_{\mathrm{C}} 99.5, \delta_{\mathrm{H}} 5.97\right)$ suggested the presence of a highly-polarised double bond. Reciprocal HMBC correlations from H-19 to $\mathrm{C}-17$ and $\mathrm{C}-18$ confirmed this connectivity (see Figure 3.5 ).
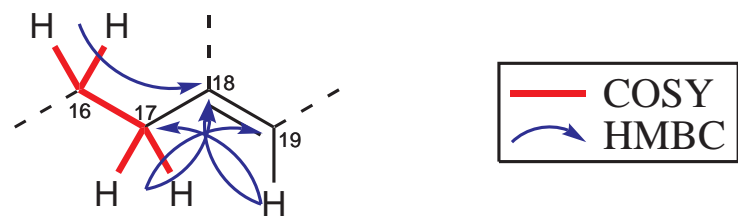

Figure 3.5. Selected COSY and HMBC correlations establishing part of the $\alpha$-pyrone containing substructure of labillaride A $(\mathbf{6 0})$.

Further HMBC correlations from H-19 to a second downfield non-protonated carbon $\left(\mathrm{C}-20: \delta_{\mathrm{C}}\right.$ 170.0) and to a second heavily shielded olefinic methine $\left(\mathrm{C}-21: \delta_{\mathrm{C}} 91.5\right.$, $\left.\delta_{\mathrm{H}} 5.41\right)$ along with a pseudo-allylic COSY correlation between H-19 and H-21 suggested a second polarised double bond. The polarised nature of the two double bonds is consistent with oxygen attachment at C-18 and C-20. Finally, HMBC correlations from $\mathrm{H}-21$ to the third deshielded non-protonated carbon $\left(\mathrm{C}-22: \delta_{\mathrm{C}} 165.4\right)$ completed the connectivity of the carbon chain. With no further olefinic carbons available to complete 
a third double bond, C-22 was assigned as a carbonyl. The upfield nature of the C-22 resonance suggested an $\alpha, \beta$-unsaturated ester moiety, and with a precedence for $\alpha$-pyrone containing compounds from this organism, a connection was made between C-18 and C-22 through a lactone linkage (see Figure 3.6). The $\gamma$-pyrone alternative was dismissed due to the lack of a ketone carbonyl ${ }^{13} \mathrm{C}$ resonance around $180 \mathrm{ppm}$, as observed in the known $\gamma$-pyrone compounds. ${ }^{59}$
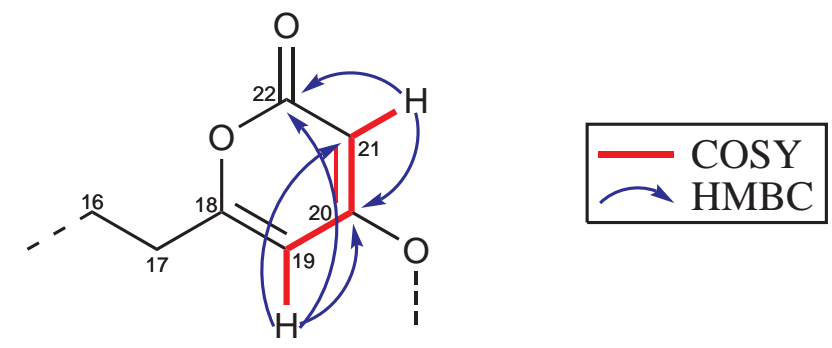

Figure 3.6. Selected COSY and HMBC correlations establishing the $\alpha$-pyrone containing substructure of labillaride A (60).

The chemical shifts assigned to the $\alpha$-pyrone moiety of $\mathbf{6 0}$ compare very favourably to those of the only known compound (54) containing an equivalent $\alpha$-pyrone, with the exception of the C-21 olefinic methine (see Table 3.2). In the original isolation paper, the authors state that a comparison of the ${ }^{13} \mathrm{C}$ chemical shifts of $\mathbf{5 4}$ to 4 -methoxy-6-methyl2-pyrone (71) "gave excellent agreement". ${ }^{59}$ A review of the literature found that the chemical shift of the olefinic methine at the $\alpha$-position of the lactone carbonyl in $\mathbf{7 1}$, at $\delta_{\mathrm{C}} 87.0$, is in fact considerably closer to that of $\mathbf{6 0}\left(\delta_{\mathrm{C}} 91.5\right)$ than $\mathbf{5 4}\left(\delta_{\mathrm{C}} 114.2\right)$. These discrepancies suggest an error in tabulating the data of $\mathbf{5 4}$ in the original isolation paper, and is consistent with the chemical shift assignment of labillaride A (60).

Table 3.2. Chemical shift differences of the $\alpha$-pyrone moiety of the known compound (54) and labillaride A (60).

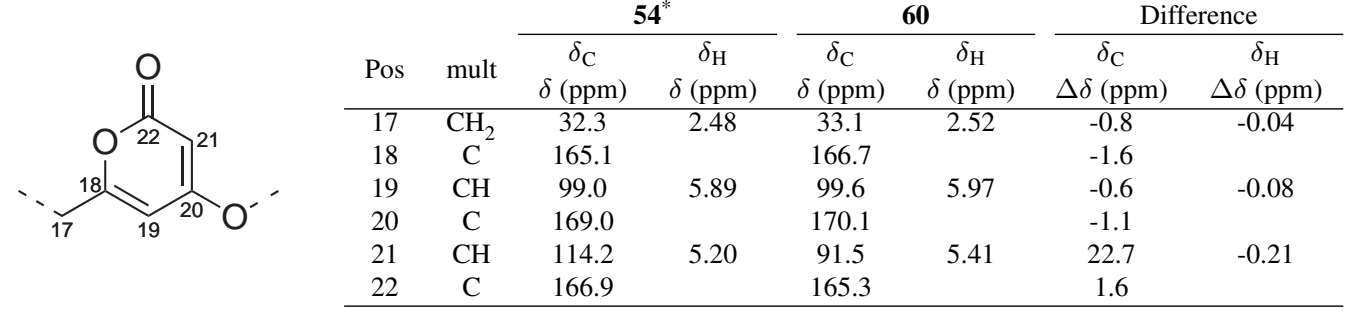

*Shin, J.; Paul, V. J.; Fenical, W. Tetrahedron Lett. 1986, 27, 5189-5192.

Two carbons, four protons and one double-bond equivalent remained unaccounted for in the structure. The multiplicity-edited HSQC displayed a large, unresolvable correlation 
at $\delta_{\mathrm{C}} 27.1$ and $\delta_{\mathrm{H}} 1.23$ which was initially assigned as one methylene pair. However, closer inspection of the ${ }^{13} \mathrm{C}$ NMR spectrum suggested this resonance may account for both remaining carbons due to its apparent double-intensity compared to those of other methylenes in the same region (see Figure 3.7). The intensity of a ${ }^{13} \mathrm{C}$ signal is influenced by such things as the nuclear Overhauser effect (NOE) and relaxation time $\left(T_{1}\right)$. Unlike ${ }^{1} \mathrm{H}$ NMR spectra, the integrated peak areas are not a reliable indicator of the number of carbons the peaks represent as relaxation times vary over a wide range and the NOE response is not the same for all ${ }^{13} \mathrm{C}$ nuclei. ${ }^{65}$ However, a comparison may be possible between carbons in similar chemical environments, assuming they have similar relaxation delays and NOE influences. Due to the high resolution of ${ }^{1} \mathrm{H}$ broadband decoupled carbon resonances, their relative integrations can be approximated from their relative heights. The approximate double-intensity of the $\delta_{\mathrm{C}} 27.1$ resonance led us to propose the coincidence of the ${ }^{13} \mathrm{C}$ chemical shifts of two carbons. The unresolvable correlation in the HSQC was therefore assigned as two methylene pairs with overlap in both the carbon and proton dimensions. This was further supported by the relative integration of the multiplet at $\sim 1.23 \mathrm{ppm}$ in the ${ }^{1} \mathrm{H}$ NMR spectrum.
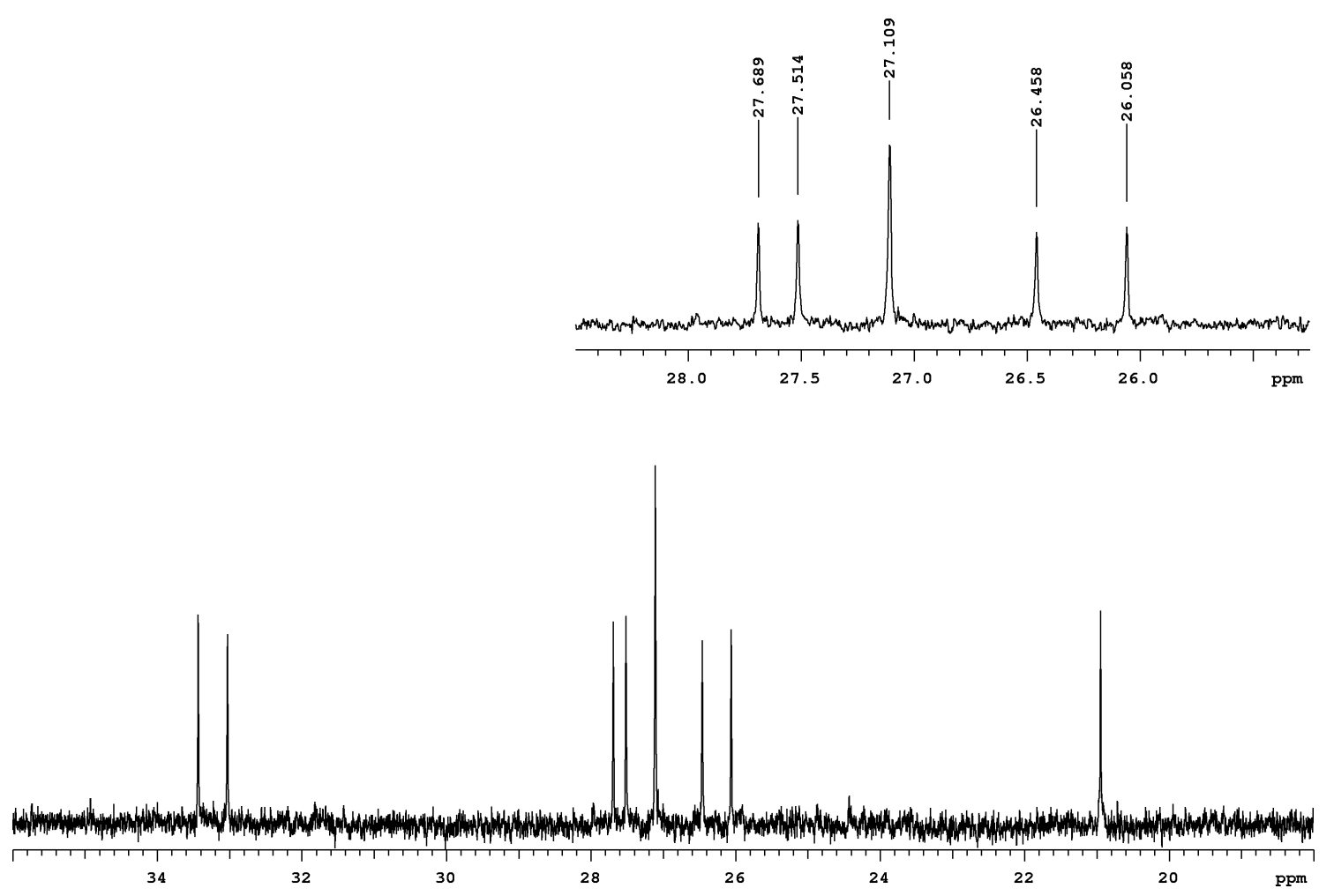

Figure 3.7. Methylene region of the ${ }^{13} \mathrm{C}$ NMR spectrum of labillaride $\mathrm{A}(\mathbf{6 0})$.

The overlapping of the chemical shifts for these methylenes suggested their presence in 
a short alkyl chain. COSY correlations observed from $\delta_{\mathrm{H}} 1.23$ to $\mathrm{H}-13 \mathrm{a}, \mathrm{H}-13 \mathrm{~b}$ and $\mathrm{H}_{2}-16$ suggested that $\mathrm{C}-13$ and $\mathrm{C}-16$ were connected via at least one of the methylene pairs. No further COSY correlations involving $\delta_{\mathrm{H}} 1.23$ were observed, suggesting that the two methylenes were in fact next to each other. This proposal is supported by the observation of HSQC-TOCSY correlations from $\mathrm{H}_{2}-16$ to $\delta_{\mathrm{H}} 1.23, \mathrm{H}-13 \mathrm{a}$ and $\mathrm{H}-13 \mathrm{~b}$. Similarly, selective excitation of $\mathrm{H}_{2}-16$ in a series of 1D-TOCSY experiments with increasing mixing times sequentially revealed $\left[\mathrm{H}_{2}-15\right.$ and $\left.\mathrm{H}_{2}-14\right], \mathrm{H}-13 \mathrm{a}, \mathrm{H}-13 \mathrm{~b}$ and then $\mathrm{H}-12 \mathrm{a}$ and $\mathrm{H}-12 \mathrm{~b}$. Further support of the assignment of the alkyl chain between C-13 and C-16 was obtained from an HMBC correlation from $\mathrm{H}_{2}-16$ to resonances at $\delta_{\mathrm{C}} 27.1$, and from $\delta_{\mathrm{H}} 1.23$ to C-13 (see Figure 3.8). Finally, with all three oxygens of the molecular formula accounted for in the $\alpha$-pyrone substructure, an ether bridge between C-6 and C-20 was proposed, connecting the two substructures. This was supported by an HMBC correlation from H-6 to C-20.

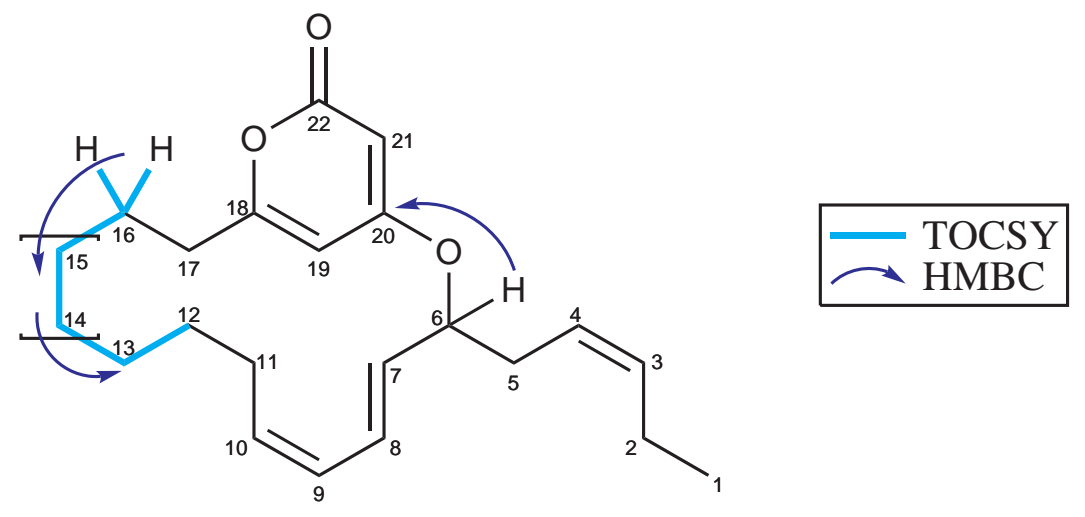

Figure 3.8. Selected TOCSY and HMBC correlations connecting the substructures of labillaride A (60), completing the alkyl chain.

Formation of the macrocyclic ring accounted for all of the elements of the molecular formula. The five double bonds, the ester carbonyl and the macrocycle accounted for seven of the eight required double-bond equivalents and thus confirmed a lactone linkage, satisfying the molecular formula. The final structure of labillaride $\mathrm{A}$ is therefore proposed to be 60. NMR data for $\mathbf{6 0}$ is presented in Table 3.3. 


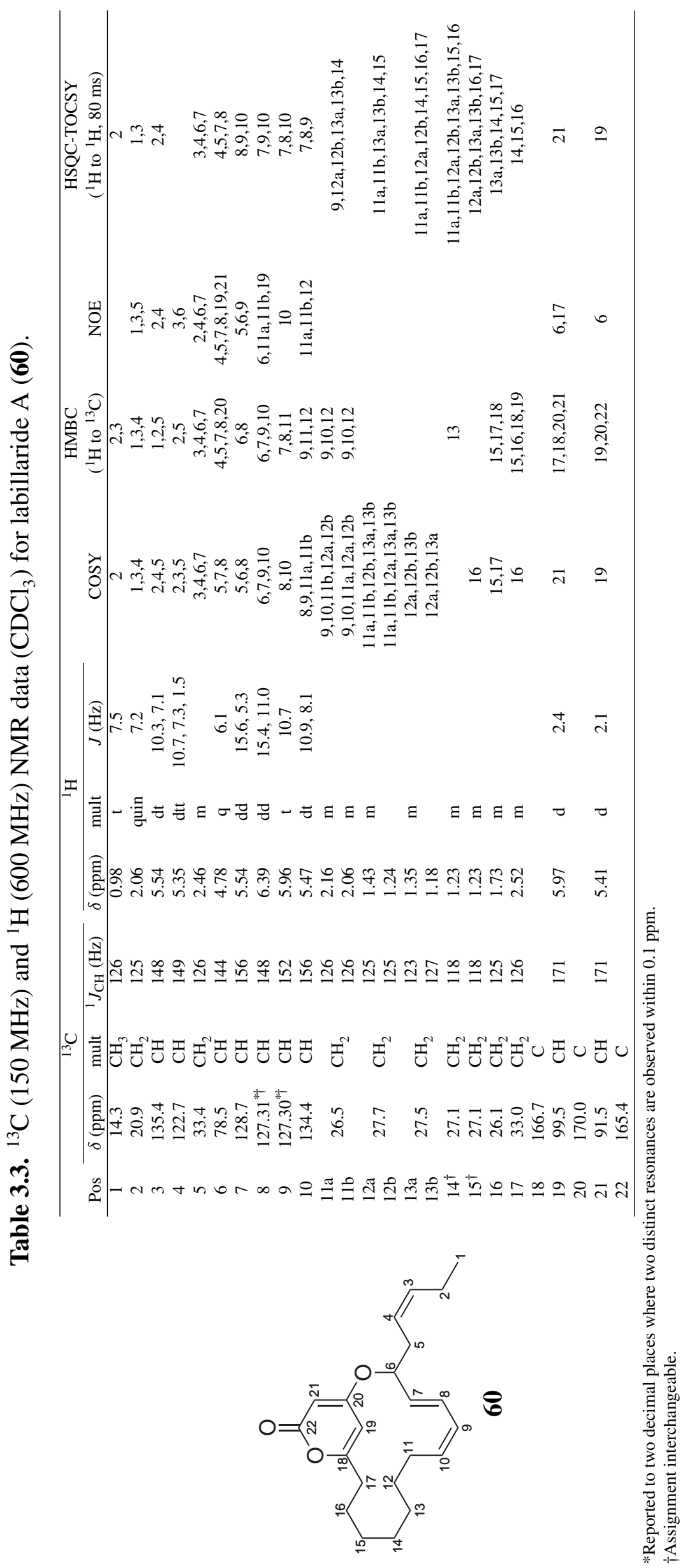




\subsection{Labillaride B}

A total of $17.3 \mathrm{mg}$ of labillaride B (61) was isolated as a colourless oil. Positive-ion mode HRESIMS analysis of $\mathbf{6 1}$ showed a characteristic pseudomolecular ion cluster $\left([\mathrm{M}+\mathrm{H}]^{+}\right.$: $\left.[\mathrm{M}+2+\mathrm{H}]^{+} ; 1: 1\right)$ indicative of the presence of bromine and consistent with a molecular formula of $\mathrm{C}_{22} \mathrm{H}_{31} \mathrm{O}_{3} \mathrm{Br}\left(423.1522[\mathrm{M}+\mathrm{H}]^{+}, \Delta 1.7 \mathrm{ppm}\right)$, requiring seven double-bond equivalents. The ${ }^{13} \mathrm{C}$ NMR spectrum contained 22 distinct carbon resonances while the ${ }^{1} \mathrm{H}$ NMR spectrum accounted for all 31 protons, which a multiplicity-edited HSQC experiment confirmed were all attached to carbon. Identifiable features of the NMR spectra again included three strongly deshielded non-protonated carbons $\left(\delta_{\mathrm{C}} 165.0,166.8\right.$ and 170.2), two strongly shielded olefinic methines $\left[\left(\delta_{\mathrm{C}} 91.2, \delta_{\mathrm{H}} 5.49\right)\right.$ and $\left(\delta_{\mathrm{C}} 99.3\right.$, $\left.\left.\delta_{\mathrm{H}} 5.90\right)\right]$, four typical olefinic methines $\left[\left(\delta_{\mathrm{C}} 124.7, \delta_{\mathrm{H}} 5.53\right),\left(\delta_{\mathrm{C}} 125.1, \delta_{\mathrm{H}} 5.33\right)\right.$, $\left(\delta_{\mathrm{C}} 133.7, \delta_{\mathrm{H}} 5.50\right)$ and $\left.\left(\delta_{\mathrm{C}} 135.7, \delta_{\mathrm{H}} 5.75\right)\right]$, a deshielded oxymethine $\left(\delta_{\mathrm{C}} 76.9, \delta_{\mathrm{H}} 5.08\right)$ and a methyl triplet $\left(\delta_{\mathrm{C}} 14.3, \delta_{\mathrm{H}} 0.99, \mathrm{t}, 7.6 \mathrm{~Hz}\right)$.

The structure of $\mathbf{6 1}$ was elucidated in a similar fashion to labillaride A $(\mathbf{6 0})$, beginning at the methyl terminus. A COSY correlation from the methyl triplet (C-1: $\left.\delta_{\mathrm{C}} 14.3, \delta_{\mathrm{H}} 0.99\right)$ to a methylene $\left(\mathrm{C}-2: \delta_{\mathrm{C}} 20.9, \delta_{\mathrm{H}} 2.10\right)$ to an olefinic methine $\left(\mathrm{C}-3: \delta_{\mathrm{C}} 133.7, \delta_{\mathrm{H}} 5.50\right)$ to a second olefinic methine $\left(\mathrm{C}-4: \delta_{\mathrm{C}} 125.1, \delta_{\mathrm{H}} 5.33\right)$ to a methylene $\left(\mathrm{C}-5: \delta_{\mathrm{C}} 27.0\right.$, $\delta_{\mathrm{H}} 2.99$ and 2.96) to a third olefinic methine $\left(\mathrm{C}-6: \delta_{\mathrm{C}} 135.7, \delta_{\mathrm{H}} 5.75\right)$ to the final typical olefinic methine $\left(\mathrm{C}-7: \delta_{\mathrm{C}} 124.7, \delta_{\mathrm{H}} 5.53\right)$ to a deshielded oxymethine $\left(\mathrm{C} 8: \delta_{\mathrm{C}} 76.9\right.$, $\left.\delta_{\mathrm{H}} 5.08\right)$ to a deshielded methine $\left(\mathrm{C}-9: \delta_{\mathrm{C}} 54.1, \delta_{\mathrm{H}} 4.18\right)$ to a methylene $\left(\mathrm{C}-10: \delta_{\mathrm{C}} 33.3\right.$, $\delta_{\mathrm{H}} 2.02$ and 1.08) to a second methylene $\left(\mathrm{C}-11: \delta_{\mathrm{C}} 22.0, \delta_{\mathrm{H}} 1.55\right.$ and 1.16) established a diene substructure (Figure 3.9, substructure A). The geometry of both double bonds were determined to be $(Z)$ on the basis of the observed ${ }^{1} \mathrm{H}-{ }^{1} \mathrm{H}$ coupling constants between H-3 and H-4, and H-6 and H-7 (10.6 and 10.9 Hz, respectively). Both assignments were supported by observed NOE enhancements from $\mathrm{H}_{2}-5$ to $\mathrm{H}_{2}-2$ and between $\mathrm{H}_{2}-5$ and $\mathrm{H}-8$.

Again, a distinctive deshielded methylene (C-17: $\delta_{\mathrm{C}} 34.3, \delta_{\mathrm{H}} 2.67$ and 2.35) was used to establish an $\alpha$-pyrone substructure. A series of sequential COSY correlations were observed starting from both proton resonances of $\mathrm{CH}_{2}-17$ to a second methylene $(\mathrm{C}-16$ : $\delta_{\mathrm{C}} 24.7, \delta_{\mathrm{H}} 1.83$ and 1.61) to a third methylene (C-15: $\delta_{\mathrm{C}} 27.1, \delta_{\mathrm{H}} 1.48$ and 1.14). HMBC 
A
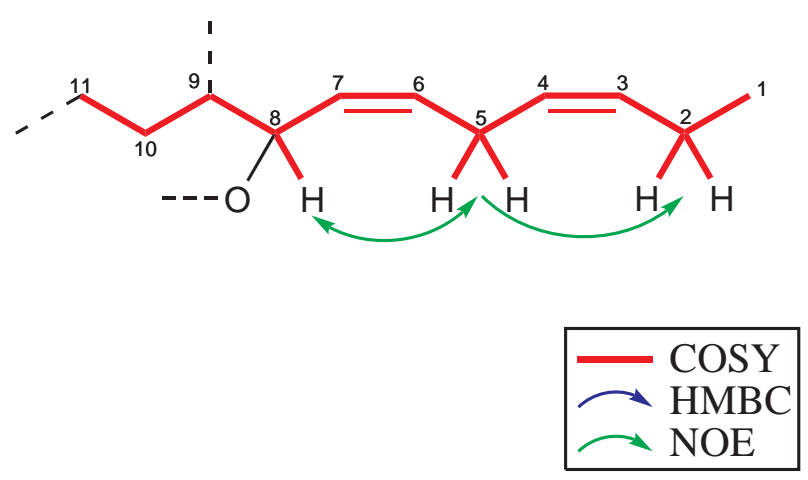

B

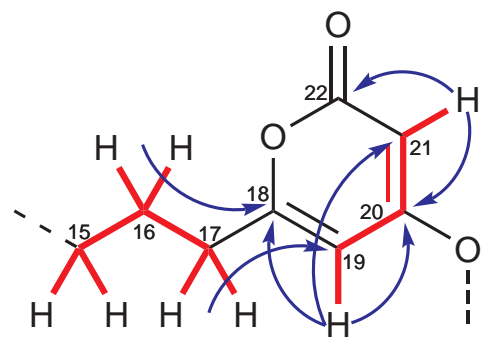

Figure 3.9. Selected COSY and HMBC correlations and NOE enhancements establishing two substructures of labillaride B (61).

correlations from both proton resonances of $\mathrm{CH}_{2}-16$ to a deshielded non-protonated carbon $\left(\mathrm{C}-18: \delta_{\mathrm{C}} 166.8\right)$ along with an $\mathrm{HMBC}$ correlation from both proton resonances of $\mathrm{CH}_{2}-17$ to a strongly shielded olefinic methine $\left(\mathrm{C}-19: \delta_{\mathrm{C}} 99.3, \delta_{\mathrm{H}} 5.90\right)$ again suggested a highly-polarised double bond. HMBC correlations from H-19 to a second downfield nonprotonated carbon (C-20: $\left.\delta_{\mathrm{C}} 170.2\right)$ and to a second strongly shielded olefinic methine $\left(\mathrm{C}-21, \delta_{\mathrm{C}} 91.2, \delta_{\mathrm{H}} 5.49\right)$ along with a pseudo-allylic COSY correlation between $\mathrm{H}-19$ and H-21 established a second highly-polarised double bond. Finally, an HMBC correlation from $\mathrm{H}-21$ to the final non-protonated carbonyl carbon $\left(\mathrm{C}-22: \delta_{\mathrm{C}} 165.0\right)$ completed the connectivity of the carbon chain and suggested an $\alpha$-pyrone substructure the same as labillaride A (60). The highly-polarised nature of the two double bonds is consistent with oxygen attachment at C-18 and C-20, while the deshielded nature of the C-22 carbonyl once again suggested a lactone moiety (Figure 3.9, substructure B). No long-range HMBC correlations were observed from either the proton resonances of $\mathrm{CH}_{2}-17$ or $\mathrm{CH}-19$ to $\mathrm{C}-22$, however the carbon and proton chemical shifts of the $\alpha$-pyrone system compared very favourably with those of labillaride A (see Table 3.4).

Table 3.4. Chemical shift differences of the $\alpha$-pyrone moiety for labillarides A $(\mathbf{6 0})$ and $\mathrm{B}(\mathbf{6 1})$.

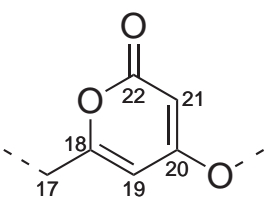

\begin{tabular}{|c|c|c|c|c|c|c|c|}
\hline \multirow[b]{2}{*}{ Pos } & \multirow[b]{2}{*}{ mult } & \multicolumn{2}{|c|}{ Labillaride A (60) } & \multicolumn{2}{|c|}{ Labillaride B (61) } & \multicolumn{2}{|c|}{ Difference } \\
\hline & & $\begin{array}{c}\delta_{\mathrm{C}} \\
\delta(\mathrm{ppm})\end{array}$ & $\begin{array}{c}\delta_{\mathrm{H}} \\
\delta(\mathrm{ppm})\end{array}$ & $\begin{array}{c}\delta_{\mathrm{C}} \\
\delta(\mathrm{ppm})\end{array}$ & $\begin{array}{c}\delta_{\mathrm{H}} \\
\delta(\mathrm{ppm})\end{array}$ & $\begin{array}{c}\delta_{\mathrm{C}} \\
\Delta \delta(\mathrm{ppm})\end{array}$ & $\begin{array}{c}\delta_{\mathrm{H}} \\
\Delta \delta(\mathrm{ppm})\end{array}$ \\
\hline $17 \mathrm{a}$ & $\mathrm{CH}_{2}$ & 33.1 & 2.52 & 34.3 & 2.67 & -1.2 & -0.15 \\
\hline $\begin{array}{c}1 / \mathrm{b} \\
18\end{array}$ & $\mathrm{C}^{2}$ & 166.7 & & 166.8 & & -0.1 & \\
\hline 19 & $\mathrm{CH}$ & 99.6 & 5.97 & 99.3 & 5.90 & 0.3 & 0.07 \\
\hline 20 & $\mathrm{C}$ & 170.1 & & 170.2 & & -0.1 & \\
\hline 21 & $\mathrm{CH}$ & 91.5 & 5.41 & 91.2 & 5.49 & 0.3 & -0.08 \\
\hline 22 & $\mathrm{C}$ & 165.3 & & 165.0 & & 0.3 & \\
\hline
\end{tabular}


An HMBC correlation from $\mathrm{H}-8$ to $\mathrm{C}-20$ established an enol ether oxygen bridge between these centres, as in labillaride A (60). With only three diastereotopic methylene pairs and a bromine left to assign, the bromine atom was tentatively assigned to position C-9 based on the somewhat downfield ${ }^{13} \mathrm{C}$ chemical shift. One-bond carbon-proton coupling constants are dependent on a variety of factors, including increasing with dihedral angular distortion and substitution of electron-withdrawing groups. ${ }^{66}$ This precedence supported the attachment of bromine, an electronegative atom, to C-9, resulting in a large ${ }^{1} J_{\mathrm{CH}}$ value for this carbon $(155 \mathrm{~Hz})$. The value also compared favourably with that observed for the methine position of 2-bromobutane $(152 \mathrm{~Hz})$.

Analysis of the HMBC spectrum of labillaride B (61), along with 1D-TOCSY and HSQCTOCSY experiments, led to the construction of the macrocycle connecting the alkyl chains of the diene and $\alpha$-pyrone substructures. An HMBC correlation from both proton resonances of $\mathrm{CH}_{2}-10$ to a methylene $\left(\mathrm{C}-12: \delta_{\mathrm{C}} 25.9, \delta_{\mathrm{H}} 1.34\right.$ and 1.26) positioned this carbon next to C-11. Further HMBC correlations from both proton resonances of $\mathrm{CH}_{2}-11$ to a methylene $\left(\mathrm{C}-13: \delta_{\mathrm{C}} 26.4, \delta_{\mathrm{H}} 1.14\right.$ and 1.01$)$, and from $\mathrm{H}-12$ a to the final methylene $\left(\mathrm{C}-14: \delta_{\mathrm{C}} 26.8, \delta_{\mathrm{H}} 1.34\right.$ and 1.24) suggested the linear arrangement of C-10 to C-14, accounting for all proton and carbon resonances. An HMBC correlation from both proton resonances of $\mathrm{CH}_{2}-16$ to $\mathrm{C}-14$ positioned this carbon next to the $\mathrm{C}-15$ methylene, completing the macrocyclic ring (Figure 3.10).

Selective excitation of H-9 in a series of 1D-TOCSY experiments with increasing mixing times sequentially revealed H-10a,b, H-11a,b and then H-12a,b. Similarly, selective excitation of H-17a sequentially revealed H-16a,b, H-15a,b H-14a,b and then H-13a,b. These data supported the linear arrangement of C-11 to C-15. The assignment of this alkyl chain was also supported by an HSQC-TOCSY experiment with a mixing time of $80 \mathrm{~ms}$. The HSQC-TOCSY experiment displays the TOCSY data differentiated by the ${ }^{13} \mathrm{C}$ chemical shifts of the carbons to which the excited protons are attached. TOCSY correlations were observed from the proton resonances of $\mathrm{CH}_{2}-10$ to $\mathrm{H}-12 \mathrm{a}$ and $\mathrm{H}-12 \mathrm{~b}$, from the proton resonances of $\mathrm{CH}_{2}-12$ to $\mathrm{H}-14 \mathrm{a}$ and $\mathrm{H}-14 \mathrm{~b}$, and from the proton resonances of $\mathrm{CH}_{2}-14$ to $\mathrm{H}-16 \mathrm{a}$ and $\mathrm{H}-16 \mathrm{~b}$. 

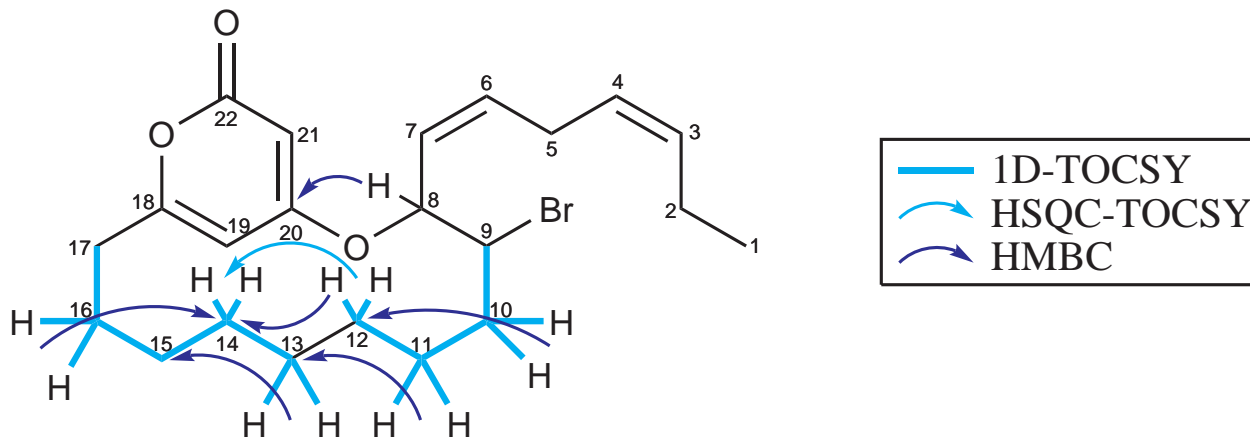

Figure 3.10. Selected TOCSY and HMBC correlations connecting the substructures of labillaride B (61).

The relative configuration of labillaride B (61) was tentatively assigned on the basis of ${ }^{3} J_{\mathrm{HH}}$ values and NOE enhancements observed in a series of 1D-NOESY experiments. The ${ }^{1} \mathrm{H}-{ }^{1} \mathrm{H}$ coupling constants of $8.7 \mathrm{~Hz}$ for $\mathrm{H}-8$ and $8.5 \mathrm{~Hz}$ for $\mathrm{H}-9$ implied a dihedral angle of either approximately $0^{\circ}$ or $180^{\circ}$ between these vicinal protons. The eclipsed conformation with the protons at a dihedral angle of $0^{\circ}$ was discounted on the basis of the significant steric hindrance expected due to the overlap of several large functional groups. The anti conformer was therefore considered more reasonable (Figure 3.11).

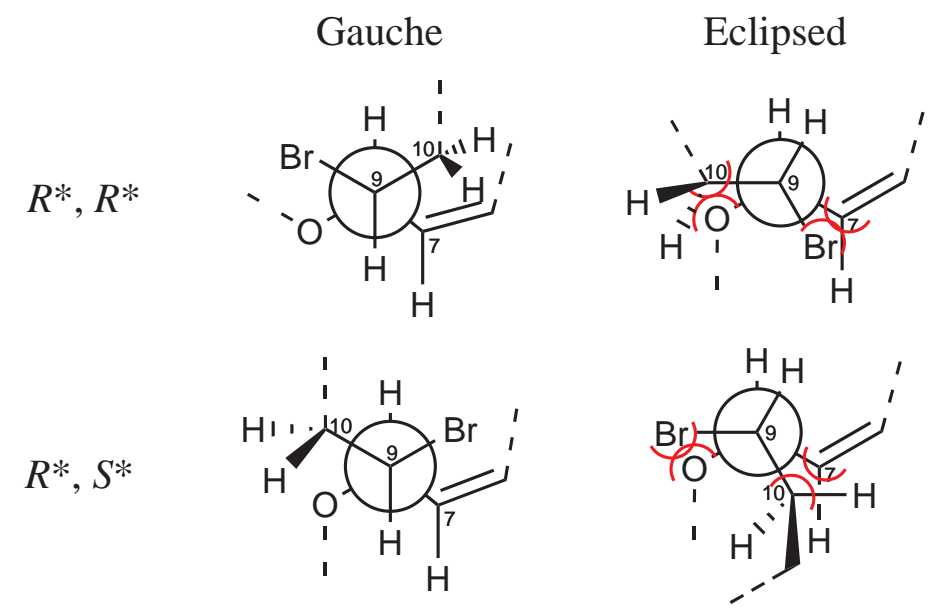

Figure 3.11. Steric hindrance discounting an eclipsed relationship between $\mathrm{H}-8$ and H-9 in both possible relative configurations of labillaride B (61).

Similarly, the coupling constants of $4.4 \mathrm{~Hz}$ for $\mathrm{H}-9$ to $\mathrm{H}_{2}-10,4.7 \mathrm{~Hz}$ for $\mathrm{H}-10$ a to $\mathrm{H}-9$, and $5.0 \mathrm{~Hz}$ for $\mathrm{H}-10 \mathrm{~b}$ to $\mathrm{H}-9$ suggested a dihedral angle of either approximately $45^{\circ}$ or $135^{\circ}$ for each vicinal relationship. Selective excitation of H-8 showed a very strong NOE enhancement to $\mathrm{H}-11 \mathrm{~b}$, which could only be achieved when each of the proton resonances of $\mathrm{CH}_{2}-10$ were in a gauche relationship to $\mathrm{H}-9$ (dihedral angle of $\sim 45^{\circ}$ ) (Figure 3.12).

Selective excitation of $\mathrm{H}-9$ showed NOE enhancements to $\mathrm{H}-7$ and $\mathrm{H}-19$. With a relative 


$$
R^{*}, R^{*}
$$

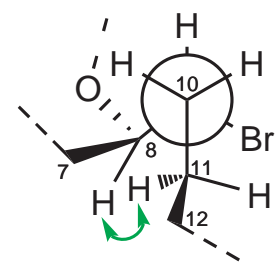

$R^{*}, S^{*}$

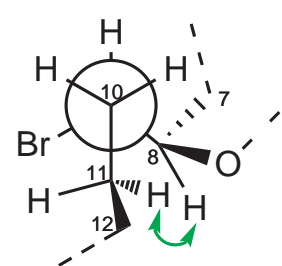

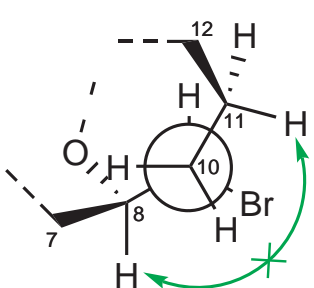

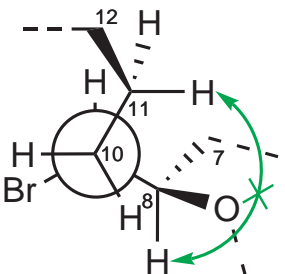

Figure 3.12. The selected NOE enhancement establishing a gauche relationship between $\mathrm{H}-9$ and $\mathrm{H}-10 \mathrm{a}$, and $\mathrm{H}-10 \mathrm{~b}$ in both possible relative configurations of labillaride $\mathrm{B}(\mathbf{6 1})$.

configuration of $R^{*}, R^{*}$ or $R^{*}, S^{*}$, and considering the two conformer restrictions detailed above, these NOE enhancements force the structure into one of two configurations, shown in Figure 3.13. The figure shows that the $R^{*}, R^{*}$ diastereomer would force either the bromine atom (as in the figure) or $\Delta_{6,7}$ into the macrocycle, causing considerable electron repulsion. This diastereomer is therefore considered possible but unlikely to adopt one of these two confirmations. In contrast, the $R^{*}, S^{*}$ diastereomer is more plausible as the structure places the bromine atom in a more favourable position outside of the ring, while satisfying the NOE enhancements observed. The relative configuration is therefore tentatively assigned as $R^{*}, S^{*}$, though there is not enough evidence to be conclusive. The final structure of labillaride B is therefore tentatively determined to be $\mathbf{6 1}$. NMR data for $\mathbf{6 1}$ is presented in Table 3.5.

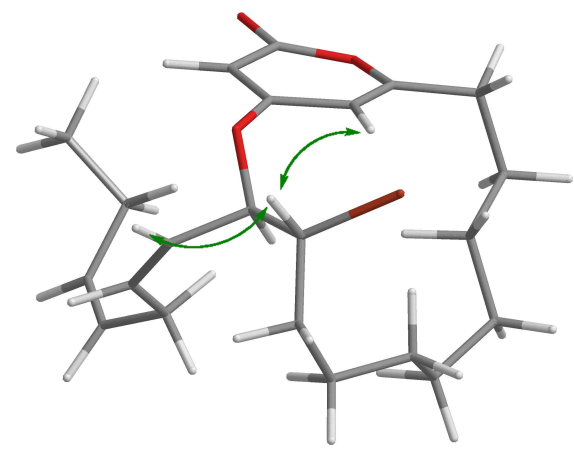

$R^{*}, R^{*}$

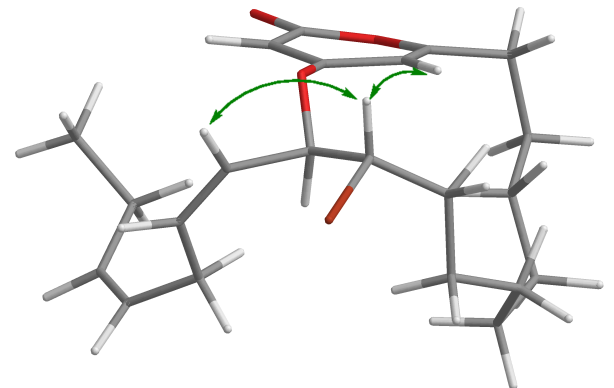

$R^{*}, S^{*}$

Figure 3.13. Selected NOE enhancements suggesting the $R^{*}, S^{*}$ relative configuration of labillaride B (61). 


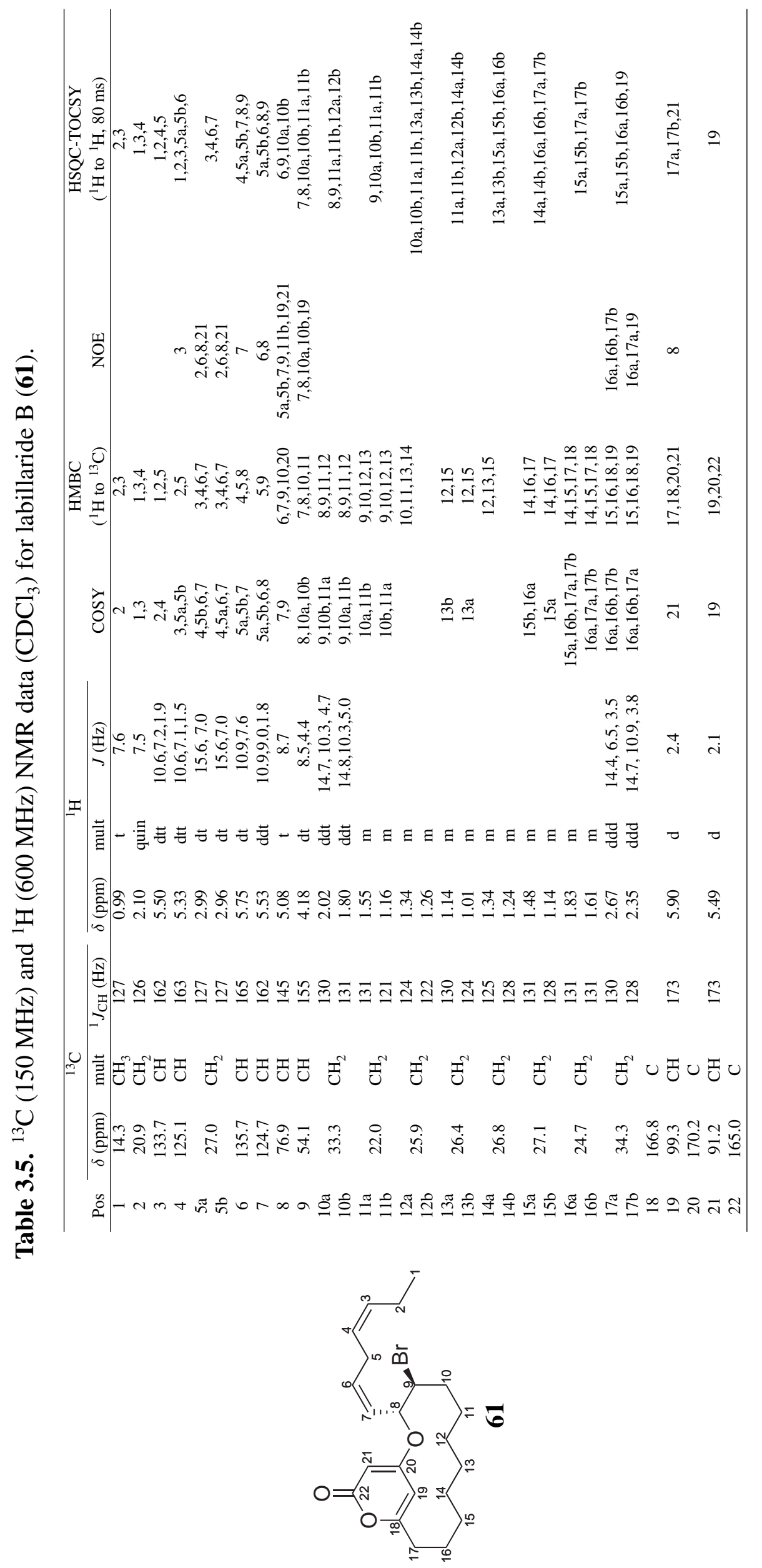




\subsection{Labillaride C}

Positive-ion mode HRESIMS analysis of the colourless oil labillaride C (62) (151.2 mg isolated in total) gave rise to a single pseudomolecular ion indicative of the molecular formula $\mathrm{C}_{22} \mathrm{H}_{30} \mathrm{O}_{3}\left(343.2259[\mathrm{M}+\mathrm{H}]^{+}, \Delta 2.7 \mathrm{ppm}\right)$, requiring eight double-bond equivalents. The ${ }^{1} \mathrm{H}$ NMR spectrum in $\mathrm{CDCl}_{3}$ accounted for all 30 protons, including a broad singlet which integrated for one proton. The multiplicity-edited HSQC spectrum showed no connectivity of this proton resonance to carbon, indicating an exchangeable proton. The ${ }^{13} \mathrm{C}$ NMR spectrum contained 22 distinct carbon resonances, including three strongly deshielded non-protonated carbons $\left(\delta_{\mathrm{C}} 165.6,166.6\right.$ and 166.7), a strongly shielded olefinic non-protonated carbon $\left(\delta_{\mathrm{C}} 107.2\right)$, a strongly shielded olefinic methine $\left(\delta_{\mathrm{C}} 102.5, \delta_{\mathrm{H}} 6.45\right)$, six typical olefinic methines $\left[\left(\delta_{\mathrm{C}} 127.4, \delta_{\mathrm{H}} 5.34\right),\left(\delta_{\mathrm{C}} 128.4, \delta_{\mathrm{H}} 5.40\right)\right.$, $\left(\delta_{\mathrm{C}} 130.8, \delta_{\mathrm{H}} 5.19\right),\left(\delta_{\mathrm{C}} 131.0, \delta_{\mathrm{H}} 5.92\right),\left(\delta_{\mathrm{C}} 132.0, \delta_{\mathrm{H}} 5.38\right)$ and $\left.\left(\delta_{\mathrm{C}} 133.2, \delta_{\mathrm{H}} 5.67\right)\right]$ and a methyl triplet $\left(\delta_{\mathrm{C}} 14.5, \delta_{\mathrm{H}} 0.95, \mathrm{t}, 7.5 \mathrm{~Hz}\right)$.

Beginning at the methyl terminus, analysis of ${ }^{1} \mathrm{H}-{ }^{1} \mathrm{H}$ coupling led to the construction of the 1,4,7-triene substructure (C-1 to C-17). A series of sequential COSY correlations starting from the methyl triplet $\left(\mathrm{C}-1: \delta_{\mathrm{C}} 14.5, \delta_{\mathrm{H}} 0.95\right)$ to a methylene $\left(\mathrm{C}-2: \delta_{\mathrm{C}} 20.6\right.$, $\left.\delta_{\mathrm{H}} 2.07\right)$ to an olefinic methine $\left(\mathrm{C}-3: \delta_{\mathrm{C}} 132.0, \delta_{\mathrm{H}} 5.38\right)$ to a second olefinic methine $(\mathrm{C}-4$ : $\left.\delta_{\mathrm{C}} 127.4, \delta_{\mathrm{H}} 5.34\right)$ and then to a methylene $\left(\mathrm{C}-5: \delta_{\mathrm{C}} 25.86, \delta_{\mathrm{H}} 3.01\right.$ and 2.90$)$ established the first section. The geometry of the double bond was determined to be $(Z)$ on the basis of the observed coupling constant of $10.7 \mathrm{~Hz}$ for $\mathrm{H}-3$, and an NOE enhancement between $\mathrm{H}_{2}-2$ and $\mathrm{H}_{2}-5$. Further COSY correlations from both proton resonances of $\mathrm{CH}_{2}-5$ to a third olefinic methine $\left(\mathrm{C}-6: \delta_{\mathrm{C}} 128.4, \delta_{\mathrm{H}} 5.40\right)$ to a fourth olefinic methine $\left(\mathrm{C}-7: \delta_{\mathrm{C}} 131.0, \delta_{\mathrm{H}} 5.92\right)$ to a methine $\left(\mathrm{C}-8: \delta_{\mathrm{C}} 30.6, \delta_{\mathrm{H}} 4.76\right)$ to an olefinic methine (C-9: $\left.\delta_{\mathrm{C}} 133.2, \delta_{\mathrm{H}} 5.67\right)$ to the final typical olefinic methine $\left(\mathrm{C}-10: \delta_{\mathrm{C}} 130.8, \delta_{\mathrm{H}} 5.19\right)$ extended this substructure to the third double bond. Coupling constants $(10.5 \mathrm{~Hz}, \mathrm{H}-6 ; 10.4 \mathrm{~Hz}$, H-7; $11.0 \mathrm{~Hz}, \mathrm{H}-9 ; 11.2 \mathrm{~Hz}, \mathrm{H}-10)$ defined both $\Delta_{6-7}$ and $\Delta_{9-10}$ as (Z). Observed NOE enhancements between $\mathrm{H}_{2}-5$ and $\mathrm{H}-8$, and $\mathrm{H}-8$ and $\mathrm{H}_{2}-11$ confirmed these assignments. A long alkyl chain was constructed through a series of sequential COSY correlations starting from $\mathrm{H}-10$ to a linear chain of seven methylenes [(C-11: $\delta_{\mathrm{C}} 26.9, \delta_{\mathrm{H}} 1.95$ and 1.85), (C-12: $\delta_{\mathrm{C}} 29.0, \delta_{\mathrm{H}} 1.25$ and 1.13), (C-13: $\left.\delta_{\mathrm{C}} 27.3, \delta_{\mathrm{H}} 0.94\right),\left(\mathrm{C}-14: \delta_{\mathrm{C}} 29.3\right.$, 
$\left.\delta_{\mathrm{H}} 0.86\right),\left(\mathrm{C}-15: \delta_{\mathrm{C}} 25.91, \delta_{\mathrm{H}} 1.42\right.$ and 1.33), (C-16: $\delta_{\mathrm{C}} 28.4, \delta_{\mathrm{H}} 1.87$ and 1.38) and $\left(\mathrm{C}-17: \delta_{\mathrm{C}} 33.6, \delta_{\mathrm{H}} 2.47\right.$ and 2.36)] to complete the triene substructure (Figure 3.14).

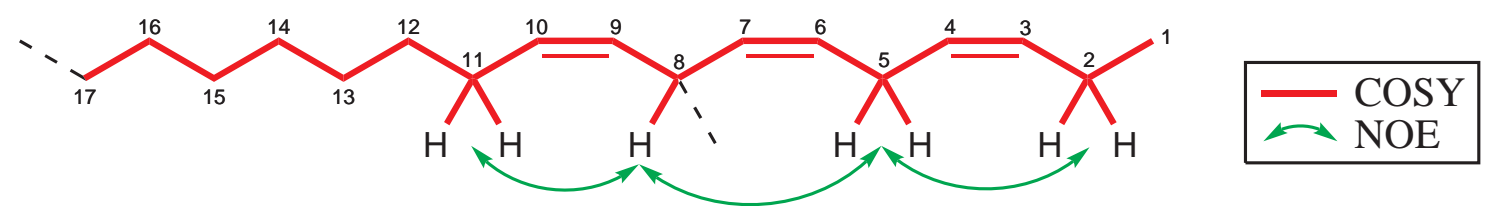

Figure 3.14. Selected COSY correlations and NOE enhancements establishing the 1,4,7-triene substructure of labillaride C (62).

An $\alpha$-pyrone substructure was established from the C-16 and C-17 methylenes. HMBC correlations from $\mathrm{H}-16 \mathrm{a}$ to a deshielded non-protonated carbon $\left(\mathrm{C}-18: \delta_{\mathrm{C}} 165.6\right)$ and from both proton resonances of $\mathrm{CH}_{2}-17$ to a shielded olefinic methine $\left(\mathrm{C}-19: \delta_{\mathrm{C}} 102.5, \delta_{\mathrm{H}} 6.45\right)$ established the first highly-polarised double bond in the now characteristic $\alpha$-pyrone substructure. HMBC correlations from H-19 to the second deshielded non-protonated $\left(\mathrm{C}-20: \delta_{\mathrm{C}}\right.$ 166.6) and shielded non-protonated $\left(\mathrm{C}-21: \delta_{\mathrm{C}} 107.3\right)$ carbons suggested the presence of the second highly-polarised double bond, supporting the attachment of oxygen at C-18 and C-20. HMBC correlations from H-7 and H-9 to C-21 established the direct connection between C-8 and C-21. This connectivity was supported by HMBC correlations from $\mathrm{H}-8$ to $\mathrm{C}-21$ and the final carbon resonance $\left(\mathrm{C}-22: \delta_{\mathrm{C}} 165.3\right)$. With no further olefinic carbons left unaccounted for, C-22 was again assigned as a ester carbonyl completing the $\alpha$-pyrone substructure through a lactone linkage to C-18 (see Figure 3.15).

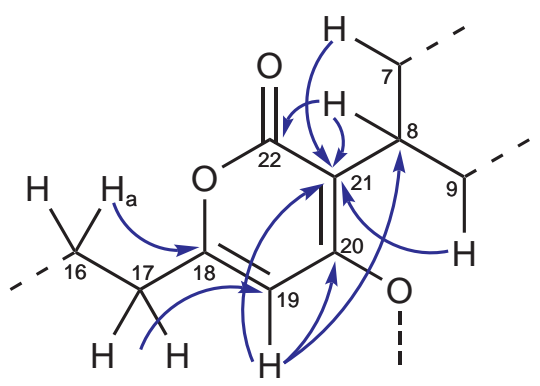

Figure 3.15. Selected HMBC correlations establishing the $\alpha$-pyrone substructure of labillaride C (62).

Every carbon resonance was now accounted for, while the $\alpha$-pyrone, triene and macrocyclic moieties accounted for all eight double-bond equivalents. The final remaining proton from the molecular formula unaccounted for was satisfied by assigning position C-20 as an alcohol. The final structure of labillaride C is therefore as proposed to be $\mathbf{6 2}$. NMR data for $\mathbf{6 2}$ is presented in Table 3.6. 


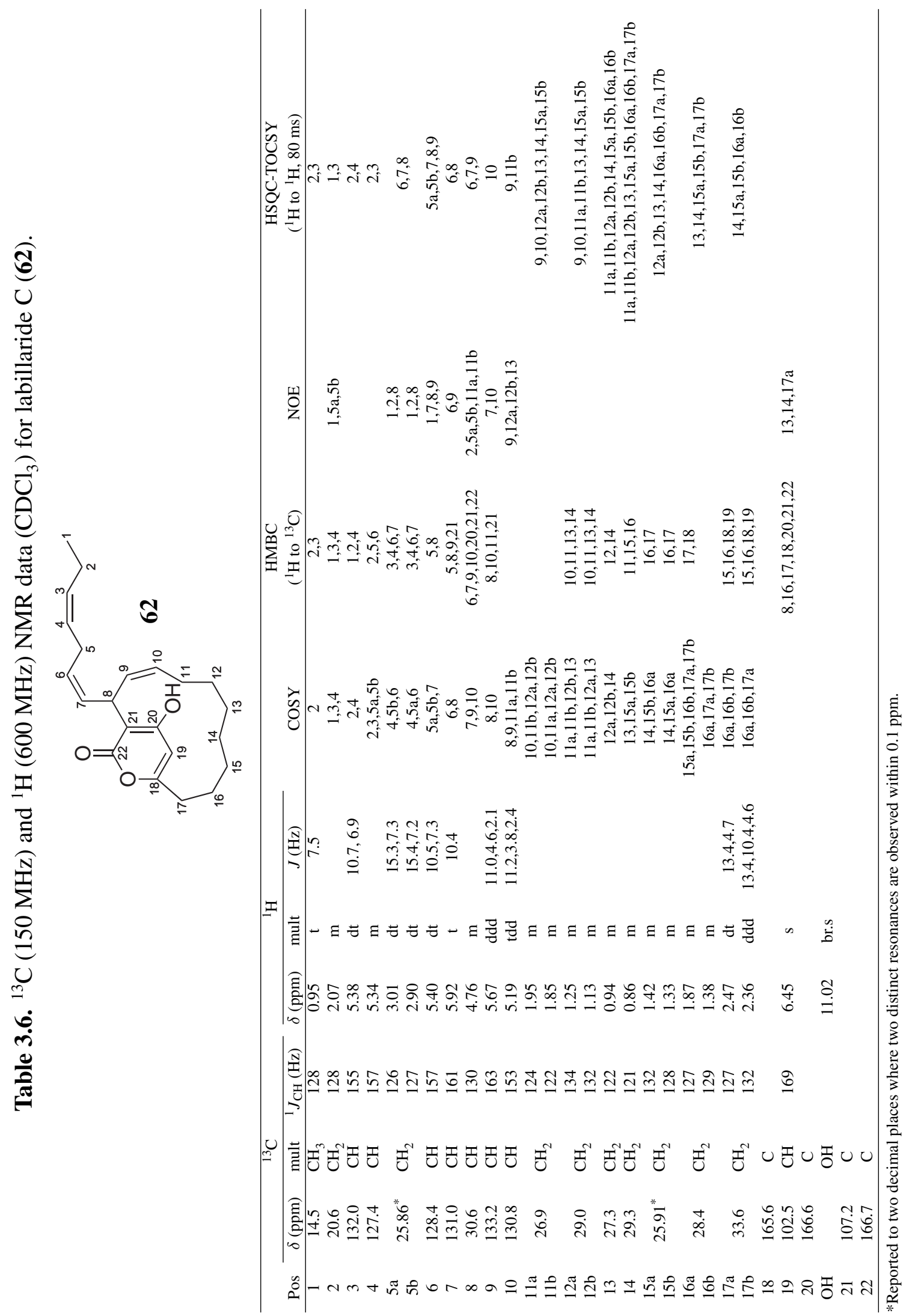




\subsection{Labillaride D}

Labillaride D (63) was isolated as a colourless oil (20.4 mg isolated in total). Positiveion mode HRESIMS showed a single pseudomolecular ion indicative of the molecular formula $\mathrm{C}_{22} \mathrm{H}_{30} \mathrm{O}_{3}\left(365.2093[\mathrm{M}+\mathrm{Na}]^{+}, \Delta 0.0 \mathrm{ppm}\right)$. The structure was elucidated in the same fashion as labillaride $\mathrm{C}(\mathbf{6 2})$. Again, the ${ }^{1} \mathrm{H}$ and ${ }^{13} \mathrm{C} \mathrm{NMR}$ spectra in $\mathrm{CDCl}_{3}$ accounted for all 30 protons and 22 carbons respectively, while the multiplicity-edited HSQC experiment confirmed one broad proton singlet to be exchangeable due to its lack of connectivity to carbon. The only major difference in the NMR data of $\mathbf{6 3}$ compared to 62 was a larger coupling constant for two of the olefinic methines $\left[\left(\delta_{\mathrm{C}} 128.9, \delta_{\mathrm{H}} 5.53\right)\right.$ and $\left(\delta_{\mathrm{C}} 130.7, \delta_{\mathrm{H}} 5.86\right)$, both with a $15.3 \mathrm{~Hz}$ coupling constant], suggesting an $(E)$ geometry across a double bond.

Analysis of the 2D NMR spectra of $\mathbf{6 3}$ allowed the construction of the structure of labillaride D (Figure 3.16). A series of sequential COSY correlations starting from the methyl triplet terminus $\left(\delta_{\mathrm{C}} 14.4, \delta_{\mathrm{H}} 0.94\right)$ constructed a 1,4,7-triene substructure $(\mathrm{C}-1$ to C-17) very similar to that of $\mathbf{6 2}$. The geometry of $\Delta_{3-4}$ and $\Delta_{9-10}$ were determined to be (Z) on the basis of the observed coupling constants $(10.6 \mathrm{~Hz}, \mathrm{H}-3 ; 10.8 \mathrm{~Hz}, \mathrm{H}-4 ; 10.5 \mathrm{~Hz}$, H-9; $10.6 \mathrm{~Hz}, \mathrm{H}-10$ ), and NOE enhancements from $\mathrm{H}_{2}-5$ to $\mathrm{H}_{2}-2$, and from $\mathrm{H}-8$ to $\mathrm{H}_{2}-11$. The coupling constants (15.3 Hz for both H-6 and H-7) defined $\Delta_{6-7}$ as $(E)$, confirmed by an observed NOE enhancement from H-8 to H-6.
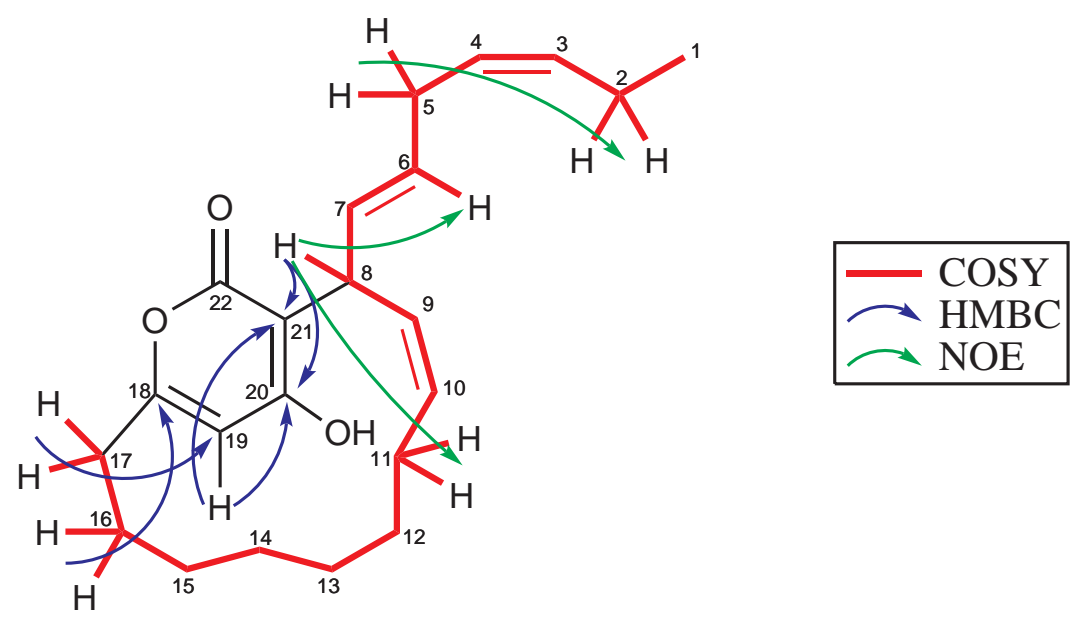

Figure 3.16. Selected COSY and HMBC correlations and NOE enhancements establishing the structure of labillaride D (63).

HMBC correlations were used to construct an $\alpha$-pyrone moiety once again. HMBC 
correlations from both proton resonances of $\mathrm{CH}_{2}-16$ to a deshielded non-protonated carbon $\left(\mathrm{C}-18: \delta_{\mathrm{C}} 165.8\right)$ and from both proton resonances of $\mathrm{CH}_{2}-17$ to a shielded olefinic methine $\left(\mathrm{C}-19: \delta_{\mathrm{C}} 101.5, \delta_{\mathrm{H}} 6.13\right)$ established the first highly-polarised double bond. HMBC correlations from H-19 to the two carbons of the second highly-polarised double bond [(C-20: $\left.\delta_{\mathrm{C}} 164.8\right)$ and $\left.\left(\mathrm{C}-21: \delta_{\mathrm{C}} 106.8\right)\right]$ supported the attachment of oxygen at C-18 and $\mathrm{C}-20$, expanding the $\alpha$-pyrone to the second double bond. No HMBC correlations to C-22 were observed, however the clear similarities to labillaride C (62) led to the confident assignment of the $\alpha$-pyrone ring. HMBC correlations were observed from H-8 into the $\alpha$-pyrone ring, indicating the same carbon bridge connectivity from the long carbon chain as 62 .

The final structure of labillaride $\mathrm{D}$ is therefore shown in $\mathbf{6 3}$, the $\Delta_{6-7}(E)$ isomer of labillaride C (62). NMR data for $\mathbf{6 3}$ is presented in Table 3.7.

Labillarides C (62) and D (63) are the first reported macrocyclic pyrones of this nature to exhibit a carbon-to-carbon bridge from the alkyl chain into the pyrone moiety (direct C-8 to $\mathrm{C}-21$ connectivity). 


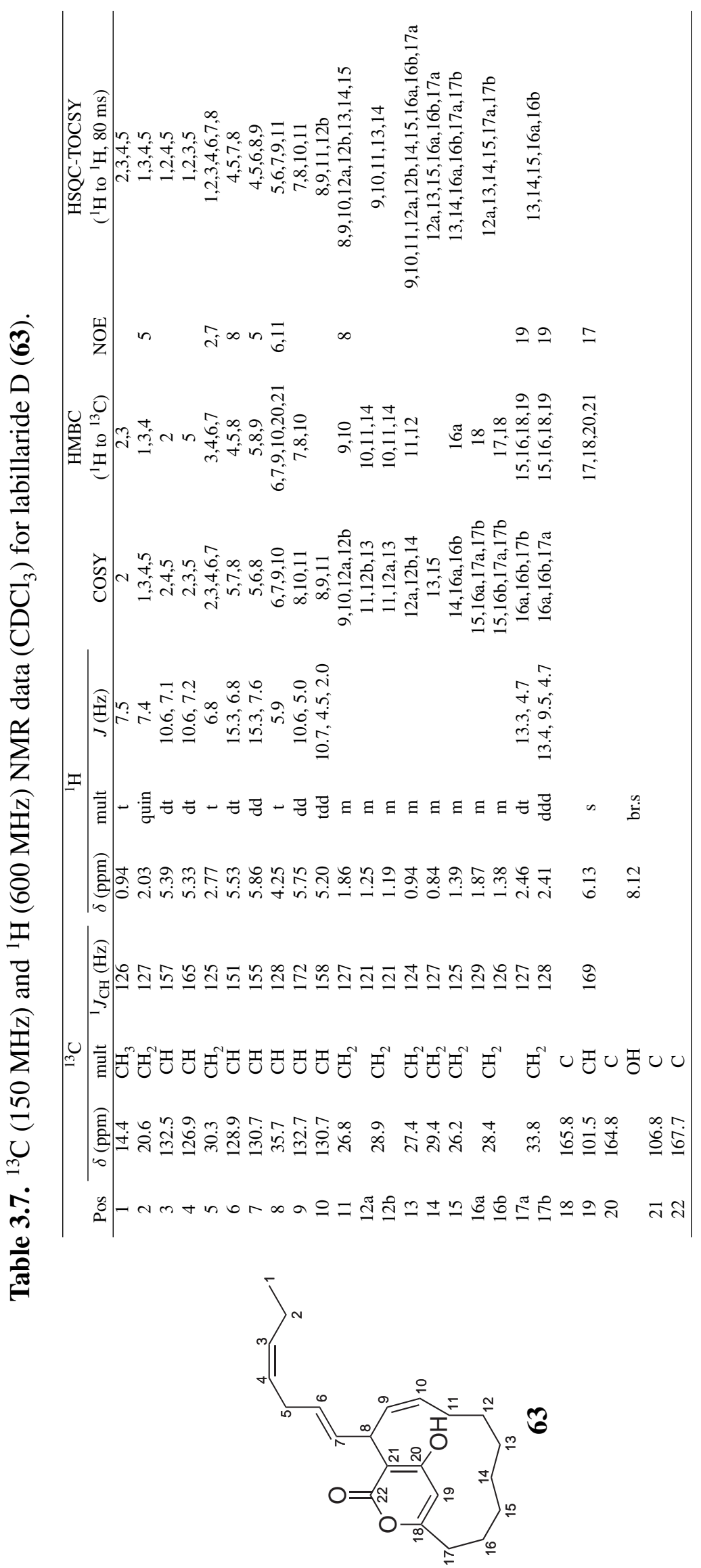




\subsection{Labillaride E}

Labillaride E (64) was isolated as a colourless oil (2.0 mg isolated in total). Positiveion mode HRESIMS analysis of $\mathbf{6 4}$ gave rise to two pseudomolecular ions indicative of the molecular formula $\mathrm{C}_{22} \mathrm{H}_{30} \mathrm{O}_{5}\left(375.2163[\mathrm{M}+\mathrm{H}]^{+}, \Delta 0.7 \mathrm{ppm}\right.$, and 397.2005 $\left.[\mathrm{M}+\mathrm{Na}]^{+}, \Delta 4.8 \mathrm{ppm}\right)$, requiring eight double-bond equivalents. The ${ }^{13} \mathrm{C}$ NMR spectrum contained 22 distinct resonances while the multiplicity-edited HSQC spectrum, as well as establishing direct ${ }^{1} \mathrm{H}$ to ${ }^{13} \mathrm{C}$ connectivity, accounted for 28 of the 30 protons indicating the presence of two exchangeable protons. Identifiable features of the NMR spectra in $\mathrm{CDCl}_{3}$ included three strongly deshielded non-protonated carbons $\left(\delta_{\mathrm{C}} 162.5,170.2\right.$ and 171.0), a strongly shielded olefinic non-protonated carbon $\left(\delta_{\mathrm{C}} 99.7\right)$, a strongly shielded olefinic methine $\left(\delta_{\mathrm{C}} 96.3, \delta_{\mathrm{H}} 5.98\right)$, four typical olefinic methines $\left[\left(\delta_{\mathrm{C}} 127.0, \delta_{\mathrm{H}} 5.73\right)\right.$, $\left(\delta_{\mathrm{C}} 129.5, \delta_{\mathrm{H}} 5.63\right),\left(\delta_{\mathrm{C}} 134.9, \delta_{\mathrm{H}} 5.51\right)$ and $\left.\left(\delta_{\mathrm{C}} 136.1, \delta_{\mathrm{H}} 5.84\right)\right]$, three oxymethines $\left[\left(\delta_{\mathrm{C}} 70.8, \delta_{\mathrm{H}} 4.30\right),\left(\delta_{\mathrm{C}} 73.3, \delta_{\mathrm{H}} 4.05\right)\right.$ and $\left.\left(\delta_{\mathrm{C}} 89.5, \delta_{\mathrm{H}} 5.42\right)\right]$, an allylic methine $\left(\delta_{\mathrm{C}} 51.3\right.$, $\left.\delta_{\mathrm{H}} 3.15\right)$ and a methyl triplet $\left(\delta_{\mathrm{C}} 9.8, \delta_{\mathrm{H}} 0.92, \mathrm{t}, 7.4 \mathrm{~Hz}\right)$.

Analysis of the ${ }^{1} \mathrm{H}-{ }^{1} \mathrm{H}$ coupling established a 17 carbon, 1,6-diene substructure (C-1 to C-17). A series of sequential COSY correlations starting from the methyl triplet (C-1: $\left.\delta_{\mathrm{C}} 9.8, \delta_{\mathrm{H}} 0.92\right)$ to a methylene $\left(\mathrm{C}-2: \delta_{\mathrm{C}} 30.0, \delta_{\mathrm{H}} 1.56\right)$ to an oxymethine $\left(\mathrm{C}-3: \delta_{\mathrm{C}} 73.3\right.$, $\left.\delta_{\mathrm{H}} 4.05\right)$ to an olefinic methine $\left(\mathrm{C}-4: \delta_{\mathrm{C}} 136.1, \delta_{\mathrm{H}} 5.84\right)$ to a second olefinic methine $\left(\mathrm{C}-5: \delta_{\mathrm{C}} 127.0, \delta_{\mathrm{H}} 5.73\right)$ established the first section of the substructure. Coupling constants (15.4 Hz, H-4 and H-5) and observed NOE enhancements between H-3 and H-5 defined $\Delta_{4-5}$ as $(E)$. Further COSY correlations from H-5 to a deshielded oxymethine $\left(\mathrm{C}-6: \delta_{\mathrm{C}} 89.5, \delta_{\mathrm{H}} 5.45\right)$ to a deshielded methine $\left(\mathrm{C}-7: \delta_{\mathrm{C}} 51.3, \delta_{\mathrm{C}} 3.15\right)$ to an oxymethine $\left(\mathrm{C}-8: \delta_{\mathrm{C}} 70.8, \delta_{\mathrm{H}} 4.30\right)$ to an olefinic methine (C-9: $\left.\delta_{\mathrm{C}} 129.5, \delta_{\mathrm{H}} 5.63\right)$ to the fourth typical olefinic methine $\left(\mathrm{C}-10: \delta_{\mathrm{C}} 134.9, \delta_{\mathrm{H}} 5.51\right)$ to a linear chain of seven methylenes $[(\mathrm{C}-11$ : $\delta_{\mathrm{C}} 27.2, \delta_{\mathrm{H}} 2.09$ and 2.00), (C-12: $\left.\delta_{\mathrm{C}} 29.4, \delta_{\mathrm{H}} 1.22\right),\left(\mathrm{C}-13: \delta_{\mathrm{C}} 27.5, \delta_{\mathrm{H}} 1.00\right.$ and 0.90), $\left(\mathrm{C}-14: \delta_{\mathrm{C}} 29.3, \delta_{\mathrm{H}} 1.09\right.$ and 1.00$),\left(\mathrm{C}-15: \delta_{\mathrm{C}} 26.4, \delta_{\mathrm{H}} 1.20\right),\left(\mathrm{C}-16: \delta_{\mathrm{C}} 26.2, \delta_{\mathrm{H}} 1.72\right.$ and 1.63) and (C-17: $\delta_{\mathrm{C}} 35.2, \delta_{\mathrm{H}} 2.62$ and 2.27)] completed the long alkyl-chain substructure. Selective excitation of $\mathrm{H}-17 \mathrm{~b}$ in a series of 1D-TOCSY experiments with increasing mixing times sequentially revealed $\mathrm{H}-17 \mathrm{~b}, \mathrm{H}-16 \mathrm{a}$ and $\mathrm{H}-16 \mathrm{~b}, \mathrm{H}_{2}-15, \mathrm{H}-14 \mathrm{a}$ and $\mathrm{H}-14 \mathrm{~b}$, $\mathrm{H}-13 \mathrm{a}$ and $\mathrm{H}-13 \mathrm{~b}, \mathrm{H}_{2}-12$ and then $\mathrm{H}-11 \mathrm{a}$ and $\mathrm{H}-11 \mathrm{~b}$, supporting the assignment of the 
C-11 to C-17 alkyl chain. Coupling constants $(10.5 \mathrm{~Hz}, \mathrm{H}-9$ and $10.8 \mathrm{~Hz}, \mathrm{H}-10)$ and an observed NOE enhancement from H-8 to H-11b defined $\Delta_{9-10}$ as (Z) (Figure 3.17).

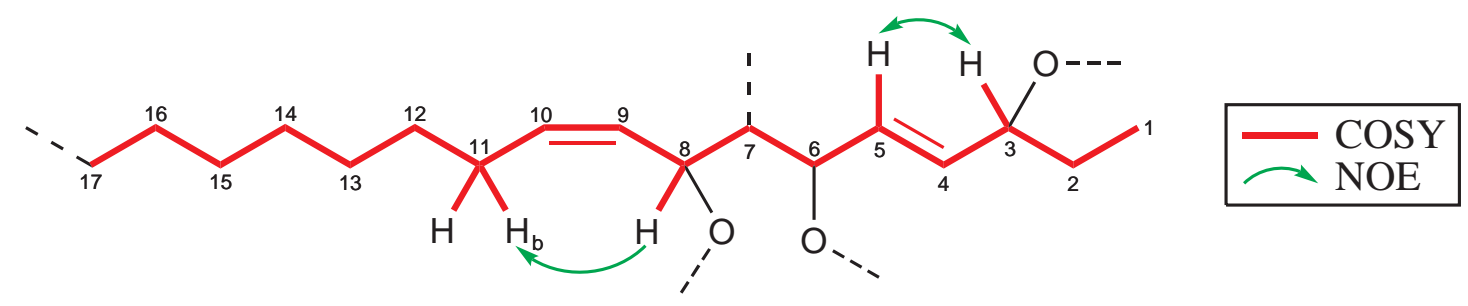

Figure 3.17. Selected COSY correlations establishing the 1,6-diene substructure of labillaride E (64).

As before, an $\alpha$-pyrone substructure was constructed starting from the distinctive C-16 and $\mathrm{C}-17$ methylenes. $\mathrm{HMBC}$ correlations from both proton resonances of $\mathrm{CH}_{2}-16$ to a deshielded non-protonated carbon $\left(\mathrm{C}-18: \delta_{\mathrm{C}} 170.2\right)$ and from both proton resonances of $\mathrm{CH}_{2}-17$ to a strongly shielded methine $\left(\mathrm{C}-19: \delta_{\mathrm{C}} 96.3, \delta_{\mathrm{H}} 5.98\right)$ indicated the first of the two highly-polarised double bonds. HMBC correlations from H-19 to the second downfield non-protonated carbon $\left(\mathrm{C}-20: \delta_{\mathrm{C}} 171.0\right)$ and to a strongly shielded nonprotonated carbon $\left(\mathrm{C}-21: \delta_{\mathrm{C}} 99.7\right)$ suggested the second highly-polarised double bond, supporting the attachment of oxygen at C-18 and C-20. Crosspeak intensities in HMBC experiments depend on the magnitude of long-range coupling. ${ }^{67}$ The standard HMBC experiment employed by this group has a coherence transfer delay optimised for $8 \mathrm{~Hz}$. Here, an HMBC experiment optimised for a coherence transfer delay of $4 \mathrm{~Hz}$ was performed with the hope of seeing four-bond HMBC correlations, which typically have smaller ${ }^{13} \mathrm{C}-{ }^{1} \mathrm{H}$ coupling constants. This spectrum revealed HMBC correlations from $\mathrm{H}-$ $17 \mathrm{~b}$ and $\mathrm{H}-19$ to the final deshielded non-protonated lactone carbonyl (C-22: $\left.\delta_{\mathrm{C}} 162.5\right)$. Once again, this supported an $\alpha$-pyrone moiety, with an oxygen bridge connecting C-18 and C-22 (see Figure 3.18).
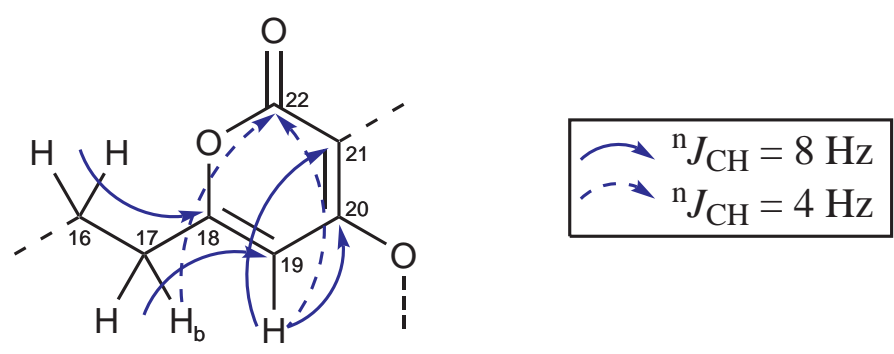

Figure 3.18. Selected HMBC correlations establishing the $\alpha$-pyrone substructure of labillaride E (64). 
HMBC correlations from both H-6 and H-8 to C-21 were observed, establishing connectivity between C-7 and C-21. This was confirmed by HMBC correlations from H-7 to C-20, C-21 and C-22, and a weak homo-allylic COSY correlation between H-7 and H-19. A further HMBC correlation from H-6 to C-20 indicated a second connectivity from the alkyl chain into the pyrone ring through an oxygen bridge between C- 6 and C-20, forming a dihydrofuran (see Figure 3.19).

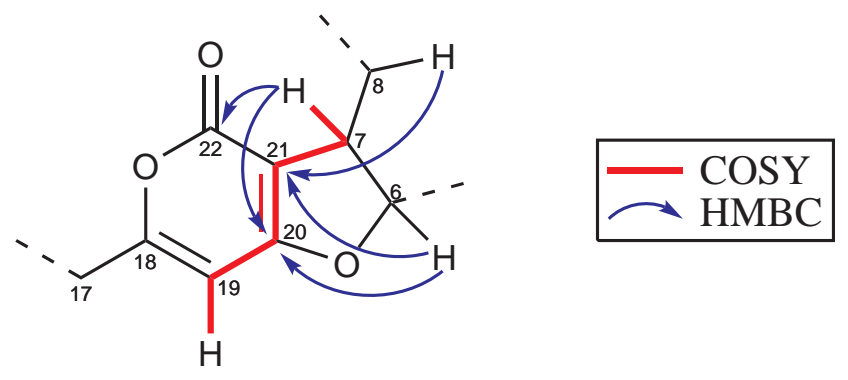

Figure 3.19. Selected COSY and HMBC correlations connecting the substructures of labillaride E (64).

The dihydrofuro[3,2-c]pyran-4-one moiety is present, though uncommon, in terrestrial organisms. To the author's knowledge, no such examples have been reported from the marine environment. Phelligridimer A (72), a macrocyclic metabolite reported in 2005 from the Chinese medicinal fungus Phellinus igniarius, is one of the few compounds of natural origin to contain this moiety. ${ }^{68}$ The ${ }^{13} \mathrm{C}$ chemical shifts of the dihydrofuro[3,2c]pyran-4-one fragment of $\mathbf{6 4}$ compared very favourably to those of $\mathbf{7 2}$, with the exception of the non-protonated carbon at positions C-18 and C-6 in 64 and 72, respectively (see Table 3.8). This is most likely due the differing substituents at this position, specifically an alkyl chain in $\mathbf{6 4}$ as opposed to a conjugated alkene in $\mathbf{7 2 .}$<smiles>O=c1oc(/C=C/c2cc(O)c(-c3cc(O)c(O)cc3/C=C/c3cc(O)c(-c4cc(O)c(O)cc4O)c(=O)o3)c3c2C([C@H]2Oc4cc(/C=C/O)oc(=O)c42)[C@H](c2ccc(O)c(O)c2)O3)cc(O)c1-c1ccc(O)c(O)c1</smiles>

All detected carbon resonances were now accounted for. The presence of the dihydrofuro[3,2-c]pyran-4-one ring system accounted for five of the eight double-bond equiva- 
Table 3.8. ${ }^{13} \mathrm{C}$ chemical shift differences of dihydrofuro[3,2-c]pyran-4-one moiety for labillaride E (64) and phelligridimer A (72).

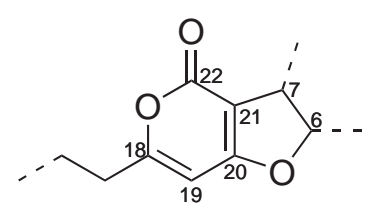

64

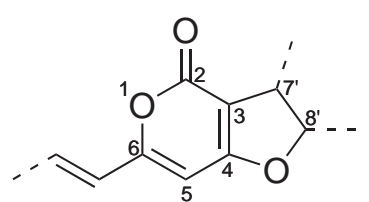

72

\begin{tabular}{|c|c|c|c|c|c|}
\hline \multirow[b]{2}{*}{ mult } & \multicolumn{2}{|c|}{ Labillaride E (65) } & \multicolumn{2}{|c|}{ Phelligridimer A (72)* } & \multirow{2}{*}{$\begin{array}{c}\text { Difference } \\
\delta_{\mathrm{C}} \Delta \delta(\mathrm{ppm})\end{array}$} \\
\hline & Pos & $\delta_{\mathrm{C}} \delta(\mathrm{ppm})$ & $\overline{\mathrm{Pos}}$ & $\delta_{\mathrm{C}} \delta(\mathrm{ppm})$ & \\
\hline $\mathrm{C}$ & 22 & 162.5 & 2 & 163.0 & -0.5 \\
\hline $\mathrm{C}$ & 21 & 99.7 & 3 & 99.3 & 0.4 \\
\hline $\mathrm{C}$ & 20 & 171.0 & 4 & 170.4 & 0.6 \\
\hline $\mathrm{CH}$ & 19 & 96.3 & 5 & 95.0 & 1.3 \\
\hline $\mathrm{C}$ & 18 & 170.2 & 6 & 162.8 & 7.4 \\
\hline $\mathrm{CH}$ & 7 & 51.2 & $7^{\prime}$ & 51.4 & -0.2 \\
\hline $\mathrm{CH}$ & 6 & 89.5 & $8^{\prime}$ & 89.6 & -0.1 \\
\hline
\end{tabular}

lents, while the diene chain and macrocycle completed the requirements of the molecular formula. The final two protons from the molecular formula unaccounted for were satisfied by assigning positions $\mathrm{C}-3$ and $\mathrm{C}-8$ as alcohols.

The ${ }^{1} \mathrm{H}$ NMR spectrum of labillaride E (64) showed H-7 to be split into a doublet of doublets of 9.2 and $1.6 \mathrm{~Hz}$. The large splitting was assumed to be due to coupling to $\mathrm{H}-8$, while the very small splitting appeared to be due to vicinal coupling to H-6. The broad doublet ${ }^{1} \mathrm{H}$ signal of $\mathrm{H}-6$ was suspected of being broadened by this small coupling to $\mathrm{H}-7$, supporting the claim. A series of homonuclear decoupled ${ }^{1} \mathrm{H}$ NMR experiments were performed in order to prove this assignment. Selective decoupling of H-6 caused the doublet of doublets of $\mathrm{H}-7$ to collapse into a doublet of $9.2 \mathrm{~Hz}$, while selective decoupling of H-8 caused H-7 to collapse into a broad singlet (see Figure 3.20). The decoupled experiments therefore confirmed the allocation of the $1.6 \mathrm{~Hz}$ to the vicinal coupling between H-6 and H-7.

The vicinal coupling constants for cyclopentene $\left({ }^{3} J_{c i s}=7.4 \mathrm{~Hz},{ }^{3} J_{\text {trans }}=4.6 \mathrm{~Hz}\right)$ and dihydrofuran $\left({ }^{3} J_{\text {cis }}=10.7 \mathrm{~Hz},{ }^{3} J_{\text {trans }}=8.3 \mathrm{~Hz}\right)$ show very little variation between the $c$ is and trans values. ${ }^{69}$ The vicinal coupling constant of $6.5 \mathrm{~Hz}$ between $\mathrm{H}-7^{\prime}$ and $\mathrm{H}-8^{\prime}$ in phelligridimer A (72) led Shi et al. to assign a trans orientation of the two protons of the dihydrofuro[3,2-c]pyran-4-one moiety, supported by several NOE enhancements. ${ }^{68}$ These reported coupling constants show no similarity to the $1.6 \mathrm{~Hz}$ observed between H-6 and H-7 in 64, therefore further examination was required. 

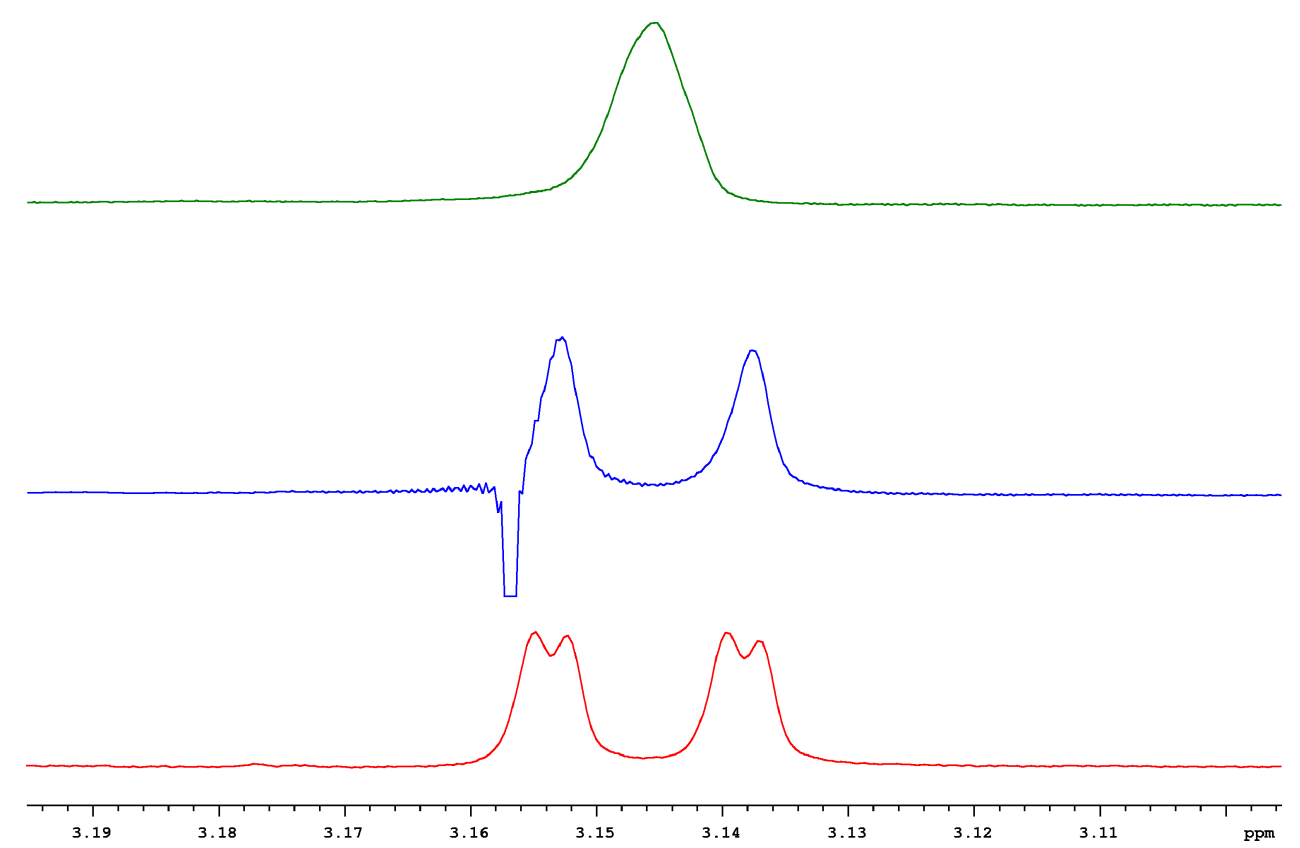

Figure 3.20. ${ }^{1} \mathrm{H}$ NMR spectrum of $\mathrm{H}-7$ of labillaride $\mathrm{E}(\mathbf{6 4})$ (red) and homonuclear decoupled ${ }^{1} \mathrm{H}$ NMR spectra of H-7 selectively decoupled at H-6 (blue) and H-8 (green).

The small coupling constant observed between H-6 and H-7 (1.6 Hz) suggested a dihedral angle close to $90^{\circ}$. This could only be achieved when the protons were held reasonably rigid in a trans relationship, with the large side-chain sitting on the opposite face of the ring to the bulky macrocycle. NOE enhancements between H-6 and H-8 supported this trans assignment (see Figure 3.21). The assignment of cis or trans relationships on fivemembered rings are notoriously difficult. In this case, however, the trans assignment is fairly confidently made due to the deviation from the normal ${ }^{3} J_{\mathrm{HH}}$ values seen in dihydrofuran rings. The final structure of labillaride $\mathrm{E}$ is therefore proposed to be $\mathbf{6 4}$. NMR data for 64 is presented in both $\mathrm{CDCl}_{3}$ (Table 3.9) and $\mathrm{C}_{6} \mathrm{D}_{6}$ (Table 3.10).
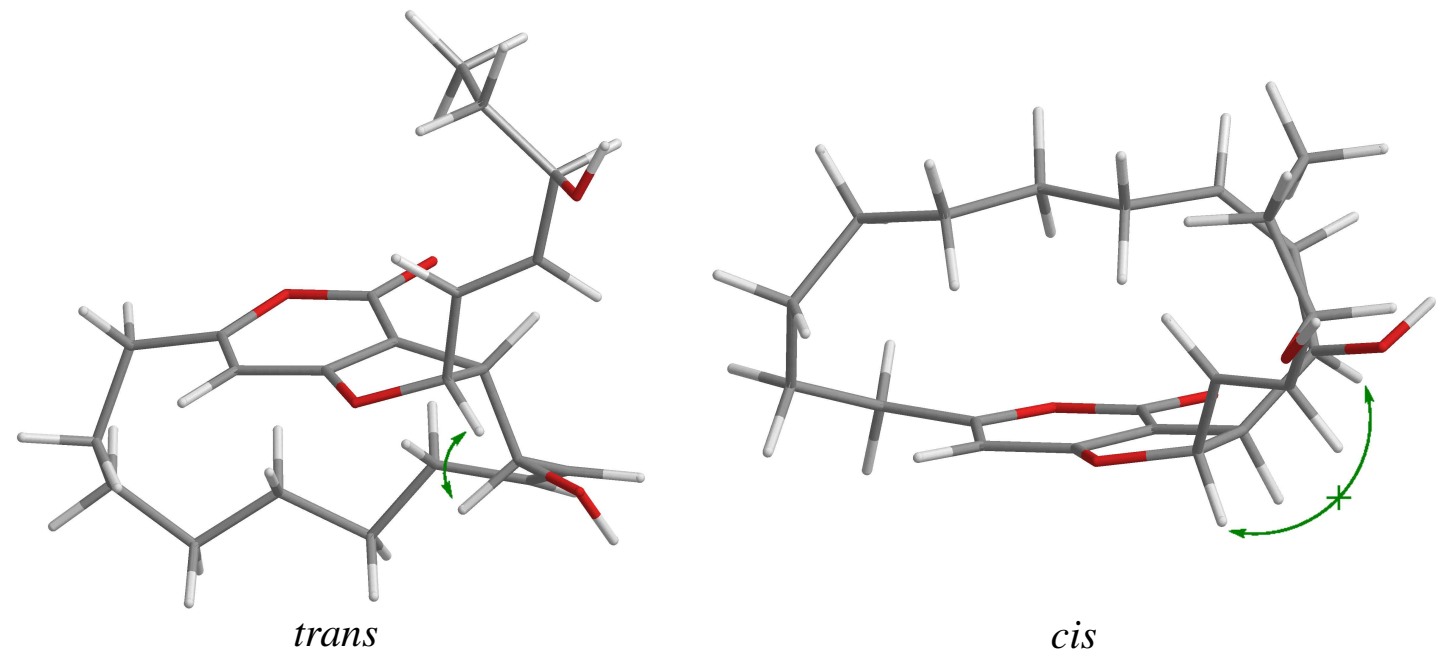

Figure 3.21. The selected NOE enhancement supporting the trans assignment of H-6 and $\mathrm{H}-7$ in labillaride $\mathrm{E}(\mathbf{6 4})$. 


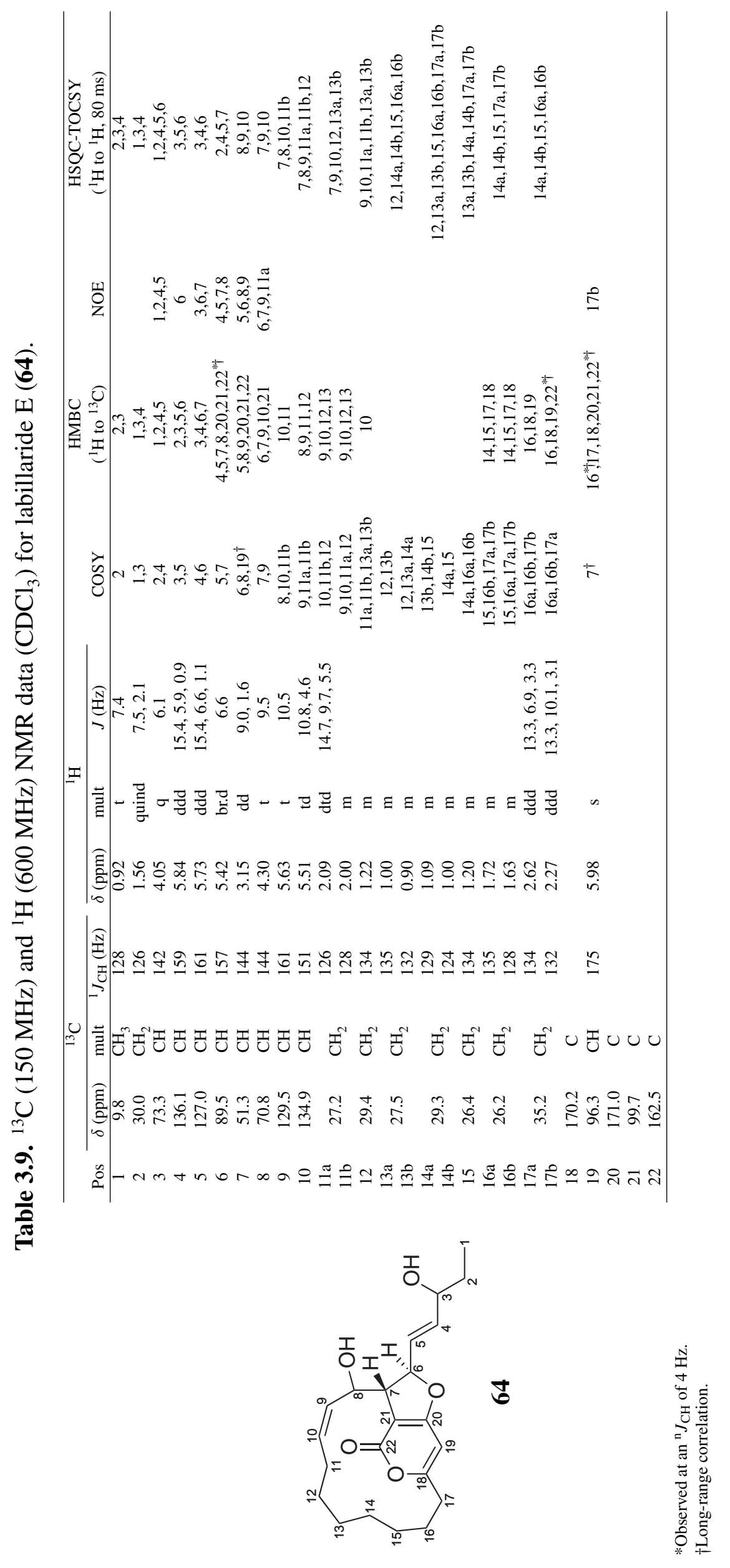




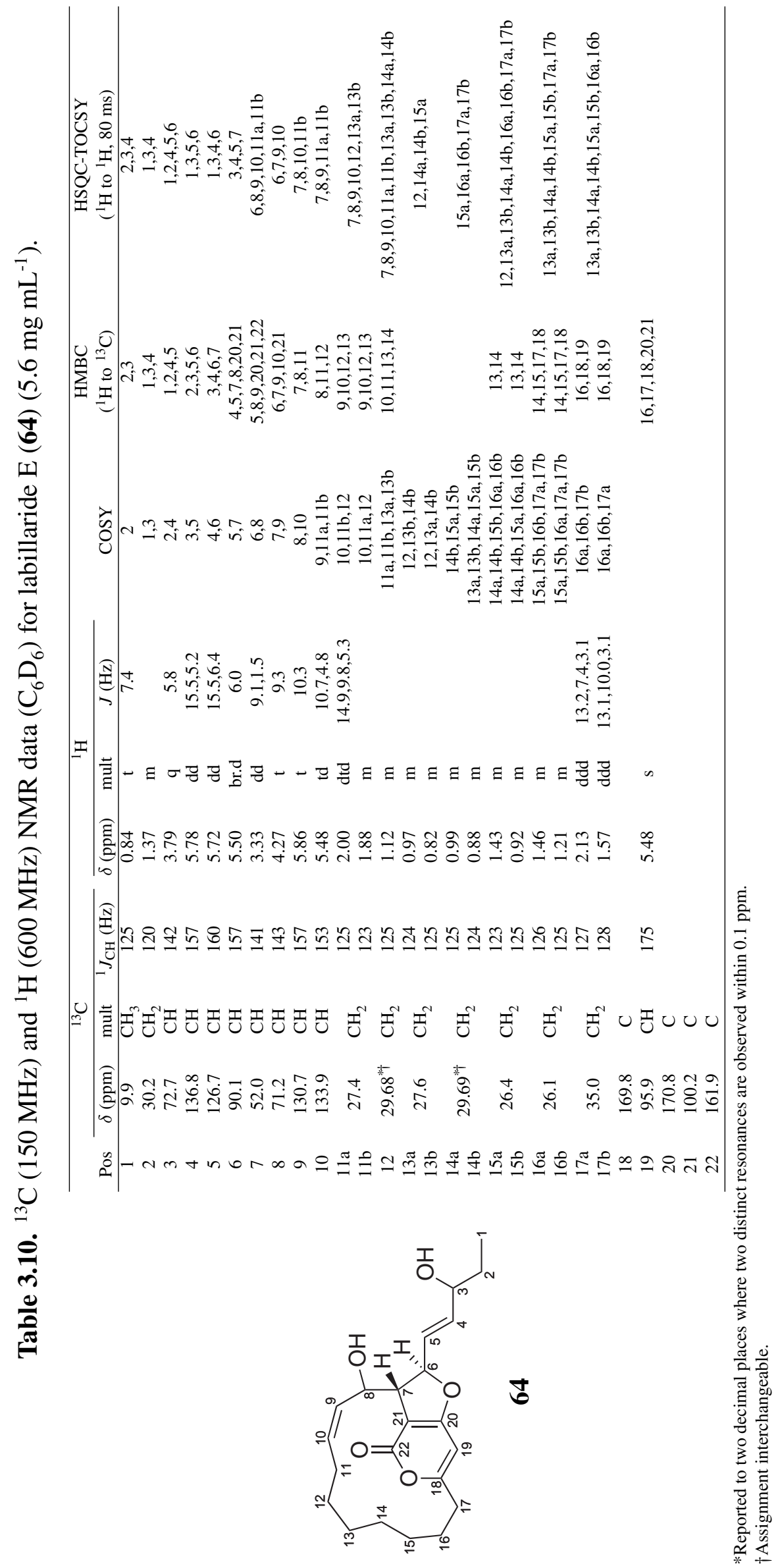




\subsection{Isolation of Labillaride E Isomers}

During the purification of the second bulk extract of Phacelocarpus labillardieri, a sample of what was thought to be labillaride E (64) appeared to exhibit "twinning" of some signals in the ${ }^{1} \mathrm{H}$ NMR spectrum, as shown in Figure 3.22. Further purification by normalphase (DIOL) HPLC gave two separable compounds, labillarides F (65) and G (66), which showed minor differences both to each other and to 64 in the ${ }^{1} \mathrm{H}$ NMR spectra (see Figure 3.23 for spectra obtained in $\mathrm{CDCl}_{3}$ and Figure 3.24 for spectra obtained in $\mathrm{C}_{6} \mathrm{D}_{6}$ ). At this point, the fractions on either side of the original labillaride E (64) sample were inspected more closely and it was found that the later eluting fraction appeared to also contain a mixture of very similar compounds. Purification of this fraction by normal-phase HPLC (DIOL) produced a fourth compound (labillaride H, 67) along with additional 64.
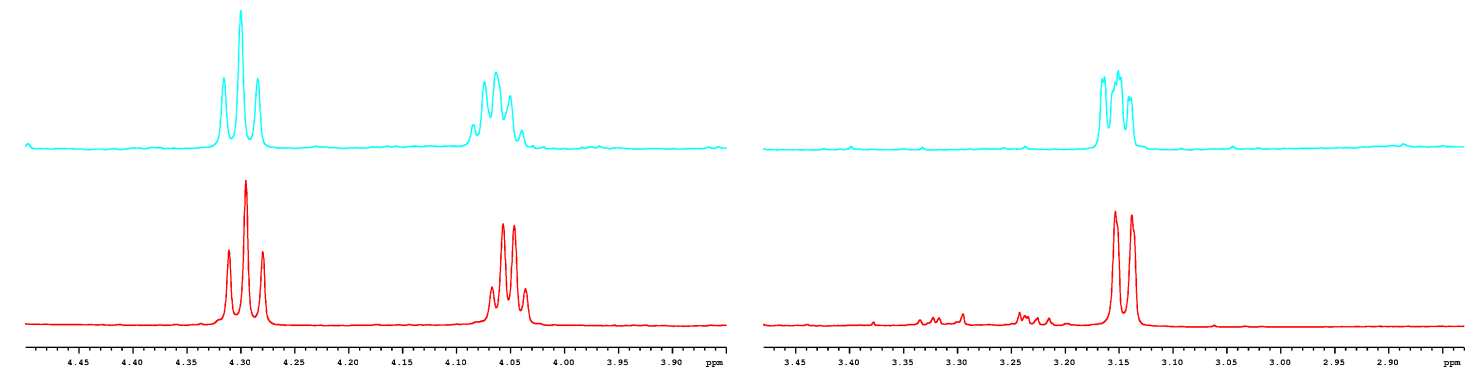

Figure 3.22. ${ }^{1} \mathrm{H}$ NMR spectra of labillaride E (64) (red) and the mixture of labillarides $F$ (65) and $\mathrm{G}(\mathbf{6 6})$ (cyan).

To confirm that all four samples were different compounds, several HPLC injections were performed using various combinations of the four samples. It was found that when injected individually under identical HPLC conditions (analytical DIOL column with $7 \%$ IPA in hexanes as the mobile phase at a flow rate of $1 \mathrm{~mL} / \mathrm{min})$, each compound exhibited a different retention time: $32.7,31.6,33.4$ and $30.3 \min$ for $\mathbf{6 4 , 6 5 , 6 6}$ and 67, respectively. Interestingly, when combinations of two pure compounds of equal concentration were injected, only one peak was observed for a combination of $\mathbf{6 4}$ and 66, and a combination of $\mathbf{6 5}$ and $\mathbf{6 7}$, while two peaks were observed with all four other two-compound combinations (see Figure 3.25). When all four compounds were injected, only two peaks were observed, supporting the idea that labillarides E (64) and G (66), and F (65) and H (67) co-elute when co-injected. 


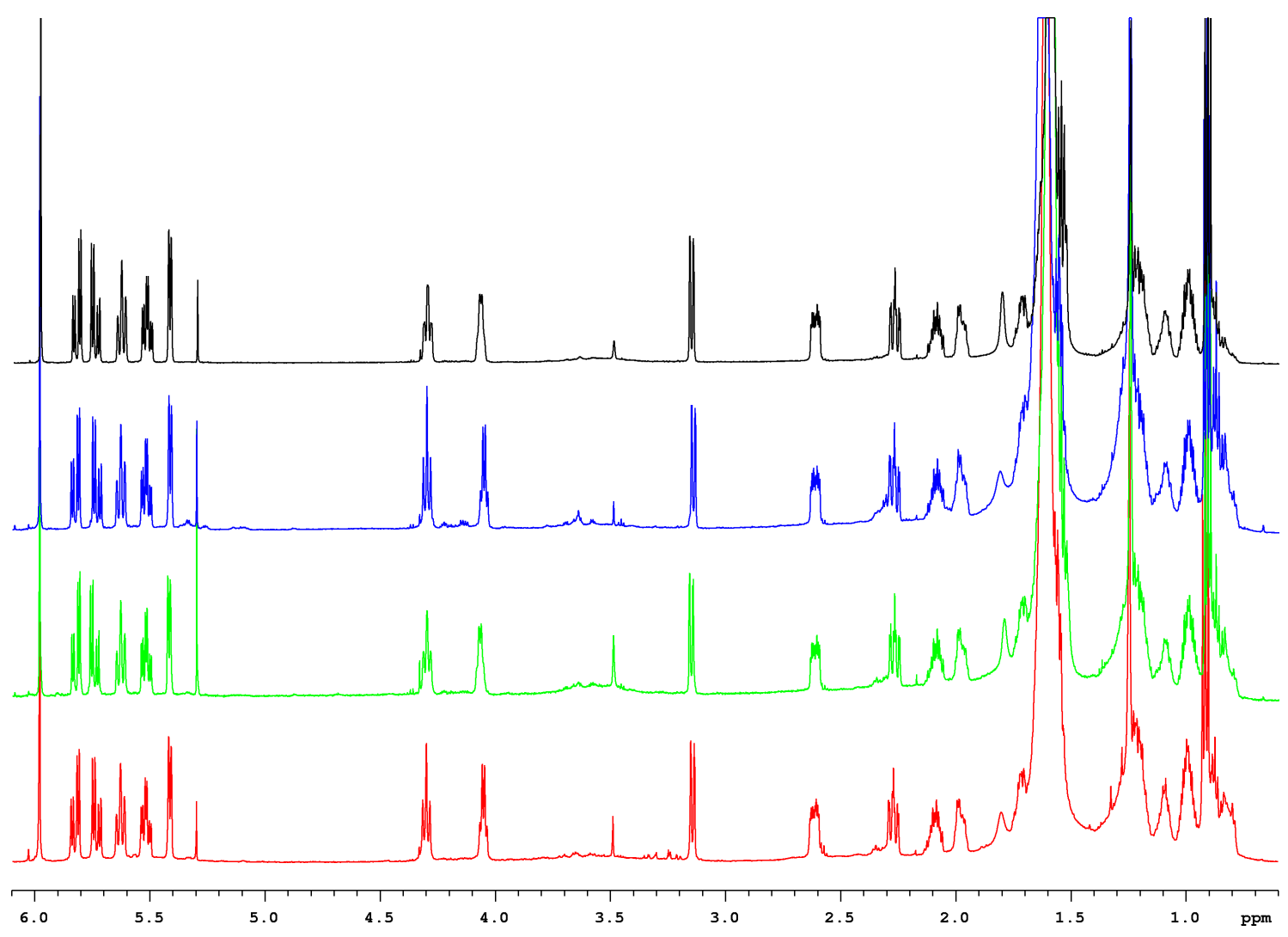

Figure 3.23. ${ }^{1} \mathrm{H}$ NMR spectra of labillarides E (64) (red), F (65) (green), G (66) (blue) and $\mathrm{H}(67)$ (black) $\left(\mathrm{CDCl}_{3}, 1.3 \mathrm{mg} \mathrm{mL}^{-1}\right)$.

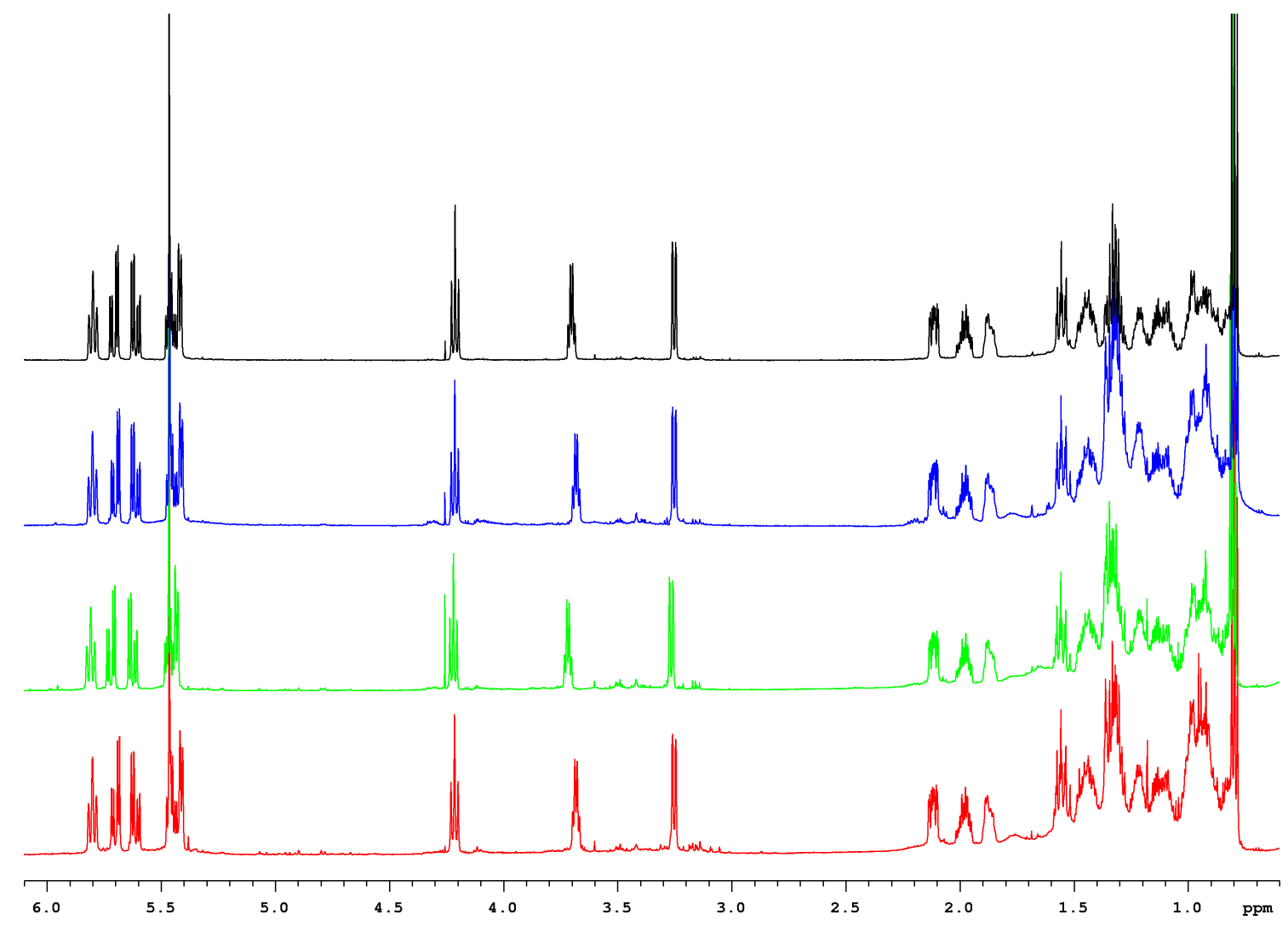

Figure 3.24. ${ }^{1} \mathrm{H}$ NMR spectra of labillarides E (64) (red), F (65) (green), G (66) (blue) and $\mathrm{H}(67)$ (black) $\left(\mathrm{C}_{6} \mathrm{D}_{6}, 1.6 \mathrm{mg} \mathrm{mL}^{-1}\right)$. 


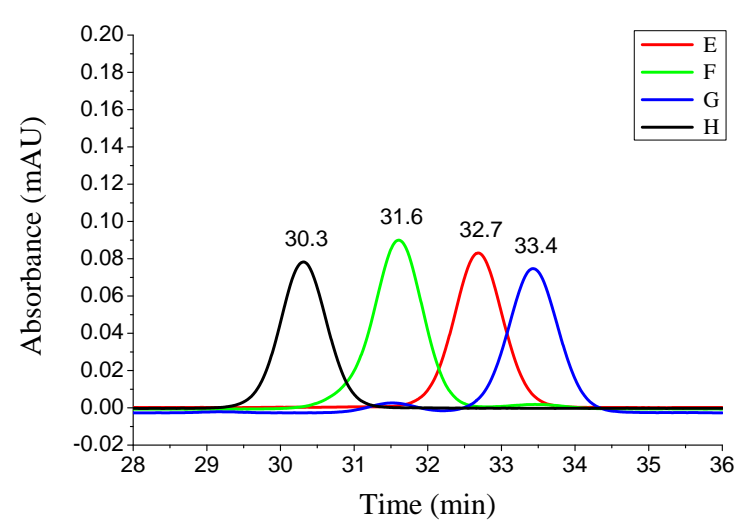

(a) Individual HPLC injections.

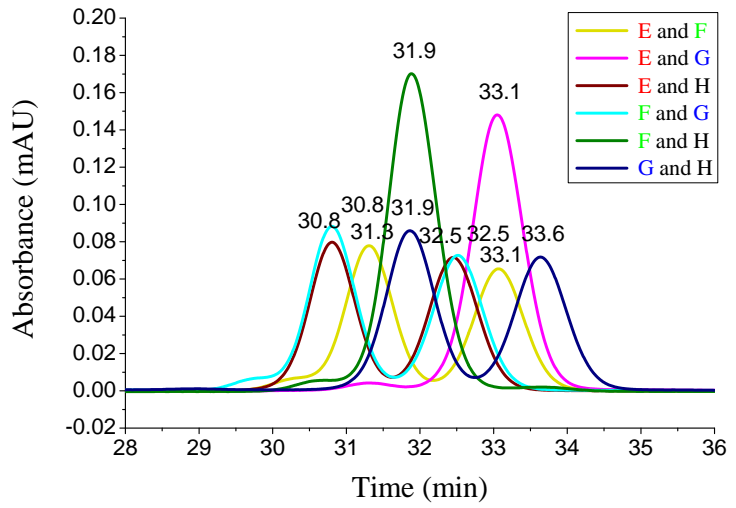

(b) Combined HPLC injections.

Figure 3.25. Single wavelength $(300 \mathrm{~nm})$ traces of HPLC injections of labillarides E (66), F (65), G (66) and $\mathrm{H}(67)$.

All four compounds have exceptionally similar chromophores (see Figure 3.26), indicating likely structural similarities. This fact, supported by the remarkably similar ${ }^{1} \mathrm{H}$ NMR spectra and identical HRESIMS data, suggested labillarides $F(65), G(66)$ and $H$ (67) are very similar stereoisomers of labillaride E (64). This number of isomers was not unreasonable, as $\mathbf{6 4}$ contains four chiral centres which gives rise to eight possible diastereomeric pairs. It is important to note that had $\mathbf{6 4}$ originally been isolated with $\mathbf{6 6}$, or had $\mathbf{6 5}$ been isolated with $\mathbf{6 7}$, their final separations would have been very challenging due to their propensities to co-elute.

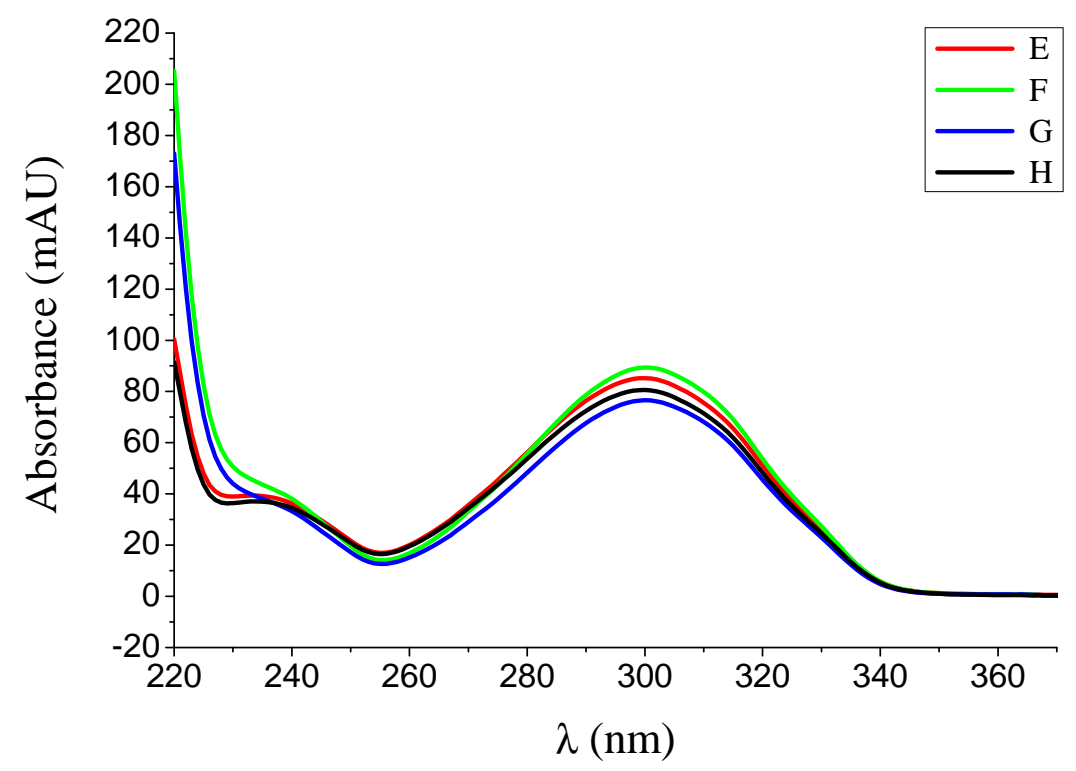

Figure 3.26. UV traces of labillarides E (64) (red), F (65) (green), G (66) (blue) and H (67) (black). 


\subsection{Labillaride F}

Positive-ion mode HRESIMS analysis of the colourless oil labillaride F (65) (0.4 mg isolated in total) gave rise to two pseudomolecular ions indicative of the molecular formula $\mathrm{C}_{22} \mathrm{H}_{30} \mathrm{O}_{5}\left(375.2162[\mathrm{M}+\mathrm{H}]^{+}, \Delta 1.2 \mathrm{ppm}\right.$, and $397.1990[\mathrm{M}+\mathrm{Na}]^{+}, \Delta$ $1.1 \mathrm{ppm}$ ), requiring eight double-bond equivalents. The ${ }^{1} \mathrm{H}$ and ${ }^{13} \mathrm{C}$ NMR spectra in $\mathrm{CDCl}_{3}$ were almost identical to that of labillaride $\mathrm{E}(\mathbf{6 4})$, including identifiable features such as three strongly deshielded non-protonated carbons $\left(\delta_{\mathrm{C}} 161.9,169.8\right.$ and 170.8), a strongly shielded olefinic non-protonated carbon $\left(\delta_{\mathrm{C}} 100.2\right)$, a strongly shielded olefinic methine $\left(\delta_{\mathrm{C}} 95.9, \delta_{\mathrm{H}} 5.48\right)$ and three oxymethines $\left[\left(\delta_{\mathrm{C}} 71.1, \delta_{\mathrm{H}} 4.27\right),\left(\delta_{\mathrm{C}} 72.7, \delta_{\mathrm{H}} 3.79\right)\right.$ and $\left.\left(\delta_{\mathrm{C}} 90.1, \delta_{\mathrm{H}} 5.50\right)\right]$.

The planar structure of $\mathbf{6 5}$ was elucidated in an identical fashion as $\mathbf{6 4}$, through a series of COSY, NOE and HMBC correlations (see Figure 3.27). A series of sequential COSY correlations starting from a methyl triplet constructed a 17 carbon, 1,6-diene chain $(\mathrm{C}-1$ to C-17). The coupling constant of $15.4 \mathrm{~Hz}$ between $\mathrm{H}-4$ and $\mathrm{H}-5$ defined $\Delta_{4-5}$ as (E), supported by the observation of an NOE enhancement between H-3 and H-5. The geometry of the second double bond was determined to be $(Z)$ on the basis of observed ${ }^{1} \mathrm{H}-{ }^{1} \mathrm{H}$ coupling constants $(10.6 \mathrm{~Hz}, \mathrm{H}-9$ and $10.7 \mathrm{~Hz}, \mathrm{H}-10)$. An NOE enhancement from $\mathrm{H}-8$ to H-11b was observed, confirming this assignment as identical to 64.

HMBC correlations from $\mathrm{H}_{2}-16$ to $\mathrm{C}-18$ and $\mathrm{H}_{2}-17$ to $\mathrm{C}-19$, and an allylic COSY correlation observed between $\mathrm{H}_{2}-17$ and $\mathrm{H}-19$ confirmed the presence of the first highlypolarised double bond. HMBC correlations from H-19 to C-20 and C-21 established the second highly-polarised double bond, while an HMBC experiment optimised for an ${ }^{\mathrm{n}} J_{\mathrm{CH}}$ of $4 \mathrm{~Hz}$ revealed a correlation from $\mathrm{H}_{2}-17$ to $\mathrm{C}-22$. Once again, this supported an $\alpha$-pyrone moiety with an ester oxygen bridge connecting C-18 and C-22. Finally, HMBC correlations from $\mathrm{H}-6$ and $\mathrm{H}-8$ to $\mathrm{C}-21$, from $\mathrm{H}-7$ to $\mathrm{C}-20, \mathrm{C}-21$ and $\mathrm{C}-22$, and from H-6 to C-20 established the five-membered heterocycle. The final two protons from the molecular formula unaccounted for were satisfied by assigning positions C-3 and C-8 as alcohols. Thus 65 is constitutionally related to 64 and the double bond geometry is conserved. 

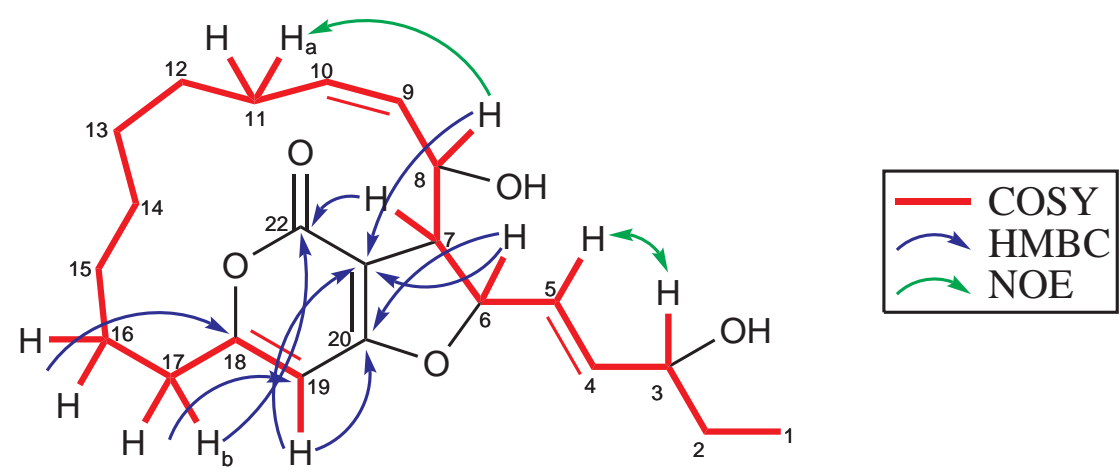

Figure 3.27. Selected COSY and HMBC correlations and NOE enhancements establishing the structure of labillaride $\mathrm{F}(\mathbf{6 5})$.

As with labillaride E (64), the relative configuration of 65 was difficult to assign. A small coupling constant observed between the vicinal protons $\mathrm{H}-6$ and $\mathrm{H}-7$ (1.6 Hz) combined with observed NOE enhancements between H-5 and H-8 again suggested a trans relationship. The final structure of labillaride $\mathrm{F}$ is therefore proposed to be $\mathbf{6 5}$. NMR data for $\mathbf{6 5}$ is presented in Table 3.11. 


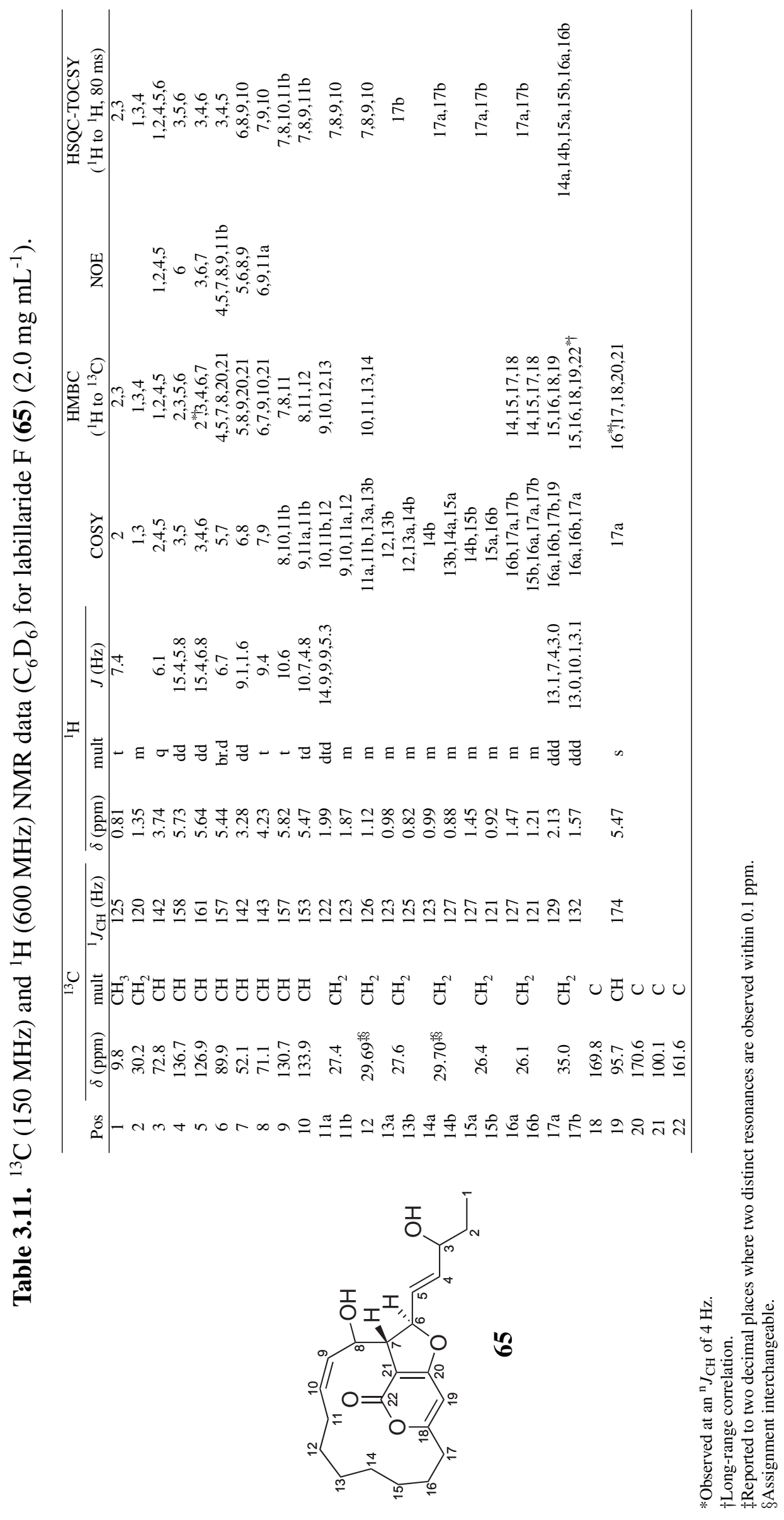




\subsection{Labillaride G}

The observation of pseudomolecular ions of the colourless oil labillaride G (66) (0.4 mg isolated in total) by HRESIMS indicated a molecular formula of $\mathrm{C}_{22} \mathrm{H}_{30} \mathrm{O}_{5}(375.2158$ $[\mathrm{M}+\mathrm{H}]^{+}, \Delta 2.1 \mathrm{ppm}$ and $\left.397.1986[\mathrm{M}+\mathrm{Na}]^{+}, \Delta 0.2 \mathrm{ppm}\right)$, requiring eight double-bond equivalents. As with labillaride F (65), the ${ }^{1} \mathrm{H}$ and ${ }^{13} \mathrm{C}$ NMR spectra of 66 were almost identical to those of labillaride E (64).

The planar structure of 66 was elucidated in an identical fashion as 64 and $\mathbf{6 5}$, through a series of COSY, NOE and HMBC correlations (see Figure 3.28). Analysis of the ${ }^{1} \mathrm{H}-{ }^{1} \mathrm{H}$ coupling established the 17 carbon 1,6-diene. HMBC correlations from $\mathrm{H}_{2}-16$ to $\mathrm{C}-18$, from $\mathrm{H}_{2}-17$ to $\mathrm{C}-19$ and C-22, and from $\mathrm{H}-19$ to C-20 and C-21 established the $\alpha$-pyrone ring. HMBC correlations from H-6 to C-20, and from H-6 and H-8 to C-21 constructed the five-membered heterocycle. The geometry of the first double bond was determined to be $(E)$ on the basis of the observed ${ }^{1} \mathrm{H}$ to ${ }^{1} \mathrm{H}$ coupling constant between $\mathrm{H}-4$ and H-5 of $15.6 \mathrm{~Hz}$. NOE enhancements between H-3 and H-5 confirmed this assignment. Coupling constants $(10.2 \mathrm{~Hz}, \mathrm{H}-9$ and $10.6 \mathrm{~Hz}, \mathrm{H}-10)$ defined $\Delta_{9-10}$ as $(Z)$, confirmed by an observed NOE enhancement between $\mathrm{H}-8$ and $\mathrm{H}_{2}-11 \mathrm{a}$.

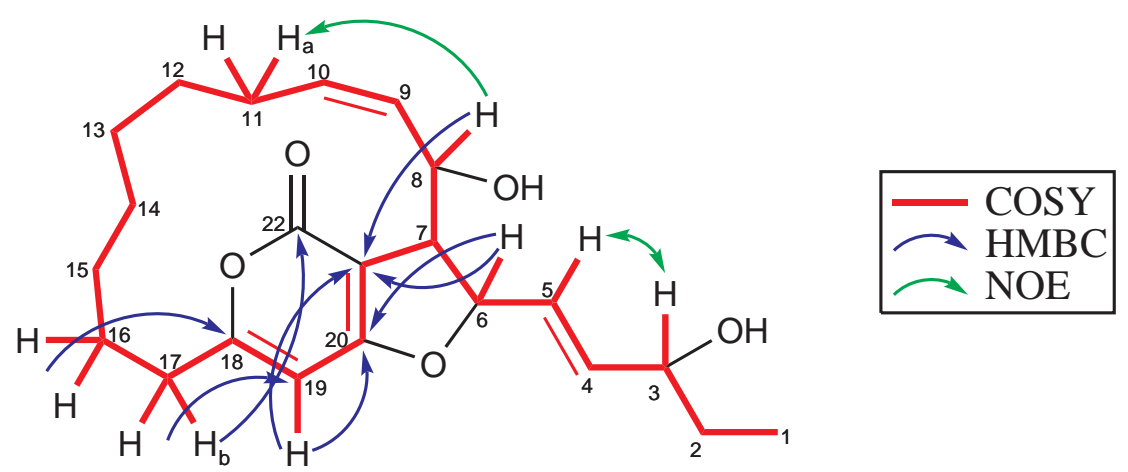

Figure 3.28. Selected COSY and HMBC correlations and NOE enhancements establishing the structure of labillaride $\mathrm{G}(\mathbf{6 6})$.

Once more, the relative configuration of $\mathbf{6 6}$ was difficult to assign though a small vicinal coupling constant observed between H-6 and H-7 (1.8 Hz) and NOE enhancement between H-6 and H-8 implied a trans relationship between these protons. The final structure of labillaride $\mathrm{G}$ is therefore determined to be $\mathbf{6 6}$. NMR data for $\mathbf{6 6}$ is presented in Table 3.12. 


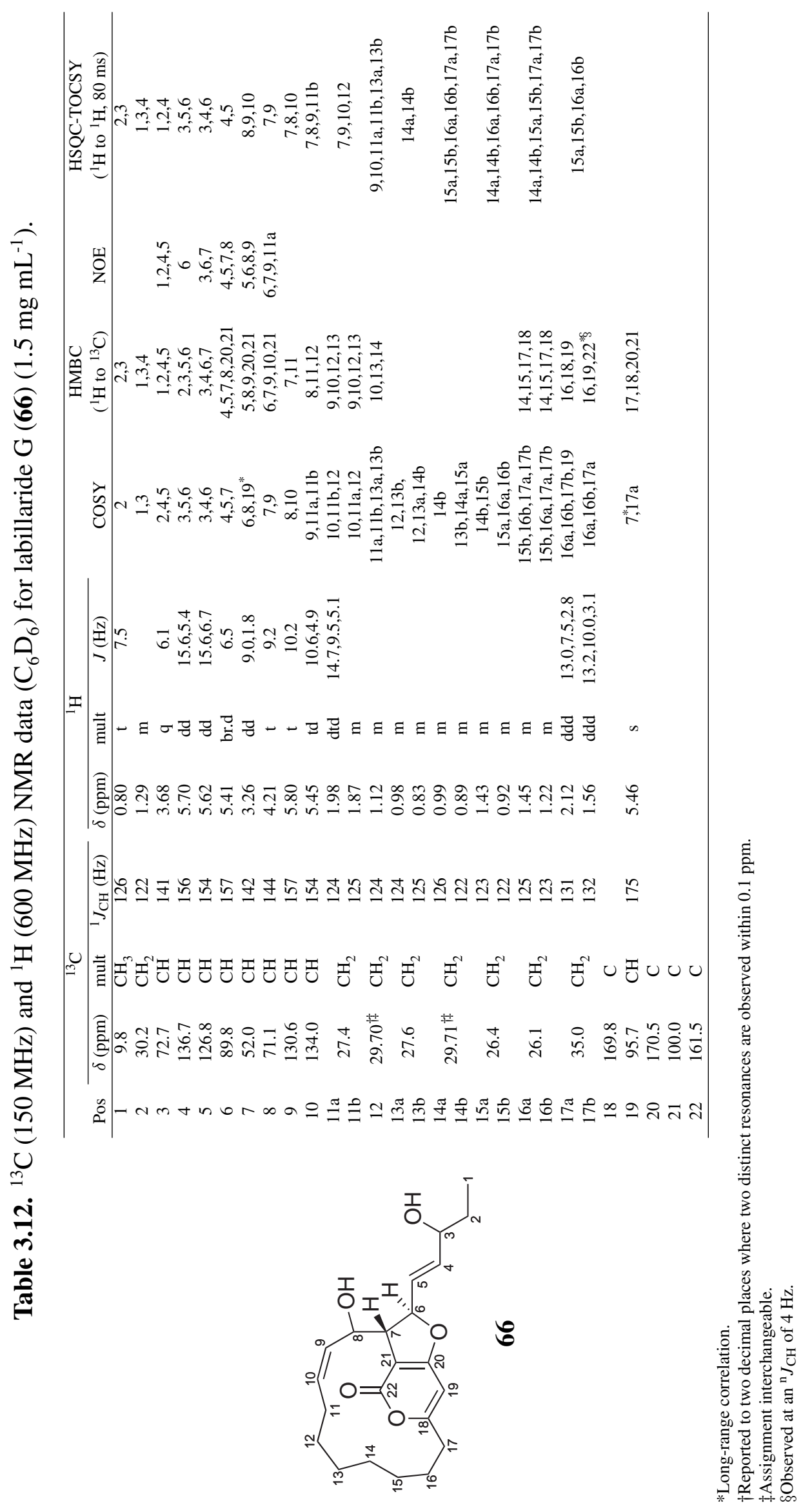




\subsection{Labillaride $\mathbf{H}$}

The observation of a pseudomolecular ion of the colourless oil labillaride $\mathrm{H}$ (67) $(1.2 \mathrm{mg}$ isolated in total) by HRESIMS once again indicated a molecular formula of $\mathrm{C}_{22} \mathrm{H}_{30} \mathrm{O}_{5}$ $\left(397.1991[\mathrm{M}+\mathrm{Na}]^{+}, \Delta 0.0 \mathrm{ppm}\right)$, requiring eight double-bond equivalents. As with labillaride $\mathrm{F}(\mathbf{6 5})$ and $\mathrm{G}(\mathbf{6 6})$, the ${ }^{1} \mathrm{H}$ and ${ }^{13} \mathrm{C}$ NMR spectra of 67 were almost identical to those of labillaride E (64).

For the final time, the planar structure of $\mathbf{6 7}$ was elucidated in an identical fashion as 64, 65 and 66, through a series of COSY, NOE and HMBC correlations (see Figure 3.28). Analysis of the ${ }^{1} \mathrm{H}-{ }^{1} \mathrm{H}$ coupling established the 17 carbon 1,6-diene while HMBC correlations established the $\alpha$-pyrone ring and the five-membered heterocycle. The geometry of double bonds $\left(\Delta_{4-5}=E, \Delta_{9-10}=Z\right)$ were determined on the basis of the observed ${ }^{1} \mathrm{H}$ to ${ }^{1} \mathrm{H}$ coupling constants and NOE enhancements.

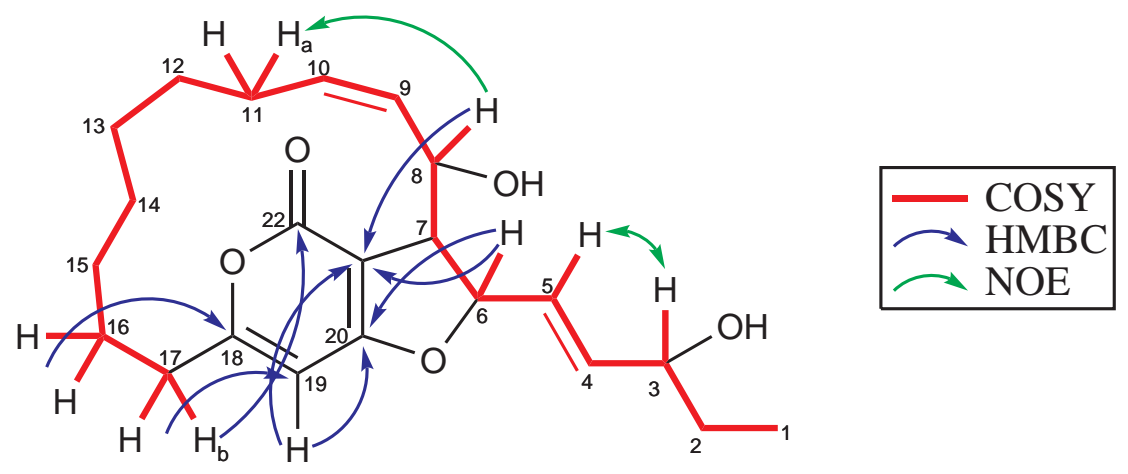

Figure 3.29. Selected COSY and HMBC correlations and NOE enhancements establishing the structure of labillaride $\mathrm{H}(67)$.

Finally, the relative configuration of $\mathbf{6 7}$ was again difficult to assign though a small vicinal coupling constant observed between H-6 and H-7 (1.4 Hz) and NOE enhancement between H-6 and H-8 implied a trans relationship between these protons. The final structure of labillaride $\mathrm{H}$ is therefore determined to be $\mathbf{6 7}$. NMR data for 67 is presented in Table 3.13. 


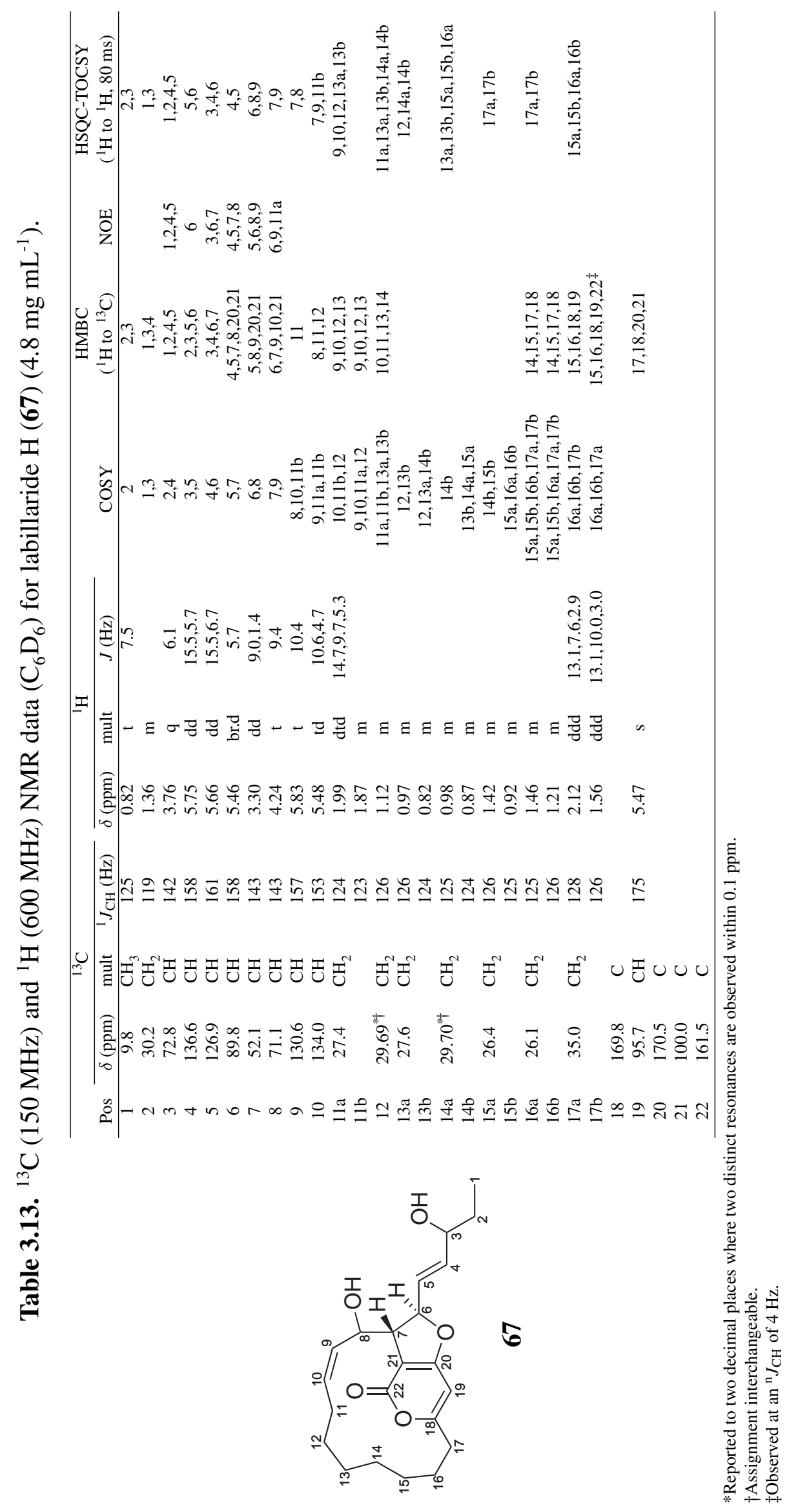




\section{Acetylation of Labillaride $\mathbf{H}$}

A synthetic derivative was prepared in order to prove the two alcohol moieties in the proposed skeleton of labillarides E-H (64-67). Labillaride H (67) was reacted with acetic anhydride in pyridine overnight. The positive-ion HRESIMS of the reaction product gave rise to a pseudomolecular ion indicative of a formula of $\mathrm{C}_{26} \mathrm{H}_{34} \mathrm{O}_{7}\left(481.2201[\mathrm{M}+\mathrm{Na}]^{+}\right.$, $\Delta 0.1 \mathrm{ppm})$, a mass increase of $84 \mathrm{Da}$, consistent with diacetylation. The NMR spectra of the product of the reaction were similar to that of $\mathbf{6 7}$ with the additional presence of two overlapping acetate methyl signals $\left[\left(\mathrm{C}-24: \delta_{\mathrm{C}} 20.65, \delta_{\mathrm{H}} 1.63\right)\right.$ and $\left(\mathrm{C}-26: \delta_{\mathrm{C}} 20.69\right.$, $\delta_{\mathrm{H}}$ 1.63)]. The observed change in the chemical shifts of the associated methine protons is entirely consistent with acetylation at centres C-3 and C-8. Similarly, HMBC correlations from $\mathrm{H}-3$ to an ester carbonyl $\left(\mathrm{C}-23: \delta_{\mathrm{C}} 169.4\right)$ and from $\mathrm{H}-8$ to a second ester carbonyl (C-25: $\left.\delta_{\mathrm{C}} 169.6\right)$ confirmed acetylation of the C-3 and C-8 hydroxyls to form 3,8-diacetyllabillaride H (73). NMR data for $\mathbf{7 3}$ are presented in Table 3.14. 


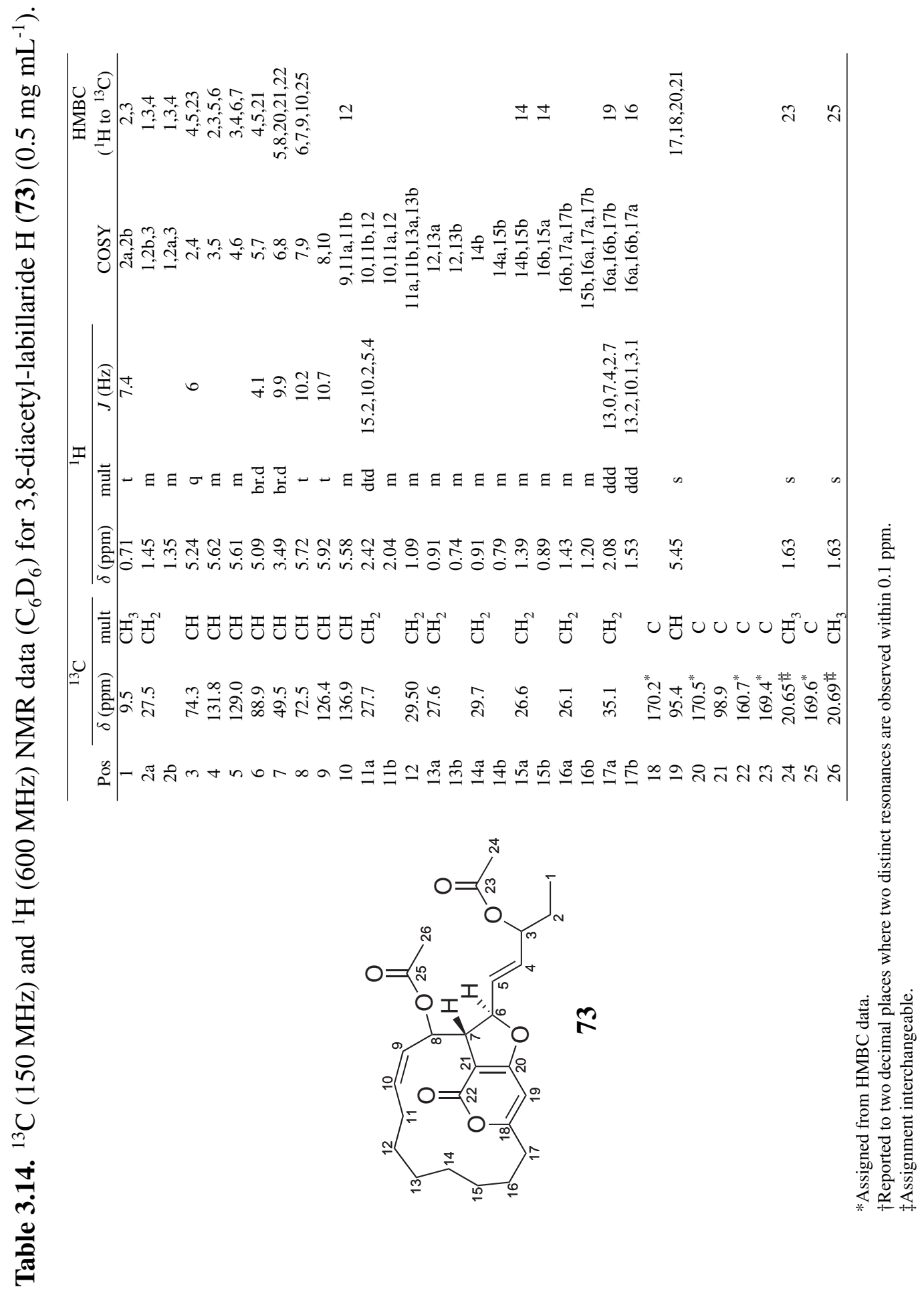




\subsection{Discussion of Isomers Labillarides $\mathbf{E}$ to $\mathbf{H}$}

Structure elucidation clearly established labillarides E-H (64-67) to be constitutionally the same; all four compounds possessed the same atom connectivity. Analysis of the coupling constants and NOE data showed no change in the double bond stereoisomerism. Furthermore, the ${ }^{1} \mathrm{H}$ and ${ }^{13} \mathrm{C}$ chemical shifts of the pyrone and alkyl-chain part of the macrocycle were almost identical, thus discounting the possibility of rotamers due to restricted rotation in this portion of the molecule. This therefore leads to the conclusion that 64-67 are diastereoisomers associated with the four chiral centres of the structures. Furthermore, the coupling constants between H-6 and H-7 are nearly identical in all four isomers, strongly suggesting conservation of their trans relative configuration. It is therefore proposed that 64-67 represent the four possible relative diastereomers involving the chiral centres C-3 and C-8, assuming the relative configuration of C-6 and C-7 is conserved.

An attempt to determine the absolute configuration of the secondary alcohols of labillarides E and H (64 and 67) using Mosher's method was unsuccessful due to lack of material (for experimental detail, see Chapter 6). ${ }^{70}$ Therefore, any configurational assignment was based on NMR data alone. Examination of the ${ }^{1} \mathrm{H}$ chemical shifts in $\mathrm{CDCl}_{3}$ showed almost no perceivable differences. Benzene is often used as an alternative NMR solvent, exploiting its ability to generate solvent-induced shifts of proton resonances in NMR spectra. ${ }^{71}$ Therefore, the ${ }^{1} \mathrm{H}$ NMR spectra were obtained in $\mathrm{C}_{6} \mathrm{D}_{6}$ in an attempt to emphasize the very slight changes in the ${ }^{1} \mathrm{H}$ chemical shifts. Initial results showed the changes to be focussed around the four chiral centres, however most of these changes were found to be more concentration-dependent rather than due to potential differences in configuration. Figure 3.30 shows the ${ }^{1} \mathrm{H}$ NMR spectra of labillaride $\mathrm{H}(67)$ at two different concentrations, illustrating the major concentration effect on the chemical shifts when the spectra were obtained in $\mathrm{C}_{6} \mathrm{D}_{6}$.

In order to ensure comparable data, the ${ }^{1} \mathrm{H}$ NMR spectra of labillarides E-H (64-67) were obtained at a standard concentration. These results are summarised in Table 3.15, showing the chemical shift differences of selected ${ }^{1} \mathrm{H}$ resonances of $\mathbf{6 5}-\mathbf{6 7}$ when compared to 


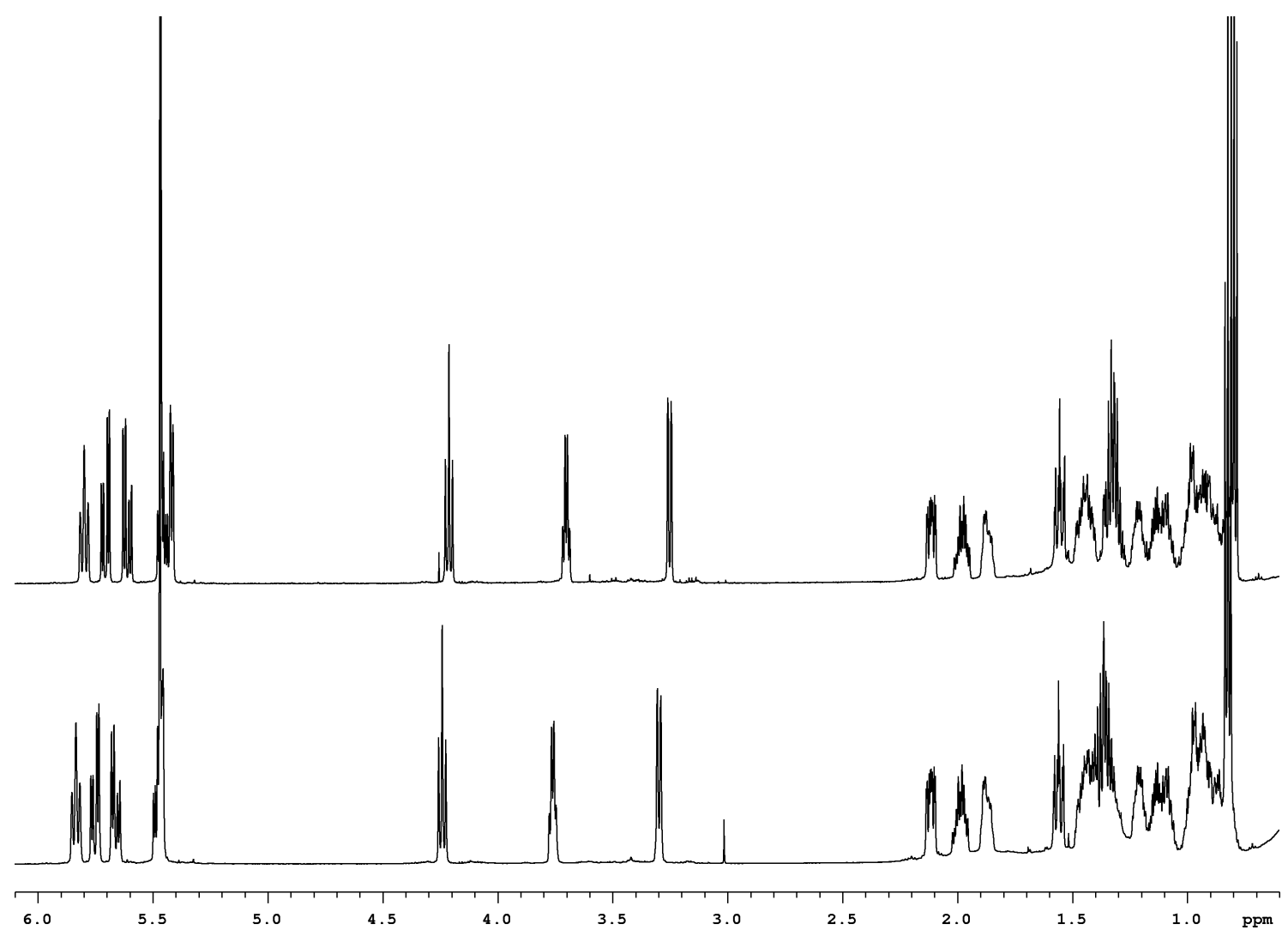

Figure 3.30. ${ }^{1} \mathrm{H}$ NMR spectra of labillaride $\mathrm{H}(67)$ in $\mathrm{C}_{6} \mathrm{D}_{6}$ at $4.8 \mathrm{mg} \mathrm{mL}^{-1}$ (bottom) and $1.6 \mathrm{mg} \mathrm{mL}^{-1}$ (top).

64, with the most significant differences in red. In $\mathrm{CDCl}_{3}$, the most notable change occurred at C-3, with both $\mathbf{6 5}$ and $\mathbf{6 7}$ showing a $0.02 \mathrm{ppm}$ shift of the ${ }^{1} \mathrm{H}$ resonance at this centre when compared to 64. The analysis was repeated in $\mathrm{C}_{6} \mathrm{D}_{6}$ and, again, the most notable difference occurred around C-3 in 65 and 67 when compared to 64, suggesting labillarides F (65) and H (67) to be C-3 epimers of labillarides E (64) and G (66).

Table 3.15. ${ }^{1} \mathrm{H}$ chemical shift differences of labillarides $\mathrm{F}-\mathrm{H}(\mathbf{6 5}-\mathbf{6 7})$ as compared to labillaride E (64).

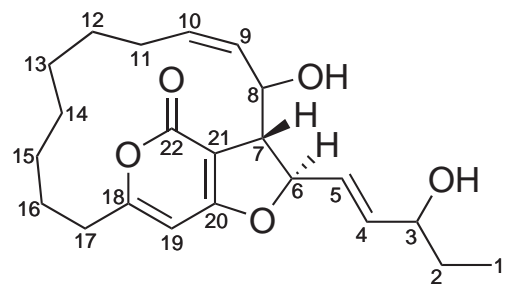

\begin{tabular}{|c|c|c|c|c|c|c|c|c|}
\hline \multirow[b]{3}{*}{ Pos } & \multicolumn{4}{|c|}{$\mathrm{CDCl}_{3}, 1.3 \mathrm{mg} \mathrm{mL}^{-1}$} & \multicolumn{4}{|c|}{$\mathrm{C}_{6} \mathrm{D}_{6}, 1.6 \mathrm{mg} \mathrm{mL}^{-1}$} \\
\hline & \multirow{2}{*}{$\begin{array}{l}\delta_{\mathrm{H}} \\
\mathbf{6 4}\end{array}$} & \multicolumn{3}{|c|}{$\Delta \delta_{\mathrm{H}}(\mathrm{ppm})$} & \multirow{2}{*}{$\begin{array}{l}\delta_{\mathrm{H}} \\
64\end{array}$} & \multicolumn{3}{|c|}{$\Delta \delta_{\mathrm{H}}(\mathrm{ppm})$} \\
\hline & & 65 & 66 & 67 & & 65 & 66 & 67 \\
\hline 1 & 0.92 & 0.01 & 0.00 & 0.01 & 0.80 & 0.00 & 0.00 & 0.00 \\
\hline 2 & - & - & - & - & - & - & - & - \\
\hline 3 & 4.05 & 0.02 & 0.00 & 0.02 & 3.68 & 0.04 & 0.00 & 0.02 \\
\hline 4 & 5.83 & 0.00 & 0.00 & 0.00 & 5.70 & 0.02 & 0.00 & 0.01 \\
\hline 5 & 5.74 & 0.00 & 0.00 & 0.00 & 5.61 & 0.01 & 0.00 & 0.00 \\
\hline 6 & 5.42 & 0.00 & 0.00 & 0.00 & 5.41 & 0.02 & 0.00 & 0.01 \\
\hline 7 & 3.15 & 0.00 & 0.00 & 0.00 & 3.25 & 0.01 & 0.00 & 0.00 \\
\hline 8 & 4.30 & 0.00 & 0.00 & 0.00 & 4.21 & 0.01 & 0.00 & 0.00 \\
\hline 9 & 5.63 & 0.00 & 0.00 & 0.00 & 5.80 & 0.01 & 0.00 & 0.00 \\
\hline 10 & 5.52 & 0.00 & 0.00 & 0.00 & 5.45 & 0.01 & 0.00 & 0.00 \\
\hline
\end{tabular}

Subtle chemical shift differences from labillaride E (64) were also observed around C-8 of labillaride F (65). This suggested that 65 may also be a C-8 epimer of 64, implying that 
labillaride F (65) is 3,8-epi-labillaride E. Assuming this to be true, and as labillaride $\mathrm{H}$ (67) is determined to be 3-epi-labillaride E, labillaride G (66) must, by default, be 8-epilabillaride $\mathrm{E}$, the fourth possible diastereomer.

Enantiomers are known to co-crystallise by effectively dimerising to form an achiral space group. The significant changes observed in the ${ }^{1} \mathrm{H}$ NMR spectra show that the conformations of labillarides E-H (64-67) change with concentration, particularly in nonhydrogen bonding solvents such as $\mathrm{C}_{6} \mathrm{D}_{6}$, potentially due to dimerisation. With this in mind, it is interesting to note that the stereoisomers that co-elute are those that appear to be $\mathrm{C}-8$ epimers, the variable chiral centre located in the relatively rigid portion of the molecule. It is therefore tempting to speculate that this co-elution is due to dimerisation through hydrogen bonding of the pseudo-enantiomeric C-8 hydroxyls.

Were it not for the twinning observed in the original mixture of labillarides F (65) and G (66), it is likely that the different compounds would never have been identified. An interesting point to note is that the original labillaride E (64) sample, purified by benchtop chromatography, was repeatedly found to have quite potent cytotoxic activity against the human leukaemia cell line HL-60 ( 600 nM). It was not until the second sample of 64 was purified by normal phase (DIOL) HPLC and tested inactive in the same assay, that the original sample was subjected to HPLC, and it was found that the activity did not correspond to the labillaride E (64) peak. Clearly a very minor impurity, not detected by NMR, was responsible for the high cytotoxicity, a issue which would likely have hampered a bioassay guided isolation of the labillarides. Work is continuing in this area in the hope of identifying the impurity responsible for this activity. 


\subsection{Labillaride I}

Labillaride I (68) was isolated as a colourless oil (48.2 $\mathrm{mg}$ in total). Positive-ion mode HRESIMS analysis of $\mathbf{6 8}$ gave rise to a pseudomolecular ion indicative of the molecular formula $\mathrm{C}_{23} \mathrm{H}_{34} \mathrm{O}_{4}\left(375.2531[\mathrm{M}+\mathrm{H}]^{+}, \Delta 0.4 \mathrm{ppm}\right)$, requiring seven doublebond equivalents. The ${ }^{13} \mathrm{C}$ NMR spectrum contained 23 distinct resonances while the the multiplicity-edited HSQC spectrum accounted for 33 of the 34 protons indicating the presence of one exchangeable proton. Identifiable features of the NMR spectra in $\mathrm{CDCl}_{3}$ included two ketone resonances $\left(\delta_{\mathrm{C}} 191.2\right.$ and 192.5), an ester carbonyl resonance $\left(\delta_{\mathrm{C}} 170.1\right)$, six typical olefinic methines $\left[\left(\delta_{\mathrm{C}} 126.9, \delta_{\mathrm{H}} 5.28\right),\left(\delta_{\mathrm{C}} 127.6, \delta_{\mathrm{H}} 5.12\right)\right.$, $\left(\delta_{\mathrm{C}} 128.7, \delta_{\mathrm{H}} 5.12\right),\left(\delta_{\mathrm{C}} 130.1, \delta_{\mathrm{H}} 5.34\right),\left(\delta_{\mathrm{C}} 131.5, \delta_{\mathrm{H}} 5.30\right)$ and $\left.\left(\delta_{\mathrm{C}} 132.6, \delta_{\mathrm{H}} 5.42\right)\right]$, a strongly shielded olefinic methine $\left(\delta_{\mathrm{C}} 98.9, \delta_{\mathrm{H}} 5.98\right)$, a shielded methine $\left(\delta_{\mathrm{C}} 62.6\right.$, $\left.\delta_{\mathrm{H}} 3.19\right)$, an oxymethyl group $\left(\delta_{\mathrm{C}} 52.5, \delta_{\mathrm{H}} 3.67\right)$ and a methyl triplet $\left(\delta_{\mathrm{C}} 14.4, \delta_{\mathrm{H}} 0.99, \mathrm{t}\right.$, $7.5 \mathrm{~Hz})$.

Beginning at the methyl terminus, analysis of the ${ }^{1} \mathrm{H}-{ }^{1} \mathrm{H}$ coupling led to the construction of the 1,4,7-triene containing substructure (C-1 to C-13) (Figure 3.31). A series of sequential COSY correlations starting from the methyl triplet $\left(\mathrm{C}-1: \delta_{\mathrm{C}} 14.4, \delta_{\mathrm{H}} 0.99\right)$ to a methylene $\left(\mathrm{C}-2: \delta_{\mathrm{C}} 20.7, \delta_{\mathrm{H}} 2.10\right)$ to an olefinic methine $\left(\mathrm{C}-3: \delta_{\mathrm{C}} 132.6, \delta_{\mathrm{H}} 5.42\right)$ to a second olefinic methine $\left(\mathrm{C}-4: \delta_{\mathrm{C}} 126.9, \delta_{\mathrm{H}} 5.28\right)$ established the first section of the substructure. The geometry of the double bond was determined to be $(Z)$ on the basis of the observed coupling constant of $10.6 \mathrm{~Hz}$ for $\mathrm{H}-3$ and $\mathrm{H}-4$, and an NOE enhancement from $\mathrm{H}_{2}-5$ to $\mathrm{H}_{2}-2$. Further COSY correlations from $\mathrm{H}-4$ to a methylene (C-5: $\delta_{\mathrm{C}} 26.1$, $\delta_{\mathrm{H}} 2.95$ and 2.89) to a olefinic methine $\left(\mathrm{C}-6: \delta_{\mathrm{C}} 130.1, \delta_{\mathrm{H}} 5.34\right)$ to further olefinic methine $\left(\mathrm{C}-7: \delta_{\mathrm{C}} 128.7, \delta_{\mathrm{H}} 5.12\right)$ to a slightly deshielded methine $\left(\mathrm{C}-8: \delta_{\mathrm{C}} 39.4, \delta_{\mathrm{H}} 4.10\right)$ extended this substructure through the second double bond. Coupling constants $(10.7 \mathrm{~Hz}, \mathrm{H}-6$ and $10.2 \mathrm{~Hz}, \mathrm{H}-7)$ defined $\Delta_{6-7}$ as (Z), supported by observed NOE enhancements between $\mathrm{H}_{2}-5$ and H-8. Finally, a series of sequential COSY correlations starting from H-8 to an olefinic methine $\left(\mathrm{C}-9: \delta_{\mathrm{C}} 127.6, \delta_{\mathrm{H}} 5.12\right)$ to the final typical olefinic methine $(\mathrm{C}-10$ : $\left.\delta_{\mathrm{C}} 131.5, \delta_{\mathrm{H}} 5.30\right)$ to a methylene $\left(\mathrm{C}-11: \delta_{\mathrm{C}} 25.4, \delta_{\mathrm{H}} 2.35\right.$ and 1.86$)$ to a methylene $(\mathrm{C}-12$ : $\delta_{\mathrm{C}} 26.5, \delta_{\mathrm{H}} 1.46$ and 1.23$)$ and finally to a third methylene (C-13: $\left.\delta_{\mathrm{C}} 26.6, \delta_{\mathrm{H}} 1.35\right)$ 
established the 1,4,7-triene chain. The geometry of the third double bond was defined as (Z) on the basis of coupling constants $(10.2 \mathrm{~Hz}, \mathrm{H}-9$ and $10.3 \mathrm{~Hz}, \mathrm{H}-10)$ and observed NOE enhancements between $\mathrm{H}-8$ and $\mathrm{H}_{2}-11$. A further COSY correlation from $\mathrm{H}-8$ to a shielded methine $\left(\mathrm{C}-21: \delta_{\mathrm{C}} 62.6, \delta_{\mathrm{H}} 3.19\right)$ completed the substructure.
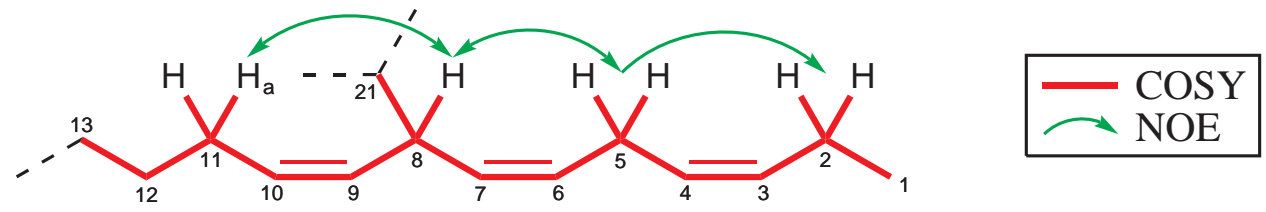

Figure 3.31. Selected COSY correlations establishing the 1,4,7-triene substructure of labillaride I (68).

A second substructure was constructed starting from a distinctive slightly deshielded methylene $\left(\mathrm{C}-17: \delta_{\mathrm{C}} 35.7, \delta_{\mathrm{H}} 2.36\right)$. A series of sequential COSY correlations starting from $\mathrm{H}_{2}-17$ to a methylene $\left(\mathrm{C}-16: \delta_{\mathrm{C}} 23.9, \delta_{\mathrm{H}} 1.88\right.$ and 1.55$)$ to a third methylene $(\mathrm{C}-15$ : $\left.\delta_{\mathrm{C}} 25.5, \delta_{\mathrm{H}} 1.29\right)$ to the final methylene $\left(\mathrm{C}-14: \delta_{\mathrm{C}} 24.4, \delta_{\mathrm{H}} 1.41\right.$ and 1.18) established the alkyl section of the second substructure. An HMBC correlation from $\mathrm{H}_{2}-16$ to a non-protonated carbon $\left(\mathrm{C}-18: \quad \delta_{\mathrm{C}}\right.$ 191.2) initially suggested a shielded ketone at this position. However, HMBC correlations from $\mathrm{H}_{2}-17$ to $\mathrm{C}-18$ and a strongly shielded olefinic methine (C-19: $\delta_{\mathrm{C}} 98.9, \delta_{\mathrm{H}}$ 5.98) implied a highly-polarised double bond. Reciprocal HMBC correlations from $\mathrm{H}-19$ to C-17 and C-18 confirmed this connectivity. Interestingly, the non-protonated carbon resonance has moved significantly downfield from the equivalent position in labillarides A-H (60-67) (from $~ 170 \mathrm{ppm}$ to $\sim 190 \mathrm{ppm}$ ), suggesting a significant change in structure at this position. A further HMBC correlation from $\mathrm{H}-19$ to the second non-protonated carbon $\left(\mathrm{C}-20: \delta_{\mathrm{C}} 192.5\right)$ suggested the enol form of a 1,3-dione, stabilised by resonance and intramolecular hydrogen bonding (see Figure 3.32). This accounted for the $\sim 20$ ppm downfield shift of the carbon resonances of positions C-18 and C-20 in $\mathbf{6 8}$ when compared to those of $\mathbf{6 0 - 6 6 .}{ }^{72}$

The substructures were joined through a series of HMBC and HSQC-TOCSY correlations. HMBC correlations from $\mathrm{H}-8$ to $\mathrm{C}-20$ and the carbonyl resonance $\left(\mathrm{C}-22\right.$ : $\left.\delta_{\mathrm{C}} 170.1\right)$ suggested connectivity to these two centres through C-21. This was confirmed by an HMBC correlation from H-19 to C-21, and HMBC correlations from H-21 to C-19, C-20 and C-22. An HMBC correlation from the oxymethyl (C-23: $\left.\delta_{\mathrm{C}} 52.3, \delta_{\mathrm{H}} 3.67\right)$ to $\mathrm{C}-22$ 


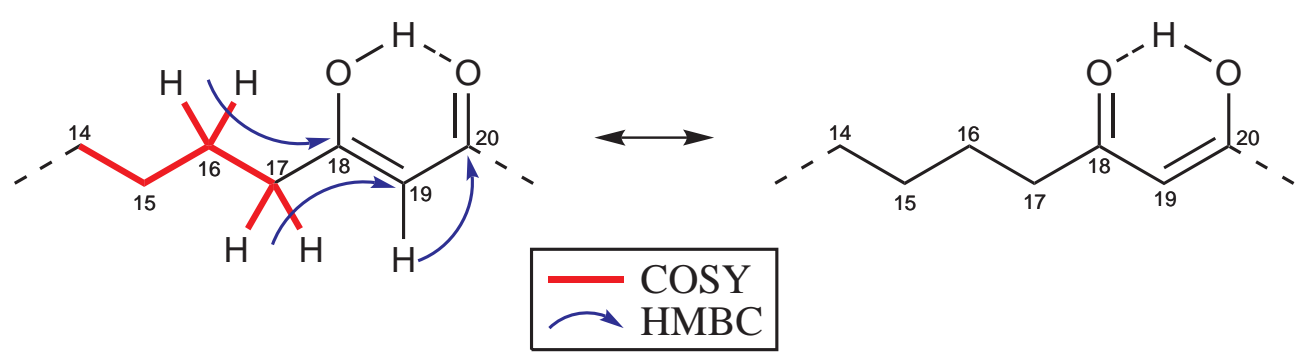

Figure 3.32. Selected COSY and HMBC correlations establishing the second substructure of labillaride I (68) in its resonance forms.

accounted for the shielded nature of C-22, a methyl ester carbonyl. HMBC correlations from both proton resonances of $\mathrm{CH}_{2}-12$ to $\mathrm{C}-14$ suggested connectivity through the $\mathrm{C}-13$ and C-14 methylenes. This was confirmed by the corresponding HMBC from $\mathrm{H}_{2}-15$ to C-13 and the observation of HSQC-TOCSY correlations from $\mathrm{H}_{2}-12$ to $\mathrm{H}_{2}-13, \mathrm{H}_{2}-14$, $\mathrm{H}_{2}-15, \mathrm{H}_{2}-16$ and finally $\mathrm{H}_{2}-17$ (Figure 3.33 ).

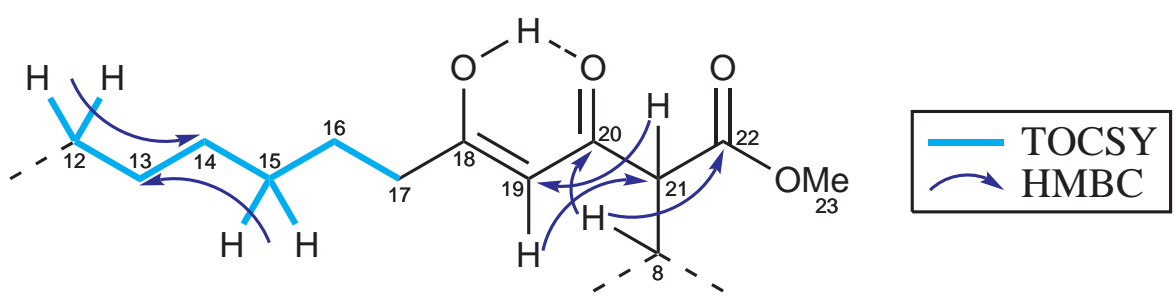

Figure 3.33. Selected TOCSY and HMBC correlations connecting the substructures of labillaride I (68).

All detected carbon resonances were now accounted for. The triene, enol form of a 1,3dione, ester and macrocycle moieties accounted for the molecular formula, satisfying the seven double-bond equivalents. The relative configuration of labillaride I was not determined as all ${ }^{1} \mathrm{H}-{ }^{1} \mathrm{H}$ coupling constants and observed NOE enhancements could be rationalised from both stereoisomers due to the significant flexibility of the 14-membered macrocycle. The final structure of labillaride I is therefore proposed to be $\mathbf{6 8}$. NMR data for $\mathbf{6 8}$ is presented in Table 3.16.

In order to determine whether labillaride I (68) was methylated in vivo or as an artefact of isolation in $\mathrm{MeOH}$, the extraction and isolation was repeated replacing $\mathrm{MeOH}$ by $\mathrm{EtOH}$ at each stage. Neither $\mathbf{6 8}$ or the ethylated version of $\mathbf{6 8}$ was detected in the $75 \%$ $\mathrm{Me}_{2} \mathrm{CO}$ in $\mathrm{H}_{2} \mathrm{O}$, however the $100 \% \mathrm{Me}_{2} \mathrm{CO}$ fraction appeared to contain some resonances suggestive of labillaride I (68), suggesting the possibliity that 68 may in fact be an artefact of methanol extraction. 


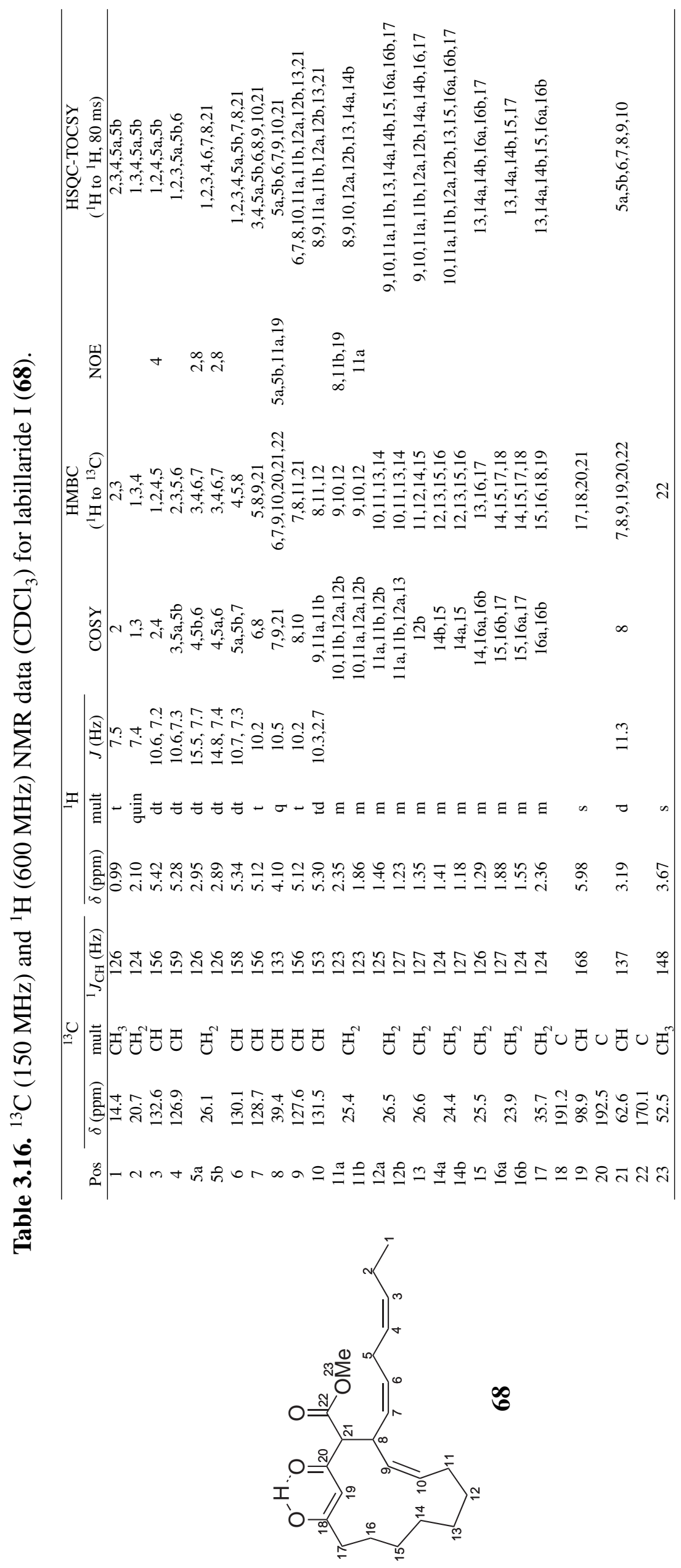




\subsection{Labillaride J}

Positive-ion mode HRESIMS analysis of the colourless oil labillaride J (69) (2.0 mg isolated in total) gave rise to a pseudomolecular ion indicative of the molecular formula $\mathrm{C}_{21} \mathrm{H}_{32} \mathrm{O}_{2}\left(317.2470[\mathrm{M}+\mathrm{H}]^{+}, \Delta 1.5 \mathrm{ppm}\right)$. The structure of 69 was elucidated in the same fashion as labillaride I (68). The molecular formula of 69 differs from 68 by the loss of $\mathrm{C}_{2} \mathrm{H}_{2} \mathrm{O}_{2}$ which is consistent with the loss of MeOCO from 68. The ${ }^{13} \mathrm{C}$ NMR spectrum in $\mathrm{CDCl}_{3}$ contained 21 distinct resonances while the the multiplicity-edited HSQC spectrum accounted for 31 of the 32 protons, again indicating the presence of one exchangeable proton. The molecular formula of 69 requires six double-bond equivalents. Again, three are accounted for by the triene chain, two by the enol form of a 1,3-dione and finally, one by the macrocycle. Identifiable moieties included two ketone carbons $\left(\delta_{\mathrm{C}} 193.6\right.$ and 194.4), six typical olefinic methines $\left[\left(\delta_{\mathrm{C}} 126.9, \delta_{\mathrm{H}} 5.32\right),\left(\delta_{\mathrm{C}} 127.8\right.\right.$, $\left.\delta_{\mathrm{H}} 5.33\right),\left(\delta_{\mathrm{C}} 130.1, \delta_{\mathrm{H}} 5.33\right),\left(\delta_{\mathrm{C}} 130.6, \delta_{\mathrm{H}} 5.16\right),\left(\delta_{\mathrm{C}} 132.0, \delta_{\mathrm{H}} 5.26\right)$ and $\left(\delta_{\mathrm{C}} 132.5\right.$, $\left.\left.\delta_{\mathrm{H}} 5.43\right)\right]$, a strongly shielded olefinic methine $\left(\delta_{\mathrm{C}} 100.5, \delta_{\mathrm{H}} 5.61\right)$ and a methyl triplet $\left(\delta_{\mathrm{C}} 14.5, \delta_{\mathrm{H}} 1.00, \mathrm{t}, 7.5 \mathrm{~Hz}\right)$, all consistent with those observed in 68 . Both the ester carbonyl and oxymethyl groups of labillaride I (68) were absent, and a new methylene $\left(\delta_{\mathrm{C}} 46.0, \delta_{\mathrm{H}} 2.44\right.$ and 2.15$)$ was observed.

Analysis of the 2D NMR spectra of $\mathbf{6 9}$ led to the construction of two substructures. Beginning at the methyl terminus (C-1: $\left.\delta_{\mathrm{C}} 14.5, \delta_{\mathrm{H}} 1.00\right)$, a COSY correlation was observed from $\mathrm{H}_{3}-1$ to a methylene $\left(\mathrm{C}-2: \delta_{\mathrm{C}} 20.8, \delta_{\mathrm{H}} 2.11\right)$ to an olefinic methine $\left(\mathrm{C}-3: \delta_{\mathrm{C}} 132.5, \delta_{\mathrm{H}} 5.43\right)$ to a second olefinic methine at $\delta_{\mathrm{H}} 5.33$. Due to significant spectral overlap at $\sim \delta_{\mathrm{H}} 5.33$, three olefinic methines were not distinguishable in the COSY spectrum. HMBC correlations were therefore used to differentiate between the three methines. An HMBC correlation from $\mathrm{H}_{2}-2$ to an olefinic methine (C-4: $\delta_{\mathrm{C}} 126.9$, $\left.\delta_{\mathrm{H}} 5.32\right)$ and from $\mathrm{H}-3$ to a methylene $\left(\mathrm{C}-5: \delta_{\mathrm{C}} 26.1, \delta_{\mathrm{H}} 2.88\right.$ and 2.84$)$ extended the chain through the first double bond. This connectivity was confirmed by the observation of allylic COSY correlations from H-3 to H-5a and H-5b.

HMBC correlations from $\mathrm{H}_{2}-5$ to two olefinic methines [(C-6: $\left.\delta_{\mathrm{C}} 127.8, \delta_{\mathrm{H}} 5.33\right)$ and $\left.\left(\mathrm{C}-7: \delta_{\mathrm{C}} 132.0, \delta_{\mathrm{H}} 5.26\right)\right]$ established the second double bond. An HMBC from H-6 to C-4 
implied the direct connectivity between C-5 and C-6, confirming the order of the olefinic methines. A series of sequential COSY correlations starting from $\mathrm{H}-7$ to a methine (C-8: $\left.\delta_{\mathrm{C}} 35.6, \delta_{\mathrm{H}} 3.87\right)$ to an olefinic methine $\left(\mathrm{C}-9: \delta_{\mathrm{C}} 130.6, \delta_{\mathrm{H}} 5.16\right)$ to the final olefinic methine $\left(\mathrm{C}-10: \delta_{\mathrm{C}} 130.1, \delta_{\mathrm{H}} 5.33\right)$ to a methylene $\left(\mathrm{C}-11: \delta_{\mathrm{C}} 25.7, \delta_{\mathrm{H}} 2.25\right.$ and 1.84) and finally to a second methylene $\left(\mathrm{C}-12: \delta_{\mathrm{C}} 27.0, \delta_{\mathrm{H}} 1.39\right.$ and 1.22$)$ completed the triene chain. Again, the order of the olefinic methines was confirmed by an HMBC correlation from $\mathrm{H}_{2}-12$ to $\mathrm{C}-10$. The geometry of all three double bonds were determined to be $(Z)$ on the basis of the observed ${ }^{1} \mathrm{H}-{ }^{1} \mathrm{H}$ coupling constants $(10.6 \mathrm{~Hz}, \mathrm{H}-3 ; 10.5 \mathrm{~Hz}, \mathrm{H}-7$; $10.3 \mathrm{~Hz}, \mathrm{H}-9$ ) and NOE enhancements between $\mathrm{H}_{2}-2$ and $\mathrm{H}_{2}-5, \mathrm{H}_{2}-5$ and $\mathrm{H}-8$, and finally H-8 and $\mathrm{H}_{2}-11$. A further COSY correlation from $\mathrm{H}-8$ to a methylene (C-21: $\delta_{\mathrm{C}} 46.0$, $\delta_{\mathrm{H}} 2.44$ and 2.15) completed the substructure (Figure 3.34).
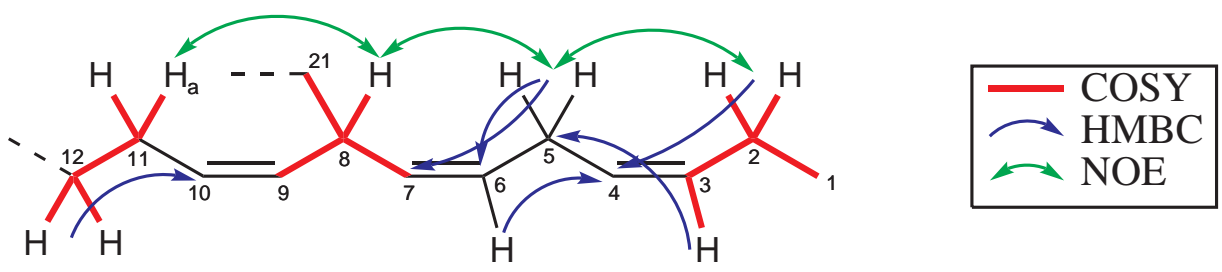

Figure 3.34. Selected COSY and HMBC correlations and NOE enhancements establishing the 1,4,7-triene substructure of labillaride $\mathbf{J}(\mathbf{6 9})$.

Starting from the distinctive slightly deshielded methylene $\left(\mathrm{C}-17: \delta_{\mathrm{C}} 37.4, \delta_{\mathrm{H}} 2.31\right)$, the second substructure was constructed. A series of sequential COSY correlations starting from $\mathrm{H}_{2}-17$ to a methylene (C-16: $\delta_{\mathrm{C}} 24.1, \delta_{\mathrm{H}} 1.76$ and 1.59) to a third methylene (C-15: $\left.\delta_{\mathrm{C}} 26.0, \delta_{\mathrm{H}} 1.34\right)$ established the beginning of the substructure. As before, an HMBC correlation from $\mathrm{H}_{2}-16$ to a non-protonated carbon (C-18: $\left.\delta_{\mathrm{C}} 194.4\right)$, from $\mathrm{H}_{2}-17$ to a strongly shielded olefinic methine $\left(\mathrm{C}-19: \delta_{\mathrm{C}} 100.5, \delta_{\mathrm{H}} 5.61\right)$, and from $\mathrm{H}-19$ to the last non-protonated carbon $\left(\mathrm{C}-20: \delta_{\mathrm{C}}\right.$ 193.6), confirmed the enol form of a 1,3-dione (see Figure 3.35).

As with 68, the substructures of $\mathbf{6 9}$ were joined through a series of HMBC and HSQC-TOCSY correlations. An HMBC correlation from H-8 to C-20 suggested direct connectivity between C-20 and C-21. This was confirmed by reciprocal HMBC correlations from $\mathrm{H}-19$ to $\mathrm{C}-21$, and from $\mathrm{H}_{2}-21$ to $\mathrm{C}-19$. The two alkyl chains were connected through the final two methylenes. An $\mathrm{HMBC}$ correlation from $\mathrm{H}_{2}-11$ to a methylene $\left(\mathrm{C}-13: \delta_{\mathrm{C}} 26.4, \delta_{\mathrm{H}} 1.34\right)$ and from $\mathrm{H}_{2}-13$ to the final methylene $\left(\mathrm{C}-14: \delta_{\mathrm{C}} 25.1\right.$, 
<smiles>CCCCPC1=CC(C)=COP1</smiles>

\section{COSY \\ HMBC}

Figure 3.35. Selected COSY and HMBC correlations establishing the second substructure of labillaride $\mathrm{J}(\mathbf{6 9})$, in its resonance forms.

$\delta_{\mathrm{H}} 1.35$ and 1.19) extended the triene substructure. HMBC correlations from both proton resonances of $\mathrm{CH}_{2}-16$ to $\mathrm{C}-14$ connected the two alkyl chains while HSQC-TOCSY correlations from $\mathrm{H}_{2}-11$ to $\mathrm{H}_{2}-12$ and $\mathrm{H}_{2}-13$, and from $\mathrm{H}_{2}-17$ to $\mathrm{H}_{2}-16, \mathrm{H}_{2}-15$ and $\mathrm{H}_{2}-14$ supported this connectivity (Figure 3.36).

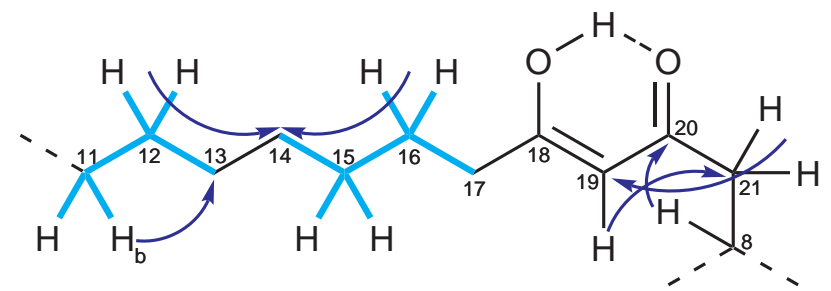

Figure 3.36. Selected TOCSY and HMBC correlations connecting the substructures of labillaride J (69).

The molecular formula was now accounted for and labillaride $\mathrm{J}$ was found to be the desmethyl ester of labillaride I. The final structure of labillaride $J$ is therefore 69. NMR data for 69 is presented in Table 3.17. 


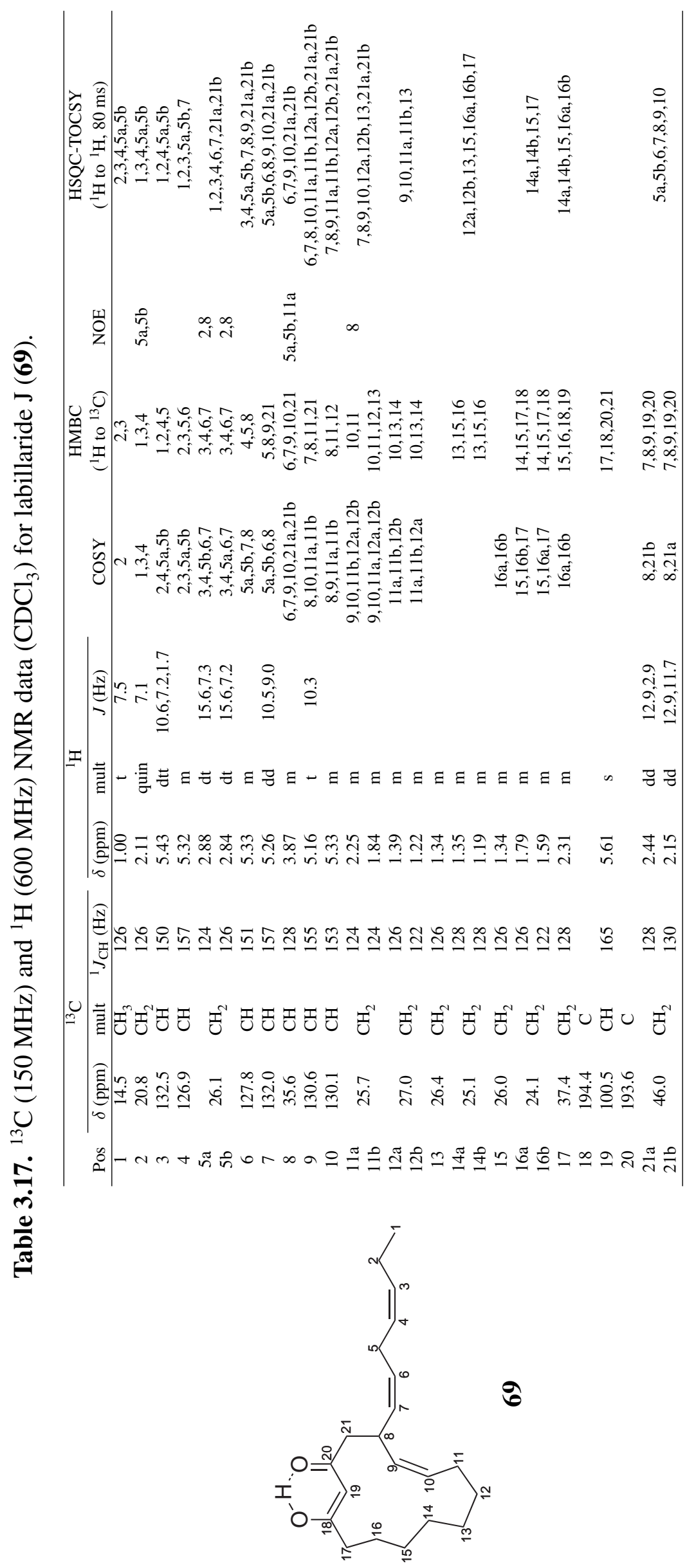




\subsection{Labillaride $\mathrm{K}$}

The observation of pseudomolecular ions of the colourless oil labillaride K (70) (0.4 mg isolated in total) by HRESIMS indicated a molecular formula of $\mathrm{C}_{21} \mathrm{H}_{32} \mathrm{O}_{2}(317.2475$ $[\mathrm{M}+\mathrm{H}]^{+}, \Delta 4.5 \mathrm{ppm}$ and $\left.339.2298[\mathrm{M}+\mathrm{Na}]^{+}, \Delta 1.1 \mathrm{ppm}\right)$, requiring six double-bond equivalents. The ${ }^{13} \mathrm{C}$ NMR spectrum contained 14 distinct resonances while two further non-protonated carbons $\left(\delta_{\mathrm{C}} 195.6\right.$ and 203.0) were observed in the HMBC spectrum. An irresolvable cluster of signals in the ${ }^{13} \mathrm{C}$ NMR spectrum in the region between $\delta_{\mathrm{C}} 29.3-$ 29.4 was assumed to contain the remaining five resonances. The ${ }^{1} \mathrm{H}$ NMR spectrum in $\mathrm{CDCl}_{3}$ accounted for all 32 protons, including signals in the $\mathrm{CH}_{2}$ envelope region $\left(\delta_{\mathrm{H}} 1.27\right.$ - 1.41) integrating for 10 protons. The multiplicity-edited HSQC showed connectivity between those protons and the carbon cluster between $\delta_{\mathrm{C}} 29.3-29.4$, indicating five overlapping methylenes. Other identifiable features of the NMR spectra included a strongly shielded olefinic methine $\left(\delta_{\mathrm{C}} 104.2, \delta_{\mathrm{H}} 5.47\right)$, six typical olefinic methines $\left[\left(\delta_{\mathrm{C}} 125.5, \delta_{\mathrm{H}} 6.32\right),\left(\delta_{\mathrm{C}} 127.1, \delta_{\mathrm{H}} 5.32\right),\left(\delta_{\mathrm{C}} 128.0, \delta_{\mathrm{H}} 5.27\right),\left(\delta_{\mathrm{C}} 128.8, \delta_{\mathrm{H}} 5.96\right)\right.$, $\left(\delta_{\mathrm{C}} 132.3, \delta_{\mathrm{H}} 5.41\right)$ and $\left.\left(\delta_{\mathrm{C}} 135.3, \delta_{\mathrm{H}} 5.68\right)\right]$, an oxymethylene $\left(\delta_{\mathrm{C}} 75.4, \delta_{\mathrm{H}} 4.49\right)$ and a methyl triplet $\left(\delta_{\mathrm{C}} 14.4, \delta_{\mathrm{H}} 0.98, \mathrm{t}, 7.6 \mathrm{~Hz}\right)$.

Analysis of the ${ }^{1} \mathrm{H}-{ }^{1} \mathrm{H}$ coupling established a 10 carbon, 1,4,6-triene substructure $(\mathrm{C}-1$ to C-10). A series of sequential COSY correlations starting from the methyl triplet (C-1: $\left.\delta_{\mathrm{C}} 14.4, \delta_{\mathrm{H}} 0.98\right)$ to a methylene $\left(\delta_{\mathrm{C}} 20.7, \delta_{\mathrm{H}} 2.08\right)$ to an olefinic methine $\left(\mathrm{C}-3: \delta_{\mathrm{C}} 132.3\right.$, $\left.\delta_{\mathrm{H}} 5.41\right)$ to a second olefinic methine $\left(\mathrm{C}-4: \delta_{\mathrm{C}} 127.1, \delta_{\mathrm{H}} 5.32\right)$ to a methylene $(\mathrm{C}-5$ : $\left.\delta_{\mathrm{C}} 26.07, \delta_{\mathrm{H}} 2.91\right)$, to a third olefinic methine (C-6: $\left.\delta_{\mathrm{C}} 128.0, \delta_{\mathrm{H}} 5.27\right)$, to a fourth olefinic methine $\left(\mathrm{C}-7: \delta_{\mathrm{C}} 128.8, \delta_{\mathrm{H}} 5.96\right)$ established the first section of the triene substructure. The geometry of both double bonds were determined to be $(Z)$ on the basis of the observed ${ }^{1} \mathrm{H}-{ }^{1} \mathrm{H}$ coupling constants $(10.6 \mathrm{~Hz}, \mathrm{H}-4 ; 10.6 \mathrm{~Hz}, \mathrm{H}-6 ; 11.1 \mathrm{~Hz}, \mathrm{H}-7)$. Further COSY correlations from H-7 to a fifth olefinic methine (C-8: $\left.\delta_{\mathrm{C}} 125.5, \delta_{\mathrm{H}} 6.32\right)$, to the final typical olefinic methine $\left(\mathrm{C}-9: \delta_{\mathrm{C}} 135.3, \delta_{\mathrm{H}} 5.68\right)$ to a methylene $\left(\mathrm{C}-10: \delta_{\mathrm{C}} 33.0, \delta_{\mathrm{H}} 2.10\right)$ completed the first substructure (see Figure 3.37, substructure A).

A furan-3-one substructure was constructed starting from a distinctive deshielded methylene $\left(\mathrm{C}-17: \delta_{\mathrm{C}} 30.9, \delta_{\mathrm{H}} 2.50\right)$ which exhibited a COSY correlation to a second methylene 
A

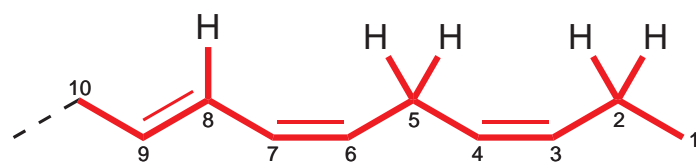

$\sim$ COSY
B

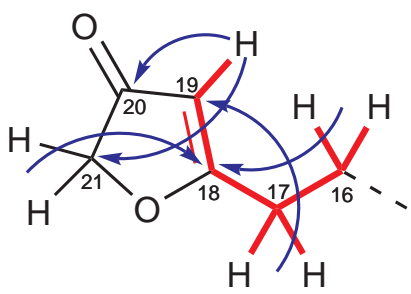

Figure 3.37. Selected COSY and HMBC correlations and NOE enhancements establishing the two substructures of labillaride K (70).

(C-16: $\left.\delta_{\mathrm{C}} 26.11, \delta_{\mathrm{H}} 1.64\right)$. An HMBC correlation from $\mathrm{H}_{2}-16$ to a non-protonated carbon (C-18: $\delta_{\mathrm{C}}$ 195.6) along with HMBC correlations from $\mathrm{H}_{2}-17$ to $\mathrm{C}-18$ and a shielded olefinic methine $\left(\mathrm{C}-19: \delta_{\mathrm{C}} 104.2, \delta_{\mathrm{H}} 5.47\right)$ suggested the presence of a highly-polarised double bond. This connectivity was supported by an allylic COSY correlation between $\mathrm{H}_{2}-17$ and $\mathrm{H}-19$, and HMBC correlations from $\mathrm{H}-19$ back to $\mathrm{C}-17$ and C-18. Further HMBC correlations were observed from H-19 to the second non-protonated carbon (C-20: $\left.\delta_{\mathrm{C}} 203.0\right)$ and to an oxymethylene $\left(\mathrm{C}-21: \delta_{\mathrm{C}} 75.4, \delta_{\mathrm{H}} 4.49\right)$. The highly-polarised nature of $\Delta_{18-19}$ and the strongly deshielded nature of C-21 is consistent with oxygen attachment at C-18 and C-21, while the lack of a second shielded olefinic carbon suggested a ketone at position C-20. With only two oxygens in the molecular formula, an oxygen bridge between C-18 and C-21 was proposed, supported by an $\mathrm{HMBC}$ correlation from $\mathrm{H}_{2}-21$ to C-18, completing the furan-3-one moiety (see Figure 3.37, substructure B). The ${ }^{13} \mathrm{C}$ and ${ }^{1} \mathrm{H}$ chemical shifts of the five-membered ring compared favourably with 5-hexyl-furan-3one (74), a synthetic compound containing this furan-3-one moiety (see Table 3.18). ${ }^{73}$

Table 3.18. Chemical shift differences of the furan-3-one moiety for labillaride K (70) and 5-hexyl-furan-3-one (74).

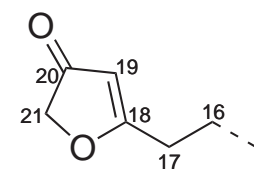

70

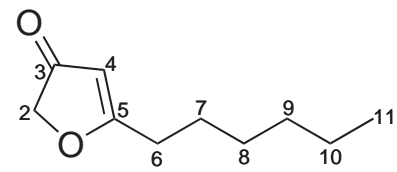

74

\begin{tabular}{|c|c|c|c|c|c|c|c|c|}
\hline \multirow[b]{2}{*}{ mult } & \multicolumn{3}{|c|}{ Labillaride K (70) } & \multicolumn{3}{|c|}{ 5-Hexyl-furan-3-one $(\mathbf{7 4})^{*}$} & \multicolumn{2}{|c|}{ Difference } \\
\hline & Pos & $\begin{array}{c}\delta_{\mathrm{C}} \\
\delta(\mathrm{ppm})\end{array}$ & $\begin{array}{c}\delta_{\mathrm{H}} \\
\delta(\mathrm{ppm})\end{array}$ & Pos & $\begin{array}{c}\delta_{\mathrm{C}} \\
\delta(\mathrm{ppm})\end{array}$ & $\begin{array}{c}\delta_{\mathrm{H}} \\
\delta(\mathrm{ppm})\end{array}$ & $\begin{array}{c}\delta_{\mathrm{C}} \\
\Delta \delta(\mathrm{ppm})\end{array}$ & $\begin{array}{c}\delta_{\mathrm{H}} \\
\Delta \delta(\mathrm{ppm})\end{array}$ \\
\hline $\mathrm{CH}_{2}$ & 16 & 26.1 & 1.64 & 7 & 25.9 & 1.67 & 0.2 & -0.03 \\
\hline $\mathrm{CH}_{2}$ & 17 & 30.9 & 2.50 & 6 & 31.3 & 2.52 & -0.4 & -0.02 \\
\hline $\mathrm{C}^{2}$ & 18 & 195.6 & & 5 & 195.7 & & -0.1 & \\
\hline $\mathrm{CH}$ & 19 & 104.2 & 5.47 & 4 & 103.9 & 5.50 & 0.3 & -0.03 \\
\hline $\mathrm{C}$ & 20 & 203.0 & & 3 & 203.0 & & 0.0 & \\
\hline $\mathrm{CH}_{2}$ & 21 & 75.4 & 4.49 & 2 & 75.2 & 4.51 & 0.2 & -0.02 \\
\hline
\end{tabular}

*Winkler, J. D.; Oh, K.; Asselin, S. M. Org. Lett. 2005, 7, 387389. 
Five methylene pairs remained unaccounted for in the structure. The chemical shifts of each of these methylene pairs were very similar $\left(\delta_{\mathrm{C}} 29.3-29.4, \delta_{\mathrm{H}} 1.27-1.41\right)$, indicative of a short unresolved alkyl chain. COSY correlations observed between $\delta_{\mathrm{H}} 1.27-1.41$ and both $\mathrm{H}_{2}-10$ and $\mathrm{H}_{2}-16$ suggested that the triene and furan-3-one substructures were connected via this alkyl chain. This proposal was supported by the observation of HMBC correlations from $\mathrm{H}-9, \mathrm{H}_{2}-10, \mathrm{H}_{2}-16$ and $\mathrm{H}_{2}-17$ to resonances at $\delta_{\mathrm{C}} 29.3-29.4$. On the basis of this evidence C-11 - C-15 were assigned as the irresolvable clusters $\left(\delta_{\mathrm{C}} 29.3-\right.$ 29.4, $\delta_{\mathrm{H}} 1.27-1.41$ ) (Figure 3.38).
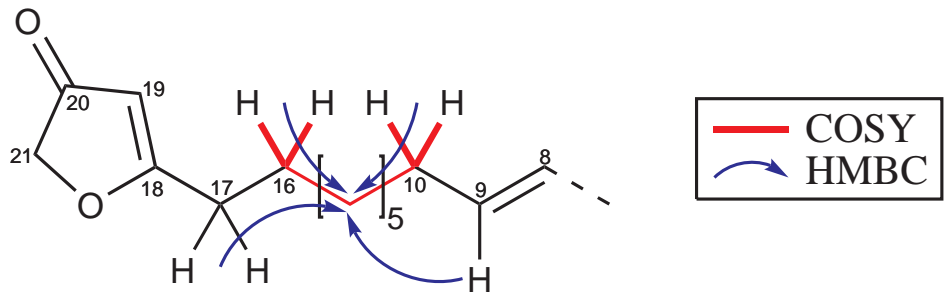

Figure 3.38. Selected COSY and HMBC correlations connecting the two substructures of labillaride K (70).

The molecular formula was now accounted for. The final structure of labillaride $\mathrm{K}$ is therefore proposed as shown in 70. NMR data for $\mathbf{7 0}$ is presented in Table 3.19 .

Table 3.19. ${ }^{13} \mathrm{C}(150 \mathrm{MHz})$ and ${ }^{1} \mathrm{H}(600 \mathrm{MHz}) \mathrm{NMR}$ data $\left(\mathrm{CDCl}_{3}\right)$ for labillaride $\mathrm{K}(\mathbf{7 0})$.

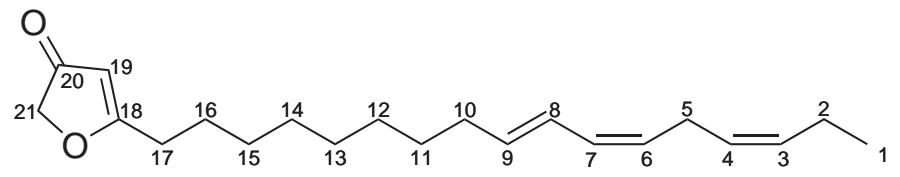

70

\begin{tabular}{|c|c|c|c|c|c|c|c|c|}
\hline \multirow[b]{2}{*}{ Pos } & \multicolumn{3}{|c|}{${ }^{13} \mathrm{C}$} & \multicolumn{3}{|c|}{${ }^{1} \mathrm{H}$} & \multirow[b]{2}{*}{ COSY } & \multirow{2}{*}{$\begin{array}{c}\text { HMBC } \\
\left({ }^{1} \mathrm{H} \text { to }{ }^{13} \mathrm{C}\right)\end{array}$} \\
\hline & $\delta(\mathrm{ppm})$ & mult & ${ }^{1} J_{\mathrm{CH}}(\mathrm{Hz})$ & $\delta(\mathrm{ppm})$ & mult & $J(\mathrm{~Hz})$ & & \\
\hline 1 & 14.4 & $\mathrm{CH}_{3}$ & 125 & 0.98 & $\mathrm{t}$ & 7.6 & 2 & 2,3 \\
\hline 2 & 20.7 & $\mathrm{CH}_{2}$ & 123 & 2.08 & quin & 7.4 & 1,3 & $1,3,4$ \\
\hline 3 & 132.3 & $\mathrm{CH}^{2}$ & 154 & 5.41 & $\mathrm{~m}$ & & 2,4 & 2,5 \\
\hline 4 & 127.1 & $\mathrm{CH}$ & 158 & 5.32 & $\mathrm{dt}$ & $10.6,7.2$ & 3,5 & $2,5,6$ \\
\hline 5 & 26.07 & $\mathrm{CH}_{2}$ & 123 & 2.91 & $\mathrm{t}$ & 7.5 & $4,6,7$ & $3,4,7,6$ \\
\hline 6 & 128.0 & $\mathrm{CH}$ & 160 & 5.27 & $\mathrm{dt}$ & $10.6,7.7$ & 5,7 & $4,5,8$ \\
\hline 7 & 128.8 & $\mathrm{CH}$ & 154 & 5.96 & $\mathrm{t}$ & 11.1 & $5,6,8$ & $5,8,9$ \\
\hline 8 & 125.5 & $\mathrm{CH}$ & 150 & 6.32 & $\mathrm{dd}$ & $15.0,11.0$ & $7,9,10$ & $6,7,10$ \\
\hline 9 & 135.3 & $\mathrm{CH}$ & 150 & 5.68 & dt & $15.1,7.0$ & 8,10 & $7,10,11$ \\
\hline 10 & 33.0 & $\mathrm{CH}_{2}$ & 125 & 2.10 & $q$ & 7.1 & 9,11 & $8,9,11$ \\
\hline $11-15$ & $29.3-29.4$ & $\mathrm{CH}_{2}$ & 123 & $1.27-1.41$ & $\mathrm{~m}$ & & & \\
\hline 16 & 26.11 & $\mathrm{CH}_{2}^{2}$ & 122 & 1.64 & quin & 7.4 & 15,17 & $15,17,18$ \\
\hline 17 & 30.9 & $\mathrm{CH}_{2}^{2}$ & 115 & 2.50 & $\mathrm{t}$ & 7.7 & $16,19,21 *$ & $15,16,18,19$ \\
\hline 18 & $195.6^{\dagger}$ & $\mathrm{C}^{2}$ & & & & & & \\
\hline 19 & 104.2 & $\mathrm{CH}$ & 182 & 5.47 & $\mathrm{~s}$ & & 17 & $17,18,20,21$ \\
\hline 20 & $203.0^{\dagger}$ & $\mathrm{C}$ & & & & & & \\
\hline 21 & 75.4 & $\mathrm{CH}_{2}$ & 152 & 4.49 & $\mathrm{~s}$ & & $17 *$ & 18,20 \\
\hline
\end{tabular}




\subsection{Degradation of Labillarides A to D}

As previously mentioned, it was found that labillarides A-D (60-63) quickly degraded when stored as lyophilised oils above $-20{ }^{\circ} \mathrm{C}$ (see Figure 3.39). Samples obtained during the purification of the second bulk extract were therefore stored submerged in liquid nitrogen in an effort to counter this instability.

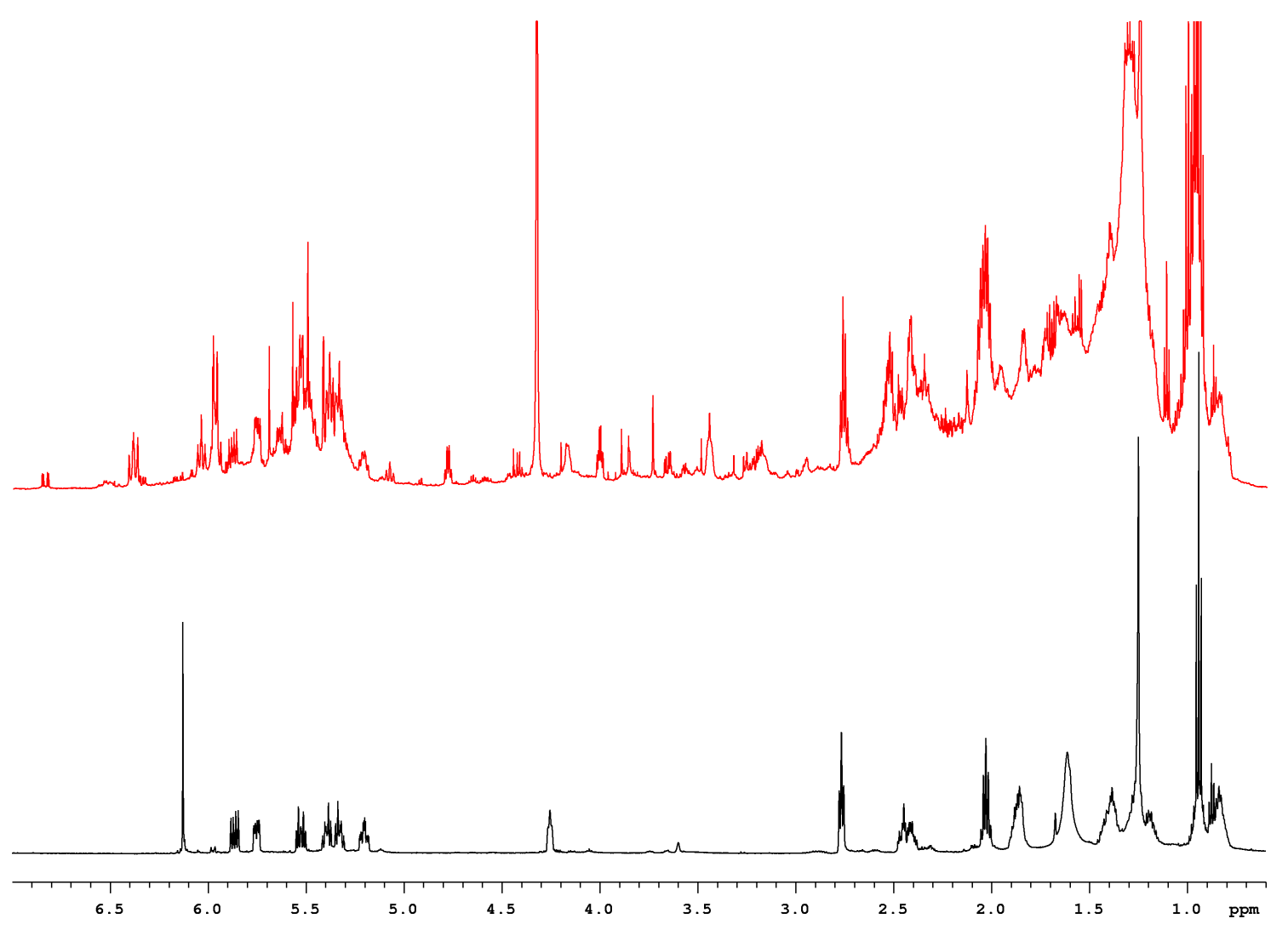

Figure 3.39. ${ }^{1} \mathrm{H}$ NMR spectra of labillaride D (63) pure (black) and degraded (red).

Unexpectedly, samples of labillaride B (61) stored at $-196{ }^{\circ} \mathrm{C}$ for a little over a year proceeded to degrade despite the precautions taken. Figure 3.40 shows the ${ }^{1} \mathrm{H}$ NMR of pure $\mathbf{6 1}$ and the degraded sample following storage in liquid nitrogen. Work is continuing in this area in the hope of isolating the degradation product or products of labillaride B (61). 


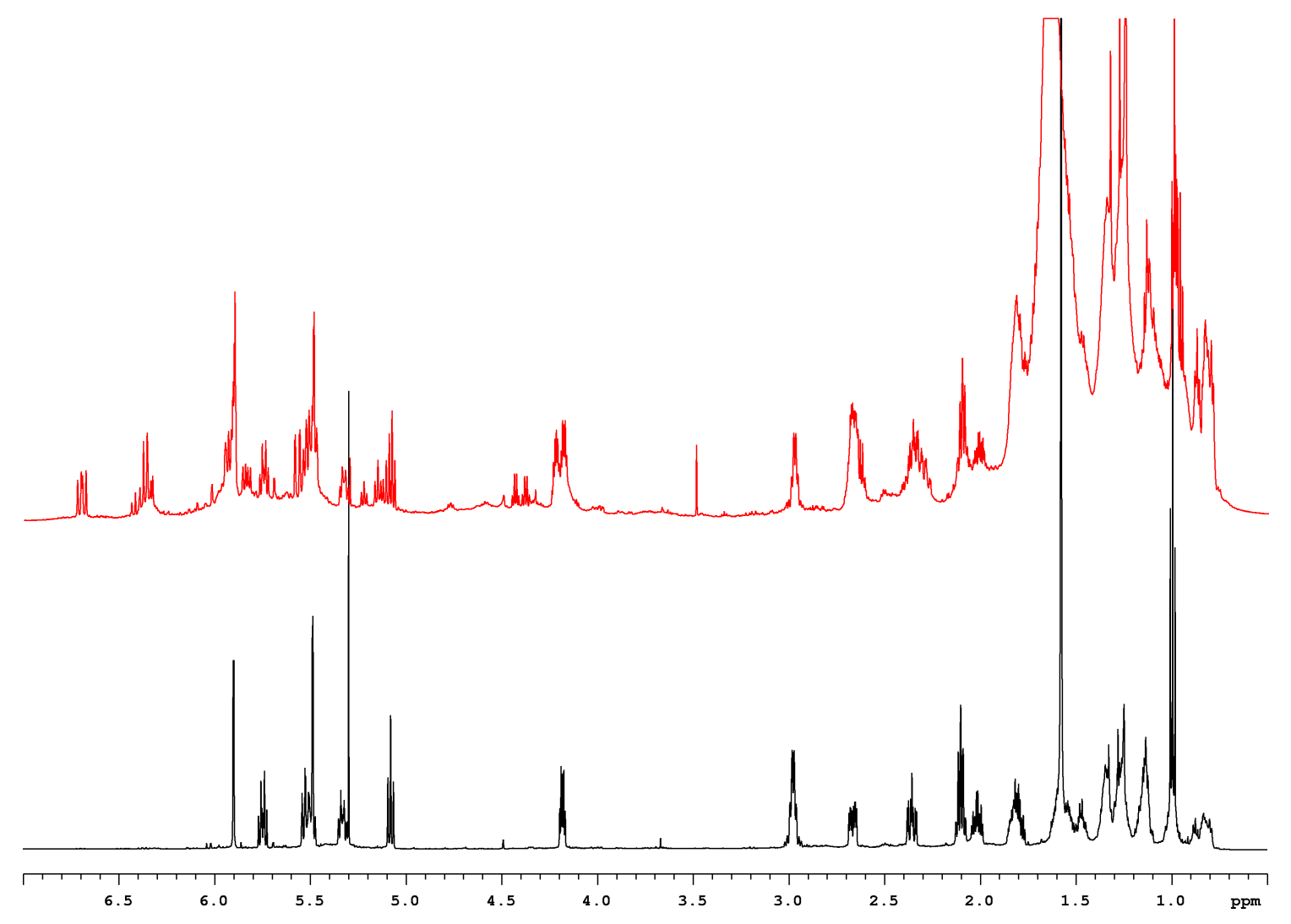

Figure 3.40. ${ }^{1} \mathrm{H}$ NMR spectra of labillaride B (61) pure (black) and degraded (red).

\section{Degradation Product of Labillarides C and D}

Labillarides C (62) and D (63) quickly degraded when stored as lyophilised oils above $-20{ }^{\circ} \mathrm{C}$. Interestingly, the ${ }^{1} \mathrm{H}$ NMR spectrum of the degraded samples of both $\mathbf{6 2}$ and 63 appeared to exhibit similar signals. Normal-phase chromatography of the degraded samples led to the isolation of the same degradation product (75) (see Figure 3.41).

Positive-ion mode HRESIMS analysis of the degradation product (75) gave rise to a single pseudomolecular ion indicative of the molecular formula $\mathrm{C}_{21} \mathrm{H}_{30} \mathrm{O}_{3}\left(353.2087[\mathrm{M}+\mathrm{H}]^{+}\right.$, $\Delta 0.1 \mathrm{ppm})$, requiring seven double-bond equivalents. The ${ }^{13} \mathrm{C}$ NMR spectrum contained 21 distinct resonances while the multiplicity-edited $\mathrm{HSQC}$ spectrum in $\mathrm{CDCl}_{3}$ accounted for 29 of the 30 protons indicating the presence of one exchangeable proton. Identifiable features of the NMR spectra included three ketone resonances $\left(\delta_{\mathrm{C}} 195.3,195.8\right.$ and 213.9), four typical olefinic methines $\left[\left(\delta_{\mathrm{C}} 124.9, \delta_{\mathrm{H}} 5.76\right),\left(\delta_{\mathrm{C}} 129.9, \delta_{\mathrm{H}} 5.38\right),\left(\delta_{\mathrm{C}} 131.5\right.\right.$, $\left.\delta_{\mathrm{H}} 5.47\right)$ and $\left.\left(\delta_{\mathrm{C}} 131.6, \delta_{\mathrm{H}} 5.08\right)\right]$, a strongly shielded olefinic methine $\left(\delta_{\mathrm{C}} 101.8, \delta_{\mathrm{H}} 5.58\right)$ and a methyl triplet $\left(\delta_{\mathrm{C}} 7.7, \delta_{\mathrm{H}} 1.02, \mathrm{t}, 7.3 \mathrm{~Hz}\right)$. The two shielded ketone resonances 


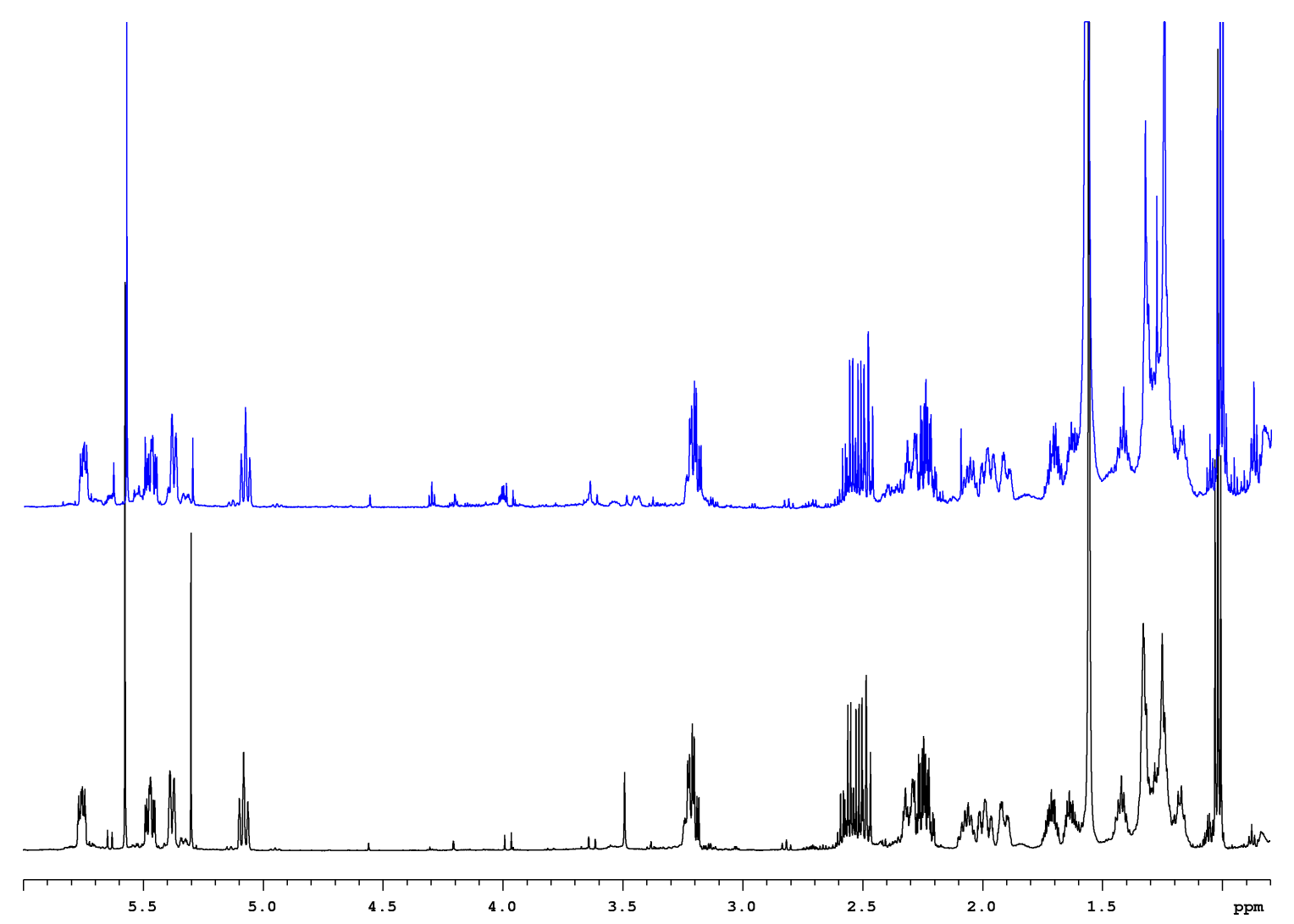

Figure 3.41. ${ }^{1} \mathrm{H}$ NMR spectra of the purified degradation product (75) from labillarides C (62) (black) and D (63) (blue).

and the strongly shielded olefinic methine suggested the presence of the enol form of a 1,3-dione, similar to that seen in labillarides H (68) and I (69).

A series of COSY and HMBC correlations lead to the construction of a 1,4-diene substructure. COSY correlations from the methyl triplet $\left(\mathrm{C}-1: \delta_{\mathrm{C}} 7.7, \delta_{\mathrm{H}} 1.02\right)$ to a methylene $\left(\mathrm{C}-2: \delta_{\mathrm{C}} 35.6, \delta_{\mathrm{H}} 2.51\right.$ and 2.58) indicated the connection between these two centres in an isolated spin system. HMBC correlations were observed from $\mathrm{H}_{3}-1$ and both proton resonances of $\mathrm{CH}_{2}-2$ to a ketone (C-3: $\left.\delta_{\mathrm{C}} 213.9\right)$. Further analysis of the HMBC spectrum revealed only one other correlation from the proton resonance of a methine (C-4: $\left.\delta_{\mathrm{C}} 47.7, \delta_{\mathrm{H}} 3.21\right)$ to the C-3 ketone, which together with the downfield nature of the ${ }^{1} \mathrm{H}$ resonance suggested its placement on the other side of the ketone. COSY correlations from $\mathrm{H}-4$ to a methylene $\left(\mathrm{C}-5: \delta_{\mathrm{C}} 28.2, \delta_{\mathrm{H}} 1.99\right.$ and 2.30) and from both proton resonances of $\mathrm{CH}_{2}-5$ to two olefinic methines [(C-6: $\left.\delta_{\mathrm{C}} 124.9, \delta_{\mathrm{H}} 5.76\right)$ and $\left(\delta_{\mathrm{C}} 129.9, \delta_{\mathrm{H}} 5.38\right)$ ] extended the substructure through to a double bond. An HMBC correlation from H-4 to C-6 established the direct connection between C-5 and C-6, constructing the order of C-5 to C-6 to C-7 through the double bond (see Figure 3.42). 

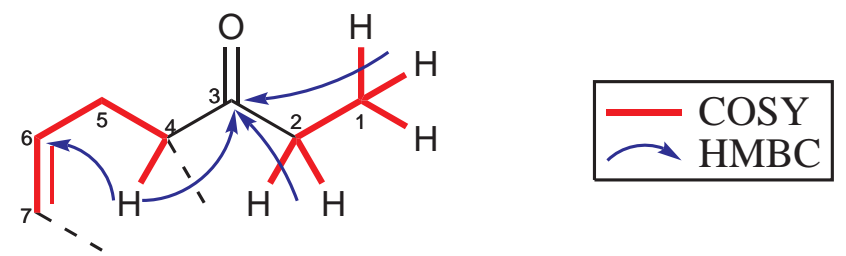

Figure 3.42. Selected COSY and HMBC correlations establishing part of the 1,4-diene substructure of the degradation product (75).

Detection of a series of ${ }^{1} \mathrm{H}-{ }^{1} \mathrm{H}$ couplings extended the substructure. COSY correlations were observed from $\mathrm{H}-7$ to a methine $\left(\mathrm{C}-8: \delta_{\mathrm{C}} 39.1, \delta_{\mathrm{H}} 3.23\right)$, from $\mathrm{H}-8$ to an olefinic methine $\left(\mathrm{C}-9: \delta_{\mathrm{C}} 131.6, \delta_{\mathrm{H}} 5.08\right)$, and from $\mathrm{H}-9$ to the fourth typical olefinic methine $\left(\mathrm{C}-10: \delta_{\mathrm{C}} 131.5, \delta_{\mathrm{H}}\right.$ 5.47). Further COSY correlations from $\mathrm{H}-10$ to a methylene $\left(\mathrm{C}-11: \delta_{\mathrm{C}} 25.0, \delta_{\mathrm{H}} 1.91\right.$ and 2.06) and from the proton resonances of $\mathrm{CH}_{2}-11$ to a second methylene $\left(\mathrm{C}-12: \delta_{\mathrm{C}} 27.0, \delta_{\mathrm{C}} 1.33\right)$ continued the substructure. Homo-allylic COSY correlations between both proton resonances of $\mathrm{CH}_{2}-5$ and $\mathrm{H}-8$, and allylic COSY correlations between $\mathrm{H}-9$ and both proton resonances of $\mathrm{CH}_{2}-11$ were also observed. A further COSY correlation from H-8 to a methine (C-21: $\left.\delta_{\mathrm{C}} 50.2, \delta_{\mathrm{H}} 2.49\right)$ and from $\mathrm{H}-21$ to $\mathrm{H}-4$ established a cyclohexene ring, completing the substructure. This connectivity was supported by HMBC correlations from $\mathrm{H}-5$ and H-7 to C-21 and from H-4 to C-8 (see Figure 3.43). The geometry of the two double bonds were determined to be $(Z)$ on the basis of the observed coupling constants $(9.8 \mathrm{~Hz}, \mathrm{H}-6$ and H-7; $10.6 \mathrm{~Hz}, \mathrm{H}-9$; $9.8 \mathrm{~Hz}$, $\mathrm{H}-10$ ) and NOE enhancements between $\mathrm{H}-8$ and both proton resonances of $\mathrm{CH}_{2}-11$.
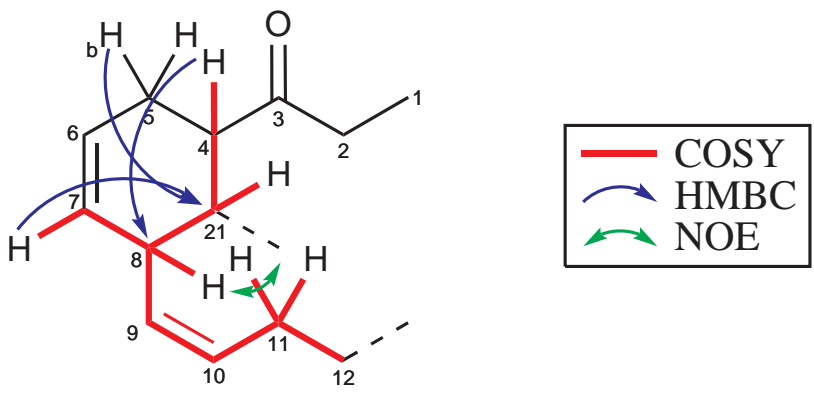

Figure 3.43. Selected COSY and HMBC correlations completing the 1,4-diene substructure of the degradation product (75).

The second substructure was constructed starting from a distinctive methylene (C-17: $\left.\delta_{\mathrm{C}} 38.6, \delta_{\mathrm{H}} 2.24\right)$. A series of sequential COSY correlations starting from $\mathrm{H}_{2}-17$ to a methylene $\left(\mathrm{C}-16: \delta_{\mathrm{C}} 24.2, \delta_{\mathrm{H}} 1.63\right.$ and 1.72$)$ to a third methylene $\left(\mathrm{C}-15: \delta_{\mathrm{C}} 27.9, \delta_{\mathrm{H}} 1.26\right.$, 1.42) established the beginning of the substructure. HMBC correlations from both proton 
resonances of $\mathrm{CH}_{2}-16$ to a non-protonated carbon $\left(\mathrm{C}-18: \delta_{\mathrm{C}} 195.3\right)$, from $\mathrm{H}_{2}-17$ to a strongly shielded olefinic methine $\left(\mathrm{C}-19: \delta_{\mathrm{C}} 101.8, \delta_{\mathrm{H}} 5.58\right)$, and from $\mathrm{H}-19$ to the last non-protonated carbon $\left(\mathrm{C}-20: \delta_{\mathrm{C}} 195.8\right)$ confirmed the presence of an enol form of a 1,3-dione as suggested by the chemical shifts (see Figure 3.44).
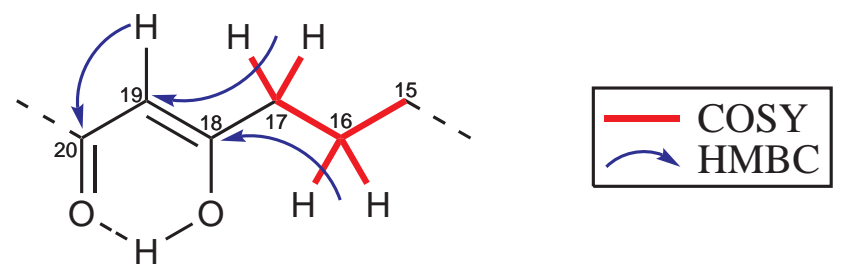

Figure 3.44. Selected COSY and HMBC correlations establishing the second substructure of the degradation product (75).

The substructures were joined by a series of HMBC and HSQC-TOCSY correlations. An HMBC correlation from H-19 to C-21 suggested direct connectivity between C-20 and C-21. This connectivity was confirmed by HMBC correlations from H-4 to C-20, and from $\mathrm{H}-21$ to $\mathrm{C}-19$ and $\mathrm{C}-20$. Two methylenes remained unaccounted for in the structure, both exhibiting very similar carbon resonances $\left[\left(\delta_{\mathrm{C}} 26.07, \delta_{\mathrm{H}} 1.18\right.\right.$ and 1.26$)$ and $\left(\delta_{\mathrm{C}} 26.09, \delta_{\mathrm{H}} 1.24\right.$ and 1.32)]. HMBC correlations from both proton resonances of one of these methylenes $\left(\mathrm{C}-13: \delta_{\mathrm{C}} 26.09, \delta_{\mathrm{H}} 1.24\right.$ and 1.32) to C-11 suggested direct connectivity between $\mathrm{C}-12$ and $\mathrm{C}-13$. Further HMBC correlations from both proton resonances of $\mathrm{CH}_{2}-13$ to the final methylene $\left(\mathrm{C}-14: \delta_{\mathrm{C}} 26.07, \delta_{\mathrm{H}} 1.18\right.$ and 1.26$)$ and $\mathrm{C}-15$ connected the two substructures through an alkyl chain. Similarly, HMBC correlations from both proton resonances of $\mathrm{CH}_{2}-14$ to $\mathrm{C}-12$ and $\mathrm{C}-16$ supported this connectivity. Finally, this was confirmed by the observation of HSQC-TOCSY correlations from $\mathrm{H}_{2}-15$ to $\mathrm{H}-14 \mathrm{~b}$ and $\mathrm{H}-13 \mathrm{~b}$ (see Figure 3.45).

The relative configuration of $\mathbf{7 5}$ was assigned on the basis of ${ }^{3} J_{\mathrm{HH}}$ values and NOE enhancements observed in a 2D-NOESY experiment. The coupling of the proton resonance of the methine $\mathrm{CH}-21(\mathrm{t}, 10.8 \mathrm{~Hz})$ suggested an antiperiplanar relationship to both $\mathrm{H}-4$ and $\mathrm{H}-8$, implying all three protons occupy axial positions in the cyclohexene ring and placing the large alkyl groups in the preferred equatorial positions. Similarly, the coupling constants of $\mathrm{H}-4(11.6 \mathrm{~Hz})$ and $\mathrm{H}-5 \mathrm{a}(11.9 \mathrm{~Hz})$ again indicated an antiperiplanar relationship between these two resonances, positioning $\mathrm{H}-5 \mathrm{a}$ axially. Allylic ${ }^{4} J_{\mathrm{HH}}$ values are proportional to $\cos ^{2} \phi$, where $\phi$ is the dihedral angle between the $\mathrm{C}-\mathrm{H}$ bond and 

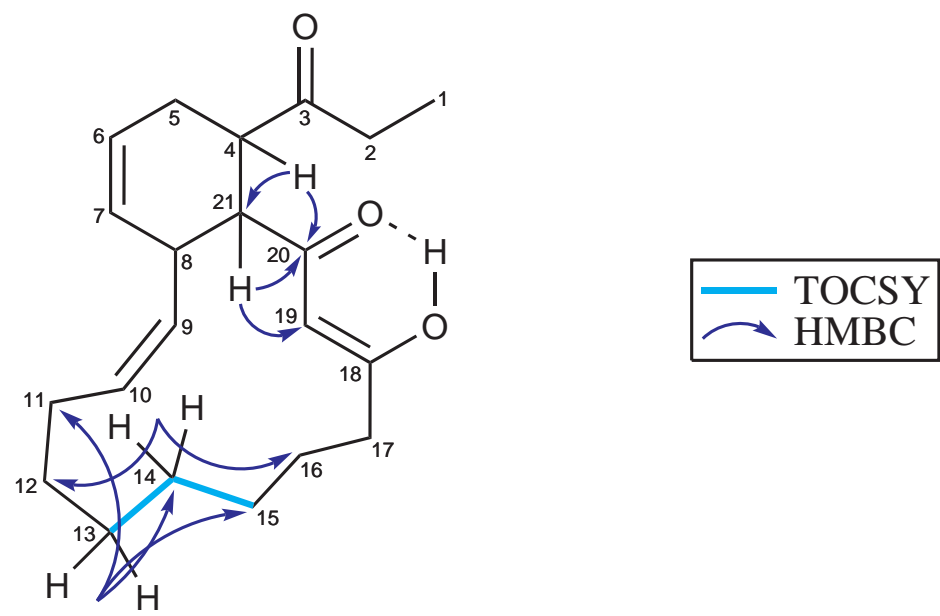

Figure 3.45. Selected TOCSY and HMBC correlations connecting the degradation product (75).

the $\pi$-orbital of the double bond. ${ }^{74}$ Therefore the considerably stronger observed allylic COSY correlation between $\mathrm{H}-7$ and $\mathrm{H}-5$ a compared to that of $\mathrm{H}-7$ and $\mathrm{H}-5$ b supported the assignment of H-5a as axial. Finally, an observed NOE enhancement between the 1,3diaxial protons $\mathrm{H}-5 \mathrm{a}$ and $\mathrm{H}-21$ supported the proposed relative configuration (see Figure $3.46)$.
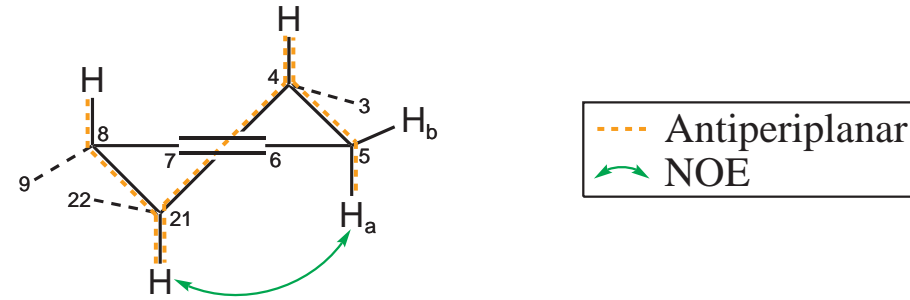

Figure 3.46. The selected NOE enhancement and antiperiplanar relationships used to determine the relative configuration of the degradation product (75).

All proton and carbon resonances were now accounted for. The alkene, enol form of a 1,3dione, ketone, cyclohexene and macrocycle moieties accounted for the molecular formula, satisfying the seven double-bond equivalents. The final structure of the degradation product is therefore determined to be $\mathbf{7 5}$. NMR data for $\mathbf{7 5}$ is presented in Table 3.20. 


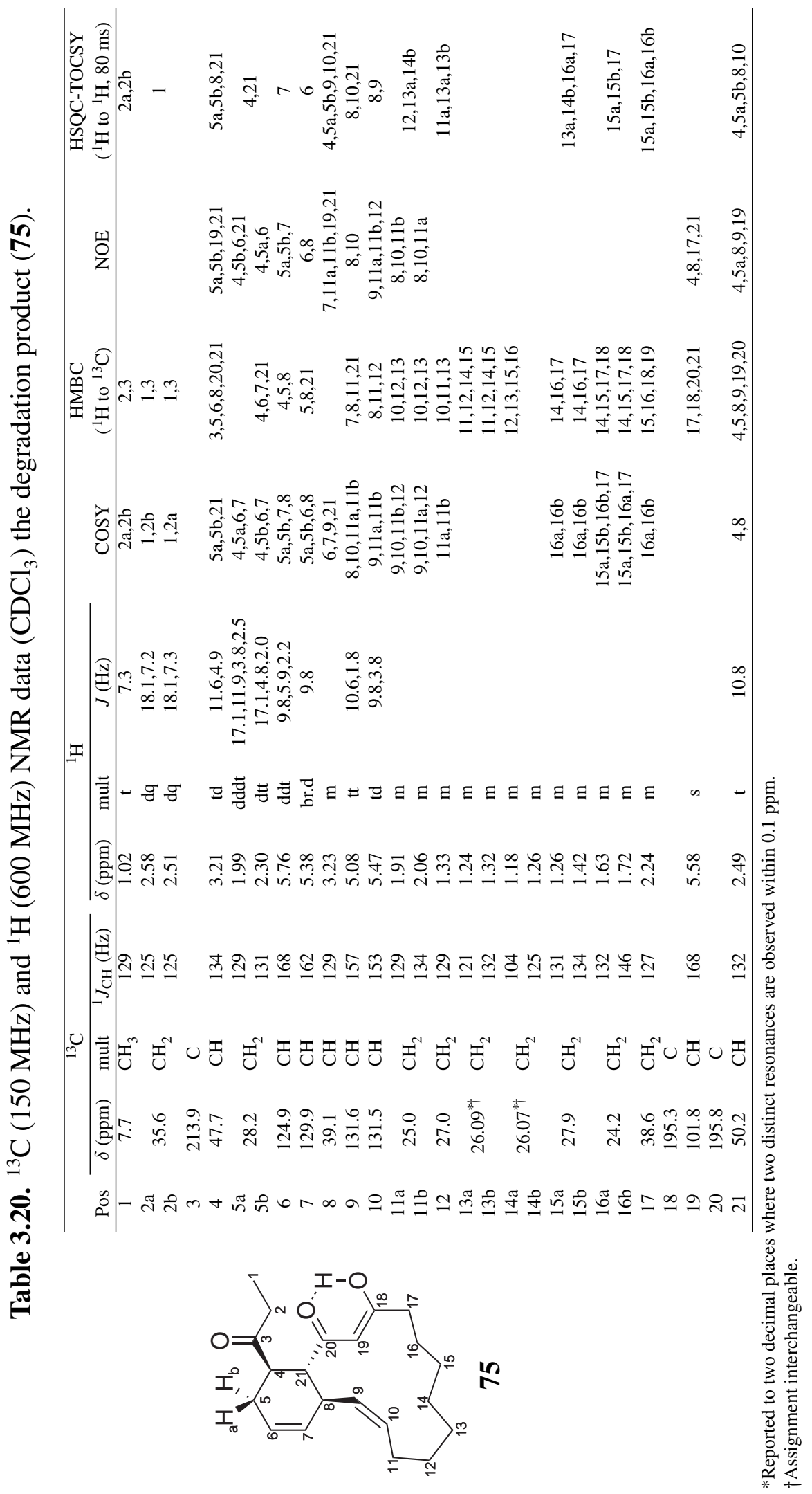


A possible degradation pathway is proposed in Scheme 3.3. The $\alpha$-pyrone ring is opened by $\mathrm{H}_{2} \mathrm{O}$, followed by decarboxylation, oxidative attack by $\mathrm{O}_{2}$, nucleophilic opening of the peroxide and finally, loss of $\mathrm{OH}^{-}$to form the ketone leading to the formation of $\mathbf{7 5}$.<smiles>C/C=C\C/C=C\C=C/[C@H](CO)C1=C2CCCCCCCC=C(C=C1O)OC2=O</smiles>

$62 \Delta=Z$

$63 \Delta=E$
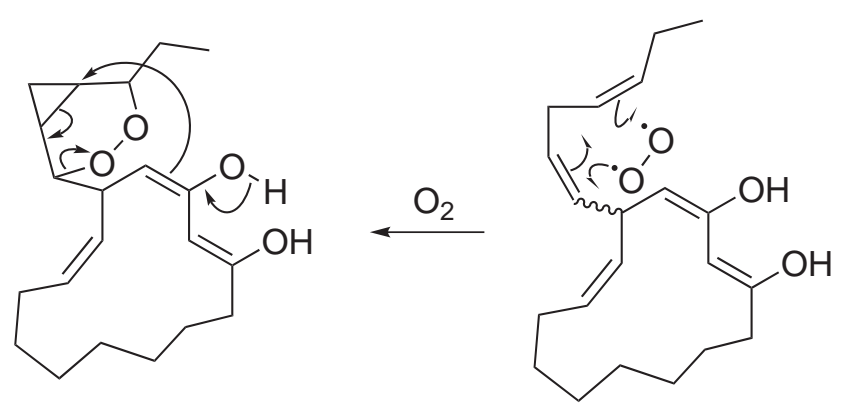

$-\mathrm{CO}_{2}$
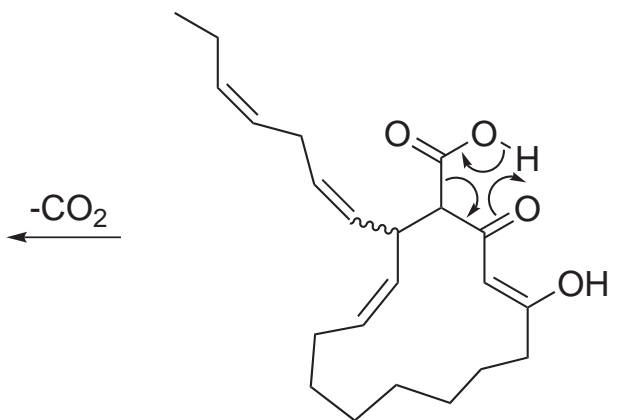

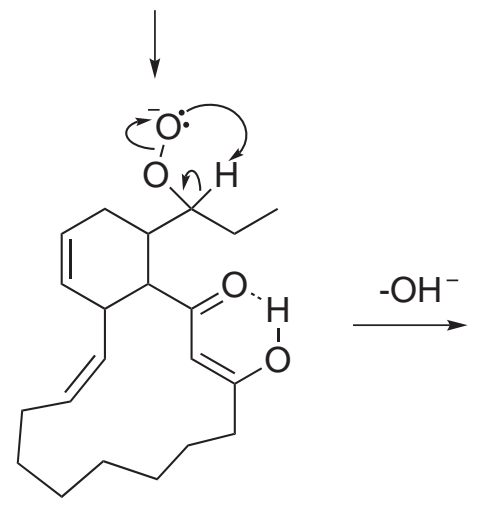<smiles>CCC(=O)C1CC=CC(/C=C/CCCCCCCC(=CC(=O)O)C2CCCCC2)C1C</smiles>

75

Scheme 3.3. A proposed degradation pathway of labillarides C (62) and D (63) to the degradation product (75).

Oxylipins in general are found to be unstable when concentrated, and storage in toluene/ethanol solutions appears to retard this degradation, ${ }^{75}$ a much more practical storage method than the liquid nitrogen employed during this study. 


\subsection{Biological Activity of Labillarides A to K}

Labillarides A-K (60-70) were evaluated for cytotoxicity against the human leukaemia cell line HL-60 and for antibacterial activity against the $\mathrm{MC}^{2} 155$ strain of Mycobacterium smegmatis at the School of Biological Sciences, VUW. Labillarides A (60), B (61) and I (68) all showed moderate activity against HL-60 ${ }^{76}$ while labillaride C (62) was the only metabolite to exhibit antibacterial activity (see Table 3.21). ${ }^{77}$

Table 3.21. Biological activity of labillarides A-K (60-70).

\begin{tabular}{ccc}
\hline \multirow{2}{*}{ Labillaride } & \multicolumn{2}{c}{$\mathrm{IC}_{50}(\mu \mathrm{M})$} \\
\cline { 2 - 3 } & $\mathrm{HL}^{*} 60^{*}$ & $M$. smegmatis $\mathrm{MC}^{2} 155^{\dagger}$ \\
\hline $\mathrm{A}(\mathbf{6 0})$ & 7.7 & Inactive \\
$\mathrm{B}(\mathbf{6 1})$ & 6.9 & Not tested \\
$\mathrm{C}(\mathbf{6 2})$ & Inactive & 36.5 \\
$\mathrm{D}(\mathbf{6 3})$ & Inactive & Inactive \\
$\mathrm{E}(\mathbf{6 4})$ & Inactive & Inactive \\
$\mathrm{F}(\mathbf{6 5})$ & Inactive & Inactive \\
$\mathrm{G}(\mathbf{6 6})$ & $\sim 12$ & Inactive \\
$\mathrm{H}(\mathbf{6 7})$ & Inactive & Inactive \\
$\mathrm{I}(\mathbf{6 8})$ & 2.5 & Inactive \\
$\mathrm{J}(\mathbf{6 9})$ & $\sim 11$ & Inactive \\
$\mathrm{K}(\mathbf{7 0})$ & $\sim 12$ & Inactive \\
\hline
\end{tabular}

*Tested up to $10 \mu \mathrm{M}$.

$\dagger$ Tested up to $50 \mu \mathrm{M}$.

\subsection{Oxylipins from Marine Macro-algae}

The term oxylipin was first introduced in literature in 1991 to encompass "oxygenated compounds which are formed from fatty acids by reaction(s) involving at least one step of mono- or dioxygenase-catalysed oxygenation." 78 Marine flora are prolific producers of polyunsaturated fatty acids, in particular $\mathrm{C}_{20}$ and $\mathrm{C}_{22} \omega-3$ fatty acids. ${ }^{79}$ The metabolism of these fatty acids to oxylipins was initially thought to be exclusively among red algae (Rhodophyta), however more recent studies have shown brown (Phaeophyta) and green (Chlorophyta) algae also produce a wide range. ${ }^{80}$

Typical examples of oxylipins include the prostaglandins $\mathrm{PGE}_{2}$ (76) and $\mathrm{PGF}_{2 \alpha}$ (77), 
and the constanolactones A (78) and B (79). ${ }^{81,82}$ The class is extensive and therefore a detailed review of marine algal oxylipins is beyond the scope of this report. Several reviews of oxylipins are available in literature and the focus will therefore be limited to those containing a macrocyclic moiety. ${ }^{79,80,83}$

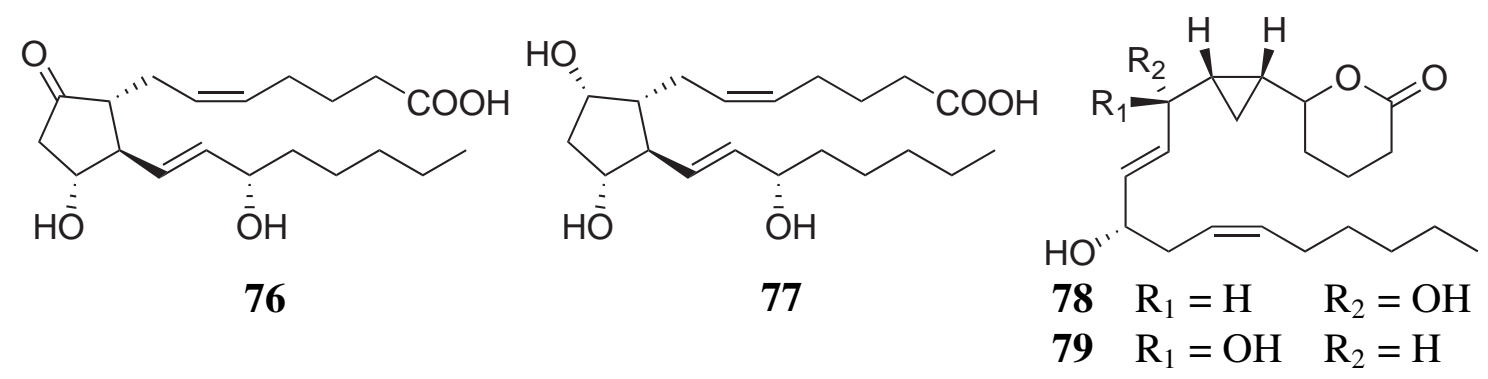

Other than the polyunsaturated $\alpha$ - and $\gamma$-pyrone macrocycles previously reported from Phacelocarpus labillardieri and described in Section 3.1 (49-51, 53-57 and 59), there are few examples of oxylipin macrocycles. Hybridalactone $(\mathbf{8 0})$, along with an unnamed minor oxylipin (81), was reported from a collection of the red alga Laurencia hybrida in $1981 .{ }^{84}$ The correct enantiomer of $\mathbf{8 0}$ was synthesised in 1984 based on the absolute configuration predicted by a biogenic proposal published earlier the same year. ${ }^{85,86}$ In 1989, ecklonialactones A (82) and B (83) were isolated from the brown alga Ecklonia stolonifera. ${ }^{87}$ Although the extract of E. stolonifera showed no antifeedant activity, 82 exhibited weak activity compared with the control. ${ }^{87}$ The structures of the $\mathrm{C}_{18}$ compounds $\mathbf{8 2}$ and $\mathbf{8 3}$ are very similar to those of $\mathrm{C}_{20}$ metabolites $\mathbf{8 0}$ and $\mathbf{8 1}$, suggesting a similar biogenic pathway. ${ }^{79}$

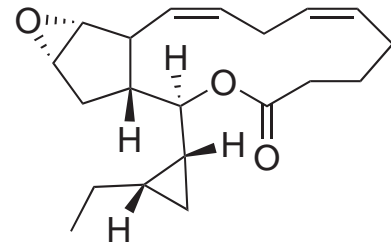

80

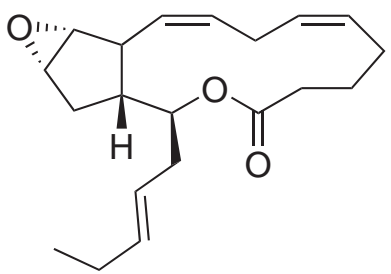

81

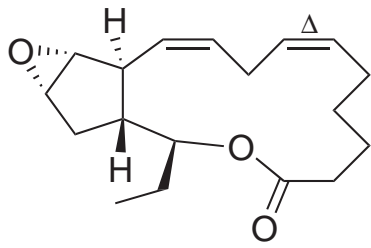

82

$83 \Delta$ saturated

Finally, eiseniachlorides A-C (84-86), eiseniaiodides A (87) and B (88), and three unnamed oxylipins (89-91) were reported from a Japanese collection of the brown alga Eisenia bicyclis in 2003. ${ }^{88}$ Compounds 84-89 each contain a chlorine or an iodine atom, making these structures particularly unusual. Only three other chlorinated $\mathrm{C}_{18}$ oxylipins have been reported to date. ${ }^{88}$ Possible biogenic pathways for 84-91 were postulated 
starting from octadecatetraenoic acid and involving lipoxygenase enzymes in a similar fashion to those discussed below (Section 3.19). ${ }^{88}$

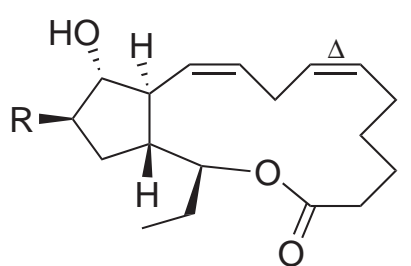

$84 \mathrm{R}=\mathrm{Cl}$

$85 \mathrm{R}=\mathrm{Cl}, \Delta$ saturated

$87 \mathrm{R}=\mathrm{I}$

$88 \quad \mathrm{R}=\mathrm{I}, \Delta$ saturated

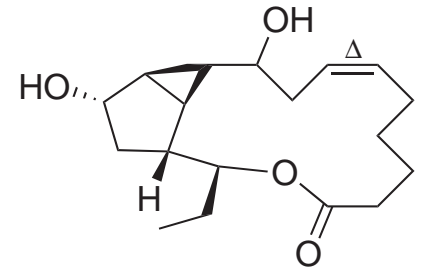

90

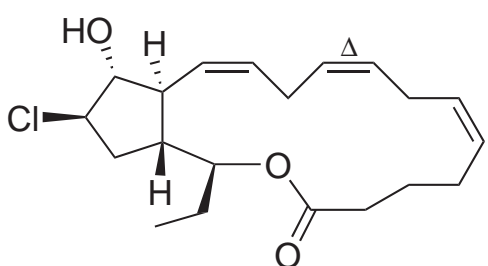

86

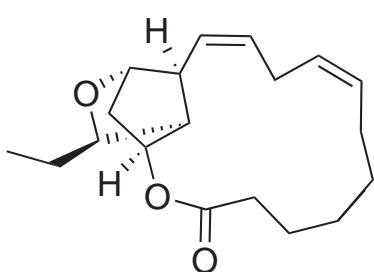

89

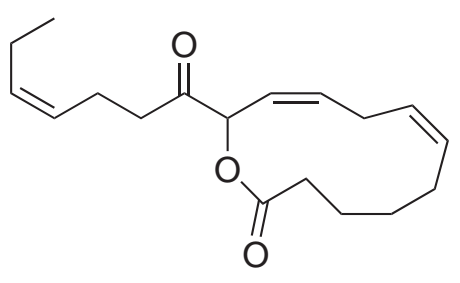

91 


\subsection{Labillaride Biogenesis}

The biogenic origins of many oxylipins have been investigated. ${ }^{79}$ Many, if not all oxylipin biogenic pathways are proposed to involve the lipoxygenases (LPOs), dioxygenase enzymes which incorporate molecular oxygen into unsaturated fatty acids with a $(Z, Z)$ 1,4-pentadiene moiety. ${ }^{89}$ The most common example of such pathways is the conversion of arachidonic acid (92) to several different hydroperoxyeicosatetraenoic acids (HPETEs) by the 5-, 12-, and 15-LPOs (see Scheme 3.4) as part of the Arachidonic Acid Cascade. ${ }^{90}$ Further transformations of the hydroperoxide are well documented, including conversion to an alcohol via a peroxidase (POX) reduction, or intramolecular rearrangement to form an alcohol and an epoxide. ${ }^{91}$ Epoxidase catalysed insertion of an oxygen across a double bond to form an epoxide also has precedence in oxylipin biogenesis. ${ }^{91}$

92
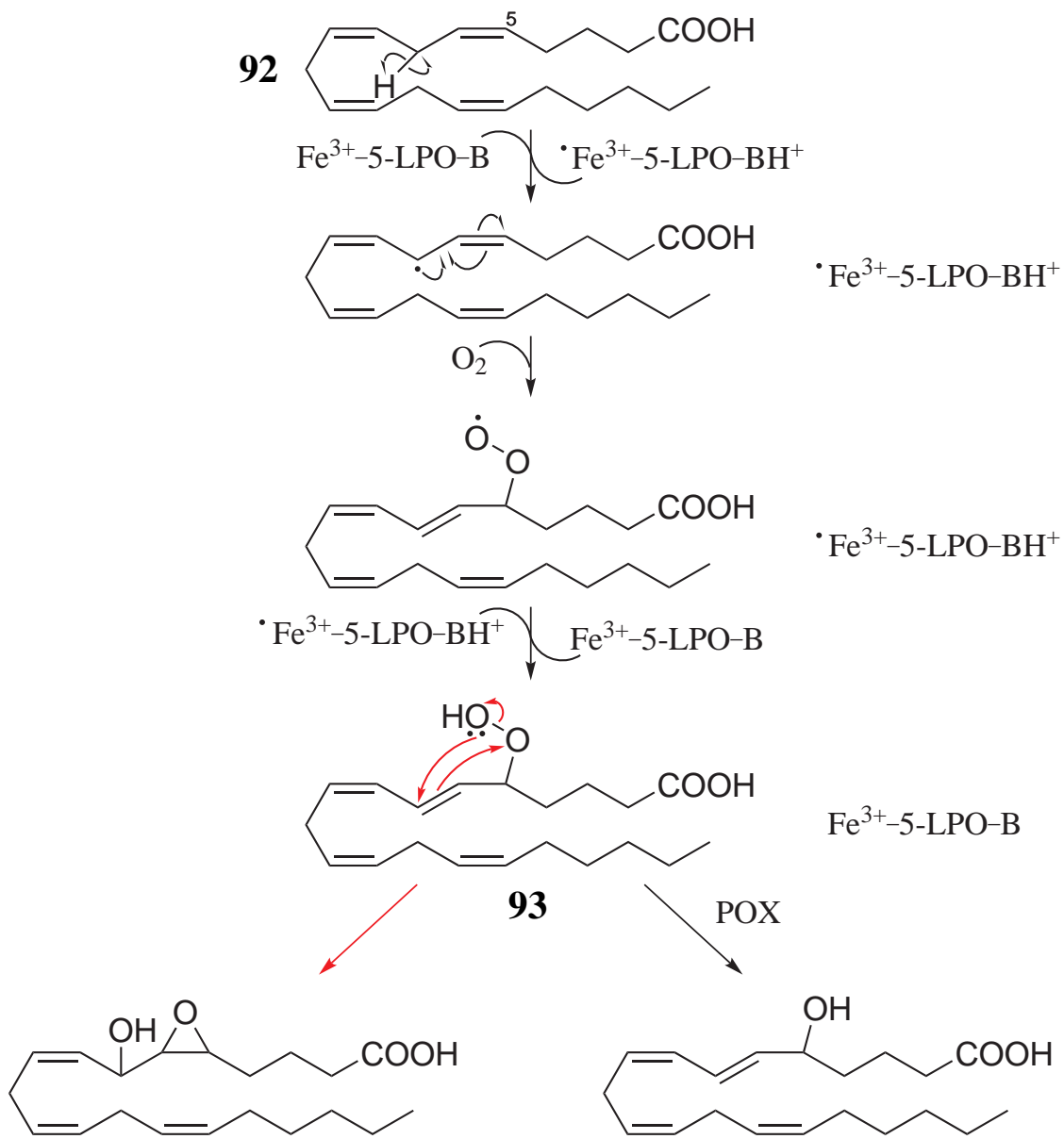

Scheme 3.4. The 5-LPO-catalysed oxidation of arachidonic acid (92) to 5-HPETE $(\mathbf{9 3})^{90}$ and two proposed transformations from the hydroperoxide. 


\section{Biogenesis of Labillarides A to $\mathrm{H}$}

Starting from an oxylipin premise, plausible biogenic pathways for labillarides A-H (60-67) are proposed to start from the common $\alpha$-pyrone precursor (94) formed from the fatty acid docosahexaenoic acid (95). The pathway from 95 is initiated by an "ene" type reaction, involving reaction of singlet oxygen with an alkene, ${ }^{92}$ producing a hydroperoxide at C-18 followed by an intramolecular rearrangement to form an epoxide. Lactonisation followed by dehydration, oxidation and hydrogenation (shown in Scheme $3.5)$ yields the $\alpha$-pyrone precursor 94 , numbered to coincide with the numbering of the labillarides. The order of the steps in this scheme, as with all of those proposed below, is flexible, for instance the oxidation may occur prior to the lactonisation.

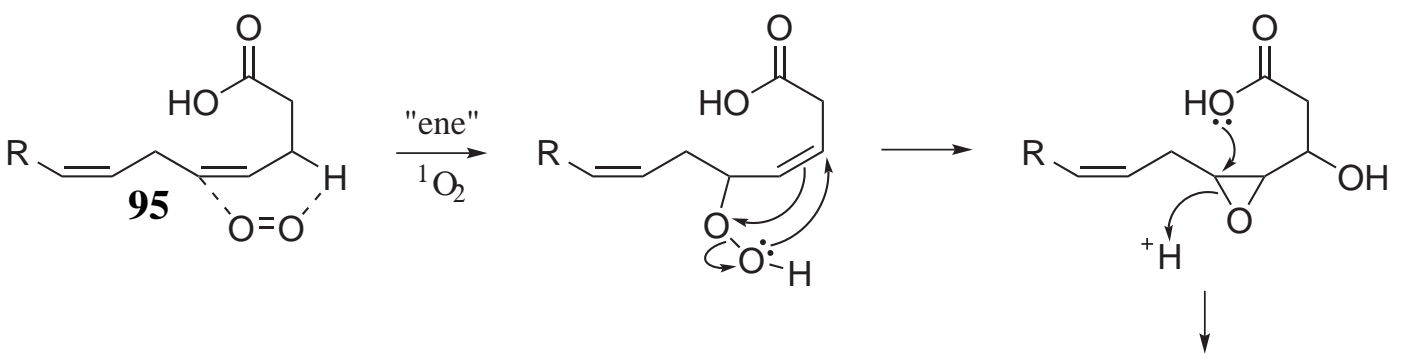<smiles>[R]C=CCC1=CC(=O)CC(=O)O1</smiles><smiles>[R]C=CCc1cc(O)cc(=O)o1</smiles><smiles>[R]CC=CCC=CCC=CCC=CCC</smiles>

Scheme 3.5. A proposed biogenesis of the $\alpha$-pyrone precursor (94).

An alternative pathway for the formation of this $\alpha$-pyrone precursor $(\mathbf{9 4})$ can be proposed that involves polyketide synthase (PKS). The basic biochemical reactions of eukaryotic fatty acid synthase (FAS) and polyketide synthase (PKS) are the same, although the enzymes involved differ. ${ }^{93}$ The FAS pathway is a multi-step process initiated by condensation of malonate (96) and a fatty acid with release of a $\mathrm{CO}_{2}$ molecule. ${ }^{93}$ Unlike FAS, the predominant PKS pathway in eukaryotic organisms will accept a variety of starter units, with malonate (96) as the propogator. The pathway then skips the reduction 
and dehydration steps, stopping at the condensation step, resulting in linear carbon chains with 1,3-ketone oxidation patterns (see Scheme 3.6).

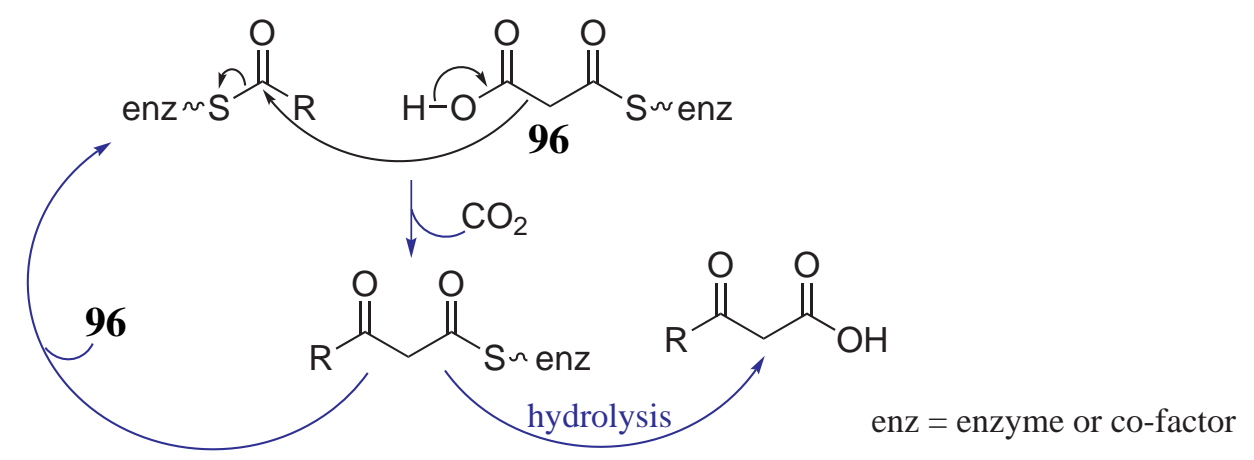

Scheme 3.6. A simplified polyketide synthase producing polyketone products.

The chloroplast fatty acids of eukaryotic algae are largely polyenoic acids, of which the $\mathrm{C}_{18} \omega-3$ fatty acid $\alpha$-linolenic acid (97) is a major constituent. ${ }^{94}$ With 97 as the starter unit, the 1,3,5-oxidation pattern observed in $\mathbf{9 4}$ can be constructed through two cycles of PKS acetate addition followed by lactonisation and dehydration to form 94 (Scheme 3.7).<smiles>[R]CCC(=O)O</smiles><smiles>[R]CCC(=O)CC(=O)CC(=O)O</smiles><smiles>C[As]C</smiles>

$R$<smiles>[R]CCCCC(=O)CC(=O)O</smiles><smiles>[R]CCc1cc(O)cc(=O)o1</smiles><smiles>C1=CCC1</smiles>

94<smiles>[R]CCC1=CC(=O)CC(=O)O1</smiles><smiles>CC=O</smiles><smiles>[R]CCC1(O)CC2CC(=O)CCC2O1</smiles>

PKS = polyketide synthase

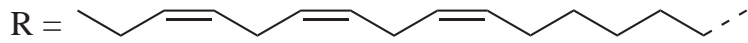

Scheme 3.7. An alternative proposed biogenesis of the $\alpha$-pyrone precursor (94).

The biogenesis of labillaride A (60) from 94 is proposed to follow the mechanism outlined in Scheme 3.8. Oxidation at $\Delta_{6,7}$ of $\mathbf{9 4}$ by an epoxidase, followed by deprotonation at the $\alpha$-position of the diketone, nucleophilic opening of the epoxide and finally, dehydration across the C-7-C-8 bond leads to the formation of $\mathbf{6 0}$.

Haloperoxidase enzymes were suggested in the biosynthesis of halogenated marine natural products nearly 30 years ago. ${ }^{95}$ Since then, various haloperoxidases have been 
<smiles>CC/C=C\C/C=C\C/C=C\CCCCCCCC1=CC(=O)CC(=O)O1</smiles>

94<smiles>C/C=C\CC(/C=C\C=C/CCCCCCCc1cc(OC2=CC(=O)OC2)cc(=O)o1)CC</smiles>

60<smiles>C/C=C\CC1OC1C/C=C\CCCCCCC1OC1=O</smiles>

$\stackrel{-\mathrm{H}^{+}}{\longrightarrow}$<smiles>C/C=C\CC1OC1C/C=C\CCCCCCCC1=CC(=O)CC(=O)O1</smiles>

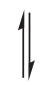<smiles>CC/C=C\CC(Oc1cc(CCCCCCCO)oc(=O)c1)C(O)(CO)C(C)O</smiles><smiles>CC/C=C\CC1(C)OC1C/C=C\CCCCCCC</smiles>

$\mathrm{EPO}=$ an epoxidase

Scheme 3.8. A proposed biogenesis of labillaride A $(\mathbf{6 0})$.

discovered in many marine organisms, of which most are the vanadium-dependent haloperoxidases. ${ }^{95}$ Vanadium bromoperoxidases (V-BrPOs) have been isolated from all the different classes of marine algae, including Rhodophyta. The overall reaction scheme of $\mathrm{V}$-BrPOs is summarised in Scheme 3.9, where the enzyme catalyses the oxidation of bromide by hydrogen peroxide to produce a bromonium ion, or a biological equivalent. This bromonium ion can then either react with an organic substrate $(\mathrm{R})$, or with another equivalent of hydrogen peroxide. ${ }^{95}$

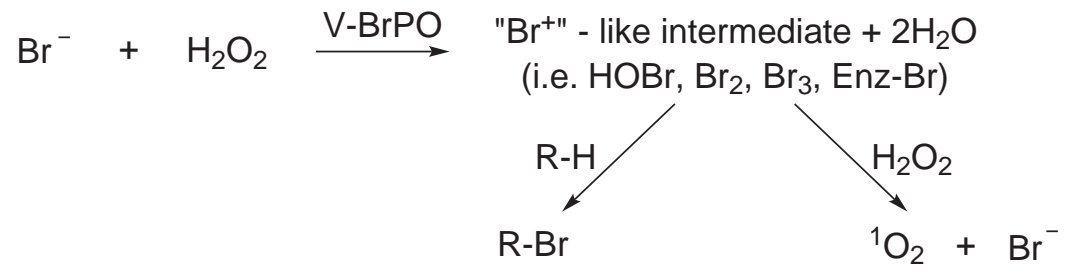

Scheme 3.9. Overall reaction scheme of vanadium bromoperoxidases. ${ }^{95}$

The formation of labillaride B (61) is proposed to involve an intramolecular cyclisation catalysed by vanadium bromoperoxidase, similar to that proposed for the cyclisation of laurediols. ${ }^{96-98}$ The $\alpha$-pyrone precursor (94) undergoes a 1,3-H migration, followed by deprotonation at the $\alpha$-position of the diketone and tautomerisation resulting in an enolate. Nucleophilic attack by the oxygen at C-8 of the double bond followed by attack of the double bond onto the bromonium ion, or a biological equivalent, results in the formation of 61 (Scheme 3.10). 


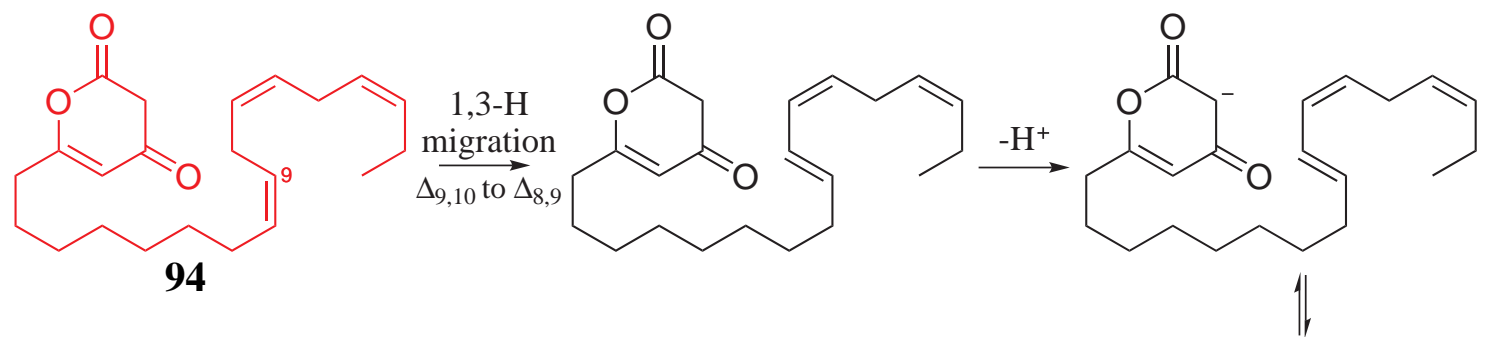

$\mathrm{V}-\mathrm{BrPO}=\mathrm{a}$ bromoperoxidase

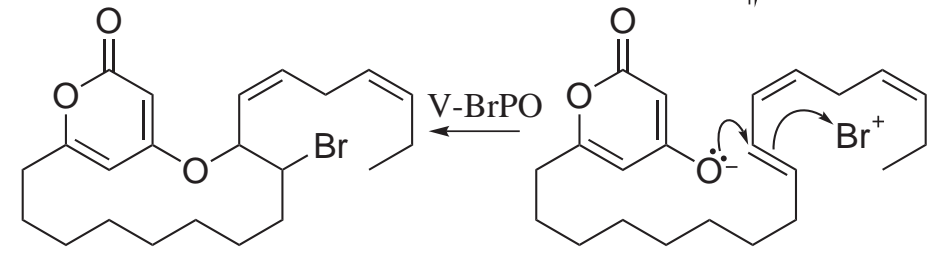

61

Scheme 3.10. A proposed biogenesis of labillaride B (61).

Labillarides C (62) and D (63) are proposed to follow a similar lipoxygenase-initiated mechanism (Scheme 3.11). A peroxidase reduction of the hydroperoxide at C-6 results in an alcohol which is converted to a good leaving group by substitution with a phosphate ion, or similar moiety. Deprotonation at the $\alpha$-position of the diketone followed by nucleophilic attack by the carbanion at the $\mathrm{C}-8$ double bond and loss of the leaving group results in the formation of 62 or $\mathbf{6 3 .}$<smiles>[R20]C(C)(C)OC1=CC(=O)CC(CCCCC/C=C\CC(O)/C=C\CC)=CC1=O</smiles>

94

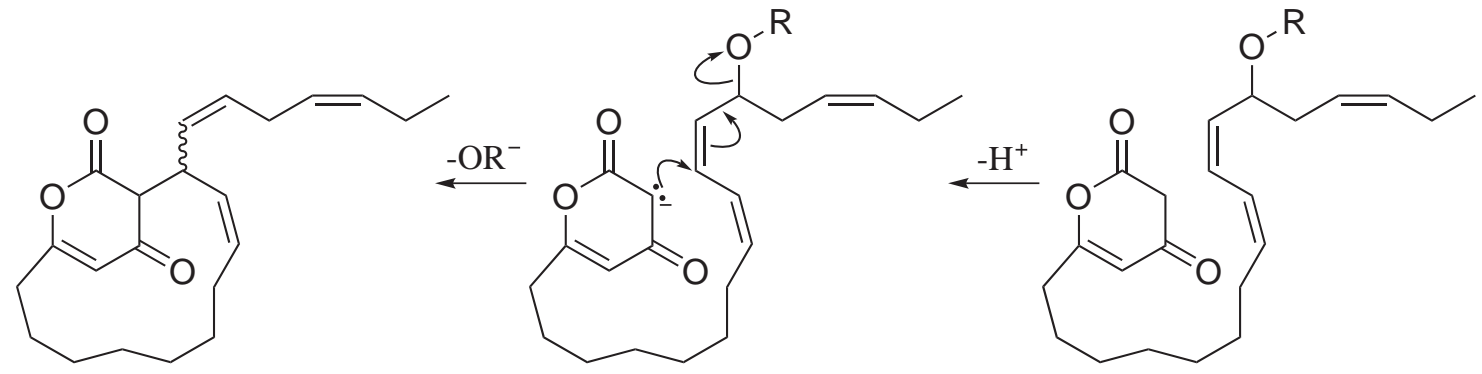

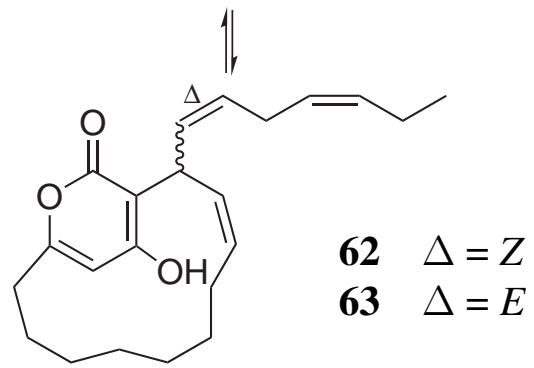

$\mathrm{LPO}=\mathrm{a}$ lipoxygenase $\mathrm{POX}=$ a peroxidase $\mathrm{R}=\mathrm{PO}_{3}{ }^{3-}$ or similar

Scheme 3.11. A proposed biogenesis of labillarides C (62) and D (63). 
In an analogous fashion, labillarides E-H (64-67) are proposed to follow the mechanism outlined in Scheme 3.12. A hydroperoxide formation from a lipoxygenase at C-3 and subsequent reduction by a peroxidase followed by a second lipoxygenase product at C-6 which undergoes an intramolecular rearrangement to form an epoxide, establishes the C-3 and C-8 alcohols. Deprotonation at the $\alpha$-position of the diketone followed by nucleophilic attack by the carbanion at the epoxide is followed by conversion of the alcohol to a good leaving group. A second deprotonation at the $\alpha$-position to the diketone followed by enolisation results in nucleophilic attack by the oxygen at the C-6 position, ejecting the leaving group, completing the formation of the 64-67 framework.
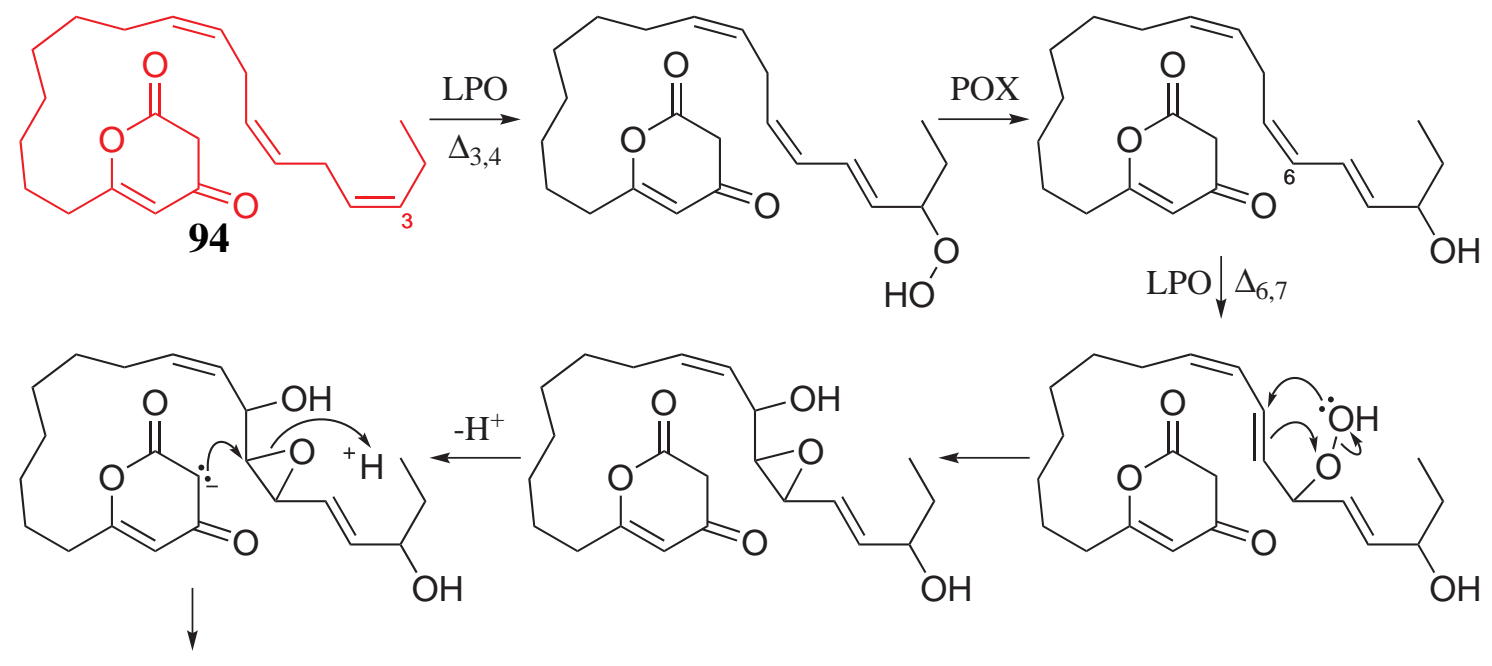

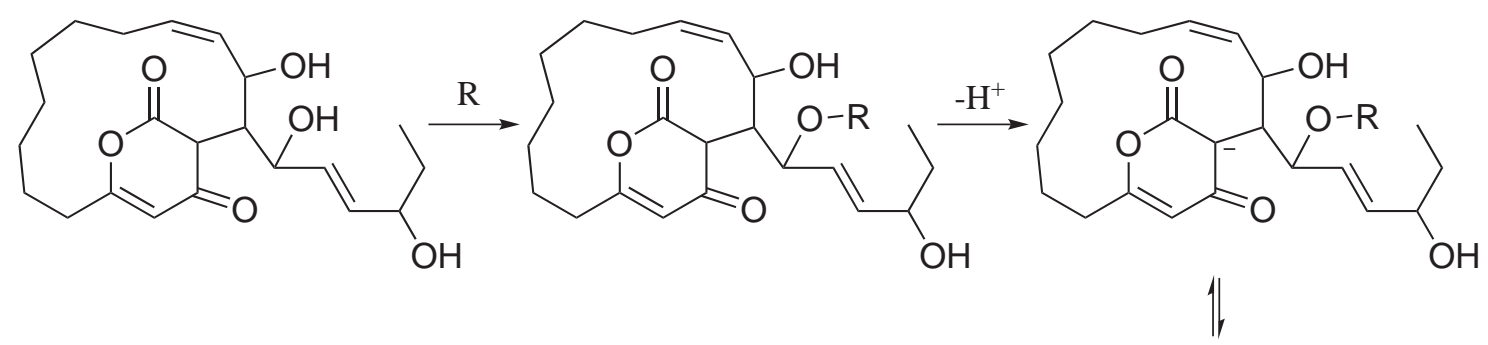

$$
\begin{aligned}
& \mathrm{LPO}=\text { a lipoxygenase } \\
& \mathrm{POX}=\text { a peroxidase } \\
& \mathrm{R}=\mathrm{PO}_{3}{ }^{3-} \text { or similar }
\end{aligned}
$$

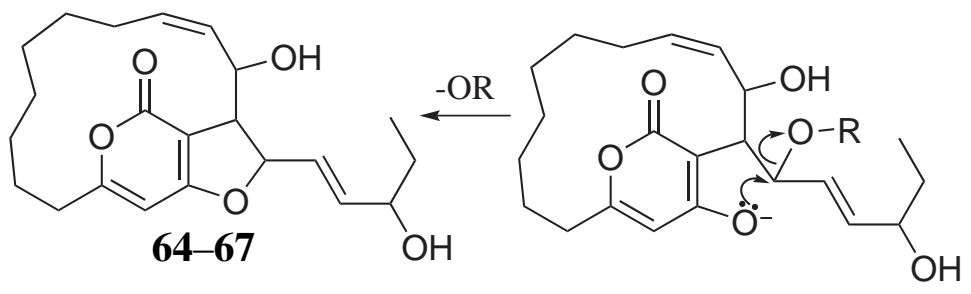

Scheme 3.12. A proposed biogenesis of labillarides E-H (64-67).

\section{Biogenesis of Labillarides I and J}

A possible biogenic pathway for labillarides I (68) and J (69), which could alternatively be artifacts of isolation, can also be proposed starting from labillaride $\mathbf{C}(\mathbf{6 2})$. The $\alpha-$ 
pyrone ring is opened by $\mathrm{H}_{2} \mathrm{O}$, resulting in the common precursor which can undergo either methylation to form $\mathbf{6 8}$, or decarboxylation and tautomerisation to form 69 (see Scheme 3.13).<smiles>CC/C=C\C/C=C\C1/C=C\CCCCCCc2cc(O)oc(=O)c21</smiles>

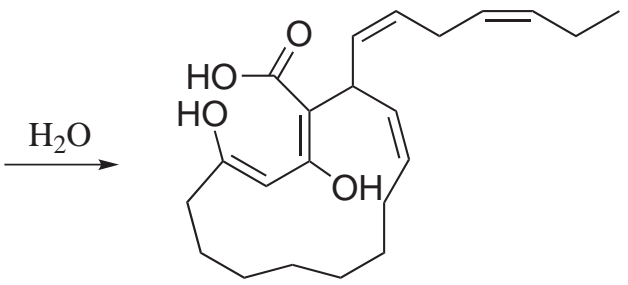

62
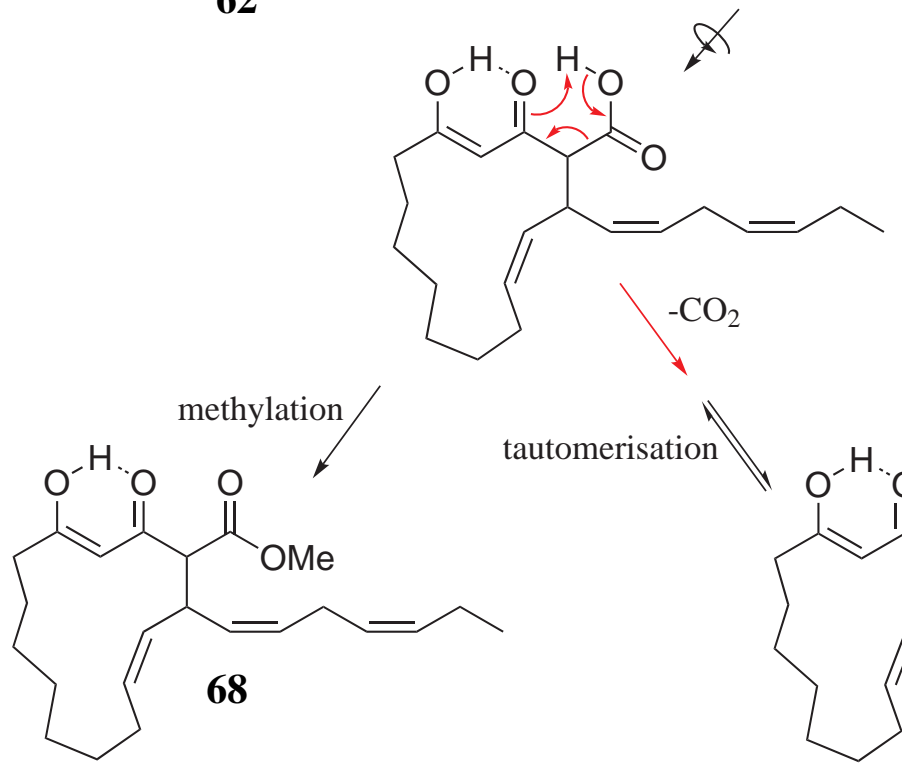

Scheme 3.13. A proposed biogenesis of labillarides I (68) and J (69).

\section{Biogenesis of Labillaride $\mathrm{K}$}

There are very few natural products with a furanone moiety reported in the literature. Interestingly, all organisms that reportedly produce furan-3-one metabolites also produce 4-hydroxy- $\alpha$-pyrones. ${ }^{99}$ During the isolation of pseudopyronines A (98) and B (99), Kong et al. found 99 to be unstable, degrading to 100 when left sitting in $\mathrm{CDCl}_{3}$ in an $\mathrm{NMR}$ tube for 10 days. ${ }^{99}$<smiles>CCCCCCc1c(O)cc(CC)oc1=O</smiles>

$98 \mathrm{n}=4$

$99 \mathrm{n}=6$<smiles>CCCCCCCC1=CC(=O)C(O)(CCCCCC)O1</smiles>

100

A possible mechanism for the formation of a furan-3-one from an $\alpha$-pyrone was proposed 
by Kong et al. (Scheme 3.14). The pyrone is oxidised by oxygen from the air to form a peroxide, which was observed in the NMR tube of the degraded sample of 99. The unstable peroxide intermediate is then proposed to be hydrolysed during HPLC purification, followed by oxidative decarboxylation and cyclisation.

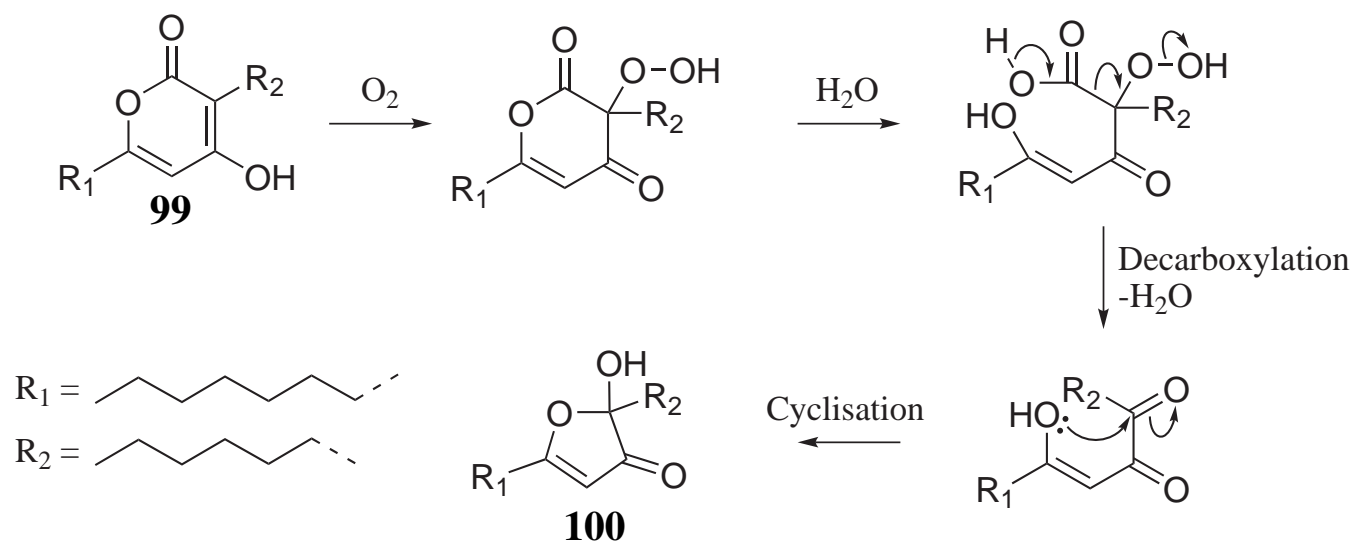

Scheme 3.14. A possible mechanism for the formation of a furan-3-one from a $\alpha$-pyrone, as proposed by Kong et al. ${ }^{99}$

By analogy, a plausible biogenesis of labillaride K (70) can be proposed assuming Nature could exploit such a process with a final biological reduction of the hemiacetal (see Scheme 3.15). Once more, a lipoxygenase initiated pathway from the $\alpha$-pyrone precursor (94) produces a hydroperoxide at C-21 followed by an ester hydrolysis, decarboxylation and loss of $\mathrm{H}_{2} \mathrm{O}$. Cyclisation is followed by reduction of the hemiacetal and, finally, a 1,3-H migration to form $\mathbf{7 0 .}$

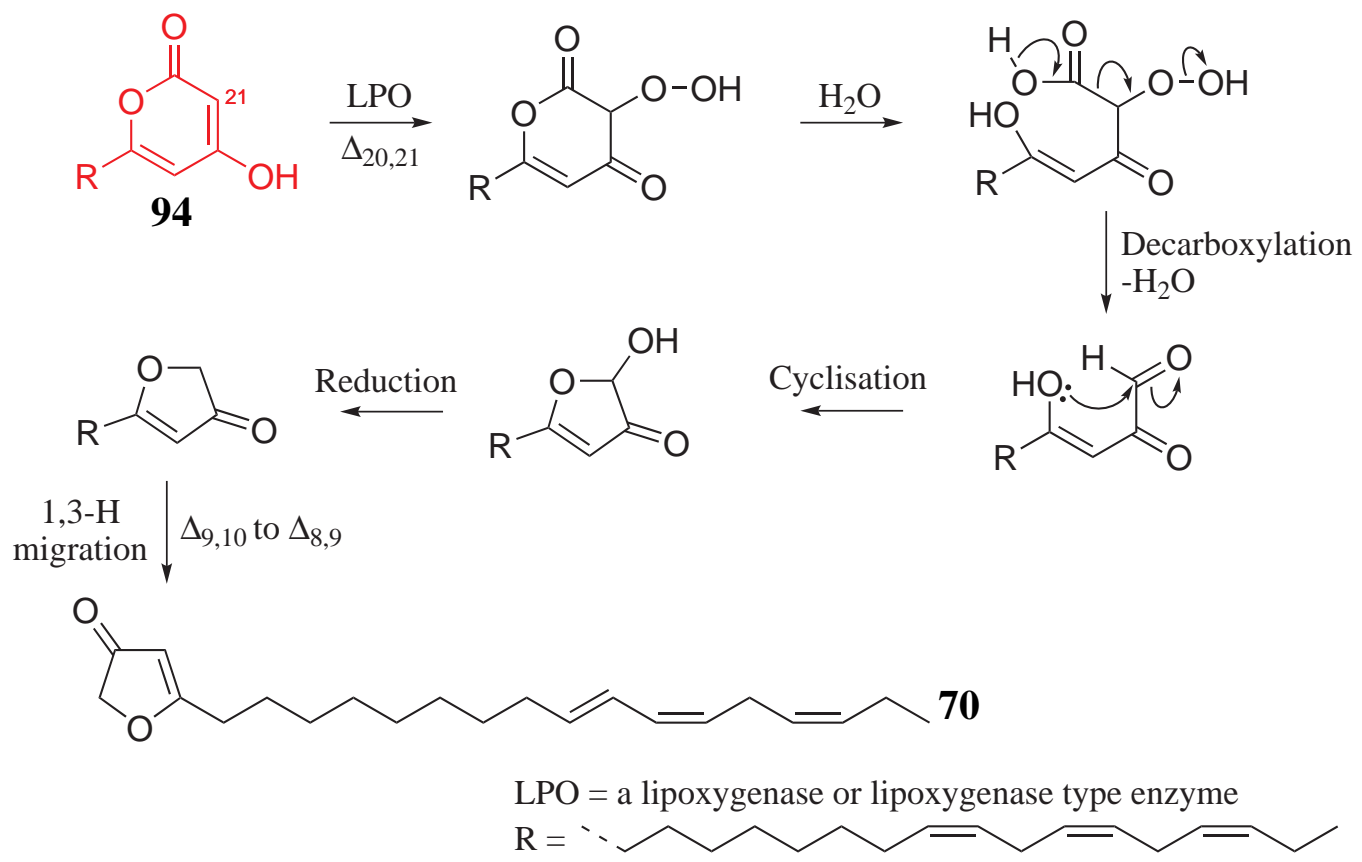

Scheme 3.15. A proposed biogenesis of labillaride K (70). 
Scheme 3.16 shows an overview of the proposed biogenic pathways of labillarides A$\mathrm{K}(\mathbf{6 0 - 7 0})$ from the fatty acids docosahexaenoic acid (95) or $\alpha$-linolenic acid (97). Similar schemes could be proposed for the known pyrones 49-57 and $\mathbf{5 9}$ from either docosahexaenoic acid (95) or eicosapentaenoic acid, the $\mathrm{C}_{20} \omega$-3 fatty acid equivalent.<smiles>CC/C=C\C/C=C\C/C=C\C/C=C\C/C=C\CCC(=O)O</smiles>

Scheme 3.5

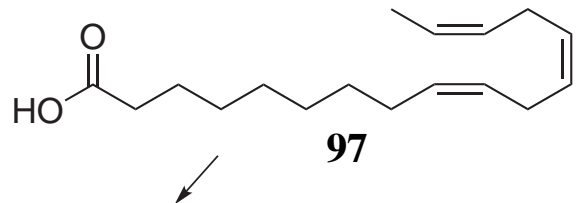

Scheme 3.7<smiles>CC/C=C\C=C/C(C/C=C\C/C=C\CC)Oc1cc(CCCCCC/C=C\CCC)oc(=O)c1</smiles>

Scheme 3.10<smiles></smiles>

61

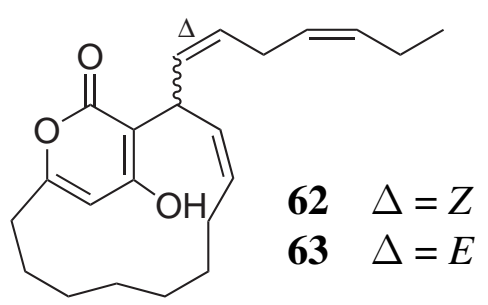

Scheme 3.12
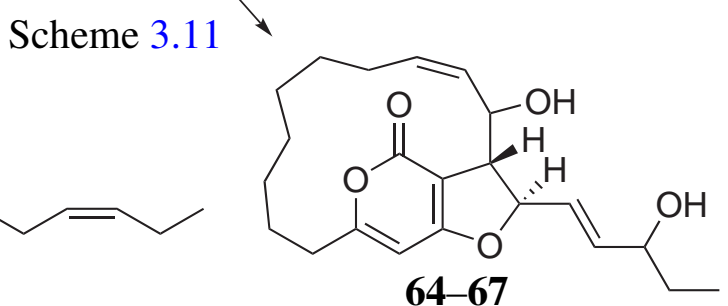

$$
62 \Delta=Z
$$<smiles>CC/C=C/C/C=C/C(/C=C/CCCCCC/C(O)=C/C(=O)O)C(=O)OC</smiles><smiles>C/C=C\CC(/C=C/C/C=C/CC)/C=C/CCCCCC/C(=C/C(=O)O)CC</smiles>

Scheme 3.16. An overview of the proposed biogenic pathways of labillarides A-K (60-70). 


\subsection{Summary}

Oxylipins are wide-spread in red algae, however macrocyclic versions are rather unusual. In particular, the nine novel polyunsaturated $\alpha$ - and $\gamma$-pyrone macrocycles reported from southern Australian specimens of Phacelocarpus labillardieri between 1982 and 1995 represent a unique group of metabolites. ${ }^{58-61}$ In this study, several collections of P. labillardieri from the northern coastal regions of the North Island of New Zealand led to the isolation of 11 new compounds, eight of which are related $\alpha$-pyrone containing macrocyclic metabolites (labillarides A-H, 60-67), adding to this repertoire. Of particular interest are labillarides $\mathrm{C}(\mathbf{6 2})$ and $\mathrm{D}(\mathbf{6 3})$, which introduce the first examples of direct carbon-to-carbon bridged macrocycles into this family of compounds, and the unusual tricyclic labillarides E-H (64-67), which possess the rare dihydrofuro[3,2,-c]pyran-4-one moiety. Also isolated were two enol macrocycles (labillarides I and J, 68 and 69) and a new furan-3-one (labillaride $\mathrm{K}, \mathbf{7 0}$ ), which are biogenically related to the macrocyclic pyrones. It is interesting to note that a small Wellington collection of P. labillardieri was examined by NMR spectroscopy and found to contain lower concentrations of the labillarides isolated from the Northland collections, and again with no sign of the known compounds previously isolated from southern Australian sources. These differences between the Australian and New Zealand studies of what has been reported as the same species may indicate a different taxonomic status.

The stability of several of the labillarides was problematic. It was found that though frozen collections of the alga, as well as extracts and crude mixtures of compounds, were quite stable, once purified some of the labillarides are remarkably unstable when stored as a solid or in an oil. This issue has been noted for oxylipins and a solution is to store such compounds in toluene/ethanol solutions. ${ }^{75}$ Interestingly, the tricyclic oxylipins labillarides E-H (64-67) did not exhibit the same instability, showing no obvious degradation by NMR analysis following over two years of storage in a $4{ }^{\circ} \mathrm{C}$ fridge.

All labillarides were tested for biological activity against the human leukaemia cell line HL-60 and for antibacterial activity against the $\mathrm{MC}^{2} 155$ strain of Mycobacterium 
smegmatis. Labillarides A (60), B (61) and I (68) exhibit moderate cytotoxicity while labillaride C (62) shows moderate antibacterial activity. Initial tests of labillaride E (64) showed repeatable potent cytotoxicity $(\sim 600 \mathrm{nM})$, however this activity was not observed when a second sample was purified by a slightly different isolation route. Upon re-purification of the original sample, despite no detection of another major constituent by HPLC, the activity did not track with 64. Such issues are not restricted to NMR guided isolation. In 1995, a P-388 bioassay guided separation lead to the isolation of phakellistatin $11(\mathbf{1 0 1})\left(\mathrm{ED}_{50} 0.2 \mu \mathrm{g} \mathrm{mL}^{-1}\right)$ from the Micronesian sponge Phakellia sp., however a synthetic sample of $\mathbf{1 0 2}$ did not exhibit this potent activity $\left(\mathrm{ED}_{50}\right.$ $\left.>10 \mu \mathrm{g} \mathrm{mL}^{-1}\right) .{ }^{100,101}$ It was found that the natural sample carried trace amounts (too small for usual NMR and chromatographic detection) of an unidentified exceptionally potent impurity.

Finally, Labillarides E-H (64-67) display significant changes in their ${ }^{1} \mathrm{H}$ NMR spectra with changes in either concentration or solvent. Were it not for the HPLC results showing different retention times and only two examples of co-elution, it would have been very easy to dismiss the subtle chemical shift variations observed between the samples, as considerably larger changes could be induced by changing the concentration or solvent. This demonstrates the need for more than a single method to determine if samples are identical, with HPLC being crucial in this case. 


\section{Chapter 4}

\section{Colensolide A: A New Nitrogenous Bromophenol from Osmundaria colensoi}

\subsection{Osmundaria colensoi}

In this study, an extract of the New Zealand marine red alga Osmundaria colensoi [(J.D. Hooker \& Harvey) R.E. Norris] (Figure 4.1, taxonomy see Table 4.1) was examined. The spectra obtained from screening $O$. colensoi with our standard protocol was recognised as being extremely interesting using the HSQC mask (Figure 4.2). Of particular note was the cluster of shielded aromatic methines centred around $\delta_{\mathrm{H}} 7$ and $\delta_{\mathrm{C}} 115$.

There have been no compounds reported to date specifically from Osmundaria colensoi, though there has been a variety of compounds isolated from different species of Osmundaria and Vidalia, which is now considered a synonym of Osmundaria. ${ }^{21,102}$ Sterol distribution studies of several species of Osmundaria and Vidalia have been reported on two occasions. ${ }^{103,104}$ Similarly, the free protein amino acid profiles of $V$. volubilis were reported in 1977, ${ }^{105}$ and the carotenoid content of a New Zealand collection of V. colensoi was summarised in 1987. ${ }^{106}$ In 1982 an $S$-methyl compound (103) was reported from several red algae, including V. volubilis. ${ }^{107}$ Re-examination of the hydrophilic fraction of

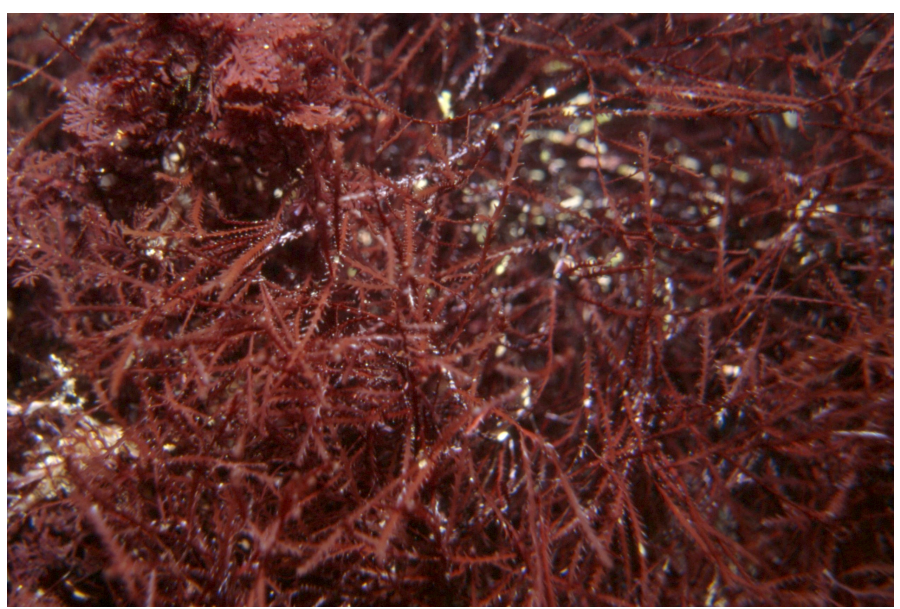

Figure 4.1. Osmundaria colensoi. Image courtesy of Malcolm Francis. 
Table 4.1. Taxonomic classification of genus Osmundaria from order Ceramiales as presented by AlgaeBase. ${ }^{21}$

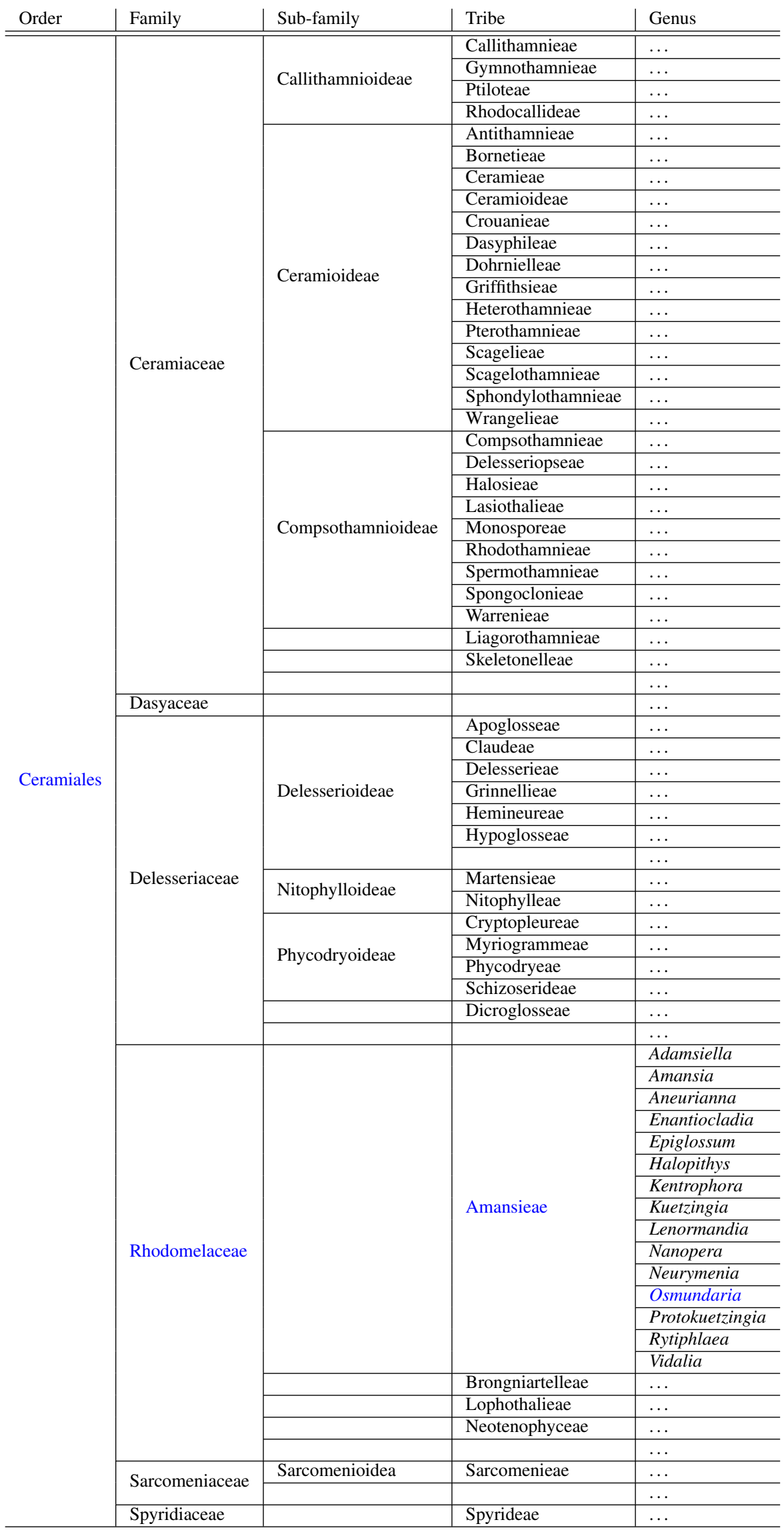




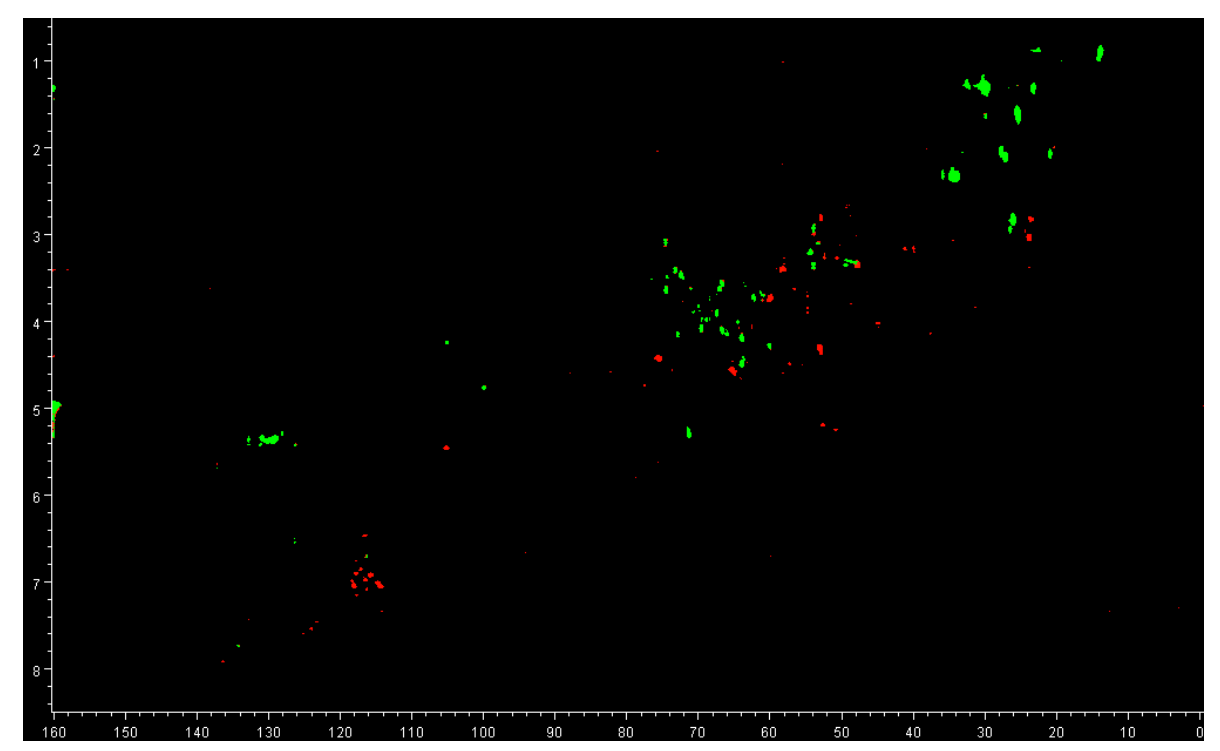

Figure 4.2. HSQC mask showing the common correlations in green and the unusual correlations in red.

this alga by the same group lead to the isolation of two $N$-methyl compounds (104 and 105), reported in 1992. ${ }^{108}$ In 1982 the halogenated cyclopentene 106 was reported from a Western Australian collection of V. spiralis. ${ }^{109}$ Vidalol A (107) and B (108) were reported in 1991 from the Caribbean red alga Vidalia obtusaloba, and were found to have antiinflammatory activity. ${ }^{110}$ Vidalenolone (109), a novel phenolic compound, was reported along with the known compounds lanosol (110) and 4-hydroxybenzyl alcohol (111) from the tropical red alga Vidalia sp. in 2002. ${ }^{111}$ In 2006 two new sulfated bromophenols (112 and 113) were reported along with three known lanosol derivatives $(\mathbf{1 1 4}, 115$ and 116), a sterol (117) and a glycoside (118). ${ }^{112}$ Finally, in 2006, the known lanosol derivative 119 was reported from Osmundaria serrata. ${ }^{113}$<smiles>COC(CCS(C)(=O)=O)C(=O)[O-]</smiles>

103<smiles>NN[C@@H](CC(=O)O)C(=O)O</smiles>

104<smiles></smiles>

105<smiles>C=C1C(Br)=C(Br)[C@H](O)[C@@H]1O</smiles>

106<smiles>Oc1cc(Cc2c(O)cc(O)c(Br)c2O)c(Br)c(Br)c1O</smiles> 
<smiles>Oc1cc(Cc2c(O)c(Br)c(O)c(Cc3cc(O)c(O)c(Br)c3Br)c2O)c(Br)c(Br)c1O</smiles>

108<smiles>[R6]Cc1cc(O[R6])c([2H])c(Br)c1Br</smiles>

$110 \mathrm{R}_{1}=\mathrm{H} \quad \mathrm{R}_{2}=\mathrm{H} \quad \mathrm{R}_{3}=\mathrm{H}$

$114 \mathrm{R}_{1}=\mathrm{H} \quad \mathrm{R}_{2}=\mathrm{H} \quad \mathrm{R}_{3}=\mathrm{Me}$

$115 \mathrm{R}_{1}=\mathrm{SO}_{3} \mathrm{~K} \quad \mathrm{R}_{2}=\mathrm{H} \quad \mathrm{R}_{3}=\mathrm{SO}_{3} \mathrm{~K}$

$119 \mathrm{R}_{1}=\mathrm{H} \quad \mathrm{R}_{2}=\mathrm{H} \quad \mathrm{R}_{3}=\mathrm{Et}$<smiles>COC1(c2ccc(O)cc2)CC=C(O)C1=O</smiles><smiles>OCc1ccc(O)cc1</smiles>

111<smiles>[X]C(=O)OCc1cc(O)c(OS(=O)(=O)Oc2cc(CO[R5]([O])([O-])O[Na])c(Br)c(Br)c2O)c(O)c1Br</smiles>

112<smiles>[X]OS(=O)(=O)OCc1cc(OS(=O)(=O)OCc2cc(O)c(OS(=O)(=O)O[Na])c(Br)c2Br)c(Br)c(Br)c1O</smiles>

113<smiles>Oc1cc(Cc2cc(O)c(O)c(Br)c2Br)c(Br)c(Br)c1O</smiles>

116<smiles>C=C(CC[C@H](C)[C@H]1CCC2C3CC=C4C[C@@H](O)CC[C@]4(C)C3CC[C@]21C)C(C)C</smiles>

117<smiles>O=C(O)[C@H](CO)O[C@H]1O[C@H](CO)[C@@H](O)[C@H](O)[C@H]1O</smiles>

118 


\subsection{Isolation}

A large-scale extraction of approximately $500 \mathrm{~g}$ of Northland collections of $O$. colensoi was performed. Following two steps of bench-top reversed-phase chromatography (PSDVB), four fractions were examined by ${ }^{1} \mathrm{H}$, COSY, HSQC and HMBC NMR experiments in an attempt to identify functional groups and fragments of molecules. Analysis of the NMR spectra revealed deshielded aromatic non-protonated carbons and shielded aromatic singlet protons, suggesting highly substituted phenols. Examination of the more recent Marine Natural Products reviews, published yearly in Natural Products Reports, revealed a similarity to a series of bromophenols isolated from various red algae. $^{114-117}$

\section{Known Bromophenols}

Further purification by HPLC $\left(\mathrm{C}_{18}\right)$ lead to the isolation of the common bromophenol lanosol (110), the methyl ether of lanosol (114), an aldehyde derivative (120), a butenone derivative (121) and rhodomelol (122). Compounds 110 and 114 have been previously reported from species of Vidalia and Osmundaria respectively, while $\mathbf{1 2 0}$ has only been reported from other genera of red algae. ${ }^{111,112}$ Both $\mathbf{1 2 1}$ and $\mathbf{1 2 2}$ have been reported once each from Polysiphonia lanosa and Rhodomela confervoides respectively. ${ }^{118,119}$

The NMR assignments of lanosol and many of its derivatives are well documented in the literature, therefore it is unnecessary to give a detailed structural elucidation of lanosol (110) and its derivatives 114 and 120 isolated during this study. Full NMR data for these compounds can be found in Appendix B.

The butenone derivative 121 was reported in 2004 along with several other bromophenols. ${ }^{118}$ A detailed analysis of the NMR data obtained in this study led to the reassignment of several ${ }^{13} \mathrm{C}$ resonances. Specifically, the assignment of the ${ }^{13} \mathrm{C}$ resonances for $\mathrm{C}-6$ and C-8 were interchanged, as were that of C-4 and C-5. The revised NMR data is presented in both $\mathrm{CD}_{3} \mathrm{OD}$ (Table 4.2) and $\left(\mathrm{CD}_{3}\right)_{2} \mathrm{CO}$ (Table 4.3). 
<smiles>CC(=O)/C=C/c1cc(O)c(O)c(Br)c1Br</smiles>

121

Table 4.2. ${ }^{13} \mathrm{C}(150 \mathrm{MHz})$ and ${ }^{1} \mathrm{H}(600 \mathrm{MHz}) \mathrm{NMR}$ data $\left(\mathrm{CD}_{3} \mathrm{OD}\right)$ for (3E)-4-(2,3-dibromo-4,5-dihydroxyphenyl)-3-butene-2-one (121).

\begin{tabular}{|c|c|c|c|c|c|c|c|c|}
\hline \multirow[b]{2}{*}{ Pos } & \multicolumn{3}{|c|}{${ }^{13} \mathrm{C}$} & \multicolumn{3}{|c|}{${ }^{1} \mathrm{H}$} & \multirow[b]{2}{*}{ COSY } & \multirow{2}{*}{$\begin{array}{c}\text { HMBC } \\
\left({ }^{1} \mathrm{H} \text { to }{ }^{13} \mathrm{C}\right.\end{array}$} \\
\hline & $\delta(\mathrm{ppm})$ & mult & ${ }^{1} J_{\mathrm{CH}}(\mathrm{Hz})$ & $\overline{\delta(\mathrm{ppm})}$ & mult & $J(\mathrm{~Hz})$ & & \\
\hline 1 & 127.6 & $\mathrm{C}$ & & & & & & \\
\hline 2 & 119.6 & $\mathrm{C}$ & & & & & & \\
\hline 3 & 114.8 & C & & & & & & \\
\hline 4 & 149.0 & C & & & & & & \\
\hline 5 & 146.6 & $\mathrm{C}$ & & & & & & \\
\hline 6 & 113.0 & $\mathrm{CH}$ & 161 & 7.18 & $\mathrm{~s}$ & & & $2,3,4,5,7$ \\
\hline 7 & 145.1 & $\mathrm{CH}$ & 158 & 7.95 & d & 16.1 & 8 & $2,5 * 6,8,9$ \\
\hline 8 & 128.1 & $\mathrm{CH}$ & 159 & 6.52 & d & 16.1 & 7 & $1,7,9,10$ \\
\hline 9 & 200.8 & C & & & & & & \\
\hline 10 & 27.3 & $\mathrm{CH}_{3}$ & 127 & 2.37 & $\mathrm{~s}$ & & & $7,8,9$ \\
\hline
\end{tabular}

Table 4.3. ${ }^{13} \mathrm{C}(150 \mathrm{MHz})$ and ${ }^{1} \mathrm{H}(600 \mathrm{MHz}) \mathrm{NMR}$ data $\left(\left(\mathrm{CD}_{3}\right)_{2} \mathrm{CO}\right)$ for (3E)-4-(2,3-dibromo-4,5-dihydroxyphenyl)-3-butene-2-one (121).

\begin{tabular}{|c|c|c|c|c|c|c|c|c|}
\hline \multirow[b]{2}{*}{ Pos } & \multicolumn{3}{|c|}{${ }^{13} \mathrm{C}$} & \multicolumn{3}{|c|}{${ }^{1} \mathrm{H}$} & \multirow[b]{2}{*}{ COSY } & \multirow{2}{*}{$\begin{array}{c}\text { HMBC } \\
\left({ }^{1} \mathrm{H} \text { to }{ }^{13} \mathrm{C}\right)\end{array}$} \\
\hline & $\delta(\mathrm{ppm})$ & mult & ${ }^{1} J_{\mathrm{CH}}(\mathrm{Hz})$ & $\overline{\delta(\mathrm{ppm})}$ & mult & $J(\mathrm{~Hz})$ & & \\
\hline 1 & 127.9 & $\mathrm{C}$ & & & & & & \\
\hline 2 & 118.9 & $\mathrm{C}$ & & & & & & \\
\hline 3 & 114.3 & $\mathrm{C}$ & & & & & & \\
\hline 4 & 147.9 & $\mathrm{C}$ & & & & & & \\
\hline 5 & 146.0 & $\mathrm{C}$ & & & & & & \\
\hline 6 & 113.3 & $\mathrm{CH}$ & 159 & 7.33 & $\mathrm{~s}$ & & & $2,3,4,5,7$ \\
\hline 7 & 142.7 & $\mathrm{CH}$ & 159 & 7.86 & d & 16.1 & 8 & $1,2,5,6,8,9$ \\
\hline 8 & 128.8 & $\mathrm{CH}$ & 159 & 6.54 & d & 16.1 & 7 & $1,2,7,9,10$ \\
\hline 9 & 197.6 & $\mathrm{C}$ & & & & & & \\
\hline 10 & 27.7 & $\mathrm{CH}_{3}$ & 126 & 2.33 & s & & & $7,8,9$ \\
\hline
\end{tabular}

Rhodomelol (122) was reported along with its methyl ester, methylrhodomelol (123), in 1985. ${ }^{119}$ The only NMR assignments of $\mathbf{1 2 2}$ and $\mathbf{1 2 3}$ were reported on semi-synthetic derivatives. As a result, the NMR data reported for rhodomelol was incomplete and therefore a detailed analysis of the NMR spectra obtained in this study was performed. The full NMR assignment of $\mathbf{1 2 2}$ is presented in $\mathrm{CD}_{3} \mathrm{OD}$ (Table 4.4) and $\left(\mathrm{CD}_{3}\right)_{2} \mathrm{CO}$ (Table 4.5). The position of the diastereotopic proton resonances of $\mathrm{CH}_{2}-10$ were assigned based on both their chemical shift and the ${ }^{3} J_{\mathrm{HH}}$ coupling constants observed with H-11. The chemical shift of H-10a is expected to be slightly higher upfield than H-10b due to the shielding effect of the hydroxyl group on C-11. In addition, the dihedral angle of the vicinal protons $\mathrm{H}-10 \mathrm{a}$ and $\mathrm{H}-11$ is closer to $90^{\circ}$ than that of $\mathrm{H}-10 \mathrm{~b}$ and $\mathrm{H}-11$, therefore a smaller coupling constant is expected. 


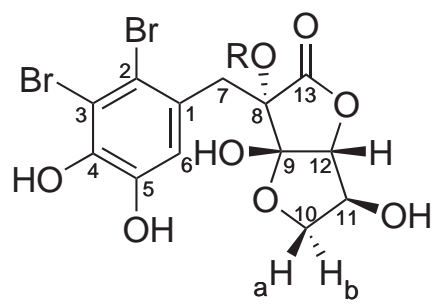

$122 \mathrm{R}=\mathrm{H}$

$123 \mathrm{R}=\mathrm{Me}$

Table 4.4. ${ }^{13} \mathrm{C}(150 \mathrm{MHz})$ and ${ }^{1} \mathrm{H}(600 \mathrm{MHz}) \mathrm{NMR}$ data $\left(\mathrm{CD}_{3} \mathrm{OD}\right)$ for rhodomelol (122).

\begin{tabular}{|c|c|c|c|c|c|c|c|c|c|}
\hline \multirow[b]{2}{*}{ Pos } & \multicolumn{3}{|c|}{${ }^{13} \mathrm{C}$} & \multicolumn{3}{|c|}{${ }^{1} \mathrm{H}$} & \multirow{2}{*}{\multicolumn{2}{|c|}{$\begin{array}{c}\text { HMBC } \\
\left({ }^{1} \mathrm{H} \text { to }{ }^{13} \mathrm{C}\right)\end{array}$}} & \multirow[b]{2}{*}{ NOE } \\
\hline & $\delta(\mathrm{ppm})$ & mult & ${ }^{1} J_{\mathrm{CH}}(\mathrm{Hz})$ & $\overline{\delta(\mathrm{ppm})}$ & mult & $J(\mathrm{~Hz})$ & & & \\
\hline 1 & 128.2 & $\mathrm{C}$ & & & & & & & \\
\hline 2 & 117.9 & $\mathrm{C}$ & & & & & & & \\
\hline 3 & 113.6 & $\mathrm{C}$ & & & & & & & \\
\hline 4 & 144.9 & $\mathrm{C}$ & & & & & & & \\
\hline 5 & 145.7 & $\mathrm{C}$ & & & & & & & \\
\hline 6 & 119.2 & $\mathrm{CH}$ & 165 & 7.03 & $\mathrm{~s}$ & & & $2,3,4,5,8$ & $7 a, 7 b, 12$ \\
\hline $7 \mathrm{a}$ & & & 128 & 3.37 & d & 14.9 & $7 b$ & $4,2,5,6,8,9,13$ & $6,7 b, 12$ \\
\hline $7 \mathrm{~b}$ & 41.7 & $\mathrm{CH}_{2}$ & 133 & 3.11 & d & 14.7 & $7 \mathrm{a}$ & $4,2,5,6,8,9,13$ & $6,7 \mathrm{a}$ \\
\hline 8 & 79.4 & $\mathrm{C}$ & & & & & & & \\
\hline 9 & 109.0 & C & & & & & & & \\
\hline $10 \mathrm{a}$ & & & 151 & 4.09 & dd & $9.7,3.1$ & $10 b, 11$ & $9,11,12$ & $10 b, 11$ \\
\hline $10 \mathrm{~b}$ & 76.6 & $\mathrm{CH}_{2}$ & 151 & 4.24 & $\mathrm{dd}$ & $9.8,5.9$ & $10 \mathrm{a}, 11$ & 9,12 & $10 \mathrm{a}, 11$ \\
\hline 11 & 75.5 & $\mathrm{CH}$ & 166 & 4.41 & $\mathrm{dd}$ & $5.6,3.4$ & $10 a, 10 b$ & $9,10,12$ & $10 \mathrm{a}, 10 \mathrm{~b}, 12$ \\
\hline 12 & 88.2 & $\mathrm{CH}$ & 154 & 4.59 & $\mathrm{~s}$ & & & $9,10,11,13$ & $6,7 \mathrm{a}, 11$ \\
\hline 13 & 176.5 & $\mathrm{C}$ & & & & & & & \\
\hline
\end{tabular}

Table 4.5. ${ }^{13} \mathrm{C}(150 \mathrm{MHz})$ and ${ }^{1} \mathrm{H}(600 \mathrm{MHz}) \mathrm{NMR}$ data $\left(\left(\mathrm{CD}_{3}\right)_{2} \mathrm{CO}\right)$ for rhodomelol (122).

\begin{tabular}{|c|c|c|c|c|c|c|c|c|}
\hline \multirow[b]{2}{*}{ Pos } & \multicolumn{3}{|c|}{${ }^{13} \mathrm{C}$} & \multicolumn{3}{|c|}{${ }^{1} \mathrm{H}$} & \multirow[b]{2}{*}{ COSY } & \multirow{2}{*}{$\begin{array}{c}\text { HMBC } \\
\left({ }^{1} \mathrm{H} \text { to }{ }^{13} \mathrm{C}\right)\end{array}$} \\
\hline & $\delta(\mathrm{ppm})$ & mult & ${ }^{1} J_{\mathrm{CH}}(\mathrm{Hz})$ & $\overline{\delta(\mathrm{ppm})}$ & mult & $J(\mathrm{~Hz})$ & & \\
\hline 1 & 128.4 & $\mathrm{C}$ & & & & & & \\
\hline 2 & 117.8 & $\mathrm{C}$ & & & & & & \\
\hline 3 & 112.8 & $\mathrm{C}$ & & & & & & \\
\hline 4 & 144.3 & $\mathrm{C}$ & & & & & & \\
\hline 5 & 144.7 & $\mathrm{C}$ & & & & & & \\
\hline 6 & 119.1 & $\mathrm{CH}$ & 164 & 7.12 & $\mathrm{~s}$ & & & $1,2,3,4,5,7$ \\
\hline $7 \mathrm{a}$ & & & 127 & 3.39 & d & 14.8 & $7 \mathrm{~b}$ & $1,2,5,6,8,9,13$ \\
\hline $7 \mathrm{~b}$ & 41.1 & $\mathrm{CH}_{2}$ & 132 & 3.18 & d & 15.0 & $7 \mathrm{a}$ & $1,2,6,8,9,13$ \\
\hline 8 & 78.7 & $\mathrm{C}$ & & & & & & \\
\hline 9 & 108.6 & $\mathrm{C}$ & & & & & & \\
\hline $10 \mathrm{a}$ & & & 150 & 4.18 & $\mathrm{dd}$ & $9.8,5.6$ & $10 \mathrm{~b}, 11$ & 9,12 \\
\hline $10 \mathrm{~b}$ & 76.3 & $\mathrm{CH}_{2}$ & 150 & 4.09 & $\mathrm{dd}$ & $9.7,3.1$ & $10 \mathrm{a}, 11$ & $9,11,12$ \\
\hline 11 & 75.2 & $\mathrm{CH}$ & 154 & 4.45 & $\mathrm{dd}$ & $5.5,3.2$ & $10 \mathrm{a}, 10 \mathrm{~b}$ & $9,10,12$ \\
\hline 12 & 87.1 & $\mathrm{CH}$ & 165 & 4.65 & $\mathrm{~s}$ & & & $9,10,11,13$ \\
\hline 13 & 174.2 & $\mathrm{C}$ & & & & & & \\
\hline
\end{tabular}

\section{A New Bromophenol}

A more detailed review of the bromophenols was performed and the known structures compared to the NMR data obtained from the semi-purified fractions with a particular emphasis on analysing fragments of molecules in the semi-purified fractions. The aim of this technique was to look for fragments that did not appear to be present in compounds reported in the literature. The HMBC experiment in particular is a very useful tool, as it 
allows the identification of non-protonated carbons. By examining features such as methyl splitting patterns in the ${ }^{1} \mathrm{H}$ NMR spectrum, and the positioning of diagnostic functional groups such as ketones through HMBC correlations, structural fragments were identified.

This analysis lead to the identification in the semi-purified fractions of the known bromophenol compounds described previously. But, more interestingly, it also highlighted the presence of a compound that appeared to display different spectral characteristics to all previously reported bromophenols. Specifically, an isolated diastereotopic methylene pair was found to connect with several carbon environments that did not appear in any of the known compounds. Figure 4.3 shows the ${ }^{1} \mathrm{H}$, COSY, HSQC and HMBC NMR spectra of the fraction. Of particular interest were the HMBC correlations from the methylene pair (red) to the deshielded methylene pair (green) and the strongly deshielded methine (blue). Further purification by HPLC $\left(\mathrm{C}_{18}\right)$ lead to the isolation of a novel bromophenol, colensolide A (124).

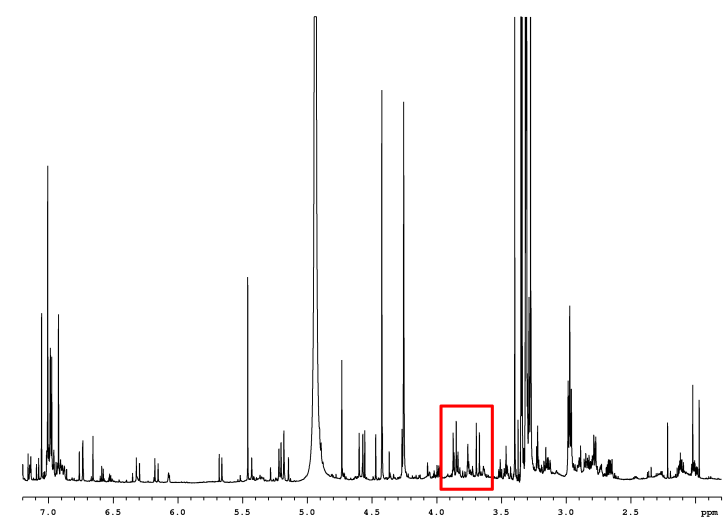

(a) ${ }^{1} \mathrm{H}$ NMR spectrum

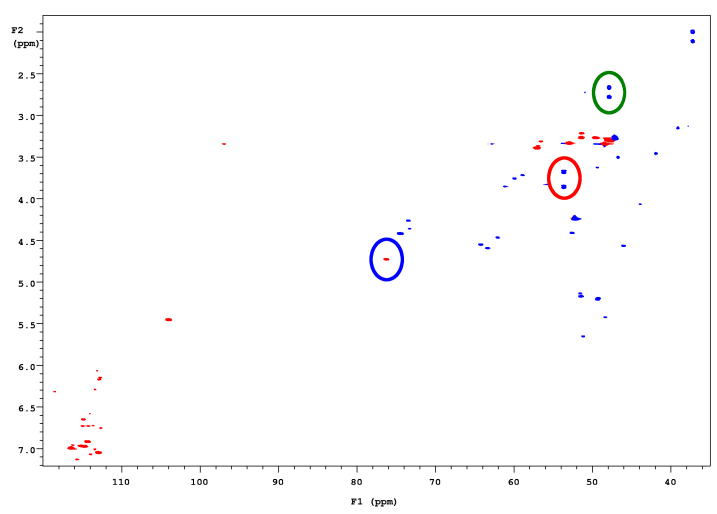

(c) HSQC spectrum

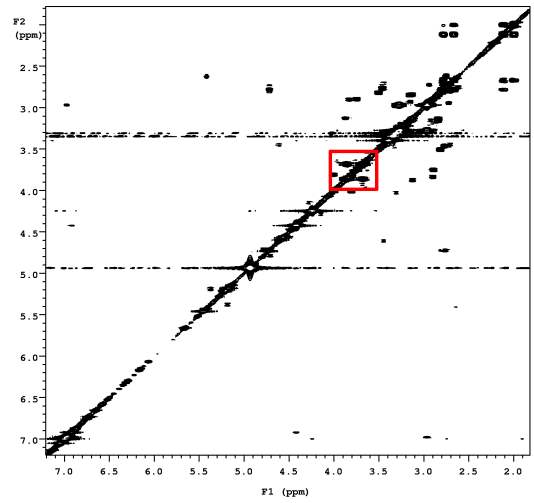

(b) COSY spectrum

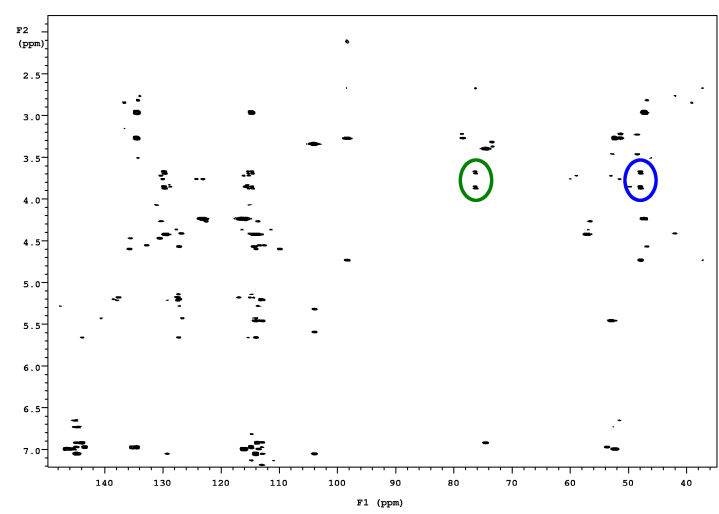

(d) HMBC spectrum

Figure 4.3. NMR spectra of a semi-purified fraction of $O$. colensoi showing correlations of interest. 


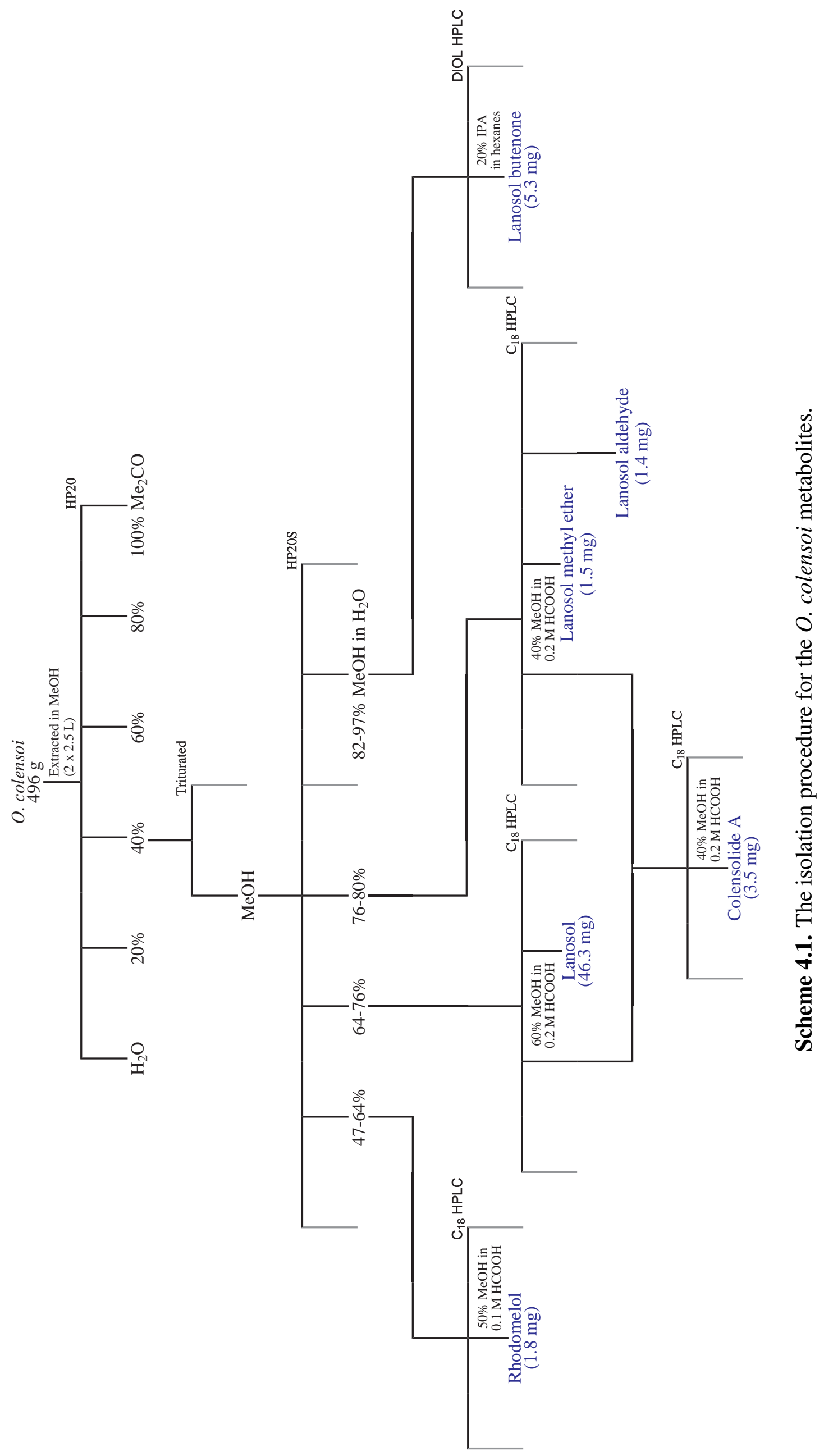




\subsection{Colensolide A}

Colensolide A (124) was isolated as a colourless oil (3.5 $\mathrm{mg}$ in total). The observation of characteristic pseudomolecular ion clusters $\left([\mathrm{M}+\mathrm{H}]^{+}:[\mathrm{M}+2+\mathrm{H}]^{+}:[\mathrm{M}+4+\mathrm{H}]^{+}\right.$; $1: 2: 1)$ by HRESIMS indicated a molecular formula of $\mathrm{C}_{13} \mathrm{H}_{15} \mathrm{~N}_{3} \mathrm{O}_{4} \mathrm{Br}_{2}$ (417.9386 $\left[\mathrm{M}-\mathrm{H}_{2} \mathrm{O}+\mathrm{H}\right]^{+}, \Delta 2.6 \mathrm{ppm}$ and $\left.435.9496[\mathrm{M}+\mathrm{H}]^{+}, \Delta 1.5 \mathrm{ppm}\right)$, requiring seven double-bond equivalents. The ${ }^{13} \mathrm{C}$ NMR spectrum contained 13 distinct resonances while the multiplicity-edited $\mathrm{HSQC}$ spectrum in $\mathrm{CD}_{3} \mathrm{OD}$, as well as establishing direct ${ }^{1} \mathrm{H}$ to ${ }^{13} \mathrm{C}$ connectivity, accounted for 11 of the 15 protons indicating the likely presence of four exchangeable protons. This was partially confirmed by the observation of 13 of the 15 protons when the ${ }^{1} \mathrm{H}$ spectrum was recorded in $d_{6}$-DMSO. Identifiable features in the $\mathrm{CD}_{3} \mathrm{OD}$ NMR spectra included one carbonyl resonance $\left(\delta_{\mathrm{C}} 163.9\right)$, two strongly deshielded aromatic resonances $\left[\left(\delta_{\mathrm{C}} 145.2\right)\right.$ and $\left.\left(\delta_{\mathrm{C}} 146.4\right)\right]$, four aromatic resonances $\left[\left(\delta_{\mathrm{C}} 114.4\right),\left(\delta_{\mathrm{C}} 116.2\right),\left(\delta_{\mathrm{C}} 116.4, \delta_{\mathrm{H}} 6.98\right)\right.$ and $\left.\left(\delta_{\mathrm{C}} 130.9\right)\right]$, a strongly deshielded methine $\left(\delta_{\mathrm{C}} 77.7, \delta_{\mathrm{H}} 4.74\right)$, two slightly deshielded methylenes $\left[\left(\delta_{\mathrm{C}} 55.1, \delta_{\mathrm{H}} 3.86\right.\right.$ and 3.68$)$ and $\left(\delta_{\mathrm{C}} 49.0, \delta_{\mathrm{H}} 2.79\right.$ and 2.67)], an aliphatic methylene $\left(\delta_{\mathrm{C}} 38.6, \delta_{\mathrm{H}} 2.12\right.$ and 2.00$)$ and an oxymethyl group $\left(\delta_{\mathrm{C}} 51.0, \delta_{\mathrm{H}} 3.28\right)$.

\section{Construction of the Bromophenol Substructure}

Analysis of the HMBC spectrum of $\mathbf{1 2 4}$ led to the construction of the 2,3-dibromo4,5-dihydroxybenzyl substructure. HMBC correlations from the aromatic methine (C-6: $\left.\delta_{\mathrm{C}} 116.4, \delta_{\mathrm{H}} 6.98\right)$ to five aromatic non-protonated carbons $\left(\mathrm{C}-1: \delta_{\mathrm{C}} 130.9, \mathrm{C}-2: \delta_{\mathrm{C}} 116.2\right.$, C-3: $\delta_{\mathrm{C}} 114.4, \mathrm{C}-4: \delta_{\mathrm{C}} 146.4$ and C-5: $\left.\delta_{\mathrm{C}} 145.2\right)$ established a penta-substituted benzene moiety. The strongly deshielded nature of C-4 and C-5 is consistent with oxygen attachment at both these carbons. This is supported by the relatively shielded nature of the carbon resonances of positions C-2, C-3 and C-6. Strong HMBC correlations from both proton resonances of a deshielded methylene $\left(\mathrm{C}-7: \delta_{\mathrm{C}} 55.1, \delta_{\mathrm{H}} 3.86\right.$ and 3.68) to the aromatic non-protonated carbons C-1 and C-2 and the aromatic methine C-6 indicated the attachment of this methylene to C-1. Weak allylic COSY correlations between H-6 and both proton resonances of $\mathrm{CH}_{2}-7$ supported this attachment. This assignment partially 
accounts for the deshielded nature of $\mathrm{C}-7$ although the observed ${ }^{1} \mathrm{H}$ and ${ }^{13} \mathrm{C}$ shifts could not be entirely explained on this basis. Weak, long-range HMBC correlations from H-7a to C-3 and C-5 established the order of the carbon chain around the aromatic ring, indicating C-4 to be para to the methylene attachment.

Crosspeak intensities in HMBC experiments depend in part on the magnitude of the longrange coupling. ${ }^{120}$ In aromatic systems, two- and four-bond couplings $\left({ }^{2} J_{\mathrm{CH}}\right.$ and ${ }^{4} J_{\mathrm{CH}}$ respectively) tend to be small, while three-bond couplings $\left({ }^{3} J_{\mathrm{CH}}\right)$ are large. ${ }^{121}$ However, hydroxy substitution at the carbon involved increases the magnitude of the ${ }^{2} J_{\mathrm{CH}}$ value. ${ }^{67}$ This precedent supports the order of the carbon resonances around the aromatic ring. HMBC correlations from H-6 to C-1 and C-3 were weak (two- and four-bond coupling, respectively), while strong correlations were observed to C-2 and C-4 (both three-bond couplings), and to C-5, a large two-bond coupling due to hydroxyl substitution. The relatively shielded chemical shifts of the remaining non-protonated aromatic carbon resonances $\left(\mathrm{C}-2: \delta_{\mathrm{C}} 114.4\right.$ and $\left.\mathrm{C}-3: \delta_{\mathrm{C}} 116.2\right)$ suggested bromine attachment at these two positions (Figure 4.4).
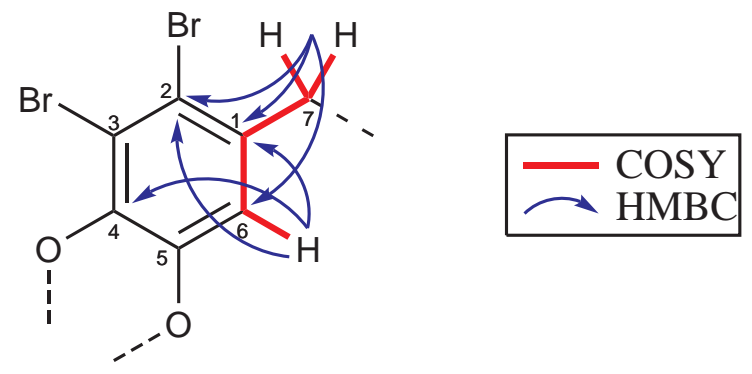

Figure 4.4. Selected COSY and HMBC correlations establishing bromophenol substructure of colensolide A (124).

Finally, the ${ }^{13} \mathrm{C}$ chemical shifts of the benzene ring compared favourably with the known compounds containing this 2,3-dibromo-4,5-dihydroxybenzyl moiety isolated in this study (see Table 4.6).

\section{Construction of the Bicyclic Substructure}

COSY correlations from a slightly deshielded methylene (C-14: $\delta_{\mathrm{C}} 38.6, \delta_{\mathrm{H}} 2.12$ and $2.00)$ to a more strongly deshielded methylene $\left(\mathrm{C}-15: \delta_{\mathrm{C}} 49.0, \delta_{\mathrm{H}} 2.79\right.$ and 2.67) indicated 
Table 4.6. A comparison of ${ }^{13} \mathrm{C}$ chemical shifts of positions $1-6$ in colensolide $\mathrm{A}$ (124), lanosol (110), lanosol methyl ether (114) and rhodomelol (122).

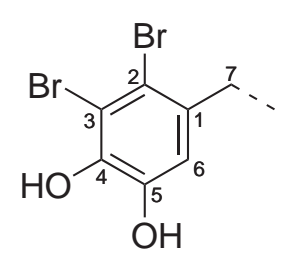

\begin{tabular}{cccccc}
\hline & & \multicolumn{4}{c}{${ }^{13} \mathrm{C}[\delta(\mathrm{ppm})]$} \\
\cline { 3 - 6 } Pos & mult & $\mathbf{1 2 4}$ & $\mathbf{1 1 0}$ & $\mathbf{1 1 4}$ & $\mathbf{1 2 2}$ \\
\hline 1 & $\mathrm{C}$ & 131.2 & 134.1 & 131.0 & 128.2 \\
2 & $\mathrm{C}$ & 116.2 & 114.1 & 115.3 & 117.9 \\
3 & $\mathrm{C}$ & 114.4 & 114.2 & 114.5 & 113.6 \\
4 & $\mathrm{C}$ & 146.5 & 146.2 & 145.3 & 144.9 \\
5 & $\mathrm{C}$ & 145.2 & 144.6 & 146.3 & 145.7 \\
6 & $\mathrm{CH}$ & 116.4 & 114.8 & 115.8 & 119.2 \\
\hline
\end{tabular}

the connection between these two centres in an isolated spin system. The high ${ }^{1} J_{\mathrm{CH}}$ values H-15a: $143 \mathrm{~Hz}, \mathrm{H}-15 \mathrm{~b}: 133 \mathrm{~Hz}$ and deshielded chemical shift of C-15 was indicative of nitrogen attachment. This was confirmed by the observation of a downfield shift of the carbon and proton resonances and significant increase in the ${ }^{1} J_{\mathrm{CH}}$ values $\mathrm{H}-15 \mathrm{a}: 151 \mathrm{~Hz}$, H-15b: $148 \mathrm{~Hz}$ when colensolide A (124) was exposed to TFA in an NMR tube to form acidified colensolide A (125). NMR data for $\mathbf{1 2 5}$ are presented in Table 4.10.

The deshielded nature of the carbon and proton resonances of the C-7 methylene and the relatively large ${ }^{1} J_{\mathrm{CH}}$ values of $\mathrm{H}-7 \mathrm{a}$ and $\mathrm{H}-7 \mathrm{~b}$ (136 and $135 \mathrm{~Hz}$, respectively) again were indicative of nitrogen attachment at this position. Once more, the NMR spectrum of the acidified derivative $\mathbf{1 2 5}$ showed a downfield shift of the carbon and proton resonances and significant increase in the ${ }^{1} J_{\mathrm{CH}}$ values $\left(\mathrm{H}_{2}-7: 147 \mathrm{~Hz}\right)$, supporting this assignment. HMBC correlations from H-15a to a nitrogen (N-8: $\left.\delta_{\mathrm{N}}-319.3\right)$, from H-15b to C-7, and from both proton resonances of $\mathrm{CH}_{2}-7$ to $\mathrm{C}-15$ indicated that $\mathrm{C}-7$ and $\mathrm{C}-15$ were connected through the same nitrogen. Selective excitation of the methylene protons $\mathrm{H}-7 \mathrm{a}$ and $\mathrm{H}-7 \mathrm{~b}$ showed NOE enhancements to $\mathrm{H}-15 \mathrm{a}$ and $\mathrm{H}-15 \mathrm{~b}$, confirming this connectivity (Figure 4.5).
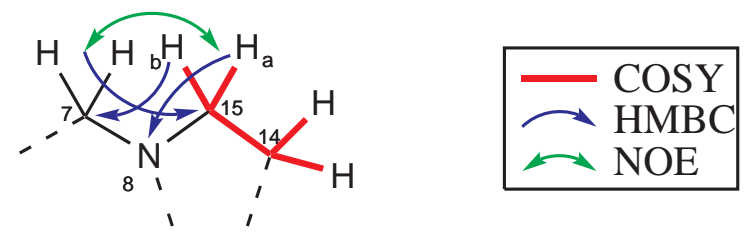

Figure 4.5. Selected COSY and HMBC correlations and NOE enhancements establishing part of the bicyclic substructure of colensolide A (124).

HMBC correlations from both proton resonances of $\mathrm{CH}_{2}-7$ to a strongly deshielded methine $\left(\mathrm{C}-9: \delta_{\mathrm{C}} 77.7, \delta_{\mathrm{H}} 4.74\right)$ completed the substitution around the tertiary amine. This was confirmed by a significant increase in the ${ }^{1} J_{\mathrm{CH}}$ value for C-9 in the NMR 
spectrum of the acidified derivative (164 Hz in 124 increased to $175 \mathrm{~Hz}$ in 125), and HMBC correlations from $\mathrm{H}-9$ to $\mathrm{C}-7, \mathrm{~N}-8$ and C-15. The strongly deshielded nature of C-9 along with the very large ${ }^{1} J_{\mathrm{CH}}$ value indicated connectivity to another heteroatom. An HMBC correlation from $\mathrm{H}-9$ to a second nitrogen $\left(\mathrm{N}-10: \delta_{\mathrm{N}}-291.1\right)$, along with a COSY correlation between H-9 and H-10 when the spectrum was recorded in $d_{6^{-}}$ DMSO, supported this aminal assignment (Figure 4.6). Table 4.7 shows the chemical shift differences observed around the tertiary amine when colensolide A (124) was acidified to 125.
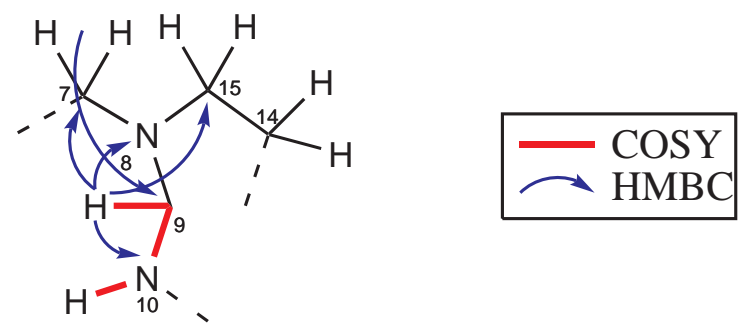

Figure 4.6. Selected COSY and HMBC correlations establishing more of the bicyclic substructure of colensolide A (124).

Table 4.7. Chemical shift differences of colensolide A (124) and acidified colensolide A (125).

\begin{tabular}{|c|c|c|c|c|c|c|c|c|c|c|}
\hline \multirow[b]{2}{*}{ Pos } & \multirow[b]{2}{*}{ mult } & \multicolumn{3}{|c|}{ Colensolide A (124) } & \multicolumn{3}{|c|}{ Acidified colensolide A (125) } & \multicolumn{3}{|c|}{ Difference } \\
\hline & & $\begin{array}{c}\delta_{\mathrm{H}} \\
\delta(\mathrm{ppm}) \\
\end{array}$ & $\begin{array}{l}\delta_{\mathrm{C}} \text { or } \delta_{\mathrm{N}} \\
\delta(\mathrm{ppm})\end{array}$ & ${ }^{1} J_{\mathrm{CH}}(\mathrm{Hz})$ & $\begin{array}{c}\delta_{\mathrm{H}} \\
\delta(\mathrm{ppm})\end{array}$ & $\begin{array}{c}\delta_{\mathrm{C}} \text { or } \delta_{\mathrm{N}} \\
\delta(\mathrm{ppm})\end{array}$ & ${ }^{1} J_{\mathrm{CH}}(\mathrm{Hz})$ & $\begin{array}{c}\delta_{\mathrm{H}} \\
\delta \Delta(\mathrm{ppm})\end{array}$ & $\begin{array}{c}\delta_{\mathrm{C}} \text { or } \delta_{\mathrm{N}} \\
\delta \Delta(\mathrm{ppm})\end{array}$ & $\Delta^{1} J_{\mathrm{CH}}(\mathrm{Hz})$ \\
\hline $\begin{array}{l}7 \mathrm{a} \\
7 \mathrm{~b}\end{array}$ & $\mathrm{CH}_{2}$ & $\begin{array}{l}3.86 \\
3.68\end{array}$ & 55.1 & $\begin{array}{l}136 \\
135\end{array}$ & 4.50 & 56.7 & 146 & $\begin{array}{l}0.64 \\
0.82\end{array}$ & 1.6 & $\begin{array}{l}10 \\
11\end{array}$ \\
\hline 8 & $\mathrm{~N}$ or $\mathrm{NH}^{+}$ & & -319.3 & & & -298.9 & & & 20.4 & \\
\hline 9 & $\mathrm{CH}$ & 4.74 & 77.7 & 164 & 5.39 & 81.4 & 175 & 0.65 & 3.7 & 11 \\
\hline $\begin{array}{l}15 \mathrm{a} \\
15 \mathrm{~b}\end{array}$ & $\mathrm{CH}_{2}$ & $\begin{array}{l}2.79 \\
2.67\end{array}$ & 49.0 & $\begin{array}{l}143 \\
133\end{array}$ & $\begin{array}{l}3.48 \\
3.40\end{array}$ & 50.9 & $\begin{array}{l}151 \\
148\end{array}$ & $\begin{array}{l}0.69 \\
0.73\end{array}$ & 1.9 & $\begin{array}{c}9 \\
15\end{array}$ \\
\hline
\end{tabular}

Further HMBC correlations from $\mathrm{H}-9$ to a shielded carbonyl (C-11: $\left.\delta_{\mathrm{C}} 163.9\right)$ suggested an amide moiety. HMBC correlations from both proton resonances of $\mathrm{CH}_{2}-15$ to a strongly deshielded non-protonated carbon $\left(\mathrm{C}-13: \delta_{\mathrm{C}} 99.7\right)$ positioned this carbon next to the $\mathrm{C}-14$ methylene. An HMBC correlation from the oxymethyl (C-16: $\delta_{\mathrm{C}} 51.0$, $\left.\delta_{\mathrm{H}} 3.28\right)$ to $\mathrm{C}-13$ and $\mathrm{HMBC}$ correlations from both proton resonances of $\mathrm{CH}_{2}-14$ to a third nitrogen $\left(\mathrm{N}-12: \delta_{\mathrm{N}}-280.5\right)$ accounted for the strongly deshielded nature of C-13, as a hemi-aminal ether. 
The ${ }^{15} \mathrm{~N}$ HSQC spectra recorded in $d_{6}$-DMSO showed that both $\mathrm{N}-10$ and N-12 were secondary amides $\left[\left(\mathrm{N}-10: \delta_{\mathrm{N}}-290.6, \delta_{\mathrm{H}} 7.12\right)\right.$ and $\left.\left(\mathrm{N}-12: \delta_{\mathrm{N}}-279.6, \delta_{\mathrm{H}} 7.32\right)\right]$. HMBC correlations were observed from $\mathrm{H}-10$ to $\mathrm{C}-9$ and C-11 and from $\mathrm{H}-12$ to $\mathrm{C}-11$ and $\mathrm{C}-13$, suggested a urea moiety connecting $\mathrm{N}-10$ and $\mathrm{N}-12$ through the C-11 carbonyl. This assignment was supported by the observed chemical shifts of both $\mathrm{N}-10$ and $\mathrm{N}-12$ being consistent with amides, which generally occur in the range -210 to $-300 \mathrm{ppm}$; urea occurs at -302.8 ppm. ${ }^{122}$ Finally, an HMBC correlation between H-9 and C-13 completed the connectivity of these two centres and created the bicyclic substructure containing an imidazolone moiety (Figure 4.7).

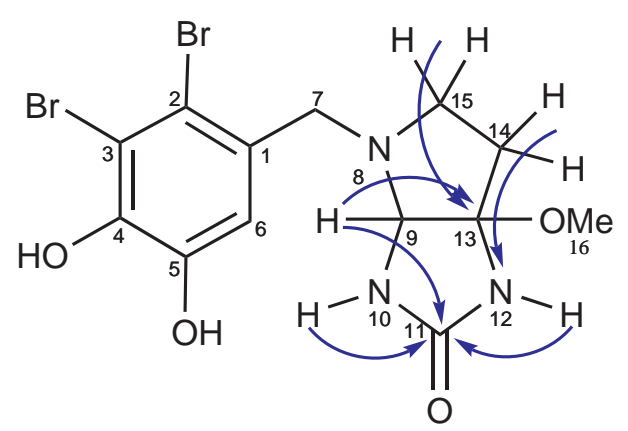

Figure 4.7. Selected HMBC correlations establishing the bicyclic substructure of colensolide A (124).

All detected carbon and nitrogen resonances were now accounted for. The observed chemical shift of $\mathrm{N}-8\left(\delta_{\mathrm{N}}-319.3\right)$ is consistent with an alkylamine which generally occurs in the range of -310 to $-380 \mathrm{ppm},{ }^{122}$ while the acidified counterpart $\left(\delta_{\mathrm{H}}-298.9\right)$ is consistent with an ammonium ion $(-290$ to -360$) .{ }^{123}$ The presence of the benzene ring and the bicyclic system accounted for six double-bond equivalents and the seventh was accounted for by the presence of the carbonyl carbon of the imidazolone moiety. The final two protons from the molecular formula unaccounted for were satisfied by assigning positions C-4 and C-5 as hydroxyls, assigning the ring as an orthohydroquinone.

The relative configuration of colensolide A (124) was assigned on the basis of NOE enhancements observed in a series of 1D-NOESY experiments. Selective excitation of the methine proton $\mathrm{H}-9$ showed NOE enhancements to $\mathrm{H}-14 \mathrm{a}, \mathrm{H}-15 \mathrm{a}$ and $\mathrm{H}_{3}-16$. Selective excitation of H-14a showed NOE enhancements to its geminal partner H-14b, H-9, H-15a and $\mathrm{H}_{3}-16$, while selective excitation of $\mathrm{H}-14 \mathrm{~b}$ showed NOE enhancements to its geminal partner H-14a and H-15b. This series of NOE enhancements determined the cis-fused 
bicyclic ring system with $\mathrm{H}-9, \mathrm{H}_{3}-16, \mathrm{H}-14 \mathrm{a}$ and $\mathrm{H}-15 \mathrm{a}$ on the same face of the five membered ring (Figure 4.8).

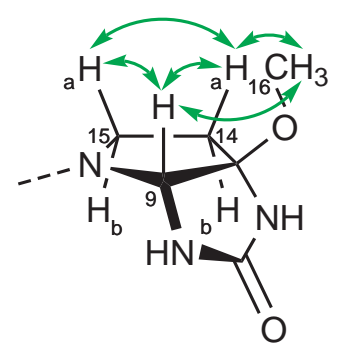

Figure 4.8. Selected NOE enhancements used to determine the relative configuration of colensolide A (124).

Selective excitation of the methyl protons $\mathrm{H}_{3}-16$ showed expected NOE enhancements to $\mathrm{H}-9$ and $\mathrm{H}-14 \mathrm{a}$, and interestingly, weakly to $\mathrm{H}-14 \mathrm{~b}$. This is not unreasonable due to the free rotation of the $\mathrm{C}-13-\mathrm{OMe}$ bond and the relative angles of the two methylene protons in the five membered ring. Optical rotation measurements were negligible $\left([\alpha]_{\mathrm{D}}^{25}-2\right.$ to $-6(c 0.35, \mathrm{MeOH}))$, which may imply a racemic mixture of the two enantiomers. The final structure of colensolide $A$ is therefore shown in 124. NMR data for $\mathbf{1 2 4}$ is presented in both $\mathrm{CD}_{3} \mathrm{OD}$ (Table 4.8) and $d_{6}$-DMSO (Table 4.9).

\subsection{Synthetic Derivatives of Colensolide A}

\section{Methylation of Colensolide A (124)}

The exchangeable hydroquinone protons of $\mathbf{1 2 4}$ were not observed when the ${ }^{1} \mathrm{H}$ NMR spectrum was acquired in $d_{6}$-DMSO so synthetic derivatives were prepared to confirm the proposed structure. Colensolide A (124) was subjected to $\mathrm{TMSCHN}_{2}$ for $45 \mathrm{~min}$. The NMR spectra of the product of the reaction were similar to those of $\mathbf{1 2 4}$ with the additional presence of a second oxymethyl signal $\left(\mathrm{C}-17: \delta_{\mathrm{C}} 60.7, \delta_{\mathrm{H}} 3.80\right)$ and the upfield shift of C-1, C-3, C-4, C-5 and C-6 $\left(\delta_{\mathrm{C}} 136.9, \delta_{\mathrm{C}} 122.3, \delta_{\mathrm{C}} 151.6, \delta_{\mathrm{C}} 146.7\right.$ and $\delta_{\mathrm{C}} 118.3$ respectively), all consistent with the formation of a methyl ether on an aromatic ring. An HMBC correlation from $\mathrm{H}_{3}-17$ to $\mathrm{C}-5$ confirmed methylation of the C-5 hydroxyl to form 5-0-methylcolensolide A (126). The unexpected mono-methylation was attributed to 


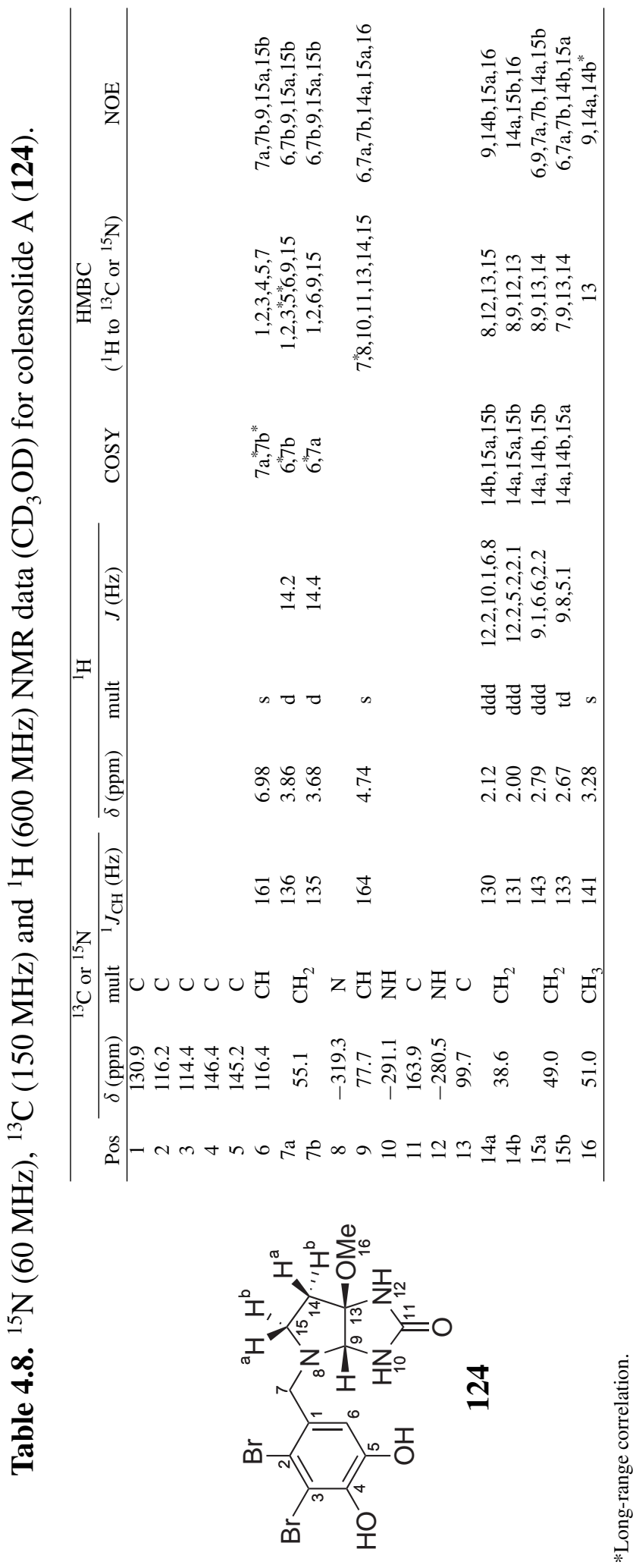




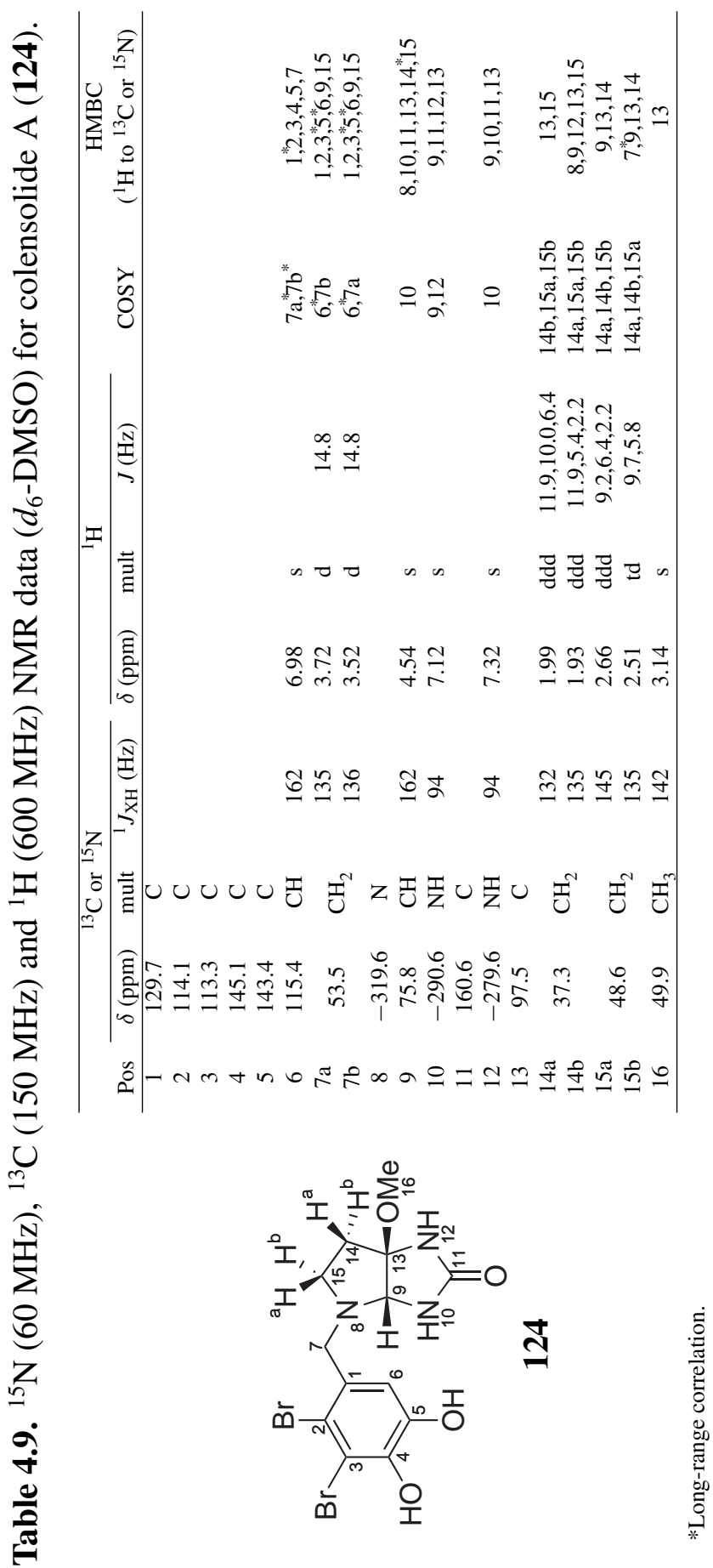




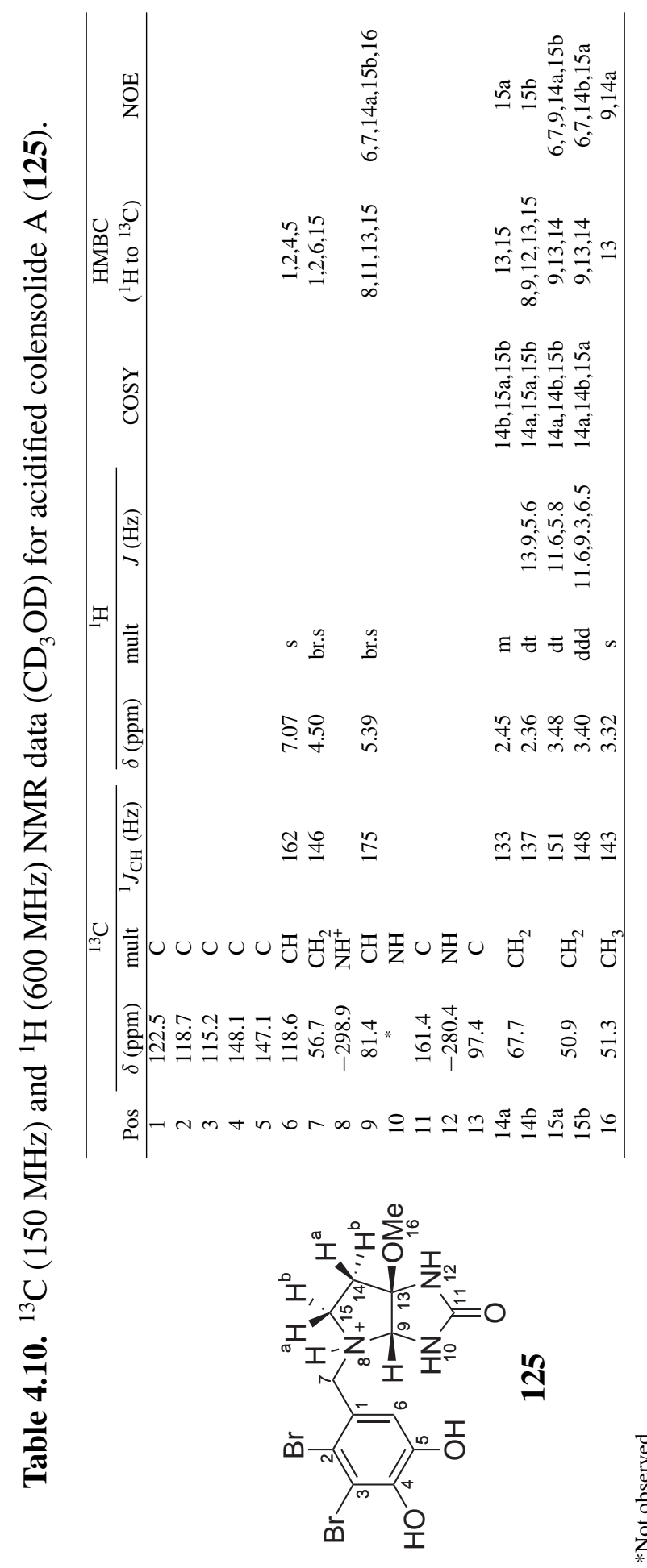


steric hindrance. It is proposed that the TMS group on the reactive diazomethane group was blocked from the C-4 hydroxyl by the the adjacent bromine atom and previously methylated C-5 phenol. NMR data for $\mathbf{1 2 6}$ are presented in Table 4.11.

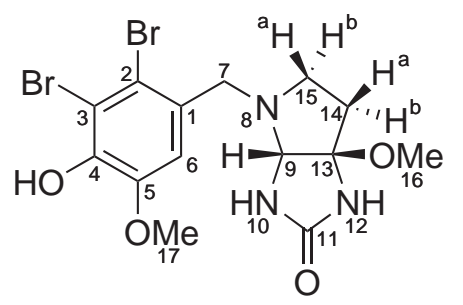

126

\section{Methylation of 5-O-Methylcolensolide A (126)}

Following the failure to exhaustively methylate the hydroxy groups of colensolide A, further methylation was attempted. 5-O-Methylcolensolide A (126) was exposed to MeI for several hours. The NMR spectra of the product of the reaction were similar to those of 126 with the additional presence of a third oxymethyl signal $\left(\mathrm{C}-18: \delta_{\mathrm{C}} 56.7, \delta_{\mathrm{H}} 3.88\right)$ and the further upfield shift of C-4 $\left(\delta_{\mathrm{C}} 154.0\right)$ consistent with the formation of a methyl ether. An $\mathrm{HMBC}$ correlation from $\mathrm{H}_{3}-18$ to $\mathrm{C}-4$ confirmed methylation of the $\mathrm{C}-4$ hydroxyl to form 4,5-di- $O$-methylcolensolide A (127). NMR data for $\mathbf{1 2 7}$ are presented in Table 4.12.

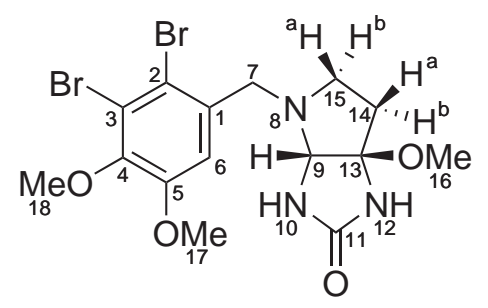

127 


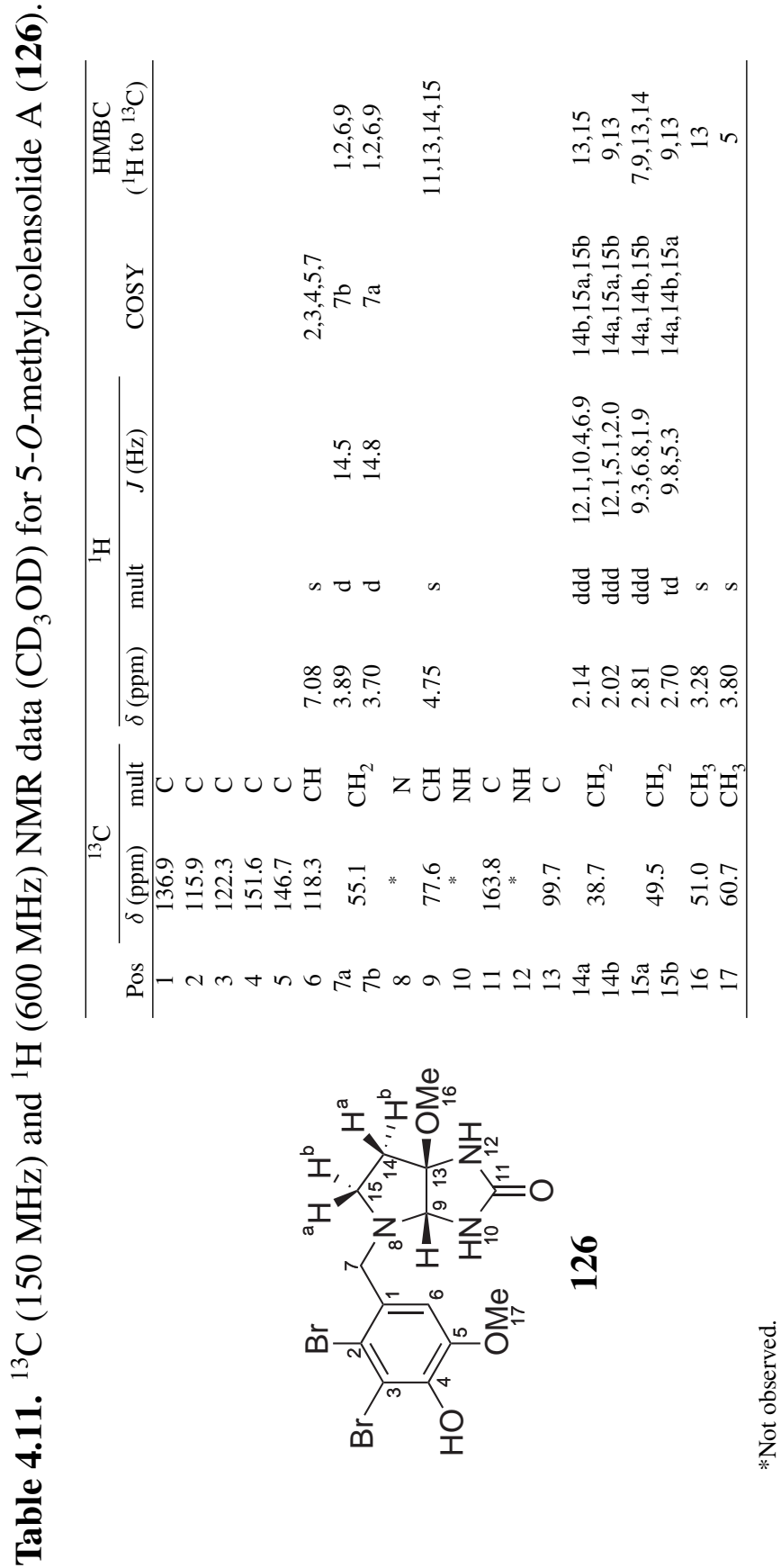



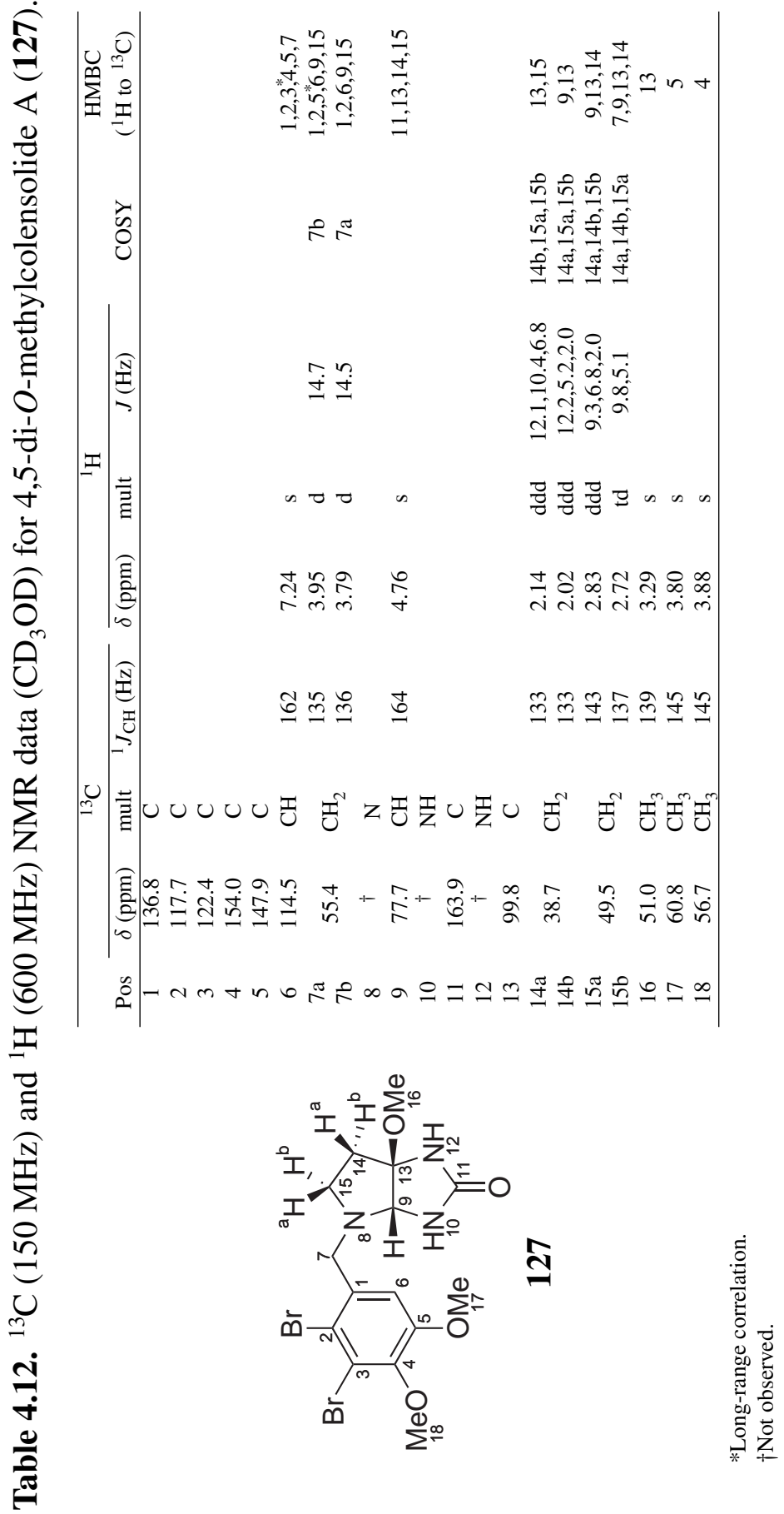


\subsection{Biological Activity}

Colensolide A (124), 4,5-di- $O$-methylcolensolide A (127), lanosol (110), lanosol methyl ether (114), lanosol aldehyde (120), lanosol butenone (121) and rhodomelol (122) were evaluated for cytotoxicity against the human leukaemia cell line HL-60 and for antibacterial activity against the $\mathrm{MC}^{2} 155$ strain of Mycobacterium smegmatis at the School of Biological Sciences, VUW. Lanosol butenone (121) was the only metabolite tested to show activity against HL-60 ${ }^{76}$ while lanosol methyl ether (114), lanosol butenone (121) and rhodomelol (122) all exhibited antibacterial activity (see Table 4.13). ${ }^{77}$

Table 4.13. Biological activity of colensolide A (124), 4,5-di- $O$-methylcolensolide A (127), lanosol (110), lanosol methyl ether (114), lanosol aldehyde (120), lanosol butenone (121) and rhodomelol (122).

\begin{tabular}{ccc}
\hline \multirow{2}{*}{ Compound } & \multicolumn{2}{c}{$\mathrm{IC}_{50}(\mu \mathrm{M})$} \\
\cline { 2 - 3 } & HL-60* & M. smegmatis $\mathrm{MC}^{2} 155^{\dagger}$ \\
\hline $\mathbf{1 2 4}$ & Inactive & Inactive \\
$\mathbf{1 2 7}$ & Inactive & Inactive \\
$\mathbf{1 1 0}$ & Inactive & Inactive \\
$\mathbf{1 1 4}$ & Inactive & 7.8 \\
$\mathbf{1 2 0}$ & Inactive & Inactive \\
$\mathbf{1 2 1}$ & 8.0 & 26.1 \\
$\mathbf{1 2 2}$ & Inactive & 28.1 \\
\hline
\end{tabular}

*Tested up to $10 \mu \mathrm{M}$.

$\dagger$ Tested up to $100 \mu \mathrm{M}$. 


\subsection{Bromophenols}

In the 1970s, the scientific community generally considered the some 200 natural organohalogen compounds reported to date to be isolation artifacts or abnormalities in nature. Over thirty years later and with numbers now exceeding 3800, opinions have changed. ${ }^{124}$ The single largest source of biogenic organohalogens are marine organisms, ${ }^{124}$ which synthesise a wide range of compounds, from simple haloalkanes to complex phenols, terpenes, pyrroles and indoles. ${ }^{114-117,124}$ In many cases, these halogenated marine metabolites possess biological activities of pharmacological interest, including antifungal, antibacterial, antiviral, and anti-inflammatory activities. ${ }^{95}$

The marine environment is a rich source of various important anions, including sulfate, chloride, bromide and iodide, in concentrations of 885, 19000,65 and $0.06 \mathrm{mg} \mathrm{L}^{-1}$ respectively. ${ }^{125}$ Despite the obvious excess of chloride over bromide, marine plants and animals make use of the facile oxidation of bromide to bromine (or hypobromite) and biobromination processes to produce an impressive array of organobromine metabolites. The main enzymes responsible for the incorporation of halogen atoms in organic compounds in nature are haloperoxidases, which catalyse the formation of halogenated organic compounds at the expense of hydrogen peroxide. The bromoperoxidase enzymes responsible for bromide oxidation have been isolated from nearly 100 species of terrestrial and marine organisms, and chloroperoxidase and other peroxidases also have the ability to oxidise bromide. ${ }^{126}$ Rhodophyta in particular have been known to be a rich source of bromine for many years, and by the 1920s many algae were known to concentrate it. ${ }^{127}$ This fact was exploited during World War II when bromine was extracted on an industrial scale from Rhodomela larix for use in chemical warfare agents. ${ }^{125}$

Examples of such brominated compounds are the simple phenols that have been isolated from taxonomically diverse seaweeds such as the brown algae Fucus vesiculosus ${ }^{128}$ and Leathesia nana, ${ }^{129-131}$ and the red algae Lenormandia prolifera, ${ }^{132}$ Odonthalia corymbifera, ${ }^{133}$ Polysiphonia lanosa, ${ }^{134}$ and Rhodomela larix. ${ }^{135}$ Bromophenols are widespread in the marine environment, which has been attributed to the phenol moiety's propensity to undergo electrophilic bromination. ${ }^{126}$ 
Lanosol (110) is the most abundant and widely distributed of the bromophenols. ${ }^{136}$ Found in low levels in fungi, $\mathbf{1 1 0}$ is more common in the Rhodomelaceae (Rhodophyta), particularly in the genera Polysiphonia, Rhodomela and Osmundaria. ${ }^{113,125}$ Weinstein et al. suggested that lanosol and some of its derivatives are artifacts of the extraction procedure, where the solvents $\mathrm{H}_{2} \mathrm{O}, \mathrm{MeOH}$ and $\mathrm{EtOH}$ produce lanosol, and the methyl (114) and ethyl ether (119) forms respectively. ${ }^{133}$ The potassium disulfate salt of lanosol (115) is thought to be the natural component in the seaweed. ${ }^{133,134}$ It was proposed that lanosol accumulates in nature as the moderately labile disulfate ester and thus may be readily converted to the toxic, free lanosol. ${ }^{134}$ Antialgal activity experiments using lanosol disulfate showed no influence of growth rate or the cell density of test organisms compared to the highly toxic lanosol. ${ }^{134}$ Etherification or esterification of phenolic hydroxyl groups is a common biological method of detoxification and it was proposed that this would explain the inactivity of lanosol disulfate in the antialgal tests. ${ }^{134}$ Similarly, the sulfate groups may have the role of stabilising the hydroxyl groups, as proposed for phenols and nitriles. ${ }^{125}$

There is significant variation in the bromination and hydroxylation of natural bromophenols. This review will focus on those bromophenols containing the 2,3-dibromo-4,5dihydroxybenzyl moiety, of which there are 49 reported to date. The first reported bromophenol was dipotassium 2,3-dibromobenzyl alcohol 4,5-disulfate (128) which was isolated from the red alga Polysiphonia lanosa in 1966. ${ }^{137}$ Lanosol (110) was reported in the same paper as an acid hydrolysis product of 128. In 1972 this disulfate was re-isolated from an extract of a French collection of $P$. lanosa, although the positioning of the sulfate groups was revised to the 4,7-disulfate (115). ${ }^{138}$ Three further isolations of $\mathbf{1 1 5}$ from three different red algae genera have been reported. ${ }^{112,133,139}$ The author could not find an original paper reporting the first isolation of lanosol (110), though a 1953 paper reported antibacterial activity from U.S.A. sources of Rhodomela larix in which a bromophenolic compound was reported to be the likely source. ${ }^{140}$ Lanosol has since been reported from a further 11 species of red algae (eight genera), ${ }^{11,134,136,139,141-146}$ and two brown algae. ${ }^{128,129,131}$ A variety of activities have been reported, including antialgal, ${ }^{134}$ antifeedant, ${ }^{139} \alpha$-glucosidase inhibition, ${ }^{143}$ cytotoxicity ${ }^{145}$ and isocitrate lyase (ICL) inhibitory. ${ }^{146}$ In 1967, two lanosol derivative 
(114 and 120) were reported from R. larix. ${ }^{135}$ Compound 114 has since been reported from a further 12 species of red algae (seven genera), ${ }^{112,133,136,139,142,144-149}$ and two brown algae. ${ }^{128,129,131}$ Various activities have been reported including potent growth stimulatory activity, ${ }^{148}$ potent feeding deterrent activity, ${ }^{139}$ cytotoxicity ${ }^{145}$ and ICL inhibitory activity. ${ }^{146}$ Compound $\mathbf{1 2 0}$ has since been reported from a further five species of red algae (four genera), ${ }^{136,142,144,145}$ and a brown alga. ${ }^{129,131}$ A third lanosol derivative (129) was isolated from P. lanosa in $1972 .{ }^{150}$ The structure was confirmed in 1974, following the isolation from another red alga. ${ }^{151}$ The cytotoxic activity of 129 was reported in 2004. ${ }^{145}$ In 1977, two diphenols (116 and 130) were reported from the Japanese red alga Rhodomela larix. ${ }^{142}$ Compound $\mathbf{1 1 6}$ has since been reported from a further four species of red algae (three genera), ${ }^{112,129,131,139,144,152}$ and a brown alga, ${ }^{129,131}$ while $\mathbf{1 3 0}$ has been reported from a further three species of red algae (two genera), ${ }^{139,144,146,147,152}$ and one brown alga. ${ }^{129,131}$ Both 116 and $\mathbf{1 3 0}$ have been reported to have antifeedant and cytotoxic activity. ${ }^{129,139,152}$ The diphenol ether 131, a cytotoxic, antifeedant and $\alpha$-glucosidase inhibiting compound, was reported from the Japanese red alga $R$. larix in 1980 and has since been reported from two other species of red algae (two genera), ${ }^{143,144,152}$ and a brown alga. ${ }^{129,131}$ In 1985, rhodomelol (122) and methylrhodomelol (123) were reported from Polysiphonia lanosa. ${ }^{119}$ Rhodomelol was reported to have anti-HIV-1 integrase activity in a 1997 study. ${ }^{153}$ Vidalol A (107) and B (108) were reported in 1991 from the Caribbean red alga Vidalia obtusaloba, and were found to have anti-inflammatory activity. ${ }^{110}$ In 1997 the antifeedant diphenol 132 was reported from the Japanese red alga Odonthalia corymbifera. ${ }^{139}$<smiles>[R6]Cc1cc(O[R6])c([2H])c(Br)c1Br</smiles>

$110 \mathrm{R}_{1}=\mathrm{H}$

$114 \mathrm{R}_{1}=\mathrm{H}$

$\mathrm{R}_{2}=\mathrm{H}$

$\mathrm{R}_{2}=\mathrm{H}$

$115 \mathrm{R}_{1}=\mathrm{SO}_{3} \mathrm{~K} \quad \mathrm{R}_{2}=\mathrm{H}$

$119 \mathrm{R}_{1}=\mathrm{H}$

$128 \mathrm{R}_{1}=\mathrm{SO}_{3} \mathrm{~K}$

$129 \mathrm{R}_{1}=\mathrm{H}$
$\mathrm{R}_{2}=\mathrm{H}$

$\mathrm{R}_{2}=\mathrm{SO}_{3} \mathrm{~K}$

$\mathrm{R}_{2}=\mathrm{H}$<smiles>O=Cc1cc(O)c(O)c(Br)c1Br</smiles>

120 


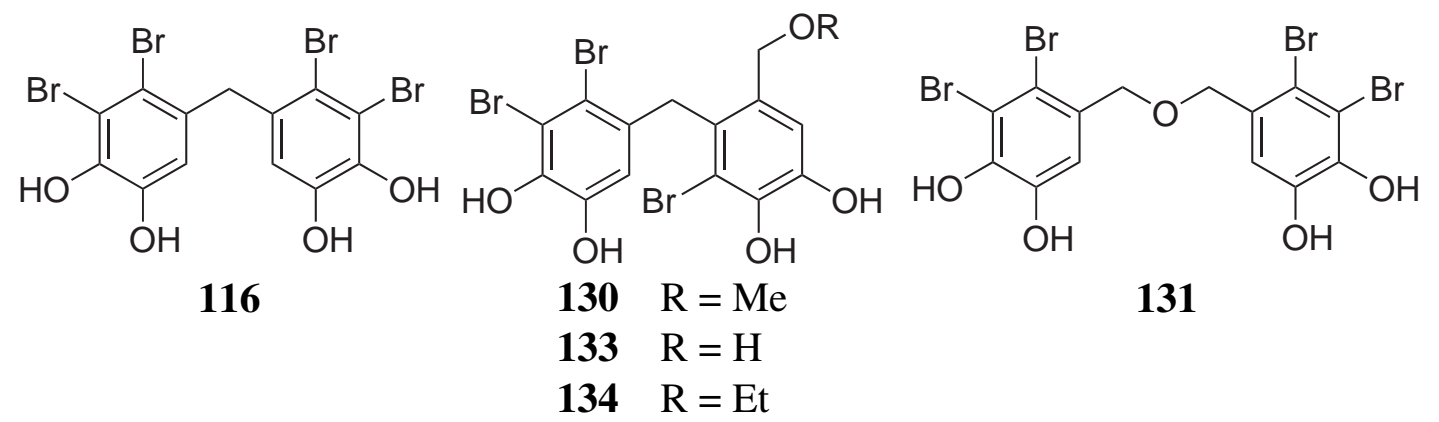<smiles>[R]C1(Cc2cc(O)c(O)c(Br)c2Br)C(=O)O[C@H]2[C@@H](O)CO[C@@]21O</smiles>

$122 \mathrm{R}=\mathrm{H}$

$123 \mathrm{R}=\mathrm{Me}$<smiles>Oc1cc(Cc2c(O)c(Br)c(Br)c(Cc3cc(O)c(O)c(Br)c3Br)c2O)c(Br)c(Br)c1O</smiles><smiles>Oc1cc(Cc2c(O)cc(O)c(Br)c2O)c(Br)c(Br)c1O</smiles>

107<smiles>COCc1cc(O)c(O)c(Cc2cc(O)c(O)c(Br)c2Br)c1Br</smiles>

132

A resurgence of bromophenol isolation started in 2003. A study of the Chinese red alga Rhodomela confervoides resulted in five new compounds (133-137). ${ }^{144,152,154,155}$ Surprisingly, several of these metabolites were reported as novel compounds in as many as three different papers by the same authors. ${ }^{144,152,154,155}$ Bromophenols 133 and 134 are both reported to have antibacterial activity. ${ }^{152}$ Compound $\mathbf{1 3 3}$ has since been reported from the red alga Odonthalia corymbifera, and is reported to have ICL inhibitory activity, ${ }^{146}$ while $\mathbf{1 3 4}$ has also been isolated from a brown alga and was found to have cytotoxic activity. ${ }^{129,131}$ In 2004, the same group reported six more bromophenols from the same extract of $R$. confervoides $(\mathbf{1 2 1}, \mathbf{1 3 8}-\mathbf{1 4 2}),{ }^{118}$ and also reported the isolation of eight bromophenols from the Chinese brown alga Leathesia nana (143-150). ${ }^{129-131}$ Compound 145 was reported to have cytotoxic activity. Again, three of the compounds were reported in as many as three separate papers. ${ }^{129-131}$ In 2005, this Chinese group reported the isolation of the first nitrogen-containing compounds in this class of bromophenols, once again from the $R$. confervoides extract, including three pyrodeoxyguanosine acid derivatives (151-153) and one deoxyguanosine derivative (154). ${ }^{156}$ All were found to be inactive against several human cancer cell lines at $10 \mu \mathrm{g} / \mathrm{mL} .{ }^{156}$ Further nitrogen-containing compounds, this time $\gamma$-ureidobutyrate 
derivatives (155-158), were reported from the $R$. confervoides extract in 2006, along with the simple bromophenol 159 and bromophenol sulfates 160 and 161. ${ }^{157}$ Compounds 159161 were found to be cytotoxic against several human cancer cell lines, whilst 155-158 were found to be inactive. ${ }^{157}$ The most recent paper from this Chinese group in 2007 reported the isolation of three nucleoside base bromophenol derivatives (162-164) from the $R$. confervoides extract. ${ }^{158}$ Finally, two sulfated bromophenols (112 and 113) were reported in 2006 from the Brazilian red alga Osmundaria obtusiloba. ${ }^{112}$<smiles>Oc1cc(Cc2cc(O)c(O)c(Br)c2Cc2cc(O)c(O)c(Br)c2Br)c(Br)c(Br)c1O</smiles>

135<smiles>CC(=O)/C=C/c1cc(O)c(O)c(Br)c1Br</smiles>

121<smiles>[R]C(C)Cc1cc(O)c(O)c(Br)c1Br</smiles>

$$
\begin{array}{ll}
136 & \mathrm{R}=\mathrm{CHO} \\
137 & \mathrm{R}=\mathrm{CH}(\mathrm{OMe})_{2} \\
150 & \mathrm{R}=\mathrm{CH}_{2} \mathrm{OH}
\end{array}
$$<smiles>CS(=O)Cc1cc(O)c(O)c(Br)c1Br</smiles>

138<smiles>[R]c1cc(C(Cc2cc(O)c(O)c(Br)c2Br)C(=O)OCC)cc([R])c1[R]</smiles>

$139 \mathrm{R}_{1}=\mathrm{H} \quad \mathrm{R}_{2}=\mathrm{Br} \quad \mathrm{R}_{3}=\mathrm{OMe} \quad \mathrm{R}_{4}=\mathrm{OH}$

$140 \quad \mathrm{R}_{1}=\mathrm{Me} \quad \mathrm{R}_{2}=\mathrm{Br} \quad \mathrm{R}_{3}=\mathrm{OMe} \quad \mathrm{R}_{4}=\mathrm{OH}$

$141 \quad \mathrm{R}_{1}=\mathrm{H} \quad \mathrm{R}_{2}=\mathrm{H} \quad \mathrm{R}_{3}=\mathrm{H} \quad \mathrm{R}_{4}=\mathrm{H}$<smiles>COc1c(O)cc(C(C(=O)O)c2cc(O)c(O)c(Br)c2Br)cc1Br</smiles>

142<smiles>COCc1c(Br)c(Br)c(O)c(O)c1Cc1cc(O)c(O)c(Br)c1Br</smiles>
145<smiles>CCOCc1cc(Oc2c(COCC)cc(O)c(O)c2Br)c(O)c(Br)c1Br</smiles>

143<smiles>COC1c2c(O)c(O)c(Br)c(Br)c2C(OC)c2c(O)c(O)c(Br)c(Br)c21</smiles>

146<smiles>COc1c(O)cc(CO)c(Cc2cc(O)c(O)c(Br)c2Br)c1O</smiles>

144<smiles>Oc1cc(C2OCc3cc(O)c(O)c(Br)c32)c(Br)c(Br)c1O</smiles> 
<smiles>CO[C@]12Oc3cc(CO)c(Br)c(Br)c3O[C@]1(O)CC(CO)=CC2=O</smiles>

148<smiles>C/C(C=O)=C\c1cc(O)c(O)c(Br)c1Br</smiles>

149<smiles>O=C(O)C1CCC(=O)N1Cc1cc(O)c(O)c(Br)c1Br</smiles>

$151 \mathrm{R}=\mathrm{Me}$

$152 \mathrm{R}=\mathrm{H}$<smiles>COC(=O)C1CCC(=O)N1Cc1cc(O)c(O)c(Br)c1Cc1cc(O)c(O)c(Br)c1Br</smiles><smiles>OCC1OC(n2cnc3cnc(NCc4cc(O)c(O)c(Br)c4Br)nc32)[C@H](O)[C@@H]1O</smiles>

154<smiles>COC(=O)CCCNC(=O)NCc1cc(O)c(O)c(Br)c1Br</smiles>

155<smiles>COC(=O)CCCNC(=O)NCc1cc(O)c(O)c(Br)c1Cc1cc(O)c(O)c(Br)c1Br</smiles>

157<smiles>COC(=O)CCCN(Cc1cc(O)c(O)c(Br)c1Br)C(=O)NCc1cc(O)c(O)c(Br)c1Br</smiles>

156<smiles>COC(=O)CCCNC(=O)N(Cc1cc(O)c(O)c(Br)c1Br)Cc1cc(O)c(O)c(Br)c1Cc1cc(O)c(O)c(Br)c1Br</smiles>

158<smiles>O=S(=O)(O)CCc1cc(O)c(O)c(Br)c1Cc1cc(O)c(O)c(Br)c1Br</smiles> 
<smiles>O=c1[nH]c(=O)c2c(ncn2Cc2cc(O)c(O)c(Br)c2Cc2cc(O)c(O)c(Br)c2Br)[nH]1</smiles>

162<smiles>Nc1ncnc2c1ncn2Cc1cc(O)c(O)c(Br)c1Cc1cc(O)c(O)c(Br)c1Br</smiles>

164<smiles>O=c1[nH]c(=O)c2c(ncn2Cc2cc(O)c(O)c(Br)c2Br)[nH]c1=O</smiles>

163<smiles>[R]OS(=O)(=O)OCc1cc(O)c(OS(=O)(=O)Oc2cc(CO[R5]([R])([O-])O[Na])c(Br)c(Br)c2O)c(O)c1Br</smiles>

112<smiles>[X]OS(=O)(=O)OCc1cc(OS(=O)(=O)OCc2cc(O)c(COS(=O)(=O)O[Na])c(Br)c2Br)c(Br)c(Br)c1O</smiles>

113

\subsection{Biogenesis of Colensolide A}

The presence of nitrogen-containing sidechains in bromophenols is not unprecedented, though it is only a recent discovery. Ten such compounds have been reported to date, all from an extract of the red alga Rhodomela confervoides as detailed in Section 4.6. ${ }^{156-158}$ Attempts to mimic these compounds semi-synthetically by known alkylation methods were unsuccessful, leading to the hypothesis that there is an unprecedented enzymatic catalysed nitrogen alkyation process in the biosynthesis of these metabolites. ${ }^{158}$

The nitrogen-containing moiety of colensolide A (124) may have its origins from oxygenated histidine. A study reported in 2006 on sensitiser-mediated photo-oxidation of histidine (165) proposes a reaction scheme for the formation of the bicyclic sidechain via oxidation by singlet oxygen (molecular oxygen in its ${ }^{1} \Delta_{\mathrm{g}}$ state; ${ }^{1} \mathrm{O}_{2}$ ). ${ }^{159}$ It is suggested that these reactions occur via the formation of short-lived peroxide species that decay 
to give complex mixtures of products. The study reported that these compounds are believed to arise via internal nucleophilic cyclisation of the amine function onto the oxidised imidazole ring formed from the decomposition of the initial peroxide species (see Scheme 4.2). Previous studies have demonstrated that both free histidine residues and those in proteins, are major targets for oxidation by ${ }^{1} \mathrm{O}_{2}$. The sequence of reactions is similar to those proposed to account for the formation of cyclised products during the ${ }^{1} \mathrm{O}_{2}$-mediated oxidation of tyrosine and tryptophan, where a similar internal cyclisation of the free amine group onto the oxygenated ring system has also been characterised. ${ }^{160}$<smiles>CC#CC(=O)C(N)Cc1c[nH]cn1</smiles>

165<smiles>NC(CC1=NC2NC1OO2)C(=O)O</smiles>

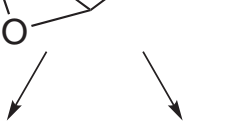<smiles>NC(CC1=NC=NC1O)C(=O)O</smiles><smiles></smiles><smiles></smiles><smiles>NC(CC1(O)C=NC=N1)C(=O)O</smiles>

Elimination of $\mathrm{H}_{2} \mathrm{O}$ Hydration of imine<smiles>NC(CC1=NC(=O)NC1O)C(=O)O</smiles>

Scheme 4.2. Simplified reaction scheme for formation of histidine photo-product as proposed by Agon et al. ${ }^{159}$

NMR analysis of crude reaction mixtures of free histidine photo-oxidation products illuminated for $20 \mathrm{~min}$ in phosphate-buffered $\mathrm{D}_{2} \mathrm{O}$ showed production of the two cisfused isomers of the bicyclic ring. ${ }^{159}$ Decarboxylation of the bicyclic product observed by Agon et al. would give the desired bicyclic moiety observed in colensolide A (124). The inclusion of the bromophenol ring could occur before or after the histidine oxidation. 


\subsection{Summary}

A novel technique was used to identify potentially novel compounds in semi-purified mixtures using 1D and 2D NMR spectroscopy. This strategy is useful if a series of known compounds are present in an extract as it helps identify leads in an organism that would otherwise likely be discarded. In this case, analysis of semi-purified mixtures led to the identification of a class of known bromophenols. By considering these known structures and analysing the ${ }^{1} \mathrm{H}$, COSY, HSQC and HMBC NMR spectra of the mixtures, it was possible to highlight and guide isolation of the novel nitrogenous bromophenol compound colensolide A (124).

Colensolide A was a minor constituent of the algal extract, and therefore any bioassay guided isolation would have been misled by the mild activity of the known major metabolites. This method is clearly useful in the search for novel compounds, especially in the presence of biologically active, well known, major constituents. 


\section{Chapter 5}

\section{Conclusion}

The challenge for natural product chemists is to find new and novel secondary metabolites through informed selection of a suitable organism and use of a robust system to guide isolation and purification. Over the course of this study, a recently neglected phylum, Rhodophyta, was re-examined using the unique NMR based screening and isolation technique employed by the VUW Marine Natural Products group. It was found that the spectroscopic comparison is very much phylum specific, suggesting that the power of the method is enhanced by restricting the analysis to related organisms. This is an important point to note if the technique is to be applied to other natural systems. An interesting extension of this work would be to examine a second seaweed phylum, such as the brown algae (Phaeophyta), to compare any chemical similarities between the primary metabolites of two phyla. Several efforts are underway to improve the spectroscopic screening technique utilised in this study, including the potential use of HMBC NMR spectroscopy and the possibility of employing a more sophisticated comparison method such as principal component analysis instead of simple averaging.

Several challenges were faced during the structural elucidation of the new compounds isolated during this study, which required the use of advanced NMR techniques. The use of HSQC-TOCSY experiments and ${ }^{3} J_{\mathrm{HH}}$ coupling constants were essential with respect to the labillaride compounds, while the ${ }^{1} \mathrm{H}$ to ${ }^{15} \mathrm{~N}$ HMBC experiment and ${ }^{1} J_{\mathrm{CH}}$ values were crucial in the elucidation of colensolide A (124).

Organisms can sometimes be found to contain a well-known class of compounds not previously reported from the specific genus or species being examined. In such cases, the challenge for the natural product chemist is to detect potentially new and novel compounds in mixtures containing a plethora of structurally similar, known metabolites. In this study, a novel technique was used to identify potentially novel compounds in semipurified mixtures using NMR spectroscopy. The HMBC experiment was found to be particularly suited to such analysis through identification of diagnostic functional groups 
and structural fragments.

There has recently been a change in attitude with regard to natural product chemistry, with Nature as a source for potential pharmaceuticals coming back into favour in the form of libraries of purified metabolites as opposed to the crude extracts previously assembled for single assay analysis. The use of narrowly focused bioassay guided isolation is not particularly appropriate in the quest to create such libraries, and new methods of isolation such as the unbiased spectroscopic based technique are required to produce new compounds of structural diversity. However, caution must be taken, even when using such spectroscopic techniques, in order to ensure that the metabolite in question is in fact responsible for any subsequent activity detected from such a library. The false activity observed for the seemingly pure sample of labillaride E (64) illustrates the potential of this problem. As libraries of metabolites are assembled, no matter what the method guiding isolation, the problem remains that the novel activity may be associated with an impurity. One possible solution may be to test the fractions around that of the natural product to act as a control, however this would become impractical with the larger libraries.

Throughout the course of this study it was found that having a range of structurally related compounds can be incredibly beneficial. The initial bioassay results for labillaride $\mathrm{E}(\mathbf{6 4})$ could easily have been accepted as an effect of the significant change in structure with respect to the other labillarides, were it not for the isolation of three other exceptionally similar structures with seemingly massive differences in biological activity. The sole isolation of the tainted sample of $\mathbf{6 4}$ would likely have led to a detailed synthesis only to find that the activity was in fact not associated with $\mathbf{6 4}$, as was found with phakellistatin 11 (101), ${ }^{100,101}$ a less than ideal method to confirm biological activity. 


\section{Chapter 6}

\section{Experimental}

\subsection{General Experimental}

NMR spectra were recorded using a Varian Unity Inova $300\left(300 \mathrm{MHz}\right.$ for ${ }^{1} \mathrm{H}$ and $75 \mathrm{MHz}$ for $\left.{ }^{13} \mathrm{C}\right)$, Inova $500\left(500 \mathrm{MHz}\right.$ for ${ }^{1} \mathrm{H}$ and $125 \mathrm{MHz}$ for $\left.{ }^{13} \mathrm{C}\right)$, or DirectDrive $600(600 \mathrm{MHz}$ for ${ }^{1} \mathrm{H}, 150 \mathrm{MHz}$ for ${ }^{13} \mathrm{C}$ and $60 \mathrm{MHz}$ for ${ }^{15} \mathrm{~N}$ ) spectrometers. Spectra recorded using the Varian DirectDrive 600 were collected with a Varian inverse-detected triple resonance $\mathrm{HCN}$ cold probe operating at $25 \mathrm{~K}$. Both the 300 and $500 \mathrm{MHz}$ instruments had both inverse-detected and normal-detected broadband probes available. All directly-detected ${ }^{1} \mathrm{H}$ and ${ }^{13} \mathrm{C}$ chemical shifts $(\delta)$ were internally referenced to the residual solvent peak. ${ }^{161}$ Indirectly-detected ${ }^{15} \mathrm{~N}$ shifts were referenced to the unified TMS scale with a $\Xi$ ratio of 10.136767. ${ }^{162}$ All HRESIMS data was obtained using either a PE Biosystem Mariner 5158 TOF mass spectrometer or a Micromass Q-TOF Premier mass spectrometer. Optical rotations were recorded on a Perkin-Elmer 241 polarimeter.

MPLC and HPLC purifications were performed with a Rainin Dynamax SD-200 HPLC system or a Varian SD-1 HPLC system. UV detection for HPLC runs was obtained with a Varian Prostar 335 Diode Array detector. MPLC solvents were either HPLC grade or glass-distilled prior to use. All solvents used in HPLC were HPLC grade. $\mathrm{H}_{2} \mathrm{O}$ used for MPLC and HPLC was glass-distilled and deionised using a MilliQ system. All solvent mixtures are reported as \% vol in vol. Normal-phase HPLC was performed using a custom-packed Phenomenex DIOL column [analytical $(4 \times 250 \mathrm{~mm}, 5 \mu \mathrm{m})$ or semi-preperative $(10 \times 250 \mathrm{~mm}, 5 \mu \mathrm{m})]$. Reversed-phase HPLC was performed using a Phenomenex Prodigy $\mathrm{C}_{18}$ column [analytical $(4.6 \times 250 \mathrm{~mm}, 5 \mu \mathrm{m})$ or semi-preperative $(10 \times 250 \mathrm{~mm}, 10 \mu \mathrm{m})]$. TLC analysis were performed using Macherey-Nagal Alufoilen SIL G/UV 254 plates. TLC plates were visualised by one or more of (1) absorbance under UV light $(\lambda=254 \mathrm{~nm})$, (2) fluorescence under UV light ( $\lambda=350 \mathrm{~nm})$, (3) dipping in $5 \% \mathrm{H}_{2} \mathrm{SO}_{4}$ in $\mathrm{MeOH}$ then heating, (3) dipping in $5 \% \mathrm{H}_{2} \mathrm{SO}_{4}$ in $\mathrm{MeOH}$ then dipping 
in $0.1 \%$ vanillin in EtOH then heating. Reversed-phase chromatography on PSDVB was performed using HP20 (Mitsubishi), HP20S or HP20SS (Supelco), or Amberchrom CG-161M (Tosohaas). Normal-phase chromatography was performed using YMC S-50 gel DIOL or Kieselgel 60 (230-400 mesh ASTM). All solvents used for bench-top chromatography were glass distilled. All reagents used were obtained commercially (at least reagent grade) and distilled where necessary.

All red algae analysed in the study were identified by Dr. Joe Zuccarello, Senior Lecturer, School of Biological Sciences, Victoria University of Wellington.

\subsection{Isolation of Costatone from Plocamium costatum}

The seaweed identified as Plocamium costatum was collected by hand using SCUBA from Albert Reef, Doubtless Bay, New Zealand ( $\left.34^{\circ} 25.2^{\prime} \mathrm{S}, 173^{\circ} 31.2^{\prime} \mathrm{E}\right)$ in December 2003. The sample was frozen immediately and kept at $-18^{\circ} \mathrm{C}$ until extraction. A voucher specimen has been deposited at the School of Chemical and Physical Sciences, Victoria University of Wellington, New Zealand.

P. costatum (126 g wet weight) was extracted for $18 \mathrm{~h}$ in $400 \mathrm{~mL} \mathrm{MeOH}$. The extract was filtered and the algal material re-extracted for $18 \mathrm{~h}$ with a further $400 \mathrm{~mL} \mathrm{MeOH}$. The extracts were combined and cyclic loaded* to $25 \%$ of the original volume on to a reversed-phase PSDVB column (HP20, $160 \mathrm{~mL}$ ). The column was successively eluted with $500 \mathrm{~mL}$ volumes of $\mathrm{H}_{2} \mathrm{O}, 30 \%$ and $75 \% \mathrm{Me}_{2} \mathrm{CO}$ in $\mathrm{H}_{2} \mathrm{O}$ and $\mathrm{Me}_{2} \mathrm{CO}$. The $75 \%$ $\mathrm{Me}_{2} \mathrm{CO}$ in $\mathrm{H}_{2} \mathrm{O}$ elution was backloaded on to a reversed-phase PSDVB column (HP20, $80 \mathrm{~mL}$ ) and successively eluted with $300 \mathrm{~mL}$ volumes of $\mathrm{H}_{2} \mathrm{O}$ and $\mathrm{MeOH}$. The $\mathrm{MeOH}$ eluent was concentrated to dryness under reduced pressure to yield $1.1 \mathrm{~g}$ of material. Approximately one tenth of this material was passed through a normal-phase column (silica, $30 \mathrm{~mL}$ ) eluted successively with $90 \mathrm{~mL}$ volumes of $20 \%, 30 \%, 40 \%$ and $50 \%$ $\mathrm{CH}_{2} \mathrm{Cl}_{2}$ in pet. ether, $\mathrm{CH}_{2} \mathrm{Cl}_{2}$ and $50 \% \mathrm{MeOH}$ in $\mathrm{CH}_{2} \mathrm{Cl}_{2}$. A total of 10 fractions were collected. Fraction $4\left(30 \% \mathrm{CH}_{2} \mathrm{Cl}_{2}\right.$ in pet. ether) was concentrated to dryness under reduced pressure to yield costatone $(\mathbf{4 4})(51 \mathrm{mg})$.

\footnotetext{
${ }^{*}$ For a detailed discussion of cyclic loading, please see page 14.
} 


\section{Costatone (44)}

Amorphous white solid; $[\alpha]_{\mathrm{D}}^{25}-48.0\left(c\right.$ 1.12, $\left.\mathrm{CH}_{2} \mathrm{Cl}_{2}\right)$; NMR data see Table B.1; HRESIMS, obsd. $m / z 390.8499: 392.8437: 394.8438: 396.8445: 398.8486(9: 24: 22$ : 8 : 1) $[\mathrm{M}-\mathrm{H}]^{-}, \mathrm{C}_{10} \mathrm{H}_{11} \mathrm{O}_{2} \mathrm{Br}_{2} \mathrm{Cl}_{2}^{-}$requires $390.8508: 392.8486: 394.8463: 396.8438$ : $398.8415, \Delta 2.4 \mathrm{ppm}$.

\subsection{Isolation of Indoles from Ballia callitricha}

The seaweed identified as Ballia callitricha was collected by hand using SCUBA from Owhiro Bay, Wellington, New Zealand in January 2005. The sample was frozen immediately and kept at $-18{ }^{\circ} \mathrm{C}$ until extraction. A voucher specimen has been deposited at the School of Chemical and Physical Sciences, Victoria University of Wellington, New Zealand.

B. callitricha (664 g wet weight) was extracted for $18 \mathrm{~h}$ in $2.5 \mathrm{~L} \mathrm{MeOH}$. The extract was filtered and the algal material re-extracted for $18 \mathrm{~h}$ with a further $2.5 \mathrm{~L} \mathrm{MeOH}$. The extracts were combined and cyclic loaded to $10 \%$ of the original volume on to a reversedphase PSDVB column (HP20, $400 \mathrm{~mL}$ ). The column was eluted successively with $1.2 \mathrm{~L}$ volumes of $\mathrm{H}_{2} \mathrm{O}, 20 \%, 40 \%, 60 \%$ and $80 \% \mathrm{Me}_{2} \mathrm{CO}$ in $\mathrm{H}_{2} \mathrm{O}$ and $\mathrm{Me}_{2} \mathrm{CO}$. The $40 \%$ $\mathrm{Me}_{2} \mathrm{CO}$ in $\mathrm{H}_{2} \mathrm{O}$ elution was backloaded on to a reversed-phase PSDVB column (HP20, $150 \mathrm{~mL}$ ) and eluted successively with $500 \mathrm{~mL}$ volumes of $\mathrm{H}_{2} \mathrm{O}$ and $\mathrm{MeOH}$. The $\mathrm{MeOH}$ eluent was concentrated to dryness under reduced pressure to yield $136 \mathrm{mg}$ of material. Approximately half (62 mg) of this material was passed through a normal-phase column (silica, $25 \mathrm{~mL}$ ) eluted successively with $100 \mathrm{~mL}$ volumes of $50 \%$ pet. ether in $\mathrm{CH}_{2} \mathrm{Cl}_{2}$, $\mathrm{CH}_{2} \mathrm{Cl}_{2}, 1 \%, 2 \%, 5 \%, 10 \%$ and $20 \%$ EtOAc in $\mathrm{CH}_{2} \mathrm{Cl}_{2}$ and $50 \% \mathrm{MeOH}$ in $\mathrm{CH}_{2} \mathrm{Cl}_{2}$. The $1 \%$ EtOAc in $\mathrm{CH}_{2} \mathrm{Cl}_{2}$ fraction was concentrated to dryness under reduced pressure. The resulting material was passed through a normal phase column (DIOL, $10 \mathrm{~mL}$ ) eluted successively with $30 \mathrm{~mL}$ volumes of pet. ether, $10 \%, 25 \%, 50 \%$ and $75 \% \mathrm{CH}_{2} \mathrm{Cl}_{2}$ in pet. ether, $\mathrm{CH}_{2} \mathrm{Cl}_{2}$ and $50 \% \mathrm{MeOH}$ in $\mathrm{CH}_{2} \mathrm{Cl}_{2}$. A total of 53 fractions were collected. 
Fractions 41-43 (75\% $\mathrm{CH}_{2} \mathrm{Cl}_{2}$ in pet. ether to $\mathrm{CH}_{2} \mathrm{Cl}_{2}$ ) were combined and concentrated to dryness under reduced pressure to yield $1 H$-indole-3-carboxaldehyde (45) $(0.4 \mathrm{mg})$.

Fraction 53 was concentrated to dryness under reduced pressure. The resulting material was separated on a semi-preparative $\mathrm{C}_{18}$ reversed-phase HPLC column with $50 \% \mathrm{CH}_{3} \mathrm{CN}$ in $\mathrm{H}_{2} \mathrm{O}$ as the mobile phase at a flow rate of $4.6 \mathrm{~mL} / \mathrm{min}$ to yield $(E)-N$-formyl-3-(1Hindol-3-yl)prop-2-enamide (46) (0.3 mg) with a retention time of $4.1 \mathrm{~min}$.

\section{$1 H$-indole-3-carboxaldehyde (45)}

Yellow oil; NMR data see Table B.2; HRESIMS, obsd. $m / z \quad 168.0424[\mathrm{M}+\mathrm{Na}]^{+}$, $\mathrm{C}_{9} \mathrm{H}_{7} \mathrm{NONa}^{+}$requires $168.0420, \Delta 2.4 \mathrm{ppm}$.

(E)- $N$-formyl-3-(1H-indol-3-yl)prop-2-enamide (46)

Amorphous yellow solid; NMR data see Table 2.1; HRESIMS, obsd. m/z 237.0634 $[\mathrm{M}+\mathrm{Na}]^{+}, \mathrm{C}_{12} \mathrm{H}_{10} \mathrm{~N}_{2} \mathrm{O}_{2} \mathrm{Na}^{+}$requires 237.0635, $\Delta 0.2 \mathrm{ppm}$.

\subsection{Isolation of Labillarides A to $\mathrm{K}$ from Phacelocarpus labillardieri}

\section{Initial Extraction of $P$. labillardieri}

The seaweed identified as Phacelocarpus labillardieri was collected by hand using SCUBA from Rimariki Island, New Zealand ( $\left.35^{\circ} 25.2^{\prime} \mathrm{S}, 174^{\circ} 26.9^{\prime} \mathrm{E}\right)$ in December 2003. The sample was frozen immediately and kept at $-18^{\circ} \mathrm{C}$ until extraction. A voucher specimen has been deposited at the School of Chemical and Physical Sciences, Victoria University of Wellington, New Zealand. 
P. labillardieri (98 g wet weight) was extracted for $18 \mathrm{~h}$ in $400 \mathrm{~mL} \mathrm{MeOH}$. The extract was filtered and cyclic loaded on to a reversed-phase PSDVB column (HP20, $80 \mathrm{~mL}$ ). The column was eluted successively with $250 \mathrm{~mL}$ volumes of $\mathrm{H}_{2} \mathrm{O}, 30 \%$ and $75 \%$ $\mathrm{Me}_{2} \mathrm{CO}$ in $\mathrm{H}_{2} \mathrm{O}$ and $\mathrm{Me}_{2} \mathrm{CO}$. The $75 \% \mathrm{Me}_{2} \mathrm{CO}$ in $\mathrm{H}_{2} \mathrm{O}$ elution was backloaded on to a PSDVB column (HP20, $40 \mathrm{~mL}$ ) and eluted successively with $150 \mathrm{~mL}$ volumes of $\mathrm{H}_{2} \mathrm{O}$ and $\mathrm{Me}_{2} \mathrm{CO}$. The $\mathrm{Me}_{2} \mathrm{CO}$ eluent was concentrated to dryness under reduced pressure to yield $1.2 \mathrm{~g}$ of material. Approximately one sixth $(200 \mathrm{mg})$ of this material was passed through a normal phase column (DIOL, $30 \mathrm{~mL}$ ) eluted successively with $100 \mathrm{~mL}$ volumes of $\mathrm{CH}_{2} \mathrm{Cl}_{2}, 1 \%, 2 \%, 5 \%, 10 \%$ and $50 \% \mathrm{EtOAc}$ in $\mathrm{CH}_{2} \mathrm{Cl}_{2}$, and $50 \% \mathrm{MeOH}$ in $\mathrm{CH}_{2} \mathrm{Cl}_{2}$. A total of 47 fractions were collected. Fraction $2\left(\mathrm{CH}_{2} \mathrm{Cl}_{2}\right)$ was concentrated to dryness under reduced pressure and passed through a normal phase column (DIOL, $30 \mathrm{~mL}$ ). The column was eluted successively with $100 \mathrm{~mL}$ volumes of pet. ether, $10 \%, 25 \%$ and $50 \%$ $\mathrm{CH}_{2} \mathrm{Cl}_{2}$ in pet. ether, $\mathrm{CH}_{2} \mathrm{Cl}_{2}$ and $50 \% \mathrm{MeOH}$ in $\mathrm{CH}_{2} \mathrm{Cl}_{2}$. A total of 41 fractions were collected. Fraction $31\left(50 \% \mathrm{CH}_{2} \mathrm{Cl}_{2}\right.$ in pet. ether) was concentrated to dryness under reduced pressure to yield labillaride C (62) (19.5 mg).

The remainder of the original $\mathrm{Me}_{2} \mathrm{CO}$ fraction was divided into six equal portions which were each passed through a normal phase column (DIOL, $8 \mathrm{~mL}$ ). The columns were eluted with $30 \mathrm{~mL}$ of $\mathrm{CH}_{2} \mathrm{Cl}_{2}$, followed by $50 \mathrm{~mL} 50 \% \mathrm{MeOH}$ in $\mathrm{CH}_{2} \mathrm{Cl}_{2}$. Two of the $\mathrm{CH}_{2} \mathrm{Cl}_{2}$ fractions were combined and reduced to dryness under reduced pressure and passed through a normal phase MPLC column (DIOL, $250 \mathrm{~mL}$ ). The column was eluted at a flow rate of $5 \mathrm{~mL} / \mathrm{min}$ with pet. ether for $150 \mathrm{~min}$, from pet. ether to $25 \% \mathrm{CH}_{2} \mathrm{Cl}_{2}$ in pet. ether at a solvent gradient of $25.0 \% / \mathrm{min}, 25 \% \mathrm{CH}_{2} \mathrm{Cl}_{2}$ in pet. ether for $149 \mathrm{~min}$, from $25 \% \mathrm{CH}_{2} \mathrm{Cl}_{2}$ in pet. ether to $50 \% \mathrm{CH}_{2} \mathrm{Cl}_{2}$ in pet. ether at a solvent gradient of $25.0 \% / \mathrm{min}$, $50 \% \mathrm{CH}_{2} \mathrm{Cl}_{2}$ in pet. ether for $149 \mathrm{~min}$, from $50 \% \mathrm{CH}_{2} \mathrm{Cl}_{2}$ in pet. ether to $\mathrm{CH}_{2} \mathrm{Cl}_{2}$ at a solvent gradient of $50.0 \% / \mathrm{min}, \mathrm{CH}_{2} \mathrm{Cl}_{2}$ for $149 \mathrm{~min}$, from $\mathrm{CH}_{2} \mathrm{Cl}_{2}$ to $50 \% \mathrm{CH}_{2} \mathrm{Cl}_{2}$ in EtOAc at a solvent gradient of $50 \% / \mathrm{min}$ and $50 \% \mathrm{CH}_{2} \mathrm{Cl}_{2}$ in EtOAc for $149 \mathrm{~min}$. A total of 22 fractions were collected over $750 \mathrm{~min}$.

Fractions 17-18 $\left(\mathrm{CH}_{2} \mathrm{Cl}_{2}\right.$ to $50 \% \mathrm{CH}_{2} \mathrm{Cl}_{2}$ in EtOAc) were combined and concentrated to dryness under reduced pressure. The resulting material was passed through a normal phase column (DIOL, $30 \mathrm{~mL}$ ) and the column was eluted successively with $100 \mathrm{~mL}$ 
volumes of $20 \%, 40 \%, 60 \%$ and $80 \% \mathrm{CH}_{2} \mathrm{Cl}_{2}$ in pet. ether, $\mathrm{CH}_{2} \mathrm{Cl}_{2}$ and $50 \% \mathrm{MeOH}$ in $\mathrm{CH}_{2} \mathrm{Cl}_{2}$. A total of 75 fractions were collected. Fractions $14-18$ (20\% to $40 \% \mathrm{CH}_{2} \mathrm{Cl}_{2}$ in pet. ether) were combined and concentrated under reduced pressure to yield labillaride A (60) (4.6 mg).

Fraction 19 (50\% $\mathrm{CH}_{2} \mathrm{Cl}_{2}$ in EtOAc) was concentrated to dryness under reduced pressure and the resulting material was passed through a normal phase column (DIOl, $250 \mathrm{~mL}$ ). The column was eluted at a flow rate of $5 \mathrm{~mL} / \mathrm{min}$ with $70 \% \mathrm{CH}_{2} \mathrm{Cl}_{2}$ in pet. ether for $200 \mathrm{~min}$, from $70 \% \mathrm{CH}_{2} \mathrm{Cl}_{2}$ in pet. ether to $\mathrm{CH}_{2} \mathrm{Cl}_{2}$ at a solvent gradient of $30.0 \% / \mathrm{min}$ and $\mathrm{CH}_{2} \mathrm{Cl}_{2}$ for $100 \mathrm{~min}$. A total of 31 fractions were collected over $300 \mathrm{~min}$. Fractions 29-31 $\left(\mathrm{CH}_{2} \mathrm{Cl}_{2}\right)$ were combined and concentrated to dryness under reduced pressure and the resulting material was passed through a normal phase column (DIOL, $30 \mathrm{~mL}$ ). The column was eluted successively with $100 \mathrm{~mL}$ volumes of $50 \%$ and $70 \% \mathrm{CH}_{2} \mathrm{Cl}_{2}$ in pet. ether, $\mathrm{CH}_{2} \mathrm{Cl}_{2}$ and $50 \% \mathrm{MeOH}$ in $\mathrm{CH}_{2} \mathrm{Cl}_{2}$. A total of 44 fractions were collected. Fractions 6-7 (50\% $\mathrm{CH}_{2} \mathrm{Cl}_{2}$ in pet. ether) were combined and concentrated to dryness under reduced pressure to yield labillaride A (60) $(19.6 \mathrm{mg})$. Fractions $36-38\left(\mathrm{CH}_{2} \mathrm{Cl}_{2}\right)$ were combined and concentrated to dryness under reduced pressure to yield a mixture of labillaride C (62) and labillaride D (63) (2.6 mg).

The $50 \% \mathrm{MeOH}$ in $\mathrm{CH}_{2} \mathrm{Cl}_{2}$ fractions from the original six DIOL columns were combined and concentrated to dryness under reduced pressure. The resulting material was divided into two equal portions which were each passed through a normal phase column (DIOL, $30 \mathrm{~mL}$ ). The columns were eluted successively with $30 \mathrm{~mL}$ volumes of $\mathrm{CH}_{2} \mathrm{Cl}_{2}, 1 \%, 2 \%$, $5 \%, 10 \%$ and $50 \%$ EtOAc in $\mathrm{CH}_{2} \mathrm{Cl}_{2}$ and $50 \% \mathrm{MeOH}$ in $\mathrm{CH}_{2} \mathrm{Cl}_{2}$. A total of 81 fractions were collected for each run.

Fractions 12-25 and 23-31 from each of the runs respectively were combined and concentrated to dryness under reduced pressure. The resulting material was backloaded on to $5 \mathrm{~mL}$ Amberchrom and the column was eluted successively with $15 \mathrm{~mL}$ volumes of $20 \%, 30 \%, 40 \%, 50 \%, 60 \%, 70 \%$ and $80 \% \mathrm{MeOH}$ in $\mathrm{H}_{2} \mathrm{O}, \mathrm{MeOH}$ and $\mathrm{Me}_{2} \mathrm{CO}$. The $80 \% \mathrm{MeOH}$ in $\mathrm{H}_{2} \mathrm{O}$ fraction was concentrated to dryness under reduced pressure and the resulting material was passed through a normal phase column (DIOL, $30 \mathrm{~mL}$ ). The 
column was eluted successively with $90 \mathrm{~mL}$ volumes of $\mathrm{CH}_{2} \mathrm{Cl}_{2}, 1 \%, 2 \%, 5 \%, 10 \%$, $20 \%$ and $50 \%$ THF in $\mathrm{CH}_{2} \mathrm{Cl}_{2}$ and $50 \% \mathrm{MeOH}$ in $\mathrm{CH}_{2} \mathrm{Cl}_{2}$. A total of 92 fractions were collected. Fractions 27-35 (1-2\% THF in $\left.\mathrm{CH}_{2} \mathrm{Cl}_{2}\right)$ were combined and concentrated to dryness under reduced pressure. The resulting material was separated on an analytical DIOL normal phase HPLC column with 7\% IPA in hexanes as the mobile phase at a flow rate of $1 \mathrm{~mL} / \mathrm{min}$ to yield labillaride $\mathrm{E}(\mathbf{6 4})(1.6 \mathrm{mg})$ a retention time of $37.5 \mathrm{~min}$.

Fractions 26-40 and 32-43 from each of the runs respectively were combined and concentrated to dryness under reduced pressure. The resulting material was passed through a normal phase column (DIOL, $30 \mathrm{~mL}$ ) eluted successively with $90 \mathrm{~mL}$ volumes of $\mathrm{CH}_{2} \mathrm{Cl}_{2}, 1 \%, 2 \%, 5 \%, 10 \%, 20 \%$ and $50 \%$ THF in $\mathrm{CH}_{2} \mathrm{Cl}_{2}$ and $50 \% \mathrm{MeOH}$ in $\mathrm{CH}_{2} \mathrm{Cl}_{2}$. A total of 64 fractions were collected. Fractions 26-40 were combined and concentrated to dryness under reduced pressure. The resulting material was cyclic loaded on to $1.5 \mathrm{~mL}$ Amberchrom which was transferred to the top of a prepacked Amberchrom column (300 $\times 11 \mathrm{~mm}$ internal diameter). The column was eluted at a flow rate of $5 \mathrm{~mL} / \mathrm{min}$ with $40 \% \mathrm{MeOH}$ in $\mathrm{H}_{2} \mathrm{O}$ for $10 \mathrm{~min}$, from $40 \%$ to $80 \% \mathrm{MeOH}$ in $\mathrm{H}_{2} \mathrm{O}$ at a solvent gradient of $0.67 \% / \mathrm{min}, 80 \% \mathrm{MeOH}$ in $\mathrm{H}_{2} \mathrm{O}$ for $10 \mathrm{~min}$, from $80 \% \mathrm{MeOH}$ in $\mathrm{H}_{2} \mathrm{O}$ to $\mathrm{MeOH}$ at a solvent gradient of $2.00 \% / \mathrm{min}$ and $\mathrm{MeOH}$ for $10 \mathrm{~min}$. A total of 110 fractions were collected at a rate of $5 \mathrm{~mL} /$ fraction. Fractions $76-85$ were combined and concentrated to dryness under reduced pressure. The resulting material was separated on an analytical DIOL normal phase HPLC column with 7\% IPA in hexanes as the mobile phase at a flow rate of $1 \mathrm{~mL} / \mathrm{min}$ to yield labillaride $\mathrm{H}(\mathbf{6 7})(1.2 \mathrm{mg})$ and a labillaride $\mathrm{E}(\mathbf{6 4})(0.4 \mathrm{mg})$ with retention times of 33.2 and 36.0 min respectively.

\section{Large-scale Extraction of $P$. labillardieri}

The remainder of the collection of Phacelocarpus labillardieri screened above (268 $\mathrm{g}$ wet weight) was extracted for $18 \mathrm{~h}$ in $2 \mathrm{~L} \mathrm{MeOH}$. The extract was filtered and the algal material re-extracted for $18 \mathrm{~h}$ with a further $2 \mathrm{~L} \mathrm{MeOH}$. The second extract was filtered and the algal material re-extracted for $18 \mathrm{~h}$ with a third $2 \mathrm{~L} \mathrm{MeOH}$. The extracts were combined and cyclic loaded to $25 \%$ of the original volume on to a reversed-phase PSDVB 
column (HP20, 1 L). The column was eluted successively with $3 \mathrm{~L}$ volumes of $\mathrm{H}_{2} \mathrm{O}, 20 \%$, $40 \%, 60 \%$ and $80 \% \mathrm{Me}_{2} \mathrm{CO}$ in $\mathrm{H}_{2} \mathrm{O}$ and $\mathrm{Me}_{2} \mathrm{CO}$. The $80 \% \mathrm{Me}_{2} \mathrm{CO}$ in $\mathrm{H}_{2} \mathrm{O}$ elution was backloaded on to a PSDVB column (HP20, $500 \mathrm{~mL}$ ) and eluted successively with $1.5 \mathrm{~L}$ volumes of $\mathrm{H}_{2} \mathrm{O}$ and $\mathrm{Me}_{2} \mathrm{CO}$. The $\mathrm{Me}_{2} \mathrm{CO}$ eluent was concentrated to dryness under reduced pressure and the material was passed through a normal phase column (DIOL, $250 \mathrm{~mL}$ ). The column was eluted at a flow rate of $8 \mathrm{~mL} / \mathrm{min}$ with $\mathrm{CH}_{2} \mathrm{Cl}_{2}$ for $110 \mathrm{mins}$, from $\mathrm{CH}_{2} \mathrm{Cl}_{2}$ to $50 \% \mathrm{MeOH}$ in $\mathrm{CH}_{2} \mathrm{Cl}_{2}$ at a solvent gradient of $50 \% / \mathrm{min}$, and $50 \% \mathrm{MeOH}$ in $\mathrm{CH}_{2} \mathrm{Cl}_{2}$ for $94 \mathrm{~min}$. A total of five fractions were collected over $205 \mathrm{~min}$. Fractions 3-4 $\left(\mathrm{CH}_{2} \mathrm{Cl}_{2}\right)$ were combined and concentrated to dryness under reduced pressure and the resulting material was passed through a normal phase column (DIOL, $250 \mathrm{~mL}$ ). The column was eluted at a flow rate of $16 \mathrm{~mL} / \mathrm{min}$ with $25 \% \mathrm{CH}_{2} \mathrm{Cl}_{2}$ in pet. ether for $36 \mathrm{mins}$, from $25 \% \mathrm{CH}_{2} \mathrm{Cl}_{2}$ in pet. ether to $\mathrm{CH}_{2} \mathrm{Cl}_{2}$ at a solvent gradient of $1 \% / \mathrm{min}$, and $\mathrm{CH}_{2} \mathrm{Cl}_{2}$ for $36 \mathrm{~min}$. A total of 18 fractions of $128 \mathrm{~mL}$ were collected.

Fraction $2\left(25 \% \mathrm{CH}_{2} \mathrm{Cl}_{2}\right.$ in pet. ether) was concentrated to dryness under reduced pressure. The resulting material was passed through a normal phase column (DIOL, $30 \mathrm{~mL}$ ) eluted successively with $100 \mathrm{~mL}$ volumes of $5 \% \mathrm{CH}_{2} \mathrm{Cl}_{2}$ in pet. ether and $\mathrm{CH}_{2} \mathrm{Cl}_{2}$. A total of 33 fractions were collected. Fractions $12-14\left(25 \% \mathrm{CH}_{2} \mathrm{Cl}_{2}\right.$ in pet. ether) were combined and concentrated to dryness under reduced pressure. The resulting material was separated on an analytical DIOL normal phase HPLC column with 1\% IPA in hexanes as the mobile phase at a flow rate of $1 \mathrm{~mL} / \mathrm{min}$ to yield labillaride $\mathrm{B}(\mathbf{6 1})(3.6 \mathrm{mg})$ and a labillaride A (60) (1.5 mg) with retention times of 7.2 and 10.5 min respectively.

Fractions 4-5 were combined and concentrated to dryness under reduced pressure. The resulting material was separated repeatedly on a semi-preparative DIOL normal phase HPLC column with $10 \%$ IPA in hexanes as the mobile phase at a flow rate of $6.25 \mathrm{~mL} / \mathrm{min}$ to yield labillaride D (63) (7.6 mg) and a labillaride C (62) (53.0 mg) with retention times of 10.2 and $11.7 \mathrm{~min}$ respectively. 


\section{Second Large-scale Extraction of $P$. labillardieri}

The seaweed identified as Phacelocarpus labillardieri was collected by hand using SCUBA from Rimariki Island, New Zealand ( $\left.35^{\circ} 25.5^{\prime} \mathrm{S}, 174^{\circ} 26.9^{\prime} \mathrm{E}\right)$ in November 2006. The sample was frozen immediately and kept at $-18{ }^{\circ} \mathrm{C}$ until extraction. A voucher specimen has been deposited at the School of Chemical and Physical Sciences, Victoria University of Wellington, New Zealand.

P. labillardieri (245 g wet weight) was extracted for $18 \mathrm{~h}$ in $1.8 \mathrm{~L} \mathrm{MeOH}$. The extract was filtered and the algal material re-extracted for $18 \mathrm{~h}$ with a further $1.8 \mathrm{~L} \mathrm{MeOH}$. The extracts were combined and cyclic loaded to $25 \%$ of the original volume on to a reversedphase PSDVB column (HP20, $500 \mathrm{~mL}$ ). The column was eluted successively with $2 \mathrm{~L}$ volumes of $\mathrm{H}_{2} \mathrm{O}, 30 \%$ and $75 \% \mathrm{Me}_{2} \mathrm{CO}$ in $\mathrm{H}_{2} \mathrm{O}$ and $\mathrm{Me}_{2} \mathrm{CO}$. The $75 \% \mathrm{Me}_{2} \mathrm{CO}$ in $\mathrm{H}_{2} \mathrm{O}$ elution was backloaded on to a PSDVB column (HP20, $240 \mathrm{~mL}$ ) and eluted successively with $750 \mathrm{~mL}$ volumes of $\mathrm{H}_{2} \mathrm{O}$ and $\mathrm{Me}_{2} \mathrm{CO}$. The $\mathrm{Me}_{2} \mathrm{CO}$ eluent was concentrated to dryness under reduced pressure and the resulting material was passed through a normal phase column (DIOL, $250 \mathrm{~mL}$ ). The column was eluted at a flow rate of $4.5 \mathrm{~mL} / \mathrm{min}$ with $\mathrm{CH}_{2} \mathrm{Cl}_{2}$ for 220 mins, from $\mathrm{CH}_{2} \mathrm{Cl}_{2}$ to $50 \% \mathrm{MeOH}$ in $\mathrm{CH}_{2} \mathrm{Cl}_{2}$ at a solvent gradient of $10 \% / \mathrm{min}$, and $50 \% \mathrm{MeOH}$ in $\mathrm{CH}_{2} \mathrm{Cl}_{2}$ for $220 \mathrm{~min}$. A total of eight fractions were collected over $445 \mathrm{~min}$.

Fraction $1\left(\mathrm{CH}_{2} \mathrm{Cl}_{2}\right)$ was concentrated to dryness under reduced pressure to yield $268 \mathrm{mg}$ of material of which approximately one fifth was passed through a normal phase column (DIOL, $25 \mathrm{~mL}$ ). The column was eluted at a flow rate of $3 \mathrm{~mL} / \mathrm{min}$ with pet. ether for $8 \mathrm{~min}$, from pet. ether to $5 \% \mathrm{CH}_{2} \mathrm{Cl}_{2}$ in pet. ether at a solvent gradient of $0.12 \% / \mathrm{min}, 5 \%$ $\mathrm{CH}_{2} \mathrm{Cl}_{2}$ in pet. ether for $17 \mathrm{~min}$, from $5 \% \mathrm{CH}_{2} \mathrm{Cl}_{2}$ in pet. ether to $\mathrm{CH}_{2} \mathrm{Cl}_{2}$ at a solvent gradient of $11.9 \% / \mathrm{min}$, and $\mathrm{CH}_{2} \mathrm{Cl}_{2}$ for $25 \mathrm{~min}$. A total of 62 fractions were collected over 100 min. Fraction 6 was concentrated to dryness under reduced pressure. The resulting material was separated on an analytical $\mathrm{C}_{18}$ reversed-phase HPLC column with $90 \% \mathrm{MeCN}$ in $\mathrm{H}_{2} \mathrm{O}$ as the mobile phase at a flow rate of $1 \mathrm{~mL} / \mathrm{min}$ to yield labillaride $\mathrm{J}$ (69) $(2.0 \mathrm{mg})$ with a retention time of $17.3 \mathrm{~min}$. Fractions $7-10$ were combined and concentrated to dryness under reduced pressure to yield labillaride I (68) (9.1 mg). 
Fractions 33-37 were combined and concentrated to dryness under reduced pressure to yield labillaride B (61) (2.9 mg).

The remainder of the original fraction 1 was divided into four equal portions which were each passed through a normal phase column (DIOL, $25 \mathrm{~mL}$ ). The first column was eluted at a flow rate of $3 \mathrm{~mL} / \mathrm{min}$ with pet. ether for $100 \mathrm{~min}$, from pet. ether to $10 \% \mathrm{CH}_{2} \mathrm{Cl}_{2}$ in pet. ether at a solvent gradient of $0.15 \% / \mathrm{min}, 10 \% \mathrm{CH}_{2} \mathrm{Cl}_{2}$ in pet. ether for $16 \mathrm{~min}$, from $10 \% \mathrm{CH}_{2} \mathrm{Cl}_{2}$ in pet. ether to $\mathrm{CH}_{2} \mathrm{Cl}_{2}$ at a solvent gradient of $5.63 \% / \mathrm{min}$, and $\mathrm{CH}_{2} \mathrm{Cl}_{2}$ for $25 \mathrm{~min}$. The second and third columns were eluted at a flow rate of $3 \mathrm{~mL} / \mathrm{min}$ with pet. ether for 16 mins, from pet. ether to $10 \% \mathrm{CH}_{2} \mathrm{Cl}_{2}$ in pet. ether at a solvent gradient of $0.15 \% / \mathrm{min}, 10 \% \mathrm{CH}_{2} \mathrm{Cl}_{2}$ in pet. ether for $16 \mathrm{~min}$, from $10 \% \mathrm{CH}_{2} \mathrm{Cl}_{2}$ in pet. ether to $\mathrm{CH}_{2} \mathrm{Cl}_{2}$ at a solvent gradient of $5.63 \% / \mathrm{min}$, and $\mathrm{CH}_{2} \mathrm{Cl}_{2}$ for $25 \mathrm{~min}$. The fourth column was eluted at a flow rate of $2 \mathrm{~mL} / \mathrm{min}$ with pet. ether for $24 \mathrm{mins}$, from pet. ether to $10 \%$ $\mathrm{CH}_{2} \mathrm{Cl}_{2}$ in pet. ether at a solvent gradient of $0.10 \% / \mathrm{min}, 10 \% \mathrm{CH}_{2} \mathrm{Cl}_{2}$ in pet. ether for $24 \mathrm{~min}$, from $10 \% \mathrm{CH}_{2} \mathrm{Cl}_{2}$ in pet. ether to $\mathrm{CH}_{2} \mathrm{Cl}_{2}$ at a solvent gradient of $3.75 \% / \mathrm{min}$, and $\mathrm{CH}_{2} \mathrm{Cl}_{2}$ for $38 \mathrm{~min}$. A total of $133,86,99$ and 86 fractions for each run respectively were collected at a rate of $5 \mathrm{~mL} /$ fraction.

Fractions $11-18,12-23,12-23$ and $13-24$ (pet. ether, $0.6 \%$ to $3.3 \%, 0.6 \%$ to $3.3 \%$ and $0.9 \%$ to $3.6 \% \mathrm{CH}_{2} \mathrm{Cl}_{2}$ in pet. ether respectively) from each of the runs respectively were combined and concentrated to dryness under reduced pressure to yield labillaride I (68) (33.7 mg).

Fractions $86-93,49-61,50-61$ and $50-60$ (5.6\% to $7.3 \%, 9.4 \%$ to $10.0 \%, 9.6 \%$ to $10.0 \%$ and $9.9 \%$ to $10.0 \% \mathrm{CH}_{2} \mathrm{Cl}_{2}$ in pet. ether respectively) from each of the runs respectively were combined and concentrated to dryness under reduced pressure. The resulting material was separated repeatedly on a semi-preparative DIOL normal phase HPLC column with $2 \% \mathrm{Me}_{2} \mathrm{CO}$ in hexanes as the mobile phase at a flow rate of $6.25 \mathrm{~mL} / \mathrm{min}$ to yield labillaride K (70) (0.4 mg) with a retention time of $13.9 \mathrm{~min}$.

Fractions $110-133,67-86,70-99$ and $67-86(55.0 \%$ to $100 \%, 50.5 \%$ to $100 \%, 77.6 \%$ to $100 \%$ and $75.6 \%$ to $100 \% \mathrm{CH}_{2} \mathrm{Cl}_{2}$ in pet. ether respectively) from each of the runs respectively were combined and concentrated to dryness under reduced pressure. The 
resulting material was passed through a normal phase column (DIOL, $5 \mathrm{~mL}$ ) eluted successively with $100 \mathrm{~mL}$ volumes of $5 \% \mathrm{CH}_{2} \mathrm{Cl}_{2}$ in pet. ether and $\mathrm{CH}_{2} \mathrm{Cl}_{2}$. The $5 \%$ $\mathrm{CH}_{2} \mathrm{Cl}_{2}$ in pet. ether fraction was concentrated to dryness under reduced pressure and was separated repeatedly on a semi-preparative DIOL normal phase HPLC column with $1 \%$ IPA in hexanes as the mobile phase at a flow rate of $6.25 \mathrm{~mL} / \mathrm{min}$ to yield labillaride A (60) $(0.8 \mathrm{mg})$ with a retention time of $10.6 \mathrm{~min}$.

Fractions 3 and $4\left(\mathrm{CH}_{2} \mathrm{Cl}_{2}\right.$ to $50 \% \mathrm{MeOH}$ in $\left.\mathrm{CH}_{2} \mathrm{Cl}_{2}\right)$ of the original DIOL column were combined and reduced to dryness under reduced pressure to yield $1.3 \mathrm{~g}$ of material of which approximately one quarter was passed through a normal phase column (DIOL, $250 \mathrm{~mL}$ ). The column was eluted at a flow rate of $10 \mathrm{~mL} / \mathrm{min}$ with $10 \%$ IPA in pet. ether for $100 \mathrm{~min}$. A total of two fractions were collected over $100 \mathrm{~min}$. Fraction 2 with a retention time of 46 to 86 min was separated on a semi-preperative DIOL normal phase HPLC column with 5\% IPA in hexanes as the mobile phase at a flow rate of $6.25 \mathrm{~mL} / \mathrm{min}$ to yield labillaride C (62) (69.6 mg) and a mixture of labillaride C (62) and labillaride D (63) with retention times of 17.1 and 14.6 min respectively. The mixture was separated repeatedly on a semi-preperative DIOL normal phase HPLC column with 10\% IPA in hexanes as the mobile phase at a flow rate of $6.25 \mathrm{~mL} / \mathrm{min}$ to yield labillaride $\mathrm{D}(\mathbf{6 3})$ $(3.2 \mathrm{mg})$ with a retention time of $7.9 \mathrm{~min}$.

Fraction $7\left(50 \% \mathrm{MeOH}\right.$ in $\mathrm{CH}_{2} \mathrm{Cl}_{2}$ ) of the original DIOL column was divided into four equal portions which were each passed through a normal phase column (DIOL, $25 \mathrm{~mL}$ ). The columns were eluted successively with $100 \mathrm{~mL}$ volumes of $\mathrm{CH}_{2} \mathrm{Cl}_{2}, 2 \%$ and $10 \%$ EtOAc in $\mathrm{CH}_{2} \mathrm{Cl}_{2}$ and $50 \% \mathrm{MeOH}$ in $\mathrm{CH}_{2} \mathrm{Cl}_{2}$. The $2 \%$ EtOAc in $\mathrm{CH}_{2} \mathrm{Cl}_{2}$ fractions were combined and concentrated to dryness under reduced pressure. The resulting material was separated on a semi-preparative DIOL normal phase HPLC column with 10\% IPA in hexanes as the mobile phase at a flow rate of $6.25 \mathrm{~mL} / \mathrm{min}$. A total of four fractions were collected over $20 \mathrm{~min}$. Fraction 4 with a retention time of 13.8 to $15.3 \mathrm{~min}$ was separated on an analytical DIOL normal phase HPLC column with 7\% IPA in hexanes as the mobile phase at a flow rate of $1 \mathrm{~mL} / \mathrm{min}$ to yield labillaride $\mathrm{F}(\mathbf{6 5})(0.5 \mathrm{mg})$ and labillaride $\mathrm{G}(\mathbf{6 6})$ $(0.4 \mathrm{mg})$ with retention times of 26.7 and $28.0 \mathrm{~min}$ respectively. 


\section{Ethanol Extraction of P. labillardieri}

Phacelocarpus labillardieri (24 g wet weight) was extracted for $18 \mathrm{~h}$ in $150 \mathrm{~mL}$ EtOH. The extract was filtered and the algal material re-extracted for $18 \mathrm{~h}$ with a further $150 \mathrm{~mL}$ EtOH. The extracts were combined and cyclic loaded to $25 \%$ of the original volume on to a reversed-phase PSDVB column (HP20, $20 \mathrm{~mL}$ ). The column was eluted successively with $60 \mathrm{~mL}$ volumes of $\mathrm{H}_{2} \mathrm{O}, 30 \%$ and $75 \% \mathrm{Me}_{2} \mathrm{CO}$ in $\mathrm{H}_{2} \mathrm{O}$ and $\mathrm{Me}_{2} \mathrm{CO}$. The $75 \%$ $\mathrm{Me}_{2} \mathrm{CO}$ in $\mathrm{H}_{2} \mathrm{O}$ elution was backloaded on to a reversed-phase PSDVB column (HP20, $20 \mathrm{~mL}$ ) and eluted successively with $100 \mathrm{~mL}$ volumes of $\mathrm{H}_{2} \mathrm{O}$ and $\mathrm{Me}_{2} \mathrm{CO}$. The $\mathrm{Me}_{2} \mathrm{CO}$ eluent was concentrated to dryness under reduced pressure and the resulting material was passed through a normal phase column (DIOL, $25 \mathrm{~mL}$ ). The column was eluted at a flow rate of $5 \mathrm{~mL} / \mathrm{min}$ with $\mathrm{CH}_{2} \mathrm{Cl}_{2}$ for 20 mins, from $\mathrm{CH}_{2} \mathrm{Cl}_{2}$ to $50 \% \mathrm{EtOH}$ in $\mathrm{CH}_{2} \mathrm{Cl}_{2}$ at a solvent gradient of $10 \% / \mathrm{min}$, and $50 \% \mathrm{EtOH}$ in $\mathrm{CH}_{2} \mathrm{Cl}_{2}$ for $20 \mathrm{~min}$. A total of 10 fractions were collected over $45 \mathrm{~min}$.

Fraction $1\left(\mathrm{CH}_{2} \mathrm{Cl}_{2}\right)$ was concentrated to dryness under reduced pressure and the resulting material was passed through a normal phase column (DIOL, $25 \mathrm{~mL}$ ). The column was eluted at a flow rate of $5 \mathrm{~mL} / \mathrm{min}$ with pet. ether for $5 \mathrm{~min}$, from pet. ether to $5 \% \mathrm{CH}_{2} \mathrm{Cl}_{2}$ in pet. ether at a solvent gradient of $0.17 \% / \mathrm{min}, 5 \% \mathrm{CH}_{2} \mathrm{Cl}_{2}$ in pet. ether for $10 \mathrm{~min}$, from $5 \% \mathrm{CH}_{2} \mathrm{Cl}_{2}$ in pet. ether to $\mathrm{CH}_{2} \mathrm{Cl}_{2}$ at a solvent gradient of $19.0 \% / \mathrm{min}$, and $\mathrm{CH}_{2} \mathrm{Cl}_{2}$ for $15 \mathrm{~min}$. A total of 69 fractions were collected over $65 \mathrm{~min}$. No labillaride I (68), or its ethyl ester equivalent, was detected.

\section{Acetylation of Labillaride H (67) to 3,8-Diacetyl-labillaride H (73)}

A solution of $67(100 \mu \mathrm{g}, 0.3 \mu \mathrm{mol})$ in $500 \mu \mathrm{L}$ of freshly distilled $\mathrm{Ac}_{2} \mathrm{O}$ and $500 \mu \mathrm{L}$ of freshly distilled pyridine was stirred under argon at RT overnight. The reaction was quenched with $\mathrm{H}_{2} \mathrm{O}(1 \mathrm{~mL})$ and the resulting mixture was cyclic loaded on to $2 \mathrm{~mL}$ Amberchrom and eluted with $100 \mathrm{~mL} \mathrm{H}_{2} \mathrm{O}$, followed by $10 \mathrm{~mL} \mathrm{Me}_{2} \mathrm{CO}$. The $\mathrm{Me}_{2} \mathrm{CO}$ fraction was concentrated to dryness under reduced pressure to yield 3,8-diacetyllabillaride H (73) (0.1 mg). 
Attempted Preparation of Mosher's esters of Labillarides E (64) and H (67)

To a solution of 64 or $\mathbf{6 7}(150 \mu \mathrm{g}, 0.4 \mu \mathrm{mol})$ in $1 \mathrm{~mL} 0.02 \mathrm{M} \mathrm{DMAP}$ in $\mathrm{CH}_{2} \mathrm{Cl}_{2}(0.6 \mathrm{mg}$, $24.5 \mu \mathrm{mol})$, either $(R)$ - or $(S)$-MPTACl $(1.5 \mu \mathrm{L}, 8.1 \mu \mathrm{mol})$ was added under argon and the mixture stirred at RT overnight. The reaction mixture was concentrated to dryness under reduced pressure, then $1 \mathrm{~mL} \mathrm{Me}_{2} \mathrm{CO}$ added and the reaction was quenched with $1 \mathrm{~mL}$ of $\mathrm{H}_{2} \mathrm{O}$. The resulting mixture was cyclic loaded on to $2 \mathrm{~mL}$ Amberchrom and washed with $10 \mathrm{~mL}$ of $1 \mathrm{M} \mathrm{HCl}, 1 \mathrm{M} \mathrm{NaOH}$, and finally brine. The column was then eluted with $6 \mathrm{~mL}$ $\mathrm{Me}_{2} \mathrm{CO}$ and this fraction was concentrated to dryness under reduced pressure. The NMR spectra of reaction products showed complex mixtures of several products which, due to the small sample mass, was too complex to interpret.

\section{Labillaride A (60)}

Colourless oil; $[\alpha]_{\mathrm{D}}^{25}-15.4$ (c 0.07, MeOH); UV (hexanes) $\lambda_{\max } 236 \mathrm{~nm}, 290 \mathrm{~nm}$; NMR data see Table 3.3; HRESIMS, obsd. $m / z 343.2280[\mathrm{M}+\mathrm{H}]^{+}, \mathrm{C}_{22} \mathrm{H}_{31} \mathrm{O}_{3}$ requires $343.2268, \Delta 3.6 \mathrm{ppm}$.

\section{Labillaride B (61)}

Colourless oil; UV (hexanes) $\lambda_{\max } 290 \mathrm{~nm}$; NMR data see Table 3.5; HRESIMS, obsd. $m / z 423.1522: 425.1503(1: 1)[\mathrm{M}+\mathrm{H}]^{+}, \mathrm{C}_{22} \mathrm{H}_{32} \mathrm{O}_{3} \mathrm{Br}^{+}$requires 423.1529: 425.1512, $\Delta 1.7 \mathrm{ppm}$.

\section{Labillaride C (62)}

Colourless oil; $[\alpha]_{\mathrm{D}}^{25}+268.0($ ( $0.10, \mathrm{MeOH})$; UV (hexanes) $\lambda_{\max } 295 \mathrm{~nm}$; NMR data see Table 3.6; HRESIMS, obsd. $m / z 343.2259[\mathrm{M}+\mathrm{H}]^{+}, \mathrm{C}_{22} \mathrm{H}_{31} \mathrm{O}_{3}$ requires 343.2268, $\Delta$ $2.7 \mathrm{ppm}$. 


\section{Labillaride D (63)}

Colourless oil; $[\alpha]_{\mathrm{D}}^{25}-93.0(c 0.31, \mathrm{MeOH})$; UV (hexanes) $\lambda_{\max } 295 \mathrm{~nm}$; NMR data see Table 3.7; HRESIMS, obsd. $m / z 365.2093[\mathrm{M}+\mathrm{Na}]^{+}, \mathrm{C}_{22} \mathrm{H}_{30} \mathrm{O}_{3} \mathrm{Na}$ requires 365.2093, $\Delta$ $0.0 \mathrm{ppm}$.

\section{Labillaride E (64)}

Colourless oil; $[\alpha]_{\mathrm{D}}^{25}+135.2(c 0.04, \mathrm{MeOH})$; UV (hexanes) $\lambda_{\max } 300 \mathrm{~nm}$; NMR data see Tables $3.9\left(\mathrm{CDCl}_{3}\right)$ and $3.10\left(\mathrm{C}_{6} \mathrm{D}_{6}\right)$; HRESIMS, obsd. $m / z 375.2163[\mathrm{M}+\mathrm{H}]^{+}, \mathrm{C}_{22} \mathrm{H}_{31} \mathrm{O}_{5}$ requires 375.2166, $\Delta 0.7$ ppm, obsd. $m / z 397.2005[\mathrm{M}+\mathrm{Na}]^{+}, \mathrm{C}_{22} \mathrm{H}_{30} \mathrm{O}_{5} \mathrm{Na}$ requires $397.1986, \Delta 4.8 \mathrm{ppm}$.

\section{Labillaride F (65)}

Colourless oil; $[\alpha]_{\mathrm{D}}^{25}+111.7(c 0.04, \mathrm{MeOH})$; UV (hexanes) $\lambda_{\max } 300 \mathrm{~nm}$; NMR data see Table 3.11; HRESIMS, obsd. $m / z 375.2162[\mathrm{M}+\mathrm{H}]^{+}, \mathrm{C}_{22} \mathrm{H}_{31} \mathrm{O}_{5}$ requires 375.2166, $\Delta$ 1.2 ppm, obsd. $m / z 397.1990[\mathrm{M}+\mathrm{Na}]^{+}, \mathrm{C}_{22} \mathrm{H}_{30} \mathrm{O}_{5} \mathrm{Na}$ requires 397.1986, $\Delta 1.1 \mathrm{ppm}$.

\section{Labillaride G (66)}

Colourless oil; $[\alpha]_{\mathrm{D}}^{25}+99.7(c 0.03, \mathrm{MeOH})$; UV (hexanes) $\lambda_{\max } 300 \mathrm{~nm}$; NMR data see Table 3.12; HRESIMS, obsd. $m / z$ 375.2158 $[\mathrm{M}+\mathrm{H}]^{+}, \mathrm{C}_{22} \mathrm{H}_{31} \mathrm{O}_{5}$ requires 375.2166, $\Delta$ 2.1 ppm, obsd. $m / z 397.1986[\mathrm{M}+\mathrm{Na}]^{+}, \mathrm{C}_{22} \mathrm{H}_{30} \mathrm{O}_{5} \mathrm{Na}$ requires 397.1986, $\Delta 0.2 \mathrm{ppm}$.

\section{Labillaride H (67)}

Colourless oil; $[\alpha]_{\mathrm{D}}^{25}+93.5(c 0.10, \mathrm{MeOH})$; UV (hexanes) $\lambda_{\max } 300 \mathrm{~nm}$; NMR data see Table 3.13; HRESIMS, obsd. $m / z$ 397.1991 [M + Na $]^{+}, \mathrm{C}_{22} \mathrm{H}_{30} \mathrm{O}_{5} \mathrm{Na}$ requires 397.1991, $\Delta 0.0 \mathrm{ppm}$. 


\section{Labillaride I (68)}

Colourless oil; $[\alpha]_{\mathrm{D}}^{25}-7.3(c 0.79, \mathrm{MeOH})$; UV (pet. ether) $\lambda_{\max } 280 \mathrm{~nm}$; NMR data see Table 3.16; HRESIMS, obsd. $m / z$ 375.2531 $[\mathrm{M}+\mathrm{H}]^{+}, \mathrm{C}_{23} \mathrm{H}_{35} \mathrm{O}_{4}^{+}$requires 375.2530, $\Delta$ $0.4 \mathrm{ppm}$.

\section{Labillaride J (69)}

Colourless oil; $[\alpha]_{\mathrm{D}}^{25}-55.3(c$ 0.19, $\mathrm{MeOH}) ; \mathrm{UV}\left(\mathrm{CH}_{3} \mathrm{CN}\right) \lambda_{\max } 278 \mathrm{~nm}$; NMR data see Table 3.17; HRESIMS, obsd. $m / z$ 317.2470 $[\mathrm{M}+\mathrm{H}]^{+}, \mathrm{C}_{21} \mathrm{H}_{33} \mathrm{O}_{2}^{+}$requires 317.2475, $\Delta$ $1.5 \mathrm{ppm}$.

\section{Labillaride K (70)}

Colourless oil; $[\alpha]_{\mathrm{D}}^{25}-15.4\left(c\right.$ 0.03, MeOH); UV (hexanes) $\lambda_{\max } 237 \mathrm{~nm}, 300 \mathrm{~nm}$; NMR data see Table 3.19; HRESIMS, obsd. $m / z$ 317.2489 $[\mathrm{M}+\mathrm{H}]^{+}, \mathrm{C}_{21} \mathrm{H}_{33} \mathrm{O}_{2}^{+}$requires 317.2475, $\Delta 4.5$ ppm, obsd. $m / z 339.2298[\mathrm{M}+\mathrm{Na}]^{+}, \mathrm{C}_{21} \mathrm{H}_{32} \mathrm{O}_{2} \mathrm{Na}^{+}$requires 339.2295, $\Delta 1.1 \mathrm{ppm}$.

\section{Degradation product (75)}

Colourless oil; UV (hexanes) $\lambda_{\max } 280 \mathrm{~nm}$; NMR data see Table 3.20; HRESIMS, obsd. $m / z 353.2087[\mathrm{M}+\mathrm{Na}]^{+}, \mathrm{C}_{21} \mathrm{H}_{30} \mathrm{O}_{3} \mathrm{Na}^{+}$requires 353.2087, $\Delta 0.1 \mathrm{ppm}$.

\subsection{Isolation of Bromophenols from Osmundaria colensoi}

The seaweed identified as Osmundaria colensoi was collected by hand using SCUBA from Taheke Reef, Cavalli Island, New Zealand ( $34^{\circ} 57.8^{\prime} \mathrm{S}, 173^{\circ} 59.0^{\prime} \mathrm{E}$ ) in December 2003, and Rimariki Island and Cape Brett, New Zealand ( $\left.35^{\circ} 25.4^{\prime} \mathrm{S}, 174^{\circ} 26.9^{\prime} \mathrm{E}\right)$ 
in November 2006. The samples were frozen immediately and kept at $-18{ }^{\circ} \mathrm{C}$ until extraction. A voucher specimen has been deposited at the School of Chemical and Physical Sciences, Victoria University of Wellington, New Zealand.

O. colensoi (496 g wet weight) was extracted for $18 \mathrm{~h}$ in $2.5 \mathrm{~L} \mathrm{MeOH}$. The extract was filtered and the algal material re-extracted for $18 \mathrm{~h}$ with a further $2.5 \mathrm{~L} \mathrm{MeOH}$. The extracts were combined and cyclic loaded to $10 \%$ of the original volume on to a reversedphase PSDVB column (HP20, $400 \mathrm{~mL}$ ). The column was eluted successively with $1.2 \mathrm{~L}$ volumes of $\mathrm{H}_{2} \mathrm{O}, 20 \%, 40 \%, 60 \%$ and $80 \% \mathrm{Me}_{2} \mathrm{CO}$ in $\mathrm{H}_{2} \mathrm{O}$ and $\mathrm{Me}_{2} \mathrm{CO}$. The $40 \% \mathrm{Me}_{2} \mathrm{CO}$ in $\mathrm{H}_{2} \mathrm{O}$ elution was backloaded on to a reversed-phase PSDVB column (HP20, $160 \mathrm{~mL}$ ) and eluted successively with $500 \mathrm{~mL}$ volumes of $\mathrm{H}_{2} \mathrm{O}$ and $\mathrm{MeOH}$. The $\mathrm{MeOH}$ eluent was concentrated to dryness under reduced pressure to yield $860 \mathrm{mg}$ of material. The resulting material was triturated in $\mathrm{MeOH}(80 \mathrm{~mL})$ and the soluble fraction was cyclic loaded on to $20 \mathrm{~mL}$ of HP20SS which was transferred to the top of a reversed-phase PSDVB column (HP20S, $250 \mathrm{~mL}$ ). The column was eluted at a flow rate of $10 \mathrm{~mL} / \mathrm{min}$ with $40 \% \mathrm{MeOH}$ in $\mathrm{H}_{2} \mathrm{O}$ for 55 mins, from $40 \%$ to $80 \% \mathrm{MeOH}$ in $\mathrm{H}_{2} \mathrm{O}$ at a solvent gradient of $0.32 \% / \mathrm{min}$, $80 \% \mathrm{MeOH}$ in $\mathrm{H}_{2} \mathrm{O}$ for 50 mins, from $80 \% \mathrm{MeOH}$ in $\mathrm{H}_{2} \mathrm{O}$ to $\mathrm{MeOH}$ at a solvent gradient of $0.4 \% / \mathrm{min}$, and $\mathrm{MeOH}$ for $80 \mathrm{~min}$. A total of 43 fractions were collected over $360 \mathrm{~min}$.

Fractions 5-11 (47\% to $64 \% \mathrm{MeOH}$ in $\mathrm{H}_{2} \mathrm{O}$ ) were combined and backloaded on to a reversed-phase PSDVB column (HP20SS, $20 \mathrm{~mL}$ ) and eluted successively with $100 \mathrm{~mL}$ volumes of $\mathrm{H}_{2} \mathrm{O}$ and $\mathrm{MeOH}$. The $\mathrm{MeOH}$ eluent was concentrated to dryness under reduced pressure. The resulting material was separated on an analytical $\mathrm{C}_{18}$ reversedphase HPLC column with $50 \% \mathrm{MeOH}$ in $0.1 \mathrm{M} \mathrm{HCOOH}$ as the mobile phase at a flow rate of $1 \mathrm{~mL} / \mathrm{min}$ to yield rhodomelol $(\mathbf{1 2 2})(1.8 \mathrm{mg})$ with a retention time of $4.9 \mathrm{~min}$

Fractions $12-16\left(64 \%\right.$ to $76 \% \mathrm{MeOH}$ in $\left.\mathrm{H}_{2} \mathrm{O}\right)$ were combined and backloaded on to a reversed-phase PSDVB column (HP20SS, $20 \mathrm{~mL}$ ) and eluted successively with $100 \mathrm{~mL}$ volumes of $\mathrm{H}_{2} \mathrm{O}$ and $\mathrm{MeOH}$. The $\mathrm{MeOH}$ eluent was concentrated to dryness under reduced pressure. The resulting material was separated on a semi-preparative $\mathrm{C}_{18}$ reversed-phase HPLC column with $60 \% \mathrm{MeOH}$ in $0.2 \mathrm{M} \mathrm{HCOOH}$ as the mobile phase at a flow rate of $5 \mathrm{~mL} / \mathrm{min}$. A total of five fractions were collected over $15 \mathrm{~min}$. Fraction 4 
with a retention time of 4.6 min was backloaded on to a reversed-phase PSDVB column (Amberchrom, $2 \mathrm{~mL}$ ) and eluted with $50 \mathrm{~mL}$ of $\mathrm{H}_{2} \mathrm{O}$, followed by $10 \mathrm{~mL}$ of $\mathrm{MeOH}$. The $\mathrm{MeOH}$ eluent was concentrated to dryness under reduced pressure to yield lanosol (110) (46.3 mg). Fractions $1-2$ with retention times 0 to 2.9 and 2.9 to $3.3 \mathrm{~min}$ respectively were combined and backloaded on to a reversed-phase PSDVB column (Amberchrom, $2 \mathrm{~mL}$ ) and eluted with $50 \mathrm{~mL} \mathrm{H}_{2} \mathrm{O}$, followed by $10 \mathrm{~mL}$ of $\mathrm{MeOH}$. The $\mathrm{MeOH}$ eluent was concentrated to dryness under reduced pressure. The resulting material was separated on a semi-preparative $\mathrm{C}_{18}$ reversed-phase HPLC column with $50 \% \mathrm{MeOH}$ in $0.2 \mathrm{M}$ $\mathrm{HCOOH}$ as the mobile phase at a flow rate of $4.75 \mathrm{~mL} / \mathrm{min}$. A total of four fractions were collected over $12.5 \mathrm{~min}$. Fraction 2 with a retention time of 4.0 min was backloaded on to a reversed-phase PSDVB column (Amberchrom, $2 \mathrm{~mL}$ ) and eluted with $50 \mathrm{~mL}$ $\mathrm{H}_{2} \mathrm{O}$, followed by $10 \mathrm{~mL}$ of $\mathrm{MeOH}$. The $\mathrm{MeOH}$ eluent was concentrated to dryness under reduced pressure and the resulting material was combined with a subsequent fraction as described below.

Fractions $17-20\left(76 \%\right.$ to $80 \% \mathrm{MeOH}$ in $\left.\mathrm{H}_{2} \mathrm{O}\right)$ were combined and backloaded on to a reversed-phase PSDVB column (HP20SS, $20 \mathrm{~mL}$ ) and eluted successively with $100 \mathrm{~mL}$ volumes of $\mathrm{H}_{2} \mathrm{O}$ and $\mathrm{MeOH}$. The $\mathrm{MeOH}$ eluent was concentrated to dryness under reduced pressure. The resulting material was separated on a semi-preparative $C_{18}$ reversed-phase HPLC column with $60 \% \mathrm{MeOH}$ in $0.2 \mathrm{M} \mathrm{HCOOH}$ as the mobile phase at a flow rate of $5 \mathrm{~mL} / \mathrm{min}$. A total of four fractions were collected over $15 \mathrm{~min}$.

Fraction 1 with a retention time of 0 to 7.5 min was backloaded on to a reversed-phase PSDVB column (Amberchrom, $2 \mathrm{~mL}$ ) and eluted with $50 \mathrm{~mL} \mathrm{H}_{2} \mathrm{O}$, followed by $10 \mathrm{~mL}$ of $\mathrm{MeOH}$. The $\mathrm{MeOH}$ eluent was concentrated to dryness under reduced pressure. The resulting material was separated repeatedly on a semi-preparative $C_{18}$ reversed-phase HPLC column with $50 \% \mathrm{MeOH}$ in $0.2 \mathrm{M} \mathrm{HCOOH}$ as the mobile phase at a flow rate of $4.75 \mathrm{~mL} / \mathrm{min}$. A total of six fractions were collected over $15 \mathrm{~min}$. Fraction 2 with a retention time of 4.9 min was backloaded on to a reversed-phase PSDVB column (Amberchrom, $2 \mathrm{~mL}$ ) and eluted with $50 \mathrm{~mL} \mathrm{H}_{2} \mathrm{O}$, followed by $10 \mathrm{~mL}$ of $\mathrm{MeOH}$. The $\mathrm{MeOH}$ eluent was concentrated to dryness under reduced pressure. The resulting material was combined with the fraction detailed above and was separated on a semi-preparative 
$\mathrm{C}_{18}$ reversed-phase HPLC column with $40 \% \mathrm{MeOH}$ in $0.2 \mathrm{M} \mathrm{HCOOH}$ as the mobile phase at a flow rate of $4.75 \mathrm{~mL} / \mathrm{min}$ to yield colensolide A (124) $(3.5 \mathrm{mg})$ with a retention time of $5.4 \mathrm{~min}$.

Fraction 3 with a retention time of 9.6 to 10.3 min was backloaded on to a reversed-phase PSDVB column (Amberchrom, $2 \mathrm{~mL}$ ) and eluted with $50 \mathrm{~mL} \mathrm{H}_{2} \mathrm{O}$, followed by $10 \mathrm{~mL}$ of $\mathrm{MeOH}$. The $\mathrm{MeOH}$ eluent was concentrated to dryness under reduced pressure. The resulting material was separated on a semi-preparative $\mathrm{C}_{18}$ reversed-phase HPLC column with $60 \% \mathrm{MeOH}$ in $0.2 \mathrm{M} \mathrm{HCOOH}$ as the mobile phase at a flow rate of $5 \mathrm{~mL} / \mathrm{min}$ to yield 2,3-dibromo-4,5-dihydroxybenzyl methyl ether (114) $(1.5 \mathrm{mg}$ ) and 2,3-dibromo4,5-dihydroxybenzaldehyde (120) (1.4 mg) with retention times of 10.1 and $11.1 \mathrm{~min}$ respectively.

Fractions $26-30\left(82 \%\right.$ to $97 \% \mathrm{MeOH}$ in $\mathrm{H}_{2} \mathrm{O}$ ) of the original HP20S column were combined and backloaded on to a reversed-phase PSDVB column (HP20SS, $20 \mathrm{~mL}$ ) and eluted successively with $100 \mathrm{~mL}$ volumes of $\mathrm{H}_{2} \mathrm{O}$ and $\mathrm{MeOH}$. The $\mathrm{MeOH}$ eluent was concentrated to dryness under reduced pressure. The resulting material was separated on a semi-preparative DIOL normal phase HPLC column with 20\% IPA in hexanes as the mobile phase at a flow rate of $5 \mathrm{~mL} / \mathrm{min}$ to yield (3E)-4-(2,3-dibromo-4,5dihydroxyphenyl)-3-butene-2-one (121) (4.6 mg) with a retention time of $7.5 \mathrm{~min}$.

\section{Acidification of colensolide A (124)}

To a sample of $124(1.7 \mathrm{mg}, 3.9 \mu \mathrm{mol})$ in $\mathrm{CD}_{3} \mathrm{OD}(250 \mu \mathrm{L})$ in a $3 \mathrm{~mm}$ NMR tube, TFA $(0.5 \mu \mathrm{L}, 6.7 \mu \mathrm{mol})$ was added to yield acidified colensolide A (125) $(1.7 \mathrm{mg})$.

\section{Methylation of Colensolide A (124) to 5-O-Methylcolensolide A (126)}

To a sample of $124(1.1 \mathrm{mg}, 2.5 \mu \mathrm{mol})$ in $500 \mu \mathrm{L}$ of dry $\mathrm{CH}_{3} \mathrm{CN}, 2.0 \mathrm{M} \mathrm{TMSCHN}{ }_{2}$ in diethyl ether (50 $\mu \mathrm{L}, 100 \mu \mathrm{mol})$ was added. The reaction was left to stir under argon at RT for $45 \mathrm{~min}$ and then quenched with $2 \% \mathrm{AcOH}(2 \mathrm{~mL})$ and left overnight. The 
resulting mixture was cyclic loaded on to $2 \mathrm{~mL}$ Amberchrom and eluted with $100 \mathrm{~mL}$ $\mathrm{H}_{2} \mathrm{O}$, followed by $10 \mathrm{~mL}$ aliquots of $20 \%, 40 \%, 60 \%$ and $80 \% \mathrm{Me}_{2} \mathrm{CO}$ in $\mathrm{H}_{2} \mathrm{O}$ and $\mathrm{Me}_{2} \mathrm{CO}$. The $80 \% \mathrm{Me}_{2} \mathrm{CO}$ in $\mathrm{H}_{2} \mathrm{O}$ fraction was concentrated to dryness under reduced pressure to yield 5-O-methylcolensolide A (126) $(0.7 \mathrm{mg})$.

\section{Methylation of 5-O-Methylcolensolide A (126) to 4,5-Di- $O$-methyl- colensolide A (127)}

To a sample of $126(0.7 \mathrm{mg}, 1.6 \mu \mathrm{mol})$ in $500 \mu \mathrm{L}$ of dry $\mathrm{CH}_{3} \mathrm{CN}$ with $\mathrm{K}_{2} \mathrm{CO}_{3}(2.1 \mathrm{mg}$, $15.2 \mu \mathrm{mol})$, MeI $(10 \mu \mathrm{L}, 160.6 \mu \mathrm{mol})$ was added. The reaction was left to stir under argon at RT for $24 \mathrm{~h}$ and then quenched with $\mathrm{H}_{2} \mathrm{O}(2 \mathrm{~mL})$. The resulting mixture was cyclic loaded on to $2 \mathrm{~mL}$ Amberchrom and eluted with $100 \mathrm{~mL} \mathrm{H}_{2} \mathrm{O}$, followed by $10 \mathrm{~mL}$ $\mathrm{MeOH}$. The $\mathrm{MeOH}$ fraction was concentrated to dryness under reduced pressure and the resulting material was separated on a analytical DIOL normal phase HPLC column with $20 \%$ IPA in hexanes as the mobile phase at a flow rate of $1 \mathrm{~mL} / \mathrm{min}$ to yield 4,5 -di- $O$ methylcolensolide A (127) (0.2 mg) with a retention time of $7.7 \mathrm{~min}$.

\section{Lanosol (110)}

Amorphous brown solid; NMR data see Tables B.3 $\left(\mathrm{CD}_{3} \mathrm{OD}\right)$ and B.4 $\left(\left(\mathrm{CD}_{3}\right)_{2} \mathrm{CO}\right)$; HRESIMS, obsd. $m / z 278.8646: 280.8626: 282.8600(1: 2: 1)\left[\mathrm{M}-\mathrm{H}_{2} \mathrm{O}+\mathrm{H}\right]^{+}$, $\mathrm{C}_{7} \mathrm{H}_{5} \mathrm{O}_{2} \mathrm{Br}_{2}^{+}$requires $278.8651: 280.8631: 282.8611, \Delta 1.6 \mathrm{ppm}$.

\section{2,3-Dibromo-4,5-dihydroxybenzyl methyl ether (114)}

Yellow oil; NMR data see Tables B.5 $\left(\mathrm{CD}_{3} \mathrm{OD}\right)$ and B.6 $\left(\left(\mathrm{CD}_{3}\right)_{2} \mathrm{CO}\right)$.

\section{2,3-Dibromo-4,5-dihydroxybenzaldehyde (120)}

Yellow oil; NMR data see Tables B.7 $\left(\mathrm{CD}_{3} \mathrm{OD}\right)$ and B.8 $\left(\left(\mathrm{CD}_{3}\right)_{2} \mathrm{CO}\right)$. 
Yellow amorphous solid; NMR data see Tables $4.2\left(\mathrm{CD}_{3} \mathrm{OD}\right)$ and $4.3\left(\left(\mathrm{CD}_{3}\right)_{2} \mathrm{CO}\right)$.

\section{Rhodomelol (122)}

Brown oil; NMR data see Tables $4.4\left(\mathrm{CD}_{3} \mathrm{OD}\right)$ and $4.5\left(\left(\mathrm{CD}_{3}\right)_{2} \mathrm{CO}\right)$.

\section{Colensolide A (124)}

Yellow oil; $[\alpha]_{\mathrm{D}}^{25}-2$ to $-6(c 0.35, \mathrm{MeOH}) ; \mathrm{UV}(\mathrm{MeOH}) \lambda_{\max } 293 \mathrm{~nm}$; NMR data see Tables $4.8\left(\mathrm{CD}_{3} \mathrm{OD}\right)$ and $4.9\left(d_{6}\right.$-DMSO); HRESIMS, obsd. $m / z 417.9386: 419.9374$ : $421.9368(1: 2: 1)\left[\mathrm{M}-\mathrm{H}_{2} \mathrm{O}+\mathrm{H}\right]^{+}, \mathrm{C}_{13} \mathrm{H}_{14} \mathrm{~N}_{3} \mathrm{O}_{3} \mathrm{Br}_{2}^{+}$requires $417.9396: 419.9377$ : 421.9358, $\Delta 2.6$ ppm, obsd. $m / z 435.9496: 437.9468: 439.9474(1: 2: 1)[\mathrm{M}+\mathrm{H}]^{+}$, $\mathrm{C}_{13} \mathrm{H}_{16} \mathrm{~N}_{3} \mathrm{O}_{4} \mathrm{Br}_{2}^{+}$requires $435.9502: 437.9482: 439.9464, \Delta 1.5 \mathrm{ppm}$.

\section{5-O-Methylcolensolide A (126)}

Colourless oil; NMR data see Table 4.11; HRESIMS, obsd. $m / z$ 449.9666 : 451.9641 : $453.9628(1: 2: 1)[\mathrm{M}+\mathrm{H}]^{+}, \mathrm{C}_{14} \mathrm{H}_{18} \mathrm{~N}_{3} \mathrm{O}_{4} \mathrm{Br}_{2}^{+}$requires 449.9659: $451.9639: 453.9621$, $\Delta 1.7 \mathrm{ppm}$.

\section{4,5-Di- $O$-methyloxycolensolide A (127)}

Colourless oil; NMR data see Table 4.12; HRESIMS, obsd. $m / z$ 463.9824 : 465.9803 : $467.9762(1: 2: 1)[\mathrm{M}+\mathrm{H}]^{+}, \mathrm{C}_{15} \mathrm{H}_{20} \mathrm{~N}_{3} \mathrm{O}_{4} \mathrm{Br}_{2}^{+}$requires $463.9821: 465.9801: 467.9783$, $\Delta 0.6 \mathrm{ppm}$. 


\section{Appendix A}

\section{Existing Sponge Screening Protocol ${ }^{*}$}

\section{Preparation}

\section{Equipment Needed (per Screen)}

- 1 x Screen column loaded with $80 \mathrm{~mL}$ of HP20 equilibrated in distilled $\mathrm{MeOH}$

- 1 x Backloading column loaded with $40 \mathrm{~mL}$ of $\mathrm{HP} 20$ equilibrated in distilled $\mathrm{MeOH}$

\section{NMR Standard}

Prepare a standard of 1,3,5-tribromobenzene in $\mathrm{CDCl}_{3}$ by dissolving $78.9 \mathrm{mg}$ of 1,3,5tribromobenzene in $5 \mathrm{~mL}$ of $\mathrm{CDCl}_{3}$.

\section{Procedure}

1. Voucher Sample Preparation

- Take a voucher specimen of ca. $10 \mathrm{~g}$ of sponge material ensuring that both the ectoderm and the endoderm are represented.

- Label and store the voucher sample in 75\% IPA in $\mathrm{H}_{2} \mathrm{O}$.

2. Extraction

- Extract ca. $100 \mathrm{~g}$ of sponge material in $400 \mathrm{~mL}$ of distilled $\mathrm{MeOH}$ overnight.

- Filter the first extract and set aside. Re-extract the sponge material (and any filter paper/celite as necessary) in $400 \mathrm{~mL}$ of distilled $\mathrm{MeOH}$ overnight.

*Last updated: $13 / 11 / 06$ 
- Filter the second extract.

- Keep all sponge material (and any filter paper/celite as necessary) until the screen is complete at which time it may be discarded.

3. Cyclic Loading

- Pass the second extract through the screen column with a flow rate of ca. $10 \mathrm{~mL} / \mathrm{min}$.

- Pass the first extract through the screen column with a flow rate of ca. $10 \mathrm{~mL} / \mathrm{min}$. Combine the eluent with that of the second extract.

- Dilute the combined eluents with $800 \mathrm{~mL}$ of distilled $\mathrm{H}_{2} \mathrm{O}$. Pass the diluted eluents back through the screen column at a flow rate of ca. $10 \mathrm{~mL} / \mathrm{min}$.

- Dilute the eluent with $1.6 \mathrm{~L}$ of distilled $\mathrm{H}_{2} \mathrm{O}$. Pass the diluted eluent back through the screen column at a flow rate of ca. $10 \mathrm{~mL} / \mathrm{min}$.

- The eluent should be kept until the screen is complete at which time it may be discarded.

4. Elution

- Elute the screen column with $250 \mathrm{~mL}$ of distilled $\mathrm{H}_{2} \mathrm{O}$ at a flow rate of ca. $10 \mathrm{~mL} / \mathrm{min}$. The $\mathrm{H}_{2} \mathrm{O}$ eluent can be discarded immediately.

- Elute the screen column with $250 \mathrm{~mL}$ of $30 \%$ distilled $\mathrm{Me}_{2} \mathrm{CO}$ in distilled $\mathrm{H}_{2} \mathrm{O}\left(75 \mathrm{~mL} \mathrm{Me}_{2} \mathrm{CO}\right.$ to $\left.175 \mathrm{~mL} \mathrm{H}_{2} \mathrm{O}\right)$ at a flow rate of ca. $10 \mathrm{~mL} / \mathrm{min}$.

- Elute the screen column with $250 \mathrm{~mL}$ of $75 \%$ distilled $\mathrm{Me}_{2} \mathrm{CO}$ in distilled $\mathrm{H}_{2} \mathrm{O}\left(187.5 \mathrm{~mL} \mathrm{Me} \mathrm{CO}_{2}\right.$ to $\left.62.5 \mathrm{~mL} \mathrm{H}_{2} \mathrm{O}\right)$ at a flow rate of ca. $10 \mathrm{~mL} / \mathrm{min}$.

- Elute the screen column with $250 \mathrm{~mL}$ of distilled $\mathrm{Me}_{2} \mathrm{CO}$ at a flow rate of ca. $10 \mathrm{~mL} / \mathrm{min}$.

5. Backloading the $75 \%$ Acetone Fraction

- Dilute the $75 \% \mathrm{Me}_{2} \mathrm{CO}$ fraction with $250 \mathrm{~mL}$ of distilled $\mathrm{H}_{2} \mathrm{O}$. Pass the diluted eluent through the backloading column at a flow rate of ca. $8 \mathrm{~mL} / \mathrm{min}$.

- Dilute the eluent with $500 \mathrm{~mL}$ of distilled $\mathrm{H}_{2} \mathrm{O}$. Pass the diluted eluent back through the backloading column at a flow rate of ca. $8 \mathrm{~mL} / \mathrm{min}$. 
- The eluent should be kept until the screen is complete at which time it may be discarded.

- Elute the backloading column with $150 \mathrm{~mL}$ of distilled $\mathrm{Me}_{2} \mathrm{CO}$.

6. Processing the $75 \%$ Acetone Fraction

- Evaporate the $\mathrm{Me}_{2} \mathrm{CO}$ eluent of the backloading column to dryness and transfer to a pre-weighed sample vial. Evaporate to dryness and record the mass.

- Sub-sample approximately $30 \mathrm{mg}$ of material for NMR analysis if necessary.

- Prepare an NMR sample in ca. $700 \mu \mathrm{L}$ of $\mathrm{CD}_{3} \mathrm{OD}$ in a $5 \mathrm{~mm}$ NMR tube.

- Add $10 \mu \mathrm{L}$ of the 1,3,5-tribromobenzene standard (representing $507 \mathrm{nmol}$ of 1,3,5-tribromobenzene) to the NMR tube.

7. NMR Analysis of the $75 \%$ Acetone Fraction

- Run a ${ }^{1} \mathrm{H}$ spectrum of the sample on the $600 \mathrm{MHz}$ instrument using the standard Screen $1 \mathrm{H}$ parameter set. (Experiment time: ca. 4 min)

- Make a note "Standard Added" in the sample text.

- Run a COSY spectrum of the sample using the standard ScreenCOSY parameter set. (Experiment time: ca. $20 \mathrm{~min}$ )

- Run an HSQC spectrum of the sample using the standard ScreenHSQC parameter set. (Experiment time: ca. $4 \mathrm{~h}$ )

- Process appropriately and export HSQC phasefile.

- Add HSQC phasefile to HSQC mask.

- Apply HSQC mask to HSQC phasefile.

8. Assigning Hit Values to the Screen

- Threshold set at 3\%.

- Signal strength

- An arbitrary value indicating how the strength of the interesting peaks. 
- Weak - 1. Medium - 2. Strong - 3 (remember to consider the subsampling factor if necessary).

- Number of interesting peaks

- Indicates how many red peaks in the HSQC. Something exhibiting more than 20 non-masked peaks will score a 10.

- Uniqueness of interesting peaks

- An arbitrary value indicating whether non-masked peaks represent something interesting (1-10).

- Available mass

- The total mass of the available sponge material (including that used for the screen) in $\mathrm{kg}$ is multiplied by 10 and rounded to the nearest integer. If more than $1 \mathrm{~kg}$ of sponge material is available the score is 10 .

- Recollectability

- Collected locally -3 . Collected from Northland -2 . Other -1 .

- Sum all 5 hit values. A score of 20 would be considered average.

9. Backloading the $30 \%$ Acetone Fraction

- Dilute the $30 \% \mathrm{Me}_{2} \mathrm{CO}$ fraction with $250 \mathrm{~mL}$ of distilled $\mathrm{H}_{2} \mathrm{O}$. Pass the diluted eluent through the backloading column at a flow rate of ca. $8 \mathrm{~mL} / \mathrm{min}$.

- Dilute the eluent with $500 \mathrm{~mL}$ of distilled $\mathrm{H}_{2} \mathrm{O}$. Pass the diluted eluent back through the backloading column at a flow rate of ca. $8 \mathrm{~mL} / \mathrm{min}$.

- The eluent should be kept until the screen is complete at which time it may be discarded.

- Elute the backloading column with $150 \mathrm{~mL}$ of distilled $\mathrm{MeOH}$.

10. Processing the $30 \%$ Acetone Fraction

- Evaporate the $\mathrm{MeOH}$ eluent of the backloading column to dryness and transfer to a pre-weighed sample vial. Evaporate to dryness and record the mass.

- Sub-sample approximately $30 \mathrm{mg}$ of material for NMR analysis if necessary. 
- Prepare an NMR sample in ca. $700 \mu \mathrm{L}$ of $\mathrm{CD}_{3} \mathrm{OD}$ in a $5 \mathrm{~mm}$ NMR tube.

11. NMR Analysis of the $30 \%$ Acetone Fraction

- Run a ${ }^{1} \mathrm{H}$ spectrum of the sample on the $600 \mathrm{MHz}$ instrument using the standard Screen1H parameter set. (Experiment time: ca. 4 min)

12. Processing the $100 \%$ Acetone Fraction

- Evaporate the $\mathrm{Me}_{2} \mathrm{CO}$ eluent of the screen column to dryness and transfer to a pre-weighed sample vial. Evaporate to dryness and the record mass.

- Sub-sample approximately $30 \mathrm{mg}$ of material for NMR analysis if necessary.

- Prepare an NMR sample in ca. $700 \mu \mathrm{L}$ of $\mathrm{CDCl}_{3}$ in a $5 \mathrm{~mm}$ NMR tube.

13. NMR Analysis of the $100 \%$ Acetone Fraction

- Run a ${ }^{1} \mathrm{H}$ spectrum of the sample on the $600 \mathrm{MHz}$ instrument using the standard Screen1H parameter set. (Experiment time: ca. 4 min) 


\section{Standard NMR Parameter Sets for Screening}

\section{Screen1H (Standard Pulse-acquire)}

$\begin{array}{lll}\text { Acquisition: } & \text { acquisition delay } & 10 \mathrm{~ms} \\ \text { nutation angle } & 60^{\circ} \\ \text { acquisition time } & 4 \mathrm{~s}(38462 \text { complex points }) \\ \text { steady-state scans } & \text { none } \\ \text { number of transients } & 64 \\ \text { temperature } & 20{ }^{\circ} \mathrm{C} \\ \text { spectral width } & 14 \mathrm{ppm} \text { to }-2 \mathrm{ppm} \\ \text { total time } & \mathrm{ca} .4 \mathrm{~min} \\ \text { fourier number } & 65536 \text { complex points } \\ \text { Processing: } & \text { neighting }\end{array}$

\section{ScreenCOSY (Absolute Value Gradient COSY)}

$\begin{array}{lll}\text { Acquisition: } & \text { acquisition delay } & 2 \mathrm{~s} \\ & \text { gradient strength } & 10 \mathrm{Gcm}^{-1} \\ & \text { gradient duration } & 1 \mathrm{~ms} \\ & \text { gradient stabilisation delay } & 500 \mu \mathrm{s} \\ & \text { number of increments } & 512 \\ & \text { acquisition time } & 213 \mathrm{~ms}(1153 \text { complex points }) \\ & \text { steady state scans } & 16 \\ & \text { number of transients } & 1 \\ & \text { temperature } & 20{ }^{\circ} \mathrm{C} \\ & \text { spectral width }\left(\mathrm{F}_{2} \& \mathrm{~F}_{1}\right) & 9 \mathrm{ppm} \text { to } 0 \text { ppm } \\ & \text { total time } & \text { ca. } 20 \text { min } \\ \text { fourier number }\left(\mathrm{F}_{2} \& \mathrm{~F}_{1}\right) & 2048 \text { complex points } \\ \text { Processing: } & \text { sinebell }\end{array}$




\section{ScreenHSQC (Adiabatic Gradient-enhanced HSQC)}

\begin{tabular}{|c|c|c|}
\hline \multirow[t]{21}{*}{ Acquisition: } & steady-state gradient strength & $13 \mathrm{Gcm}^{-1}$ \\
\hline & steady-state gradient duration & $2 \mathrm{~ms}$ \\
\hline & acquisition delay & $1.5 \mathrm{~s}$ \\
\hline & TANGO gradient strength & $10 \mathrm{Gcm}^{-1}$ \\
\hline & TANGO gradient duration & $2 \mathrm{~ms}$ \\
\hline & adiabatic sweep pulse bandwidth & $300 \mathrm{ppm}$ \\
\hline & encoding gradient strength & $10 \mathrm{Gcm}^{-1}$ \\
\hline & encoding gradient time & $4 \mathrm{~ms}$ \\
\hline & decoding gradient strength & $-6 \mathrm{Gcm}^{-1}$ \\
\hline & decoding gradient time & $2.4 \mathrm{~ms}$ \\
\hline & number of increments & 512 \\
\hline & acquisition time & $213 \mathrm{~ms}$ (1153 complex points) \\
\hline & broadband ${ }^{13} \mathrm{C}$ decoupling shape & WURST40 \\
\hline & broadband ${ }^{13} \mathrm{C}$ decoupling bandwidth & 200 ppm \\
\hline & steady state scans & 64 \\
\hline & number of transients & 8 \\
\hline & temperature & $20^{\circ} \mathrm{C}$ \\
\hline & spectral width in $\mathrm{F}_{2}$ & $9 \mathrm{ppm}$ to $0 \mathrm{ppm}$ \\
\hline & spectral width in $\mathrm{F}_{1}$ & $160 \mathrm{ppm}$ to $0 \mathrm{ppm}$ \\
\hline & ${ }^{1} J_{\mathrm{CH}}$ selection & $140 \mathrm{~Hz}$ \\
\hline & total time & ca. $4 \mathrm{~h}$ \\
\hline \multirow[t]{3}{*}{ Processing: } & fourier number in $\mathrm{F}_{2}$ & 2048 complex points \\
\hline & fourier number in $F_{1}$ & 1024 complex points \\
\hline & weighting $\left(\mathrm{F}_{2} \& \mathrm{~F}_{1}\right)$ & gaussian \\
\hline
\end{tabular}




\section{NMR Data for the Known Compounds}

\section{Costatone}

Table B.1. ${ }^{13} \mathrm{C}(150 \mathrm{MHz})$ and ${ }^{1} \mathrm{H}(600 \mathrm{MHz}) \mathrm{NMR}$ data $\left(\mathrm{CDCl}_{3}\right)$ for costatone (44).

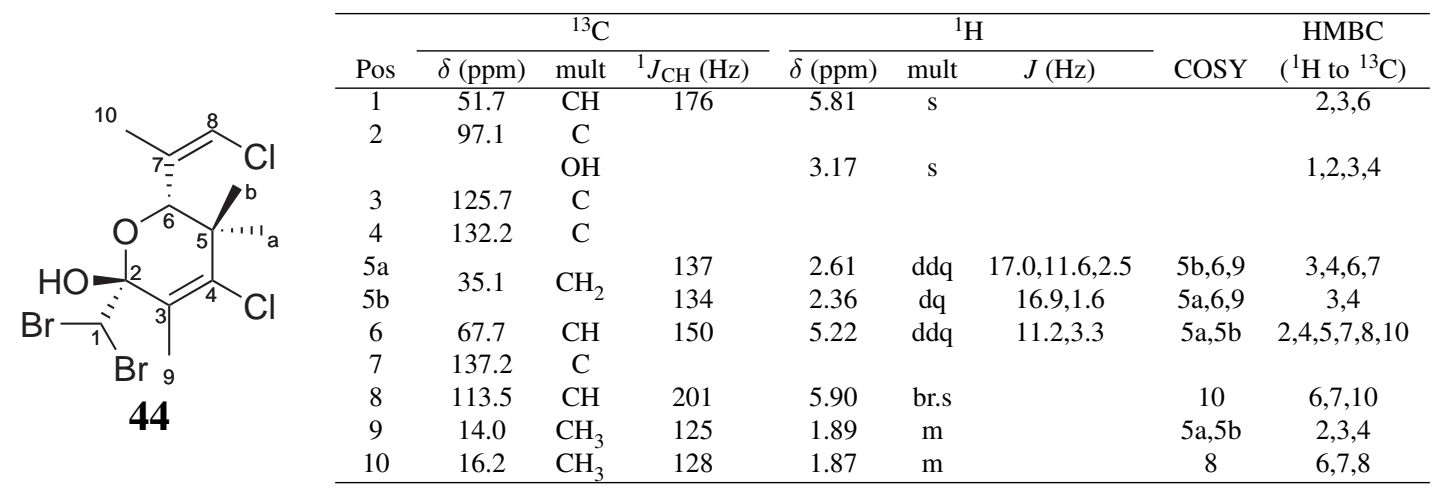

\section{$1 H$-Indole-3-carboxaldehyde}

Table B.2. ${ }^{13} \mathrm{C}(150 \mathrm{MHz})$ and ${ }^{1} \mathrm{H}(600 \mathrm{MHz}) \mathrm{NMR}$ data $\left(\mathrm{CDCl}_{3}\right)$ for $1 H$-indole-3-carboxaldehyde (45).

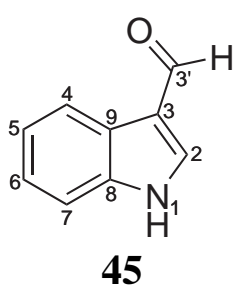

*Not observed.

\begin{tabular}{|c|c|c|c|c|c|c|c|}
\hline \multirow[b]{2}{*}{ Pos } & \multicolumn{2}{|c|}{${ }^{13} \mathrm{C}$ or ${ }^{15} \mathrm{~N}$} & \multicolumn{3}{|c|}{${ }^{1} \mathrm{H}$} & \multirow[b]{2}{*}{ COSY } & \multirow{2}{*}{$\begin{array}{c}\mathrm{HMBC} \\
\left({ }^{1} \mathrm{H} \text { to }{ }^{13} \mathrm{C}\right) \\
\end{array}$} \\
\hline & $\delta(\mathrm{ppm})$ & mult & $\overline{\delta(\mathrm{ppm})}$ & mult & $J(\mathrm{~Hz})$ & & \\
\hline 1 & & $\mathrm{NH}$ & 8.73 & br.s & & 2 & \\
\hline 2 & 135.3 & $\mathrm{CH}$ & 7.86 & d & 3.1 & 1 & $3,3^{\prime}, 8,9$ \\
\hline 3 & 119.9 & C & & & & & \\
\hline 4 & 122.2 & $\mathrm{CH}$ & 8.33 & d & 8.8 & 5 & $3,6,8$ \\
\hline 5 & 123.2 & $\mathrm{CH}$ & 7.33 & $\mathrm{td}$ & $7.1,1.6$ & 4,6 & 7,9 \\
\hline 6 & 124.6 & $\mathrm{CH}$ & 7.34 & $\mathrm{td}$ & $7.2,1.9$ & 5,7 & 4,8 \\
\hline 7 & 111.6 & $\mathrm{CH}$ & 7.45 & $\mathrm{~m}$ & & 6 & 5,9 \\
\hline 8 & 136.7 & $\mathrm{C}$ & & & & & \\
\hline 9 & 124.5 & C & & & & & \\
\hline $3^{\prime}$ & 185.3 & $\mathrm{CH}$ & 10.08 & s & & & $2,3,9$ \\
\hline
\end{tabular}




\section{Lanosol}<smiles>OCc1cc(O)c(O)c(Br)c1Br</smiles>

110

Table B.3. ${ }^{13} \mathrm{C}(150 \mathrm{MHz})$ and ${ }^{1} \mathrm{H}(600 \mathrm{MHz}) \mathrm{NMR}$ data $\left(\mathrm{CD}_{3} \mathrm{OD}\right)$ for lanosol (110).

\begin{tabular}{|c|c|c|c|c|c|}
\hline \multirow[b]{2}{*}{ Pos } & \multicolumn{2}{|c|}{${ }^{13} \mathrm{C}$} & \multicolumn{2}{|c|}{${ }^{1} \mathrm{H}$} & \multirow{2}{*}{$\begin{array}{c}\text { HMBC } \\
\left({ }^{1} \mathrm{H} \text { to }{ }^{13} \mathrm{C}\right)\end{array}$} \\
\hline & $\delta(\mathrm{ppm})$ & mult & $\overline{\delta(\mathrm{ppm})}$ & mult & \\
\hline 1 & 134.1 & $\mathrm{C}$ & & & \\
\hline 2 & 114.1 & C & & & \\
\hline 3 & 114.2 & C & & & \\
\hline 4 & 146.2 & C & & & \\
\hline 5 & 144.6 & C & & & \\
\hline 6 & 114.8 & $\mathrm{CH}$ & 7.01 & $\mathrm{~s}$ & $1,2,4,5,7$ \\
\hline 7 & 65.6 & $\mathrm{CH}_{2}$ & 4.56 & $\mathrm{~s}$ & $1,2,5,6$ \\
\hline
\end{tabular}

Table B.4. ${ }^{13} \mathrm{C}(150 \mathrm{MHz})$ and ${ }^{1} \mathrm{H}(600 \mathrm{MHz}) \mathrm{NMR}$ data $\left(\left(\mathrm{CD}_{3}\right)_{2} \mathrm{CO}\right)$ for lanosol (110).

\begin{tabular}{|c|c|c|c|c|c|c|}
\hline \multirow[b]{2}{*}{ Pos } & \multicolumn{3}{|c|}{${ }^{13} \mathrm{C}$} & \multicolumn{2}{|c|}{${ }^{1} \mathrm{H}$} & \multirow{2}{*}{$\begin{array}{c}\text { HMBC } \\
\left({ }^{1} \mathrm{H} \text { to }{ }^{13} \mathrm{C}\right)\end{array}$} \\
\hline & $\delta(\mathrm{ppm})$ & mult & ${ }^{1} J_{\mathrm{CH}}$ & $\overline{\delta(\mathrm{ppm})}$ & mult & \\
\hline 1 & 134.6 & C & & & & \\
\hline 2 & 113.3 & C & & & & \\
\hline 3 & 113.4 & C & & & & \\
\hline 4 & 145.5 & C & & & & \\
\hline 5 & 143.8 & C & & & & \\
\hline 6 & 114.5 & $\mathrm{CH}$ & 163 & 7.18 & $\mathrm{~s}$ & $1,2,4,5,7$ \\
\hline 7 & 65.0 & $\mathrm{CH}_{2}$ & 144 & 4.56 & $\mathrm{~s}$ & $1,2,5 * 6$ \\
\hline
\end{tabular}




\section{2,3-Dibromo-4,5-dihydroxybenzyl methyl ether}<smiles>COCc1cc(O)c(O)c(Br)c1Br</smiles>

114

Table B.5. ${ }^{13} \mathrm{C}(150 \mathrm{MHz})$ and ${ }^{1} \mathrm{H}(600 \mathrm{MHz}) \mathrm{NMR}$ data $\left(\mathrm{CD}_{3} \mathrm{OD}\right)$ for 2,3-dibromo-4,5-dihydroxybenzyl methyl ether (114).

\begin{tabular}{|c|c|c|c|c|c|}
\hline \multirow[b]{2}{*}{ Pos } & \multicolumn{2}{|c|}{${ }^{13} \mathrm{C}$} & \multicolumn{2}{|c|}{${ }^{1} \mathrm{H}$} & \multirow{2}{*}{$\begin{array}{c}\text { HMBC } \\
\left({ }^{1} \mathrm{H} \text { to }{ }^{13} \mathrm{C}\right)\end{array}$} \\
\hline & $\delta(\mathrm{ppm})$ & mult & $\delta(\mathrm{ppm})$ & mult & \\
\hline 1 & 131.0 & $\mathrm{C}$ & & & \\
\hline 2 & 115.3 & $\mathrm{C}$ & & & \\
\hline 3 & 114.5 & $\mathrm{C}$ & & & \\
\hline 4 & 145.3 & $\mathrm{C}$ & & & \\
\hline 5 & 146.3 & $\mathrm{C}$ & & & \\
\hline 6 & 115.8 & $\mathrm{CH}$ & 6.92 & $\mathrm{~s}$ & $1,2,3,4,5,7$ \\
\hline 7 & 74.5 & $\mathrm{CH}_{2}$ & 4.42 & $\mathrm{~s}$ & 6,8 \\
\hline 8 & 58.5 & $\mathrm{CH}_{3}$ & 3.39 & $\mathrm{~s}$ & 7 \\
\hline
\end{tabular}

Table B.6. ${ }^{13} \mathrm{C}(150 \mathrm{MHz})$ and ${ }^{1} \mathrm{H}(600 \mathrm{MHz})$ NMR data $\left(\left(\mathrm{CD}_{3}\right)_{2} \mathrm{CO}\right)$ for 2,3-dibromo-4,5-dihydroxybenzyl methyl ether (114).

\begin{tabular}{|c|c|c|c|c|c|c|}
\hline \multirow[b]{2}{*}{ Pos } & \multicolumn{3}{|c|}{${ }^{13} \mathrm{C}$} & \multicolumn{2}{|c|}{${ }^{1} \mathrm{H}$} & \multirow{2}{*}{$\begin{array}{c}\text { HMBC } \\
\left({ }^{1} \mathrm{H} \text { to }{ }^{13} \mathrm{C}\right)\end{array}$} \\
\hline & $\delta(\mathrm{ppm})$ & mult & ${ }^{1} J_{\mathrm{CH}}$ & $\delta(\mathrm{ppm})$ & mult & \\
\hline 1 & 131.3 & $\mathrm{C}$ & & & & \\
\hline 2 & 114.5 & $\mathrm{C}$ & & & & \\
\hline 3 & 113.7 & $\mathrm{C}$ & & & & \\
\hline 4 & 145.7 & $\mathrm{C}$ & & & & \\
\hline 5 & 144.7 & $\mathrm{C}$ & & & & \\
\hline 6 & 115.6 & $\mathrm{CH}$ & 164 & 7.05 & $\mathrm{~s}$ & $1,2,3,4,5,7$ \\
\hline 7 & 75.1 & $\mathrm{CH}_{2}$ & 144 & 4.39 & $\mathrm{~s}$ & $1,2,3,5,6,8$ \\
\hline 8 & 58.4 & $\mathrm{CH}_{3}$ & 139.9 & 3.38 & $\mathrm{~s}$ & 7 \\
\hline
\end{tabular}




\section{2,3-Dibromo-4,5-dihydroxybenzaldehyde}<smiles>O=Cc1cc(O)c(O)c(Br)c1Br</smiles>

120

Table B.7. ${ }^{13} \mathrm{C}(150 \mathrm{MHz})$ and ${ }^{1} \mathrm{H}(600 \mathrm{MHz})$ NMR data $\left(\mathrm{CD}_{3} \mathrm{OD}\right)$ for 2,3-dibromo-4,5-dihydroxybenzaldehyde (120).

\begin{tabular}{|c|c|c|c|c|c|}
\hline \multirow[b]{2}{*}{ Pos } & \multicolumn{2}{|c|}{${ }^{13} \mathrm{C}$} & \multicolumn{2}{|c|}{${ }^{1} \mathrm{H}$} & \multirow{2}{*}{$\begin{array}{c}\text { HMBC } \\
\left({ }^{1} \mathrm{H} \text { to }{ }^{13} \mathrm{C}\right)\end{array}$} \\
\hline & $\delta(\mathrm{ppm})$ & mult & $\delta(\mathrm{ppm})$ & mult & \\
\hline 1 & 128.3 & $\mathrm{C}$ & & & \\
\hline 2 & 122.2 & $\mathrm{C}$ & & & \\
\hline 3 & 114.8 & $\mathrm{C}$ & & & \\
\hline 4 & 152.5 & $\mathrm{C}$ & & & \\
\hline 5 & 146.6 & $\mathrm{C}$ & & & \\
\hline 6 & 114.4 & $\mathrm{CH}$ & 7.34 & $\mathrm{~s}$ & $1,2,3,4,4,5,7$ \\
\hline 7 & 192.7 & $\mathrm{CH}$ & 10.13 & $\mathrm{~s}$ & $1,5,6$ \\
\hline
\end{tabular}

Table B.8. ${ }^{13} \mathrm{C}(150 \mathrm{MHz})$ and ${ }^{1} \mathrm{H}(600 \mathrm{MHz}) \mathrm{NMR}$ data $\left(\left(\mathrm{CD}_{3}\right)_{2} \mathrm{CO}\right)$ for 2,3-dibromo-4,5-dihydroxybenzaldehyde (120).

\begin{tabular}{|c|c|c|c|c|c|c|}
\hline \multirow[b]{2}{*}{ Pos } & \multicolumn{3}{|c|}{${ }^{13} \mathrm{C}$} & \multicolumn{2}{|c|}{${ }^{1} \mathrm{H}$} & \multirow{2}{*}{$\begin{array}{c}\text { HMBC } \\
\left({ }^{1} \mathrm{H} \text { to }{ }^{13} \mathrm{C}\right)\end{array}$} \\
\hline & $\delta(\mathrm{ppm})$ & mult & ${ }^{1} J_{\mathrm{CH}}$ & $\overline{\delta(\mathrm{ppm})}$ & mult & \\
\hline 1 & 128.3 & $\mathrm{C}$ & & & & \\
\hline 2 & 121.6 & $\mathrm{C}$ & & & & \\
\hline 3 & 114.4 & $\mathrm{C}$ & & & & \\
\hline 4 & 151.4 & $\mathrm{C}$ & & & & \\
\hline 5 & 145.8 & C & & & & \\
\hline 6 & 114.5 & $\mathrm{CH}$ & 166 & 7.42 & $\mathrm{~s}$ & $1,2,3,4,4,5,7$ \\
\hline 7 & 191.3 & $\mathrm{CH}$ & 184 & 10.15 & $\mathrm{~s}$ & $1,5,6$ \\
\hline
\end{tabular}




\section{Appendix C}

\section{${ }^{1}$ H NMR Spectra of the Known Compounds}

\section{Costatone}

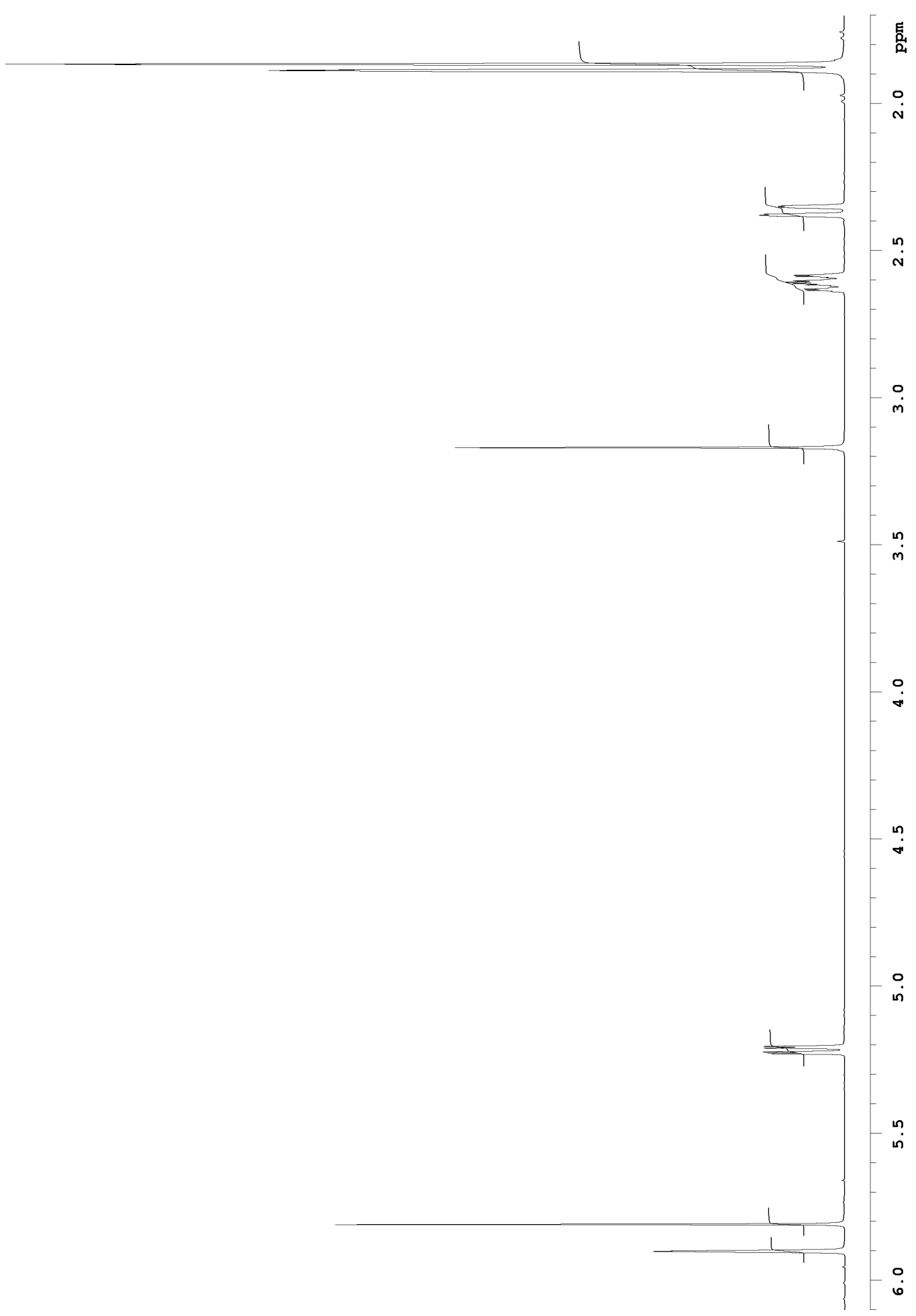

${ }^{1} \mathrm{H}$ NMR spectrum of costatone (44) $\left(600 \mathrm{MHz}, \mathrm{CDCl}_{3}\right)$ 


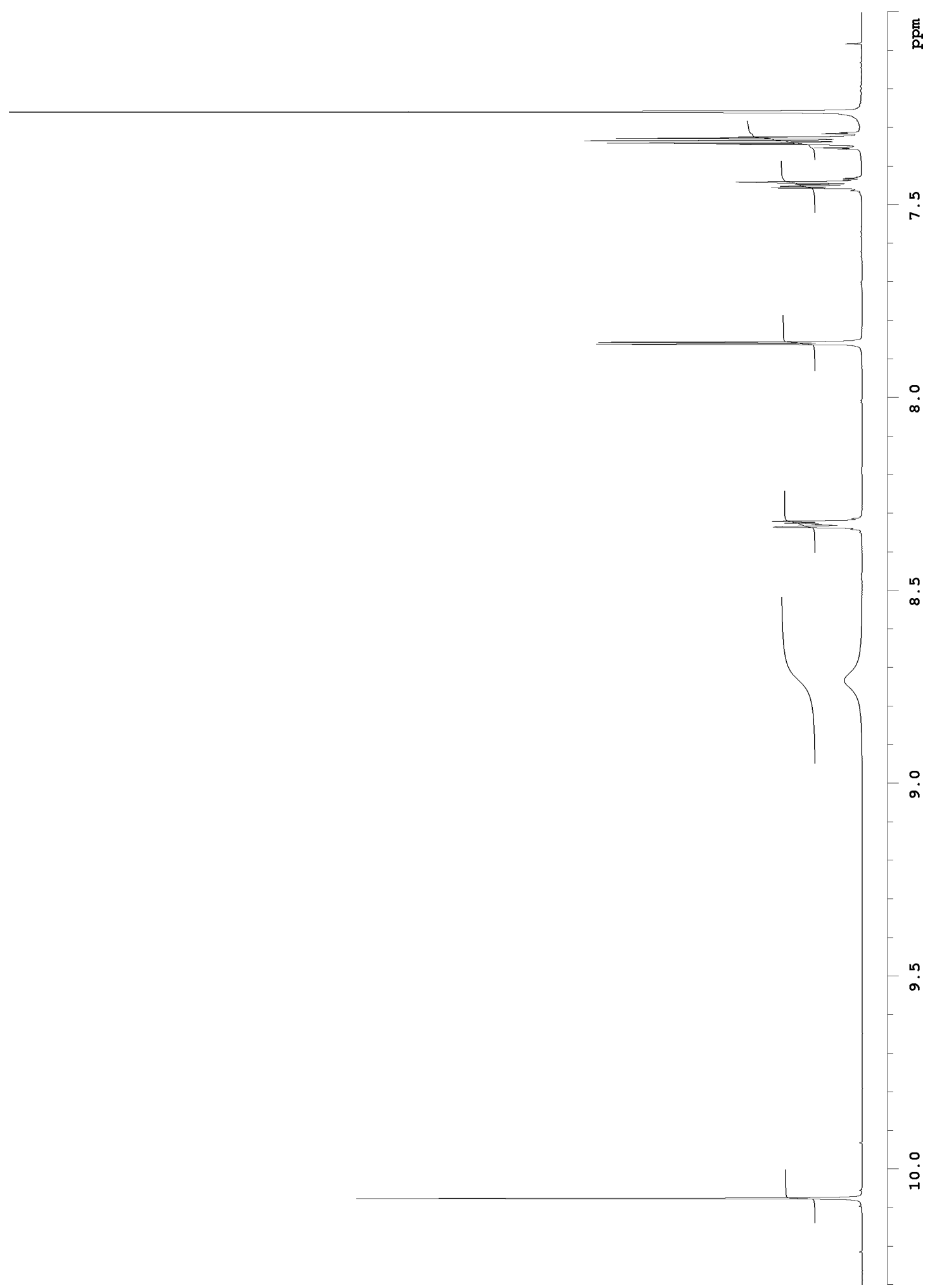

${ }^{1} \mathrm{H}$ NMR spectrum of $1 \mathrm{H}$-indole-3-carboxaldehyde (45) $\left(600 \mathrm{MHz}, \mathrm{CDCl}_{3}\right)$ 


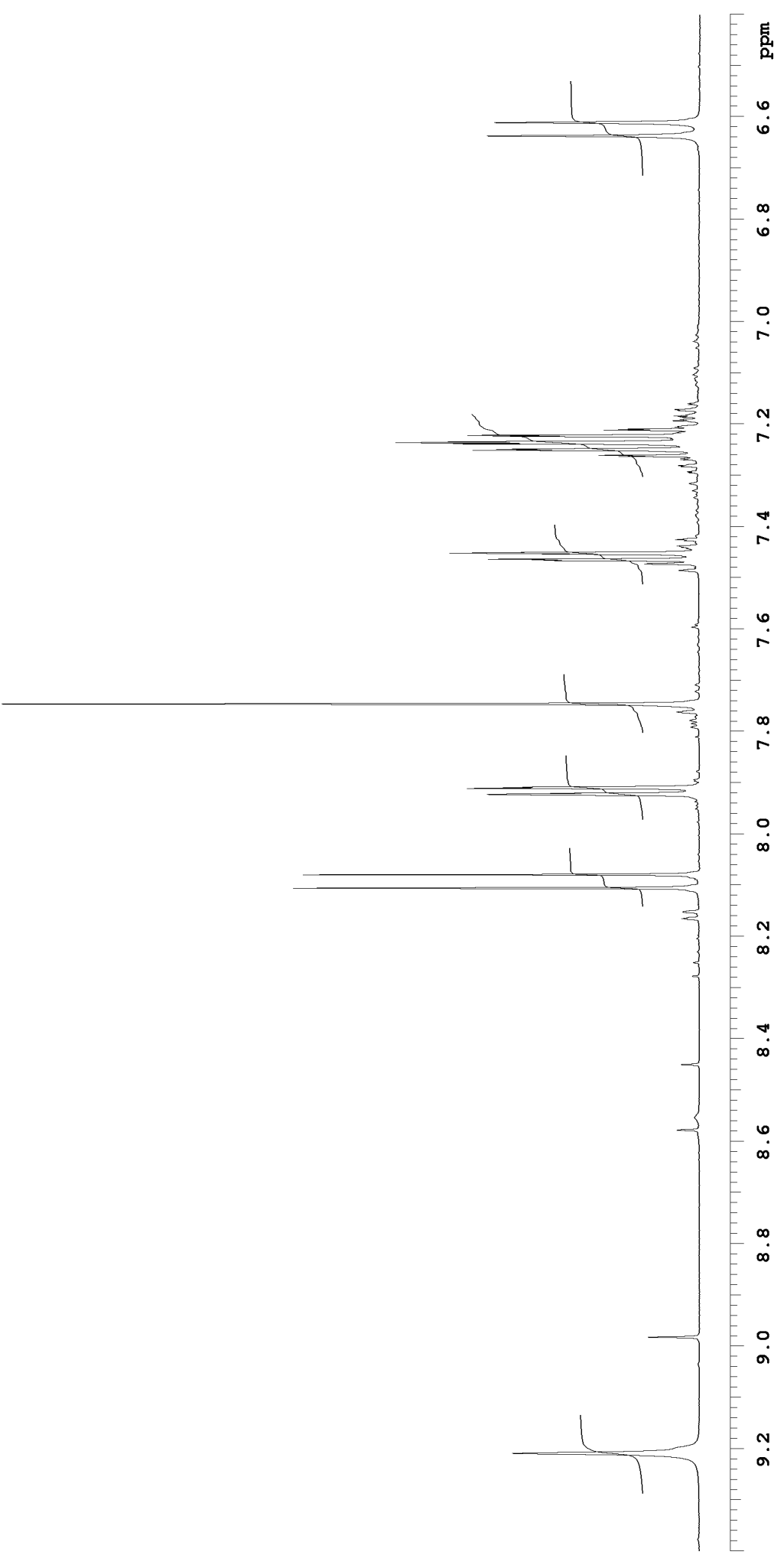

${ }^{1} \mathrm{H}$ NMR spectrum of $(E)-N$-formyl-3-( $1 H$-indol-3-yl)prop-2-enamide (46) $\left(600 \mathrm{MHz}, \mathrm{CD}_{3} \mathrm{OD}\right)$ 


\section{Lanosol}

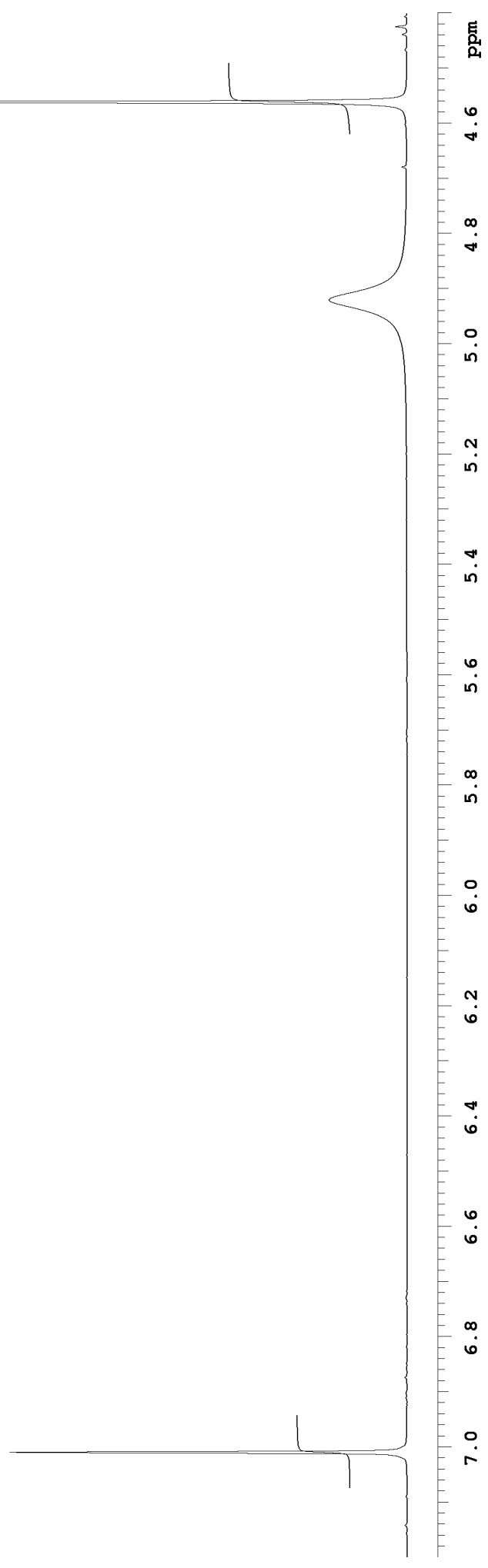

${ }^{1} \mathrm{H}$ NMR spectrum of lanosol (110) $\left(600 \mathrm{MHz}, \mathrm{CD}_{3} \mathrm{OD}\right)$ 
2,3-Dibromo-4,5-dihydroxybenzyl methyl ether

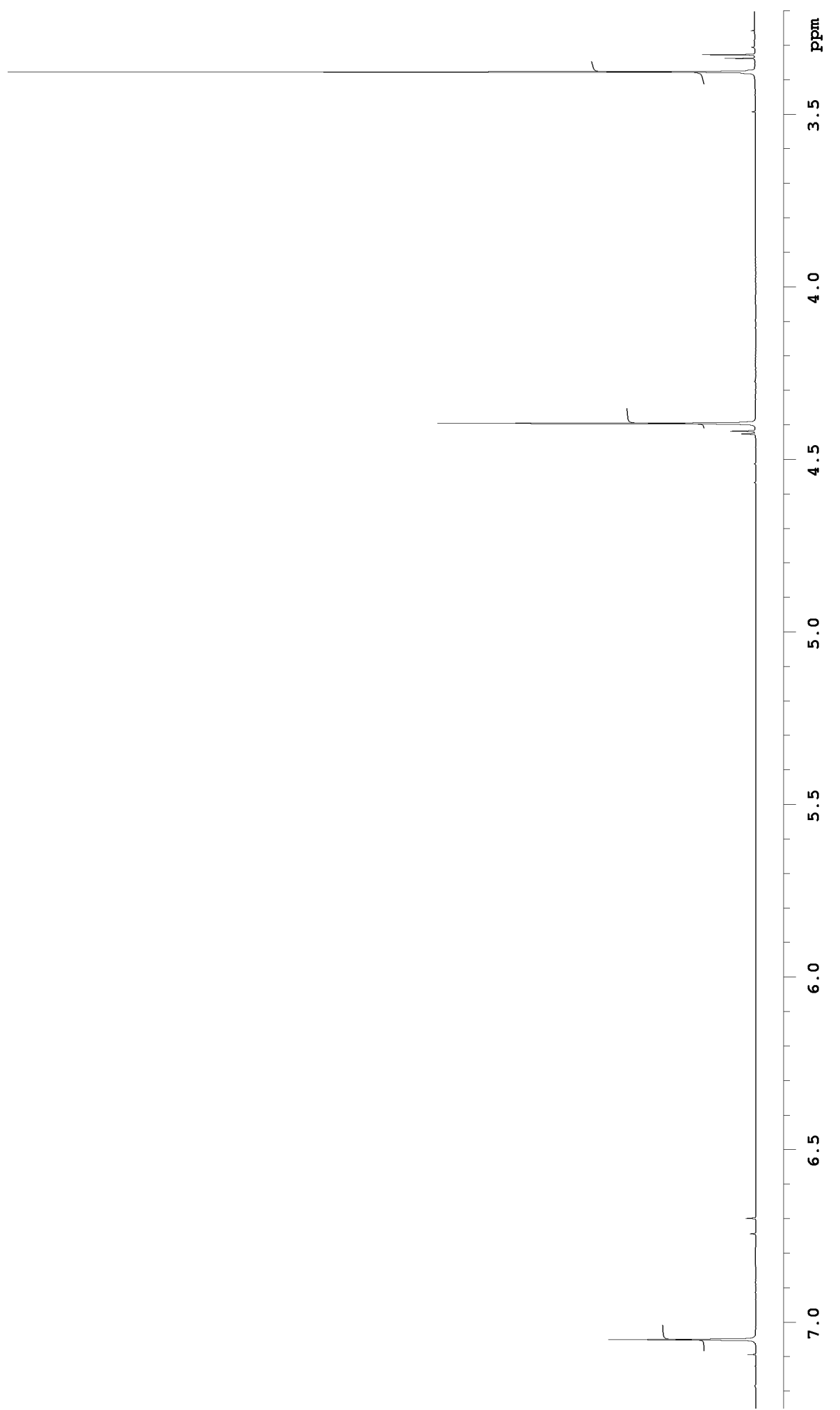

${ }^{1} \mathrm{H}$ NMR spectrum of 2,3-dibromo-4,5-dihydroxybenzyl methyl ether (114) $\left(600 \mathrm{MHz},\left(\mathrm{CD}_{3}\right)_{2} \mathrm{CO}\right)$ 


\section{2,3-Dibromo-4,5-dihydroxybenzaldehyde}

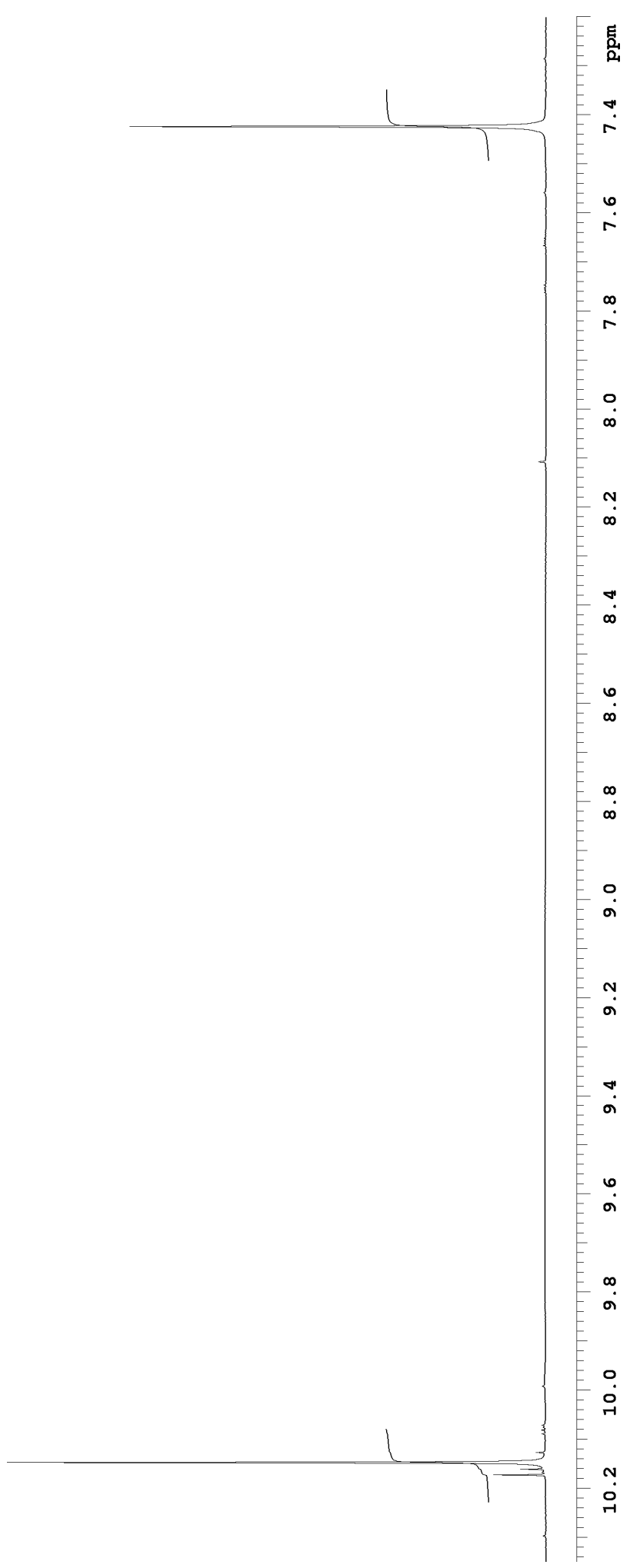

${ }^{1} \mathrm{H}$ NMR spectrum of 2,3-dibromo-4,5-dihydroxybenzaldehyde (120) $\left(600 \mathrm{MHz},\left(\mathrm{CD}_{3}\right)_{2} \mathrm{CO}\right)$ 


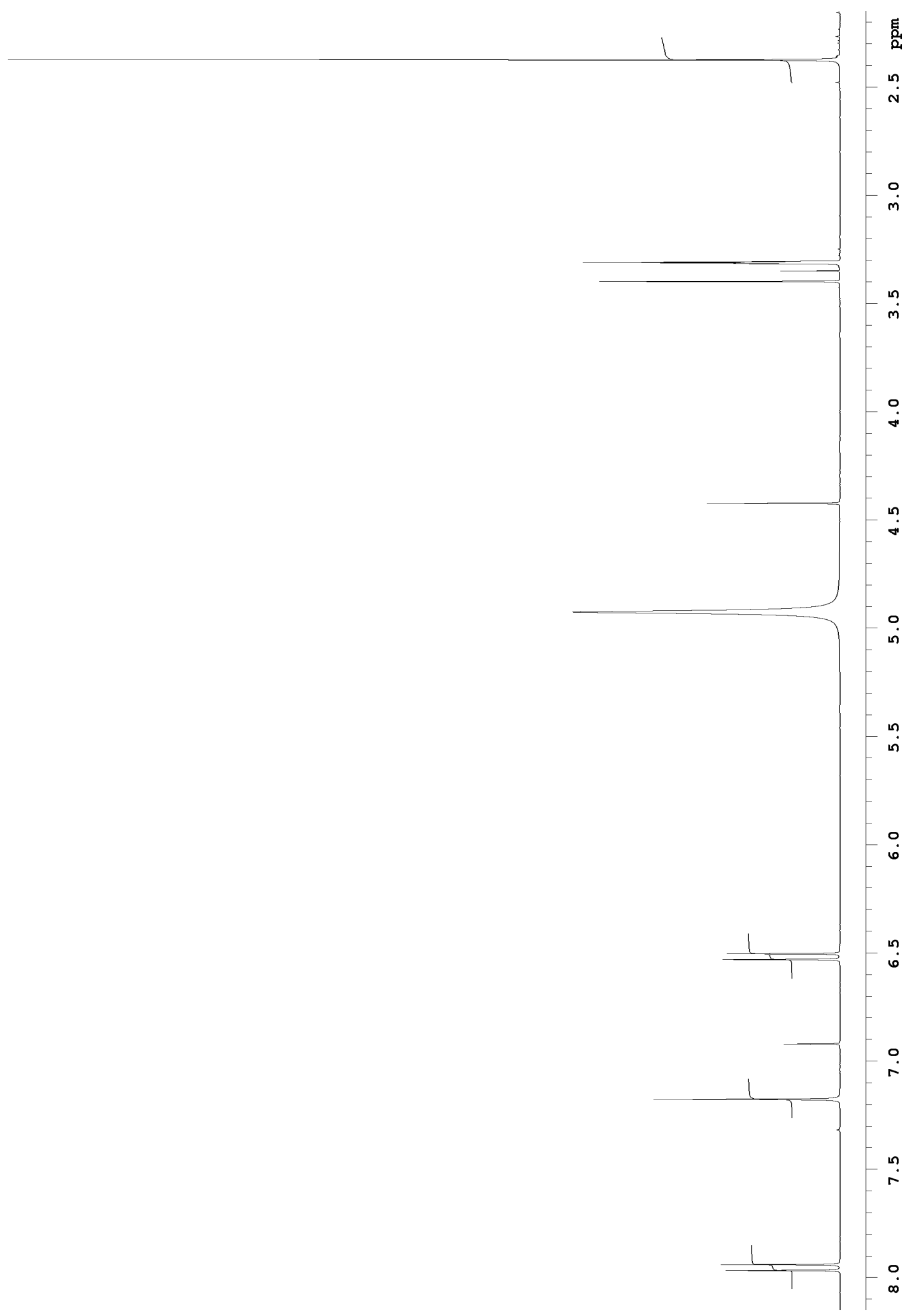

${ }^{1} \mathrm{H}$ NMR spectrum of (3E)-4-(2,3-dibromo-4,5-dihydroxyphenyl)-3-butene-2-one (121) $\left(600 \mathrm{MHz}, \mathrm{CD}_{3} \mathrm{OD}\right)$ 


\section{Rhodomelol}

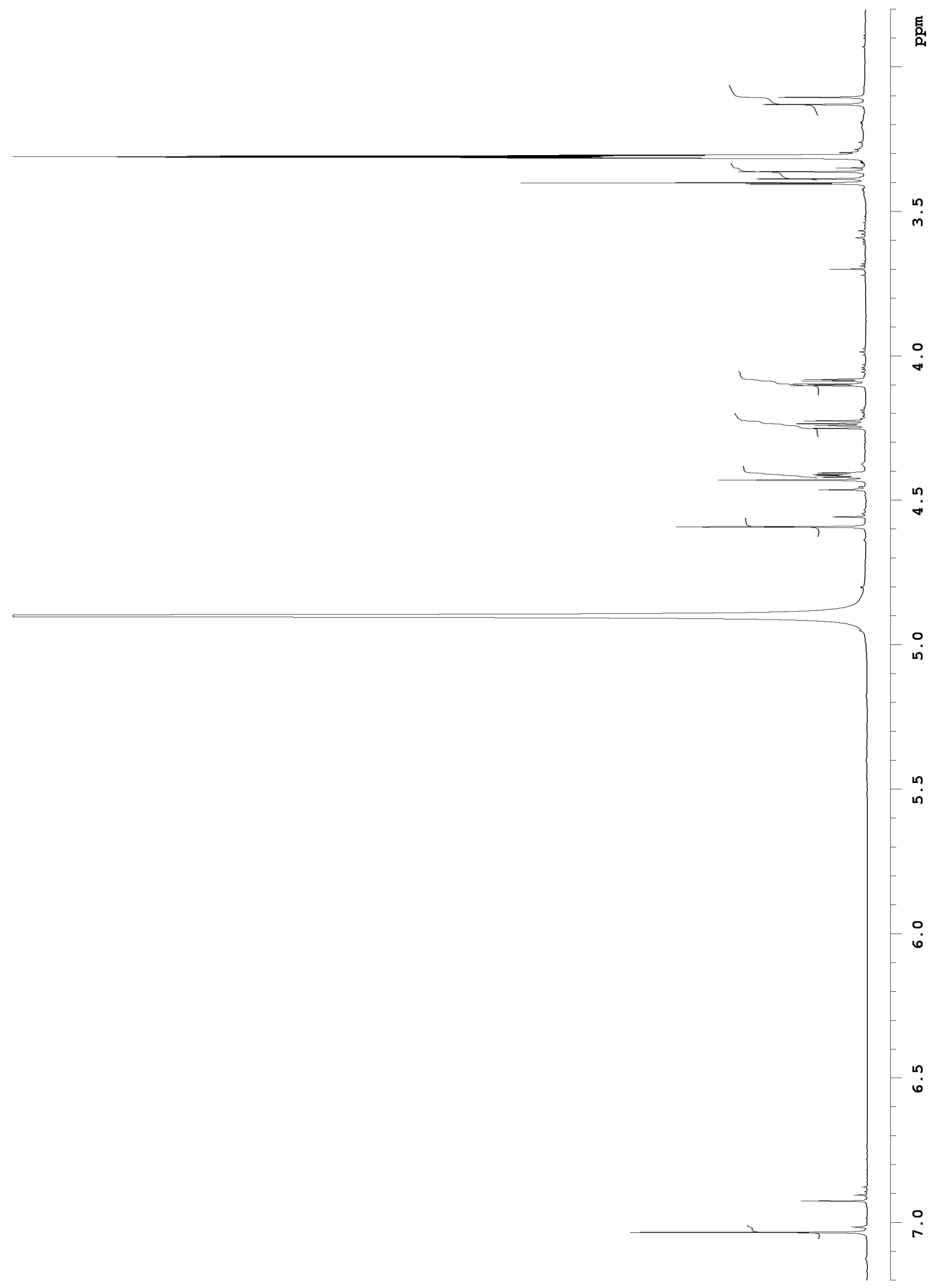

${ }^{1} \mathrm{H}$ NMR spectrum of rhodomelol (122) $\left(600 \mathrm{MHz}, \mathrm{CD}_{3} \mathrm{OD}\right)$ 
Appendix D

NMR Spectra of Labillaride A

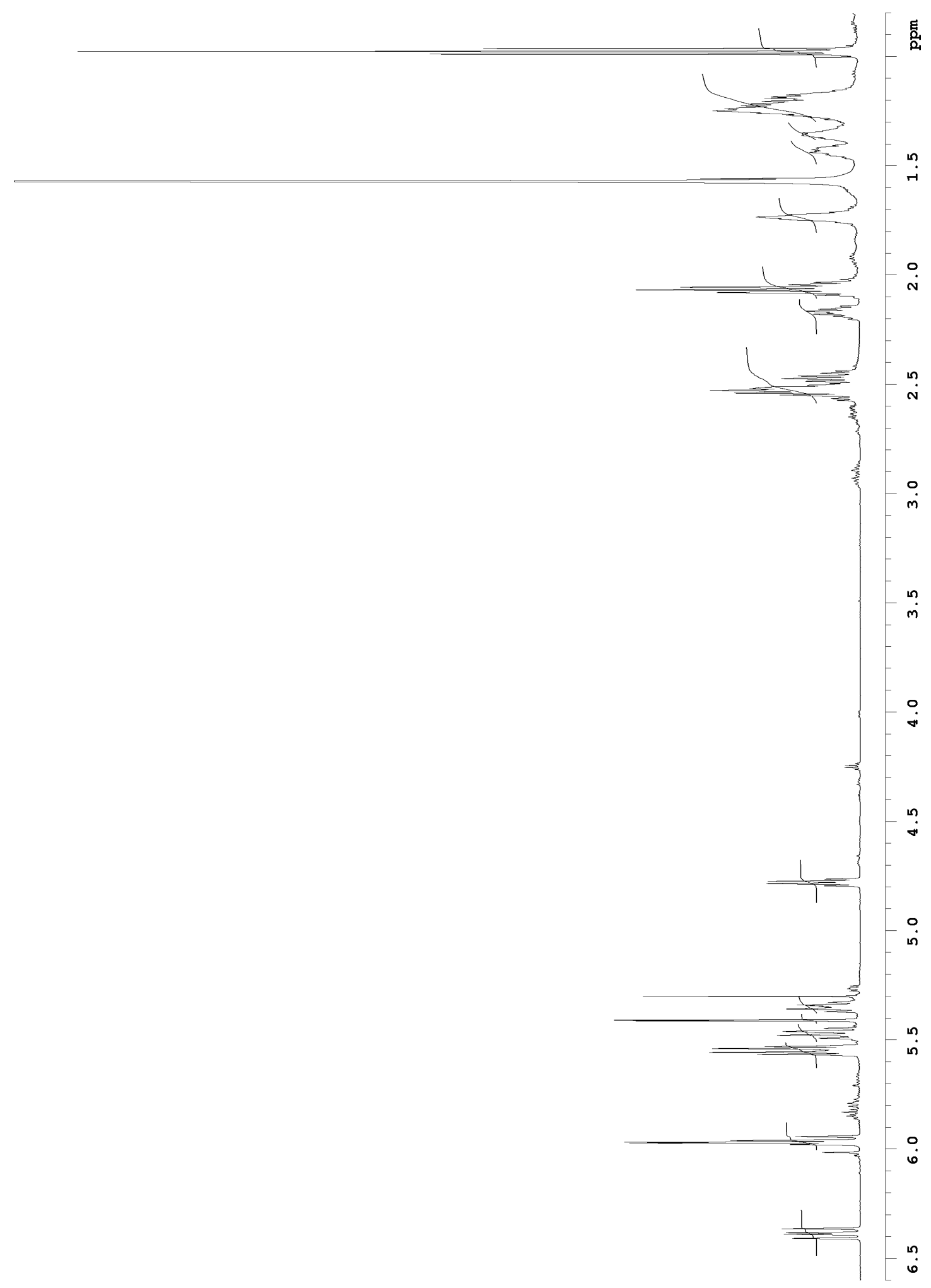

${ }^{1} \mathrm{H}$ NMR spectrum of labillaride A (60) $\left(600 \mathrm{MHz}, \mathrm{CDCl}_{3}\right)$ 


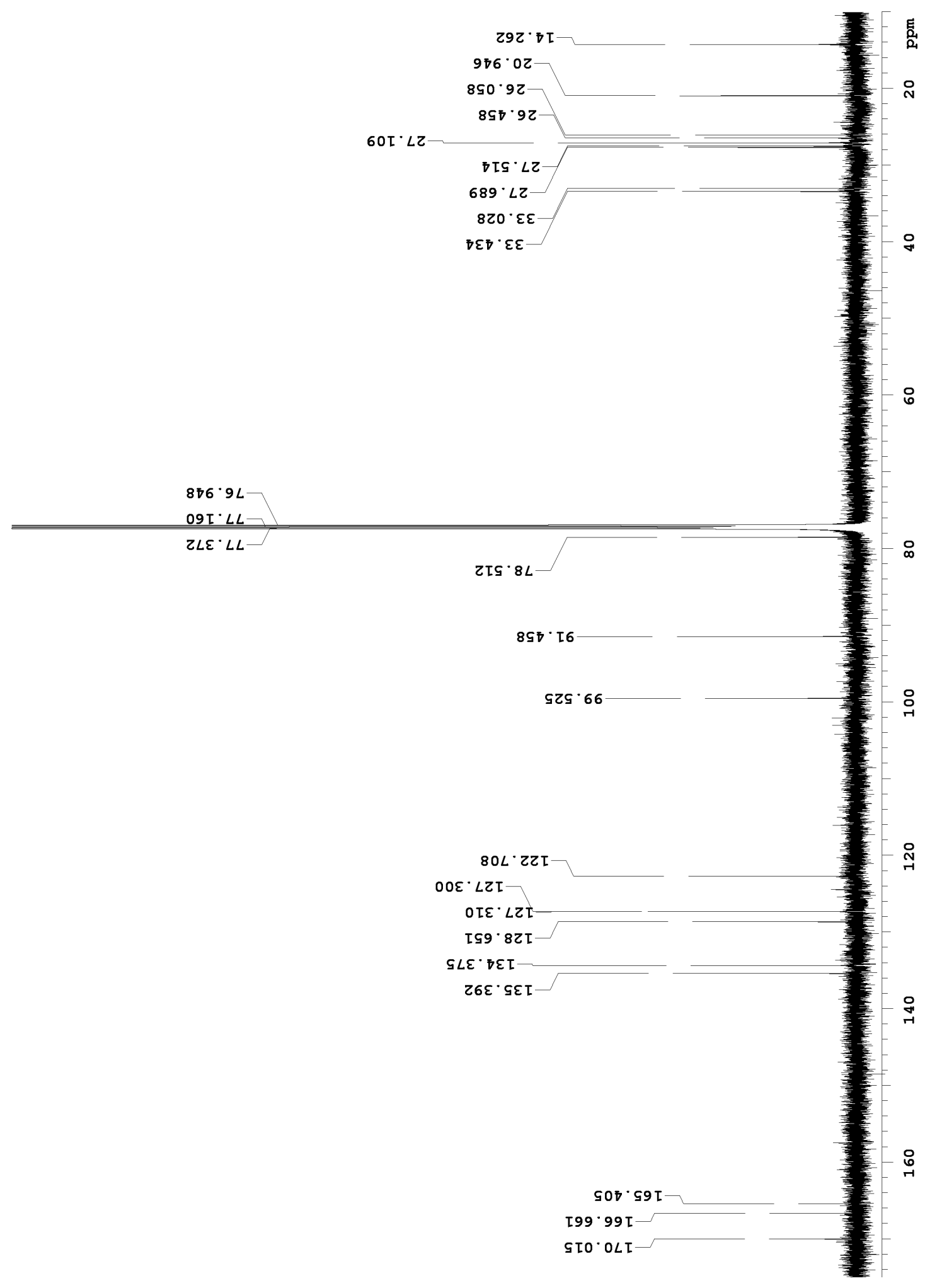

${ }^{13} \mathrm{C}$ NMR spectrum of labillaride A (60) $\left(150 \mathrm{MHz}, \mathrm{CDCl}_{3}\right)$ 


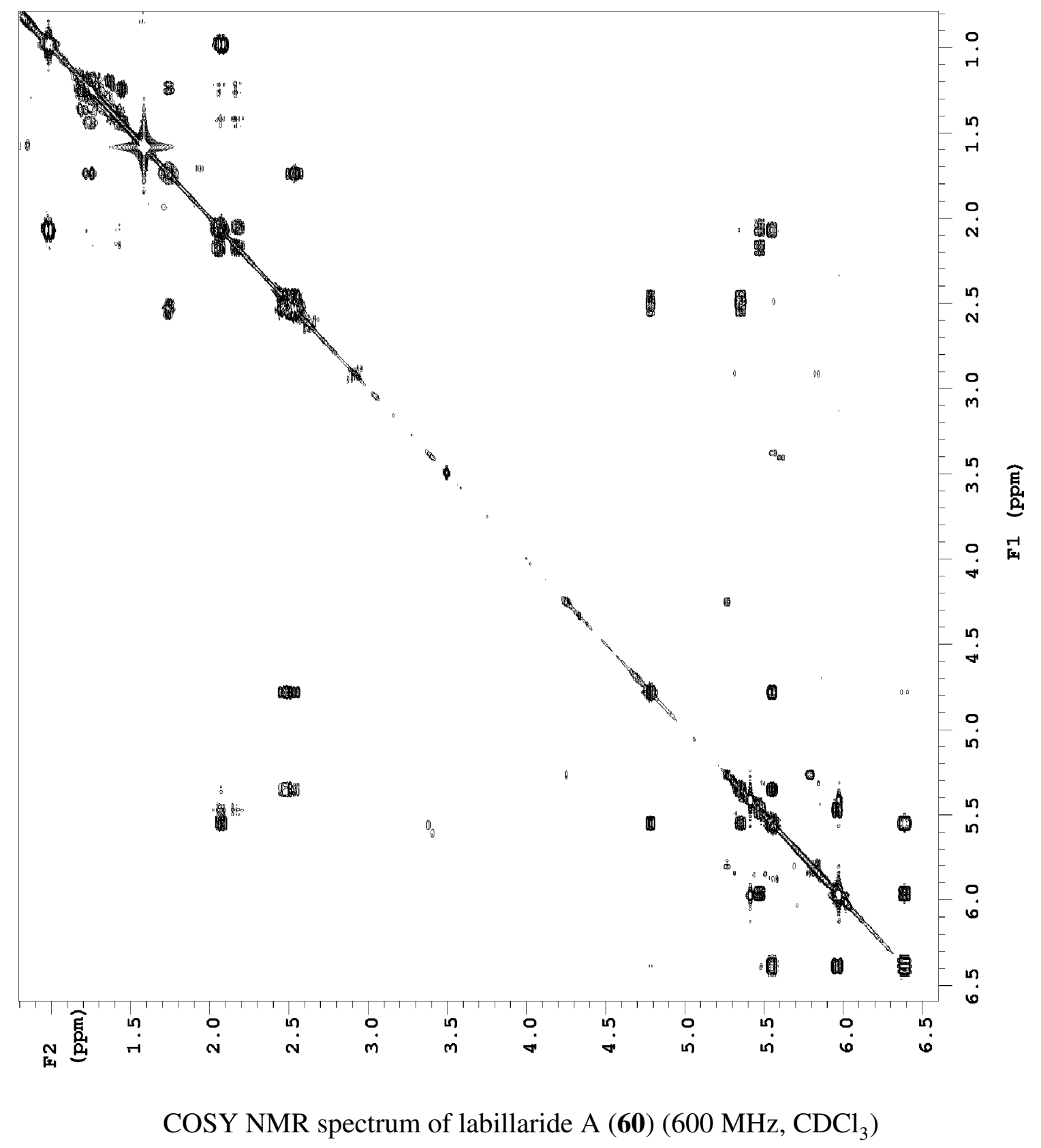




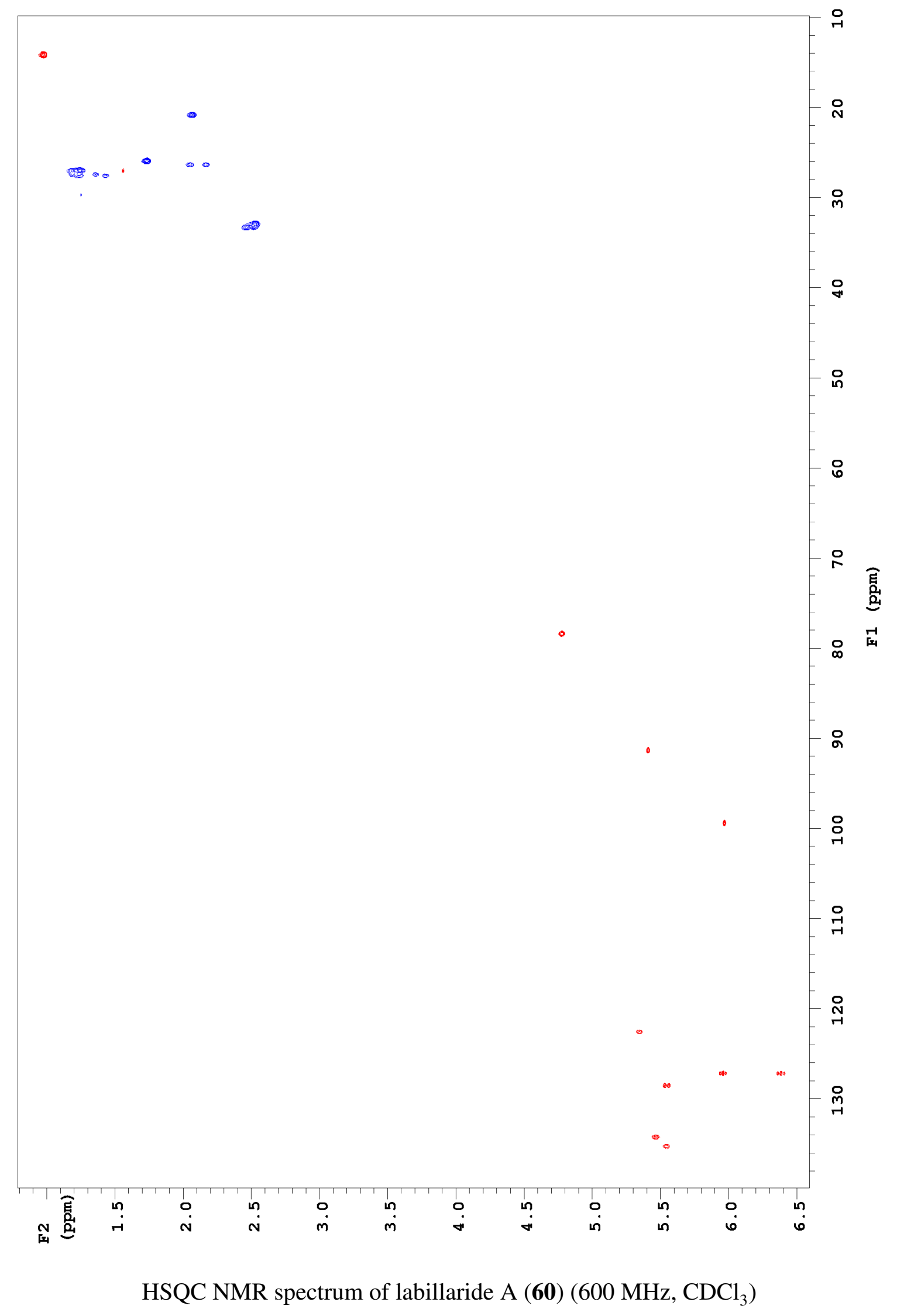




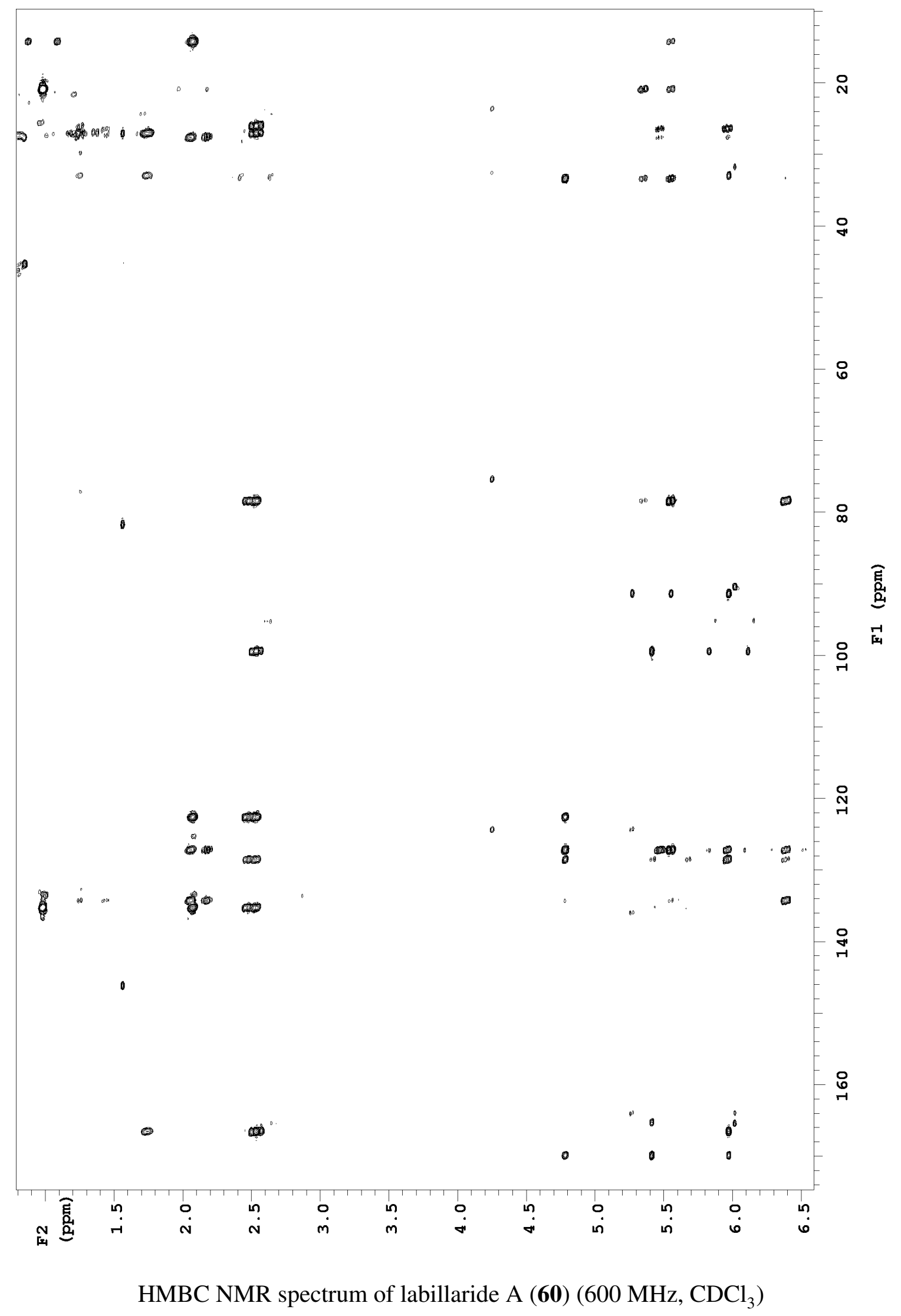




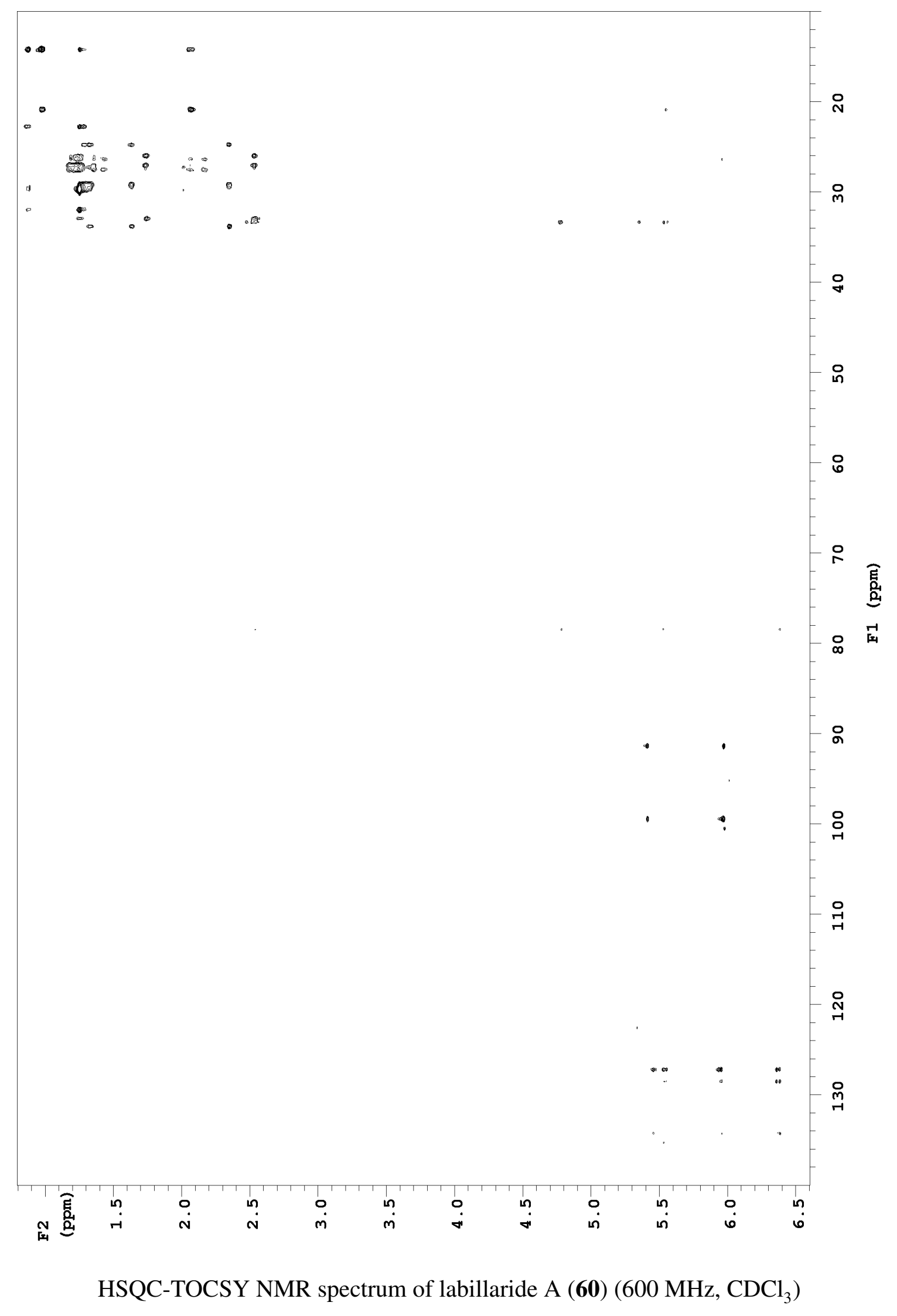


NMR Spectra of Labillaride B

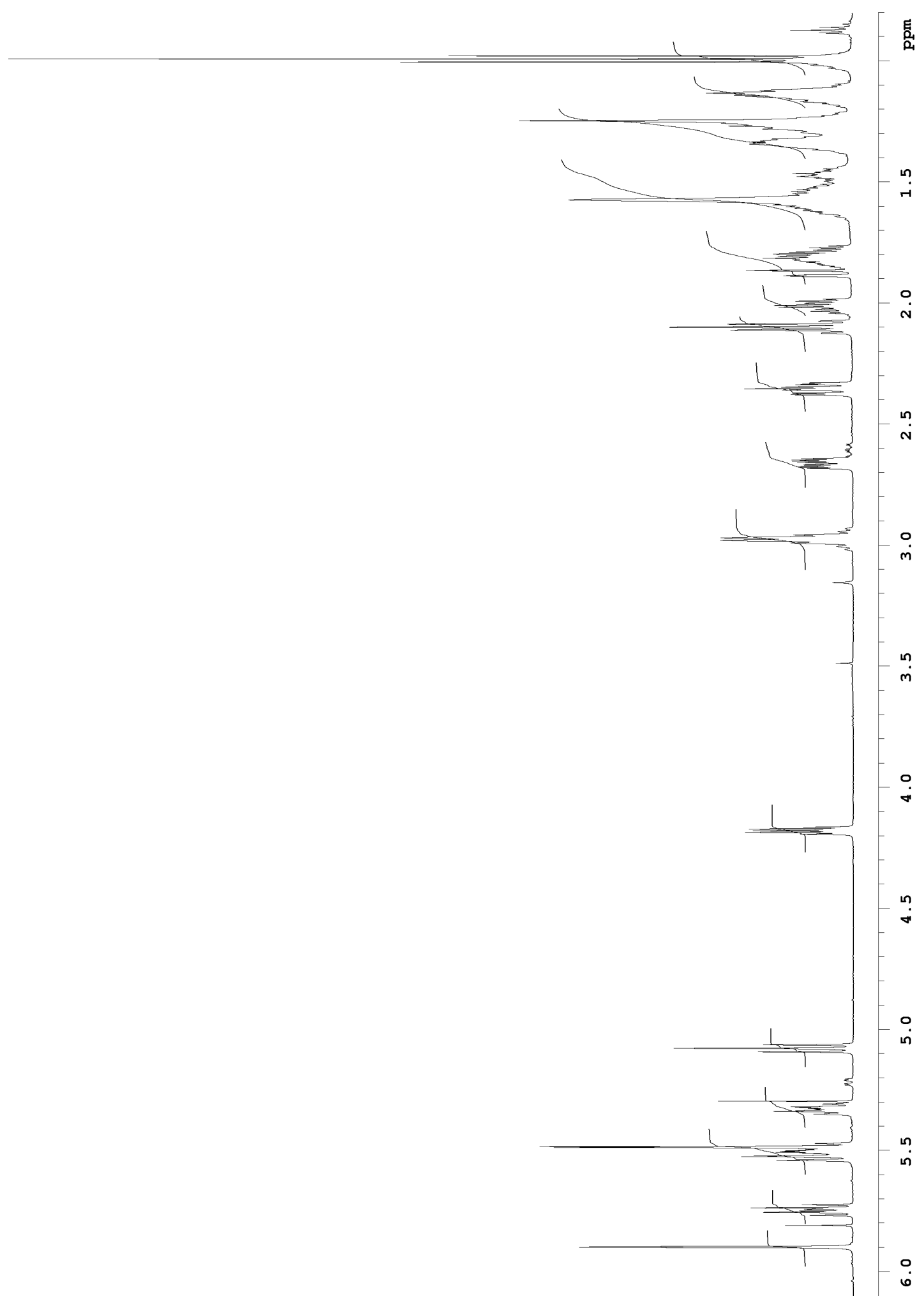

${ }^{1} \mathrm{H}$ NMR spectrum of labillaride B (61) $\left(600 \mathrm{MHz}, \mathrm{CDCl}_{3}\right)$ 


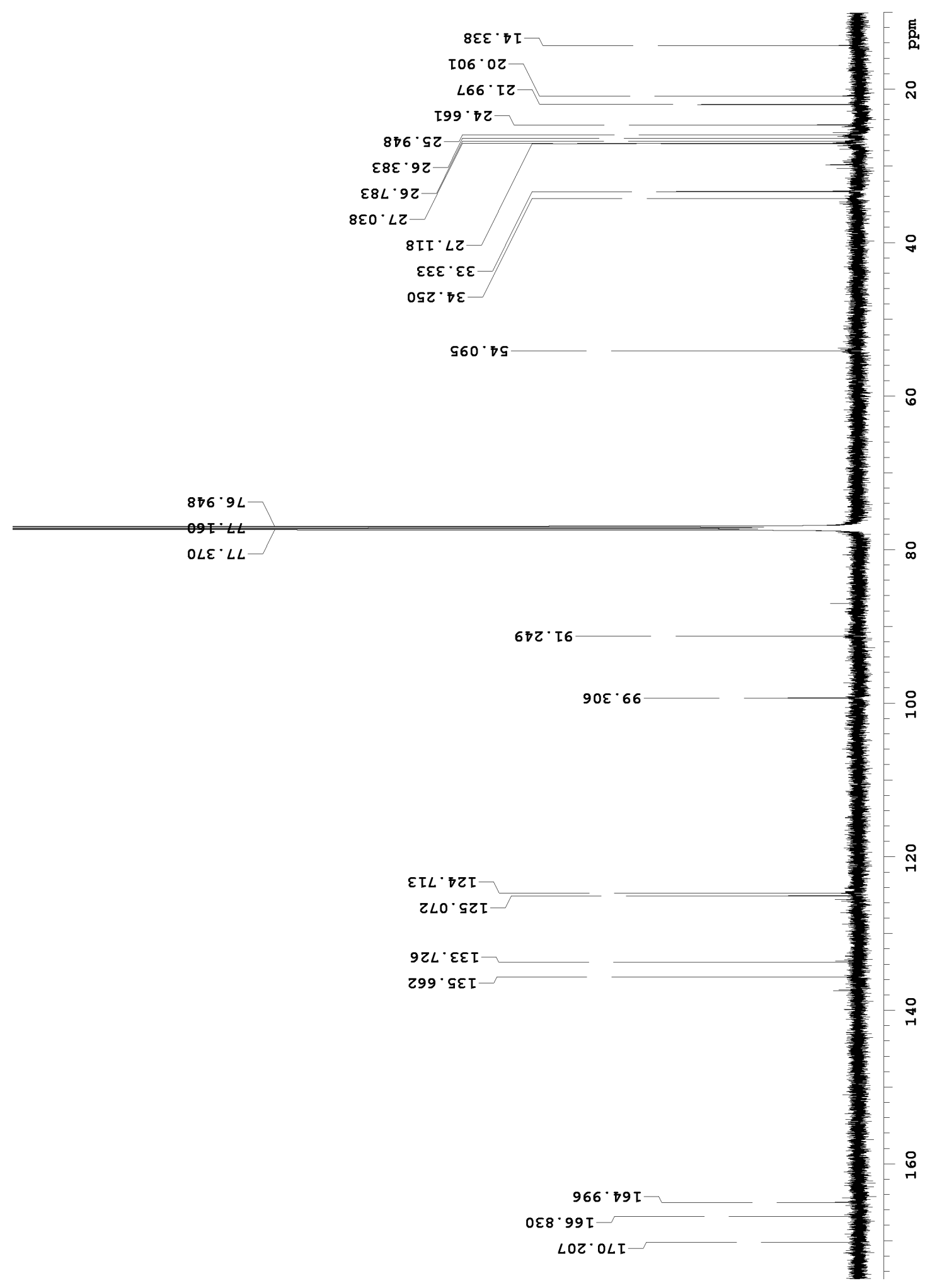

${ }^{13} \mathrm{C}$ NMR spectrum of labillaride B $(\mathbf{6 1})\left(150 \mathrm{MHz}, \mathrm{CDCl}_{3}\right)$ 


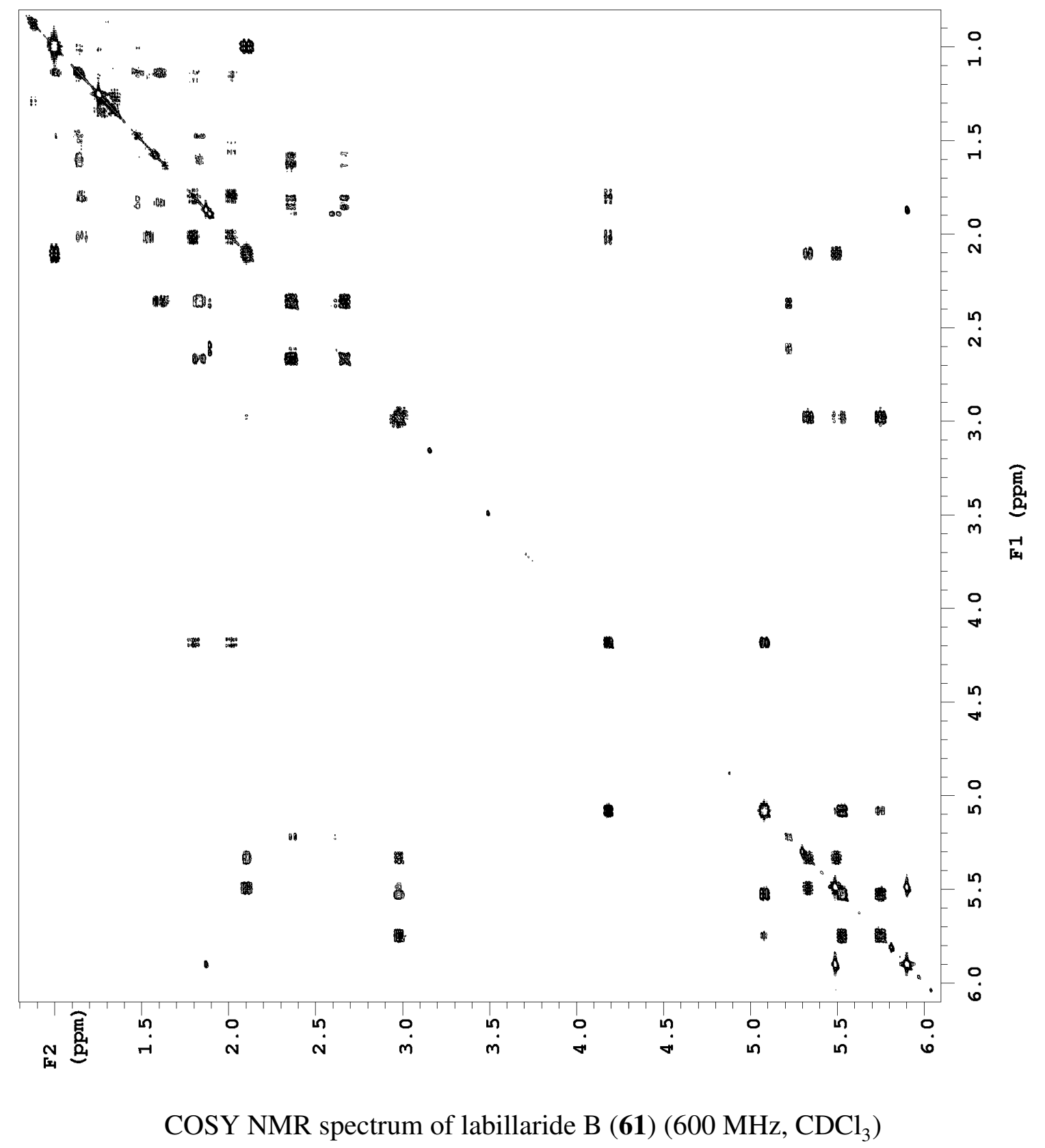




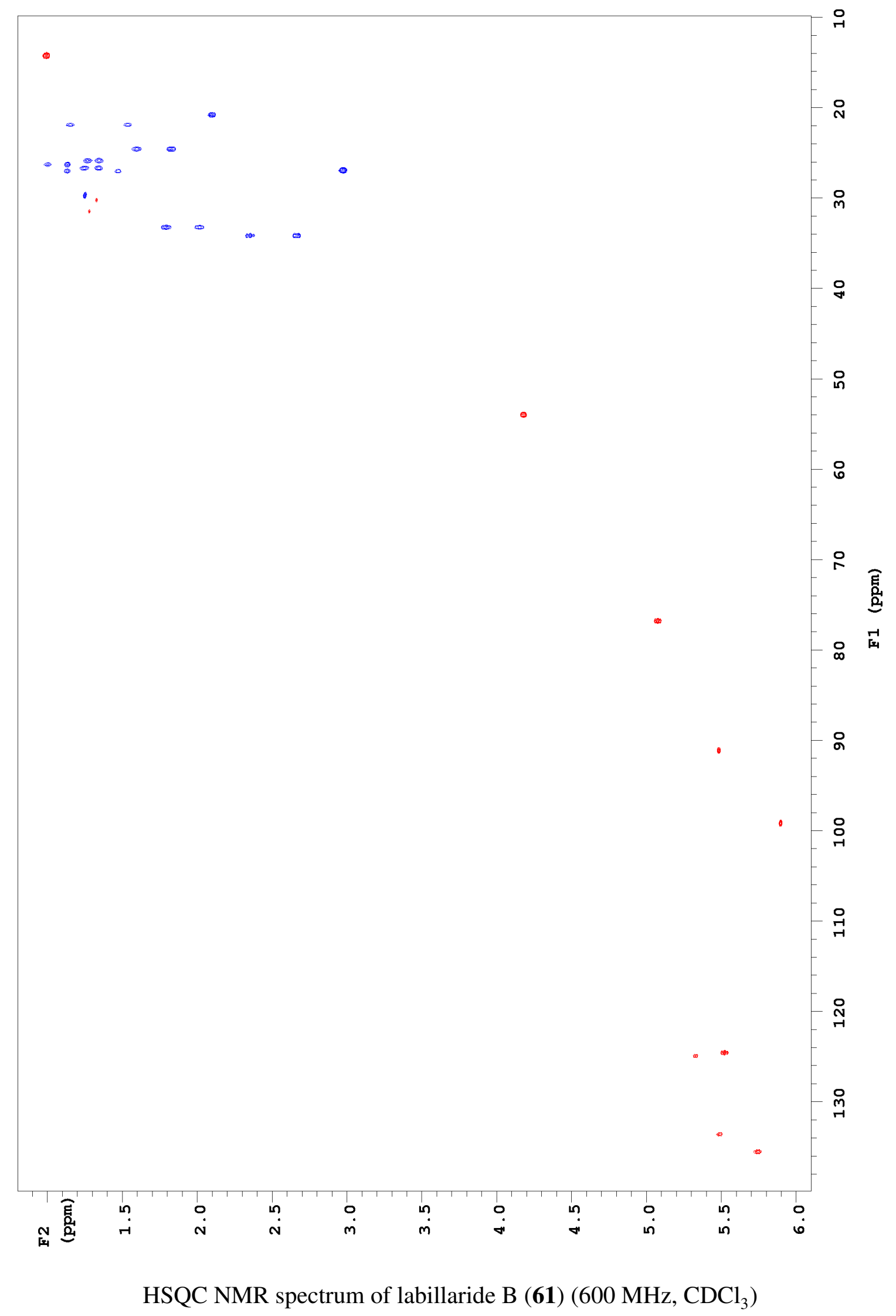




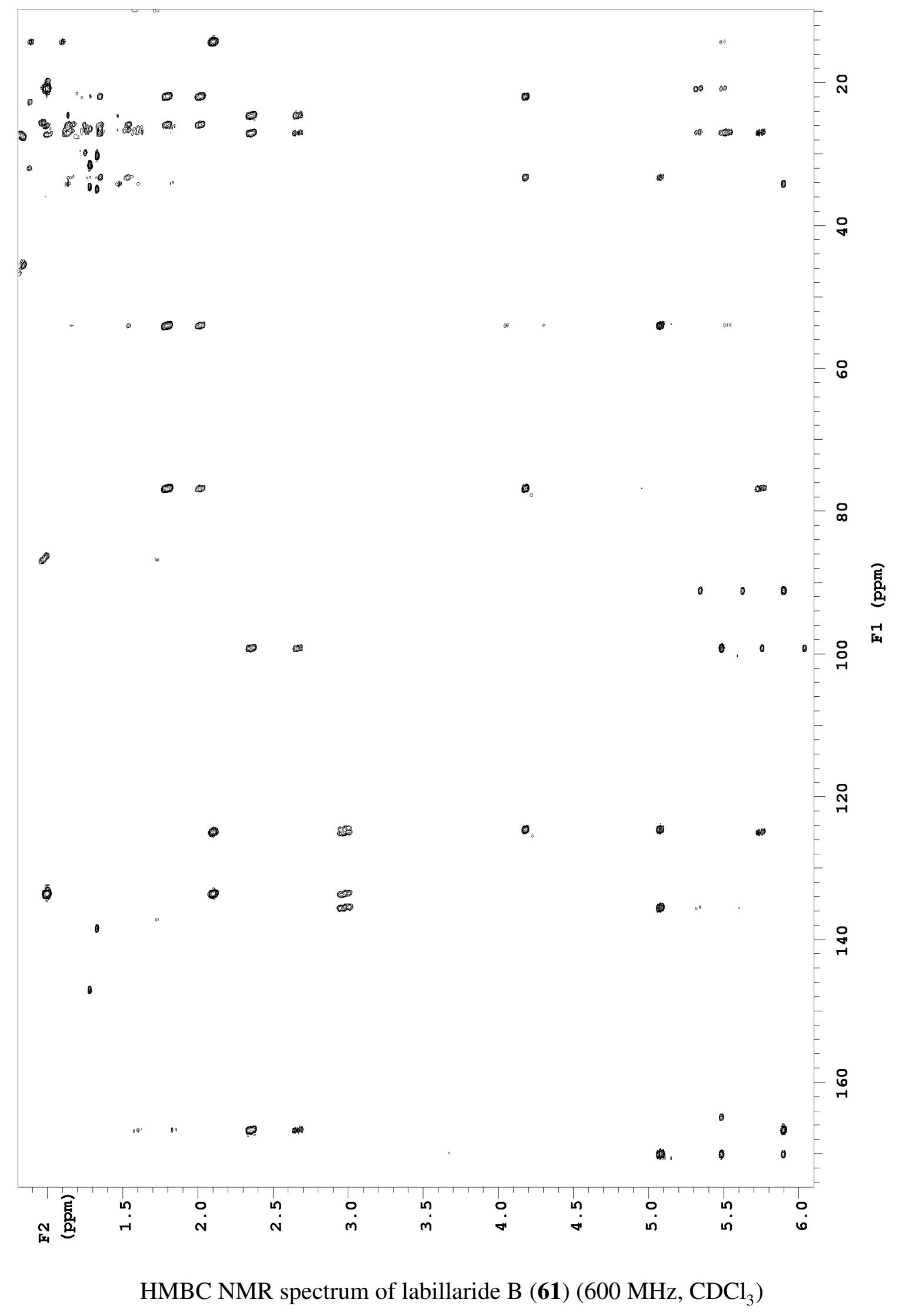




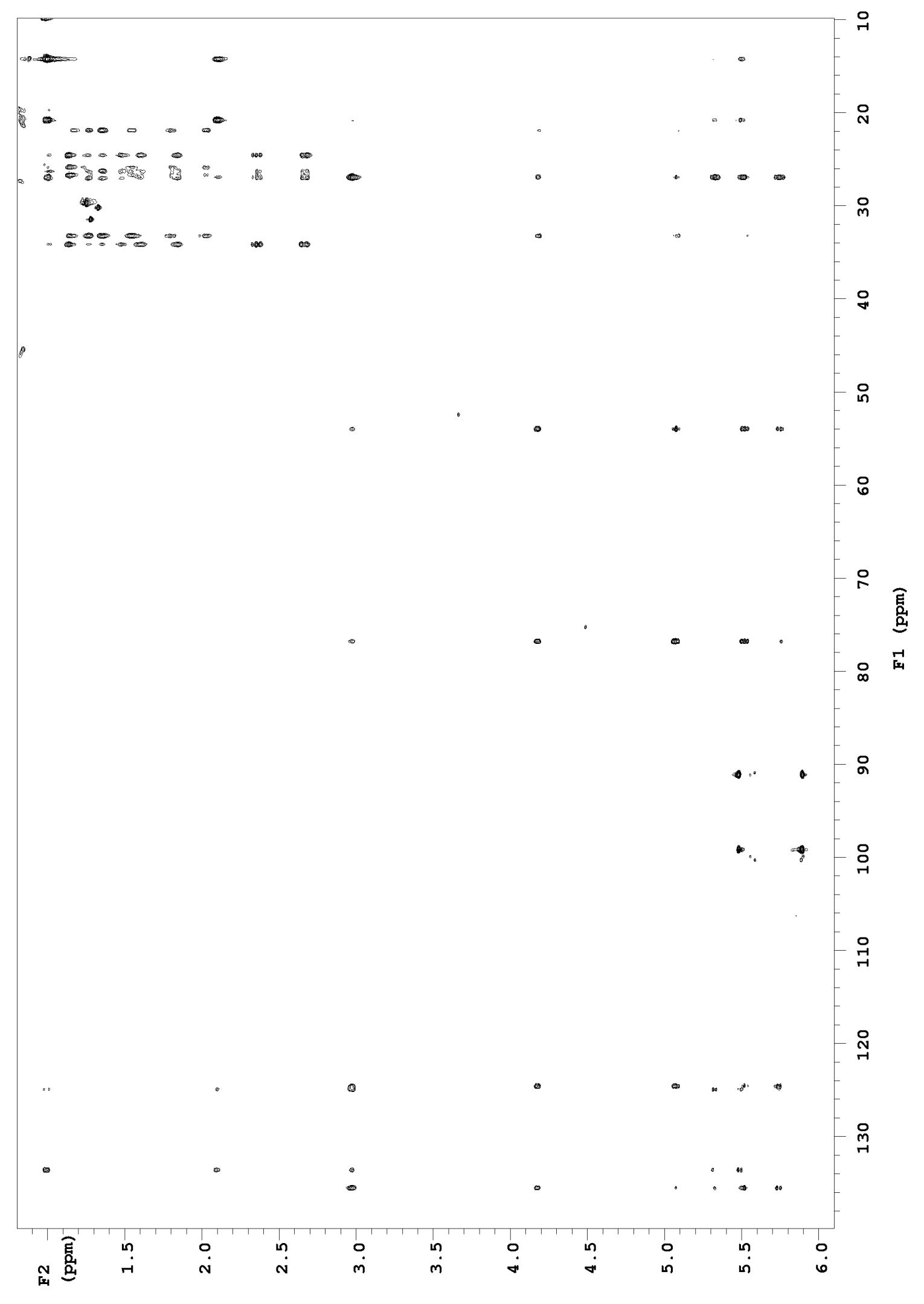

HSQC-TOCSY NMR spectrum of labillaride B (61) $\left(600 \mathrm{MHz}, \mathrm{CDCl}_{3}\right)$ 
Appendix F

NMR Spectra of Labillaride C

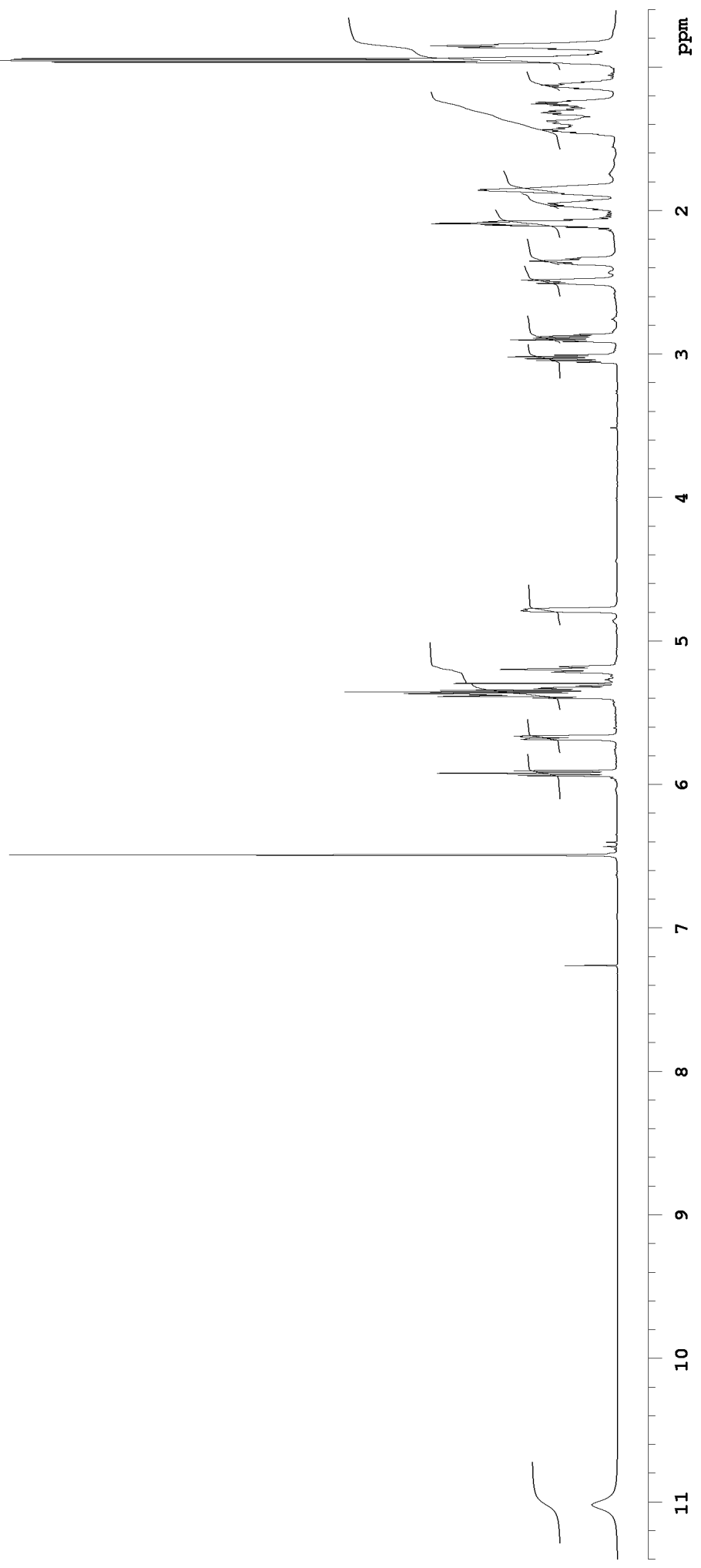

${ }^{1} \mathrm{H}$ NMR spectrum of labillaride C (62) $\left(600 \mathrm{MHz}, \mathrm{CDCl}_{3}\right)$ 


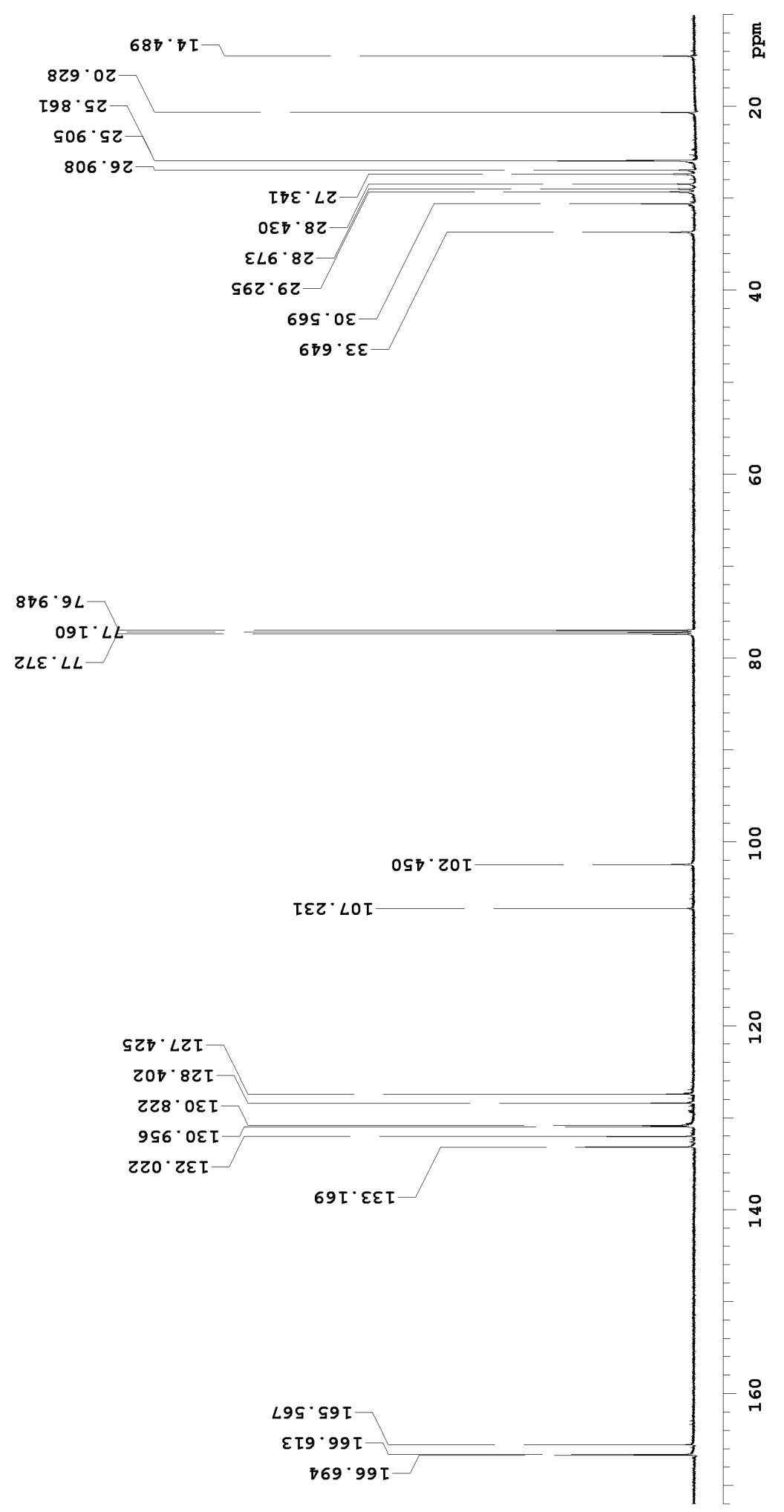

${ }^{13} \mathrm{C}$ NMR spectrum of labillaride $\mathrm{C}(\mathbf{6 2})\left(150 \mathrm{MHz}, \mathrm{CDCl}_{3}\right)$ 


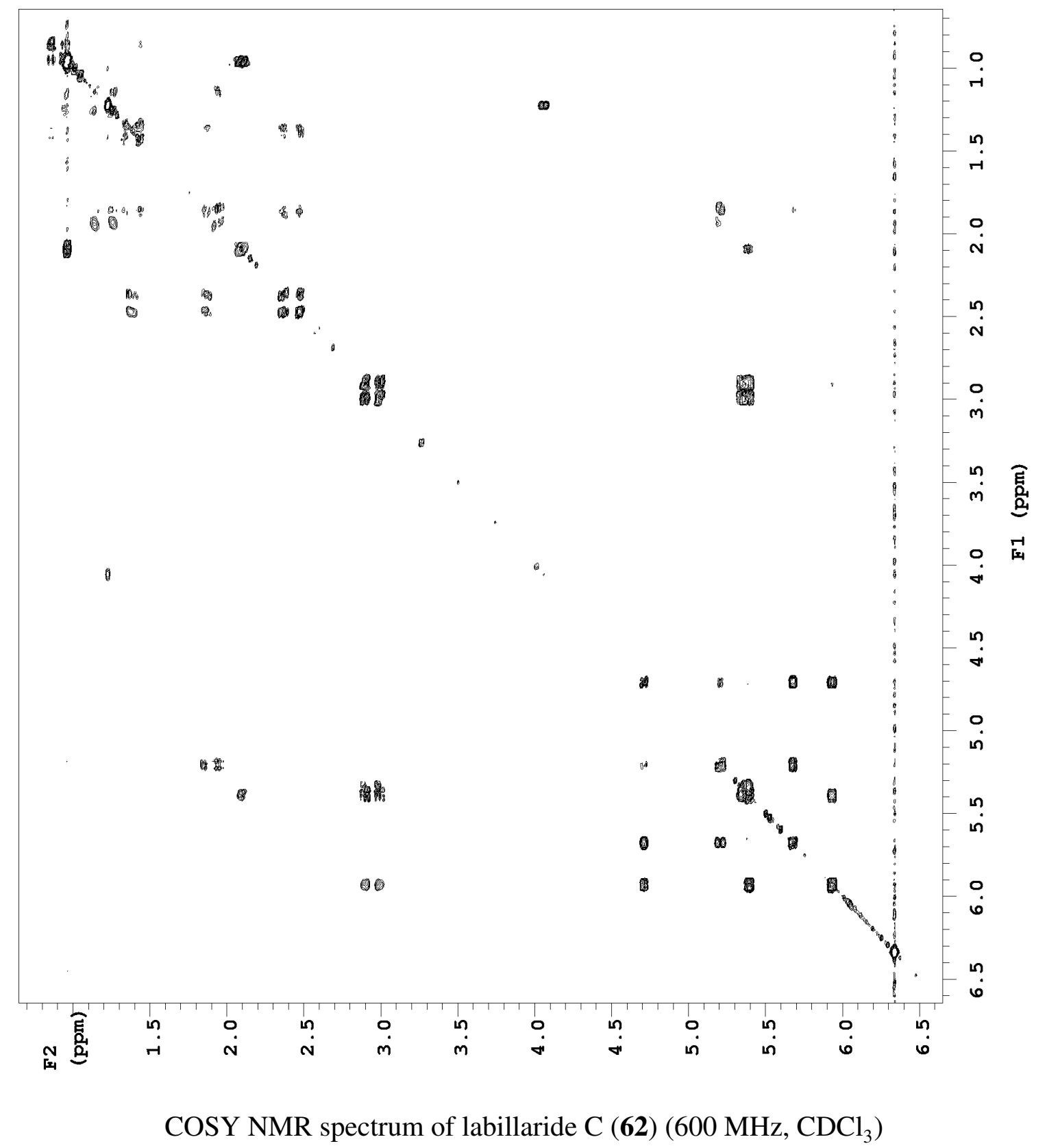




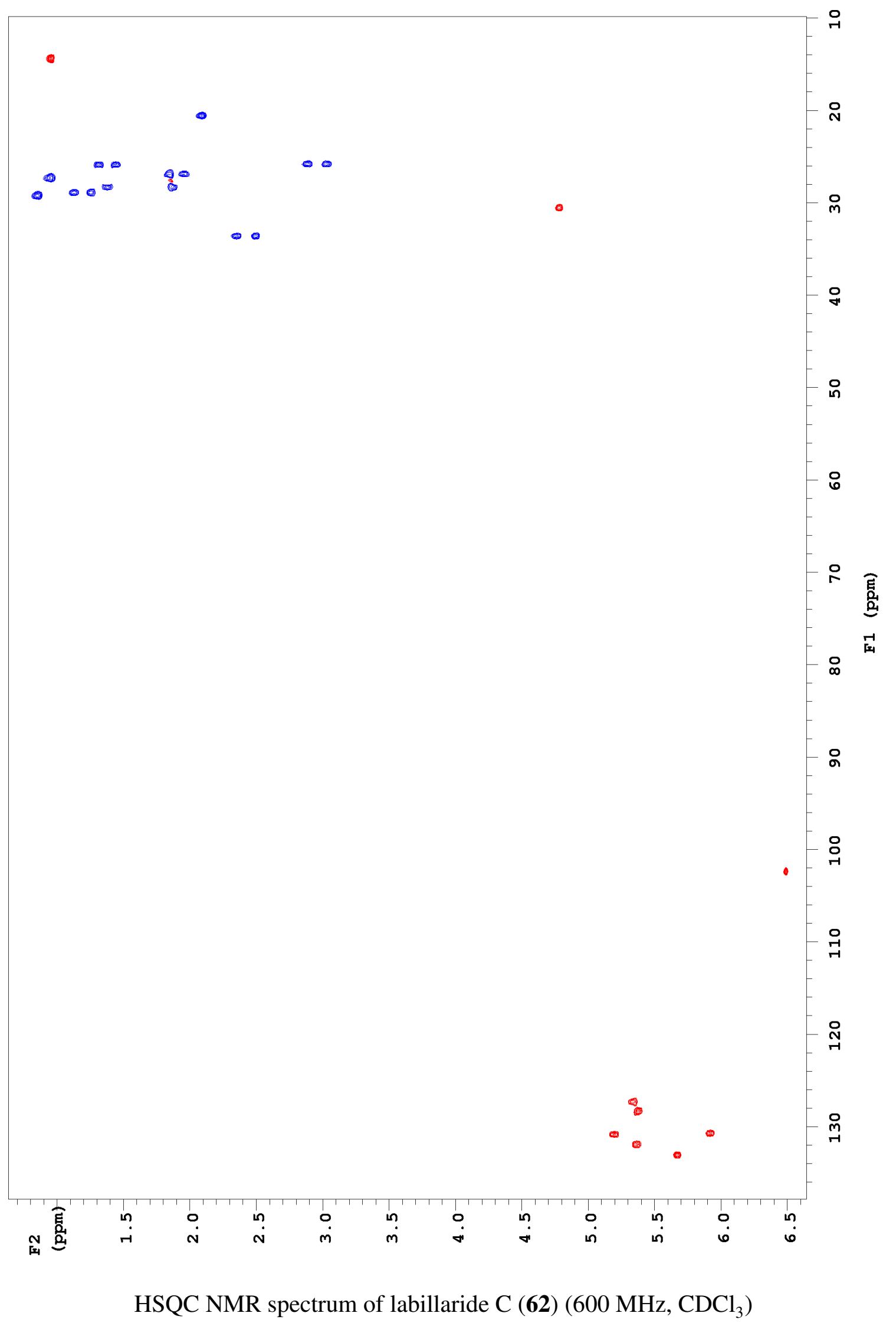




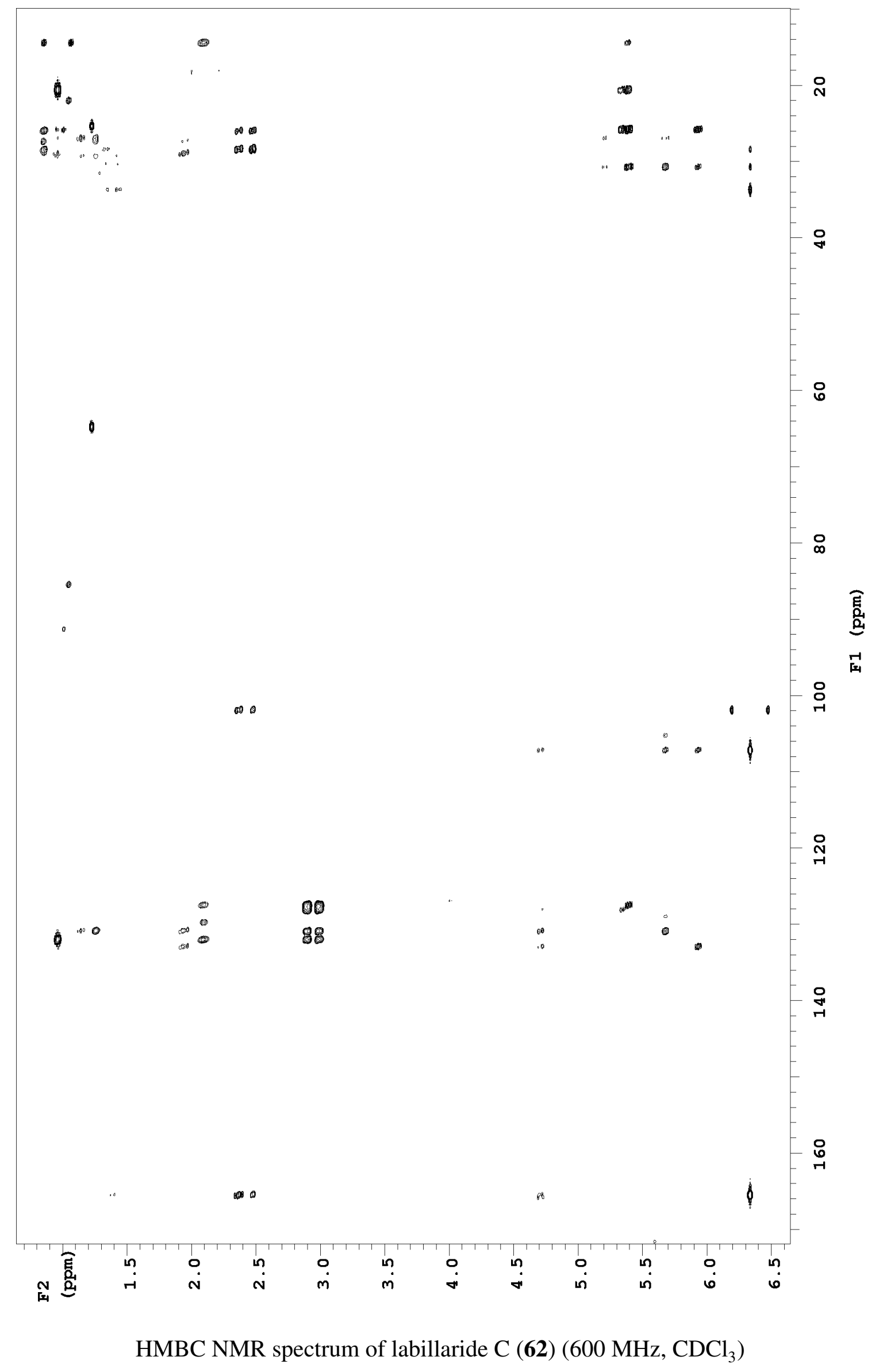




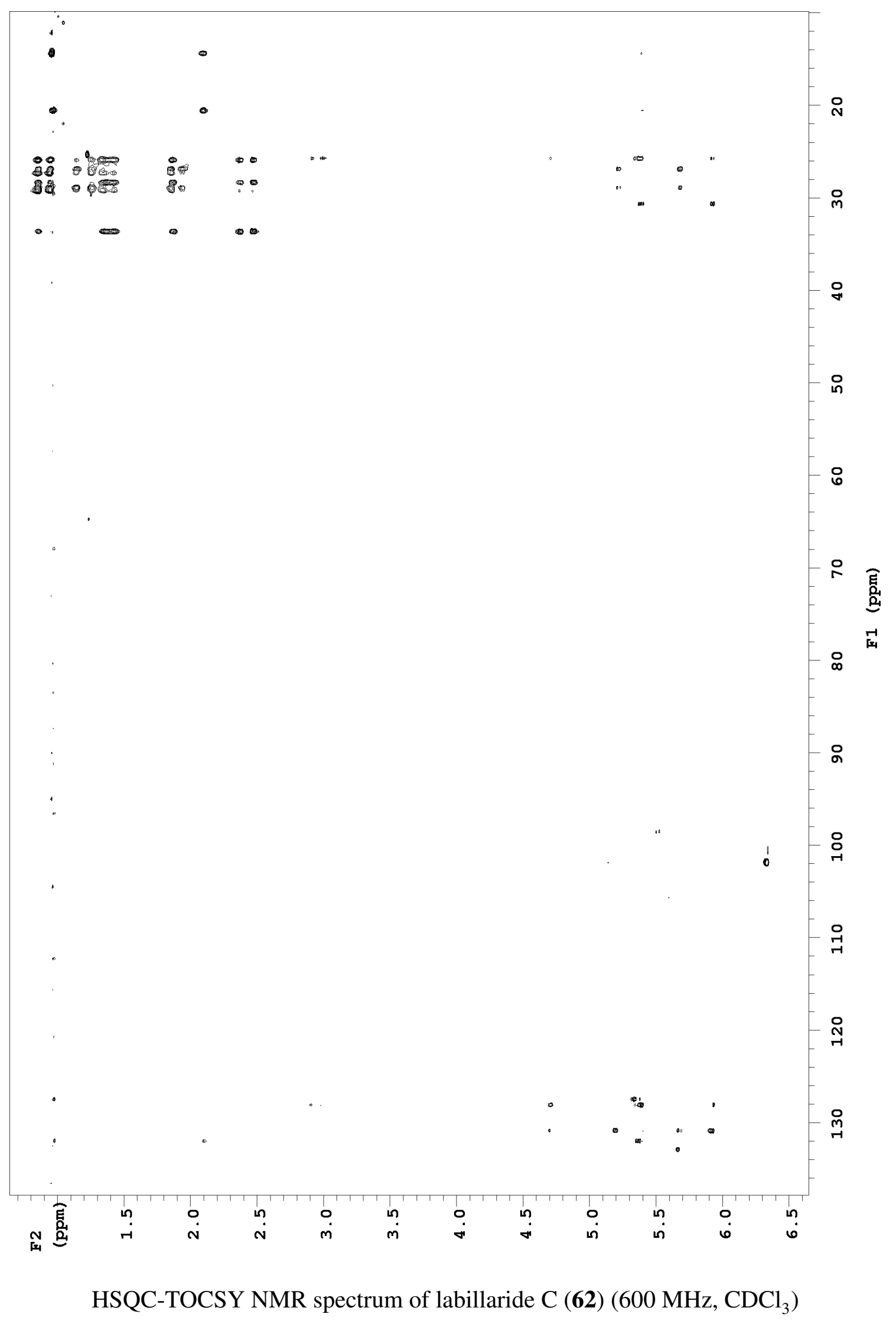


NMR Spectra of Labillaride D

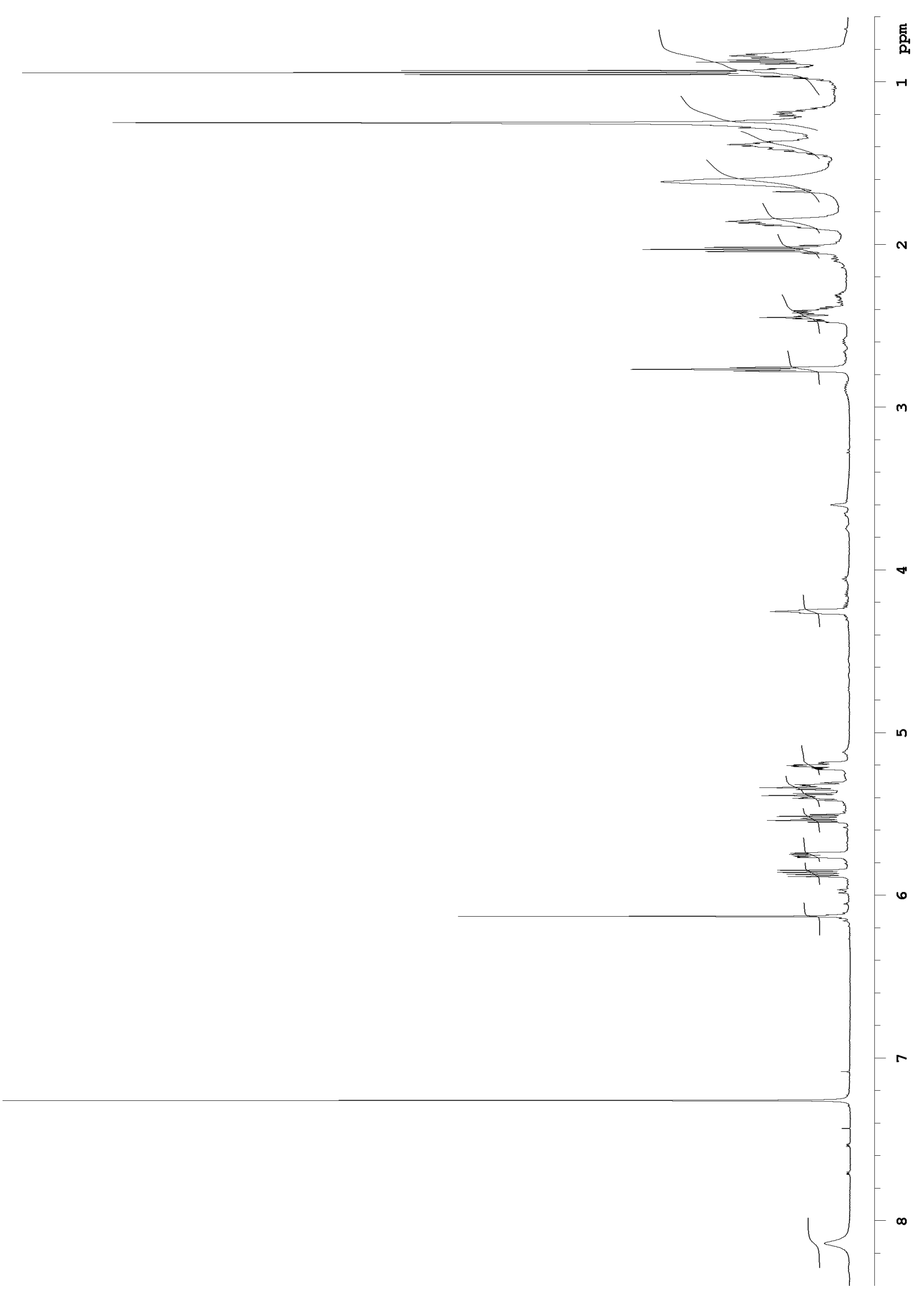

${ }^{1} \mathrm{H}$ NMR spectrum of labillaride D (63) $\left(600 \mathrm{MHz}, \mathrm{CDCl}_{3}\right)$ 


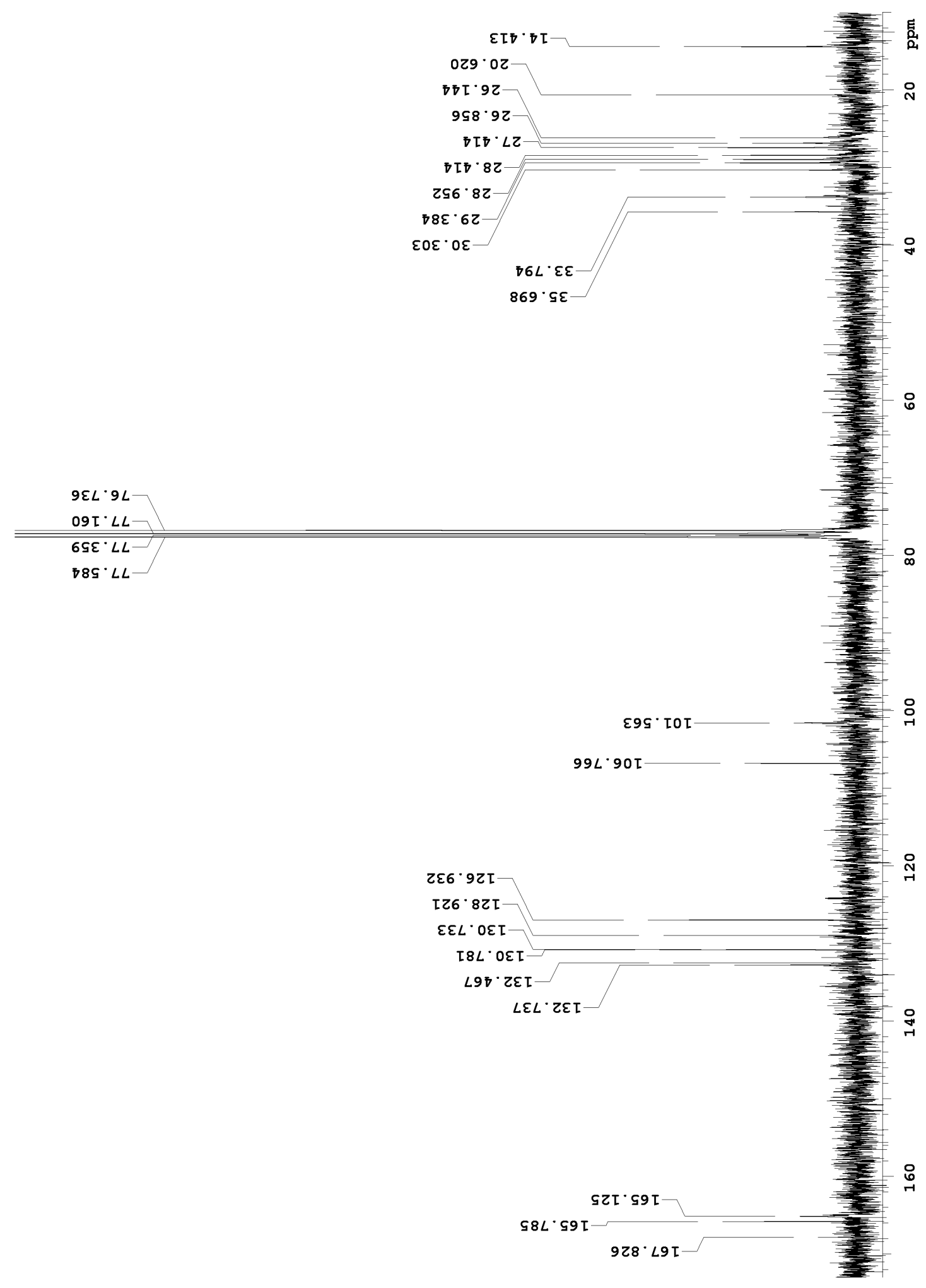

${ }^{13} \mathrm{C}$ NMR spectrum of labillaride $\mathrm{D}(\mathbf{6 3})\left(75 \mathrm{MHz}, \mathrm{CDCl}_{3}\right)$ 


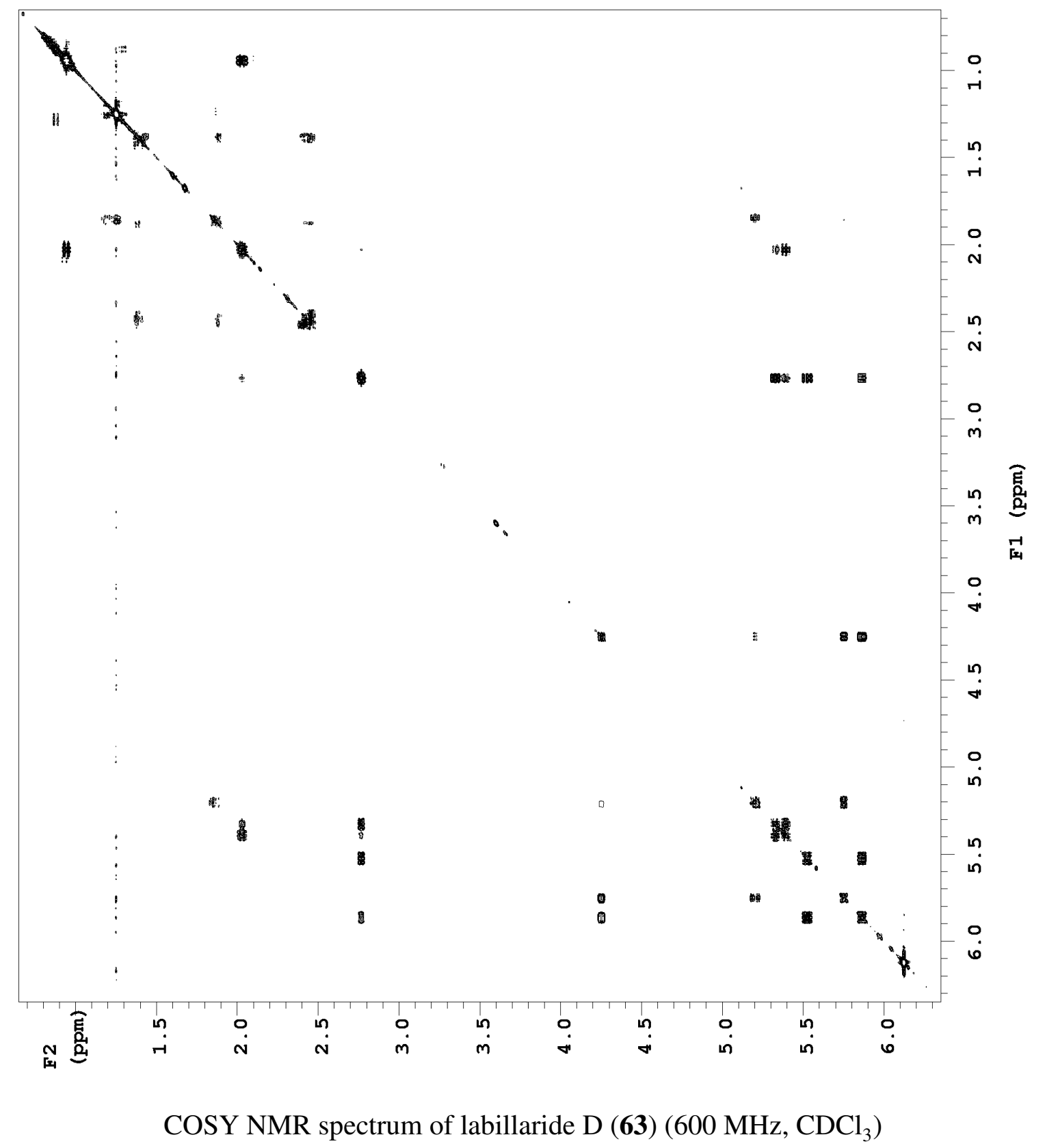




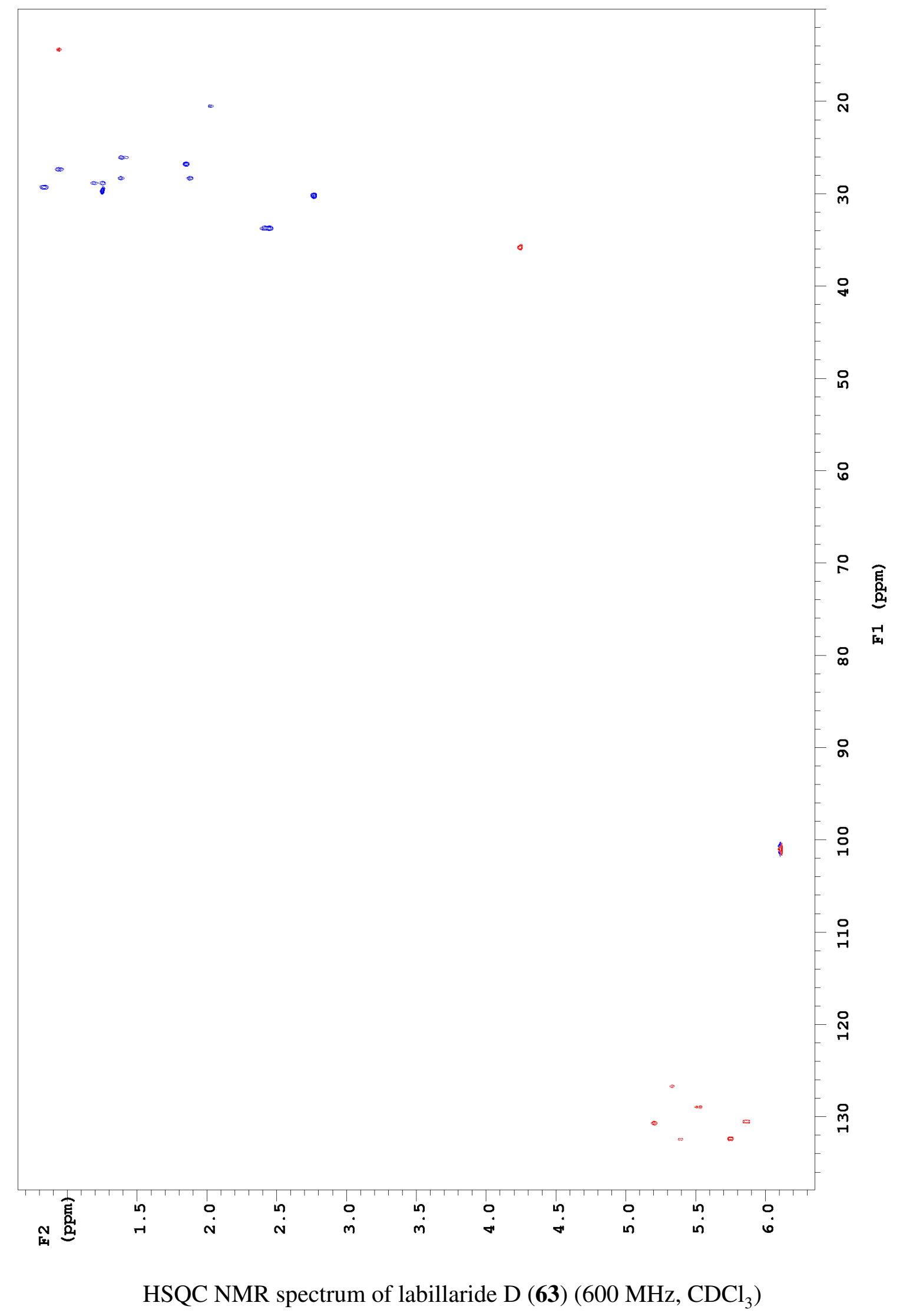




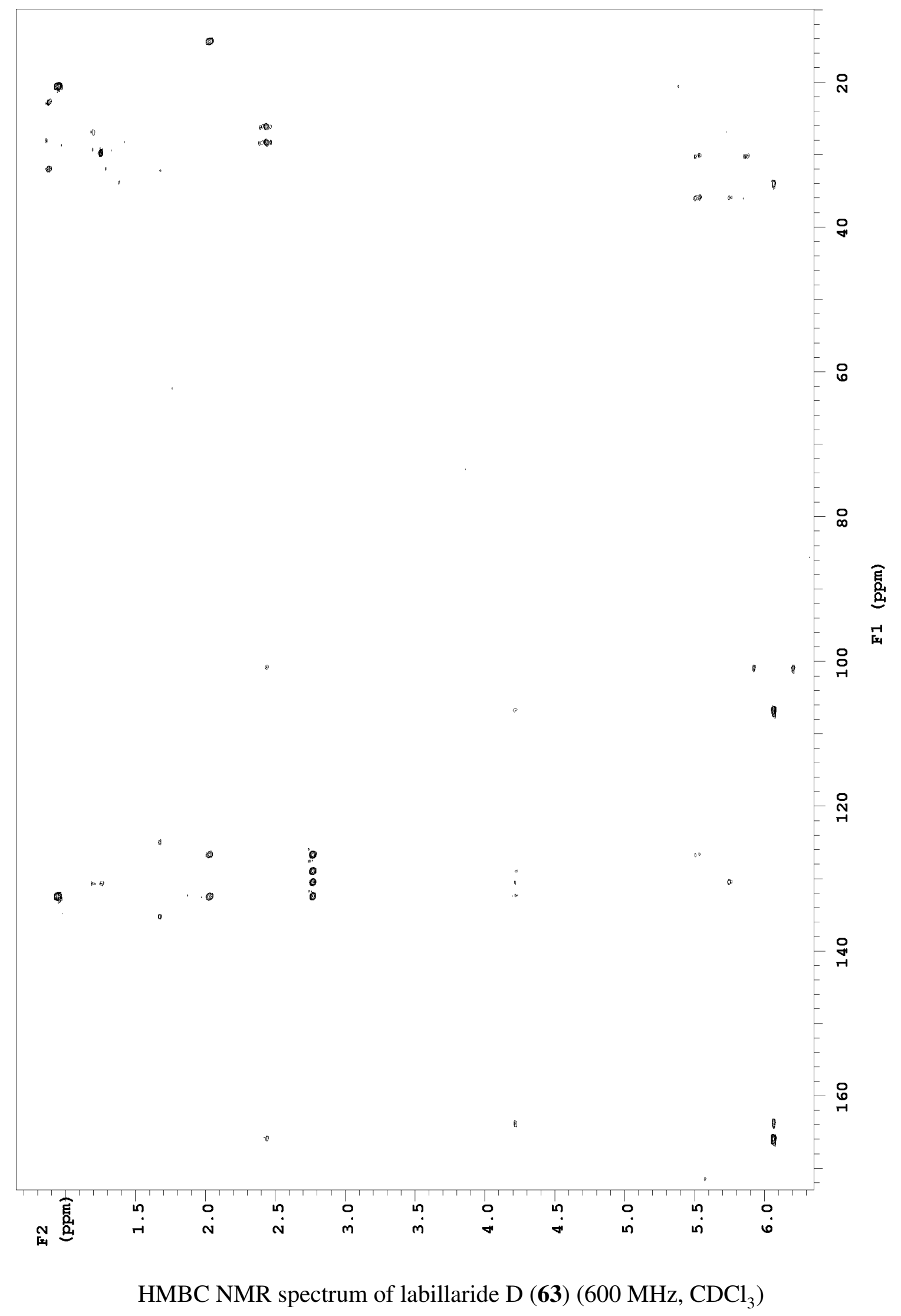




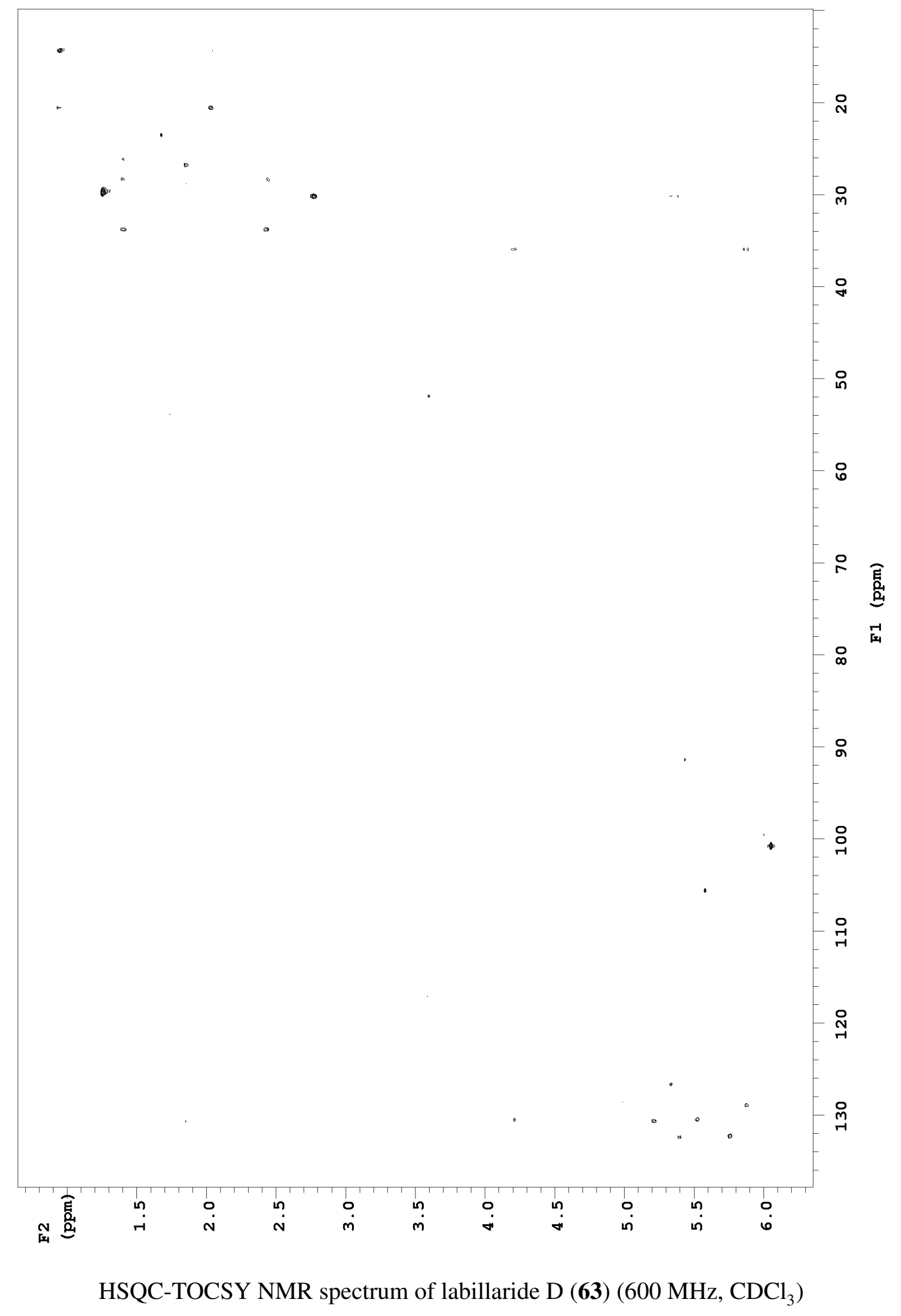


NMR Spectra of Labillaride E

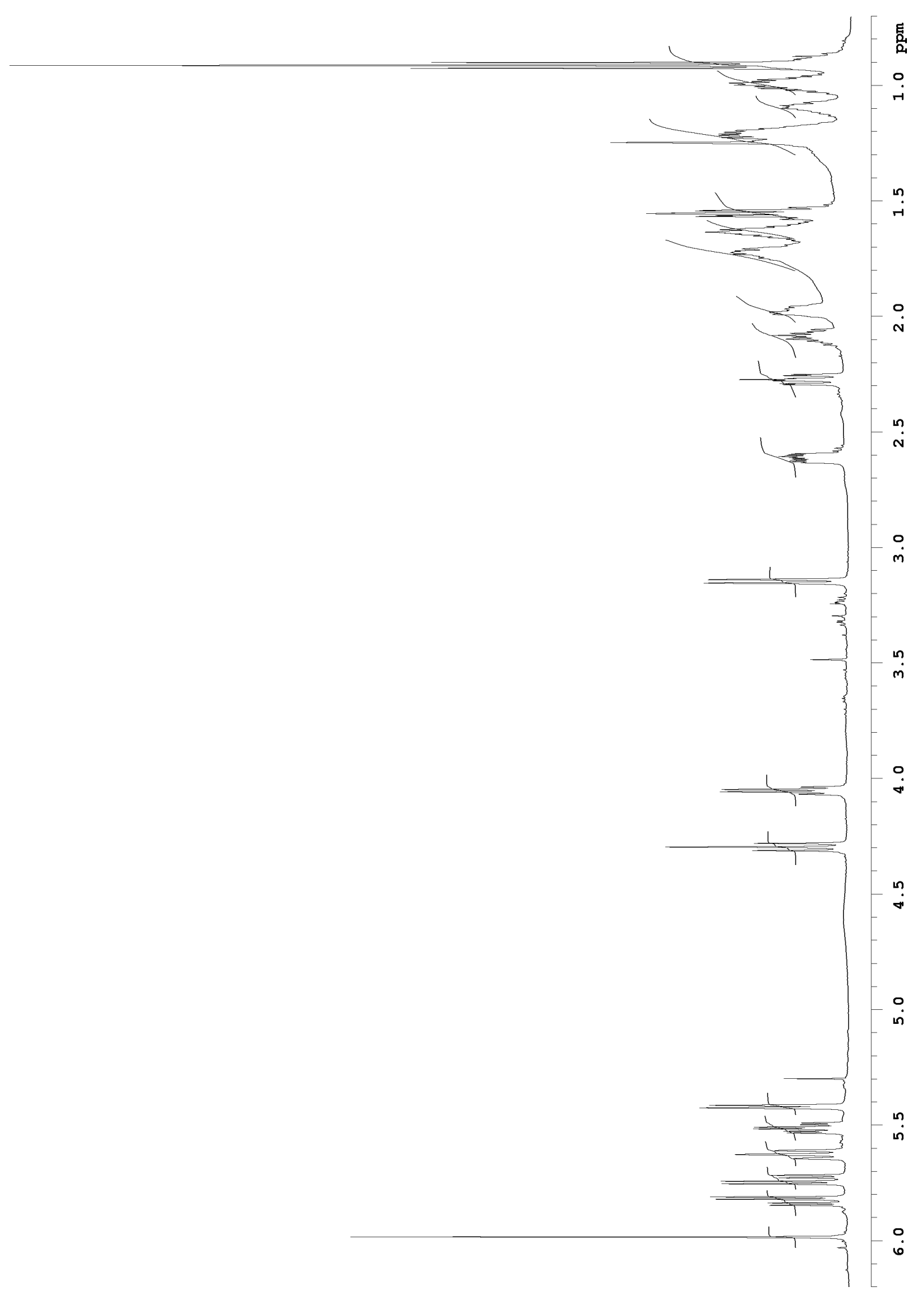

${ }^{1} \mathrm{H}$ NMR spectrum of labillaride E (64) $\left(600 \mathrm{MHz}, \mathrm{CDCl}_{3}\right)$ 


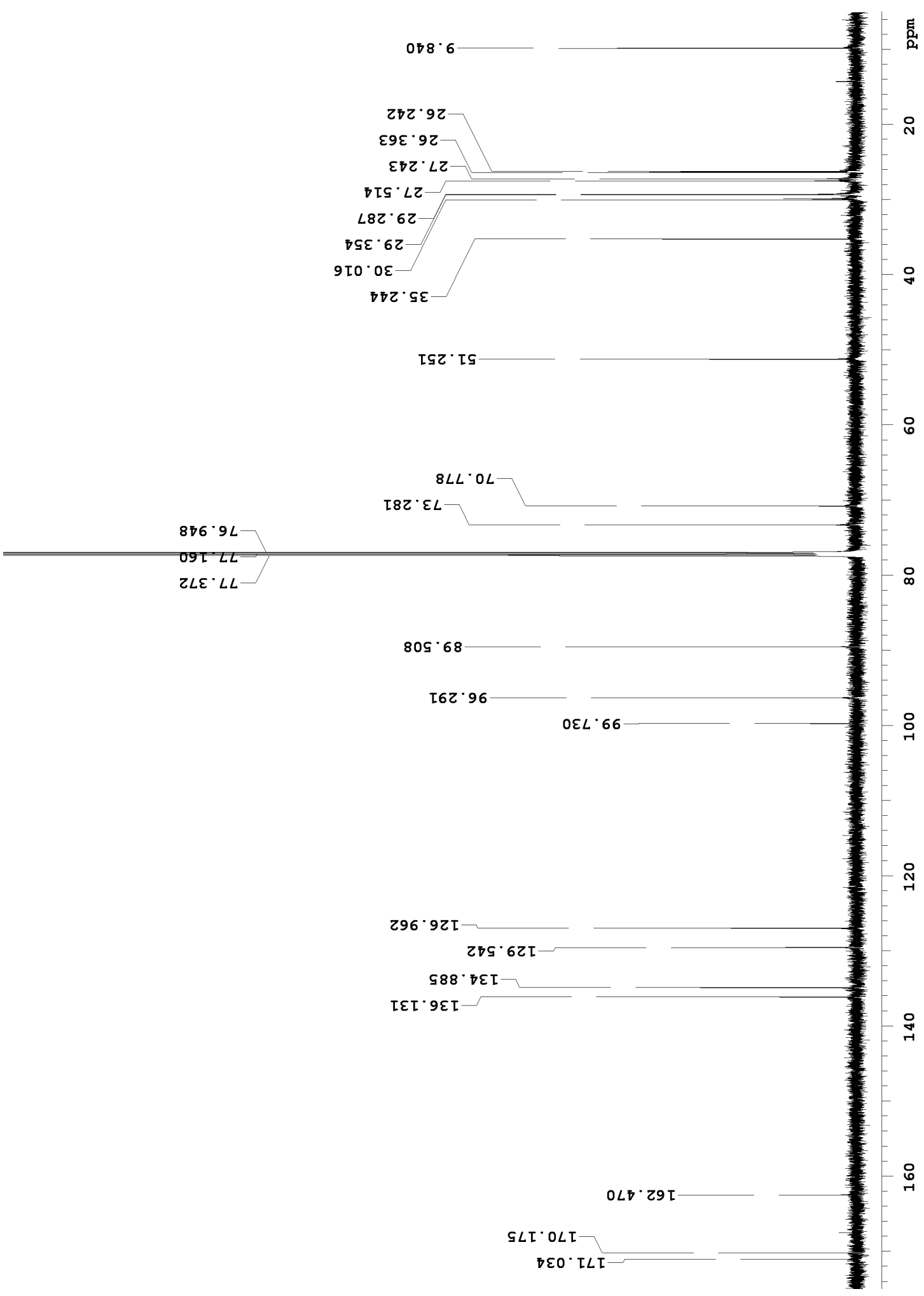

${ }^{13} \mathrm{C}$ NMR spectrum of labillaride $\mathrm{E}(\mathbf{6 4})\left(150 \mathrm{MHz}, \mathrm{CDCl}_{3}\right)$ 


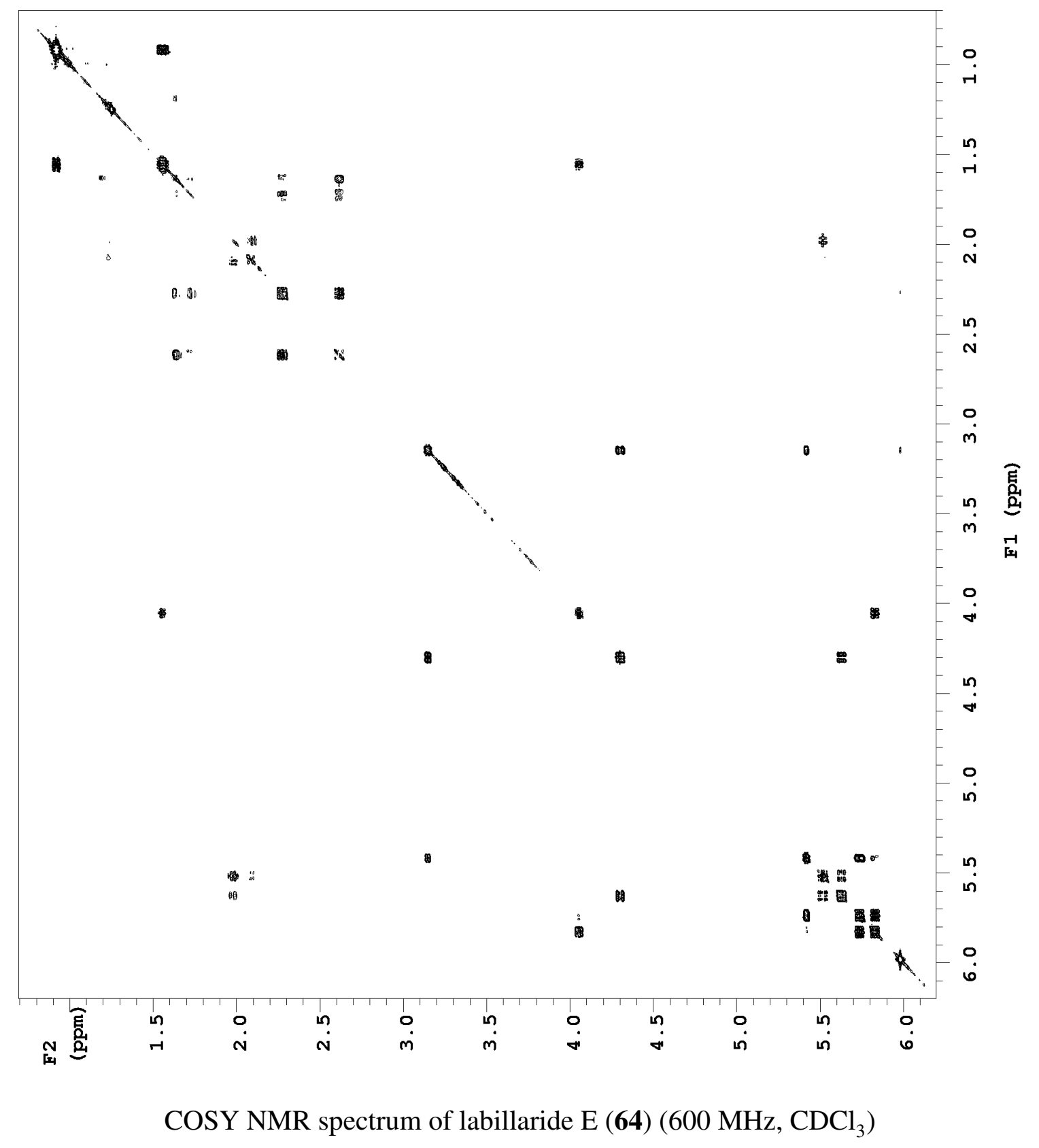




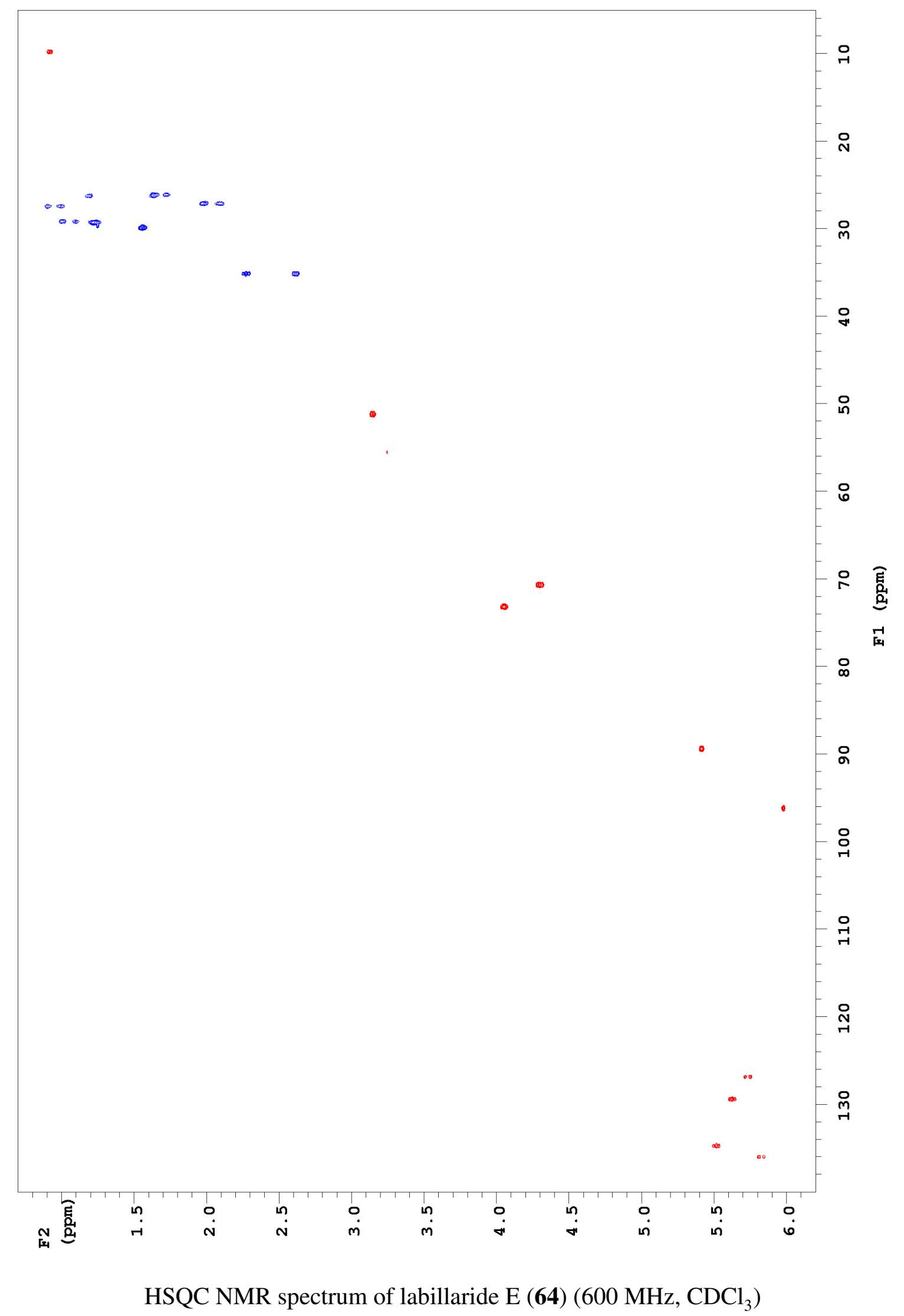




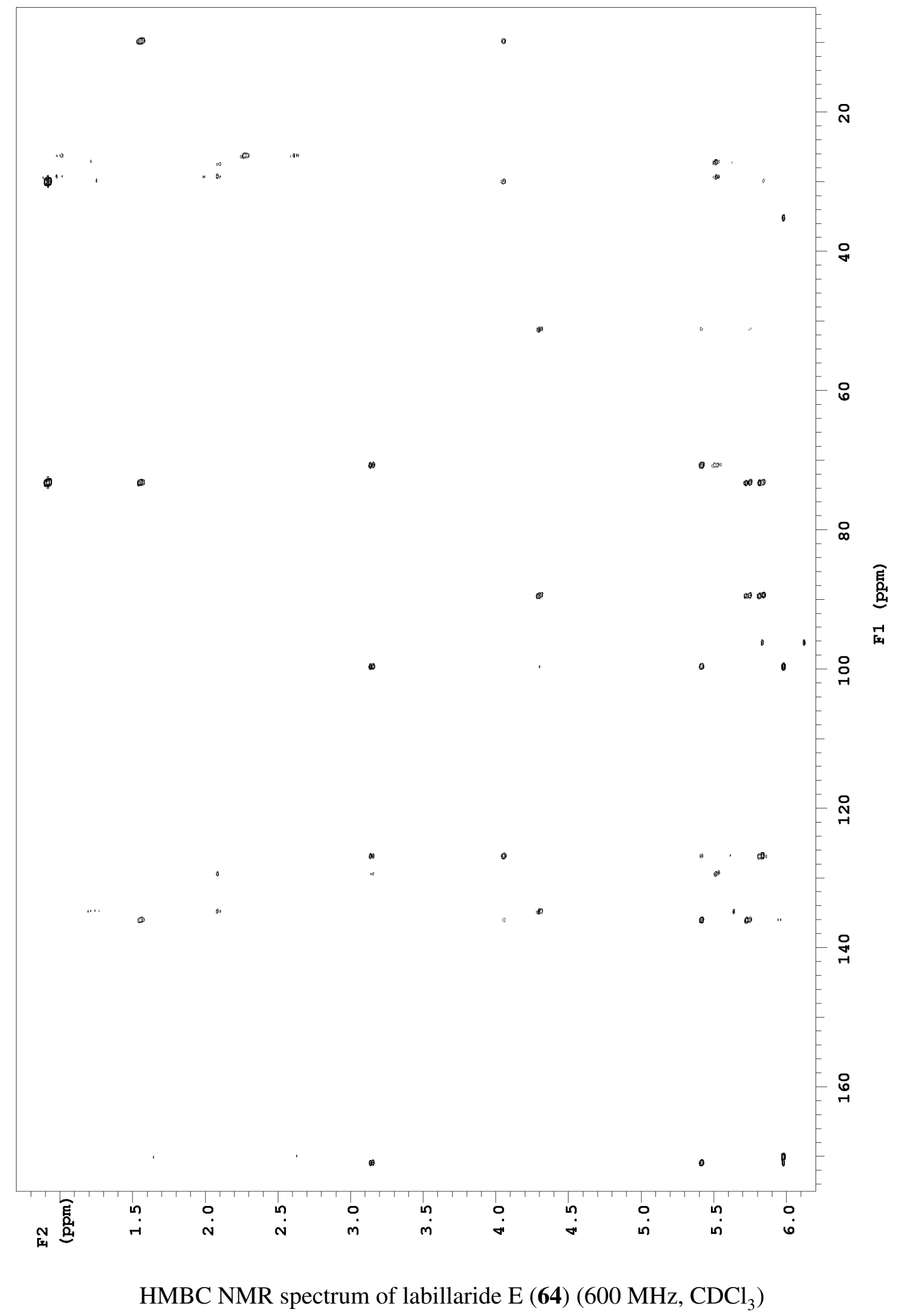




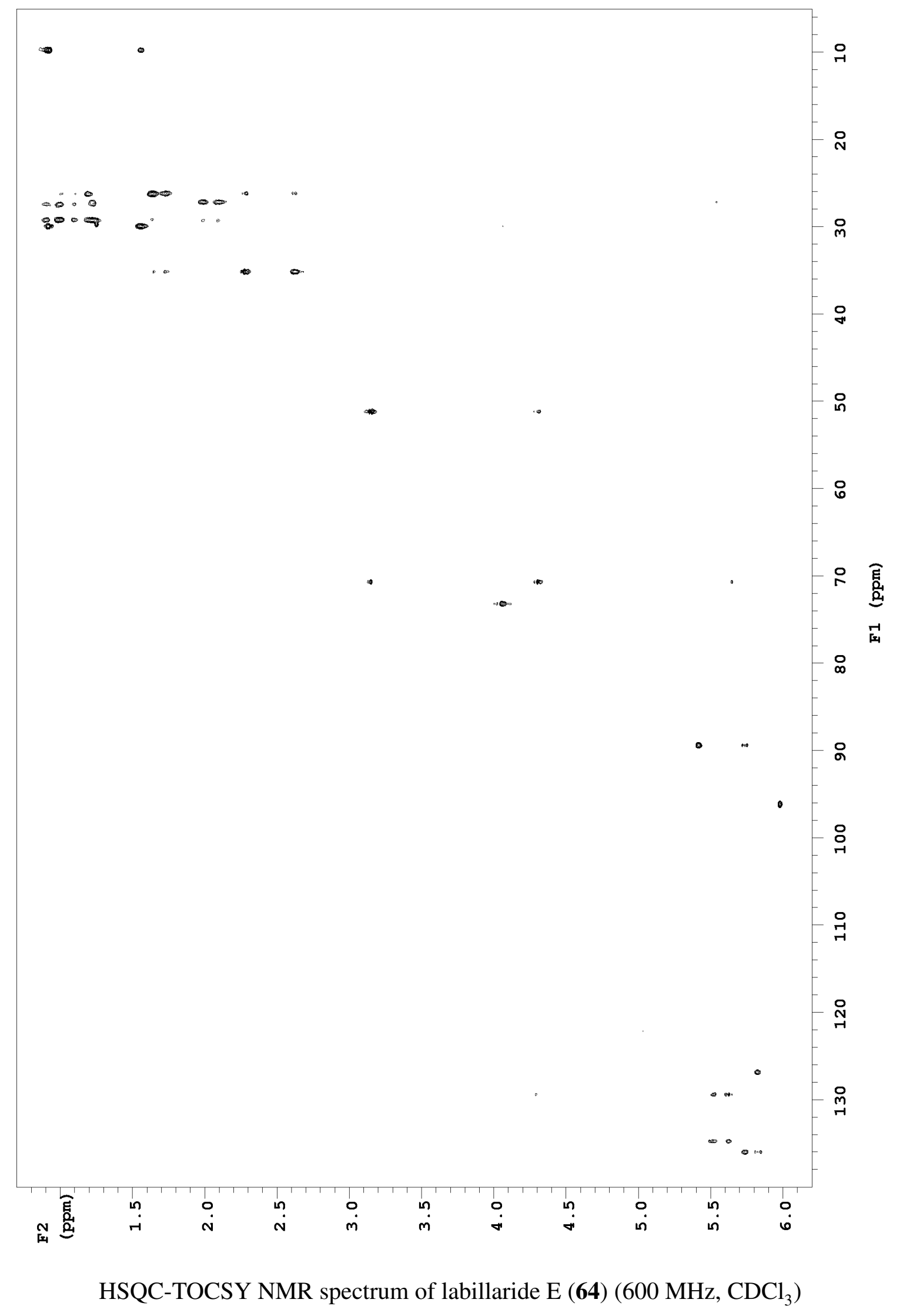




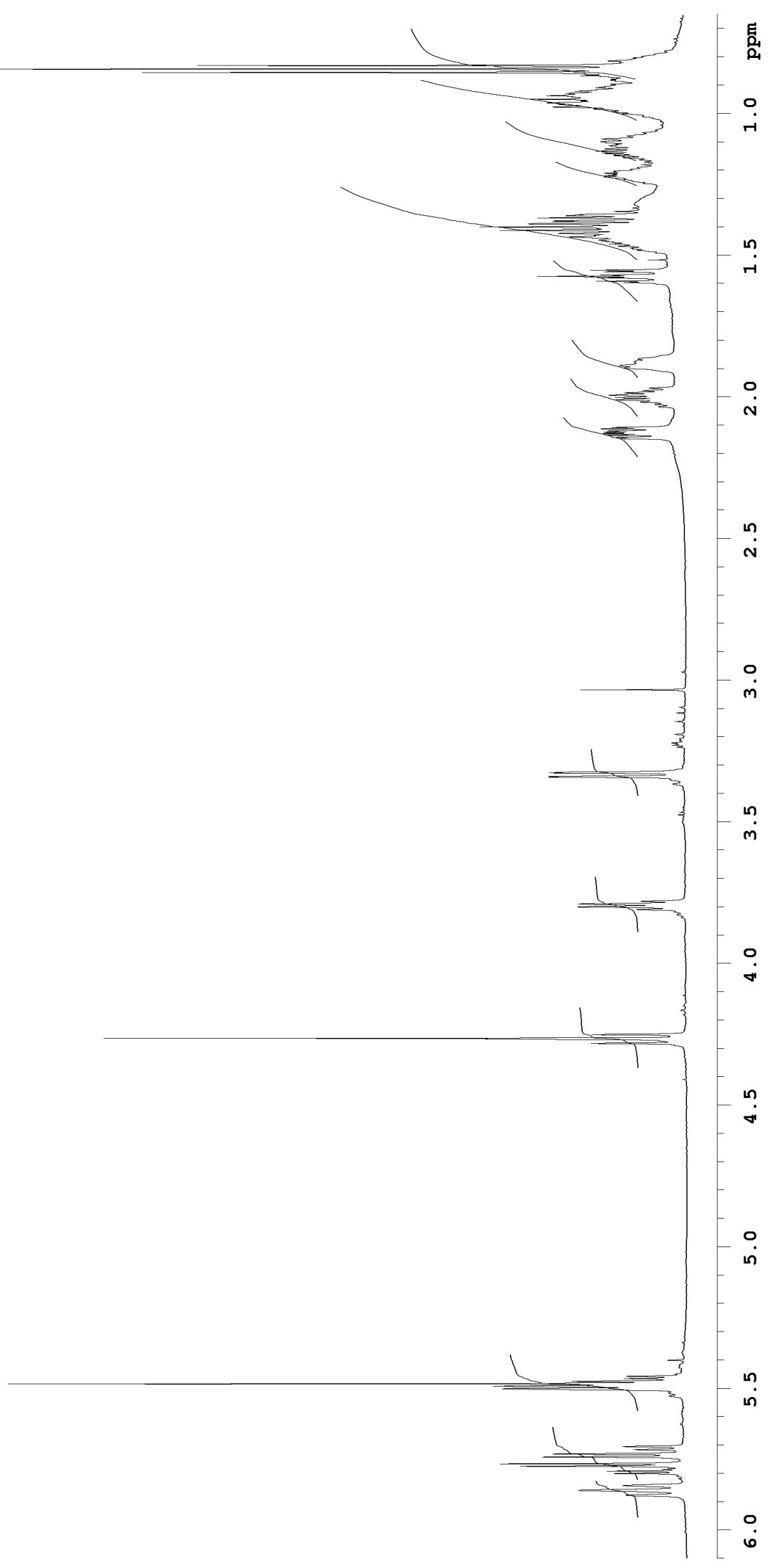

${ }^{1} \mathrm{H}$ NMR spectrum of labillaride $\mathrm{E}(\mathbf{6 4})\left(600 \mathrm{MHz}, \mathrm{C}_{6} \mathrm{D}_{6}\right)$ 


\section{Appendix I}

NMR Spectra of Labillaride F

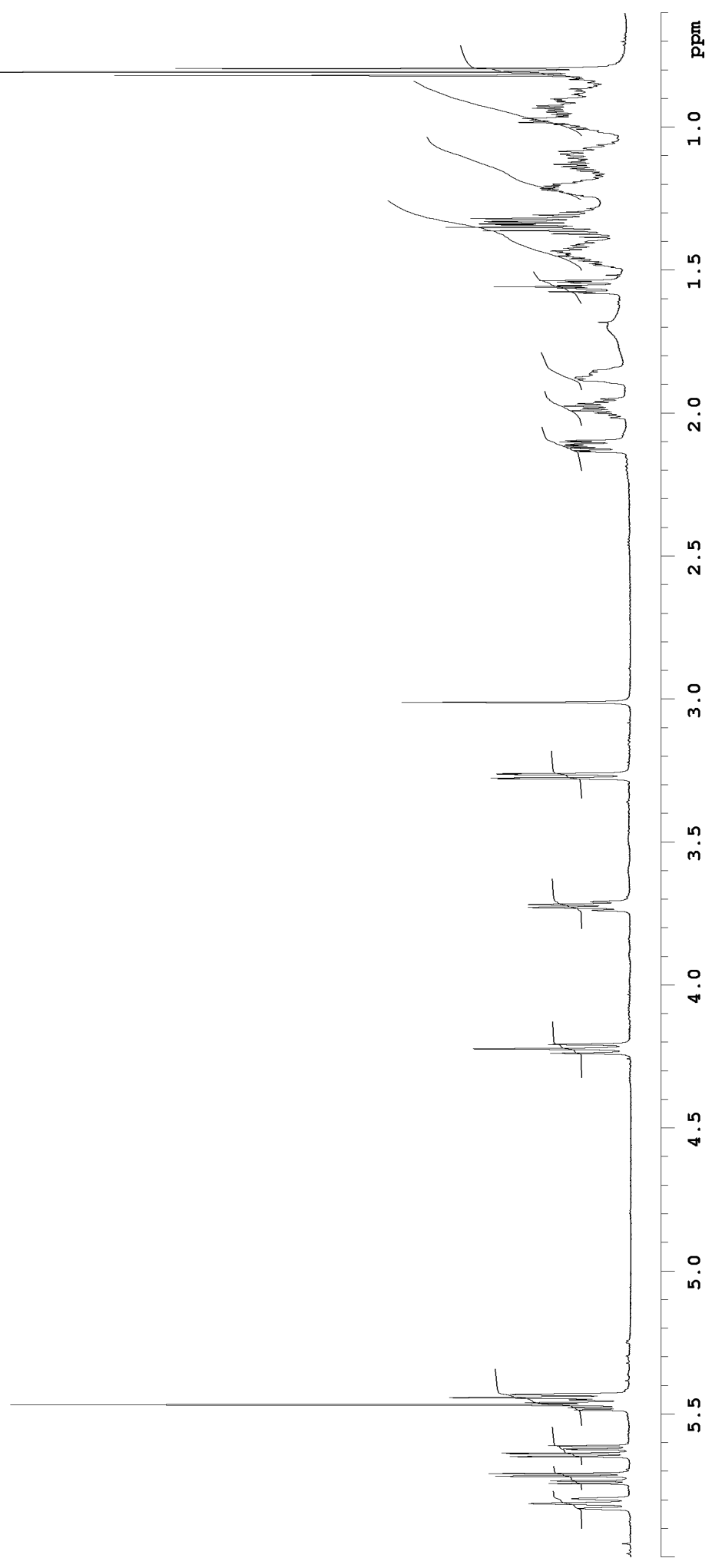

${ }^{1} \mathrm{H}$ NMR spectrum of labillaride F (65) $\left(600 \mathrm{MHz}, \mathrm{C}_{6} \mathrm{D}_{6}\right)$ 


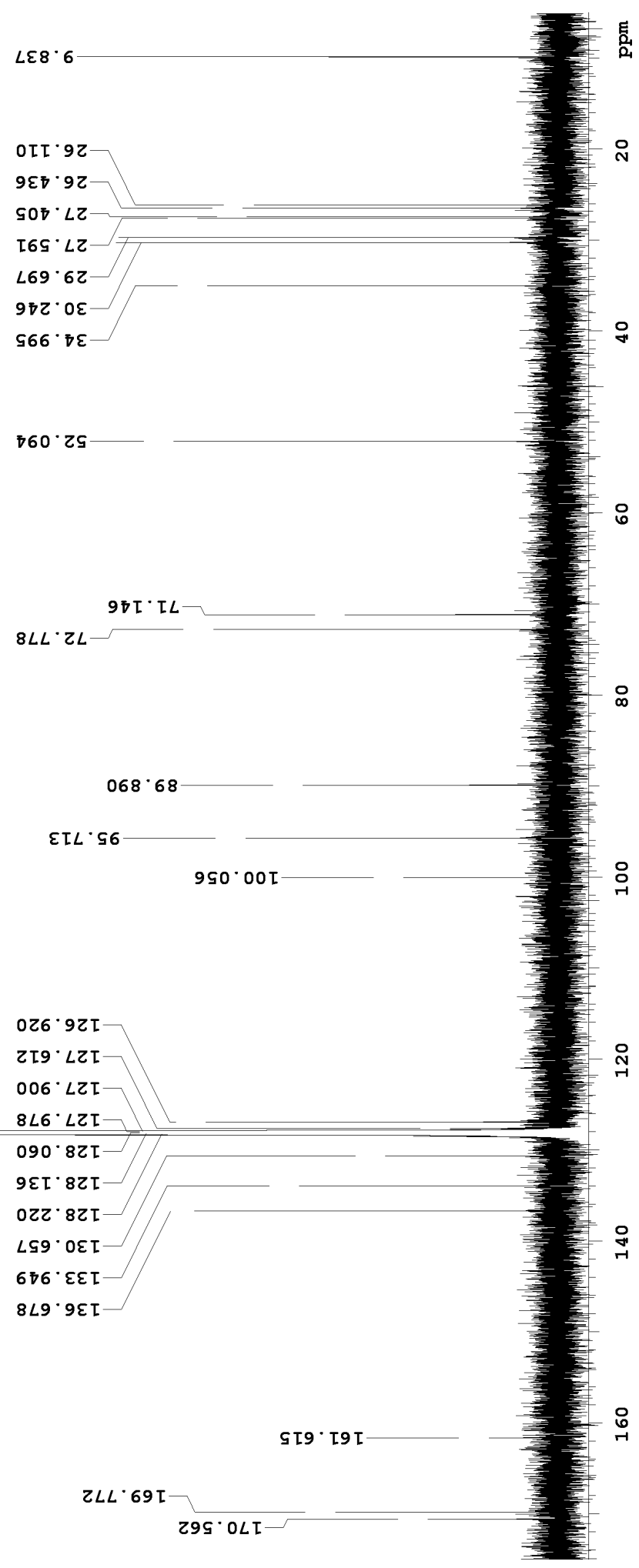

${ }^{13} \mathrm{C}$ NMR spectrum of labillaride $\mathrm{F}(\mathbf{6 5})\left(150 \mathrm{MHz}, \mathrm{C}_{6} \mathrm{D}_{6}\right)$ 


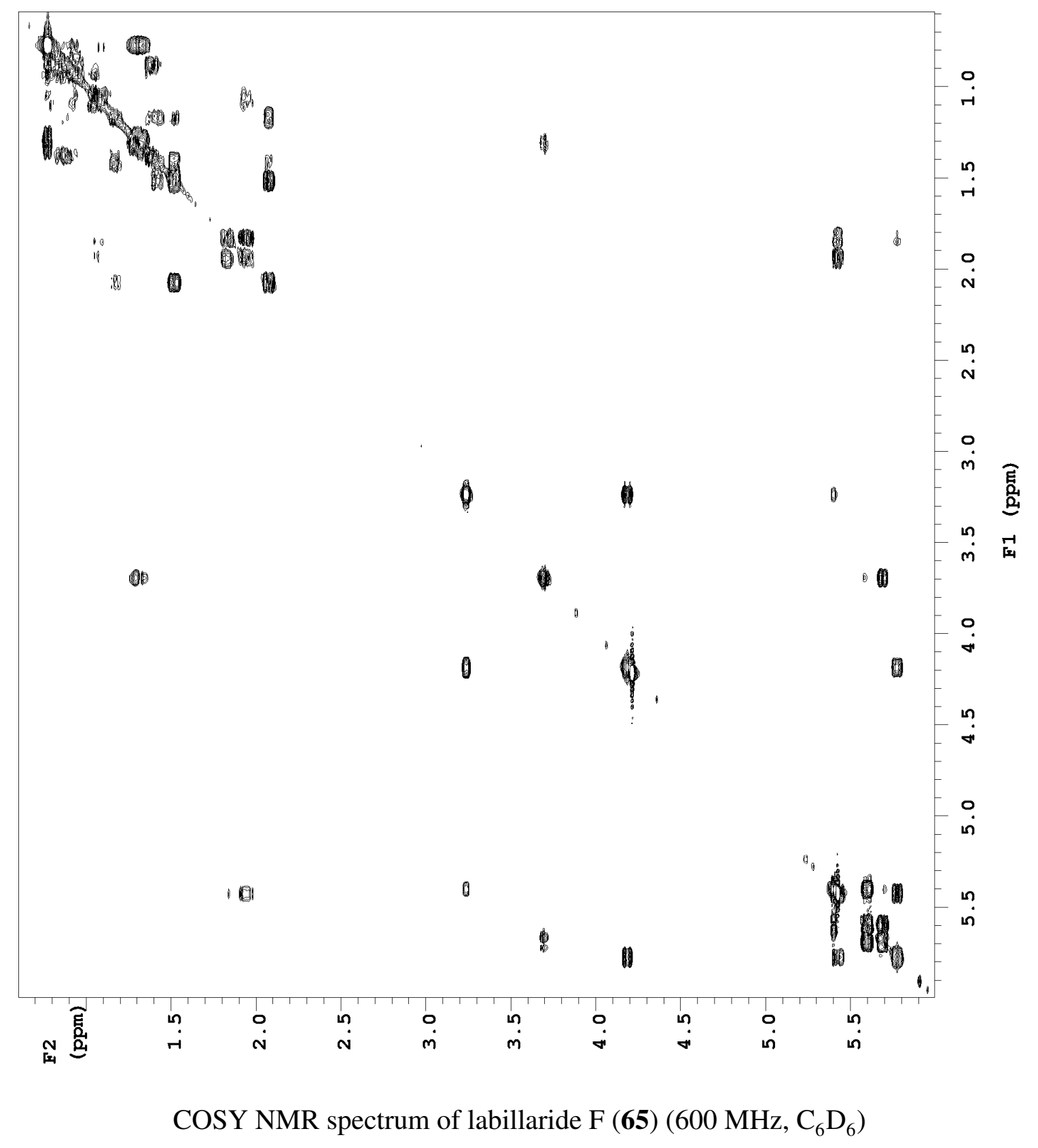




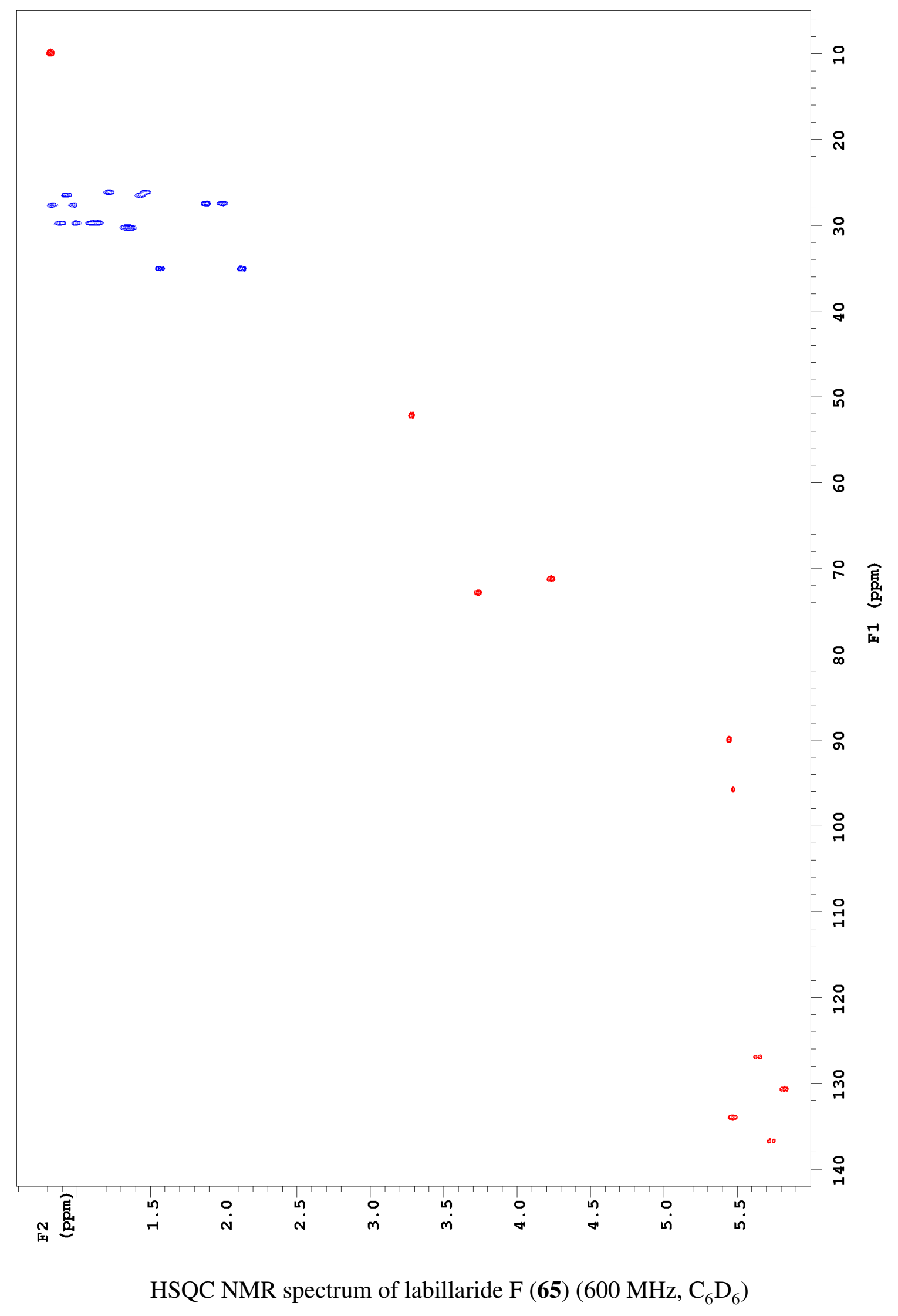




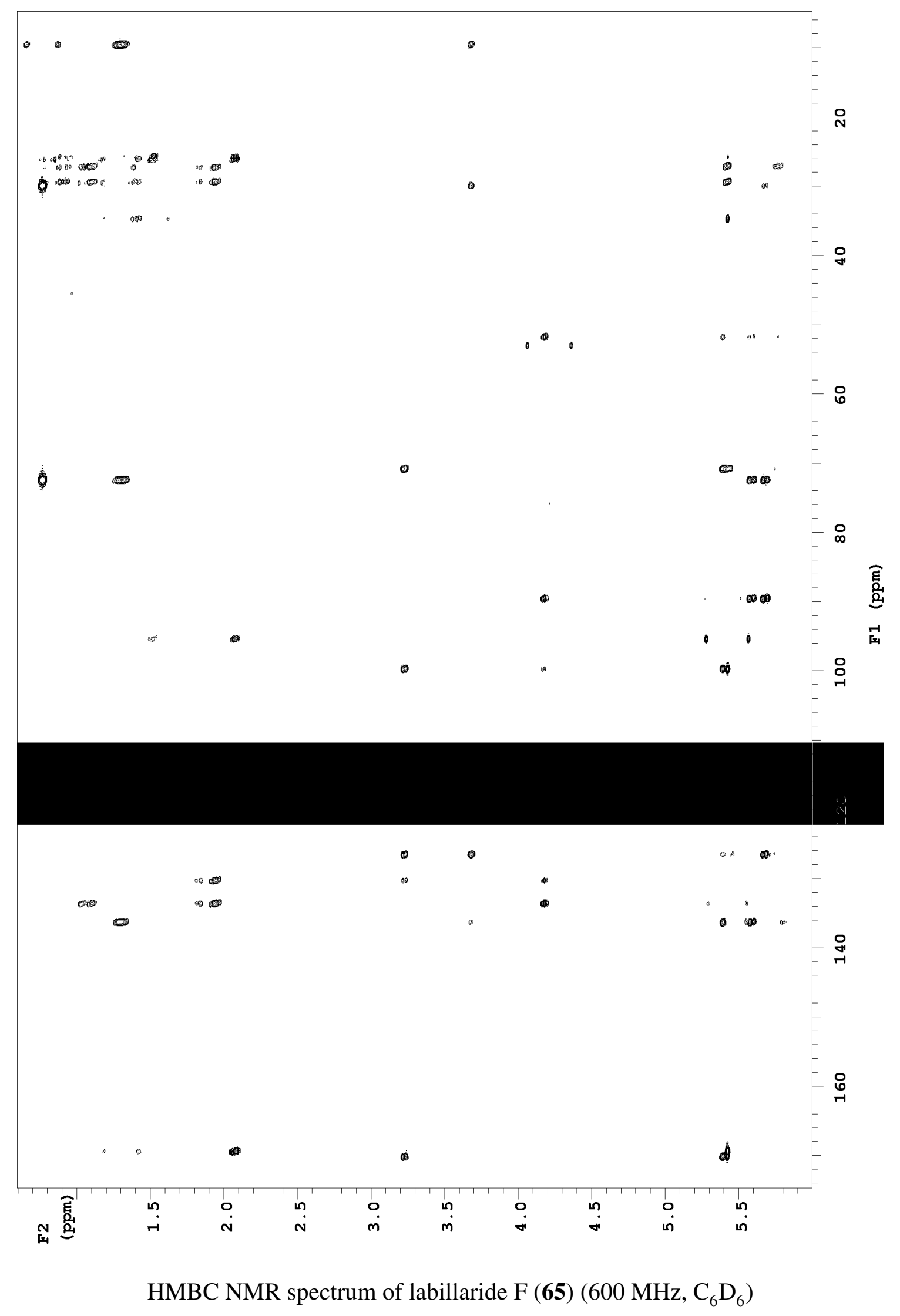




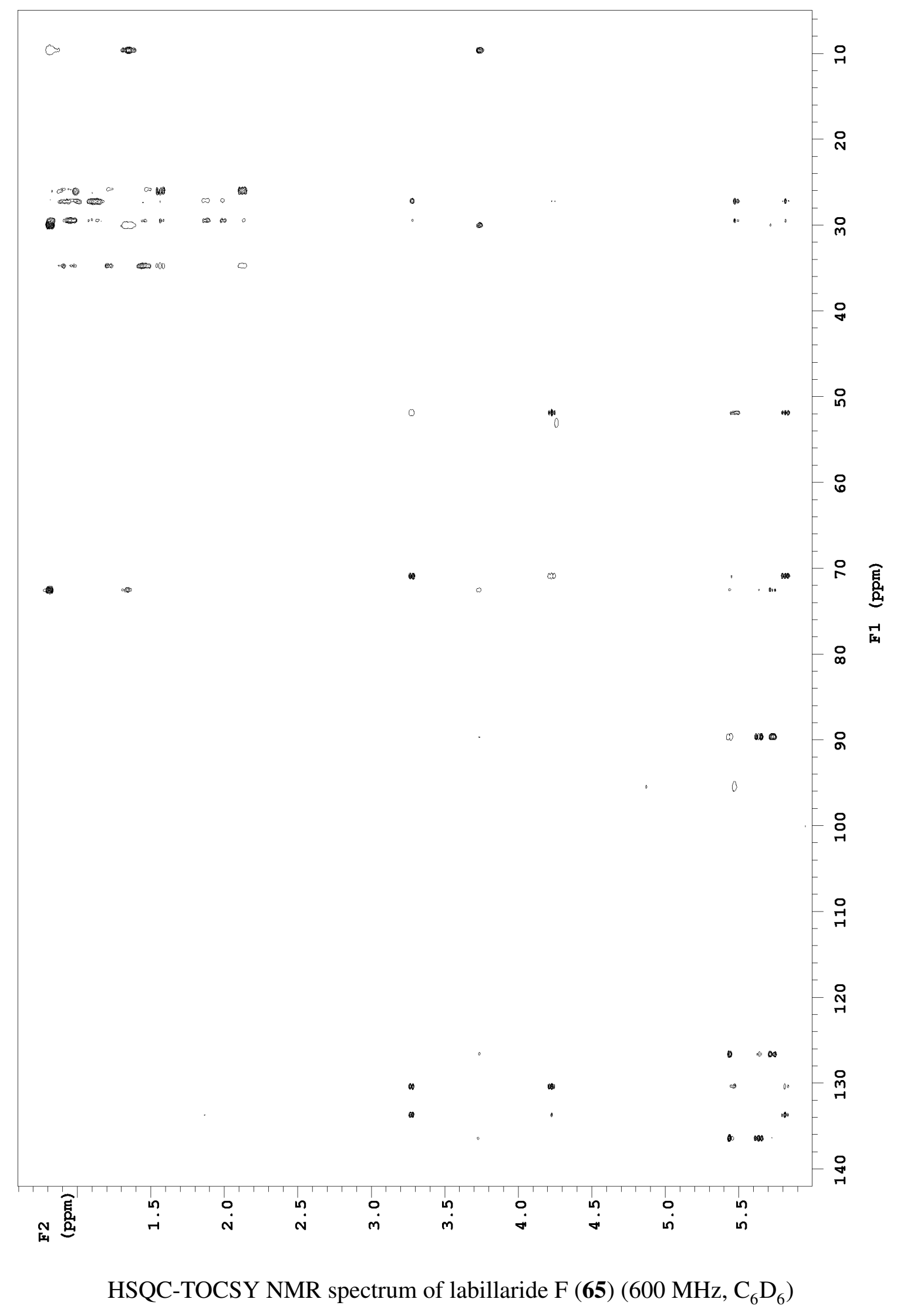


NMR Spectra of Labillaride G

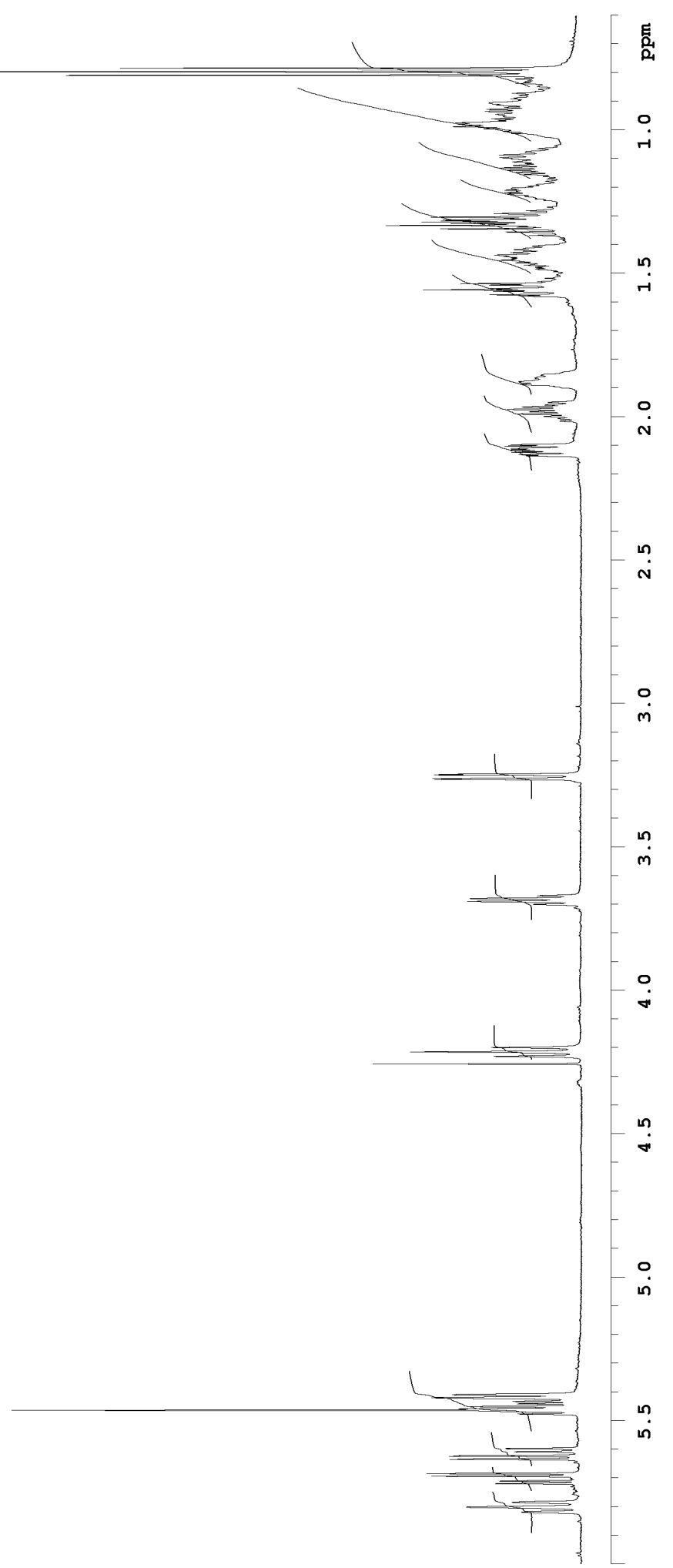

${ }^{1} \mathrm{H}$ NMR spectrum of labillaride $\mathrm{G}(\mathbf{6 6})\left(600 \mathrm{MHz}, \mathrm{C}_{6} \mathrm{D}_{6}\right)$ 


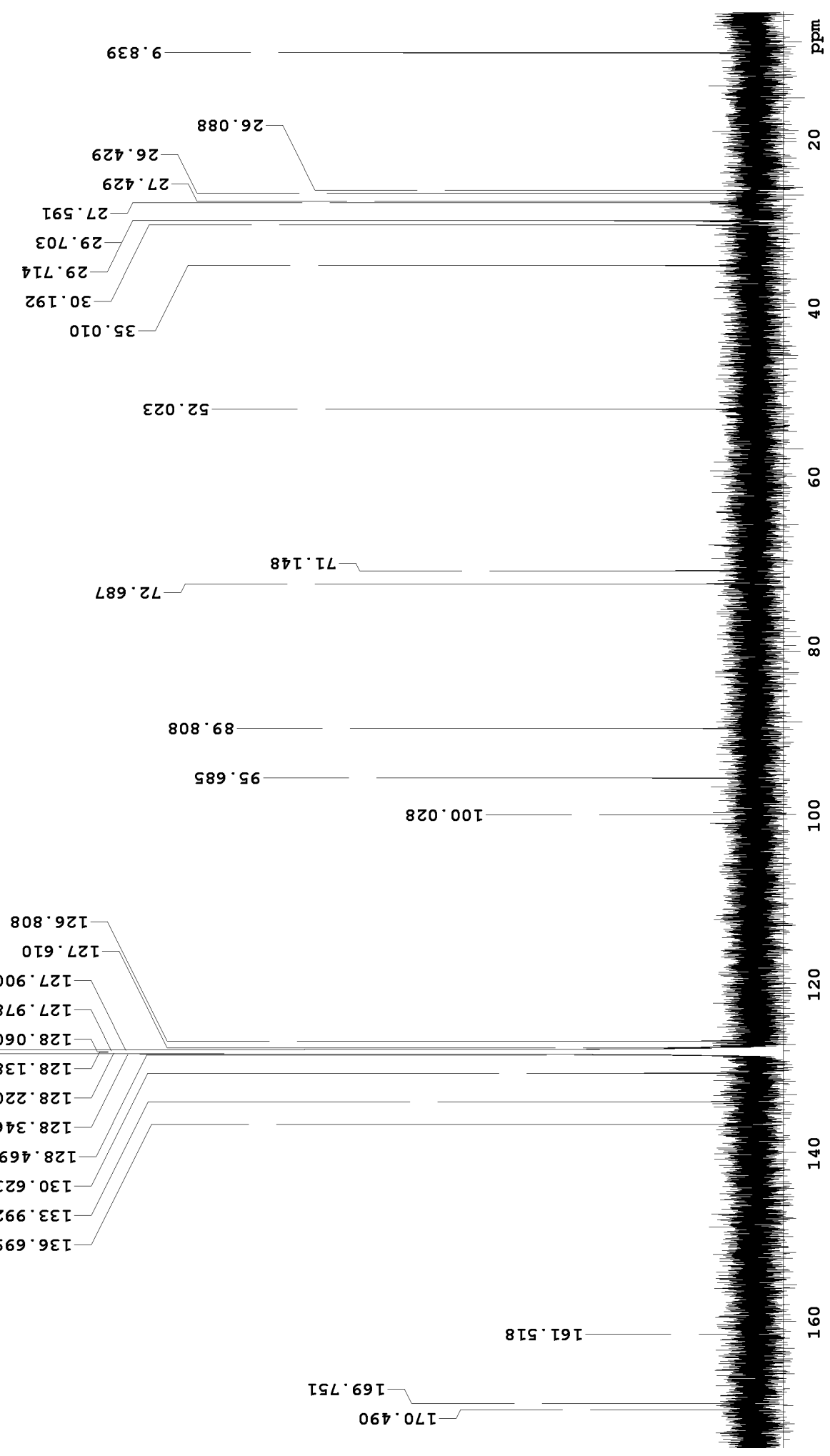

${ }^{13} \mathrm{C}$ NMR spectrum of labillaride $\mathrm{G}(\mathbf{6 6})\left(150 \mathrm{MHz}, \mathrm{C}_{6} \mathrm{D}_{6}\right)$ 


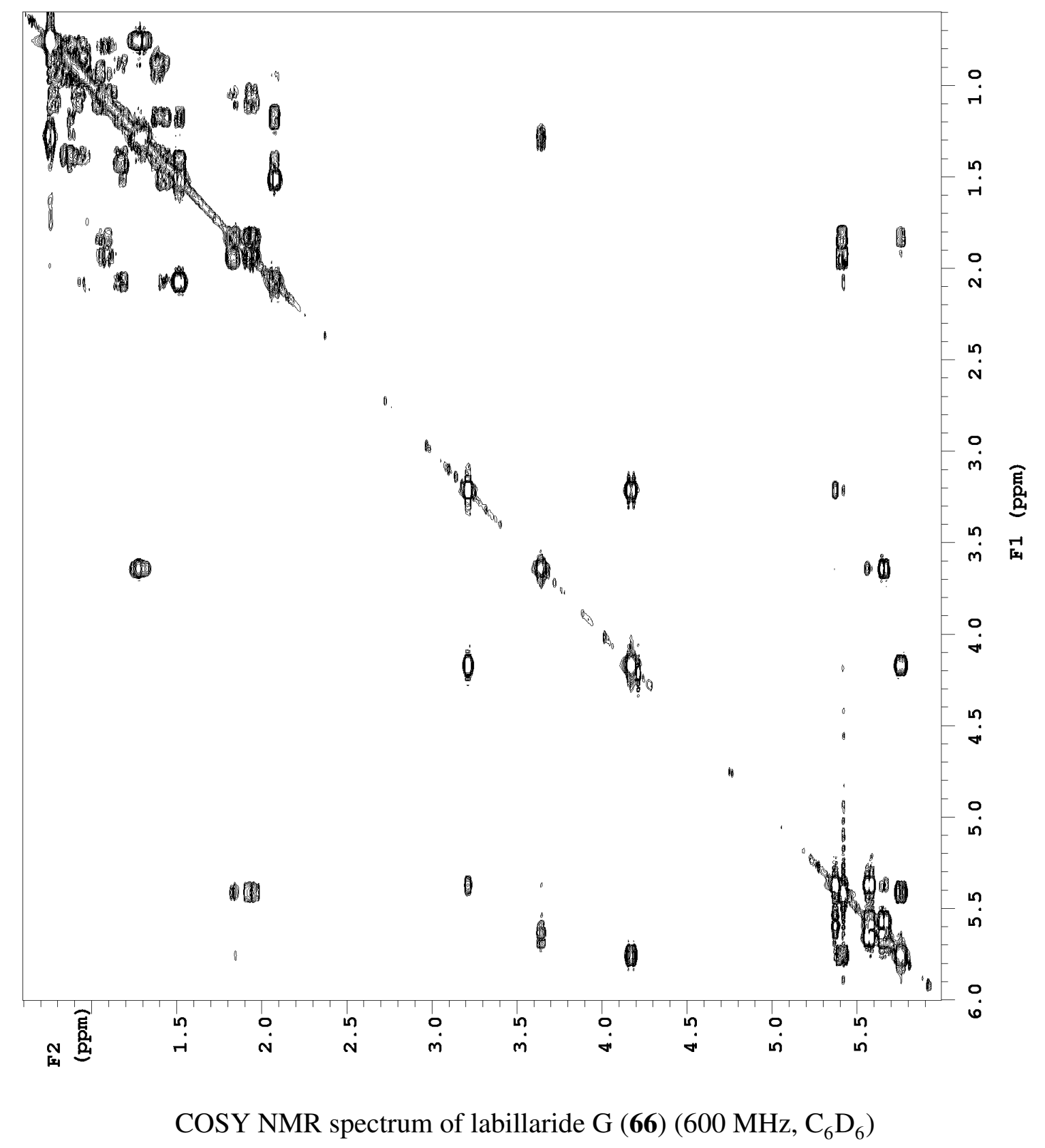




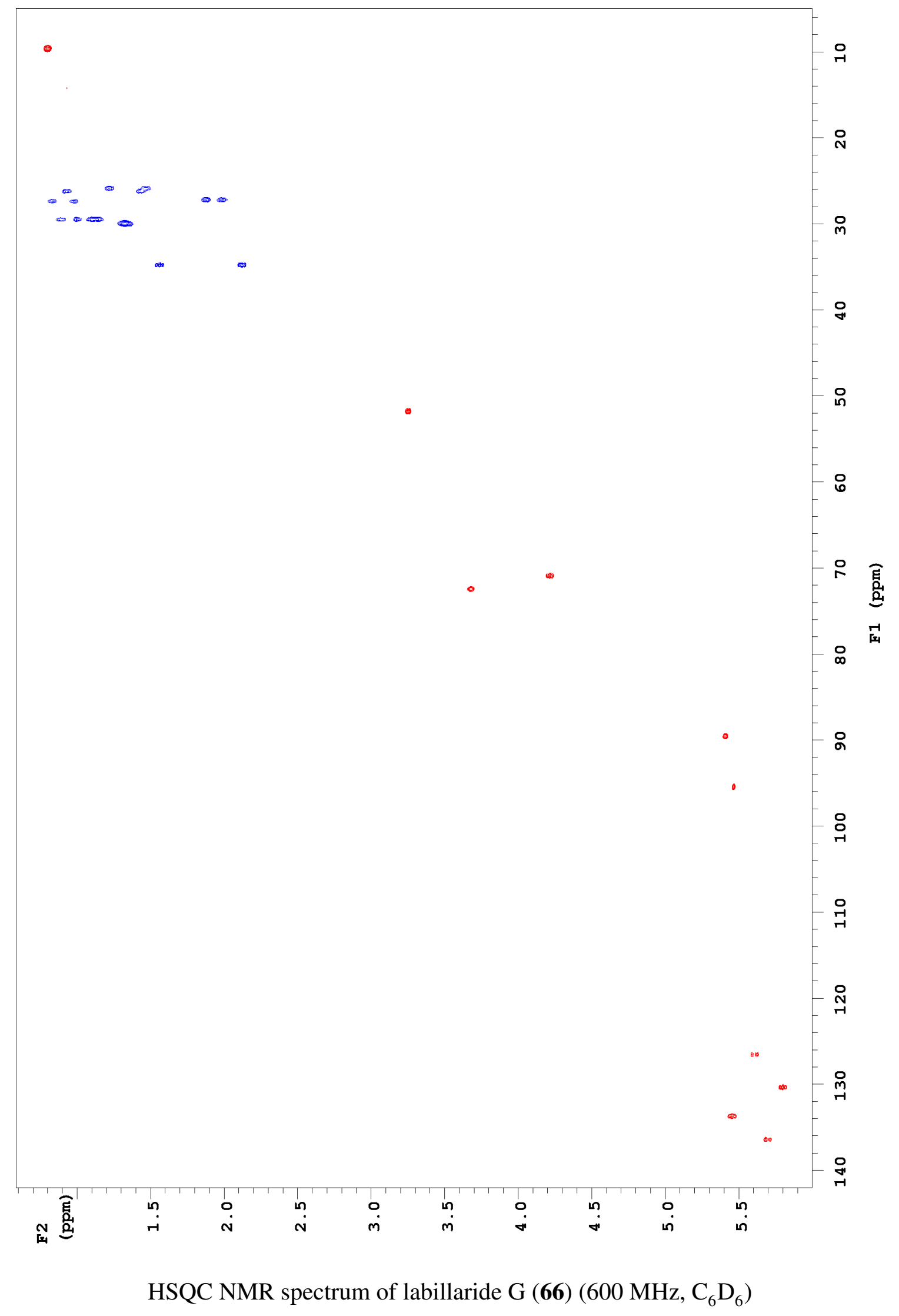




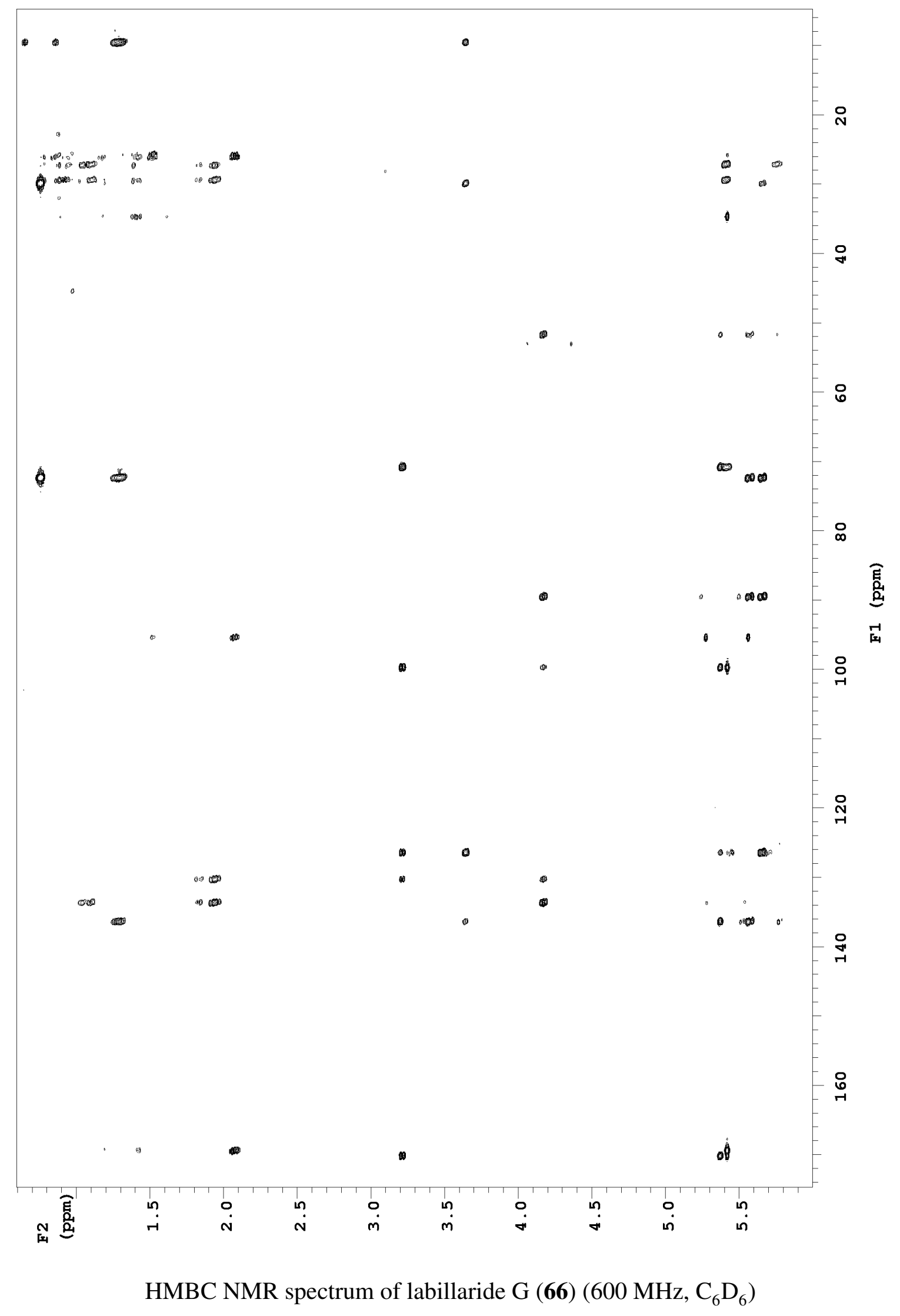




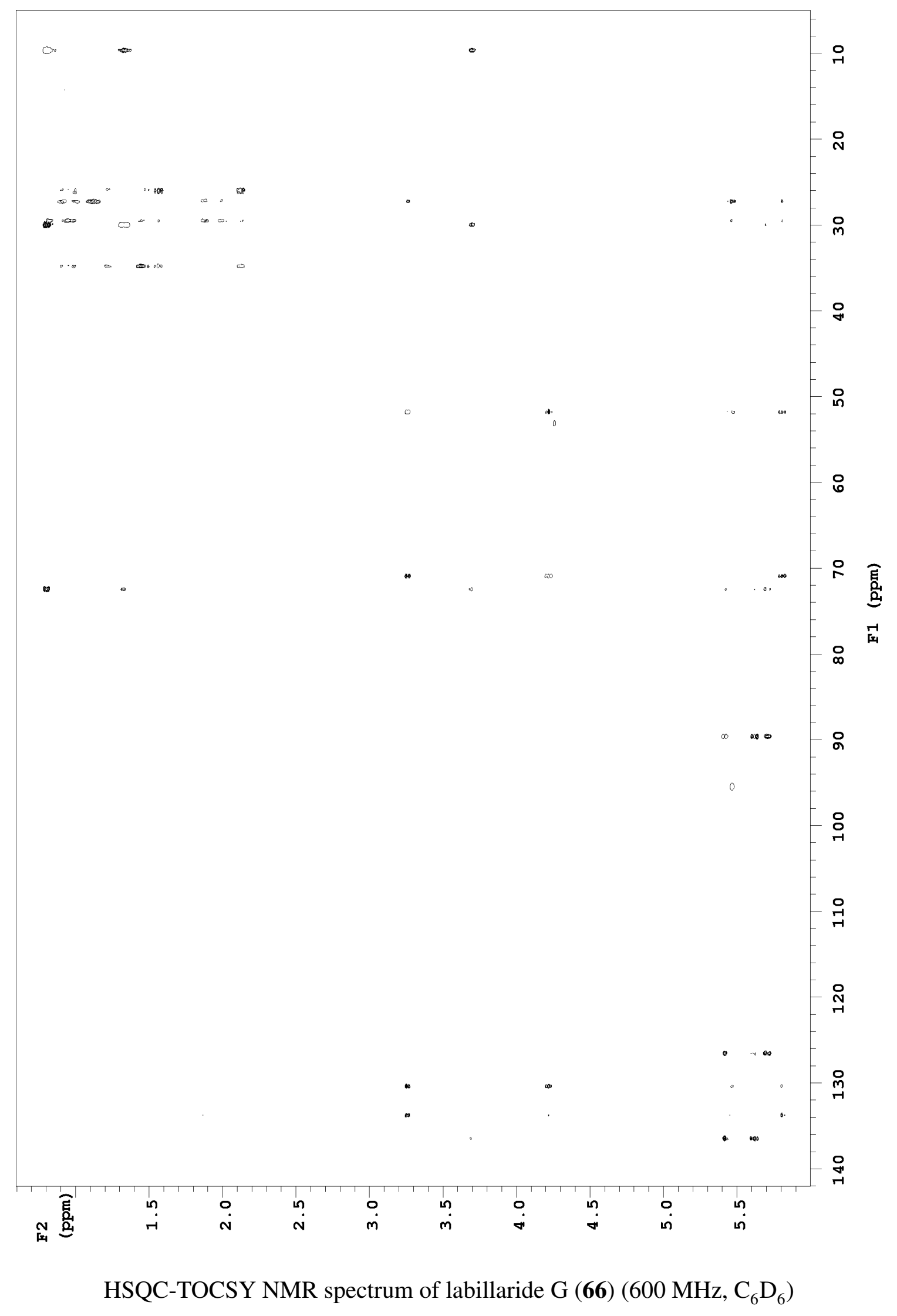




\section{NMR Spectra of Labillaride $H$}

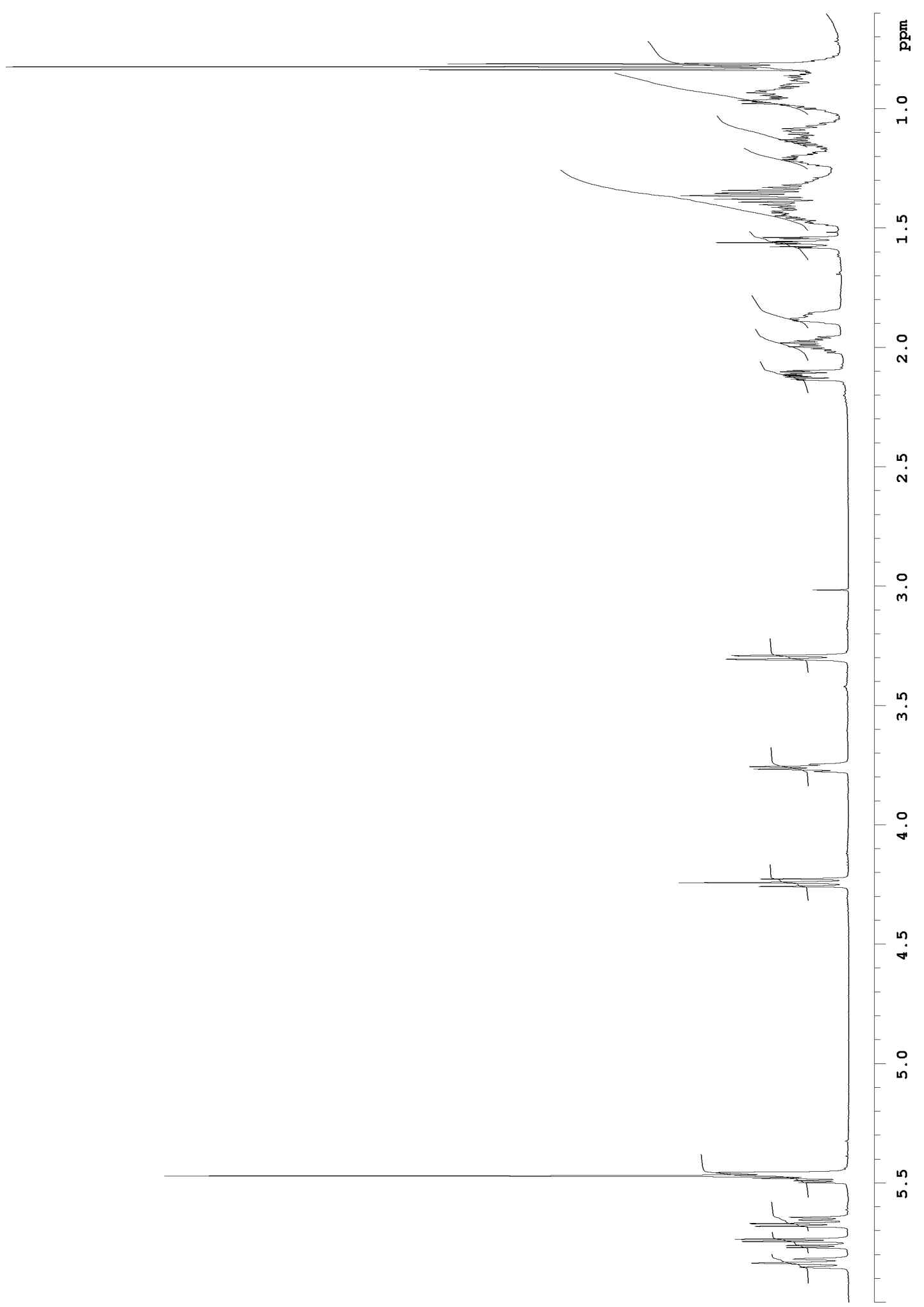

${ }^{1} \mathrm{H}$ NMR spectrum of labillaride $\mathrm{H}(67)\left(600 \mathrm{MHz}, \mathrm{C}_{6} \mathrm{D}_{6}\right)$ 


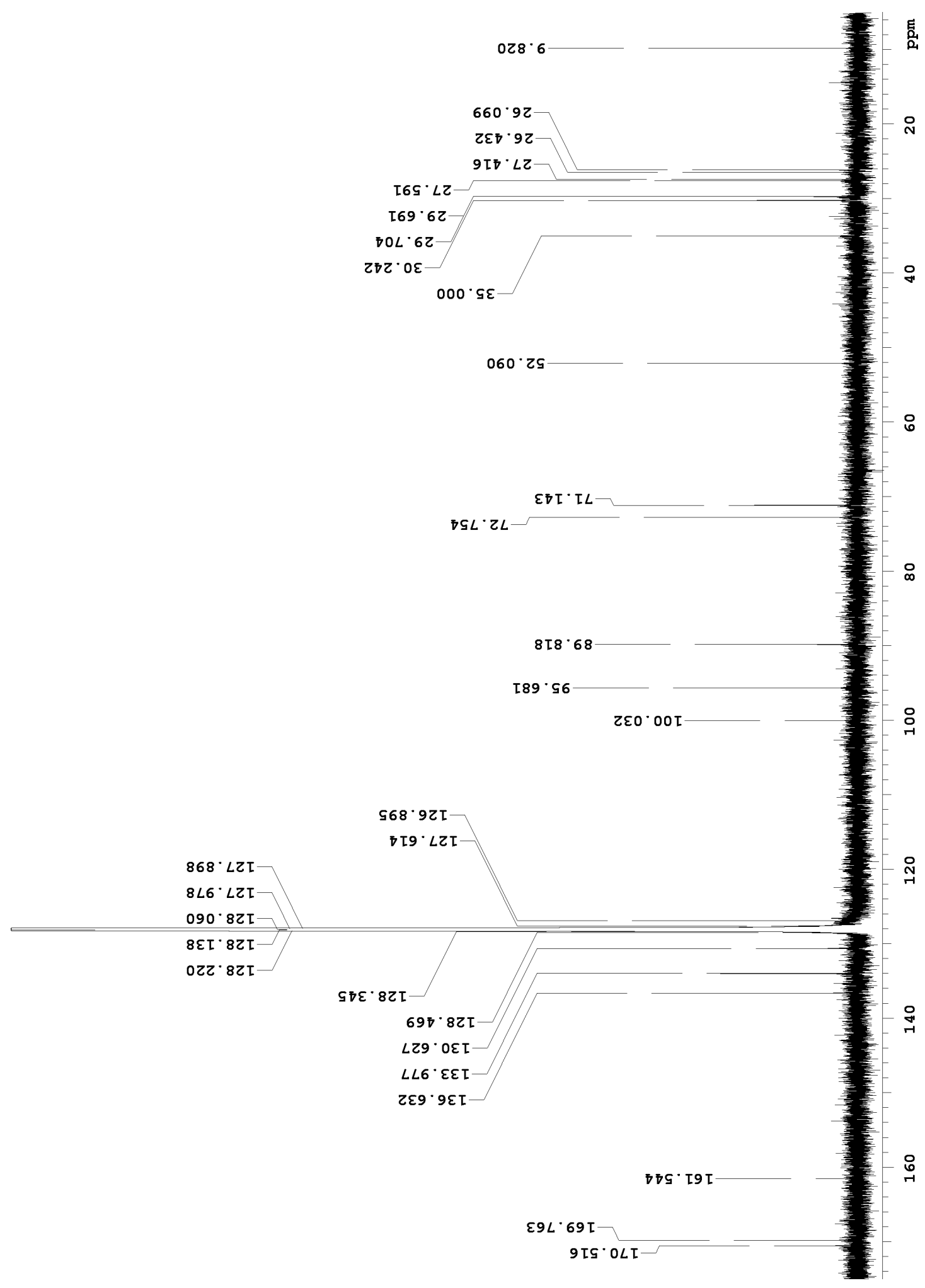

${ }^{13} \mathrm{C}$ NMR spectrum of labillaride $\mathrm{H}(67)\left(150 \mathrm{MHz}, \mathrm{C}_{6} \mathrm{D}_{6}\right)$ 


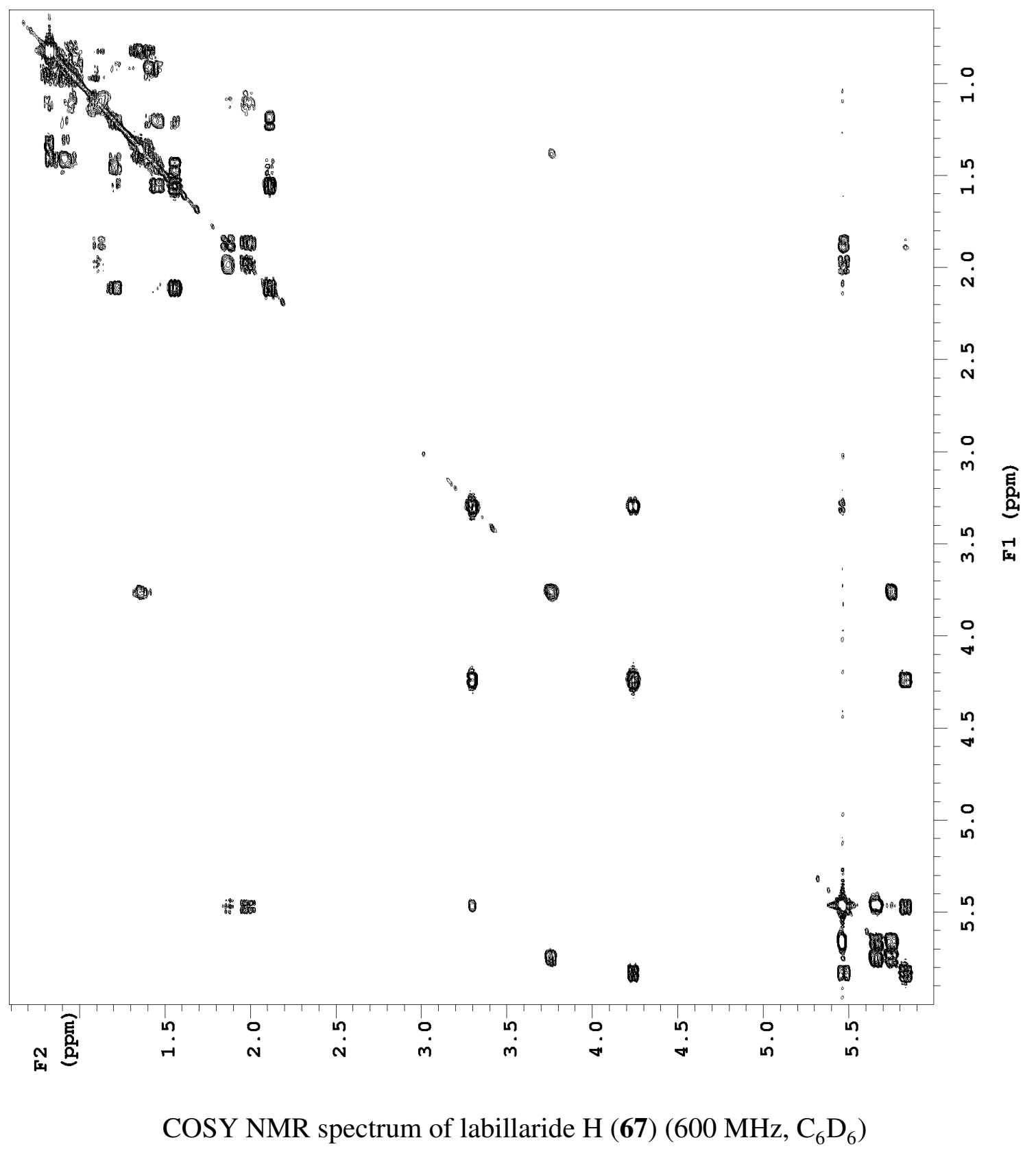




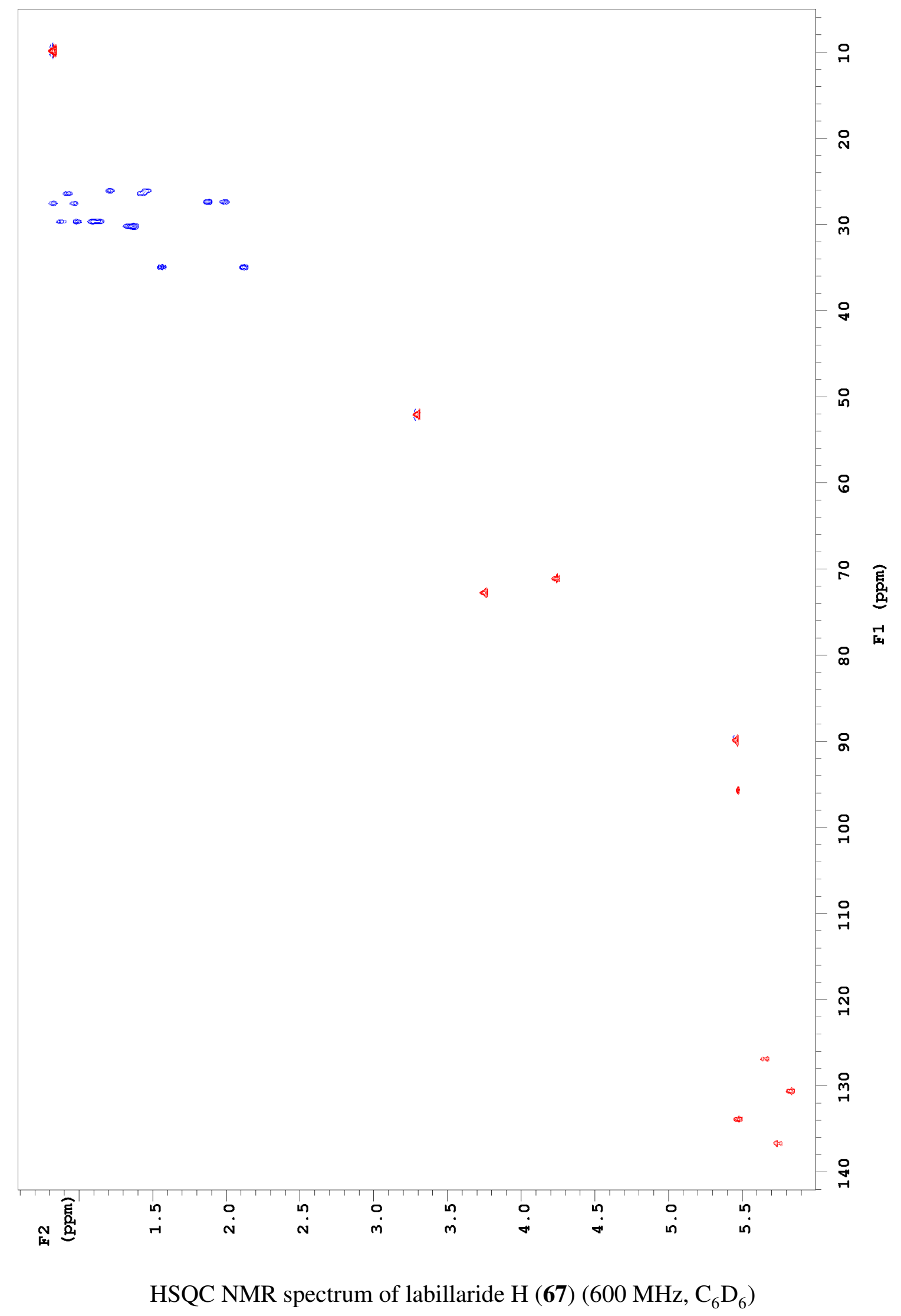




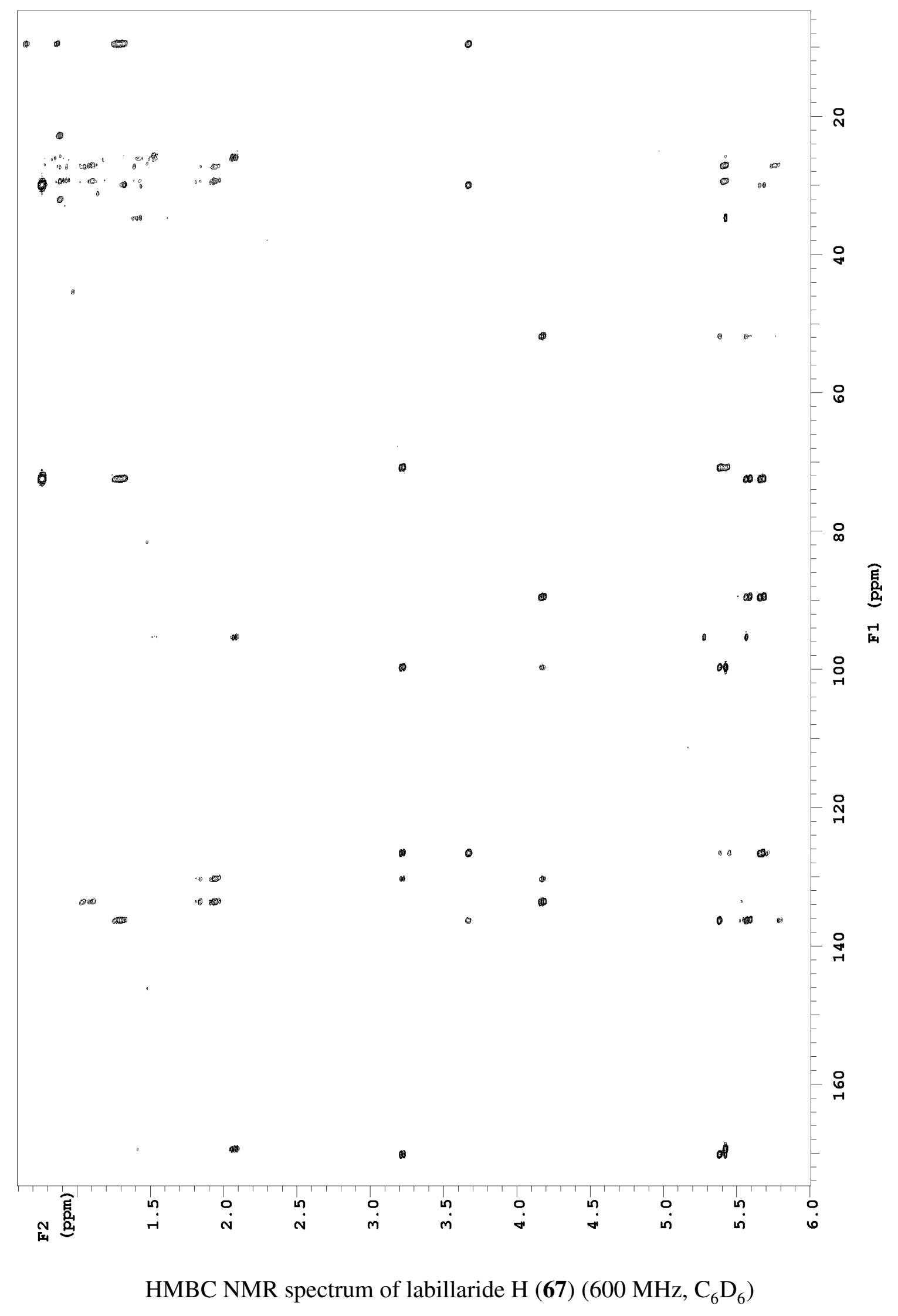




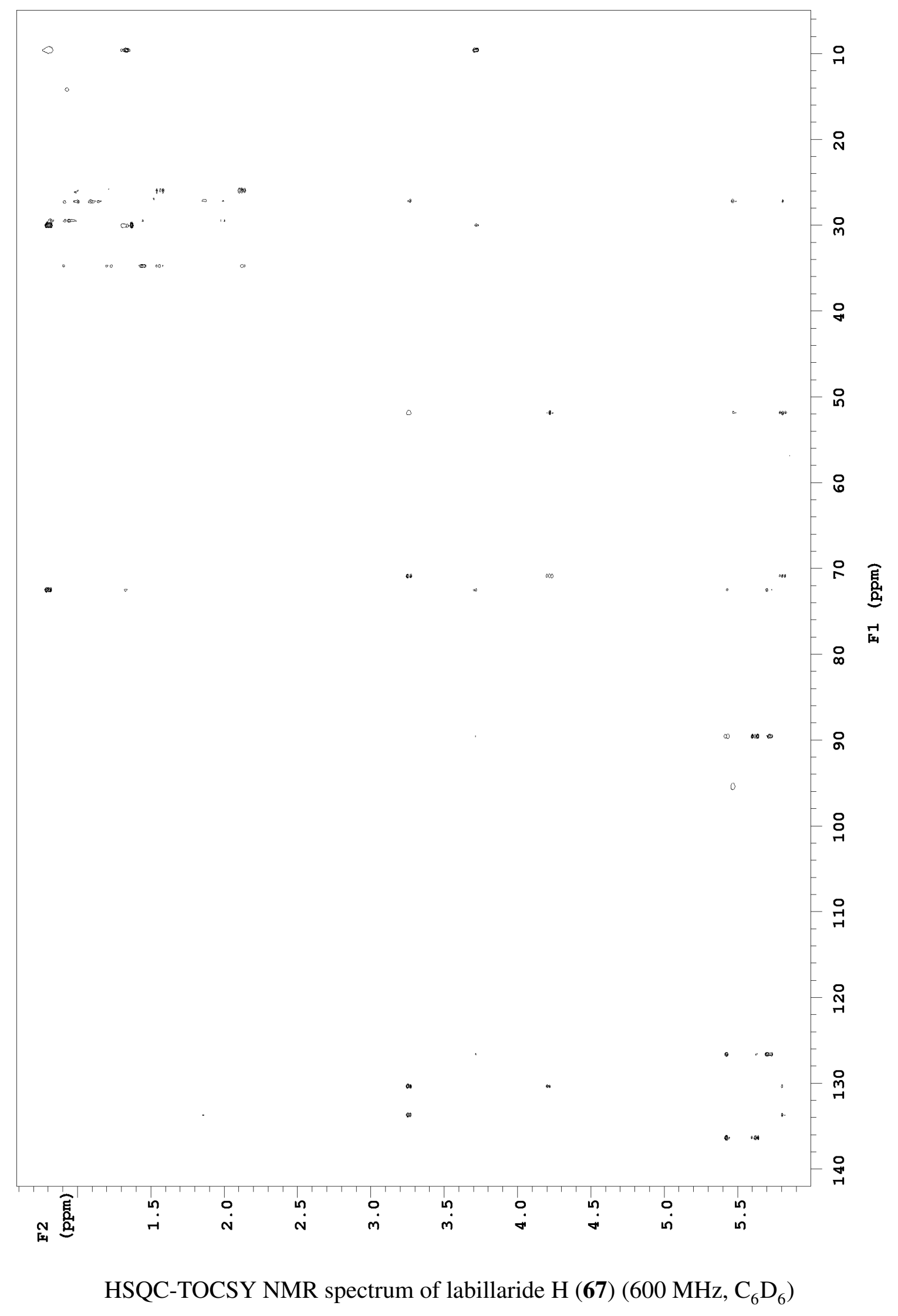


Appendix L

${ }^{1} \mathrm{H}$ NMR Spectrum of 3,8-Diacetyl-labillaride $\mathrm{H}$

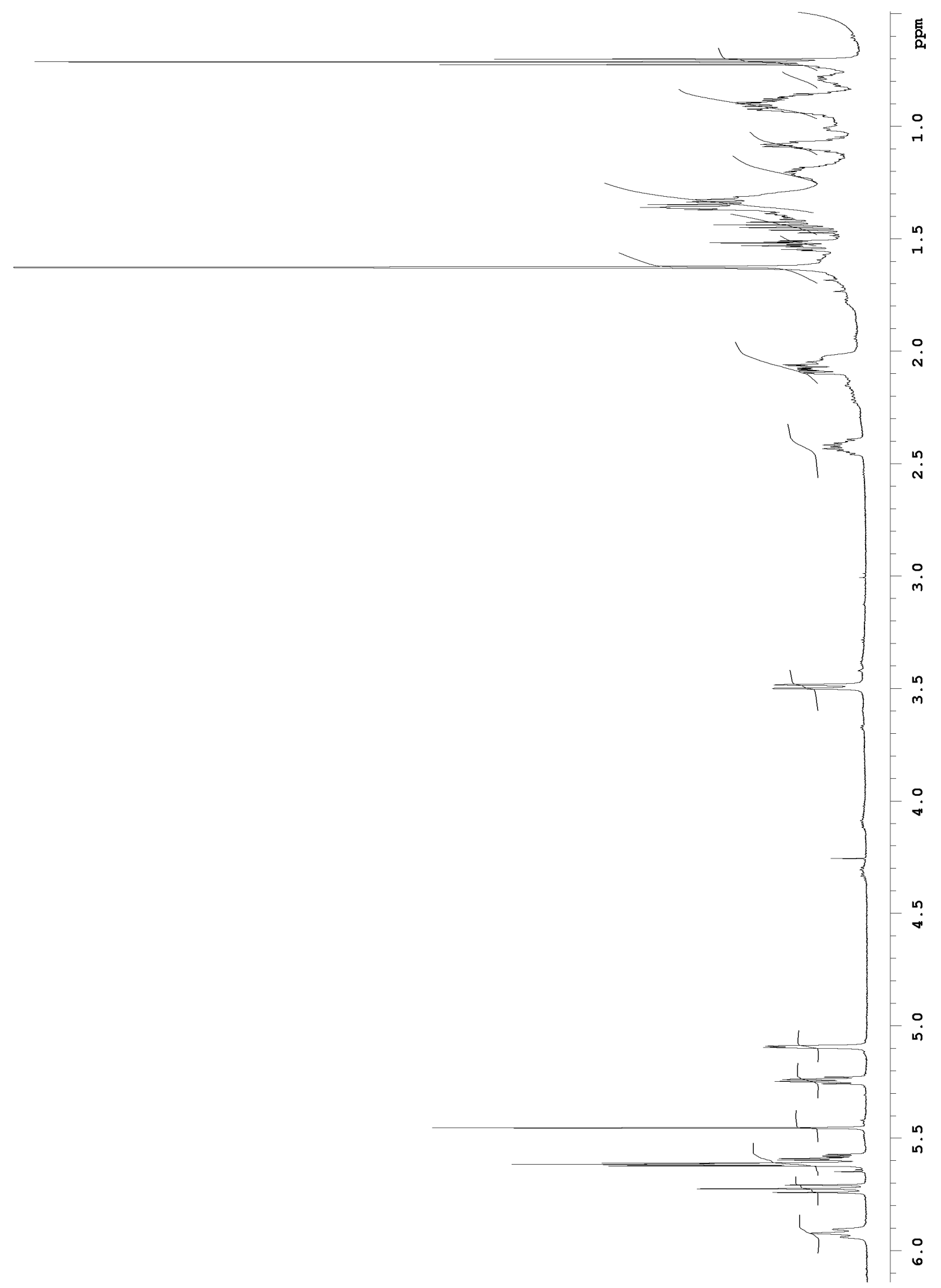

${ }^{1} \mathrm{H}$ NMR spectrum of 3,8-diacetyl-labillaride $\mathrm{H}(\mathbf{7 3})\left(600 \mathrm{MHz}, \mathrm{C}_{6} \mathrm{D}_{6}\right)$ 


\section{NMR Spectra of Labillaride I}

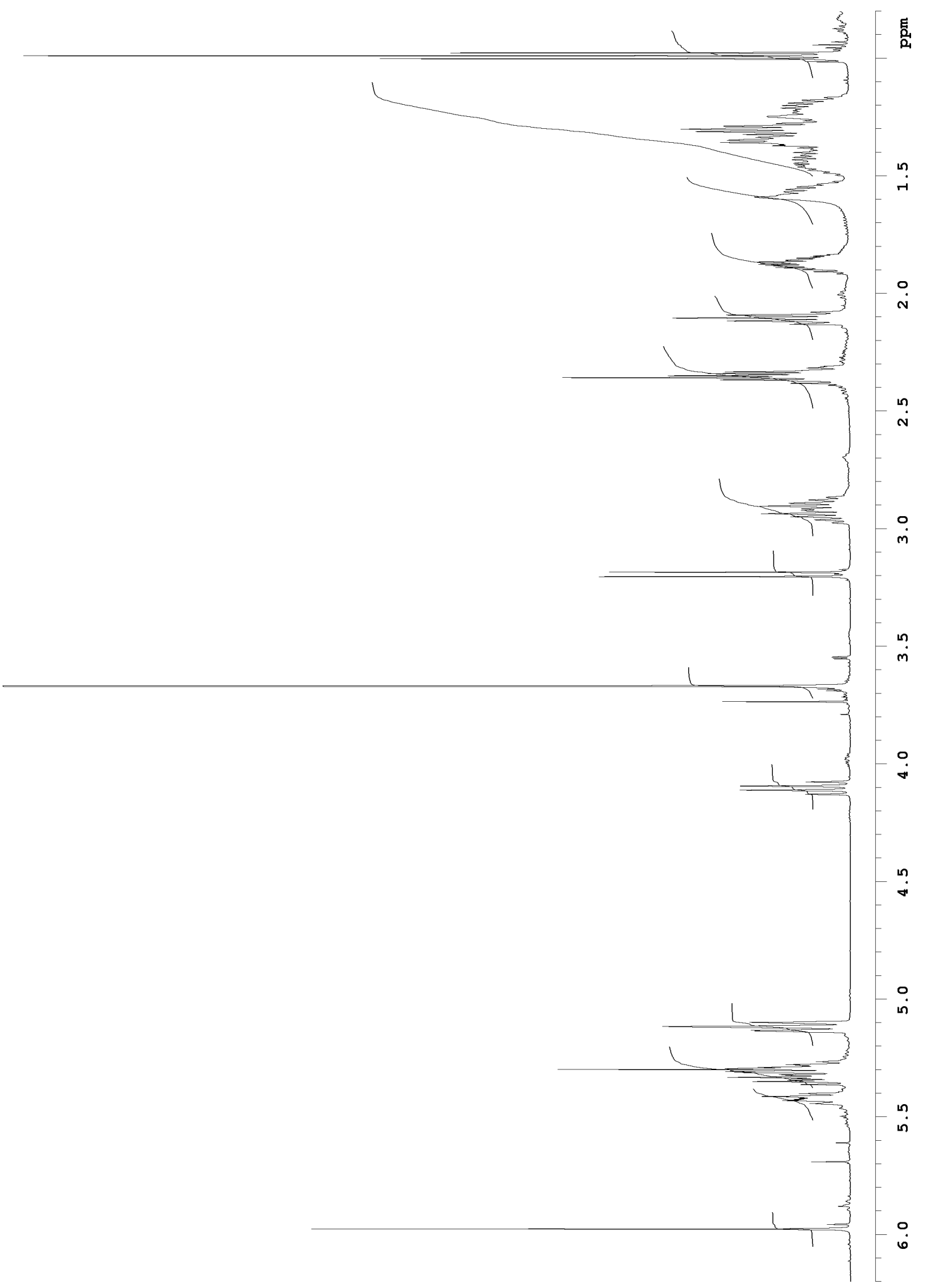

${ }^{1} \mathrm{H}$ NMR spectrum of labillaride I (68) $\left(600 \mathrm{MHz}, \mathrm{CDCl}_{3}\right)$ 


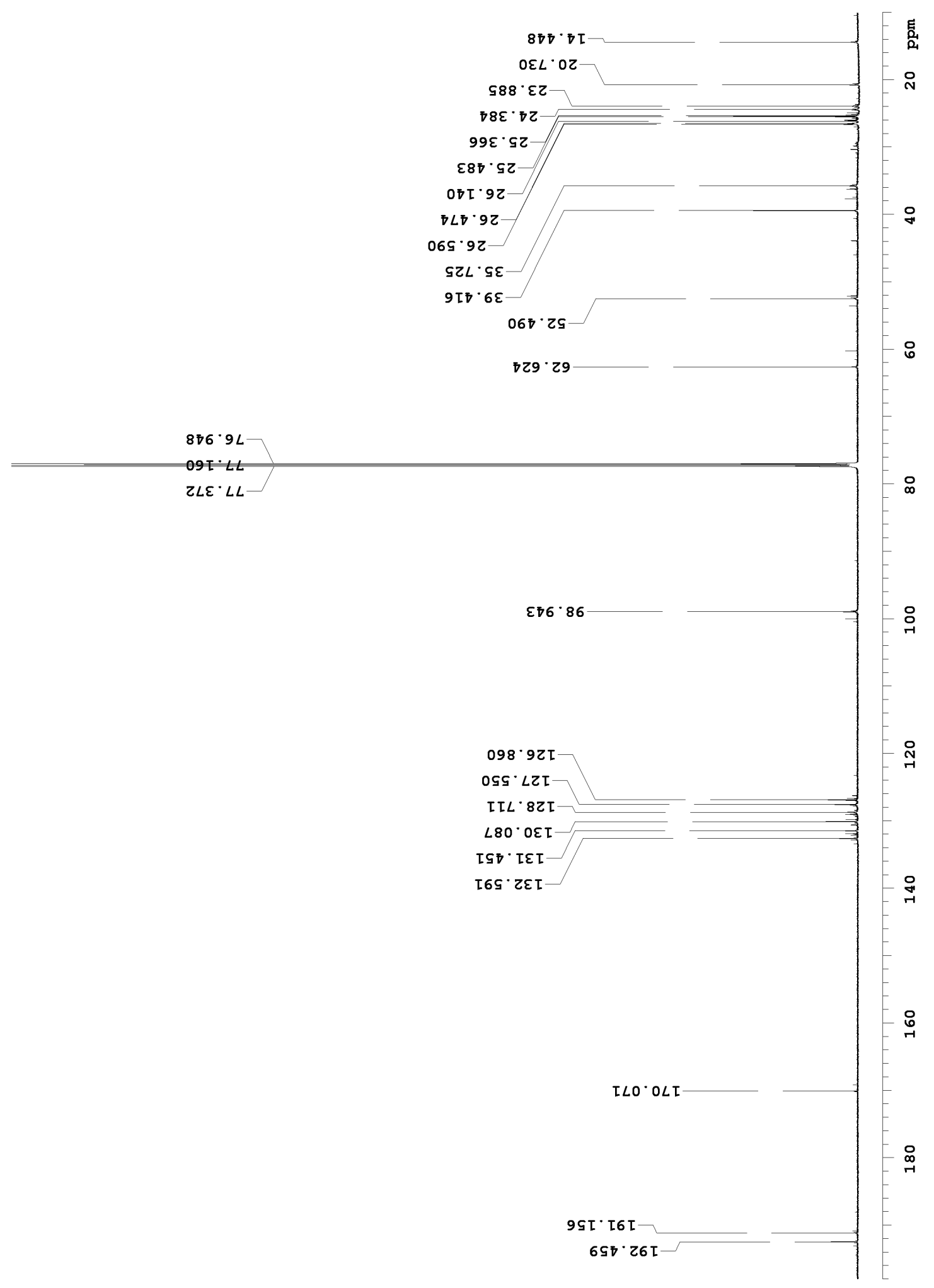

${ }^{13} \mathrm{C}$ NMR spectrum of labillaride I (68) $\left(150 \mathrm{MHz}, \mathrm{CDCl}_{3}\right)$ 


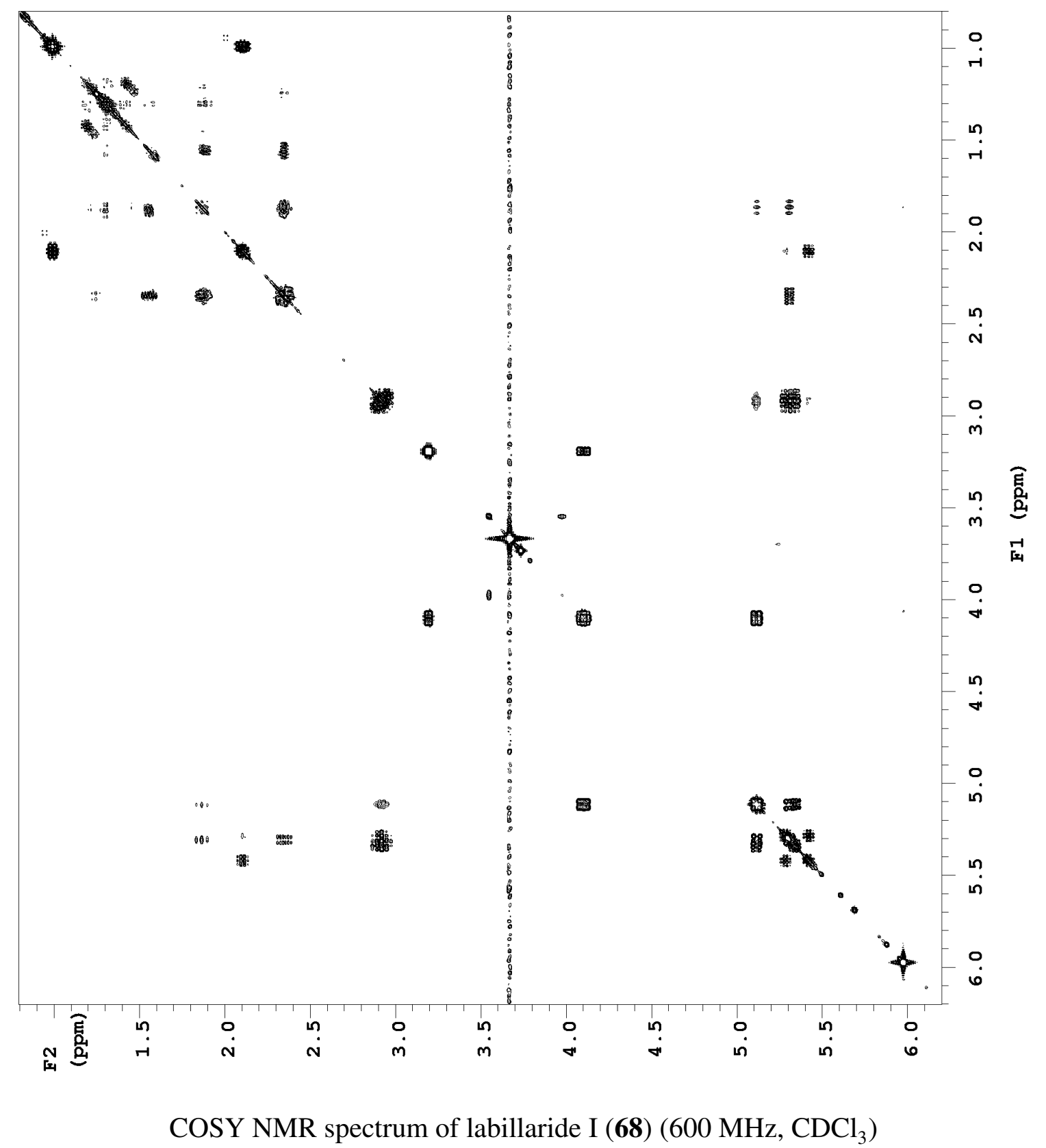




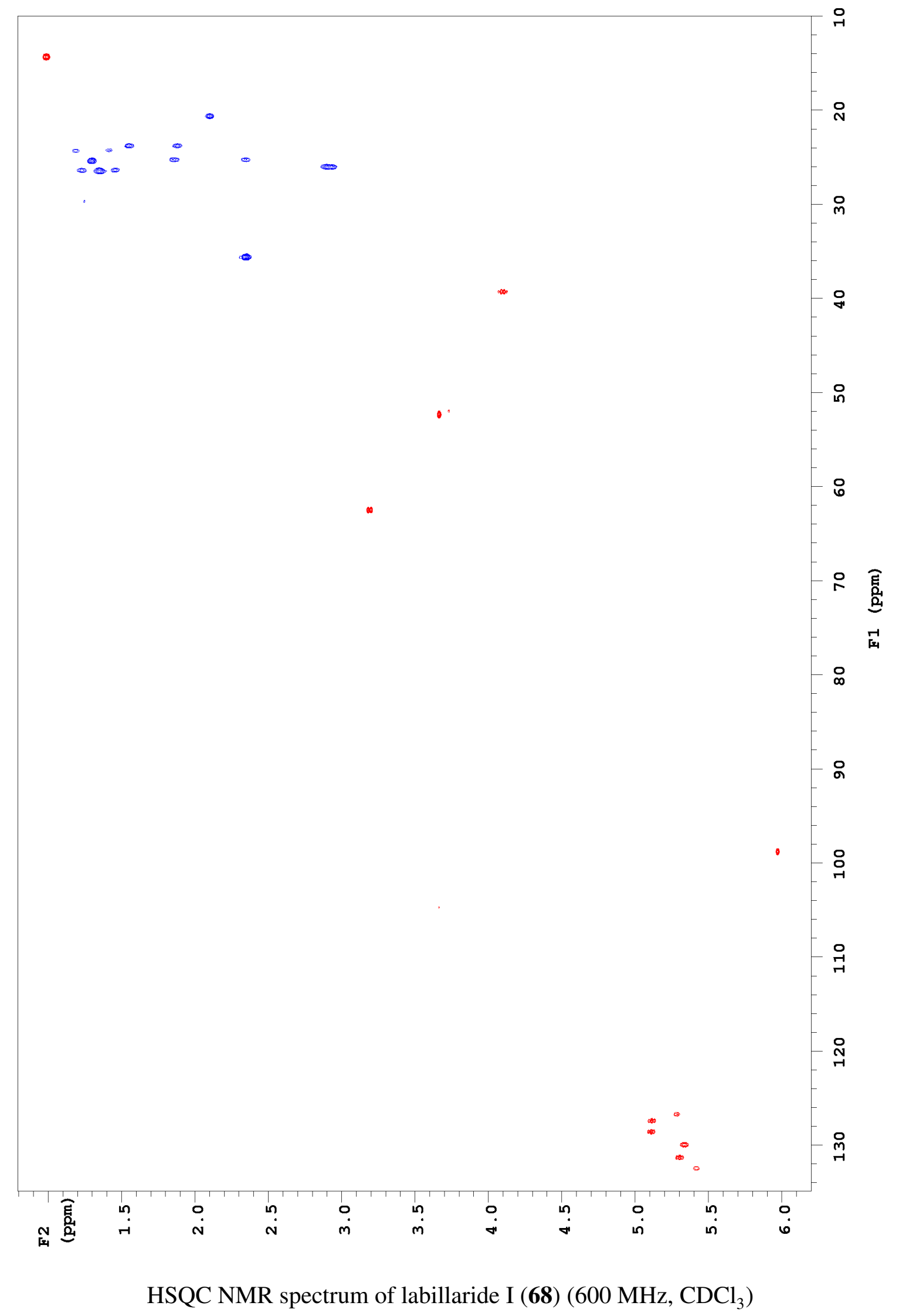




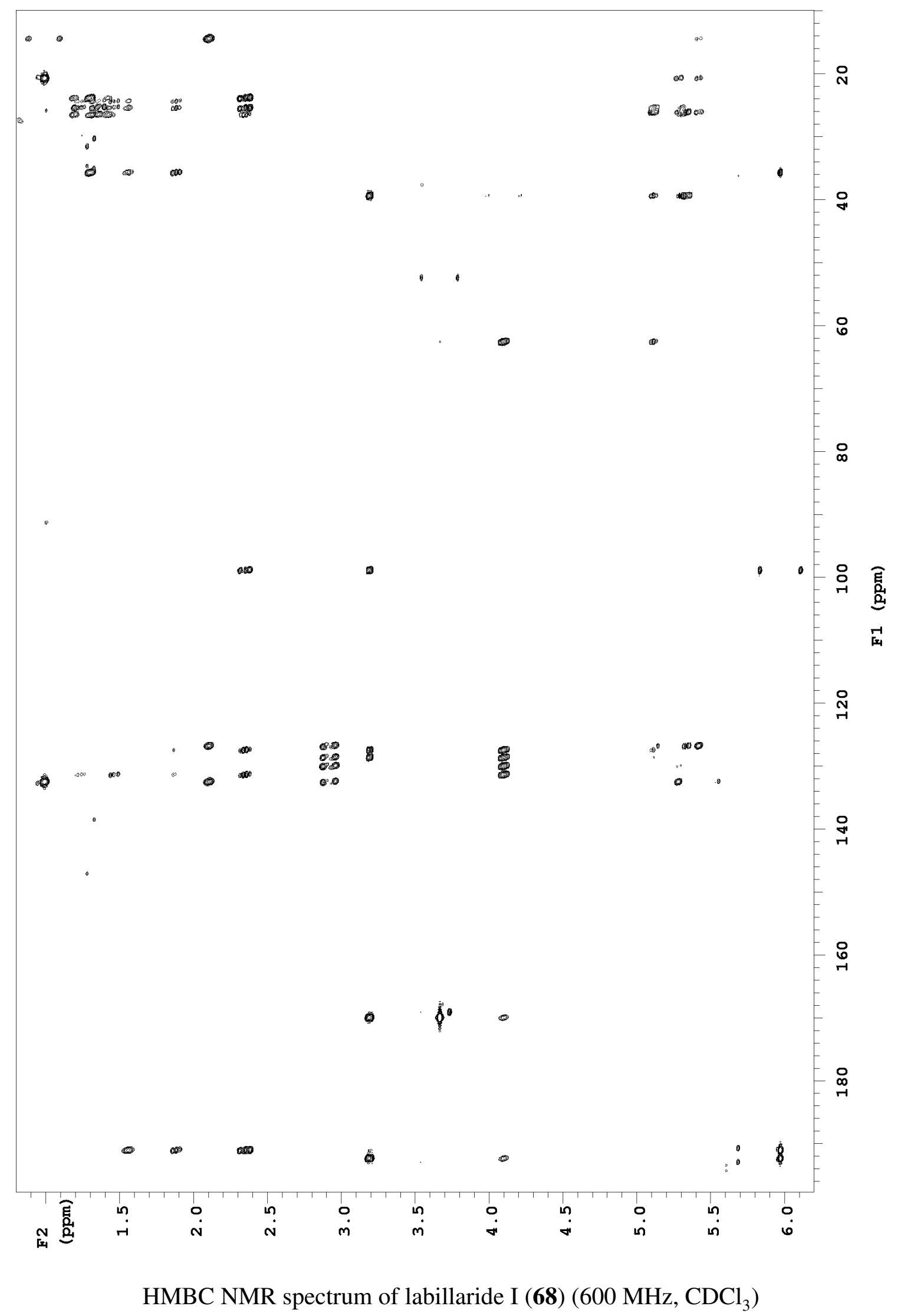




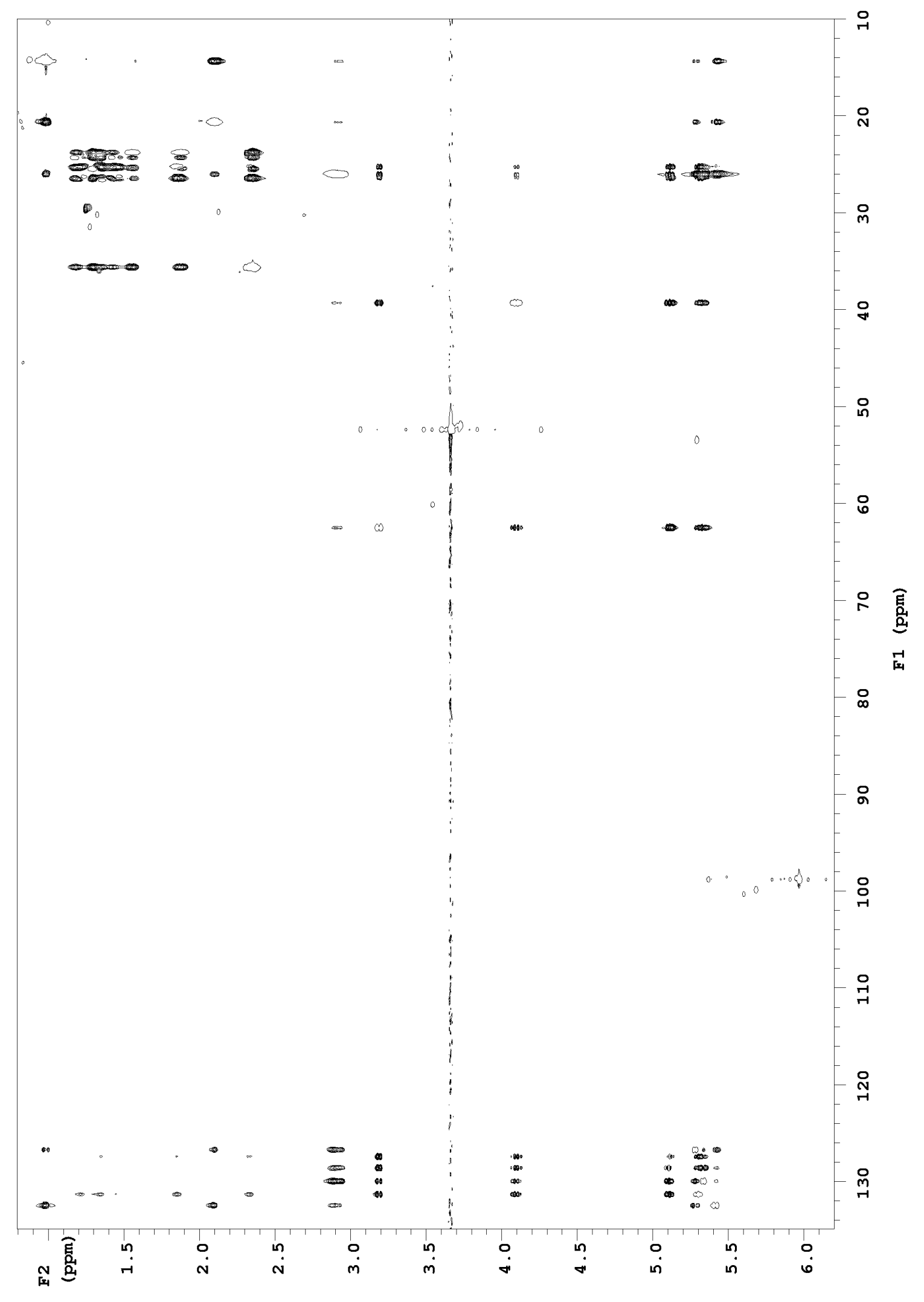

HSQC-TOCSY NMR spectrum of labillaride I (68) (600 MHz, CDCl 3 ) 
NMR Spectra of Labillaride J

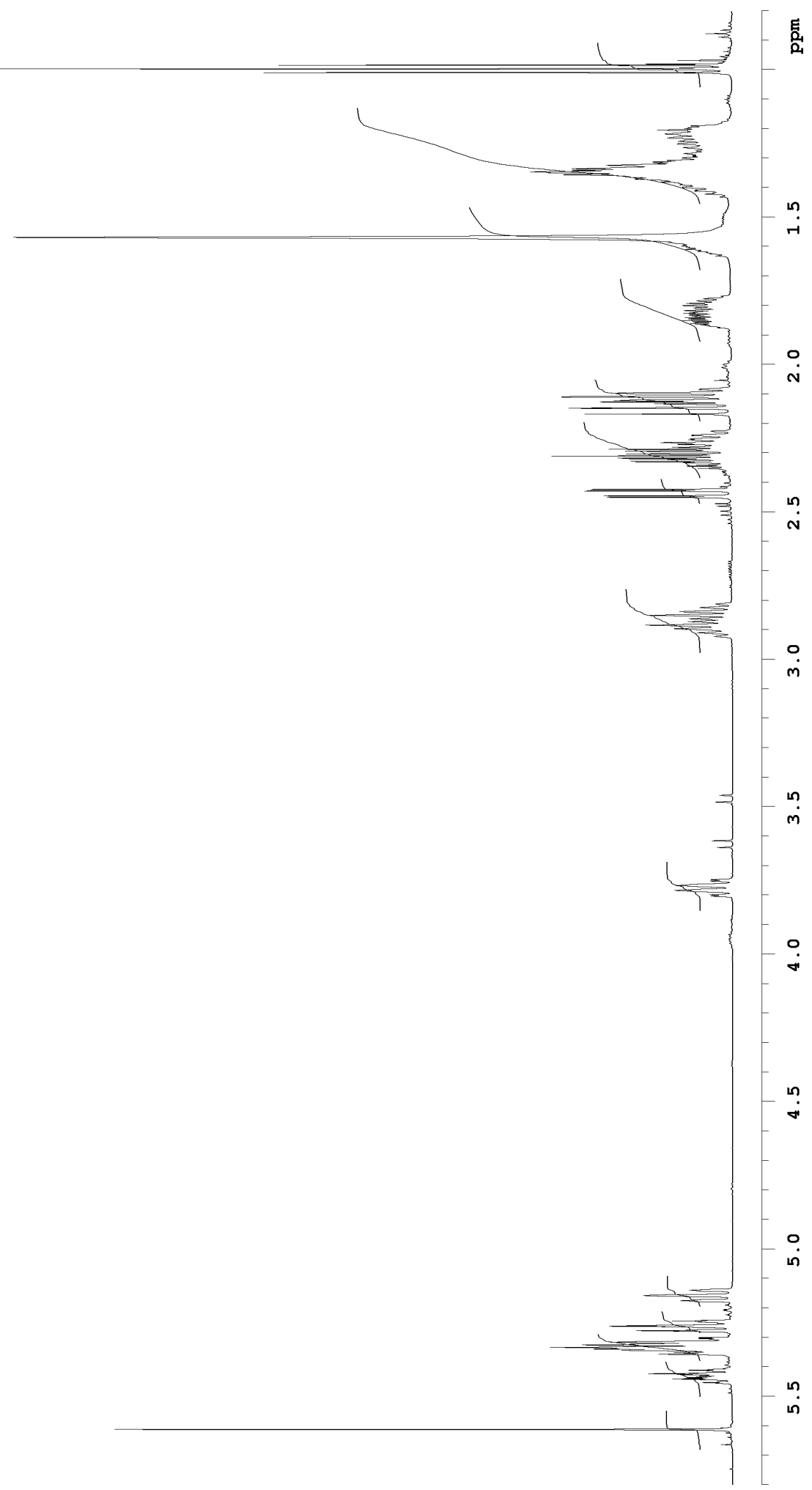

${ }^{1} \mathrm{H}$ NMR spectrum of labillaride $\mathrm{J}(\mathbf{6 9})\left(600 \mathrm{MHz}, \mathrm{CDCl}_{3}\right)$ 


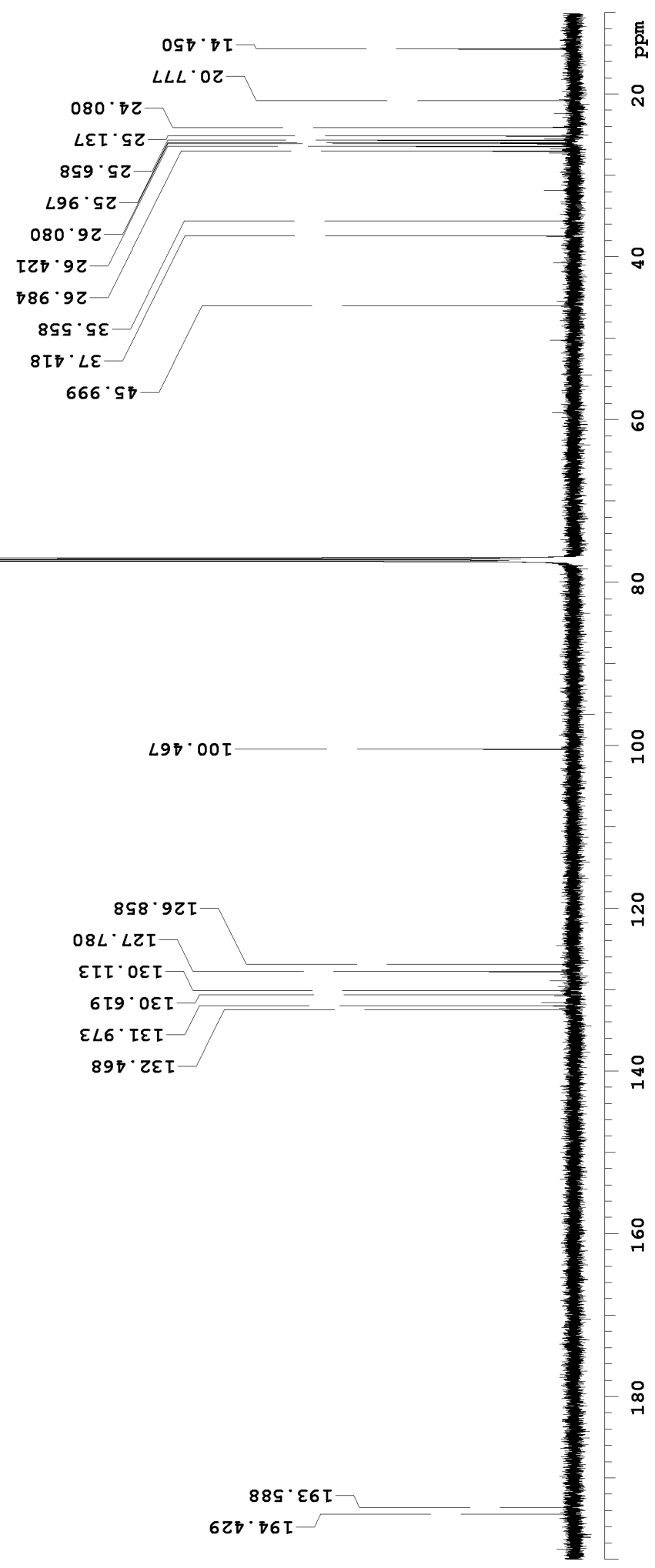

${ }^{13} \mathrm{C}$ NMR spectrum of labillaride $\mathrm{J}(\mathbf{6 9})\left(150 \mathrm{MHz}, \mathrm{CDCl}_{3}\right)$ 


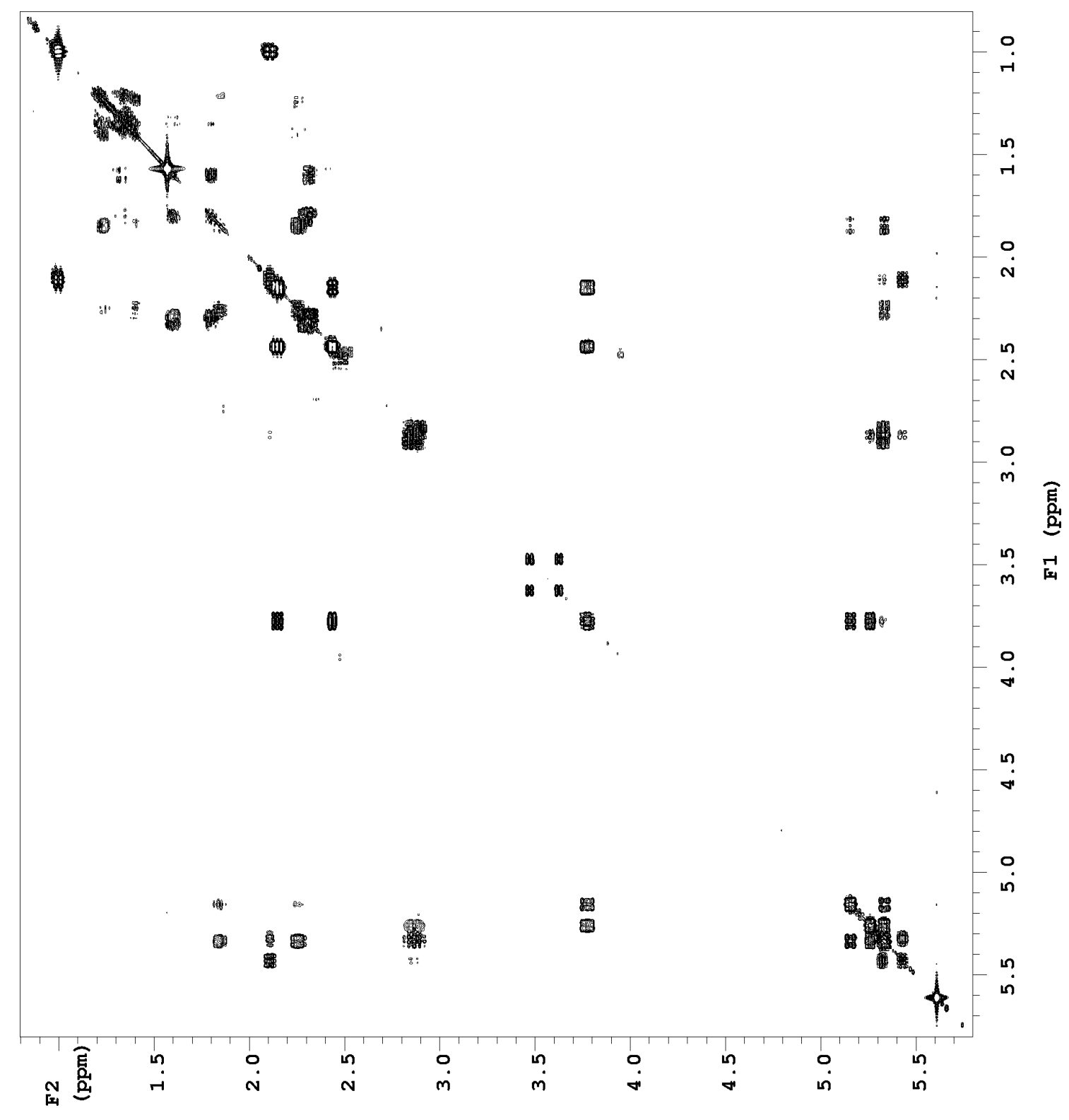

COSY NMR spectrum of labillaride J (69) $\left(600 \mathrm{MHz}, \mathrm{CDCl}_{3}\right)$ 


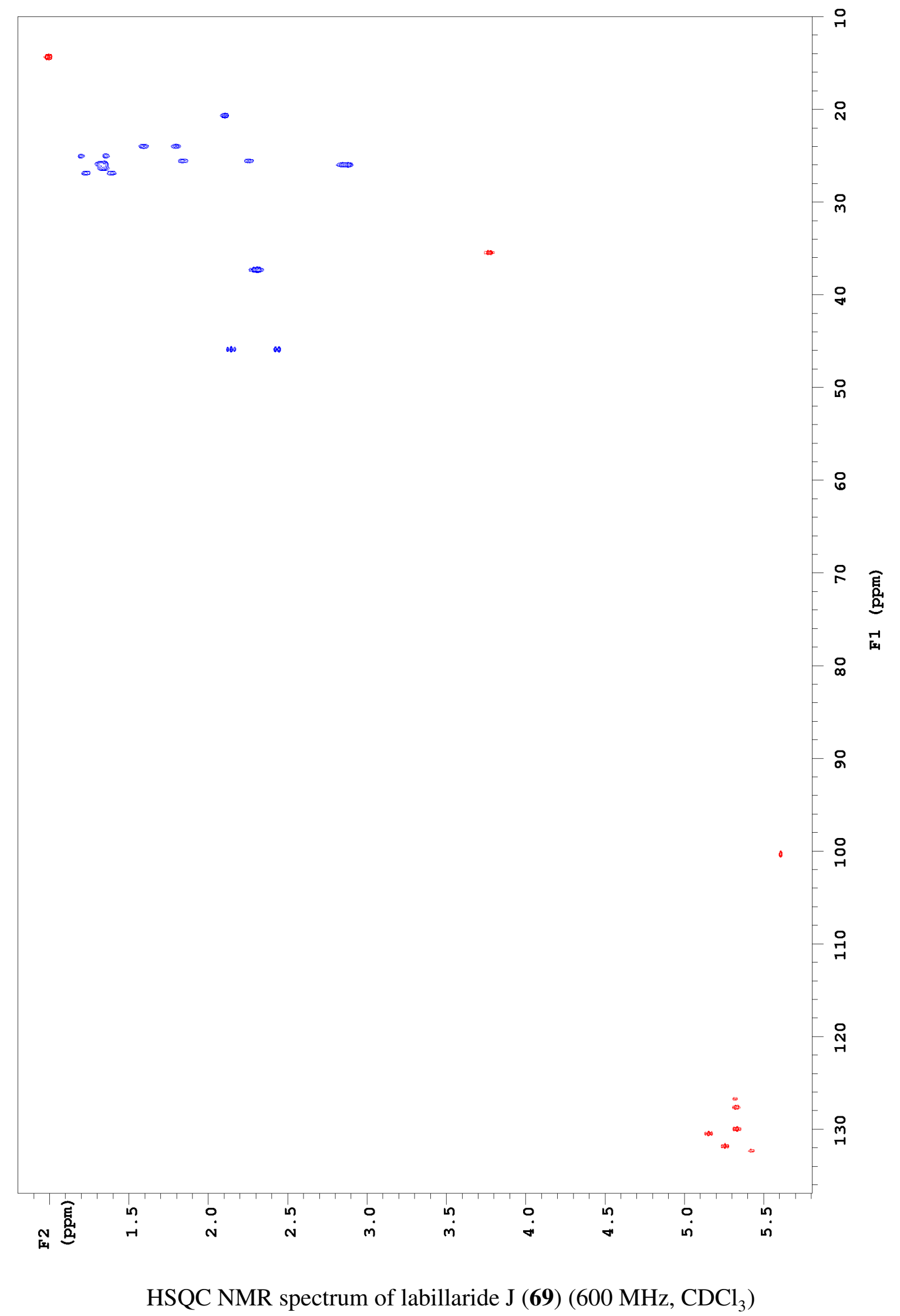




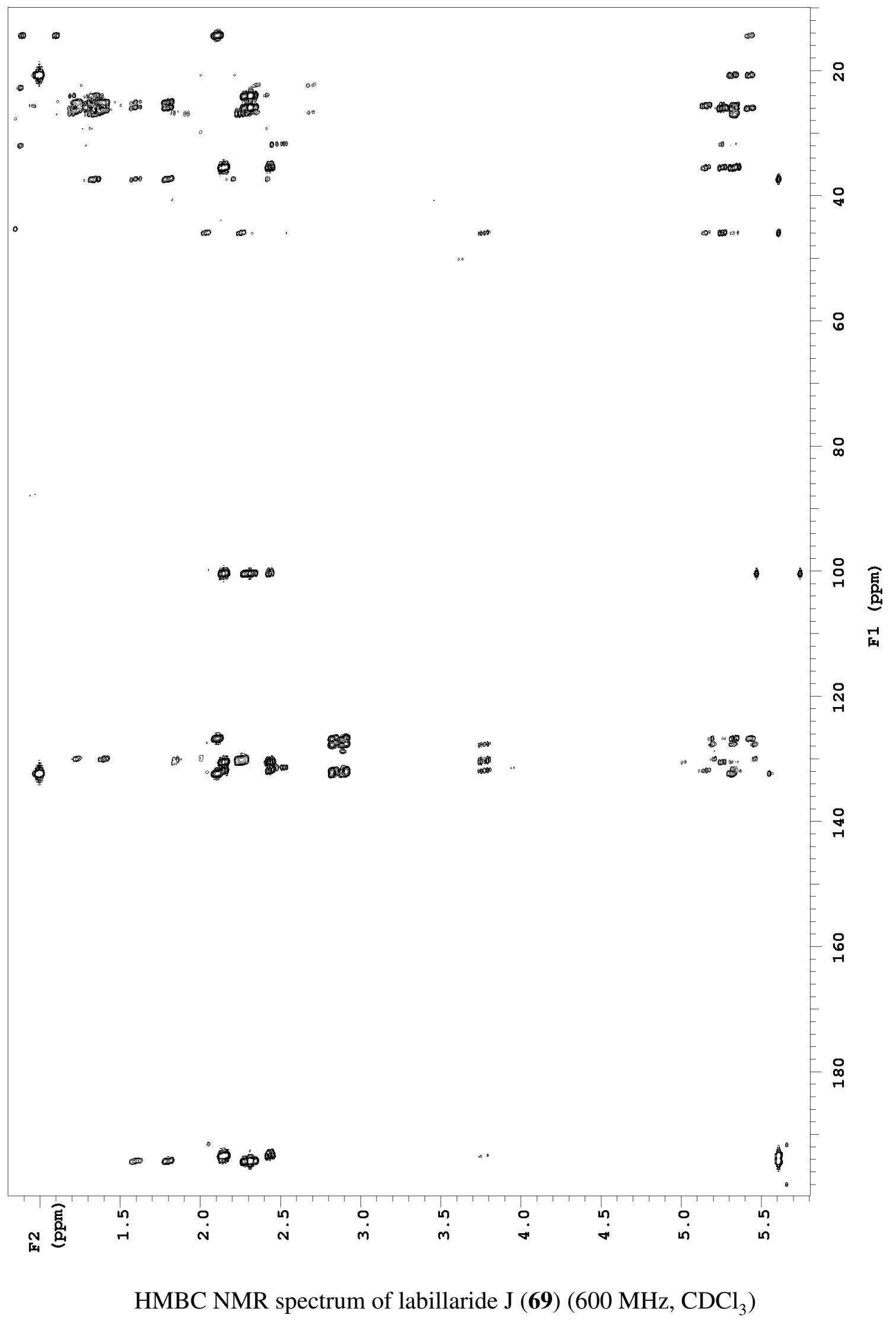




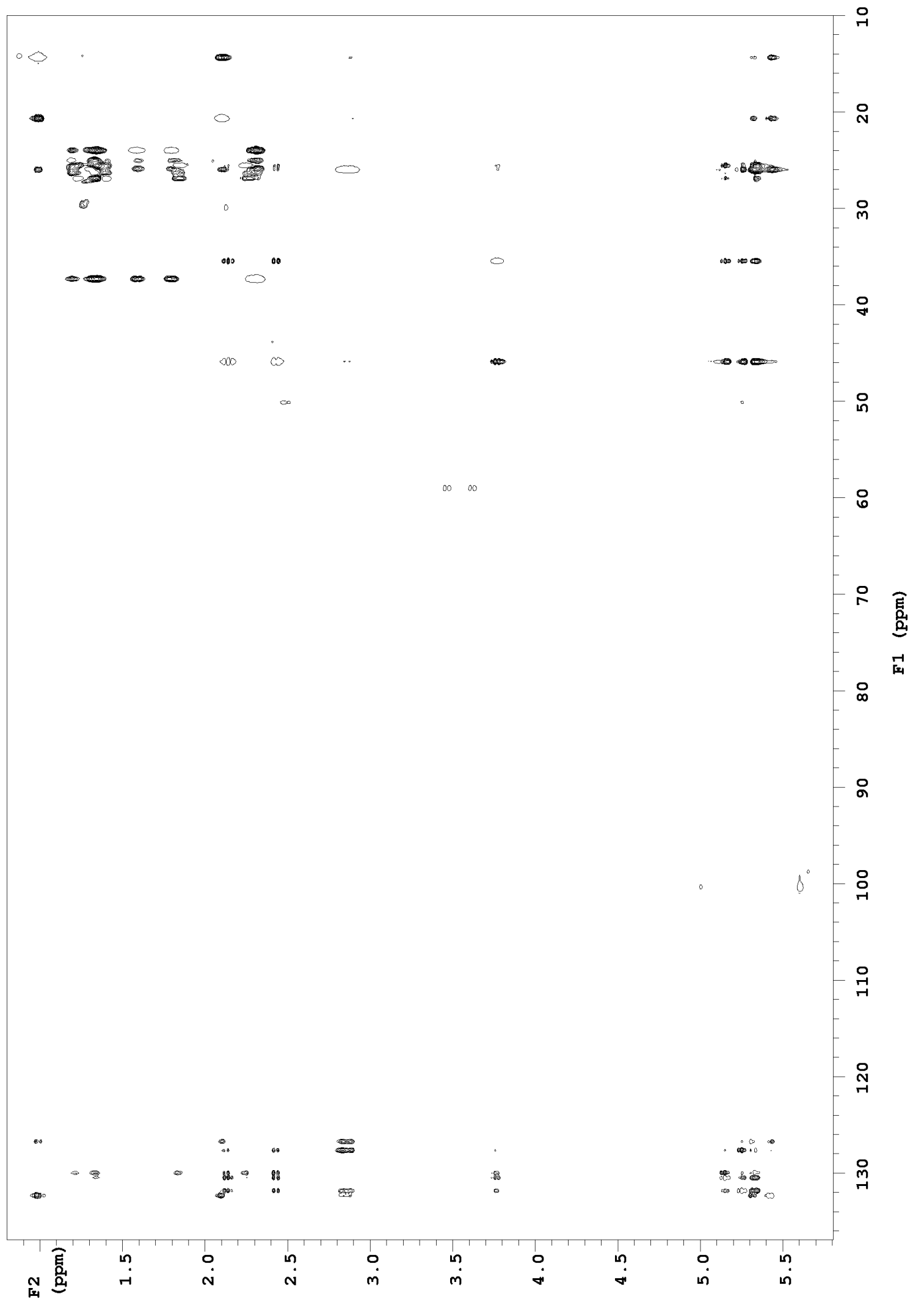

HSQC-TOCSY NMR spectrum of labillaride J (69) (600 MHz, $\mathrm{CDCl}_{3}$ ) 
Appendix $O$

NMR Spectra of Labillaride K

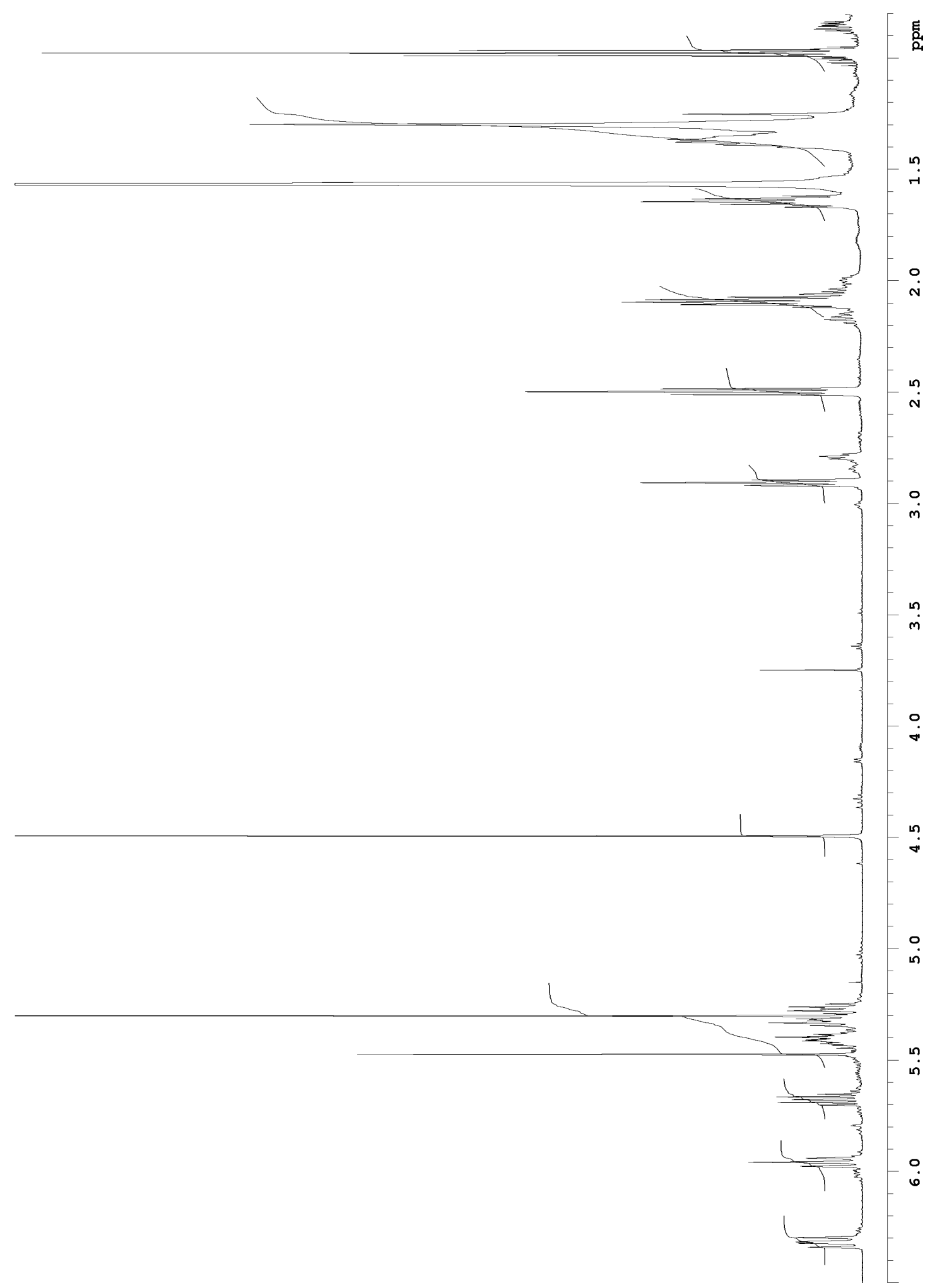

${ }^{1} \mathrm{H}$ NMR spectrum of labillaride $\mathrm{K}(\mathbf{7 0})\left(600 \mathrm{MHz}, \mathrm{CDCl}_{3}\right)$ 


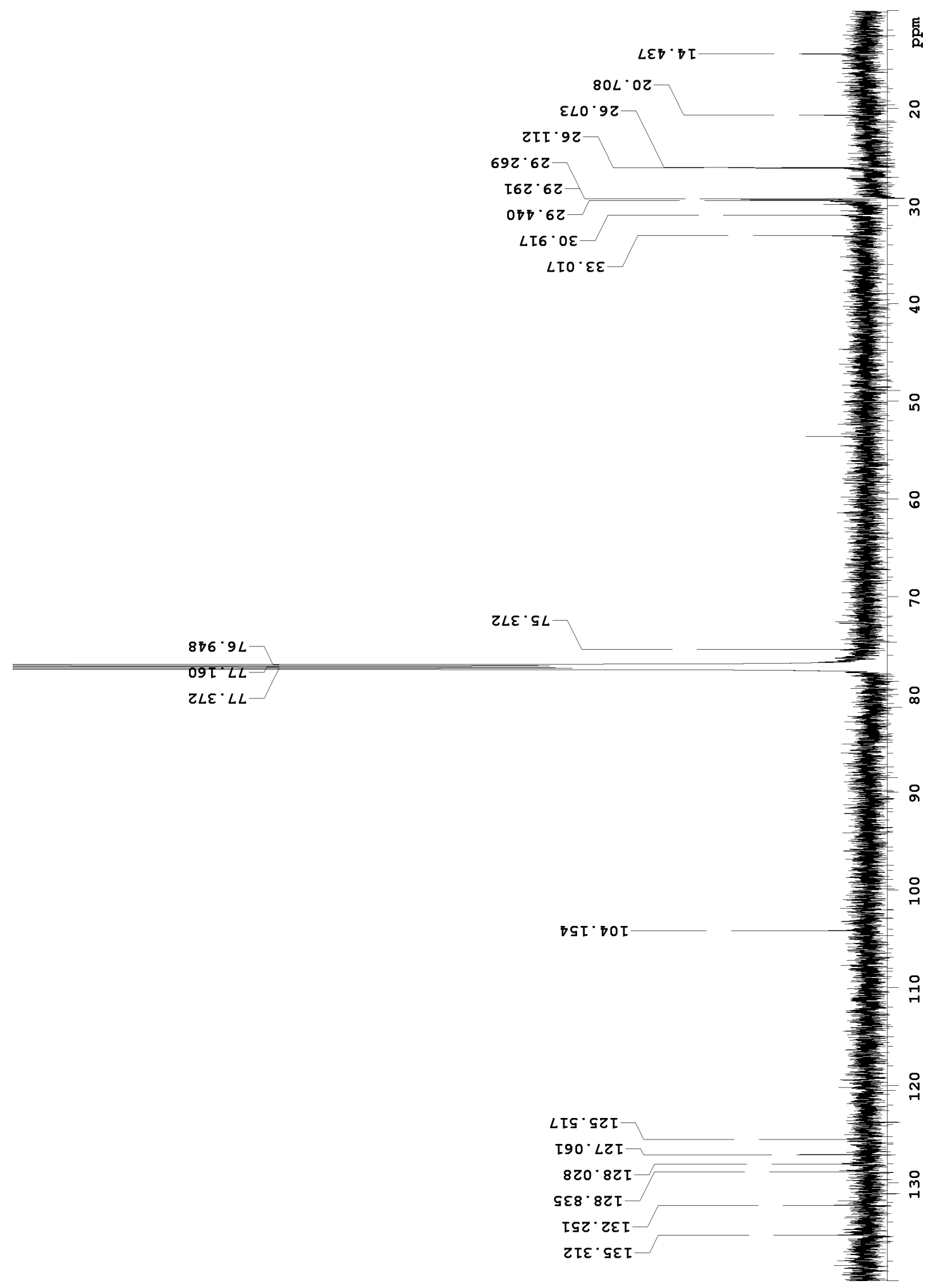

${ }^{13} \mathrm{C}$ NMR spectrum of labillaride $\mathrm{K}(\mathbf{7 0})\left(150 \mathrm{MHz}, \mathrm{CDCl}_{3}\right)$ 


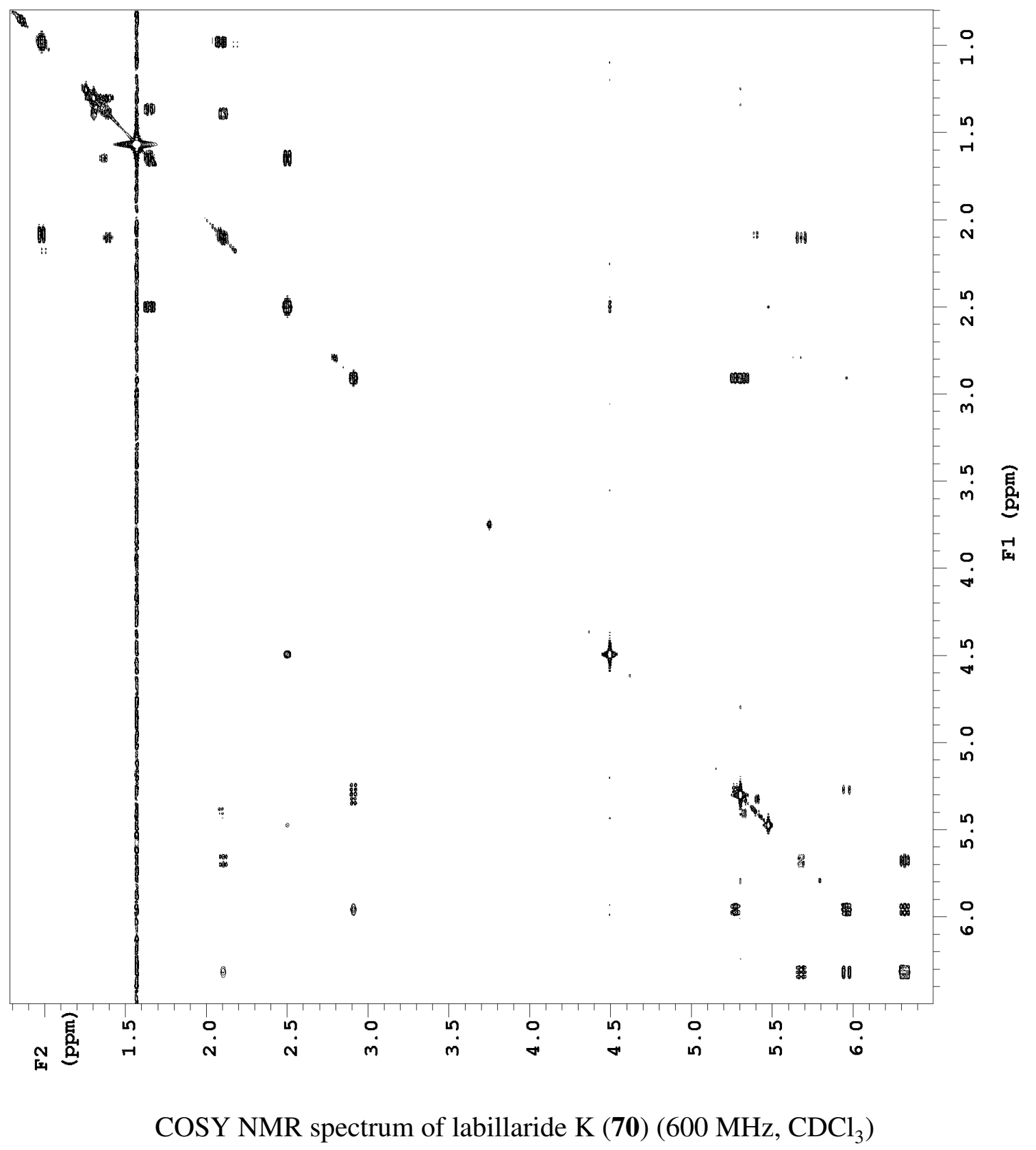




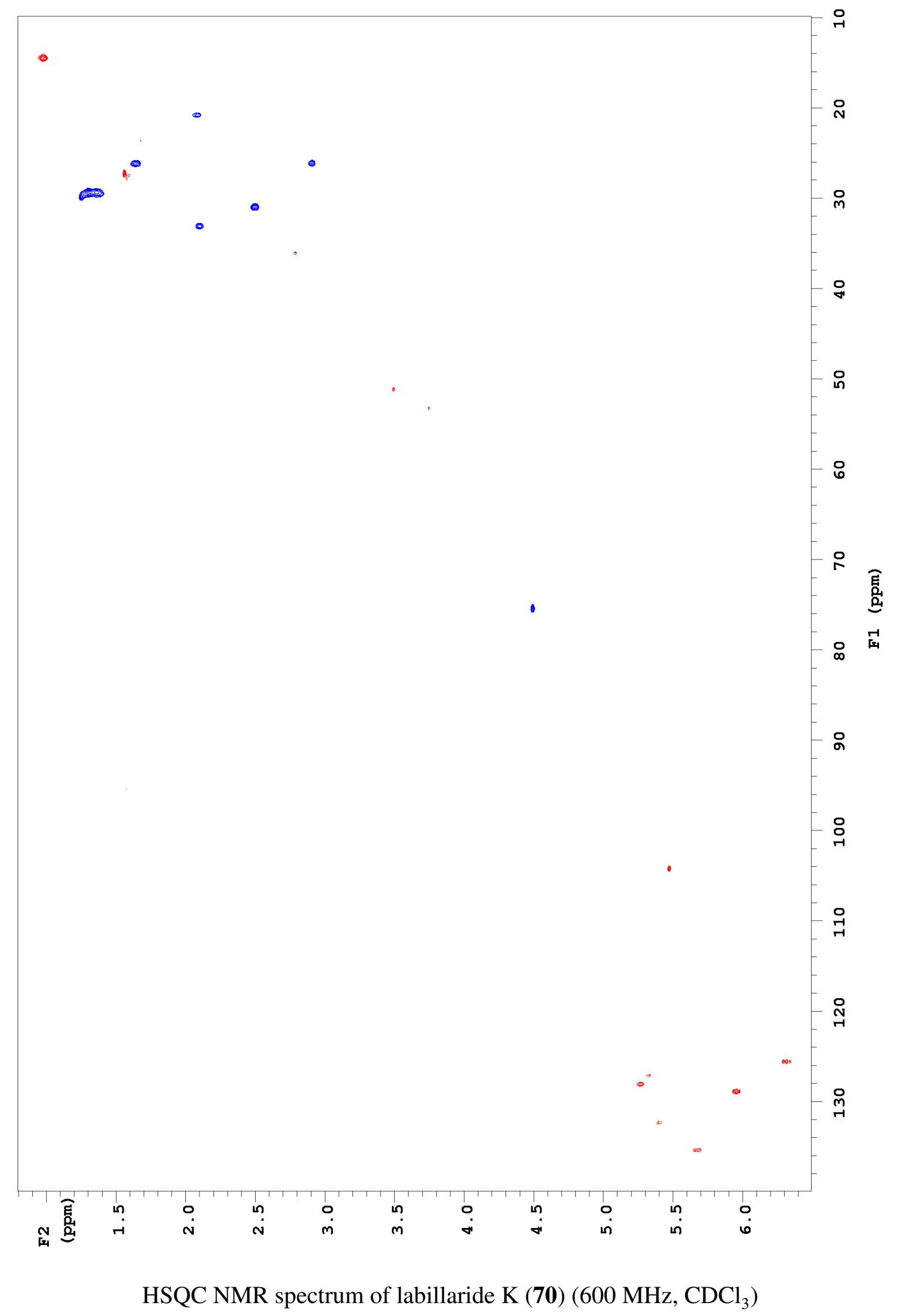




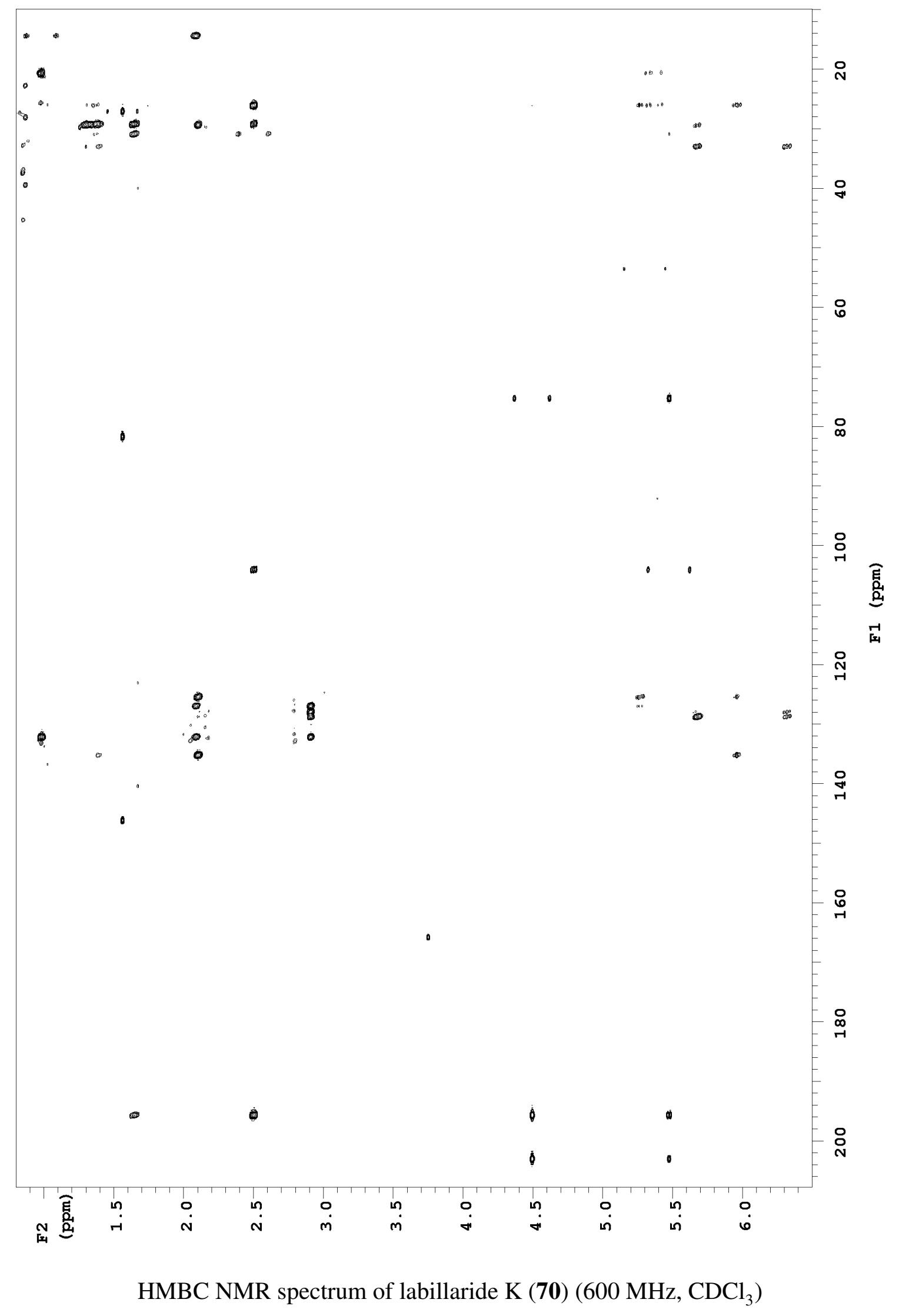


NMR Spectra of the Degradation Product

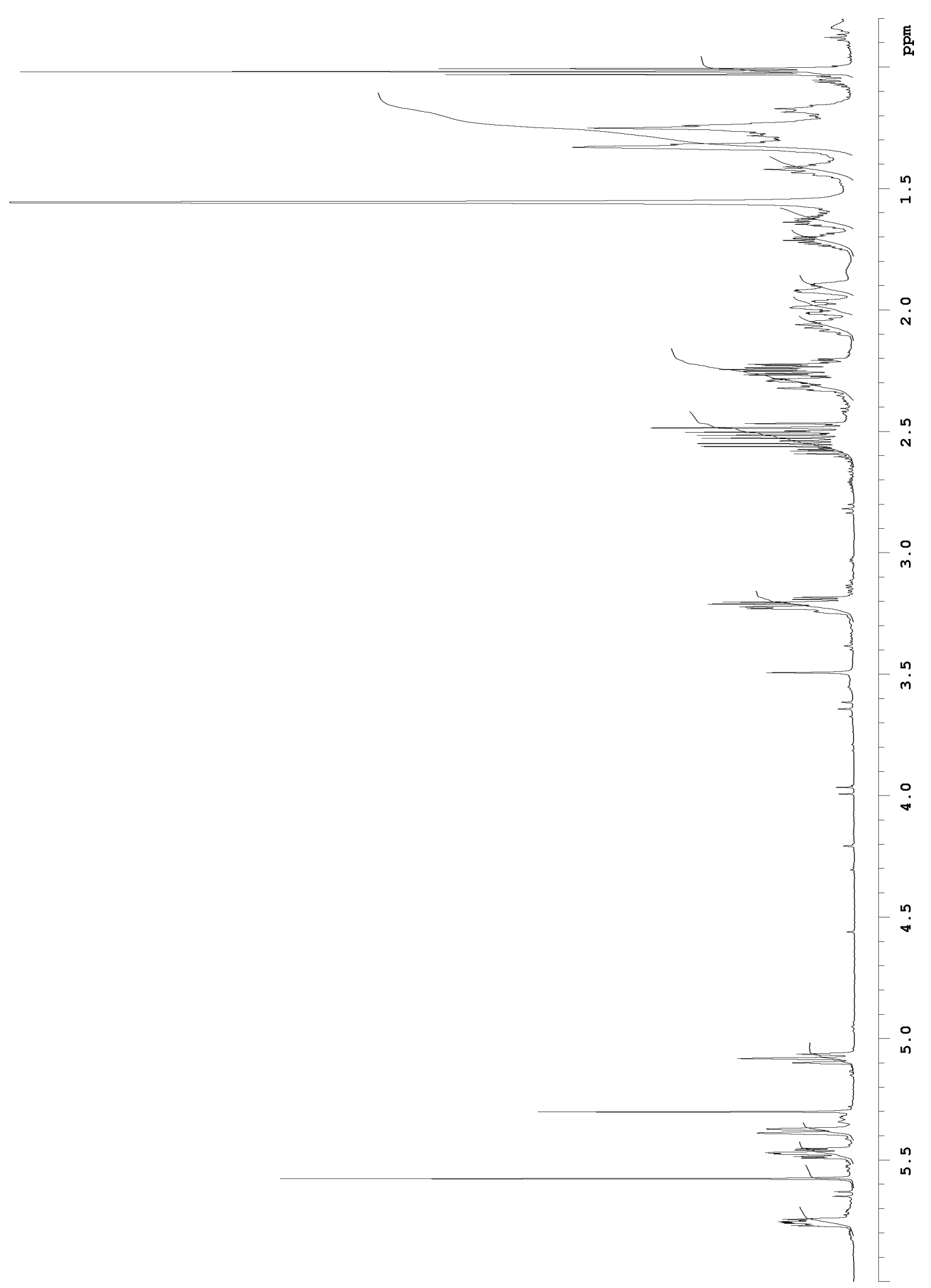

${ }^{1} \mathrm{H}$ NMR spectrum of the degradation product (75) $\left(600 \mathrm{MHz}, \mathrm{CDCl}_{3}\right)$ 


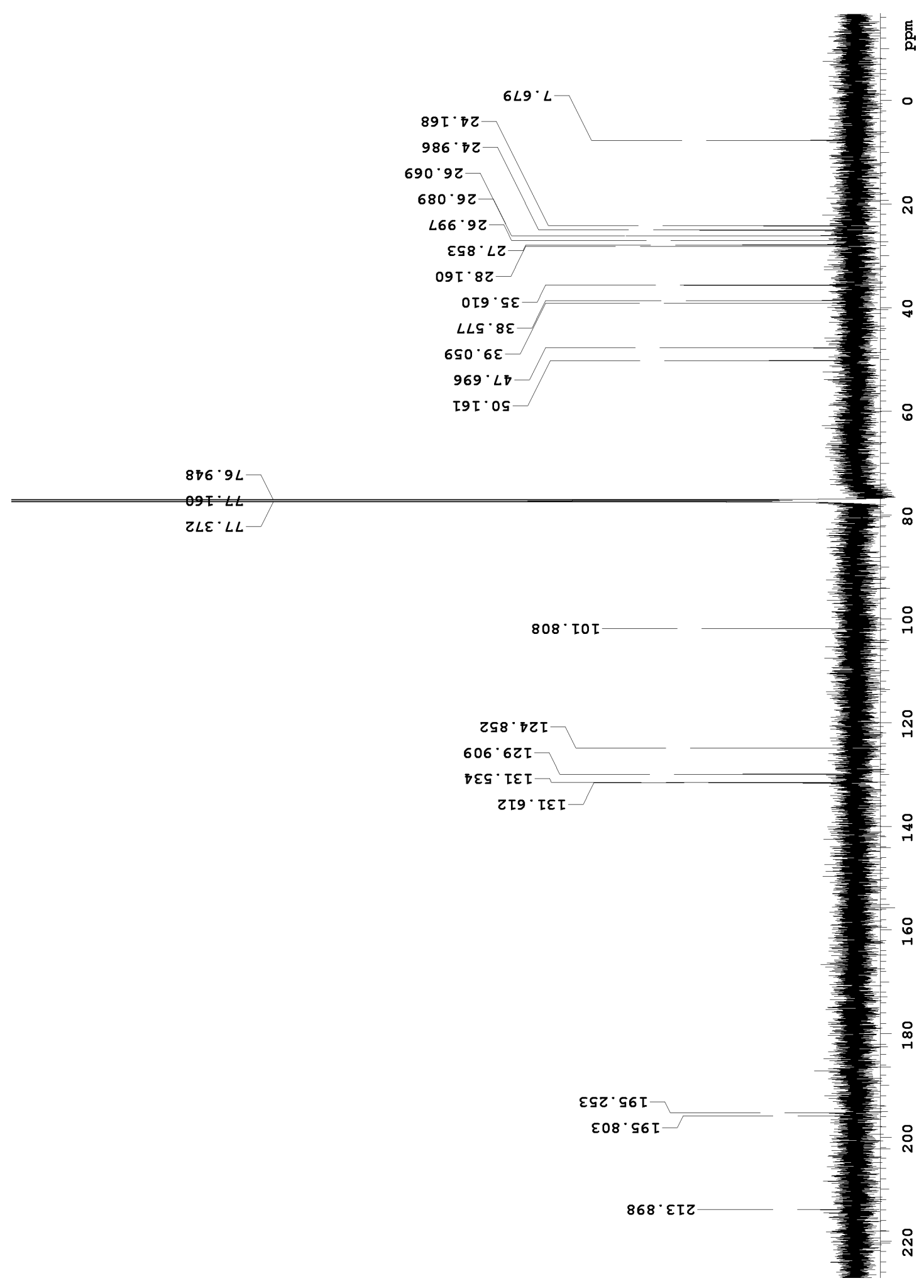

${ }^{13} \mathrm{C}$ NMR spectrum of the degradation product (75) (150 MHz, $\left.\mathrm{CDCl}_{3}\right)$ 


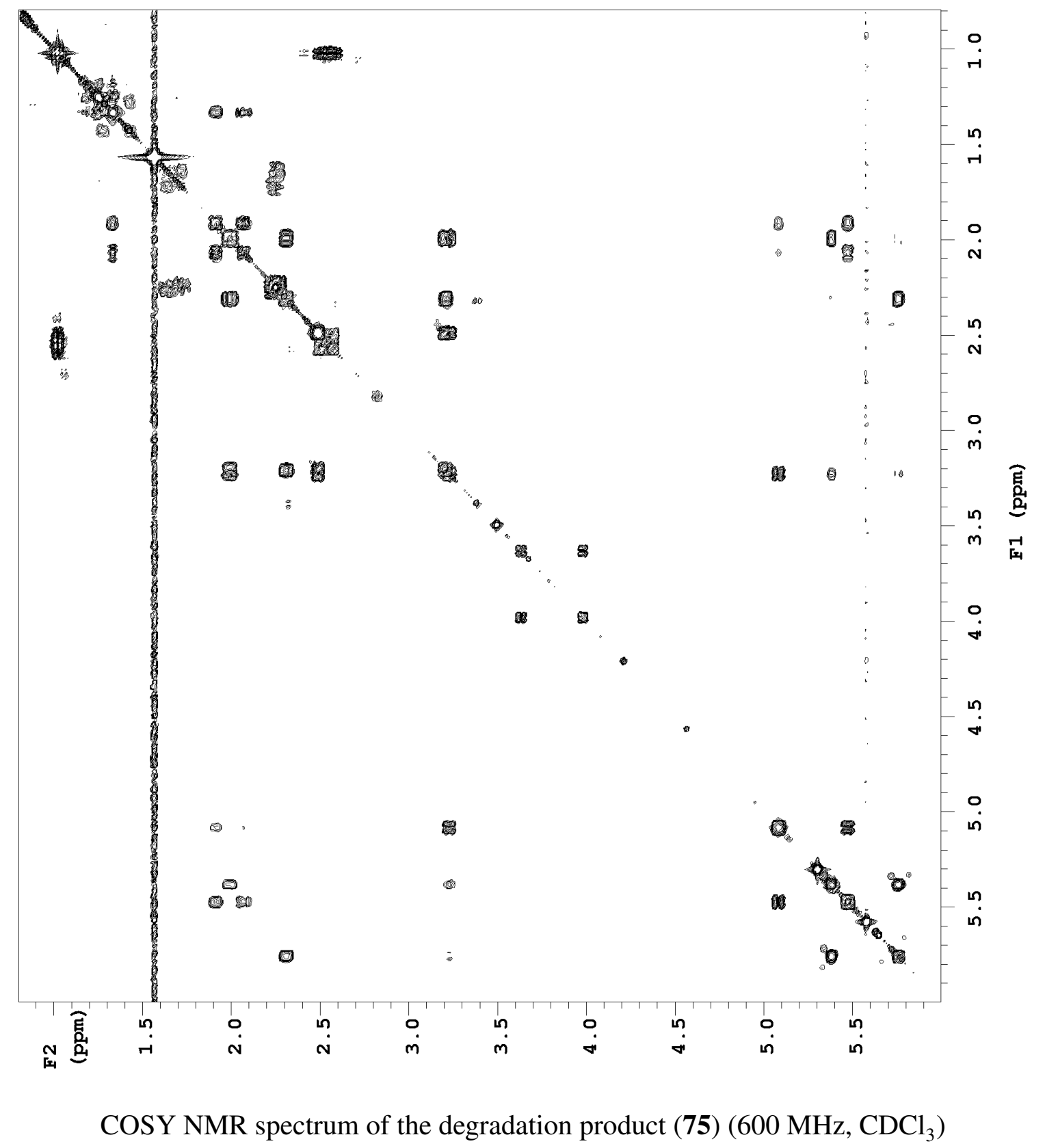




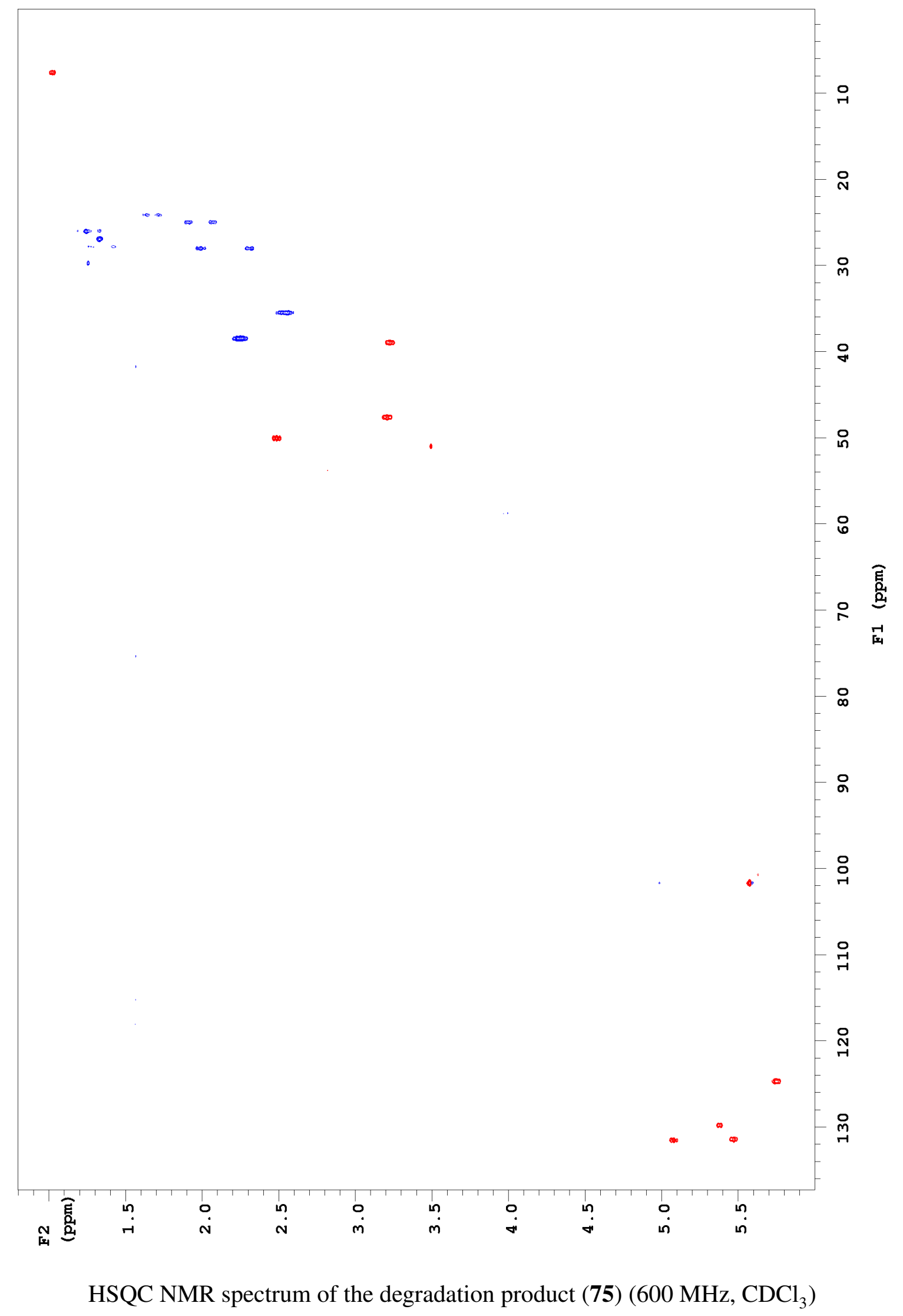




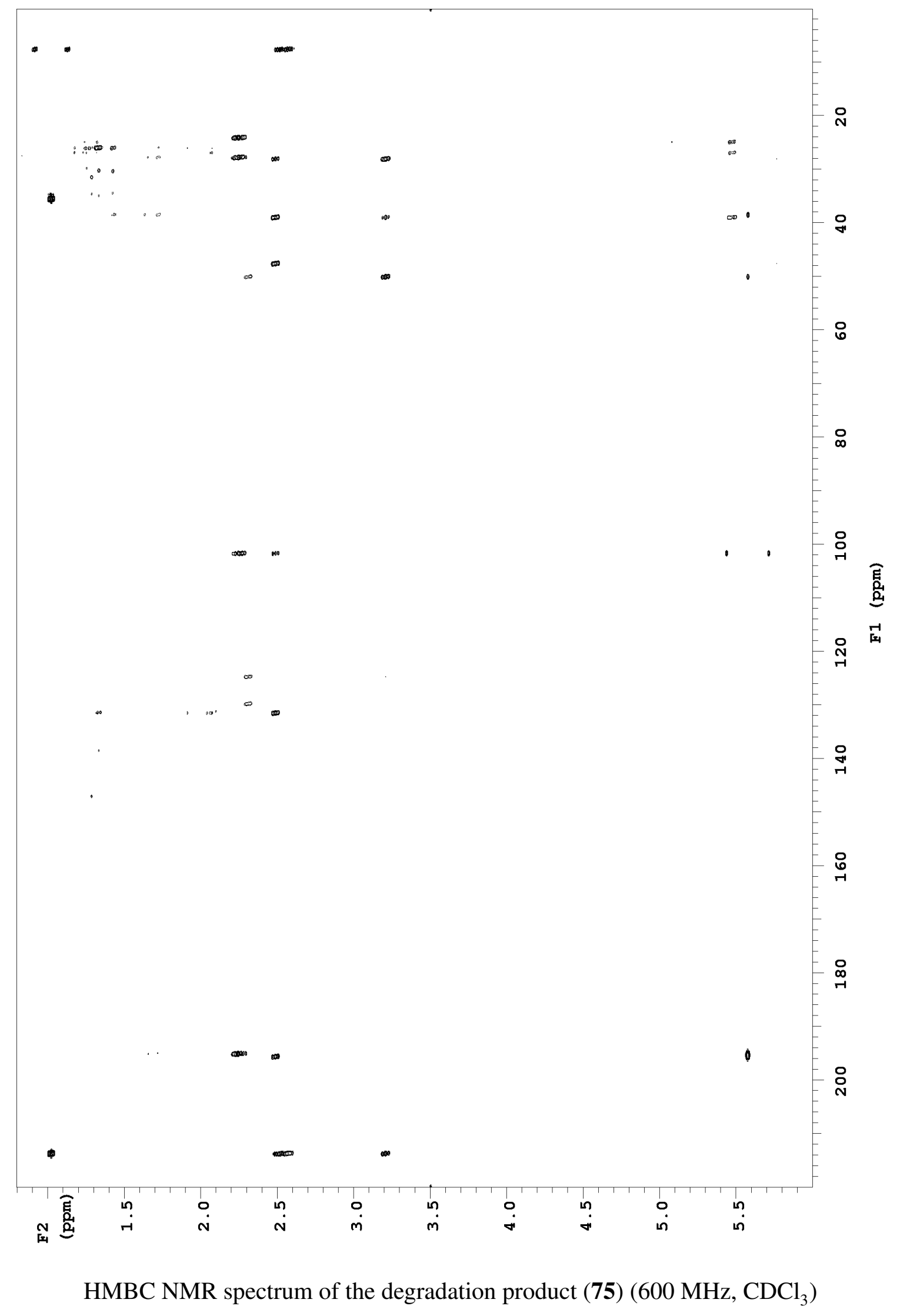




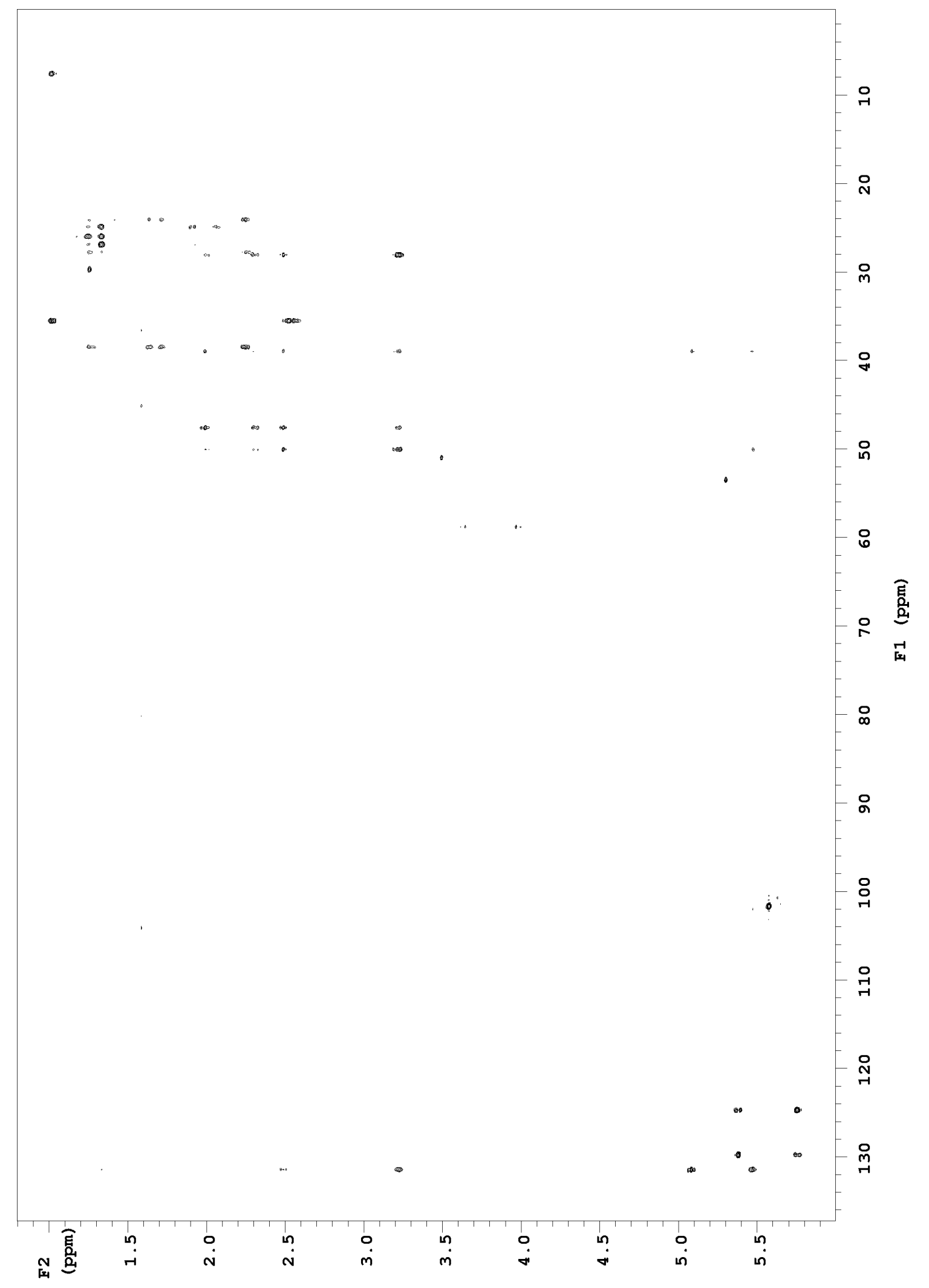

HSQC-TOCSY NMR spectrum of the degradation product (75) $\left(600 \mathrm{MHz}, \mathrm{CDCl}_{3}\right)$ 
NMR Spectra of Colensolide A

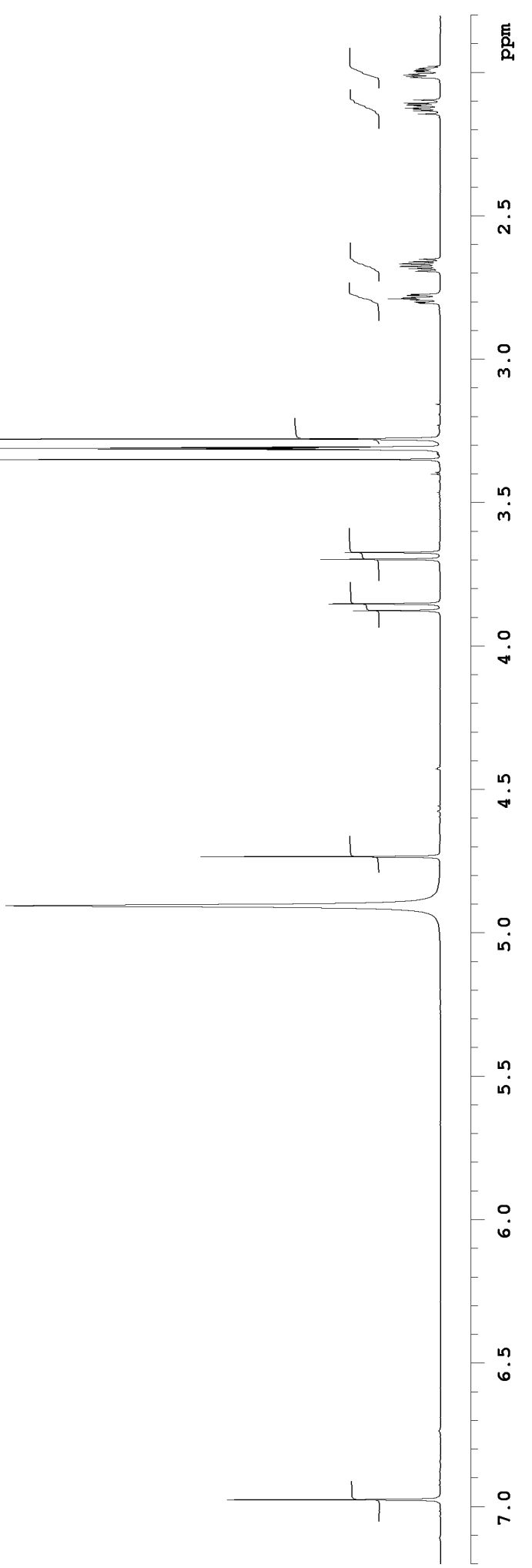

${ }^{1} \mathrm{H}$ NMR spectrum of colensolide A (124) $\left(600 \mathrm{MHz}, \mathrm{CD}_{3} \mathrm{OD}\right)$ 


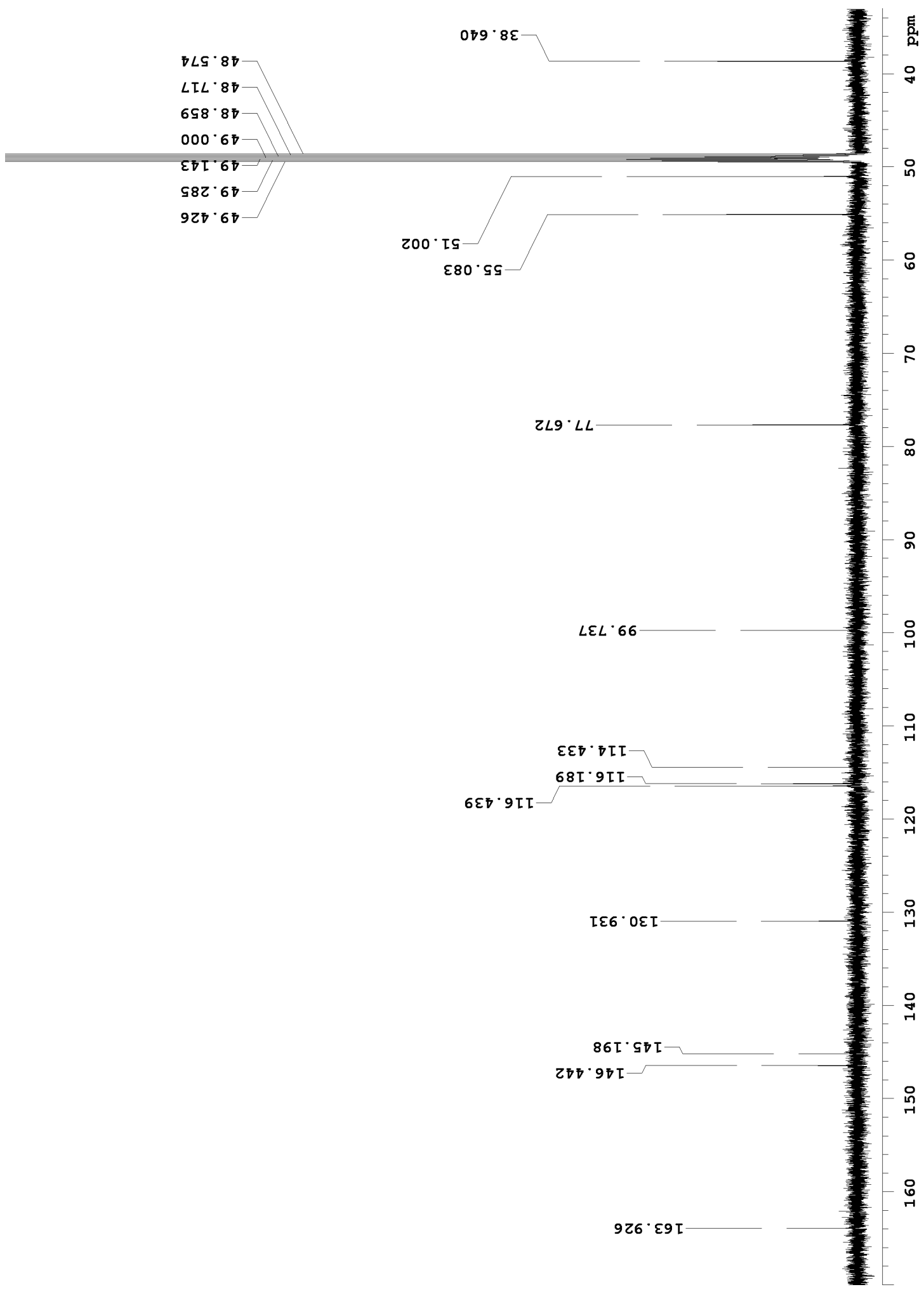

${ }^{13} \mathrm{C}$ NMR spectrum of colensolide A (124) $\left(150 \mathrm{MHz}, \mathrm{CD}_{3} \mathrm{OD}\right)$ 


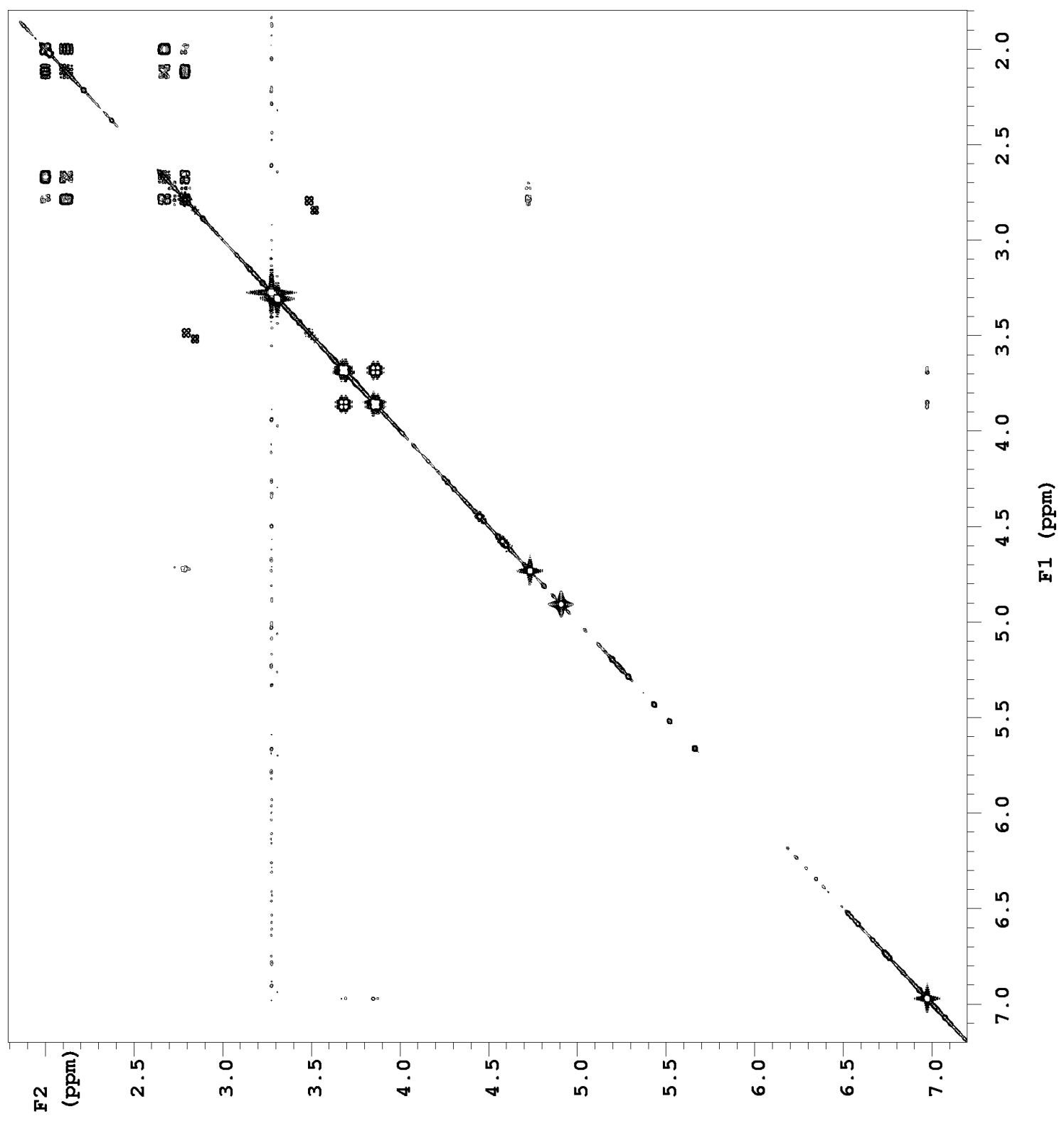

COSY NMR spectrum of colensolide A (124) (600 MHz, $\left.\mathrm{CD}_{3} \mathrm{OD}\right)$ 


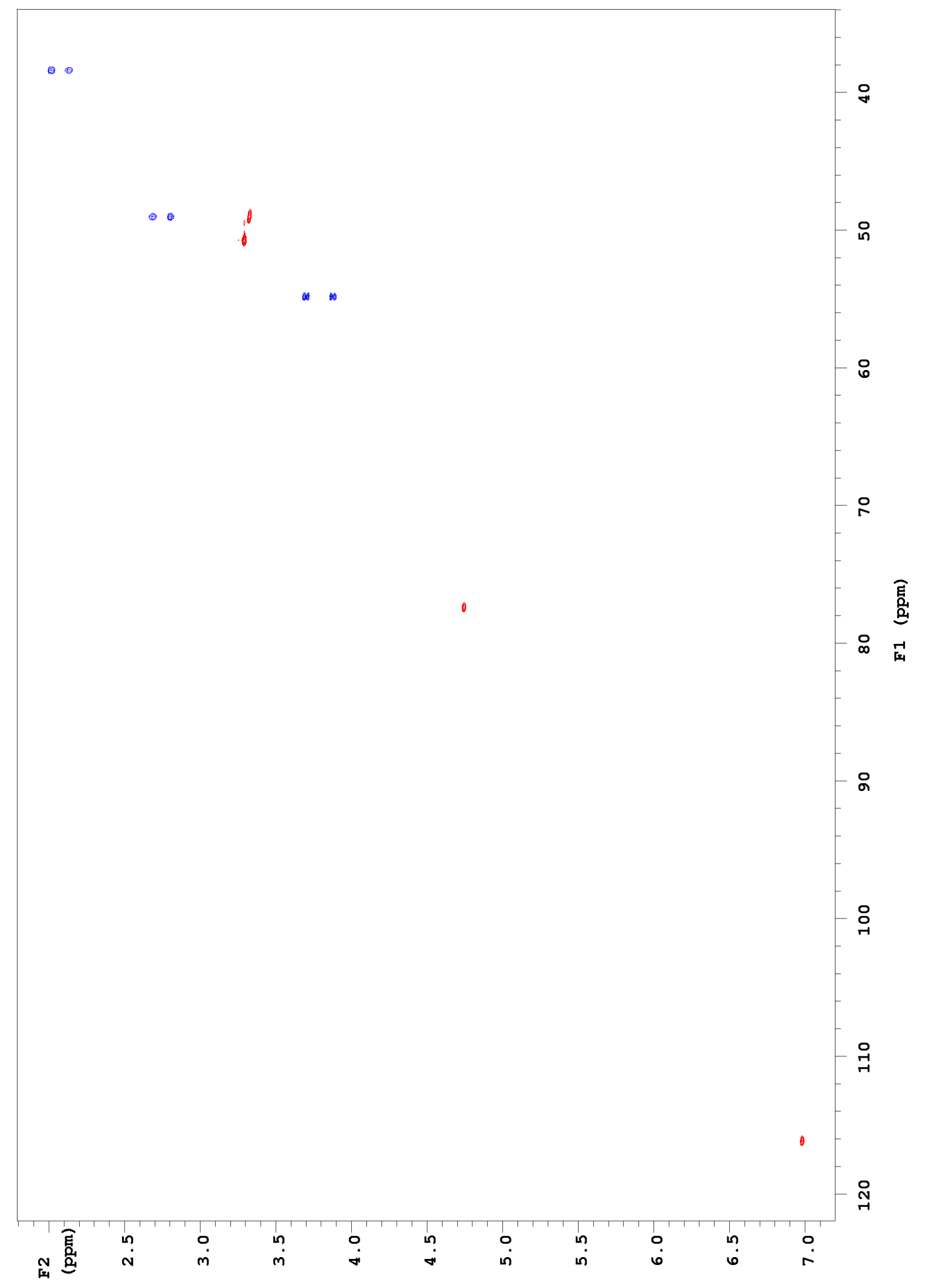

HSQC NMR spectrum of colensolide A (124) (600 MHz, $\mathrm{CD}_{3} \mathrm{OD}$ ) 


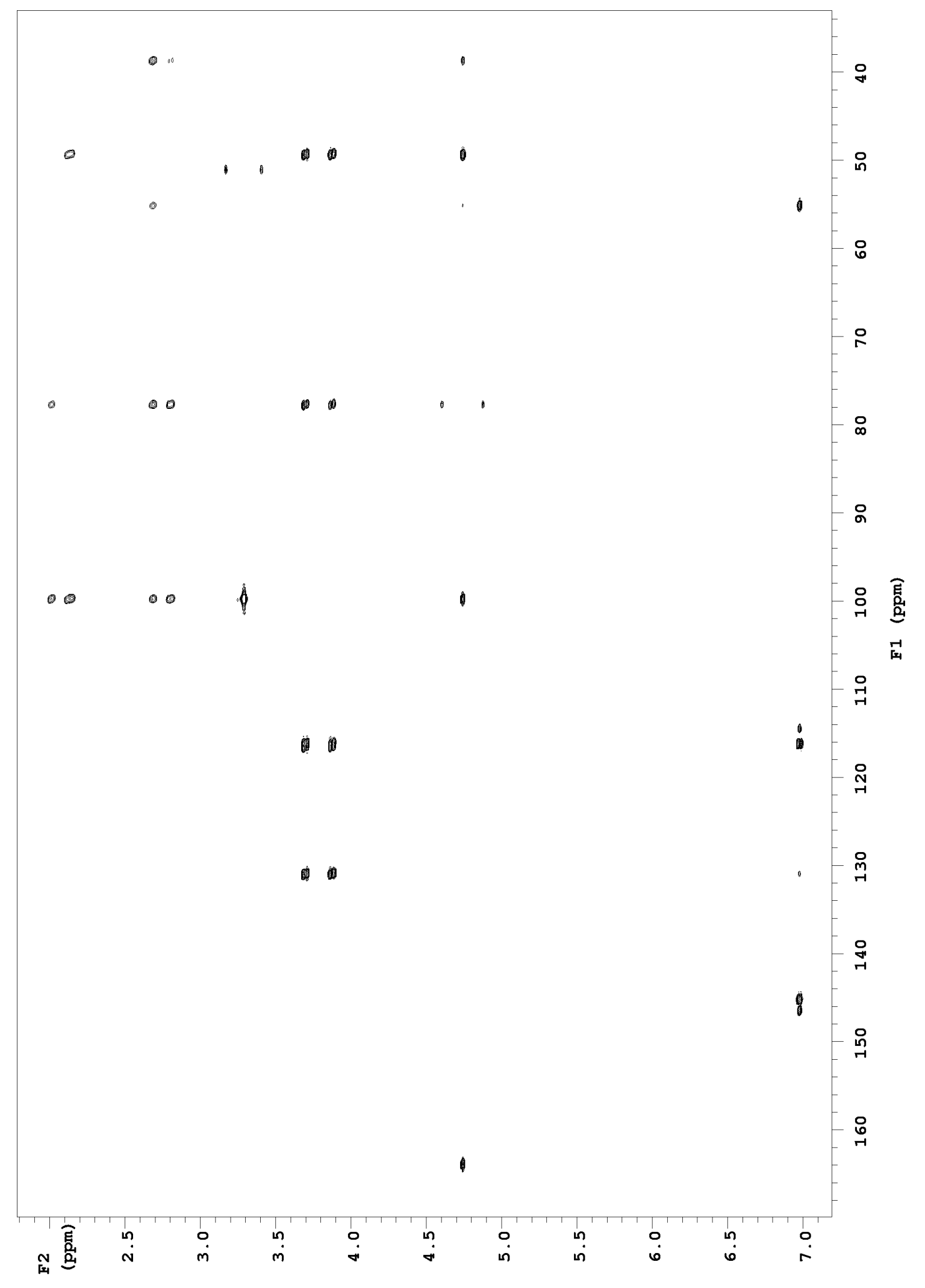

HMBC NMR spectrum of colensolide A (124) (600 MHz, $\left.\mathrm{CD}_{3} \mathrm{OD}\right)$ 


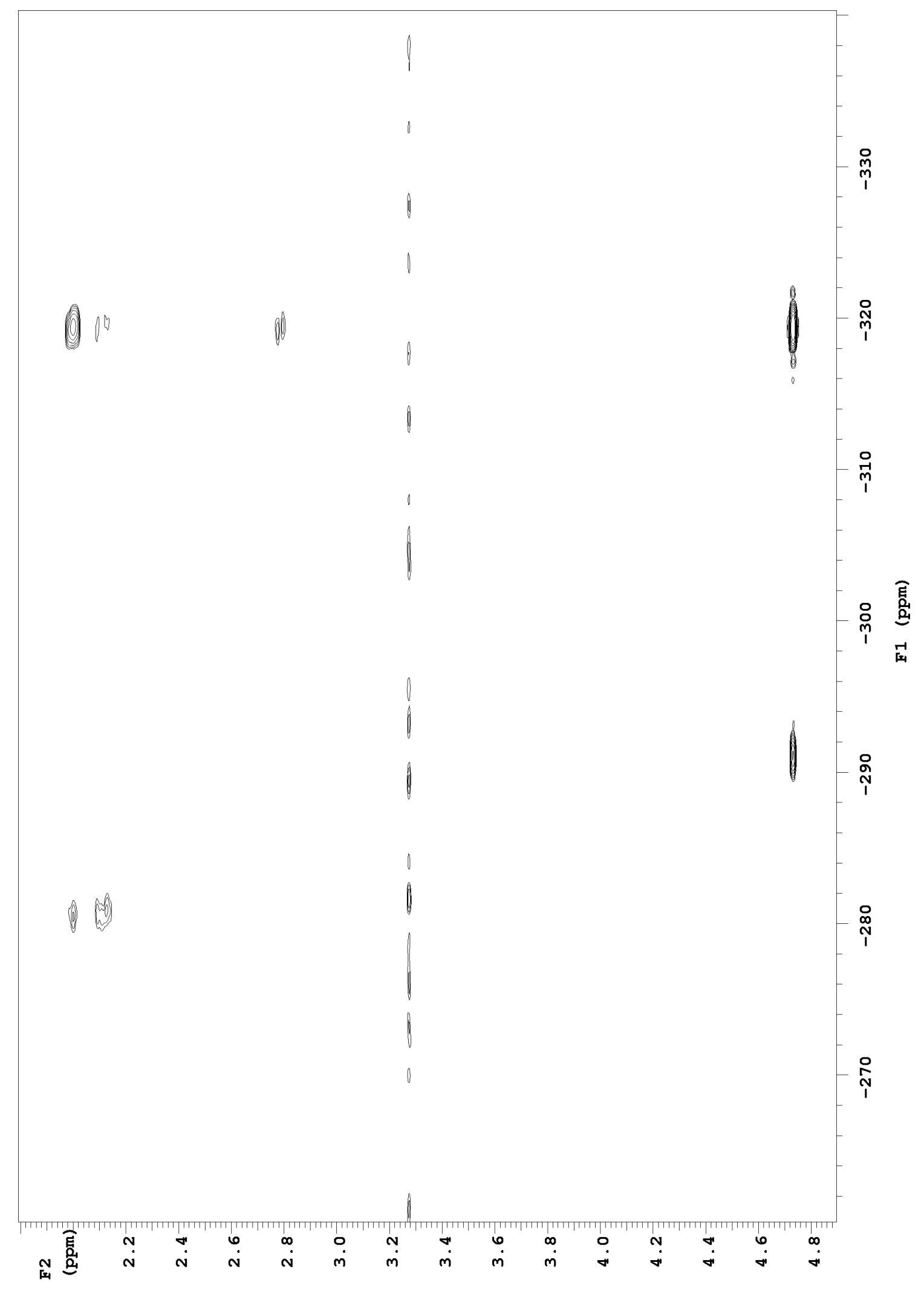

${ }^{1} \mathrm{H}$ to ${ }^{15} \mathrm{~N}$ HMBC NMR spectrum of colensolide A (124) $\left(600 \mathrm{MHz}, \mathrm{CD}_{3} \mathrm{OD}\right)$ 


\section{${ }^{1}$ H NMR Spectrum of Acidified Colensolide A}

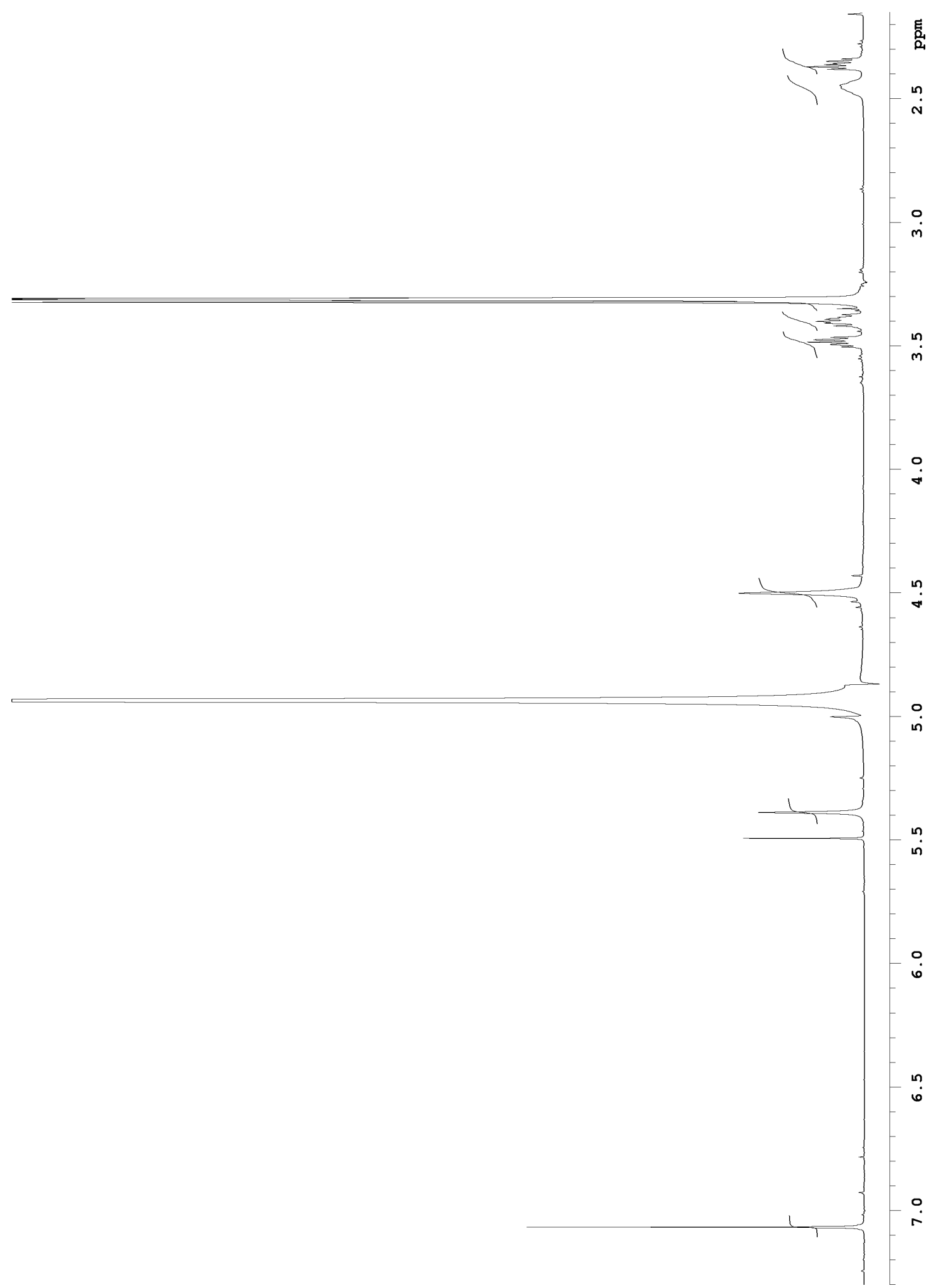

${ }^{1} \mathrm{H}$ NMR spectrum of acidified colensolide A (125) (600 MHz, $\left.\mathrm{CD}_{3} \mathrm{OD}\right)$ 


\section{Appendix $S$}

\section{${ }^{1}$ H NMR Spectrum of 5-O-Methylcolensolide A}

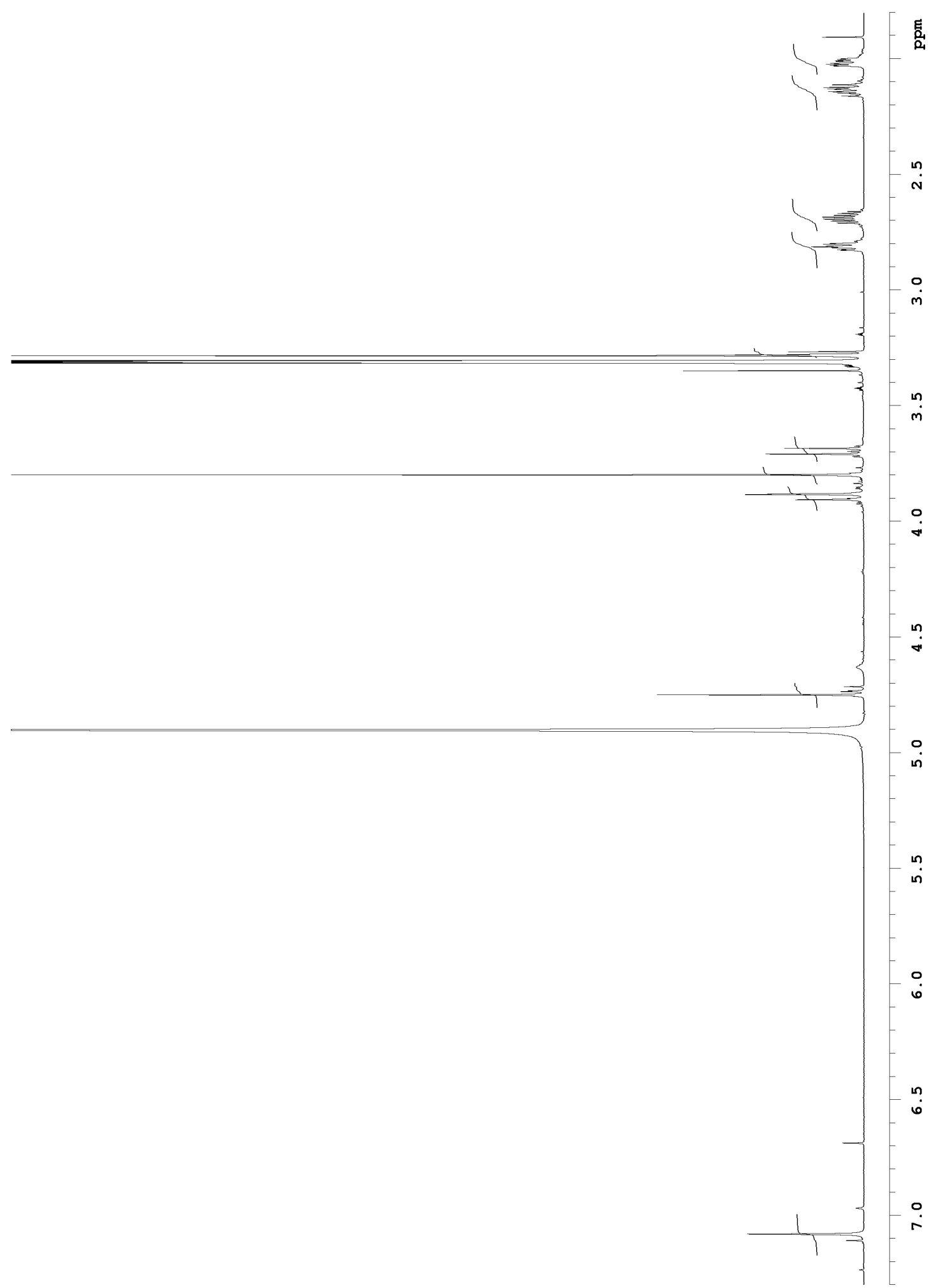

${ }^{1} \mathrm{H}$ NMR spectrum of 5-O-methylcolensolide A (126) $\left(600 \mathrm{MHz}, \mathrm{CD}_{3} \mathrm{OD}\right)$ 


\section{Appendix T}

\section{${ }^{1} \mathrm{H}$ NMR Spectrum of 4,5-Di- $O$-methylcolensolide A}

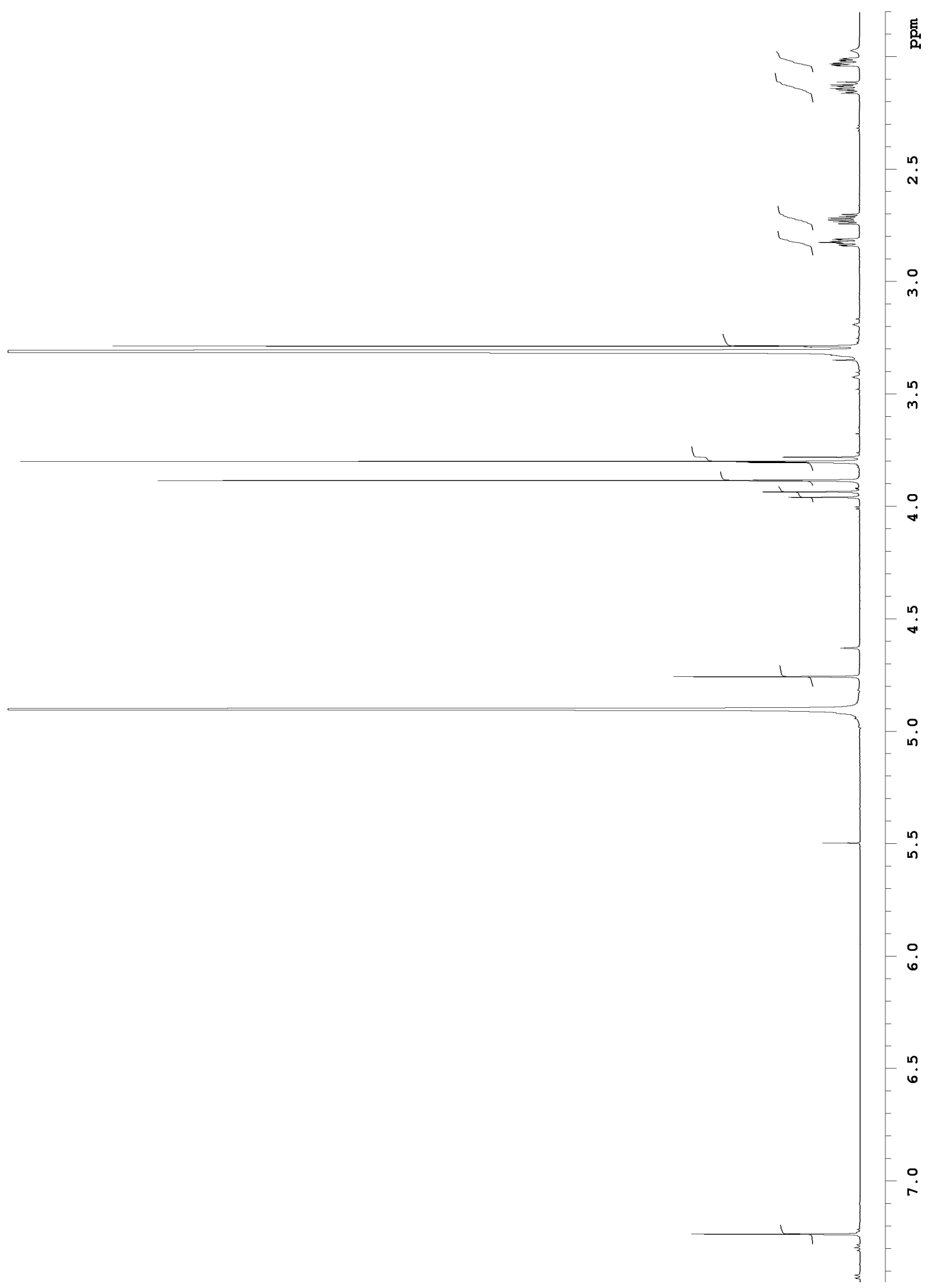

${ }^{1} \mathrm{H}$ NMR spectrum of 4,5-di- $O$-methylcolensolide A (127) $\left(600 \mathrm{MHz}, \mathrm{CD}_{3} \mathrm{OD}\right)$ 


\section{References}

1. Cragg, G. M.; Boyd, M. R.; Khanna, R.; Kneller, R.; Mays, T. D.; Mazan, K. D.; Newman, D. J.; Sausville, E. A. Pure Appl. Chem. 1999, 71, 1619-1633. 1, 2

2. Newman, D. J.; Cragg, G. M.; Snader, K. M. Nat. Prod. Rep. 2000, 17, 215-234. 1, $2,3,5$

3. Drug Discovery from Nature; Grabley, S., Thiericke, R., Eds.; Springer: Berlin, 1999. 1

4. Grabley, S.; Thiericke, R. The Impact of Natural Products of Drug Discovery. In Drug Discovery from Nature; Grabley, S., Thiericke, R., Eds.; Springer: Berlin, 1999; pp 5-6. 1

5. Baker, D. D.; Chu, M.; Oza, U.; Rajgarhia, V. Nat. Prod. Rep. 2007, 24, 1225-1244. $2,3,4,12$

6. Harvey, A. L. Curr. Opin. Biotechnol. 2007, 11, 480-484. 3

7. Newman, D. J.; Cragg, G. M. J. Nat. Prod. 2007, 70, 461-477. 3, 4, 5

8. Feher, M.; Schmidt, J. M. J. Chem. Inf. Comput. Sci. 2003, 43, 218-227. 3

9. Cragg, G. M.; Newman, D. J.; Snader, K. M. J. Nat. Prod. 1997, 60, 52-60. 3

10. Faulkner, D. J. Nat. Prod. Rep. 2000, 17, 1-6. 4

11. Newman, D. J.; Cragg, G. M. J. Nat. Prod. 2004, 67, 1216-1238. 4, 5

12. Haefner, B. Drug Discov. Today 2003, 8, 536-544. 4, 5

13. Grabley, S.; Thiericke, R. The Impact of Natural Products of Drug Discovery. In Drug Discovery from Nature; Grabley, S., Thiericke, R., Eds.; Springer: Berlin, 1999; p 26. 4

14. Miljanich, G. Curr. Med. Chem. 2004, 11, 3029-3040. 4

15. Shining a spotlight on the biodiversity of New Zealand's marine ecoregion: Experts workshop on marine biodiversity; Arnold, A., Ed.; WWF-New Zealand: Wellington, 2004; p 5.5

16. Adams, N. M. Seaweeds of New Zealand. An illustrated guide; Canterbury University Press: Christchurch, 1994. 6

17. Graham, L. E.; Wilcox, L. W. Introduction to Algae - Occurance, Relationships, Nutrition, Definition, General Features. In Algae; Prentice-Hill: New Jersey, 2000; pp 1-21. 6

18. Thomas, D. N. What are seaweeds? In Seaweeds; Smithsonian Institution Press: Washington, 2002; pp 6-7. 6

19. Graham, L. E.; Wilcox, L. W. Red Algae. In Algae; Prentice-Hill: New Jersey, 2000; pp 343-345. 7

20. Thomas, D. N. The rigours of seaweed life. In Seaweeds; Smithsonian Institution Press: Washington, 2002; p 50. 7 
21. Guiry, M.D. \& Guiry, G.M. 2008. AlgaeBase. World-wide electronic publication, National University of Ireland, Galway. http://www.algaebase.org (accessed Nov 18, 2007). 7, 8, 26, 105, 106

22. Bold, H. C.; Wynne, M. J. Division Rhodophyta. In Introduction to the Algae, 2nd ed.; Prentice-Hall, Inc.: New Jersey, 1985; p 513. 7

23. Ankisetty, S.; Nandiraju, S.; Win, H.; Park, Y. C.; Amsler, C. D.; McClintock, J. B.; Baker, J. A.; Diyabalanage, T. K.; Pasaribu, A.; Singh, M. P.; Maiese, W. M.; Walsh, R. D.; Zaworotko, M. J.; Baker, B. J. J. Nat. Prod. 2004, 67, 1295-1302. 9

24. Blunt, J. W.; Hartshorn, M. P.; McLennan, T. J.; Munro, M. H. G.; Robinson, W. T.; Yorke, S. C. Tetrahedron Lett. 1978, 1, 69-72. 9, 10

25. Suzuki, T.; Suzuki, M.; Furusaki, A.; Matsumoto, T.; Kato, A.; Imanaka, Y.; Kurosawa, E. Tetrahedron Lett. 1985, 26, 1329-1332. 9

26. Sakemi, S.; Higa, T.; Jefford, C. W.; Bernardinelli, G. Tetrahedron Lett. 1986, 27, 4287-4290. 9

27. Matsuzawa, S.; Suzuki, T.; Suzuki, M.; Matsuda, A.; Kawamura, T.; Mizuno, Y.; Kikuchi, K. FEBS Lett. 1994, 356, 272-274. 9

28. Francisco, M. E. Y.; Erickson, K. L. J. Nat. Prod. 2001, 64, 790-791. 9

29. Brito, I.; Cueto, M.; Diaz-Marrero, A. R.; Darias, J.; Martin, A. S. J. Nat. Prod. 2002, 65, 946-948. 9

30. El-Gamal, A. A.; Wang, W.-L.; Duh, C.-Y. J. Nat. Prod. 2005, 68, 815-817. 10

31. Kubota, N. K.; Iwamoto, H.; Fukazawa, Y.; Uchio, Y. Heterocycles 2005, 65, 26752682. 10

32. Jiang, Z. D.; Ketchum, S. O.; Gerwick, W. H. Phytochemistry 2000, 53, 129-133. 10

33. Wang, W.; Okada, Y.; Shi, H.; Wang, Y.; Okuyama, T. J. Nat. Prod. 2005, 68, 620622. 10

34. Blunt, J. W.; Hartshorn, M. P.; Munro, M. H. G.; Yorke, S. C. Tetrahedron Lett. 1978, 45, 4417-4418. 10

35. Bates, P.; Blunt, J. W.; Hartshorn, M. P.; Jones, A. J.; Munro, M. H. G.; Robinson, W. T.; Yorke, S. C. Aust. J. Chem. 1979, 32, 2545-2554. 10

36. Blunt, J. W.; Lake, R. J.; Munro, M. H. G.; Yorke, S. C. Aust. J. Chem. 1981, 34, 2393-2400. 10

37. Blunt, J. W.; Lake, R. J.; Munro, M. H. G. Phytochemistry 1984, 23, 1951-1954. 10

38. Blunt, J. W.; Bowman, N. J.; Munro, M. H. G.; Parsons, M. J.; Wright, G. J.; Kon, Y. K. Aust. J. Chem. 1985, 38, 519-525. 10

39. McCombs, J. D.; Blunt, J. W.; Chambers, M. V.; Munro, M. H. G.; Robinson, W. T. Tetrahedron 1988, 44, 1489-1502. 10

40. König, G. M.; Wright, A. D. J. Nat. Prod. 1994, 57, 477-485. 10, 11 
41. Sansom, C. E.; Larsen, L.; Perry, N. B.; Berridge, M. V.; Chia, E. W.; Harper, J. L.; Webb, V. L. J. Nat. Prod. 2007, 70, 2042-2044. 11

42. Schroeder, F. C.; Gibson, D. M.; Churchill, A. C. L.; Sojikul, P.; Wursthorn, E. J.; Krasnoff, S. B.; Clardy, J. Angew. Chem., Int. Ed. 2007, 46, 901-904. 12, 13

43. Dossey, A. T.; Walse, S. S.; Rocca, J. R.; Edison, A. S. ACS Chem. Biol. 2006, 1, 511-514. 12

44. Taggi, A. E.; Meinwald, J.; Schroeder, F. C. J. Am. Chem. Soc. 2004, 126, 1036410369. 13

45. Williamson, R. T.; Chapin, E. L.; Carr, A. W.; Gilbert, J. R.; Graupner, P. R.; Lewer, P.; McKamey, P.; Carney, J. R.; Gerwick, W. H. Org. Lett. 2000, 2, 289292. 13

46. Tsuda, M.; Yasuda, T.; Fukushi, E.; Kawabata, J.; Sekiguchi, M.; Fromont, J.; Kobayashi, J. Org. Lett. 2006, 8, 4235-4238. 13

47. Keyzers, R. A. Biologically Active Secondary Metabolites from New Zealand Marine Organisms, Ph.D. thesis, Victoria University of Wellington, 2003. 14, 16, 17,18

48. West, L. M. The Isolation of Secondary Metabolites from New Zealand Marine Sponges, Ph.D. thesis, Victoria University of Wellington, 2001. 14, 15, 18

49. Ryan, J. M. Novel Secondary Metabolites from New Zealand Marine Sponges, Ph.D. thesis, Victoria University of Wellington, 2007. 15, 16, 18

50. Kazlauskas, R.; Murphy, P. T.; Quinn, R. J.; Wells, R. J. Tetrahedron Lett. 1976, 49, 4451-4454. 21

51. Stierle, D. B.; Wing, R. M.; Simes, J. J. Tetrahedron Lett. 1976, 49, 4455-4458. 21, 22

52. Williams, P. G.; Grab, L. A. Tetrahedron Lett. 1984, 25, 5009-5012. 21

53. Jones, E. R. H.; Taylor, W. C. Nature (London) 1957, 179, 1138. 22

54. Wratten, S. J.; Wolfe, M. S.; Andersen, R. J.; Faulkner, D. J. Antimicrob. Agents Chemother. 1977, 11, 411-414. 22

55. Okuda, R. K.; Klein, D.; Kinnel, R. B.; Li, M.; Scheuer, P. J. Pure Appl. Chem. 1982, 54, 1907-1914. 22

56. Palermo, J. A.; Flower, P. B.; Seldes, A. M. Tetrahedron Lett. 1992, 33, 3097-3100. 22,23

57. Adams, N. M. Red Seaweeds. In Seaweeds of New Zealand. An illustrated guide; Canterbury University Press: Christchurch, 1994; pp 222-223. 25

58. Kazlauskas, R.; Murphy, P. T.; Wells, R. J.; Blackman, A. J. Aust. J. Chem. 1982, 35, 113-120. 27, 28, 103

59. Shin, J.; Paul, V. J.; Fenical, W. Tetrahedron Lett. 1986, 27, 5189-5192. 27, 34, 103

60. Blackman, A. J.; Bremner, J. B.; Paano, A. M. C.; Skerratt, J. H.; Swann, M. L. Aust. J. Chem. 1990, 43, 1133-1136. 27, 103 
61. Murray, L.; Currie, G.; Capon, R. J. Aust. J. Chem. 1995, 48, 1485-1489. 27, 103

62. Song, D.; Blond, G.; Fürstner, A. Tetrahedron 2003, 59, 6899-6904. 27

63. Sakata, K.; Iwase, Y.; Kato, K.; Ina, K.; Machiguchi, Y. Nippon Suisan Gakkaishi 1991, 57, 261-265. 28

64. Mayer, A. M. S.; Paul, V. J.; Fenical, W.; Norris, J. N.; de Carvalho, M. S.; Jacobs, R. S. Hydrobiologia 1993, 260-261, 521-529. 28

65. Silverstein, R. M.; Webster, F. X. ${ }^{13} \mathrm{C}$ NMR Spectrometry. In Spectrometric Identification of Organic Compounds, 6th ed.; John Wiley \& Sons, Inc: New York, 1998; p 221. 35

66. Silverstein, R. M.; Webster, F. X. ${ }^{13} \mathrm{C}$ NMR Spectrometry. In Spectrometric Identification of Organic Compounds, 6th ed.; John Wiley \& Sons, Inc: New York, 1998; p 233. 40

67. Hansen, P. E. Org. Magn. Reson. 1979, 12, 109-142. 51, 115

68. Wang, Y.; Wang, S.-J.; Mo, S.-Y.; Li, S.; Yang, Y.-C.; Shi, J.-G. Org. Lett. 2005, 7, 4733-4736. 52, 53

69. Nelson, J. H. Typical Magnitudes of Selected Coupling Constants. In Nuclear Magnetic Resonance Spectroscopy; Pearson Education, Inc: New Jersey, 2003; p 135.53

70. Seco, J. M.; Quiñoá, E.; Riguera, R. Tetrahedron: Asymmetry 2001, 12, 2915-2925. 69

71. Ronayne, J.; Williams, D. H. Chem. Commun. 1966, 712-714. 69

72. Silverstein, R. M.; Webster, F. X. ${ }^{13} \mathrm{C}$ NMR Spectrometry. In Spectrometric Identification of Organic Compounds, 6th ed.; John Wiley \& Sons, Inc: New York, 1998; p 234. 73

73. Winkler, J. D.; Oh, K.; Asselin, S. M. Org. Lett. 2005, 7, 387-389. 81

74. Nelson, J. H. Typical Magnitudes of Selected Coupling Constants. In Nuclear Magnetic Resonance Spectroscopy; Pearson Education, Inc: New Jersey, 2003; p 137.88

75. Gerwick, W. Scripps Institution of Oceanography, San Diego, CA. Personal communication, 2008. 90, 103

76. Chan, A. Victoria University of Wellington, New Zealand, Unpublished work, 2008. 91,126

77. Miller, C. Victoria University of Wellington, New Zealand, Unpublished work, 2008. 91,126

78. Gerwick, W. H.; Moghaddam, M.; Hamberg, M. Arch. Biochem. Biophys. 1991, 290, 436-444. 91

79. Gerwick, W. H.; Bernart, M. W. Eicosanoids and Related Compounds from Marine Algae. In Marine Biotechnology; Attaway, D. H., Zaborsky, O. R., Eds.; Plenum Press: New York, 1993; Vol. 1, pp 101-152. 91, 92, 94 
80. Gerwick, W. H. Biochim. Biophys. Acta 1994, 1211, 243-255. 91, 92

81. Gregson, R. P.; Marwood, J. F.; Quinn, R. J. Tetrahedron Lett. 1979, 46, 4505-4506. 92

82. Nagle, D. G.; Gerwick, W. H. Tetrahedron Lett. 1990, 31, 2995-2998. 92

83. Gerwick, W. H. Chem. Rev. 1993, 93, 1807-1823. 92

84. Higgs, M. D.; Mulheirn, L. J. Tetrahedron 1981, 37, 4259-4262. 92

85. Corey, E. J.; De, B.; Ponder, J. W.; Berg, J. M. Tetrahedron Lett. 1984, 25, 10151018. 92

86. Corey, E. J.; De, B. J. Am. Chem. Soc. 1984, 106, 2735-2736. 92

87. Kurata, K.; Taniguchi, K.; Shiraishi, K.; Hayama, N.; Tanaka, I.; Suzuki, M. Chem. Lett. 1989, 18, 267-270. 92

88. Kousaka, K.; Ogi, N.; Akazawa, Y.; Fujieda, M.; Yamamoto, Y.; Takada, Y.; Kimura, J. J. Nat. Prod. 2003, 66, 1318-1323. 92, 93

89. Yamamoto, S.; Suzuki, H.; Ueda, N. Prog. Lipid Res. 1997, 36, 23-41. 94

90. Voet, D.; Voet, J. G. Eicosanoid Metabolism: Prostaglandins, Prostacyclins, Thromboxanes, Leukotrienes, and Lipoxins. In Biochemistry, 3rd ed.; John Wiley \& Sons, Inc.: New Jersey, 2004; Vol. One, p 966. 94

91. Jiang, Z.-D.; Gerwick, W. H. Lipids 1997, 32, 231-235. 94

92. Wasserman, H. H.; Ives, J. L. Tetrahedron 1981, 37, 1825-1852. 95

93. Wallis, J. G.; Watts, J. L.; Browse, J. Trends Biochem. Sci. 2002, 27, 467-473. 95

94. Kenyon, C. N. J. Bacteriol. 1972, 109, 827-834. 96

95. Butler, A.; Carter-Franklin, J. N. Nat. Prod. Rep. 2004, 21, 180-188. 96, 97, 127

96. Fukuzawa, A.; Takasugi, Y.; Murai, A.; Nakamura, M.; Tamura, M. Tetrahedron Lett. 1992, 33, 2017-2018. 97

97. Fukuzawa, A.; Aye, M.; Takasugi, Y.; Nakamura, M.; Tamura, M.; Murai, A. Chem. Lett. 1994, 2307-2310. 97

98. Ishihara, J.; Kanoh, N.; Murai, A. Tetrahedron Lett. 1995, 36, 737-740. 97

99. Kong, F.; Singh, M. P.; Carter, G. T. J. Nat. Prod. 2005, 68, 920-923. 100, 101

100. Pettit, G. R.; Tan, R.; Ichihara, Y.; Williams, M. D.; Doubek, D. L.; Tackett, L. P.; Schmidt, J. M.; Cerny, R. L.; Boyd, M. R.; Hooper, J. N. A. J. Nat. Prod. 1995, 58, 961-965. 104, 137

101. Pettit, G. R.; Lippert, J. W.; Taylor, S. R.; Tan, R.; Williams, M. D. J. Nat. Prod. 2001, 64, 883-891. 104, 137

102. Adams, N. M. Red Seaweeds. In Seaweeds of New Zealand. An illustrated guide; Canterbury University Press: Christchurch, 1994; p 334. 105 
103. Fattorusso, E.; Magno, S.; Santacroce, C.; Sica, D.; Impellizzeri, G.; Mangiafico, S.; Piattelli, M.; Sciuto, S. Biochem. Syst. Ecol. 1976, 4, 135-138. 105

104. Combaut, G.; Saenger, P. Phytochemistry 1984, 23, 781-782. 105

105. Impellizzeri, G.; Mangiafico, S.; Piattelli, M.; Sciuto, S.; Fattorusso, E.; Santacroce, C.; Sica, D. Biochem. Syst. Ecol. 1977, 5, 77-80. 105

106. Czeczuga, B.; Taylor, F. J. Biochem. Syst. Ecol. 1987, 15, 5-8. 105

107. Sciuto, S.; Piattelli, M.; Chillemi, R. Phytochemistry 1982, 21, 227-228. 105

108. Patti, A.; Morrone, R.; Chillemi, R.; Piattelli, M.; Sciuto, S. J. Nat. Prod. 1992, 55, 53-57. 107

109. Kazlauskas, R.; Murphy, P. T.; Wells, R. J. Aust. J. Chem. 1982, 35, 219-220. 107

110. Wiemer, D. F.; Idler, D. D.; Fenical, W. Experientia 1991, 47, 851-853. 107, 129

111. Yoo, H.-D.; Ketchum, S. O.; France, D.; Bair, K.; Gerwick, W. H. J. Nat. Prod. 2002, 65, 51-53. 107, 109, 128

112. de Carvalho, L. R.; de Beauclair Guimaraes, S. M. P.; Roque, N. F. Rev. Bras. Bot. 2006, 29, 453-459. 107, 109, 128, 129, 131

113. Barreto, M.; Meyer, J. J. M. S. Afr. J. Bot. 2006, 72, 521-528. 107, 128

114. Blunt, J. W.; Copp, B. R.; Munro, M. H. G.; Northcote, P. T.; Prinsep, M. R. Nat. Prod. Rep. 2004, 21, 1-49. 109, 127

115. Blunt, J. W.; Copp, B. R.; Munro, M. H. G.; Northcote, P. T.; Prinsep, M. R. Nat. Prod. Rep. 2005, 22, 15-61. 109, 127

116. Blunt, J. W.; Copp, B. R.; Munro, M. H. G.; Northcote, P. T.; Prinsep, M. R. Nat. Prod. Rep. 2006, 23, 26-78. 109, 127

117. Blunt, J. W.; Copp, B. R.; Hu, W.-P.; Munro, M. H. G.; Northcote, P. T.; Prinsep, M. R. Nat. Prod. Rep. 2007, 24, 31-86. 109, 127

118. Zhao, J.; Fan, X.; Wang, S.; Li, S.; Shang, S.; Yang, Y.; Xu, N.; Lu, Y.; Shi, J. J. Nat. Prod. 2004, 67, 1032-1035. 109, 130

119. Glombitza, K. W.; Sukopp, I.; Wiedenfeld, H. Planta Med. 1985, 51, 437-440. 109, 110,129

120. Claridge, T. D. W. Correlations through the chemical bond II: Heteronuclear shift correlations. In High-Resolution NMR Techniques in Organic Chemistry; Tetrahedron Organic Chemistry Series; Elsevier Science Ltd.: Oxford, 1999; p 248. 115

121. Levy, G. C. Aromatics. In Carbon-13 Nuclear Magnetic Resonance for Organic Chemists; Wiley-Interscience: New York, 1972; pp 100-101. 115

122. Marek, R.; Lycka, A.; Kolehmainen, E.; Sievanen, E.; Tousek, J. Curr. Org. Chem. 2007, 11, 1154-1205. 118 
123. Nelson, J. H. The Chemical Shift and Examples for Selected Nuclei. In Nuclear Magnetic Resonance Spectroscopy; Pearson Education, Inc: New Jersey, 2003; p 69. 118

124. Gribble, G. W. Chemosphere 2003, 52, 289-297. 127

125. de Carvalho, L. R.; Rogue, N. F. Quím. Nova 2000, 23, 757-764. 127, 128

126. Gribble, G. W. Chem. Soc. Rev. 1999, 28, 335-346. 127

127. Craigie, J. S.; Gruenig, D. E. Science (Washington, D.C.) 1967, 157, 1058-1059. 127

128. Pedersén, M.; Fries, L. Z. Pflanzenphysiol. 1974, 74, 272-274. 127, 128, 129

129. Xu, X.; Song, F.; Wang, S.; Li, S.; Xiao, F.; Zhao, J.; Yang, Y.; Shang, S.; Yang, L.; Shi, J. J. Nat. Prod. 2004, 67, 1661-1666. 127, 128, 129, 130

130. Xu, X. L.; Fan, X.; Song, F. H.; Zhao, J. L.; Han, L. J.; Shi, J. G. Chin. Chem. Lett. 2004, 15, 661-663. 127

131. Xu, X.-L.; Fan, X.; Song, F.-H.; Zhao, J.-L.; Han, L.-J.; Yang, Y.-C.; Shi, J.-G. J. Asian Nat. Prod. Res. 2004, 6, 217-221. 127, 128, 129, 130

132. Saenger, P.; Pedersén, M.; Rowan, K. S. Phytochemistry 1976, 15, 1957-1958. 127

133. Weinstein, B.; Rold, T. L.; Clayton E. Harrell, J.; Mark W. Burns, I.; Waaland, J. R. Phytochemistry 1975, 14, 2667-2670. 127, 128, 129

134. McLachlan, J.; Craigie, J. S. J. Phycol. 1966, 2, 133-135. 127, 128

135. Katsui, N.; Suzuki, Y.; Kitamura, S.; Irie, T. Tetrahedron 1967, 23, 1185-1188. 127, 129

136. Pedersén, M.; Saenger, P.; Fries, L. Phytochemistry 1974, 13, 2273-2279. 128, 129

137. Hodgkin, J. H.; Craigie, J. S.; McInnes, A. G. Can. J. Chem. 1966, 44, 74-78. 128

138. Glombitza, K. W.; Stoffelen, H. Planta Med. 1972, 22, 391-395. 128

139. Kurata, K.; Taniguchii, K.; Takashima, K.; Hayashi, I.; Suzuki, M. Phytochemistry 1997, 45, 485-487. 128, 129

140. Mautner, H. G.; Gardner, G. M.; Pratt, R. J. Am. Pharm. Assoc. 1953, 42, 294-296. 128

141. Chevolot-Magueur, A. M.; Cave, A.; Potier, P.; Teste, J.; Chiaroni, A.; Riche, C. Phytochemistry 1976, 15, 767-771. 128

142. Kurata, K.; Amiya, T. Chem. Lett. 1977, 1435-1438. 128, 129

143. Kurihara, H.; Mitani, T.; Kawabata, J.; Takahashi, K. J. Nat. Prod. 1999, 62, 882884. 128,129

144. Fan, X.; Xu, N. J.; Shi, J. G. J. Nat. Prod. 2003, 66, 455-458. 128, 129, 130

145. Shoeib, N. A.; Bibby, M. C.; Blunden, G.; Linley, P. A.; Swaine, D. J.; Wheelhouse, R. T.; Wright, C. W. J. Nat. Prod. 2004, 67, 1445-1449. 128, 129 
146. Lee, H.-S.; Lee, T.-H.; Lee, J. H.; Chae, C.-S.; Chung, S.-C.; Shin, D.-S.; Shin, J.; Oh, K.-B. J. Agric. Food Chem. 2007, 55, 6923-6928. 128, 129, 130

147. Suzuki, M.; Kowata, N.; Kurosawa, E. Bull. Chem. Soc. Jpn. 1980, 53, 2099-2100. 129

148. Kubo, I. Pure Appl. Chem. 1989, 61, 373-375. 129

149. Kubo, I.; Ochi, M.; Shibata, K.; Hanke, F. J.; Nakatsu, T.; Tan, K. S.; Taniguchi, M.; Kamikawa, T.; Yamagiwa, Y.; et al., J. Nat. Prod. 1990, 53, 50-56. 129

150. Stoffelen, H.; Glombitza, K. W.; Murawski, U.; Bielaczek, J.; Egge, H. Planta Med. 1972, 22, 396-401. 129

151. Glombitza, K. W.; Stoffelen, H.; Murawski, U.; Bielaczek, J.; Egge, H. Planta Med. 1974, 25, 105-114. 129

152. Xu, N.; Fan, X.; Yan, X.; Li, X.; Niu, R.; Tseng, C. K. Phytochemistry 2003, 62, 1221-1224. 129, 130

153. Neamati, N.; Hong, H.; Mazumder, A.; Wang, S.; Sunder, S.; Nicklaus, M. C.; Milne, G. W. A.; Proksa, B.; Pommier, Y. J. Med. Chem. 1997, 40, 942-951. 129

154. Fan, X.; Xu, N. J.; Shi, J. G. Chin. Chem. Lett. 2003, 14, 939-941. 130

155. Fan, X.; Xu, N. J.; Shi, J. G. Chin. Chem. Lett. 2003, 14, 1045-1047. 130

156. Zhao, J.; Ma, M.; Wang, S.; Li, S.; Cao, P.; Yang, Y.; Yang, L.; Shi, J.; Xu, N.; Fan, X.; He, L. J. Nat. Prod. 2005, 68, 691-694. 130, 133

157. Ma, M.; Zhao, J.; Wang, S.; Li, S.; Yang, Y.; Shi, J.; Fan, X.; He, L. J. Nat. Prod. 2006, 69, 206-210. 131, 133

158. Ma, M.; Zhao, J.; Wang, S.; Li, S.; Yang, Y.; Shi, J.; Fan, X.; He, L. J. Nat. Prod. 2007, 70, 337-341. 131, 133

159. Agon, V. V.; Bubb, W. A.; Wright, A.; Hawkins, C. L.; Davies, M. J. Free Radical Biol. Med. 2006, 40, 698-710. 133, 134

160. Wright, A.; Bubb, W. A.; Hawkins, C. L.; Davies, M. J. Photochem. Photobiol. 2002, 76, 35-46. 134

161. Gottlieb, H. E.; Kotlyar, V.; Nudelman, A. J. Org. Chem. 1997, 62, 7512-7515. 138

162. Harris, R. K.; Becker, E. D.; de Menezes, S. M. C.; Goodfellow, R.; Granger, P. Pure Appl. Chem. 2002, 40, 489-505. 138 